\title{
UTOPÍA U OPORTUNIDAD FALLIDA Análisis crítico del Acuerdo de Paz
}

Lina M. Céspedes-Baéz Enrique Prieto-Rios

-Editores académicos- 


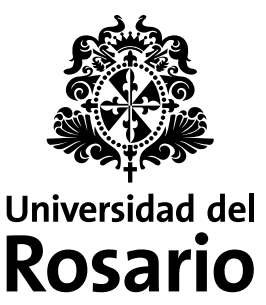





\section{Utopía u oportunidad fallida}

Análisis crítico del Acuerdo de Paz 


\title{
Utopía u oportunidad fallida. Análisis crítico del Acuerdo de Paz
}

\section{Resumen}

Este libro nació en una conversación entre los editores unas semanas antes del 2 de octubre del 2016, día en que el Acuerdo de Paz de La Habana fue sometido a plebiscito. Como muchos colombianos, nos enfrascamos en una discusión sobre diversos aspectos de lo pactado por el gobierno colombiano y las Fuerzas Armadas Revolucionarias de Colombia-FARC-. Esta inquietud de dos personas se transformó en un diálogo de veintitrés. Así, esta obra es una contribución de la Facultad de Jurisprudencia de la Universidad del Rosario al debate del fin del conflicto armado y la construcción de paz en Colombia. En él, participan profesores de esta y otras universidades colombianas con el fin de presentar una reflexión académica desde los estudios socio-jurídicos de los alcances, limitaciones y oportunidades de aprendizaje del proceso de paz y acuerdo logrado en 2016 con las FARC. En este contexto, este libro responde a la necesidad de promover una discusión informada sobre el papel del derecho y de los abogados en la estructuración e implementación de iniciativas de paz. Luego de tantos años en que los académicos han estudiado en el país la interacción conflicto armado y derecho, es esencial dar paso a una reflexión profunda que concatene esta disciplina con los escenarios de paz.

Palabras clave: Procesos de paz, conflicto armado, acuerdos de paz, Colombia, solución de conflictos, derecho internacional.

\section{Utopia or Failed Opportunity? A Critical Analysis of the Peace Agreement}

\begin{abstract}
This book is the outcome of a conversation between its editors several weeks before October 2, 2016, the date on which the Colombian people were to vote whether to approve the Havana Peace Agreement. Like many Colombians, we discussed different aspects and challenges of the agreement between the Colombian Government and the Revolutionary Armed Forces of Colombia -FARC-. This conversation between two people soon became a dialogue among twenty-three authors. This volume is a contribution of Universidad del Rosario's Law School to the ongoing debate around the end of the armed conflict and peacebuilding in Colombia. Professors from Universidad del Rosario and other Colombian universities shared their articles to offer insights from the socio-legal perspective to the debate on the Peace Agreement's advantages and disadvantages, and lessons learned in this process. In this context, this work aims at promoting an informed discussion on the role of the law and lawyers in designing and implementing peace initiatives. After many years in which scholars have devoted their research to understand the interplay between the internal armed conflict and the law, it is time to begin an in-depth analysis of the interaction between the law and post-conflict scenarios.
\end{abstract}

Keywords: Peace processes, armed conflict, peace agreements, Colombia, resolution of conflicts, international law.

Citación sugerida

Lina M. Céspedes-Baéz, Enrique Prieto-Rios (eds. acad.). Utopia u oportunidad fallida. Análisis crítico del Acuerdo del Paz. (2017). Bogotá: Editorial Universidad del Rosario.

DOI: doi.org/10.12804/tj9789587389289 


\section{Utopía u oportunidad fallida Análisis crítico del Acuerdo de Paz}

Lina M. Céspedes-Baéz

Enrique Prieto-Rios

-Editores académicos- 


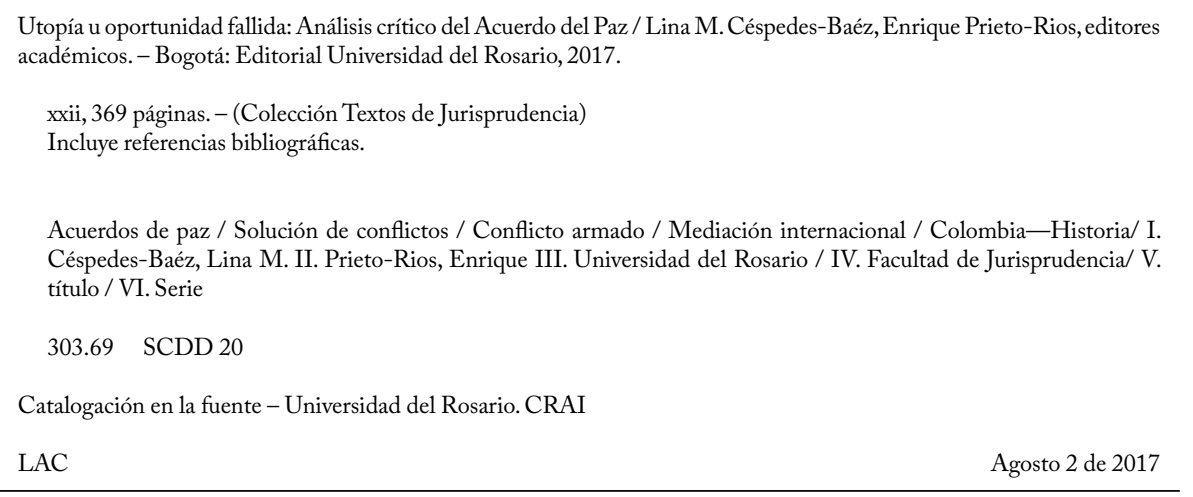

Hecho el depósito legal que marca el Decreto 460 de 1995

Editorial Universidad del Rosario

Carrera 7 No. 12B-41, of. 501 • Tel: 2970200 Ext. 3112

editorial.urosario.edu.co
Primera edición: Bogotá D. C., agosto de 2017

ISBN: 978-958-738-927-2 (impreso)

ISBN: 978-958-738-928-9 (ePub)

ISBN: 978-958-738-929-6 (pdf)

DOI: doi.org/10.12804/tj9789587389289

Coordinación editorial: Editorial Universidad del Rosario Corrección de estilo: Daniela Echeverry

Diseño de cubierta: Miguel Ramírez, Kilka DG

Diagramación: Precolombi EU-David Reyes

Impresión: Panamericana Formas e Impresos S.A.

Impreso y hecho en Colombia

Printed and made in Colombia

Los conceptos y opiniones de esta obra son responsabilidad de sus autores y no comprometen a la Universidad ni sus políticas institucionales.

El contenido de este libro fue sometido al proceso de evaluación de pares, para garantizar los altos estándares académicos. Para conocer las políticas completas visitar: editorial.urosario.edu.co

Todos los derechos reservados. Esta obra no puede ser reproducida sin el permiso previo escrito de la Editorial de la Universidad del Rosario. 


\section{Contenido}

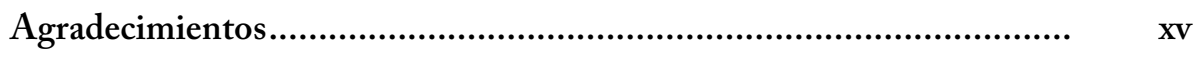

Introducción................................................................................... xvii

Lina M. Céspedes-Báez

Enrique Prieto-Rios

Las negociaciones de La Habana: ¿hubiera sido posible replicarlas

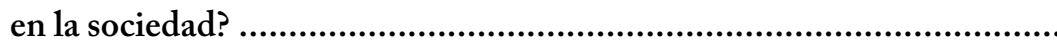

Camila de Gamboa Tapias

Las emociones en el proceso de paz colombiano

Diana Carolina Valencia-Tello

Introducción

1. El papel de las emociones en los procesos de comunicación................... 18

2. Campañas políticas y nuevas tecnologías ............................................... 24

3. Antecedentes del proceso de paz colombiano ........................................ 28

4. El papel de las emociones en las campañas políticas y el proceso de paz colombiano ……...............................................................

Consideraciones finales ....................................................................... 38

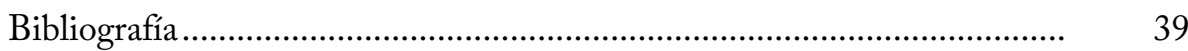

La paz como política pública y la legitimación democrática de los Acuerdos

Natalia Soledad Aprile

Mateo Gómez Vásquez

Introducción

43

1. La paz como política pública 
1.1. La paz como tema de la agenda de las políticas públicas............. 47

1.2. La decisión de la política pública de paz ...................................... 51

1.3. La puesta en práctica y la evaluación del Acuerdo de Paz .......... $\quad 55$

2. La legitimación democrática de la política pública de paz..................... 58

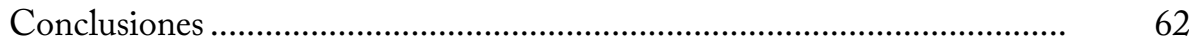

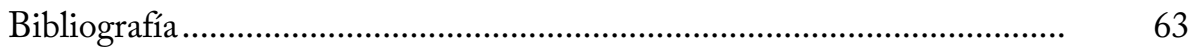

A propósito de la refrendación popular del Acuerdo suscrito entre el Gobierno de Colombia y las Farc y las lecciones aprendidas de la Ley de la Claridad de Canadá y su aplicabilidad al caso colombiano

Manuel Alberto Restrepo Medina

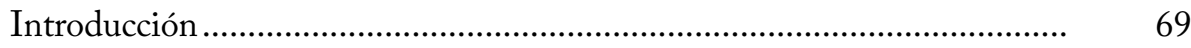

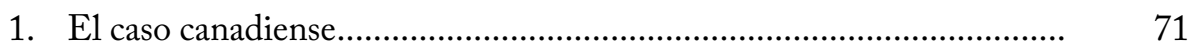

2. Aplicabilidad del caso canadiense al caso colombiano.............................. 76

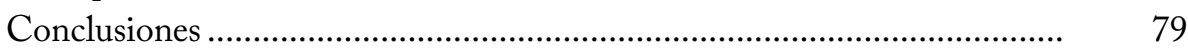

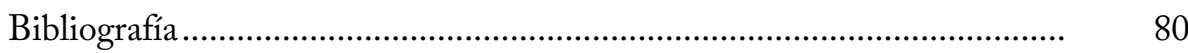

Acuerdo General y los acuerdos temáticos para la terminación del conflicto y la construcción de una paz estable y duradera: ¿acuerdo especial?

Ligia Galvis Ortiz

Beatriz Londoño-Toro

Soraya Pérez Portillo

Nicolás Felipe Mendoza Cerquera

Héctor Peña Díaz

Introducción

1. El Acuerdo Final y las garantías de los derechos humanos...................... 82

2. Obligación de aplicar los tratados internacionales de derechos humanos y los convenios de Ginebra de 1949 y sus protocolos adicionales - DIH - en el territorio nacional

3. El Acuerdo Final para la terminación del conflicto y la construcción de una paz estable y duradera es un acuerdo especial, en el marco del artículo 3 común a los convenios de Ginebra y del Protocolo Adicional II 
4. La responsabilidad del Estado y el cumplimiento del Acuerdo de Paz. 104

Conclusión ........................................................................................... 106

Bibliografía ............................................................................................ 106

Sobre la idoneidad de los procesos penales y las comisiones de la verdad para abordar situaciones de crímenes internacionales de ius cogens. Especial referencia a la Jurisdicción Especial para la Paz y la Comisión para el Esclarecimiento de la Verdad, la Convivencia y la No Repetición en Colombia Héctor Olasolo Alonso

Introducción

1. Alcance y limitaciones de los procesos penales. Especial referencia a la Jurisdicción Especial para la Paz en Colombia

1.1. Los procesos penales como instrumento para declarar y ejecutar la responsabilidad internacional individual por crímenes de ius cogens: el debate en torno a la prevención especial positiva y al énfasis en los máximos responsables

1.2. Reflexiones sobre el alcance y las limitaciones de la Jurisdicción Especial para la Paz en Colombia.

2. Alcance y limitaciones de las comisiones de la verdad. Especial atención a las situaciones en Colombia, España e Irlanda del Norte....

3. ¿Es posible superar las limitaciones de los procesos penales y las comisiones de la verdad recurriendo a ambos conjuntamente?

Conclusión 146

Bibliografía

Derecho de la inversión extranjera y acuerdos de paz: tensiones y soluciones.

René Urueña

Enrique Prieto-Rios

Introducción

1. Arbitraje como mecanismo de solución de controversias entre inversionistas extranjeros y Estados

2. Acuerdos de inversión en las negociaciones de paz colombianas........... 164

3. Una política de tierras contradictoria ................................................... 166

4. Protección de la inversión frente al Acuerdo de Paz .............................. 168 
5. Protección del Acuerdo de Paz frente a la inversión ............................... 171

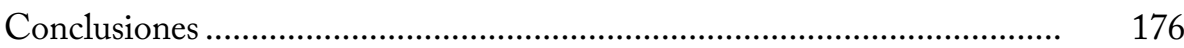

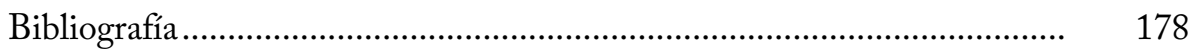

Las medidas de reparación integral establecidas en el Acuerdo Final para la terminación del conflicto y la construcción de una paz estable

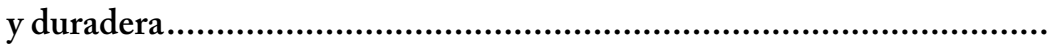

Hugo Andrés Arenas Mendoza

Introducción

1. Enfoques que se le pueden asignar a la responsabilidad patrimonial por los daños causados en el conflicto armado.

2. Principios del Acuerdo................................................................... 188

3. La reparación integral en el acuerdo..................................................... 192

3.1. La reparación integral en la doctrina administrativista colombiana

3.2. Sus principales críticas desde el punto de vista de la doctrina de la reparación transformadora.

3.3. La consagración de la reparación integral en el ordenamiento jurídico colombiano.

3.4. La reparación integral en el Acuerdo Final para la terminación del conflicto y la construcción de una paz estable y duradera

4. Las medidas de reparación integral para la construcción de la paz ........

4.1. Las medidas individuales de reparación integral para la construcción de la paz incorporadas en el Acuerdo

4.2. Las medidas colectivas de reparación integral para la construcción de la paz establecidas en el Acuerdo.

201

Conclusiones 204

Bibliografia 206

El debate por la propiedad de la tierra, el punto por donde debe comenzar una pedagogía de la paz....

Sergio Latorre Restrepo

Introducción

1. El estado del campo 
2. Lo que propone el Acuerdo en cuanto a la política de desarrollo agrario integral.

2.1. Generalidades.................................................................. 219

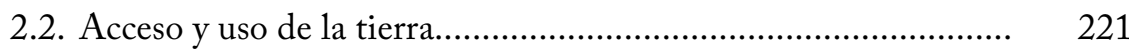

2.2.1. Dotación y acceso a tierras .............................................. 222

2.2.2. Formalización, registro e información ............................... 226

2.2.3. Organización del territorio rural ...................................... 233

2.3. Programas de desarrollo con enfoque territorial......................... 235

2.4. Planes nacionales para la Reforma Rural Integral...................... $\quad 237$

A manera de conclusión ............................................................................ 240

Bibliografía ...................................................................................... 243

La visión del Acuerdo de Paz sobre el abastecimiento de agua en el medio rural .................................................................................. 247

Andrés Gómez-Rey

Gloria Amparo Rodriguez

Introducción

1. El agua en el Acuerdo de $\mathrm{Paz}$..............................................................

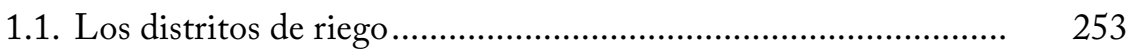

1.2. Del servicio público domiciliario de acueducto......................... 256

1.3. Estímulos a la economía solidaria y cooperativa ....................... 259

1.4. Un especial planteamiento del principio de desarrollo

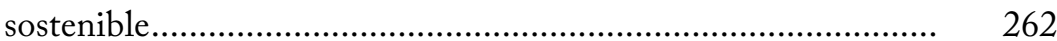

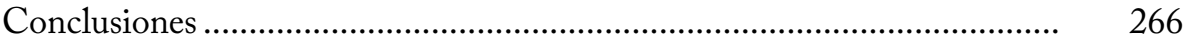

Bibliografía .......................................................................................... 269

Bioprospección y el Acuerdo de Paz ......................................................... 273

Diana Rocio Bernal-Camargo

Leonardo Güiza-Suárez

Paola Moreno Latorre

Enrique Prieto-Rios

Introducción

273

1. Acerca de la bioprospección .................................................................. 276

2. Regulación de la bioprospección ........................................................... 279

3. La bioprospección en los Acuerdos de Paz........................................... 280 
4. Los contratos de acceso a recursos genéticos y el conflicto armado en Colombia.....

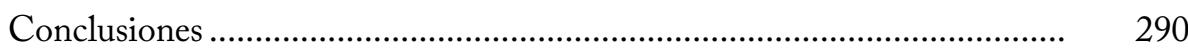

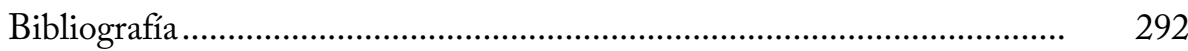

En los confines de lo posible: inclusión del enfoque de género en el Acuerdo de La Habana

1. El feminismo radical o feminismo de la guerra contra las mujeres

2. MacKinnon en Bogotá....................................................................... 303

3. Las letradas en La Habana................................................................... 311

4. Un acuerdo letrado ....................................................................... 316

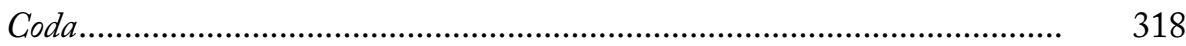

Bibliografía ....................................................................................... 319

Derecho del trabajo y construcción de paz en Colombia......................... 327 Iván Daniel Jaramillo Jassir

1. Teorías sobre construcción de paz y derecho del trabajo.......................... 328

2. Acuerdos de paz y derecho del trabajo ................................................ 331

3. Normas internacionales del trabajo y derecho del trabajo para la paz.

4. Derecho del trabajo agrario para la paz ............................................... 336

5. Acción sindical en materia de participación ciudadana y garantías para el ejercicio del derecho a la movilización y protesta social............. 340

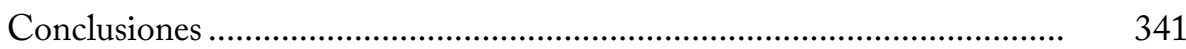

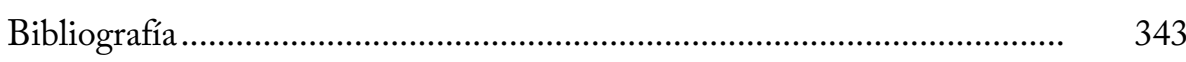

Estado empático y ciudadanía precaria: reflexiones en torno al caso emblemático de Bellavista (Bojayá-Colombia) ..................................... 345 Lina Buchely

Introducción

1. Bellavista y las burocracias "blandas" .................................................... 349

2. El estado empático: gestión emocional y estrategias de duelo ............... 352

3. El estado emocional dentro de nosotros: realidades colombianas......... 355 
4. El estado del río: dispersión, saturación, fragilidad y eficacia en la experiencia estatal de Bellavista ................................................ 362

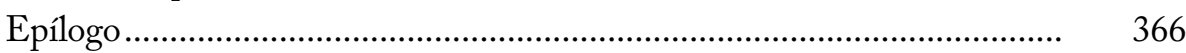

Bibliografía ..................................................................................... 367 



\section{Agradecimientos}

Tal vez, la sección de los agradecimientos es una de las partes menos leídas de un libro. Sin embargo, desde que comenzamos hace unos años a tratar de entender cómo se gestan y llevan a cabo este tipo de proyectos, hemos aprendido a identificar, analizar y a apreciar este aparte de cualquier publicación. Aquí se encuentra un fragmento esencial de la historia de una idea que después se consolidó en un proyecto, se convirtió en un resultado de un proceso de investigación y hoy se entrega a los lectores con la esperanza de que lo examinen con detenimiento, lo critiquen y, ojalá, lo conviertan en un argumento a ser mejorado o rebatido. De lo que dan cuenta la lista de personas que a continuación vamos a nombrar es que el conocimiento no se concibe en solitario, sino que es una mezcla de reflexión individual que se pone a prueba en la interacción constante con los colegas y amigos en contextos que trascienden los espacios formales de la academia.

Para comenzar, el apoyo de la Editorial de la Universidad del Rosario ha sido fundamental en todas las instancias de este proceso. Aún recordamos esa llamada que le hicimos a Juan Felipe Córdoba en septiembre de 2016 para proponerle esta idea y el apoyo entusiasta que él nos ofreció desde el principio. Le debemos a todo su equipo el que esta publicación sea una realidad, en especial a Ingrith Torres Torres, Coordinadora Editorial, y a la correctora de estilo, Daniela Echeverry. Así mismo, queremos reconocer la labor de los pares evaluadores, pues sus comentarios contribuyeron a mejorar sustancialmente el contenido de esta obra.

La contribución de los profesores de la Facultad de Jurisprudencia Andrés Gómez Rey y Natalia Soledad Aprile, de la joven investigadora Mariana Díaz-Chalela y de la asistente de investigación Carolina Torres Sarmiento fue esencial para poder revisar las artes a tiempo y poder publicar 
el libro en la fecha proyectada. Gracias por haber aceptado esta invitación y haberse sentado con nosotros a repasar puntos, comas y el orden de los pies de página, entre otros detalles fundamentales de cualquier edición. Con ustedes terminamos el libro en el mismo lugar en que se concibió, tomando café y debatiendo los retos que le esperan al país en la fase de implementación del Acuerdo.

Finalmente, a todos los autores que participaron en esta obra con sus artículos, por esa generosidad que los llevó a compartir su trabajo con nosotros y por la buena disposición con la que se adaptaron a los exigentes plazos que nos fijamos. Una idea de dos personas terminó en un diálogo de veintitrés.

Los editores 


\title{
Introducción
}

\author{
Lina M. Céspedes-Báez" \\ Enrique Prieto-Rios
}

Este libro nació en una conversación entre los editores unas semanas antes del 2 de octubre del 2016, día en que el Acuerdo de Paz de La Habana fue sometido a plebiscito. Como muchos colombianos, nos enfrascamos en una discusión sobre diversos aspectos de lo pactado por el Gobierno colombiano y las Fuerzas Armadas Revolucionarias de Colombia — FARC-. Durante la charla tocamos varios puntos que nos parecían relevantes, los cuales iban desde la extensión del documento y su incidencia en la comprensión del contenido; la interrelación entre el lenguaje de las aspiraciones y el operativo y lo que ello nos podía decir de las dificultades de la negociación; hasta los temas implícitos, ausentes o sobre los cuales más bien pesaba cierto silencio, entre otros.

\footnotetext{
* Abogada de la Universidad del Rosario, con especialización en Derecho Tributario de la misma Universidad, maestría en Estudios de Género de la Universidad Nacional de Colombia, LL. M. con concentración en Derecho Internacional de Cardozo School of Law (Nueva York) y doctorado en Derecho de Temple University (Filadelfia). Becaria Fulbright 2012-2014 y Residential Fellow del Institute for Global Law and Policy — IGLP — de la Facultad de Derecho de la Universidad de Harvard 2014-2015. Actualmente es la vicedecana de la Facultad de Jurisprudencia de la Universidad del Rosario. Correo electrónico: linam.cespedes@urosario.edu.co

** Abogado, ma Derecho Internacional y $\mathrm{Ph}$. D. en proceso de grado (tesis y defensa aprobada mayo 2017, fecha de grado noviembre 2017). Profesor principal, investigador del Grupo de Investigación en Derecho Internacional de la Facultad de Jurisprudencia de la Universidad del Rosario. Correo electrónico: enrique.prieto@urosario.edu.co
} 
Por unas cuantas horas nos dimos a esa tarea tan típicamente humana que es compartir impresiones y análisis sobre los términos de un texto que prometía poner fin a un conflicto que había sido un referente no solo de nuestras vidas sino de las de nuestros padres y abuelos. ${ }^{1}$ Esto convertía al Acuerdo en una pieza histórica, política y jurídica de suma importancia que nos conectaba a una conversación mucho más amplia que había comenzado en la década de 1980, con las primeras iniciativas de negociaciones de paz durante el gobierno del presidente Belisario Betancur, ${ }^{2}$ y que convocaba nuevamente a la población colombiana a discutir su idea de Nación a través de la búsqueda de soluciones para uno de sus mayores dilemas: la insurgencia armada.

Ese día durante nuestro intercambio de opiniones llegamos a tres conclusiones que fueron la causa inmediata de esta idea. La primera: aunque teníamos puntos de desacuerdo, la mayoría de nuestras apreciaciones coincidía. La segunda: desde que el Acuerdo se había publicado no habíamos tenido tiempo de tener este tipo de conversación de una manera ordenada y sistemática en la Facultad de Jurisprudencia de la Universidad del Rosario, ni habíamos propiciado un encuentro de este linaje con nuestros colegas y amigos de otras universidades. La tercera: las aristas e implicaciones jurídicas del Acuerdo eran tan variadas que era imposible para dos abogados como nosotros determinar siquiera con precisión meridiana los asuntos y problemas jurídicos que merecían de un examen juicioso urgente.

Estas tres conclusiones nos mostraron que era esencial incentivar un debate jurídico crítico del Acuerdo que incluyera más voces que permitieran miradas disímiles. En la diferencia de aproximación y criterio se encuentra la riqueza de la discusión y, por tanto, la generación de conocimiento. También, observamos que una aproximación desde lo sociojurídico era pertinente, por cuanto las fronteras de lo negociable para el Gobierno y las FARC no solo estaban demarcadas por consideraciones políticas y económicas, sino por cuerpos normativos internacionales y domésticos que se habían

1 Aunque la guerrilla de las FARC fue fundada en 1964, según su historia oficial, su presencia y capacidad de impactar la realidad nacional ha variado a través de las décadas. Eso ha implicado que haya sido un referente cambiante en la vida del Estado colombiano y que su importancia como factor político, económico y jurídico haya ido variando a través de la historia reciente colombiana.

2 Anna-Karina Bayer, "Peace Processes in Colombia: International Third-Party Interventions". Journal of Peace, Conflict E Development 20 (2013): 64-65. 
venido haciendo más complejos desde la década de 1990. Igualmente, concluimos que en una facultad donde se enseñe derecho es primordial dar una discusión informada y respetuosa entre la comunidad académica al respecto. El Acuerdo tiene el potencial de definir la vida jurídica del país en las décadas por venir y es responsabilidad de los estudiosos del derecho contribuir a la comprensión de su significado.

El libro lo planeamos alrededor de la siguiente pregunta: ¿qué tienen que decir los estudios sociojurídicos sobre la forma en que el Gobierno colombiano y las FARC diseñaron el fin del conflicto y sentaron las bases para la construcción de la paz en el país? Esto sin importar los resultados del plebiscito, por cuanto éramos conscientes de que el Acuerdo se había convertido en el marco de referencia de las discusiones por venir. Este documento no solo representa uno de los esfuerzos más ambiciosos en materia de procesos de paz en Colombia, sino que su contenido recoge y resume en unos cientos de páginas el conocimiento creado y acumulado en los últimos treinta años alrededor de las causas y consecuencias del conflicto; las medidas apropiadas para reparar a las víctimas y no permitir la repetición de las violaciones del derecho internacional humanitario y de los derechos humanos; y las tensiones interpretativas sobre lo que es y no es negociable. En este sentido, el Acuerdo es una versión de nuestro pasado, una evaluación del presente y una apuesta por un futuro que está abierta a la discusión y a la reinterpretación. Si algo logró este documento que salió de la mesa de negociación de La Habana fue establecer unos contenidos hito que han facilitado el debate sobre las oportunidades y las utopías del fin de una guerra y de la consecución de la paz. Hoy en día no es posible imaginarse ninguna de estas dos realidades sin hacer referencia al Acuerdo de La Habana, ya sea para defenderlo, criticarlo o reemplazarlo. Este documento es referencia obligada de cualquier iniciativa que pretenda brindar una solución a la insurgencia armada.

El libro se construyó a través de una invitación extendida a los profesores de la Facultad de Jurisprudencia de la Universidad del Rosario y a algunos colegas de otras universidades del país que han trabajado de cerca con nosotros este tema. En este proceso recibimos una serie de artículos que permitió establecer un diálogo entre los editores y los autores con miras a incluir distintas perspectivas sociojurídicas sobre el tema. Dada la urgencia de la coyuntura, los tiempos para escritura, edición y revisión fueron cortos, 
lo que permitió de alguna manera responder de manera más directa al contexto planteado por la divulgación del Acuerdo, su rechazo en el plebiscito, las negociaciones con sus opositores y la introducción de cambios en su versión final dada a conocer el 24 de noviembre del 2016. En algunos de los artículos es posible ver cómo todos estos acontecimientos impactaron y enriquecieron los análisis. La lectura y la evaluación concienzudas de los pares académicos contribuyeron a reforzar una dinámica de diálogo que nos reiteró una vez más la importancia de construir academia a través de proyectos comunes y debates sobre cuestiones que tienen un impacto en la realidad del país.

Los artículos aquí escritos se pueden agrupar en cuatro ejes temáticos: 1) reflexiones sobre el plebiscito y el papel de la participación ciudadana en una etapa de transición; 2) tensiones existentes entre el derecho internacional y el Acuerdo de Paz; 3) aspectos específicos y contingentes de la implementación del Acuerdo; y 4) estudio de caso.

En el primer eje temático se encuentran el capítulo escrito por Camila de Gamboa Tapias en el cual se propone una reflexión crítica sobre las falencias pedagógicas en la divulgación del Acuerdo, que se vieron reflejadas en la votación del plebiscito. El segundo capítulo es el de Diana Carolina Valencia-Tello, en el que se analiza el papel que jugó el uso de emociones conflictivas en el resultado del plebiscito y cómo este constante uso de emociones en la política colombiana se convierte en un obstáculo para la construcción de caminos de paz que ayuden a la reconciliación entre los diversos actores del conflicto. En el tercer capítulo, Natalia Soledad Aprile y Mateo Gómez Vázquez realizan un análisis del proceso de paz como política pública y estudian la legitimación democrática de los Acuerdos desde el rol de la ciudadanía como objetivo transversal de planeación gubernamental. Por último, se encuentra el capítulo escrito por Manuel Alberto Restrepo Medina, en el que se hace un estudio comparado del plebiscito de Colombia con la Ley de Claridad de Canadá.

En el segundo eje temático se encuentra el capítulo escrito por Ligia Galvis Ortiz, Beatriz Londoño-Toro, Soraya Pérez Portillo, Nicolás Felipe Mendoza Cerquera y Héctor Peña Díaz, en el que se analiza el Acuerdo de Paz como un acuerdo especial en el marco del artículo $3^{\circ}$ común a los Convenios de Ginebra de 1949. Le sigue el artículo escrito por Héctor Olasolo, el cual analiza la idoneidad de los procesos penales y las comisiones 
de la verdad para abordar las situaciones en las que se cometen crímenes internacionales desde la perspectiva del derecho internacional. Por último, se encuentra el capítulo escrito por René Urueña y Enrique Prieto-Rios, que aborda las tensiones existentes entre el Acuerdo de Paz y el derecho internacional de la inversión extranjera.

En el tercer eje temático, que se ocupa de los aspectos particulares y contingentes del Acuerdo, se encuentra el capítulo de Hugo Andrés Arenas Mendoza, que estudia las medidas de reparación integral establecidas en el Acuerdo y los retos existentes desde la óptica de la reparación transformadora. En ese mismo eje temático se encuentra el capítulo escrito por Sergio Latorre Restrepo, en el cual se analizan los contenidos del punto I del Acuerdo (Acuerdo de Reforma Rural Integral) y sus recientes modificaciones, en el contexto del estado actual del campo colombiano. Con base en lo anterior, Sergio propone algunos puntos de vital importancia de cara a lograr consolidar en el campo un ambiente de bienestar y equidad necesario para establecer la paz.

En el cuarto eje temático se encuentran dos capítulos que analizan el Acuerdo de Paz desde la óptica del medio ambiente. Así, el lector encontrará el capítulo escrito por Andrés Gómez-Rey y Gloria Amparo Rodríguez, en el que problematizan la visión del Acuerdo de Paz sobre el abastecimiento de agua en el medio rural, y el capítulo de Diana Rocío Bernal-Camargo, Leonardo Güiza-Suárez, Paola Moreno Latorre y Enrique Prieto-Rios, en el que se examina la bioprospección y el Acuerdo de Paz. Los dos últimos capítulos de este eje temático son el escrito por Lina M. Céspedes-Báez, que analiza la inclusión de género en los Acuerdos (tema que estuvo en el centro del debate del plebiscito), y el capítulo escrito por Iván Daniel Jaramillo Jassir, que analiza los principales desafíos para el sistema de regulación de las relaciones laborales en el contexto de la implementación del Acuerdo.

Por último, el libro termina con el capítulo escrito por Lina Buchely, el cual es el resultado de un estudio de caso en la comunidad del municipio de Bojayá. En este capítulo se problematizan tres aspectos importantes que sirven de reflexión sobre las relaciones ciudadanía-Estado en zonas de conflicto: 1) el carácter emocional de las manifestaciones oficiales desarrolladas en escenarios de conflicto; 2) la ciudadanía precaria que construyen las víctimas de violencia política inmersas actualmente en procesos de construcción de memoria histórica: perdón, duelo y reparación; 3) la 
fragmentación y ambigüedad que representan esos escenarios de discusión para el Estado colombiano en el proceso de posconflicto.

La distribución temática del libro busca reflejar el hecho de que el Acuerdo de La Habana constituye un referente sociojurídico que seguramente impactará nuestra manera de entender el rol del derecho en la generación y la solución de luchas armadas. Así, este libro pretende contribuir a esa reflexión a través de una serie de estudios que hacen explícitas esas relaciones. Sin hacer referencia al derecho no es posible ver dónde están las utopías y las oportunidades de las apuestas por la paz y las encrucijadas de la guerra.

Bogotá, julio del 2017

\section{Bibliografía}

Bayer, Anna-Karina. "Peace Processes in Colombia: International ThirdParty Interventions". Journal of Peace, Conflict E Development 20 (2013): 64-65. 


\title{
Las negociaciones de La Habana: ¿hubiera sido posible replicarlas en la sociedad?"
}

\author{
Camila de Gamboa Tapias
}

Lo querías más oscuro, apagamos la llama.

Leonard Cohen

Existen muchos retos en las transiciones democráticas después de una paz negociada en varias de las etapas de este largo y complejo proceso. $\mathrm{Me}$ quiero referir a una de las etapas más importantes de las transiciones democráticas: la refrendación de un acuerdo de paz, es decir al procedimiento democrático que legitima en la sociedad los contenidos de dichos Acuerdos. Aunque existen muchos mecanismos de refrendación democráticos a los que es posible acudir luego de que un acuerdo ha sido negociado entre un gobierno y un actor político violento, en el caso colombiano, el presidente Santos expresó desde el momento en que anunció formalmente la existencia de las negociaciones con las FARC que se convocaría a la sociedad colombiana, cuando ya estuviera firmado el Acuerdo Final, a un mecanismo de

\footnotetext{
* Este texto hace parte del proyecto de investigación "Políticas públicas frente al conflicto armado en Colombia y justicia transicional". Igualmente, se encuentra comprendido en el proyecto de investigación "Los residuos del mal en sociedades postotalitarias: respuestas desde una perspectiva democrática”, referencia FFI2012-31635, financiado por el Ministerio Español de Finanzas y Competitividad.

** Abogada de la Universidad del Rosario, maestría y doctorado en Filosofía de Binghamton University - sunY-. Profesora asociada del Centro de Estudios sobre Paz y Conflicto de la Universidad del Rosario. Correo electrónico: camila.degamboa@urosario.edu.co
} 
refrendación popular con el propósito de que los ciudadanos pudieran votar si comulgaban con el contenido de dicho Acuerdo. El Gobierno escogió llevar a cabo un plebiscito que fue avalado por la Corte Constitucional Colombiana. ${ }^{1}$

Después de conocer los resultados del plebiscito, en el que el No ganó por una mayoría muy estrecha, muchos analistas colombianos, incluso aquellos que votaron en favor de los Acuerdos, han señalado que los resultados adversos del plebiscito reflejan una de las características de la democracia: reglas claras y resultados inciertos. ${ }^{2}$ Así pues, para quienes creemos en la democracia y votamos en favor del Acuerdo Final de La Habana por el Sí, nuestra respuesta ante un resultado adverso es la aceptación de este.

Ahora bien, en lo que sigue, quisiera hacer un análisis crítico del rechazo hacia el Acuerdo de Paz de un número significativo de colombianos, no solamente de quienes votaron en su contra, sino de aquellos que se abstuvieron de votar, que, como sabemos, constituye casi un $63 \%$ del electorado apto para hacerlo. ${ }^{3}$ No pretendo poner en duda el resultado obtenido, ni tampoco analizar de forma rigurosa las razones por las que grupos diversos y muy distintos de la sociedad colombiana votaron en contra del Acuerdo. Aunque, por supuesto, mi análisis sí hará una reflexión que está vinculada a ese resultado negativo en las urnas, pero que no se refiere exclusivamente al ejercicio político por excelencia de la ciudadanía de votar, sino a lo que considero yo un déficit democrático mucho más profundo, que creo no se tuvo en cuenta cuando el Gobierno propuso que la ciudanía refrendara los acuerdos a través de un plebiscito.

Como lo expresa el informe ;Basta Ya! en su capítulo segundo, en Colombia ha existido históricamente una reticencia muy grande a la apertura democrática para todos los grupos sociales, a la que llaman "el miedo a la democracia”. Allí se considera que esto ha incidido en la prolongación del conflicto armado interno, y para solo nombrar algunos ejemplos que el

\footnotetext{
Véase Sentencia C-379 del 2016, 18 de julio. MP: Luis Ernesto Vargas Silva.

2 Véase el interesante artículo de María Paula Saffon, "Democracia para la paz", El Espectador, 14 de octubre del 2016, http://www.elespectador.com/opinion/democracia-paz

3 El voto en el plebiscito fue de 50,21\% por el No (6.431.376) y 49,79\% a favor del Acuerdo (6.377.482). La abstención fue del $63 \%$ (21.833.898). Registraduría Nacional del Estado Civil, "Resultados plebiscito", http://www.registraduria.gov.co/?page=plebiscito_2016
} 
informe analiza, este déficit o debilidad en nuestras instituciones y cultura democrática se refleja en: figuras restrictivas de participación política como el Frente Nacional; represión de las protestas sociales, estigmatización y criminalización de la oposición política, incluso llegando al asesinato de los miembros de un partido político, como ocurrió con la Unión Patriótica; ${ }^{4}$ instrumentalización de las instituciones y mecanismos democráticos por parte de partidos políticos y actores armados, etc. ${ }^{5}$ Adicionalmente a esta restricción de la participación política de muchos grupos sociales, se pueden agregar otros aspectos que igualmente están vinculados con el origen y persistencia del conflicto armado, tales como las injusticias económicas y sociales que sitúan a Colombia como uno de los países más inequitativos y desiguales de Latinoamérica. ${ }^{6}$

Estas son características propias de nuestras instituciones y de nuestra cultura política que se han exacerbado con líderes populistas que promueven perspectivas de mundo cimentadas en una visión binaria de amigos y enemigos, en las que se pretende mostrar la superioridad moral de sus concepciones de vida buena a través del miedo y con discursos de odio. ${ }^{7}$ Además, van acompañadas en muchas ocasiones de perspectivas muy simplistas acerca de los problemas y de las posibles soluciones a estos, que en la mayoría de los casos esconden agendas para promover sus propios intereses políticos. Ante esta situación, sería ingenuo o descabellado pensar que lo que necesitábamos para votar en forma más razonada, en esta transición política

4 La Unión Patriótica fue el movimiento político que surgió como resultado de las negociaciones entre el gobierno de Belisario Betancur y las FARC. Este partido político tuvo un gran apoyo popular y se eligieron 36 alcaldes, 236 concejales y 16 congresistas. Desde el inicio fueron amenazados por grupos de extrema derecha y algunos grupos del Ejército. En las siguientes dos décadas fueron asesinados más de 3000 militantes de este partido. "El saldo rojo de la Unión Patriótica", Verdad Abierta, http://www.verdadabierta.com/justicia-y-paz/157-el-saldo-rojo-de-la-union-patrioticaSee

5 Centro Nacional de Memoria Histórica, ;Basta Ya! Colombia: Memorias de Guerra y Dignidad (Bogotá: Centro Nacional de Memoria Histórica, 2013).

6 "La desigualdad en Colombia es mayor de lo que se piensa",El Tiempo, 20 de marzo del 2016, http://www.eltiempo.com/economia/sectores/desigualdad-en-colombia-es-mayor-de-lo-que-sepiensa-dice-cepal/16546686

7 El director de la campaña del Centro Democrático contra el plebiscito afirmó en una entrevista que la idea era que el electorado votara "verraco" en contra del plebiscito. Véase Juliana Ramírez, "É1 no ha sido la campaña más barata y más efectiva de la historia”. La República, 5 de octubre del 2016, http://www.larepublica.co/el-no-ha-sido-la-campa \%C3\%B1a-m \%C3\%A1s-barata-y-m \%C3\%A1sefectiva-de-la-historia_427891 
hacia la paz, implicara, primero, hacer las transformaciones institucionales y de cultura democrática, en otras palabras que deberíamos contar ya con una serie de instituciones más democráticas y con una visión más pluralista del mundo y de los diversos actores sociales, para tomar así decisiones más razonadas, pues estaríamos en una situación imposible de alcanzar.

Lo que quiero defender es que la democracia liberal ${ }^{8}$ no es un ideal impuesto desde afuera, sino que es un valor que se puede construir en el mismo ejercicio de la discusión y de la toma de decisiones. En otras palabras, la democracia deliberativa es un procedimiento que permite construir los valores e instituciones democráticas a través del análisis y la solución de los problemas reales. Para ello seguiré de cerca el modelo deliberativo de democracia propuesto por Iris Marion Young. ${ }^{9}$ La autora considera que la democracia deliberativa es un procedimiento a través del que las partes pueden discutir sus diversas posiciones explicándolas en profundidad a las otras partes involucradas en la discusión, expresando los argumentos con que las sustentan y respondiendo por ellas. En este sentido, para Young en un régimen democrático los diversos miembros de la sociedad deberían tener en principio la misma oportunidad de influir en el diseño de las políticas públicas y normas jurídicas que pueden afectar sus intereses. Así, para la autora el mejor modelo procedimental de democracia en situaciones reales es el que es capaz de garantizar la mayor participación posible tanto en el proceso de discusión de una política pública o una ley, como en el proceso de toma de decisiones de esta, pues solo cuando se tienen en cuenta las posturas de los diversos grupos afectados por esas leyes y esas políticas públicas, es posible garantizar la justicia de las decisiones que se acuerdan y, a su vez, transformar, en muchas ocasiones, las condiciones de injusticia existentes. ${ }^{10}$

8 La democracia liberal se puede mirar desde una perspectiva normativa, en la que es posible identificar ciertos principios morales en los que ella se inspira. En este sentido en un régimen liberal cada una de las personas que hace parte de ese régimen es considerada un agente moral y político que tiene el mismo valor, por tanto las instituciones democráticas, las normas legales y las prácticas sociales deben hacer honor a esta teoría igualitaria del valor de los seres humanos. Véase Ronald Dworkin, Principles for a new political debate. Is democracy possible here? (Princeton: Princeton University Press, 2006).

9 Iris Marion Young, Inclusion and democracy (Oxford: Oxford University Press, 2000).

10 Young, Inclusion and democracy. 
Por supuesto, en los regímenes democráticos reales existen muchos grupos que tienen mayores oportunidades de participar en el sistema, mientras que otros se encuentran excluidos o marginados por lo que la autora denomina injusticias estructurales. Para Young las injusticias estructurales de un sistema político democrático no solo dependen de una distribución más equitativa de recursos, derechos, obligaciones y oportunidades por parte del Estado, "sino de las condiciones institucionales que permiten que los individuos puedan desarrollar y ejercitar sus capacidades, así como la comunicación colectiva y la cooperación”. ${ }^{11} \mathrm{Y}$ en este sentido, aunque los patrones distributivos son importantes para garantizar que en una sociedad exista equidad y se garantice que todos los ciudadanos y grupos tengan un lugar similar dentro de la sociedad, hay cuestiones que no se pueden ver exclusivamente desde la distribución y que, no obstante, son esenciales para incluir a los diversos grupos sociales en condiciones de igualdad, como los procesos de toma de decisiones, la división del trabajo y la cultura. ${ }^{12}$

Me referiré especialmente, y en razón de las reflexiones que pretendo hacer en este texto, a los procesos de toma de decisiones y a la forma como Young considera que una democracia deliberativa puede precisamente garantizar que las discusiones y las decisiones que se tomen en el espacio público sean más incluyentes y, en este sentido, más legítimas y justas, para luego hacer esa misma reflexión respecto a lo que ha debido suceder antes del plebiscito en Colombia. Young considera que una decisión democrática debe guiarse por cuatro ideales normativos: inclusión, igualdad política, razonabilidad y publicidad. Una decisión es incluyente cuando se involucra

11 Iris Marion Young, Justice and the politics of difference (Pricenton: Pricenton University Press, 1990).

12 Young llama también a estas injusticias estructuras de opresión o caras de la opresión, puesto que ellas se encuentran incluidas en normas que no son cuestionadas, sino que más bien están naturalizadas, así como en hábitos y prácticas sociales de la vida cotidiana que se reproducen en las instituciones económicas, políticas y culturales, y que impiden a muchos grupos acceder a las mismas oportunidades que los grupos dominantes sí tienen en sociedades reales. Así, por ejemplo, dentro de la división del trabajo se tiene cierto tipo de creencias como que hay actividades que las cumplen mejor los hombres que las mujeres; se supone que las mujeres "naturalmente" son mejores para el cuidado de las personas o que ciertas clases sociales o razas tienen que dedicarse a trabajos domésticos, servicios en restaurantes, hoteles o de labores en el campo, y todas estas creencias y formas de dominación se producen y reproducen en las instituciones sociales, económicas y culturales sin que las cuestionemos. Young, Justice and the politics. 
en el proceso de deliberación y toma de decisiones a todos los afectados por la decisión. La igualdad política consiste en que los afectados por una decisión "deben incluirse en igualdad de condiciones". Esto implica no solamente oportunidades iguales para hablar y presentar argumentos y propuestas, sino también gozar de "libertad de dominación", en el sentido de que nadie puede estar "en la posición de coaccionar o amenazar a otros para que acepten ciertas propuestas o resultados". En una democracia deliberativa, ser razonable significa que las personas discuten con el fin de lograr acuerdos y que, en caso de no lograrlos, existen procedimientos "para llegar a decisiones y registrar el disenso cuando no haya acuerdo". ${ }^{13}$ Según Young, se es razonable cuando se está dispuesto a escuchar a los otros y a cambiar nuestras opiniones cuando estas son incorrectas, inapropiadas o injustas. Finalmente, para Young, las condiciones de inclusión, igualdad y razonabilidad "implican que la interacción entre los participantes en un proceso de toma de decisión democrático formen un público en el cual los individuos se exijan responsabilidad recíproca” ${ }^{14}$ Así, los participantes llegan a una decisión "no determinando qué preferencias tiene el mayor número de votos que las apoyan, sino expresando qué tipo de propuestas son soportadas con base en las mejores razones". Young contrasta el modelo deliberativo de democracia con el que ella denomina agregativo, en el que se considera a la democracia una competencia entre intereses privados y preferencias, como si se tratara de responder privadamente a una encuesta. ${ }^{15}$

Considero que la forma como se discutieron y se tomaron decisiones en la negociación de los Acuerdos de La Habana se caracterizó por ser un ejercicio de democracia deliberativa: existían unos puntos sustantivos sobre los que se tenía interés en discutir, previamente acordados por las partes y que tenían que ver con problemas reales de los que eran responsables tanto el Estado colombiano como las FARC; se tenía un equipo que representaba a cada parte con asesores en los diferentes temas; las posiciones que cada uno defendía tenían que ser explicadas y probablemente ser sustentadas en razones que, aunque no se compartieran por la contraparte, fueran discernibles; se tenía un conjunto de normas jurídicas tanto de derecho interno

\footnotetext{
13 Young, Inclusion and democracy, 23.

14 Young, Inclusion and democracy, 24.

15 Young, Inclusion and democracy, 19-23.
} 
como de derechos humanos que se debían respetar, y que, por tanto, servían de guía y límite a las discusiones y decisiones acordadas. Estos límites normativos podrían sintetizarse en el ideal normativo de alcanzar una paz justa, es decir una paz que reconociera los derechos de las víctimas y, a su vez, las responsabilidades institucionales, colectivas e individuales de quienes ejercieron directamente la violencia o de quienes indirectamente se sirvieron de ella, que es precisamente el ideal normativo que pretende alcanzar la justicia transicional. ${ }^{16}$ No obstante, este mismo ejercicio deliberativo no se trasladó a la sociedad. Los ciudadanos votaron en muchos casos sin conocer el Acuerdo Final, y quienes se abstuvieron de votar no se sintieron concernidos con lo que se estaba jugando en la refrendación.

La pregunta entonces es ¿cómo se hubiera podido llevar este ejercicio de deliberación democrática a la sociedad? Aunque es evidente que no se podía hacer el mismo ejercicio de las discusiones de La Habana, sí podría haberse hecho un ejercicio mucho más pedagógico para que los colombianos hubiéramos entendido mejor los contenidos de los acuerdos y lo que estaba en juego al votar en sentido positivo o negativo el Acuerdo Final. En este sentido, el proceso pedagógico no consistía en llevar a los micrófonos las disputas mientras los negociadores estaban estudiando cada uno de los puntos del Acuerdo, tampoco consistía en invitar a las personas a que se leyeran los acuerdos, ya que eran el resultado final de estos, pero no su explicación, no sus razones. Se hubiera requerido conocer luego de que cada uno de los seis puntos fueran acordados por las partes, en especial de los más sustantivos, a grandes rasgos: las posiciones de cada una de las partes al comenzar las discusiones; las razones que se esgrimían desde cada orilla; la posición a la que habían llegado al final de cada punto; lo que se cedía,

16 El secretario general de las Naciones Unidas definió la justicia transicional de la siguiente manera: "La justicia transicional abarca toda la variedad de procesos y mecanismos asociados con los intentos de una sociedad por resolver los problemas derivados de un pasado de abusos a gran escala, a fin de que los responsables rindan cuentas de sus actos, servir a la justicia y lograr la reconciliación. Tales mecanismos pueden ser judiciales o extrajudiciales y tener distintos niveles de participación internacional (o carecer por completo de ella) así como abarcar el enjuiciamiento de personas, el resarcimiento, la búsqueda de la verdad, la reforma institucional, la investigación de antecedentes, la remoción del cargo o combinaciones de todos aquellos". Organización de las Naciones Unidas —ONU一, Consejo de Seguridad, Informe del Secretario General sobre "Estado de Derecho y Justicia Transicional en sociedades en conflicto y postconflicto", http://daccess-dds-ny.un.org/doc/UNDOC/GEN/N04/395/32/ PDF/N0439532.pdf?OpenElement 
desde cada parte, lo que se reconocía al otro; los estándares normativos que habían inspirado los resultados a los que se habían llegado, y las formas en las que se garantizaba esa paz justa. De la misma manera, se debería haber incluido las peticiones hechas por los diversos grupos de colombianos que enviaron sus propuestas a los negociadores, en especial por los diversos grupos de víctimas que enviaron dichas propuestas o estuvieron presentes en La Habana. En otras palabras, la idea hubiera sido hacer mayor énfasis en el proceso de toma de decisión que en el resultado obtenido al final. Igualmente, el énfasis pedagógico debería haberse centrado más en los derechos de las víctimas y cómo se estaban protegiendo en el Acuerdo de Paz, y menos en las concesiones que se le estaban haciendo a las FARC. Así mismo, se debía resaltar la forma como el Acuerdo respondía no solo a las víctimas, sino a muchos de los colombianos que el régimen político ha excluido históricamente, y a la forma como los puntos de participación política, reforma rural integral y el problema de las drogas pretendía responder a esta exclusión.

Los medios tendrían que haberse comprometido a hacer una pedagogía que incluyera discusiones de expertos, de líderes políticos, sociales y de víctimas en favor o en contra de las propuestas, en los horarios de mayor audiencia y en todas las redes sociales. Los diversos estamentos del sistema educativo público y privado tendrían que haberse involucrado en la difusión de lo que se iba acordando, y de la forma como se había construido y concertado. Todas las instancias del Gobierno, como una política de Estado, deberían haberse sumado a llevar a la ciudadanía de todas las regiones de Colombia estas discusiones. Luego de los resultados, reacciones y observaciones de los diversos grupos sociales, se hubiera podido buscar mecanismos para hacer observaciones a los Acuerdos, con el compromiso por parte de los negociadores de discutirlos, señalando nuevamente a la sociedad los consensos que se habían logrado y las razones por las que muchas propuestas de la sociedad civil no se podían incorporar a los Acuerdos. Probablemente el periodo de negociación hubiera sido más lento, pero se hubiera podido tener un mejor conocimiento de lo que ocurría en las negociaciones, acallando las voces que querían manipular a la opinión pública con mentiras acerca de lo que se estaba acordando en La Habana.

Después del plebiscito, en la sociedad colombiana quienes discutían los Acuerdos eran los líderes políticos que representan el Sí, y quienes se 
oponían a estos, incluyendo la nueva versión del Acuerdo Final, ${ }^{17}$ pero aparecían muy poco los diversos grupos de víctimas, y en especial ese $63 \%$ de ciudadanos colombianos que se abstuvo de votar. Habría que preguntarse por qué ellos no votaron; me atrevería a decir que en muchos de los grupos que se abstuvieron de votar hay una inmensa mayoría de colombianos que no cree que su situación económica, social y política va a cambiar con un Acuerdo de Paz. No se sienten concernidos, no porque no les importe el país o la paz, sino porque sus necesidades y demandas siempre han sido desatendidas por el Estado, porque se encuentran cansados de ser excluidos por unas élites que solo los tienen en cuenta en las promesas de campaña y que olvidan cuando llegan al poder. Me pregunto si estos grupos se sienten representados por las figuras políticas que lideran el No, y es probable que para ellos sean ajenas estas disputas, y somos tan soberbios o torpes que seguimos sin escuchar sus razones de por qué no votaron.

Si el Gobierno hubiera hecho un proceso más pedagógico de los Acuerdos podría haber concitado el interés de algunos de estos grupos sociales que se abstuvieron de votar. En este sentido hubiera sido importante hacer énfasis en una distinción que hacen algunos autores entre una transición política y la justicia transicional propiamente. ${ }^{18}$ La justicia transicional es un aspecto de la transición política pero no el único. Parafraseando al filósofo norteamericano Michael Walzer, para que una transición política hacia la paz sea duradera tiene que existir una armonía y coherencia entre diferentes esferas de la justicia. Así, por ejemplo, un modelo de justicia transicional puede garantizar de la mejor forma el esclarecimiento de las atrocidades del pasado; permitir la rendición de cuentas de los actores e instituciones responsables de la violencia; contar con los mecanismos para reparar los daños sufridos por las víctimas; construir una memoria que contribuya a entender el pasado y a reconocer la dignidad de diversos grupos de ciudadanos víctimas de la violencia. Sin embargo, si a esta esfera de la justicia, es decir la transicional, no se la mira en relación con otras esferas

17 Véase "Acuerdo final para la construcción de una paz estable y duradera, con modificaciones", El Espectador, http://www.elespectador.com/files/pdf_files/597c60eb35c55f02629da71e72e51921. pdf

18 Tony Addison, "The political economy of the transition from authoritarianism", en Transitional justice and development: Making connections, editado por De Greiff P. y Duthie, R (Nueva York: ICTJ y sSRC, 2009). 
de la justicia, por ejemplo dar respuesta desde la justicia distributiva y de la justicia como reconocimiento a las injusticias históricas y estructurales de muchas de las instituciones económicas, sociales y políticas, que producen inequidad y exclusión, la justicia transicional por sí sola no puede garantizar una paz duradera. Es aquí en donde también faltó pedagogía: los Acuerdos de La Habana no trataban solo de responder a los temas propios de la justicia transicional, sino que procuraban reconocer por fin, así fuera tímidamente, problemas de injusticias estructurales que el régimen colombiano ni en tiempos de guerra ni de paz ha tomado en serio. En los puntos de desarrollo rural integral, de participación política y de solución al problema de drogas ilícitas, estaba - y aún está- la respuesta a muchos de los intereses legítimos que tiene la mayoría de los colombianos, y que el Estado y las élites nacionales y locales nunca han enfrentado. En estos puntos realmente sí se estaba constituyendo un nuevo pacto social de reformas para que en un largo plazo la sociedad colombiana pudiera llegar a ser más incluyente y más equitativa. Si esto hubiera sido más claro en la pedagogía de los Acuerdos, muy seguramente muchos de quienes se abstuvieron de votar lo hubieran hecho.

Aunque el Acuerdo firmado en el Colón contiene casi todas las propuestas hechas por los líderes políticos que se abrogaron la vocería de quienes votaron por el No en el plebiscito, ellos continúan pensando que no fue suficiente la inclusión de ajustes, aclaraciones y reformas sustanciales, y han decidido no apoyar este Acuerdo de Paz. Los días posteriores al plebiscito permitían hacer dos tipos de lecturas respecto a los líderes políticos que se tomaron la vocería del No: una lectura benevolente consistía en entender que existían muchos aspectos del Acuerdo que se podían mejorar, que había forma de clarificar y acotar muchos puntos que merecían un mejor desarrollo para garantizar los derechos de las víctimas y de los colombianos; y existía una lectura menos benevolente que se basaba en la idea de que los líderes políticos del No no estaban realmente interesados en las víctimas y en la paz, sino en sus propios intereses políticos y electorales, y que el Acuerdo Final no solo les quitaba el protagonismo de la paz, sino también implicaba la pérdida de muchos de los privilegios que muchos aspectos de los Acuerdos eliminaba. 
Hoy, después de que ya se han expedido algunas normas, entre ellas el Acto Legislativo 01 del 4 de abril del 2017, ${ }^{19}$ que regula el Sistema Integral de Verdad, Justicia, Reparación y no Repetición, persiste un ambiente de escepticismo entre muchos grupos sociales, y en algunos casos de abierto rechazo al Acuerdo Final, sin que se conozca en profundidad su contenido. Así, pareciera que la lectura menos benevolente del Acuerdo Final parece imponerse, y su implementación puede realmente estar en riesgo si los gobiernos subsiguientes no se comprometen a implementar la totalidad de los puntos del Acuerdo. ${ }^{20}$ Evocando a Walter Benjamin en las tesis Sobre el concepto de historia, ${ }^{21}$ en Colombia estamos viviendo un momento de extremo peligro de continuar la guerra, pero parece que no queremos reconocer esa realidad, y preferimos aferrarnos a nuestros intereses egoístas y privilegios; parece que preferimos seguir atrapados en la violencia y no aceptar nuestras responsabilidades provenientes del pasado y que tenemos con los ciudadanos víctimas del conflicto armado.

\section{Bibliografía}

"Acuerdo final para la construcción de una paz estable y duradera, con modificaciones". El Espectador, http://www.elespectador.com/files/ pdf_files/597c60eb35c55f02629da71e72e51921.pdf

19 Acto Legislativo 01 del 2017, 4 de abril. Por medio del cual se crea un título de disposiciones transitorias de la Constitución para la terminación del conflicto armado y la construcción de una paz estable y duradera, y se dictan otras disposiciones.

20 Algunos podrían afirmar que lo que le interesa a la sociedad es la implementación de los Acuerdos y la forma como en efecto, al final, se responde a un pasado de violencia, pero lo que vemos es que existe una carencia de legitimidad que proviene de esa ausencia de democracia deliberativa para conocer y discutir los Acuerdos, a la que antes me referí, que muchos líderes políticos han usado para su propio beneficio. Esta ausencia de legitimidad del Acuerdo Final se vio reflejada en la marcha a la que convocó el Centro Democrático el 8 de abril del 2017, en la que muchos grupos salieron a marchar contra los Acuerdos, a pesar de que ya los miembros de las FARC se encuentran en las zonas veredales y han empezado a entregar las armas. Es interesante escuchar las voces de dos desmovilizados de la guerrilla del ELN y de tres dirigentes de organizaciones sociales que impulsan la participación de la sociedad en el proceso de paz con el ELN, pues en todas sus intervenciones se señala la necesidad de hacer más pedagogía de las negociaciones en la ciudadanía, y de que exista una verdadera participación social en las negociaciones a fin de evitar la ausencia de legitimidad de los Acuerdos de La Habana. "Consejos para la Mesa de Quito". El Espectador, 3 de abril del 2017, http://colombia2020.elespectador.com/pais/consejos-para-la-mesa-de-quito

21 Manuel Reyes Mate, Medianoche en la historia. Comentarios a las tesis de Walter Benjamin, Sobre el concepto de historia (Madrid: Editorial Trotta, 2006). 
“Consejos para la Mesa de Quito”. El Espectador, 3 de abril del 2017, http://colombia2020.elespectador.com/pais/consejos-para-la-mesade-quito

"El saldo rojo de la Unión Patriótica”. Verdad Abierta, http://www.verdadabierta.com/justicia-y-paz/157-el-saldo-rojo-de-la-union-patrioticaSee

"La desigualdad en Colombia es mayor de lo que se piensa". ElTiempo, 20 de marzo del 2016, http://www.eltiempo.com/economia/sectores/ desigualdad-en-colombia-es-mayor-de-lo-que-se-piensa-dicecepal/16546686

Acto Legislativo 01 del 2017, 4 de abril. Por medio del cual se crea un título de disposiciones transitorias de la Constitución para la terminación del conflicto armado y la construcción de una paz estable y duradera, $\mathrm{y}$ se dictan otras disposiciones.

Addison, Tony. "The political economy of the transition from authoritarianism”, en Transitional justice and development: Making connections, editado por P. de Greiff y R. Duthie. Nueva York: Ictj y ssrc, 2009.

Centro Nacional de Memoria Histórica. ;Basta Ya! Colombia: Memorias de Guerra y Dignidad. Bogotá: Centro Nacional de Memoria Histórica, 2013.

Dworkin, Ronald. Principles for a new political debate. Is democracy possible here? Princeton: Princeton University Press, 2006.

Mate, Manuel Reyes. Medianoche en la historia. Comentarios a las tesis de Walter Benjamin, Sobre el concepto de historia. Madrid: Editorial Trotta, 2006. Organización de las Naciones Unidas — ONU—, Consejo de Seguridad. Informe del Secretario General sobre "Estado de Derecho y Justicia Transicional en sociedades en conflicto y postconflicto", 2004, http://daccessdds-ny.un.org/doc/UNDOC/GEN/N04/395/32/PDF/N0439532. pdf?OpenElement

Ramírez, Juliana. "El no ha sido la campaña más barata y más efectiva de la historia”. La República, 5 de octubre del 2016, http://www.larepublica.co/el-no-ha-sido-la-campa\%C3\%B1a-m\%C3\%A1s-baratay-m\%C3\%A1s-efectiva-de-la-historia_427891

Registraduría Nacional del Estado Civil. "Resultados plebiscito", http://www.registraduria.gov.co/?page=plebiscito_2016 
Saffon, María Paula. "Democracia para la paz”. El Espectador, 14 de octubre del 2016, http://www.elespectador.com/opinion/democracia-paz Sentencia C-379 del 2016, 18 de julio. MP: Luis Ernesto Vargas Silva. Young, Iris Marion. Justice and the politics of difference. Pricenton: Pricenton University Press, 1990.

Young, Iris Marion. Inclusion and democracy. Oxford: Oxford University Press, 2000. 



\title{
Las emociones en el proceso de paz colombiano*
}

\author{
Diana Carolina Valencia-Tello
}

\section{Introducción}

Según el informe ;Basta ya! Colombia: Memorias de guerra y dignidad, elaborado por el Centro Nacional de Memoria Histórica, el conflicto armado colombiano se ha prolongado por más de 50 años y, en razón a su magnitud, ferocidad y degradación, es difícil explicar las razones que han motivado la guerra. Este informe calcula que entre 1958 y el 2012 el conflicto armado ocasionó la muerte de por lo menos 220.000 personas. Otros datos señalan que el conflicto ha dejado aproximadamente 6,9 millones de desplazados, 45.000 personas desaparecidas y 27.000 personas secuestradas. ${ }^{1}$

Con la finalidad de terminar el conflicto armado, el 26 de septiembre del 2016 se firmó oficialmente en Cartagena de Indias el primer Acuerdo de Paz entre el gobierno de Juan Manuel Santos y las Fuerzas Armadas Revolucionarias de Colombia — FARC—, tras cuatro años de conversaciones en La Habana, Cuba.

* Agradezco los valiosos comentarios realizados al artículo por parte de Lina Céspedes y Enrique Prieto.

** Profesora principal de Derecho Administrativo de la Universidad del Rosario. Maestría, doctorado y posdoctorado en Derecho de Estado de la Universidad Federal del Paraná. Correo electrónico: dianac.valencia@urosario.edu.co

1 Centro de Memoria Histórica, ;Basta ya! Colombia: Memorias de Guerra y Dignidad. Informe General Grupo de Memoria Histórica (Bogotá: Departamento para la Prosperidad Social, 2013), 19. 
El Acuerdo de Paz de 297 hojas se hizo público el 24 de agosto del 2016, es decir, casi un mes antes de la firma oficial del Acuerdo y, en consecuencia, la opinión pública tuvo solo un mes para conocer su contenido, pues las negociaciones se realizaron a puerta cerrada la mayor parte del tiempo.

Con la finalidad de refrendar el Acuerdo de Paz por todos los colombianos, el presidente Santos convocó un plebiscito el 2 de octubre de 2016. El Acuerdo no fue avalado por el 50,21\% de los colombianos, lo que representa una diferencia menor del 0,5 porcentual entre los colombianos a favor y en contra del Acuerdo Final con las farc. Aun así, se debe resaltar que el gran ganador de la jornada fue la abstención, que alcanzó el 62,59\%. ${ }^{2}$

El resultado del plebiscito por la paz sorprendió no solo al Gobierno, sino también a los integrantes de la campaña por el No. E1 5 de octubre, en La República, el gerente de la campaña por el No, Juan Carlos Vélez, declaraba que: "el No fue la campaña más barata y efectiva en mucho tiempo. Su costo-beneficio es muy alto". En su opinión, la estrategia de buscar que la "gente saliera a votar verraca" funcionó. E1 dirigente explicó la campaña en los siguientes términos:

\begin{abstract}
Unos estrategas de Panamá y Brasil nos dijeron que la estrategia era dejar de explicar los acuerdos para centrar el mensaje en la indignación. En emisoras de estratos medios y altos nos basamos en la no impunidad, la elegibilidad y la reforma tributaria, mientras en las emisoras de estratos bajos nos enfocamos en subsidios. En cuanto al segmento en cada región utilizamos sus respectivos acentos. En la Costa individualizamos el mensaje de que nos íbamos a convertir en Venezuela. Y aquí el No ganó sin pagar un peso. En ocho municipios del Cauca pasamos propaganda por radio la noche del sábado centrada en víctimas. ${ }^{3}$
\end{abstract}

2 Registraduría Nacional del Estado Civil. Plebiscito, 2 de octubre del 2016, http://plebiscito. registraduria.gov.co/99PL/DPLZZZZZZZZZZZZZZZZZ_L1.htm

3 "El no ha sido la campaña más barata y efectiva de la historia". La República, 5 de octubre del 2016, http://www.larepublica.co/el-no-ha-sido-la-campaña-más-barata-y-más-efectiva-de-lahistoria_427891 
La campaña por el No al plebiscito por la paz es un ejemplo de cómo las campañas políticas utilizan de forma exagerada emociones como la esperanza y el miedo, sin que exista una reflexión responsable sobre las consecuencias que puede tener este tipo de estrategias para la cohesión social y la estabilidad del país.

En este orden de ideas, el presente artículo busca analizar cómo el exagerado apelo a emociones conflictivas en la política colombiana no ha permitido, hasta el momento, la construcción de caminos de paz que ayuden a la reconciliación entre los diversos actores del conflicto. Consideramos que después de décadas de guerra y sufrimiento es fundamental despertar otro tipo de emociones, como la compasión, para canalizar los compromisos de inclusión, igualdad o mitigación del sufrimiento, que deben existir en la sociedad para la construcción de una paz estable y duradera.

Según Martha Nussbaum, las emociones públicas tienen grandes consecuencias en el progreso de una nación, pues estas pueden impulsar la lucha por el logro de objetivos, pero también pueden descarrilarla, introduciendo o reforzando divisiones y jerarquías presentes en las sociedades. Por ello afirma que "(...) toda sociedad necesita reflexionar sobre la estabilidad de su cultura política a lo largo del tiempo y sobre la seguridad de sus valores más preciados por ella en épocas de tensión". ${ }^{4}$

Así, buscando realizar una reflexión sobre el tipo de emociones utilizadas para impulsar el proceso de paz colombiano, una versión preliminar de este artículo fue presentado en el XXVII World Congress of the International Association for the Philosophy of Law and Social Philosophy realizado en Washington D.C. en el 2015, el cual estuvo dedicado al análisis del “derecho, las razones y las emociones". Varias ideas aquí presentadas se encuentran en una fase inicial de investigación, utilizando principalmente el marco conceptual elaborado por Manuel Castells en su libro Comunicación y poder. ${ }^{5}$

En el presente artículo, primero se analizará de forma general el papel de las emociones en los procesos de comunicación, para después estudiar

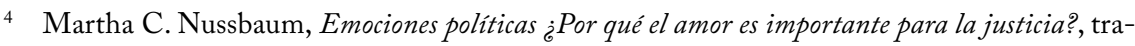
ducido por Albino Santos Mosquera. 4a ed. (Barcelona: Paidós, 2017), 15.

5 Manuel Castells, Comunicación y poder, traducido por María Hernández Díaz (Madrid: Alianza, 2011).
} 
la forma como se realizan las campañas políticas en la actualidad con las nuevas tecnologías. En la tercera sección, estudiaremos algunos antecedentes sobre el proceso de paz colombiano, para después, en la cuarta sección, tratar el papel de las emociones en las campañas políticas y el proceso de paz colombiano. Finalmente, se realizarán algunas conclusiones.

\section{El papel de las emociones en los procesos de comunicación}

Los humanos desde que nacemos necesitamos de la protección (por varios años) de otros seres humanos para sobrevivir y aprender diversas habilidades cognitivas y emocionales para socializar y comunicarnos de forma efectiva con nuestros pares. Por esto, Aristóteles categóricamente afirmaba que la propia naturaleza humana arrastra instintivamente a todos los hombres a la asociación política, porque el hombre es "un ser naturalmente sociable". ${ }^{6}$

La comunicación como habilidad social que me permite relacionarme con el otro y manifestar al mundo mis ideas y sentimientos es fundamental en la construcción de nuestras relaciones sociales, y, por ende, en la construcción de nuestras instituciones; es a través de la comunicación que establecemos significados y propósitos compartidos que nos ayudan a determinar las reglas básicas que gobiernan nuestras relaciones y las instituciones en la sociedad. En este orden de ideas, la comunicación de ideas y sentimientos es clave en todo proceso de lucha por el poder, porque es mediante ella que construimos significados entre los miembros de la comunidad, ayudando a fortalecer la legitimidad de nuestras instituciones, lo que se traduce en comportamientos más colaborativos o cooperativos entre los miembros. Pero también es mediante la comunicación que cuestionamos las instituciones existentes, al crear resistencias sobre el orden previamente establecido, lo que se refleja en comportamientos menos colaborativos en relación con los objetivos comunes planteados por las instituciones que representan la colectividad. Esto lleva a Castells a afirmar que

La capacidad para lograr el consentimiento o al menos para instar el miedo y resignación respecto al orden existente es fundamental para imponer las reglas que gobiernan las instituciones y las

6 Aristóteles, A Política, traducción de Roberto Leal Ferreira (São Paulo: Martins Fontes, 1998). 
organizaciones de la sociedad. Y en todas las sociedades esas reglas representan las relaciones de poder incorporadas en las instituciones como resultado de los procesos de lucha y compromiso entre actores sociales enfrentados que se movilizan por sus intereses bajo la bandera de sus valores. ${ }^{7}$

Así, la dominación (entendida como el poder que reside en las instituciones sociales) sobre los otros se realiza mediante procesos de comunicación que pueden lograr consentimiento o instar el miedo en los individuos pertenecientes a una determinada sociedad, buscando establecer un determinado orden con relaciones de poder definidas entre quienes tienen derecho a mandar y quienes tienen el deber de obedecer.

Por lo tanto, el poder y la contestación al poder se ejercen con ayuda de argumentos y sentimientos compartidos en las sociedades, lo que crea diversas tensiones que dan forma a las instituciones, los valores y las creencias en los individuos, los cuales varían permanentemente a través del tiempo.

La sinapsis existente entre la razón y la emoción al momento de construir las diversas relaciones de poder en las sociedades está bien documentada por varios autores. Según Cruz, la visión tradicional racionalista colocaba las emociones por fuera del campo de la razón, pero nuevos estudios han demostrado que estas forman parte del ejercicio de la racionalidad, pues tienen una inferencia directa en la toma de decisiones, tanto desde los marcos interpretativos culturales, como desde los elementos objetivos que están contenidos en la acción social y política. ${ }^{8}$

Damasio, en su libro El error de Descartes, demuestra cómo es un error colocar la razón y los sentimientos en lados opuestos, ya que los segundos tienen un marcado predominio en las labores de la razón y, en su concepto, “(...) tomar conciencia del rol preponderante de los sentimientos nos da la oportunidad de realzar sus efectos positivos y disminuir al mismo tiempo su potencialidad lesiva". ${ }^{9}$ En concreto, Damasio afirma:

\footnotetext{
7 Castells, Comunicación y poder, 34.

8 Alba Lucia Cruz Castillo, "La razón de las emociones formación social, política y cultural de las emociones". Revista Eleuthera 6 (enero-junio, 2012): 64-81.

9 Antonio R. Damasio, El error de Descartes. La razón de las emociones, traducido por Pierre Jacomet (Santiago de Chile: Editorial Andres Bello, 1996), 274.
} 
Solo sugiero que determinados aspectos del proceso de la emoción y del sentimiento son indispensables para la racionalidad. En su versión afirmativa, los sentimientos nos encaminan en la dirección adecuada, nos llevan al lugar apropiado en un espacio decisorio en que podemos poner en acción, convenientemente, los instrumentos de la lógica. Enfrentamos la incertidumbre cada vez que tenemos que hacer un juicio moral, decidir el curso de una relación personal, elegir medios que impidan la miseria en la ancianidad, planear la vida que tenemos por delante. Emociones y sentimientos, junto con la encubierta maquinaria fisiológica subyacente, nos asisten en la amedrantadora tarea de predecir el futuro incierto y planear consecuentemente nuestros actos. ${ }^{10}$

Por su parte, Jasper afirma que las emociones son parte de la cultura y, por ello, los seres humanos somos socializados o no socializados bajo determinados sentimientos y emociones; de esta forma, las emociones son fundamentales en las acciones y relaciones sociales pues moldean las expectativas sociales (lo deseable y lo no deseable). Así, son inseparables de los procesos políticos, ya que son un componente esencial del proceso interpretativo que crea el mundo de cada persona dentro de su comunidad política. ${ }^{11}$ En este sentido, Gould afirma que "en lugar de ser un impedimento para el pensamiento, sentir es uno de los muchos modos en que las personas adquieren conocimiento y comprensión". ${ }^{12}$

Según Nussbaum, todas las sociedades están llenas de emociones y las democracias liberales no son la excepción. Muchas emociones públicas tienen que ver con los objetivos de la Nación, las instituciones y sus dirigentes, pero también con la geografía y con los principios y los compromisos clave que marcaron la historia de las comunidades, así como la percepción que los ciudadanos comparten sobre un espacio público en común. ${ }^{13}$

10 Damasio, El error de Descartes, 12-13.

11 James M. Jasper, "The emotions of protest: affective and reactive emotions in and around social movements". Sociological Forum 13, n. ${ }^{\circ} 3$ (1998): 404.

12 Deborah B. Gould, "Passionate political processes: bringing emotions back into the study of social movements”, en Rethinking social momements: structure, meanings and emotions, editado por Jeff Goodwing y James M. Jasper (Lanham, Maryland: Rowman \& Littlefield Publishers, 2004), 45.

13 Nussbaum, Emociones politicas, 14-15. 
Castells, al momento de estudiar la forma en que se construyen los diversos mecanismos de poder en nuestras sociedades, analiza a Foucault, ${ }^{14}$ Weber ${ }^{15}$ y Habermas ${ }^{16}$ para determinar que existe un apoyo complementario y recíproco entre los dos mecanismos principales de formación de poder, que son la violencia y el discurso. ${ }^{17}$ La violencia o la amenaza de violencia (como forma de coacción física) es la forma más antigua y básica de poder, que todos los pueblos han usado en algún momento para instaurar un determinado orden con base en el miedo a las autoridades y las instituciones establecidas. Por su parte, los discursos (como técnica para lograr el consentimiento de otros ciudadanos sin recurrir al uso de la fuerza) utilizan la comunicación de razones y emociones entre los miembros de la comunidad para convencer a la mayoría, buscando el consentimiento y la legitimidad en las decisiones que afectan a todos.

Para Cruz, las emociones son fundamentales al momento de involucrar a los individuos en la acción política, pues los diversos procesos sociales las moldean causando que estas creen o refuercen el universo político a través del proceso de la participación en el que se desarrolla la interacción social. De esta forma, "la realidad no podría explicarse en su totalidad si no se incorpora al actor sentiente en las dinámicas humanas de interactividad e intercomunicación". ${ }^{18}$

Teniendo en cuenta lo anterior, la retórica, entendida como el arte de la persuasión y como un arte político, se caracteriza por el uso de diversas técnicas para enfrentar ideas, opiniones y argumentos que buscan convencer al auditorio sin necesitar de la coacción física o del uso de la violencia.

En la antigua Grecia, los sofistas (término que inicialmente significaba sabio) fueron los primeros que se interesaron por el debate entre ideas opuestas. El juego de los opuestos señalaba que cada hombre en sus relaciones sociales es apenas una parte del todo, y que para ser entendido, debía ser pensado en relación con su opuesto. En el derecho, el juego de los opuestos ayudó a determinar que para que exista justicia es necesario escuchar a

\footnotetext{
14 Michel Foucault, Vigilar y castigar: nacimiento de la prisión (Madrid: Siglo xxI, 2009).

15 Max Weber, Economía y sociedad (Madrid: FCE, 1993).

16 Jürgen Habermas, Problemas de legitimación en el capitalismo tardio (Madrid: Cátedra, 1999).

17 Castells, Comunicación y poder, 35.

18 Cruz Castillo, La razón, 64-81.
} 
la contraparte. En la política, este juego permitió que en las asambleas de ciudadanos se discutieran las ideas antes de llegar al consenso político. El debate de ideas implicaba desde el inicio la existencia de diversos intereses, y, a veces, una ruptura en la comunidad política, ya que la opinión de un grupo de ciudadanos podía ser diametralmente opuesta a la de otro grupo de ciudadanos. Así, la política existe cuando hay dos o más intereses/ideas en discusión, ya que todo debate político necesita de argumentos y contra argumentos. ${ }^{19}$

Para Protágoras, uno de los principales representante de los sofistas, las creencias son relativas y subjetivas, porque todo depende del punto de vista de cada persona y, por lo tanto, son imposibles las definiciones absolutas, pues lo que puede ser verdadero para una persona, puede ser falso para otra. ${ }^{20}$ Para los sofistas, todo argumento tiene dos polos que pueden ser válidos, lo que causó el uso indiscriminado de argumentos con el fin de ganar debates sin mayores referentes éticos o morales, lo cual generó el desprecio histórico por los sofistas por defender cualquier argumento como verdad a cambio de dinero. ${ }^{21}$

Teniendo en cuenta la importancia de los debates para el funcionamiento de la democracia, Aristóteles, en su libro Retórica, determinó que en todo discurso existen dos elementos principales que se coordinan para convencer. El primero son los argumentos o las razones lógicas que el orador presenta, y el segundo, no menos importante, son las emociones que el orador debe transmitir para que el público sienta empatía hacia él y hacia las ideas por él presentadas. Aunque las emociones pueden no tener relación alguna con los argumentos lógicos presentados, son fundamentales a la hora de convencer al público. ${ }^{22}$ En palabras de Aristóteles, las emociones

\section{(...) son las causas que hacen alterar los seres humanos e introducen cambios en sus juicios, en la medida en que ellas comportan dolor}

19 Carlos Cirne-Lima, Dialéctica para principiantes (São Leopoldo: Ed. Unisinos, 2002), 33-35.

20 Will Buckingham et al., O libro da filosofia, traducido por Douglas Kim (São Paulo: Globo, 2011).

21 Cirne-Lima, Dialéctica para principiantes, 33-35.

22 Moises Vale Dos Santos, Razão e emoção na arte retórica de Aristóteles (Curitiba: Ed. crv, 2014), 86 . 
y placer: tales son la ira, la compasión, el miedo y otras semejantes, así como sus contrarias ${ }^{23}$ (traducción nuestra).

Para persuadir al público el orador debe mostrarse confiable, pues el público se sentirá inclinado a transferir el contenido del discurso a la credibilidad del orador, especialmente en los casos en que existe desconocimiento sobre el asunto tratado. Según Aristóteles, para que el orador tenga credibilidad ante el público es necesario que demuestre prudencia, virtud y benevolencia, de tal forma que cuando los oradores recurren a la mentira es por falta de alguna de ellas o por la falta de todas. ${ }^{24}$

Así, las emociones presentadas por el orador son fundamentales a la hora de persuadir al público pues los sentimientos despertados mueven a las personas en dirección a un determinado juicio o alteran la severidad de este. El orador debe procurar que los oyentes experimenten algún tipo de sentimiento que sea favorable al contenido del discurso por él presentado, para inducir los juicios de los oyentes en dirección a lo que es conveniente. Aun así, para que el discurso sea legítimo se deben presentar argumentos que respeten las leyes de la lógica, pero, al mismo tiempo, se deben utilizar las emociones para mover a las multitudes, sin llegar a trasformar el discurso en manipulación. ${ }^{25}$

Aristóteles en la Retórica caracteriza trece emociones: ira, calma, amistad, enemistad, temor, confianza, vergüenza, desvergüenza, amabilidad, piedad, indignación, envidia y emulación. ${ }^{26}$ Aquí debemos resaltar el uso del juego de los opuestos para describir las emociones que pueden ser utilizadas en un discurso.

Con esto, podemos inducir que la democracia en la Antigua Grecia implicaba un proceso de permanente discusión y debate entre ciudadanos libres, quienes podían presentar sus ideas y sentimientos ante otros ciudadanos, quienes, a su vez, debían ser convencidos mediante diferentes técnicas de persuasión, que incluían argumentos lógicos y apelo de las emociones

23 Aristóteles, Retórica (Lisboa: Biblioteca de Autores Clássicos. Centro de Filosofía da Universidade de Lisboa. Imprensa Nacional-Casa da Moeda, 2005), 159.

${ }^{24}$ Aristóteles, Retórica, 16.

25 Vale Dos Santos, Razão e emoção, 90.

26 Aristóteles, Retórica. 
a favor de determinadas ideas y valores latentes en la comunidad política. En la actualidad la forma de hacer política se ha modificado totalmente en razón al surgimiento de las sociedades en masa y a las nuevas tecnologías, como veremos a continuación.

\section{Campañas políticas y nuevas tecnologías}

Para Alonso Coto y Adell, el comportamiento político en los últimos tiempos ha cambiado notablemente en razón a la creciente importancia de las telecomunicaciones y al comportamiento menos predecible y mucho más consumista de los ciudadanos. ${ }^{27}$

Castells (citando a Fallows) ${ }^{28}$ evidencia cómo la tecnología ha transformado la política por la capacidad de vincular el sistema de los medios en tiempo real con el marketing politico. Desde finales de la década de 1970, la introducción de los ordenadores en la tabulación de las encuestas posibilitó la realización de "investigaciones estratégicas" que permitieron analizar grupos seleccionados de potenciales votantes para modificar las estrategias e, inclusive, el contenido de los mensajes en la medida en que se desarrollaba la campaña política. ${ }^{29}$

Cuando la diversificación y la descentralización de los medios de comunicación fue posible en la década de 1970, debido a las nuevas tecnologías, el dominio de los medios en las actitudes y las conductas políticas de la población se hizo más amplio. ${ }^{30}$ La televisión a cable y las tertulias radiofónicas ayudaron a personalizar la audiencia y permitieron a los políticos orientar mejor su mensaje, según los diferentes grupos de interés. Los sectores ideológicos tuvieron una mayor oportunidad para presentar sus argumentos sin el filtro de los medios mayoritarios. En este contexto, la aparición del Internet permitió también ampliar la propaganda de las

27 Manuel A. Alonso Coto y Angel Adell, Marketing politico 2.0. Lo que todo candidato necesita saber para ganar las elecciones (Barcelona: Gestión 2000, 2011), 69-70.

28 James Fallows, Breaking the news. How the media undermine American democracy (Nueva York: Pantheon, 1996).

29 Manuel Castells, La era de la información. V. II., traducido por Carmen Martínez Gimeno. $7^{\mathrm{a}}$ ed. (México: Siglo xxi, 2008), 352.

30 Doris A. Garber, Mass media in American politics. 2a ed. (Washington D.C.: CQ Press, 1996); Kenneth L. Hacker, "Missing links and the evolution of electronic democratization". Midia, Culture and Society 18 (1996); Castells, La era, 353. 
campañas, los foros de debate y la conexión de los militantes. ${ }^{31}$ Las nuevas tecnologías permiten que los medios de comunicación se dirijan a audiencias específicas, interesadas en confirmar sus opiniones más que informarse en otras fuentes sobre las opiniones opuestas a las propias. ${ }^{32}$

Por lo tanto, la lógica de los medios promueve que ellos deban trabajar para aumentar las audiencias específicas y competir por el entretenimiento, al mismo tiempo que deben buscar independencia ante la política para inducir credibilidad. Esta lógica causa que las noticias estén más interesadas en el espectáculo político que en la noticia que explica e informa a la opinión pública para tener opiniones responsables sobre los temas de interés público. ${ }^{33}$

En la actualidad, los políticos y los gobiernos se volvieron dependientes de las evaluaciones diarias del impacto político de sus decisiones sobre la opinión pública, la cual es medida por encuestas y por estudios de análisis de imagen realizados por expertos contratados, mediante diversas técnicas de marketing político, usando las nuevas tecnologías disponibles. ${ }^{34}$ Esto es así a pesar del margen de error que pueden tener las encuestas, las cuales en muchas oportunidades se han mostrado poco efectivas a la hora de predecir las elecciones de la ciudadanía.

En Marketing político 2.0, se afirma que la mayoría de los candidatos en todo el mundo (en elecciones locales, municipales, sindicales, nacionales o internacionales) ha comenzado a utilizar casi todas las técnicas de marketing político, como los sondeos de opinión vía encuestas, focus groups, anuncios de televisión, campañas de imagen en los medios, telemarketing, marketing directo y, cada vez más Internet en todas sus formas, esto es, marketing móvil, redes sociales, etc. En relación con la aparición del consumidor político, los autores analizan los efectos que ha tenido el consumismo sobre la política, y señalan que los votantes “(...) quieren un producto más

31 Erick Klinenberg y Andrew Perrin, Symbolic politics in the Information Age: the 1996 presidencial campaign in cyberspace (Berkeley: University of California. Department of Sociology. Inedito, 1996); Castells, La era, 353.

32 Castells, Comunicación y poder, 263-264.

33 Todd Gitlin, The whole world is watching: mass media in the making and unmaking of the new left (Berkley: University of California Press, 1980), 28; Castells, La era, 354.

34 Diana Carolina Valencia Tello, El Estado en la era de la globalización y las nuevas tecnologías (Bogotá: Ibañez, 2015), 186. 
tangible que retórico” pues los nuevos votantes prefieren “(...) la eficiencia pragmática a los principios morales”. Así, la lucha por el poder obliga a que los candidatos deban perfilar los mensajes de manera más efectiva; es decir, deben utilizar técnicas de comercialización y venta que funcionan en el mundo empresarial, aunque estas técnicas deben ser adecuadas al universo infinitamente más complejo de la política, donde “(...) no se juega solo con dinero sino con lo más preciado que puede tener una persona: sus esperanzas". ${ }^{35}$

En estos términos, Alonso Coto y Adell presentan el marketing político como la solución para una clase política que necesita romper el desencanto y conseguir que la gente (previamente identificada) se movilice y vaya a votar. En su concepto, un marketing adecuado permite “(...) reavivar el fuego del activismo”, al usar las segmentaciones adecuadas, y diseñar los mensajes en función de las encuestas y focus group, los cuales requieren ser galvanizados por medio de técnicas publicitarias y de comunicación profesionales, además del uso de las redes sociales que ayudan a "sentir" la proximidad del candidato a los votantes. ${ }^{36}$

En este contexto, los medios de comunicación se han convertido en un campo de batalla donde las fuerzas y las personalidades políticas y los grupos de presión están en permanente competencia, tratando de debilitar a los oponentes, para obtener mayores beneficios en las encuestas, las votaciones y las decisiones del Gobierno. Por esta razón, la política en los medios de comunicación es por definición contradictoria, pues actúan diversos actores y estrategias políticas, lo que genera consecuencias inesperadas que nadie puede controlar. ${ }^{37} \mathrm{La}$ idea de diseñar los mensajes en función de las encuestas y focus group evidencia que a este tipo de política informacional no le importa la cohesión social o la idea de comunidad política y espacios de convivencia pacífica y respetuosa de los diversos grupos existentes en la sociedad.

El marketing político es plenamente consciente de las diferencias existentes entre la venta de productos comerciales y "productos políticos". Alonso Coto y Adell señalan que el mercado político es mucho más complejo, puesto que hay demandas más complicadas y conflictivas. Además,

\footnotetext{
35 Alonso Coto y Adell, Marketing político 2.0, 72-73.

36 Alonso Coto y Adell, Marketing político 2.0, 72.

37 Castells, La era, 346-349.
} 
el producto político es intangible y mucho más difícil de comprender y de crear, debido a que los productos tienen un valor simbólico y solo hay un rango disponible, lo que causa que el consumidor solo apoye un producto mientras rechaza todos los demás. También se afirma que el mercado político muchas veces no sabe lo que quiere y que la política tiene que ver con ideologías, no solo con gustos y disgustos sobre las marcas. En definitiva, “(...) la política es una actividad de mucho más largo plazo que el mero marketing empresarial". ${ }^{38}$

De esta forma, la política en la actualidad parece no estar interesada en llegar a consensos para establecer estrategias sobre los principales problemas de las sociedades, pues la "eficiencia pragmática" no tiene tiempo para debatir sobre los valores, principios y compromisos clave que deberían existir, sino, por el contrario, el interés principal se encuentra en luchar por el poder para llegar al Estado, a veces a cualquier precio.

Así, el aumento de la comunicación con ayuda de las nuevas tecnologías no implica el aumento de las capacidades de los políticos y de los ciudadanos para realizar debates responsables y llegar a consensos que beneficien a toda la comunidad. Por el contrario, la información muchas veces es contradictoria y beligerante, lo cual amplía de diversas formas la fragmentación de nuestras sociedades e impide obtener acuerdos mínimos sobre las políticas que afectan a toda la comunidad.

La política en los medios de comunicación tiene poco que ver con la idea de democracia deliberativa basada en la exposición de argumentos profundos, debates y discusiones civilizadas. Los medios pocas veces se concentran en el análisis de los argumentos. Por el contrario, se interesan más por los detalles del espectáculo político, como quién gana, quién pierde, cómo, por qué y cuál fue la última jugada política, lo que demuestra que este tipo de política se concentra mucho más en las emociones públicas, sin mayor conexión con los argumentos racionales que también deberían ser discutidos.

En este contexto, las campañas políticas muchas veces terminan deslegitimando la propia democracia. La falta de debates serios en los medios de comunicación sobre los principales problemas en nuestras sociedades

38 Alonso Coto y Adell, Marketing político 2.0, 74. 
evidencian el excesivo apelo a las emociones públicas, lo que termina siendo insuficiente para generar consensos o políticas públicas coherentes sobre los principales temas de interés público.

De otro lado, los altos costos que deben ser asumidos para entrar en la competencia política por el poder en el Estado obligan a que todo candidato a un cargo de representación popular deba disponer de importantes recursos económicos, lo cual compromete la defensa del interés general a favor de los patrocinadores.

En este sentido, el apoyo de grupos económicos a las campañas mediante el financiamiento crea profundos cuestionamientos sobre la legitimidad del candidato o del partido, debido a que difícilmente se puede representar a la mayoría cuando los candidatos son financiados por grupos económicos. Esto sin contar los casos en que se comprueba la existencia de financiamientos ilegales en las campañas.

El espectáculo político puede ser cada vez más agresivo, lo que ocasiona fuerte polarización de las campañas y de la sociedad, sin mayores posibilidades de llegar a acuerdos mínimos que permitan la existencia de una democracia sana que fortalezca la legitimidad del Estado y de sus instituciones. Un ejemplo de fuerte polarización de las campañas políticas fue la campaña del proceso de paz colombiano, pero para comprender lo sucedido, primero debemos analizar algunos antecedentes.

\section{Antecedentes del proceso de paz colombiano}

En Colombia, el conflicto armado ha sido una constante a lo largo de su historia. A finales de los años ochenta existía cierto consenso en torno a que las guerrillas tenían motivos políticos para revelarse en contra del Estado, razón por la cual para lograr la paz era justo promover un cambio político y social en las instituciones y en las políticas públicas, lo que motivó el clamor por una Constituyente que ayudara a sentar las bases de un nuevo pacto por la paz, que reconociera los intereses y las necesidades de los grupos históricamente excluidos. ${ }^{39}$

Según Lemaitre, este consenso se dio en parte porque muchos estudios académicos, libros, artículos de opinión y reportajes relacionaban la violen-

39 Julieta Lemaitre Ripoll, La paz en cuestión. La guerra y la paz en la Asamblea Constituyente de 1991 (Bogotá: Universidad de los Andes, 2011), 4-6. 
cia de los años ochenta con la de los años cincuenta, la cual se caracterizó por tener motivaciones políticas en razón a las desigualdades existentes en amplios sectores de la población y a la consecuente exclusión por parte del Estado de grupos con interés de participar del debate público. Así, no sorprende que la solución al conflicto armado en Colombia se concentrara en la inclusión de grupos de izquierda en el debate político y en la mejora de las condiciones sociales y económicas de los grupos históricamente excluidos de la sociedad colombiana. ${ }^{40}$

La nueva Constitución de 1991 representaba ese anhelo de paz de los colombianos, quienes mediante el consenso sobre importantes reformas institucionales, buscaban crear un Estado más democrático, participativo y respetuoso de los derechos humanos en todos los sectores de la sociedad, para así construir las condiciones materiales que hicieran posible la anhelada paz en Colombia.

Sin embargo, a pesar de todos los esfuerzos realizados, hasta el momento no ha sido posible concretizar la paz. Los reiterados fracasos para lograrla han generado incredulidad y escepticismo en muchos colombianos, que ya no creen en la posibilidad de alcanzarla mediante el diálogo político, lo que provoca que la única solución posible y justa sea la guerra contra los grupos ilegales, con todas las consecuencias que ello implica.

En este contexto de incredulidad hacia la paz, en las pasadas elecciones presidenciales del 2014 el tema central de debate fue precisamente el proceso de paz entre el gobierno del Presidente Santos y las farc en La Habana. En esta ocasión no existía consenso sobre las causas del conflicto armado, ni tampoco sobre los parámetros de justicia que deberían ser utilizados o los posibles caminos para la paz, razón por la cual el país estaba dividido sobre las posibilidades del diálogo. Para muchos observadores externos era insólito verificar cómo un país que lleva medio siglo de guerra sigue todavía dividido casi por mitades en torno a si es posible una solución negociada al conflicto.

La falta de consenso en torno a la paz se genera no solo por la experiencia compartida de varios procesos de paz fracasados, sino también por la falta de confianza en la negociación (que se realizó la mayor parte del

40 Lemaitre Ripoll, La paz en cuestión, 4-6. 
tiempo a puerta cerrada) y la desconfianza histórica hacia las FARc. Aun así, para muchos colombianos, medio siglo de lucha armada demuestra que el camino de las armas no tiene vencedores sino solo perdedores, por tanto el diálogo político es la mejor salida al conflicto armado, pero todavía no son claros los límites que debería tener este, ni los parámetros de justicia que deberían ser aplicados para que el proceso de paz sea considerado legítimo y constructor de paz, en una sociedad fuertemente afectada por varios años de conflicto armado.

La falta de consensos alrededor del proceso de paz, unido al desconocimiento y a la incertidumbre sobre los cambios que deberían realizarse en el ordenamiento jurídico, generó que la discusión política se caracterice por la falta de argumentos o explicaciones claras sobre los puntos a favor y en contra del proceso, lo que fue evidente en las pasadas elecciones presidenciales del 2014 y en la campaña por el Sí y por el No en el plebiscito por la paz; estas se concentraron en los sentimientos de esperanza y miedo que genera el conflicto armado, sin realizar mayores discusiones sobre los principales temas del proceso.

Así, las pasadas elecciones presidenciales del 2014 fueron un ejemplo de fuerte polarización de las dos grandes campañas (Santos y Zuluaga) en niveles nunca antes vistos. Según Álvaro Sierra, editor jefe de Semana, las campañas pasaron "(...) de la plaza pública a los estrados judiciales, con hackers, narcos y asesores asumiendo el protagonismo que deberían tener los argumentos políticos". ${ }^{41}$

La polarización de las elecciones presidenciales en Colombia causó que los ciudadanos tuvieran que decidir por dos proyectos totalmente opuestos sin ninguna posibilidad de consenso entre los grupos mayoritarios, esto fue o seguir con el proceso de paz con las Farc en Cuba votando por Santos, o continuar la guerra, apostando a la derrota militar de las FARC votando por Zuluaga. Sobre la falta de argumentos y consenso en las pasadas elecciones presidenciales, Sierra afirmó:

${ }^{41}$ Álvaro Sierra Restrepo, "Y la paz decide en estas elecciones presidenciales". Semana, 25 de mayo del 2014, http://www.semana.com/nacion/elecciones-2014/articulo/paz-decide-en-elecciones-2014/389239-3 
Toda una paradoja. El llamado proceso de paz - las negociaciones entre el Gobierno y las FARC en La Habana para poner fin al conflicto armado- despierta escaso entusiasmo entre la gente. Se encuentra en un puesto muy bajo entre las prioridades que la opinión pública expresa en las encuestas. Y una amplia mayoría de los colombianos se dice escéptica o pesimista sobre su resultado. Sin embargo, la paz se ha posicionado una vez más en la historia de las elecciones presidenciales como el tema central en el debate.

Un debate simplista, de escasos argumentos y no poca manipulación. El presidente Juan Manuel Santos ha buscado su reelección presentándose como el candidato de la paz, con palomitas de colores en su publicidad y con una palomita como prendedor en su saco en los debates que cerraron la campaña, los únicos a los cuales él asistió. Sin embargo, ha sido escasa la pedagogía que él y su gobierno han hecho para convencer a los colombianos de la necesidad del proceso, de la conveniencia de negociar con la guerrilla, de por qué esta es un interlocutor legítimo. Y si el público en las grandes ciudades no se siente “tocado" por lo que pasa en La Habana, en el resto del país, en las regiones, lo que ocurre en la isla parece abstracto y lejano.

Del otro lado, en el uribismo, el expresidente Álvaro Uribe, su candidato Óscar Iván Zuluaga y sus seguidores truenan contra una suerte de conspiración entre Santos y las FARC y enarbolan argumentos como que se negocia a espaldas del país y otras críticas que, en lugar de apuntar a una discusión racional, buscan apalancarse en los sentimientos de prevención, desconfianza y aborrecimiento que la mayoría de los colombianos experimentan ante la guerrilla. El candidato del uribismo, Óscar Iván Zuluaga, ha pasado de anunciar que romperá el proceso de negociaciones a anunciar que pondrá a las FARC condiciones tales que harían improbable que continúe. El expresidente ha llegado a hablar de "oligarquía comunistoide", como dijo en uno de sus rotundos trinos. Y sus acusaciones de que bajo este gobierno ha tenido lugar un deterioro en la seguridad es un argumento que ha calado en muchas zonas del país. ${ }^{42}$

42 Sierra Restrepo, "Y la paz decide". 
Las contradictorias posiciones de los candidatos presidenciales que pasaron a segunda vuelta son un claro ejemplo de la polarización del país, sin que exista un debate profundo sobre los argumentos a favor y en contra del proceso de paz con las FARc. En consecuencia, el resultado del plebiscito por la paz del 2 de octubre fue absolutamente coherente con la polarización registrada en las pasadas elecciones. Sin embargo, para comprender por qué a los colombianos nos cuesta llegar a consensos mínimos sobre el conflicto armado debemos entender el papel de las emociones en las campañas políticas.

\section{El papel de las emociones en las campañas políticas y el proceso de paz colombiano}

La política como práctica social que permite el debate y la persuasión para convencer se realiza a través de la comunicación de ideas y sentimientos entre individuos en colectividades específicas con el fin de llegar a acuerdos que fomentan las asociaciones y la cooperación en beneficio del conjunto de la sociedad. Por lo tanto, la política ha sido fundamental para la supervivencia de los pueblos y para el aumento del bienestar de la población, evitando el uso de la fuerza física para lograr consensos y determinar reglas de convivencia entre los individuos.

La comunicación de ideas y sentimientos determina la manera de actuar de los individuos y de las sociedades, por ello comprender el proceso de comunicación entre individuos se torna fundamental para entender cómo se construyen y se desafían las relaciones de poder existentes en las sociedades, especialmente en las campañas políticas en las que se definen los líderes que tendrán a cargo la gestión de los asuntos públicos en comunidades específicas por determinados periodos de tiempo. Castells analiza el proceso de comunicación utilizando investigaciones neurocientíficas así:

La comunicación se produce activando las mentes para compartir significado. La mente es un proceso de creación y manipulación de imágenes mentales (visuales o no) en el cerebro. Las ideas pueden verse como configuraciones de imágenes mentales. Con toda probabilidad las imágenes mentales se corresponden con patrones neuronales. (...) la mente es un proceso no un órgano. Es un proceso material que se produce en el cerebro al interactuar con el cuerpo 
propiamente dicho. Dependiendo del nivel de alerta, atención y conexión con el yo, las imágenes mentales que construyen la mente pueden ser o no conscientes. ${ }^{43}$

Para Castells, construimos la realidad como reacción ante acontecimientos reales, internos y externos, que son procesados por el cerebro según modelos mentales previamente establecidos (la mayoría de las veces de forma inconsciente) para facilitar el procesamiento de información. ${ }^{44} \mathrm{De}$ esta forma, la emoción y el racionamiento se originan del mismo proceso mental mediante la conexión de millones de neuronas que permiten crear experiencias inmediatas o que se acumulan con el tiempo, buscando orientar a la persona en la toma de decisiones con base en experiencias previas o patrones establecidos. ${ }^{45}$

El cerebro percibe las emociones como sentimientos y las emociones están profundamente arraigadas en nuestro cerebro, porque han sido inducidas por el instinto de supervivencia en el largo proceso de evolución, de forma tal que las especies o individuos que no tienen un sistema de detección emocional adecuado es improbable que sobrevivan. ${ }^{46}$

Cuando una persona es capaz de identificar sus sentimientos de forma consciente, estos le ayudan a controlar su comportamiento social y, por ende, influyen también en sus decisiones, vinculando sentimientos del pasado, del presente y del futuro. Esto sucede mediante la activación de las redes neuronales que asocian sentimientos y acontecimientos, lo que permite orientar al individuo hacia la toma de decisiones conforme sus marcos mentales, que no son arbitrarios, sino que se basan en la experiencia individual y social. ${ }^{47}$

Como ya fue discutido en la sección dos, cada vez existen más estudios que demuestran la integración entre cognición y emoción en la toma de

43 Castells, Comunicación y poder, 191-192.

${ }^{44}$ Castells, Comunicación y poder, 193-195.

45 (...) las estructuras de los marcos no son arbitrarias. Se basan en la experiencia, y surgen de la organización social que define los roles sociales en una cultura y después queda incorporada en los circuitos cerebrales (...). Las narraciones definen los roles sociales en contextos sociales. Los roles sociales se basan en marcos que existen tanto en el cerebro como en la práctica social". Castells, Comunicación y poder, 197-198.

46 Castells, Comunicación y poder, 195.
47 Castells, Comunicación y poder, 196. 
decisiones políticas, lo cual resalta que la cognición política está modelada por las emociones. De esta forma, no existe oposición entre cognición y emoción, pero es importante resaltar que existen diferentes formas de articulación entre estas para la toma de decisiones, lo que lleva a Castells a afirmar que

El procesamiento de la información (cognición) puede funcionar con o sin ansiedad (emoción) generando dos formas diferentes en la toma de decisiones, una la toma de decisiones racional como proceso de información de nueva información o modelos rutinarios de decisión basados en experiencias anteriores procesadas en los mapas cerebrales. ${ }^{48}$

En este orden de ideas, las emociones y las elecciones racionales son mecanismos complementarios cuya interacción en el proceso de toma de decisión depende del contexto del proceso, ${ }^{49}$ razón por la cual la evaluación de los acontecimientos es emocional y está determinada por los marcadores somáticos que generan los sentimientos en las personas. ${ }^{50}$

Así,los sentimientos de alerta aumentan la importancia de la evaluación racional de la decisión a ser tomada por el individuo, y los sentimientos de calma generan mayor confianza en el individuo y menor necesidad de evaluar racionalmente las decisiones a ser tomadas.

Según la teoría de la inteligencia afectiva, las emociones más importantes (pero no las únicas) para el comportamiento político son el entusiasmodepresión y el miedo-calma, las cuales se activan con base en dos sistemas

48 Castells, Comunicación y poder, 202.

49 George Marcus, W. Russell Newman y Michael Mackuen, Affective intelligence and political judgements (Chicago: University of Chicago Press, 2000); Michael Mackuen, George Marcus, W. Russell Newman y Luke John Keele, "The third way, the theory of affective intelligence and American democracy", en The affect effect, dinamics of emotions in political thinking and behaviour (Chicago: University of Chicago Press, 2007); George Marcus, "The theory of affective inteligence and civil society", Ponencia para el World Congress of the International Institute of Sociology (Budapest, 26-30 junio, 2008); Castells, Comunicación y poder, 202.

50 Michael Spezio y Ralph Adolphs, "Emotional processing and political judgement, toward integrating political psychology and decisión neuroscience", en The affect effect, dinamics of emotions in political thinking and behavior (Chicago: University of Chicago Press, 2007); Castells, Comunicación ypoder, 202. 
emocionales diferentes. El primero (entusiasmo-depresión), referente al sistema de predisposiciones, induce el entusiasmo y organiza el comportamiento para conseguir los objetivos previamente determinados. El segundo (miedo-calma) activa el sistema de vigilancia cuando se experimenta miedo o ansiedad, llevando al individuo a evaluar mejor las decisiones con base en la amenaza percibida. ${ }^{51}$ Así, las emociones influyen de forma significativa en el procesamiento de información política, ya que cuando los asuntos a ser discutidos generan miedo y ansiedad, se activa el sistema de vigilancia, lo que lleva a los individuos a evaluar mejor la información y desconfiar del statu quo.

Para Sustein, los gobiernos que funcionan correctamente aspiran a ser democracias deliberativas y cuando el miedo público aparece en escena se deben utilizar las instituciones para disiparlo cuando no tiene fundamento o se debe tener la capacidad de una respuesta apropiada, teniendo en cuenta que “(...) las democracias deliberativas evitan la tendencia de los sistemas populistas a caer presos del miedo público cundo este no tiene razón de ser y emplean salvaguardas institucionales para controlar el pánico público". ${ }^{52}$

Según Castells, la emoción influye en la opinión política de dos formas: o genera lealtad a los partidos, candidatos o líderes de opinión, según el apego a esto, o genera un examen crítico de los partidos, candidatos o líderes de opinión basado en cálculos racionales influidos por mayor ansiedad. Así, la racionalidad por sí sola nunca determina la toma de decisiones de los individuos y, en consecuencia, las emociones siempre afectarán en mayor o menor medida el procesamiento de la información política. ${ }^{53}$

Según la lógica de la lucha por el poder a cualquier precio, cuando se requiere fortalecer la movilización política a favor de un determinado candidato, las campañas deben concentrarse en activar sentimientos de miedo y esperanza en el público para lograr mayor aprobación o rechazo conforme convenga a la campaña política.

En el caso de la campaña presidencial del 2014 del presidente Santos, el mensaje central fue: “Con paz haremos más”. El color de la campaña fue

\footnotetext{
51 Castells, Comunicación y poder, 202.

52 Cass R. Sunstein, Leyes de miedo. Más allá del principio de precaución (Buenos Aires: Katz Editores, 2009), 11-12.

53 Sunstein, Leyes de miedo, 203-204.
} 
el blanco, simbolizando la paz, y de fondo se observan tres palomas, en los tres colores de la bandera de Colombia, simbolizando la unidad nacional, bajo el eslogan "Unidad por la paz". ${ }^{54}$

Evidentemente, el tema central de la campaña de Santos fue la esperanza de lograr la paz con la guerrilla de las FARC en La Habana y el correspondiente miedo de continuar en guerra, en caso de no ser elegido, ya que su principal contrincante, el candidato Zuluaga (quien pasó a la segunda vuelta) había manifestado abiertamente su desacuerdo a los diálogos de La Habana. En un discurso realizado el 25 de mayo del 2014, Santos invitó a los colombianos a apoyarlo en su apuesta de paz afirmando lo siguiente:

Ha quedado claro que en tres semanas los colombianos tendrán dos opciones: quienes queremos el fin de la guerra y los que prefieren una guerra sin fin y vamos a ganar con la paz (...) hoy empieza la campaña de la esperanza, hoy comienza la campaña de la confianza en el futuro de nuestra patria, comienza la campaña del trabajo por la paz frente a la opción exclusiva de la guerra. ${ }^{55}$

El mensaje de esperanza de Santos ilusionó a muchos colombianos con un futuro mejor, lo que es fundamental para la construcción del proceso de paz, pero también es cierto que simplificar un tema tan complejo mediante divisiones entre "quienes queremos el fin de la guerra" y quienes "prefieren una guerra sin fin" aumenta la fragmentación de la sociedad y no permite visualizar los diversos matices que existen entre posiciones contrapuestas.

La campaña electoral por la presidencia de Colombia del 2014 fue calificada como la "más sucia de su historia" por varios medios de comunicación y analistas políticos, debido a las fuertes acusaciones que permanentemente eran lanzadas por los candidatos buscando generar angustia y desconfianza en el electorado en relación con el contrincante.

${ }^{54}$ Un análisis más profundo sobre el tema puede encontrarse en: "Elecciones presidenciales en Colombia en 2014: construcción de relatos de paz". Zero, Facultad de Finanzas, Gobierno y Relaciones Internacionales de la Universidad Externado de Colombia, 29 de septiembre del 2015, http://zero.uexternado.edu.co/elecciones-presidenciales-en-colombia-en-2014-construccion-de-relatos-de-paz/

55 “'Vamos a ganar con la paz' la segunda vuelta: Juan Manuel Santos”. El Tiempo, 25 de mayo del 2014, http:/www.eltiempo.com/politica/partidos-politicos/elecciones-2014-juan-manuel-santosinvita-a-que-lo-apoyen-en-segunda-vuelta/14035816 
Entre las acusaciones principales estaba la supuesta entrada de dineros de la mafia a la campaña de Santos en el 2010 y la difusión de un video en el que Zuluaga aparentemente habla con un hacker sobre operaciones de espionaje y planes de atacar el proceso de paz con las FARc, acusaciones que fueron rotundamente negadas por los candidatos, no sin antes producir desconcierto y confusión entre los electores, quienes se concentraron en resaltar los bochornosos detalles del espectáculo político, dejando de lado el análisis de las propuestas presentadas por los candidatos. ${ }^{56}$

La forma en que se ha desarrollado la política en Colombia en los últimos años no solo es vergonzosa, sino que además genera profundos cuestionamientos sobre el Estado de derecho y la legitimidad de los candidatos (independientemente de quién gana o quién pierde) en razón a que las fronteras entre lo legal y lo ilegal, lo moral y lo inmoral, se vuelven cada vez más borrosas, lo cual afecta profundamente los consensos mínimos que deberían existir para que el gobierno electo represente a la mayoría de los ciudadanos.

Los intensos cuestionamientos sobre los candidatos causan que perdamos todos, pues la falta de consensos y de comunicación entre diversos sectores se rompe, y genera fragmentaciones en la sociedad y la existencia de comportamientos poco cívicos y poco colaborativos en torno al Estado.

En este contexto, no sorprende que la abstención en el plebiscito por la paz el 2 de octubre de 2016fuera del 62\%, lo que evidencia que el Acuerdo de Paz no logró convencer a la mayoría de la ciudadanía sobre los beneficios de finalizar el conflicto armado con las FARc. Tampoco debería sorprender que el No ganara en las urnas, teniendo en cuenta que todo raciocinio siempre se verá afectado por la emoción que despierta la situación en la persona, especialmente cuando los conflictos son complejos y no existen consensos sobre las posibles causas y soluciones que deberían considerarse en un determinado periodo de tiempo.

En nuestro concepto, el exagerado apelo a las emociones durante todo el proceso de paz con las FARC no ha permitido comprender de forma equilibrada y racional los principales argumentos a favor y en contra del

56 Hernando Salazar, "La campaña electoral en Colombia: la 'más sucia' de su historia". $B B C$ Mundo, 19 de mayo del 2014, http://www.bbc.com/mundo/noticias/2014/05/140519_colombia_elecciones_camapana_sucia_lav 
proceso, lo que es un primer obstáculo importante para lograr la reconciliación entre grupos rivales que históricamente han usado la violencia como técnica principal de dominación en razón a la imposibilidad de convencer y llegar a consensos mediante el diálogo y la cooperación.

Además, el poco tiempo dado a la ciudadanía para comprender el Acuerdo Final de 297 hojas no permitió analizar de forma responsable las consecuencias del voto, pues, como bien lo explica Castells, ${ }^{57}$ construimos nuestra realidad como reacción ante acontecimientos reales, internos y externos, que son procesados por el cerebro según modelos mentales previamente establecidos; desafortunadamente, en Colombia, el modelo mental preestablecido puede estar profundamente influenciado por el conflicto armado más largo del continente, con millones de víctimas, de daños morales y pecuniarios.

\section{Consideraciones finales}

Debido a que las emociones y las elecciones racionales son mecanismos complementarios, la evaluación inicial sobre los acontecimientos es emocional y está determinada por los marcadores somáticos que generan los sentimientos en las personas. Así, todo raciocinio siempre se verá afectado por la emoción que despierta la situación en la persona, especialmente cuando los conflictos son complejos y no existen consensos sobre las posibles causas y soluciones que deberían considerarse en un determinado periodo de tiempo.

Lo que es justo o verdadero no es absolutamente neutral u objetivo. La justicia y la verdad tienen diferentes lógicas y narraciones dependiendo de las vivencias y la posición social del actor. En un proceso de paz es fundamental que todos los actores se reconozcan como seres humanos, que merecen consideración y respeto, independientemente de las atrocidades y los errores que pudieron ser cometidos dentro del conflicto. Sentir empatía por el otro es fundamental para comprender y reconciliar a víctimas y victimarios, generando sentimientos de compasión. Es precisamente este punto el más difícil de lograr dentro de un proceso de paz.

57 Castells, Comunicación y poder, 197. 
En un sistema político en el que las campañas se fundamentan en el desprestigio del otro, movilizando sentimientos de esperanza y miedo en el electorado, difícilmente las personas pueden sentir empatía por los grupos "rivales" y mucho menos compasión. El uso indiscriminado de nuevas tecnologías con evaluaciones rápidas, estridentes y parcializadas no ayuda a la construcción de caminos de paz que permitan la reconciliación entre los diversos actores del conflicto. En nuestro concepto, dividir la sociedad entre amigos y enemigos crea estructuras mentales preconceptuosas que impide desde el inicio el diálogo entre grupos rivales, lo que termina fragmentando cada vez más las sociedades.

En este orden de ideas, consideramos que para crear verdaderos caminos de paz los colombianos debemos comprender que tras varias décadas de conflicto armado todos somos en parte víctimas y victimarios, y, por tanto, debemos estar más abiertos a colocarnos en la posición de los otros, para entender su sufrimiento, sintiendo compasión y permitiendo espacios de reconciliación que permitan la construcción conjunta de un futuro mejor para las próximas generaciones.

\section{Bibliografía}

"El no ha sido la campaña más barata y efectiva de la historia". La República, 5 de octubre del 2016, http://www.larepublica.co/el-no-ha-sido-lacampaña-más-barata-y-más-efectiva-de-la-historia_427891

"Elecciones presidenciales en Colombia en 2014: construcción de relatos de paz". Zero, Facultad de Finanzas, Gobierno y Relaciones Internacionales de la Universidad Externado de Colombia, 29 de septiembre del 2015, http://zero.uexternado.edu.co/elecciones-presidencialesen-colombia-en-2014-construccion-de-relatos-de-paz/

“Vamos a ganar con la paz' la segunda vuelta: Juan Manuel Santos”. El Tiempo, 25 de mayo del 2014, http://www.eltiempo.com/politica/ partidos-politicos/elecciones-2014-juan-manuel-santos-invita-aque-lo-apoyen-en-segunda-vuelta/14035816

Alonso Coto, Manuel A. y Angel Adell. Marketing politico 2.0. Lo que todo candidato necesita saber para ganar las elecciones. Barcelona: Gestión 2000, 2011.

Aristóteles. A Politica, traducción de Roberto Leal Ferreira. São Paulo: Martins Fontes, 1998. 
Aristóteles. Retórica. Lisboa: Biblioteca de Autores Clássicos. Centro de Filosofía da Universidade de Lisboa. Imprensa Nacional-Casa da Moeda, 2005.

Buckingham, Will. et al. O libro da fllosofia, traducido por Douglas Kim. São Paulo: Globo, 2011.

Castells, Manuel. Comunicación y poder, traducido por María Hernández Díaz. Madrid: Alianza, 2011.

Castells, Manuel. La era de la información. V. II., traducido por Carmen Martínez Gimeno. 7a ed. México: Siglo xxi, 2008.

Centro de Memoria Histórica. ;Basta ya! Colombia: Memorias de Guerra y Dignidad. Informe General Grupo de Memoria Histórica. Bogotá: Departamento para la Prosperidad Social, 2013.

Cirne-Lima, Carlos. Dialéctica para principiantes. São Leopoldo: Ed. Unisinos, 2002.

Cruz Castillo, Alba Lucia. "La razón de las emociones formación social, política y cultural de las emociones". Revista Eleuthera 6 (enerojunio, 2012): 64-81.

Damasio, Antonio R. El error de Descartes. La razón de las emociones, traducido por Pierre Jacomet. Santiago de Chile: Editorial Andres Bello, 1996. Fallows, James. Breaking the news. How the media undermine American democracy. Nueva York: Pantheon, 1996.

Foucault, Michel. Vigilar y castigar: nacimiento de la prisión. Madrid: Siglo xxi, 2009.

Garber, Doris A. Mass media in American politics. $2^{\mathrm{a}}$ ed. Washington D.C.: CQPress, 1996.

Gitlin, Todd. The whole world is watching: mass media in the making and unmaking of the new left. Berkeley: University of California Press, 1980.

Habermas, Jürgen. Problemas de legitimación en el capitalismo tardio. Madrid: Cátedra, 1999.

Hacker, Kenneth L. "Missing links and the evolution of electronic democratization”. Midia, Culture and Society 18 (1996): 213-323.

Gould, Deborah B. "Passionate political processes: bringing emotions back into the study of social movements", en Rethinking social momements: structure, meanings and emotions, editado por Jeff Goodwing y James M. Jasper, 155-175. Lanham, Maryland: Rowman \& Littlefield Publishers, 2004. 
Jasper, James M. "The emotions of protest: affective and reactive emotions in and around social movements". Sociological Forum 13, n. ${ }^{\circ} 3$ (1998): 397-424.

Klinenberg, Erick y Andrew Perrin. Symbolic politics in the Information Age: the 1996 presidencial campaign in cyberspace. Berkeley: University of California. Department of Sociology. Inedito, 1996.

Lemaitre Ripoll, Julieta. La paz en cuestión. La guerra y la paz en la Asamblea Constituyente de 1991. Bogotá: Universidad de los Andes, 2011. Mackuen, Michael, George Marcus, W. Russell Newman y Luke John Keele. "The third way, the theory of affective intelligence and American democracy", en The affect effect, dinamics of emotions in political thinking and behavior, 124-151. Chicago: University of Chicago Press, 2007.

Marcus, George, W. Russell Newman y Michael Mackuen. Affective intelligence and political judgements. Chicago: University of Chicago Press, 2000.

Marcus, George. "The theory of affective inteligence and civil society", Ponencia para el World Congress of the International Institute of Sociology. Budapest, 26-30 junio, 2008.

Nussbaum, Martha C. Emociones políticas $\dot{\vec{\zeta}}$ Por qué el amor es importante para la justicia?, traducido por Albino Santos Mosquera. $4^{\mathrm{a}}$ ed. Barcelona: Paidós, 2017.

Registraduría Nacional del Estado Civil. Plebiscito, 2 de octubre del 2016, http://plebiscito.registraduria.gov.co/99PL/ DPLZZZZZZZZZZZZZZZZZ_L1.htm

Salazar, Hernando. "La campaña electoral en Colombia: la 'más sucia' de su historia”. BBC Mundo, 19 de mayo del 2014, http://www.bbc.com/ mundo/noticias/2014/05/140519_colombia_elecciones_camapana_sucia_lav

Sierra Restrepo, Álvaro. "Y la paz decide en estas elecciones presidenciales". Semana, 25 de mayo del 2014, http://www.semana.com/nacion/ elecciones-2014/articulo/paz-decide-en-elecciones-2014/389239-3 Spezio, Michael y Ralph Adolphs. "Emotional processing and political judgement, Toward integrating political psychology and decisión neuroscience", en The affect effect, dinamics of emotions in political thinking and behavior, 71-95. Chicago, University of Chicago Press, 2007. 
Sunstein, Cass R. Leyes de miedo. Más allá del principio de precaución. Buenos Aires. Katz Editores, 2009.

Valencia Tello, Diana Carolina. El Estado en la era de la globalización y las nuevas tecnologías. Bogotá: Ibañez, 2015.

Vale Dos Santos, Moises. Razão e emoção na arte retórica de Aristóteles. $\mathrm{Cu}-$ ritiba: Ed. crv, 2014.

Weber, Max. Economía y sociedad. Madrid: FCE, 1993. 


\title{
La paz como política pública y la legitimación democrática de los Acuerdos
}

\author{
Natalia Soledad Aprile* \\ Mateo Gómez Vásquez
}

\section{Introducción}

Los acuerdos de paz tienen las virtudes y las debilidades de un castillo de naipes. Por un lado, son una muestra admirable de un ejercicio de ponderación, balance y precisión, y, por el otro, evocan la fragilidad y la inestabilidad a la que están expuestos ante cualquier intervención externa. En torno al proceso de paz colombiano y el denodado objetivo de poner fin al conflicto armado interno, corresponde hacer la misma analogía. E1 24 de agosto del 2016 se publicó el "Acuerdo final para la terminación del conflicto y la construcción de una paz estable y duradera”, pactado por las partes negociadoras luego de cinco años de arduas y profundas discusiones. Sin embargo, fue una mayoría estrecha la que, en ejercicio de un mecanismo de democracia directa, se impuso para rechazar la implementación de ese Acuerdo.

$\mathrm{El}$ análisis que proponemos en este artículo parte de una consideración muy básica y es que el imperativo de la paz en Colombia depende necesariamente de la consolidación de un proceso deliberativo amplio, leal

* Abogada de la Universidad de Buenos Aires, Argentina. Magíster en Democracia y Buen Gobierno de la Universidad de Salamanca, España. Profesora e investigadora de carrera de la Universidad del Rosario. Correo electrónico: natalia.aprile@urosario.edu.co

** Abogado de la Pontificia Universidad Javeriana, Colombia. Magíster en Democracia y Buen Gobierno de la Universidad de Salamanca, España. Profesor de posgrado de la la Universidad Externado de Colombia. Correo electrónico: mateo.gomezv@gmail.com 
e incluyente sobre los contenidos y efectos del Acuerdo, que se erija como instrumento para la consecución del conflicto. El resultado del plebiscito realizado el 2 de octubre del 2016, pese al sabor amargo que podría dejar en relación con la expectativa de emprender lo más pronto posible un camino seguro hacia la construcción de un país en paz, nos abre un espacio de reflexión interesante y un escenario de debate sugerente para instituir bases más sólidas a partir de las cuales poder levantar los cimientos de un acuerdo, esta vez edificado en piedra.

En vista de la reverdecida oportunidad y del nuevo Acuerdo Final suscrito el 12 de noviembre de 2016, que dice atender "diversas iniciativas de sectores del pueblo colombiano", ${ }^{1}$ proponemos un análisis del proceso de paz en curso desde la categoría de las políticas públicas. Esta perspectiva nos permitirá observar de qué manera se han cristalizado las distintas etapas que conforman el ciclo teórico de las políticas públicas y, sobre todo, hacer foco en el rol que cumplió la ciudadanía en la construcción de esta política de paz. El análisis dogmático que pretendemos realizar tiene como finalidad proponer un enfoque de estudio adicional a un tema generosamente debatido desde varias aristas. Al final del día, la importancia de este ejercicio de reflexión será aprender de la experiencia y contribuir con un modesto aporte en la construcción de la paz colombiana.

\section{La paz como política pública}

En el Plan Nacional de Desarrollo que se encuentra actualmente en vigencia, principal instrumento de política pública en Colombia, se ha planteado como objetivo central

construir una Colombia en paz, equitativa y educada, en armonía con los propósitos del Gobierno Nacional, con los estándares de la Organización para la Cooperación y el Desarrollo Económico

1 Mesa de Conversaciones para la Terminación del Conflicto y la Construcción de una Paz Estable y Duradera en Colombia, "Acuerdo final para la terminación del conflicto y la construcción de una paz estable y duradera", 12 de noviembre de 2016, suscrito entre el Gobierno nacional de la República de Colombia y las FARC EP, https://www.mesadeconversaciones.com.co/sites/default/ files/12-1479102292.11-1479102292.2016nuevoacuerdofinal-1479102292.pdf 
(OCDE), y con la visión de planificación de largo plazo prevista por la Agenda de Desarrollo post $2015 .^{2}$

De lo anterior es posible colegir, y las evidencias lo sostienen, que la construcción de paz mediante la superación del conflicto armado es un propósito del Gobierno que reúne las cualidades de una política pública en tanto congrega todos los esfuerzos de la administración por alinear sus ejecutorias en esa ruta. Vale la pena resaltar que en vigencia de la Constitución de 1991 es la primera vez que la construcción de paz se constituye en un pilar y objetivo transversal de la planeación estatal.

A idéntica conclusión arribó la Corte Constitucional en el examen del proyecto de ley estatutaria que reglamentó el plebiscito por la paz, cuando halló plena validez en que el presidente de la República utilizara este mecanismo de participación ciudadana para la refrendación de lo acordado, toda vez que se trataba de una política pública adelantada por su gobierno. ${ }^{3}$ Incluso, en el recuento jurisprudencial que se hizo en la mencionada sentencia, la Corte concluyó que la paz, como un objetivo constitucionalmente imperioso, atribuye "un deber estatal de diseño e implementación de acciones, normativas y de política pública, dirigidas a la superación del conflicto armado y, en general, el logro de la convivencia pacífica”. Esto quiere decir que, dentro del ordenamiento constitucional colombiano, es posible y atinado que se opte por la construcción de una política pública tendiente al logro de la paz.

Ahora bien, una declaración en este sentido implica, en concreto, que el Gobierno debe hacer algo para materializar el programa que pretende llevar a cabo. Según Shafrik, Russell y Borick, la política pública es todo lo que un gobierno decide hacer o no hacer para dar respuesta a un tema político. ${ }^{4}$ En una definición más minuciosa y, tal vez, más cercana a la realidad que pretendemos comentar, se ha señalado:

2 Ley 1753 del 2015, 9 de junio. Por la cual se expide el Plan Nacional de Desarrollo 20142018 “Todos por un nuevo país”. Diario Oficial 49.538, artículo $1^{\circ}$.

3 Sentencia C-379 del 2016, 18 de julio. MP: Luis Ernesto Vargas Silva.

4 Jay M. Shafritz, E. W. Russell y Christopher Borick, Introducing public administration (Nueva York: Routledge, 2015), 38. 
Política pública es un proceso integrador de decisiones, acciones, inacciones, acuerdos e instrumentos, adelantado por autoridades públicas con la participación eventual de los particulares, y encaminado a solucionar o prevenir una situación definida como problemática. La política pública hace parte de un ambiente determinado del cual se nutre y al cual pretende modificar o mantener. ${ }^{5}$

Bajo este marco, no puede desconocerse la conexión indisoluble de análisis que puede hacerse entre el proceso que condujo a la definición del Acuerdo de Paz en Colombia y la teoría de las políticas públicas. Precisamente, el análisis de estas constituye una corriente o metodología específica dentro de la ciencia de la administración, que propone focalizar la perspectiva de estudio sobre las acciones del Gobierno y, con esto, abordar de manera dinámica el objeto de la administración pública. Por lo anterior, es usual referirse a las políticas públicas como un proceso o ciclo con diferentes etapas. ${ }^{6}$

E1 ciclo de las políticas públicas está conformado por cuatro momentos analíticos, que es útil desligar a efectos de su estudio, pero que no obedecen a un criterio temporal, puesto que pueden no darse en el orden señalado o, incluso, confluir en determinados momentos. Así, siguiendo el esquema descrito por Shafrik, Russell y Borick, el proceso se compone de las siguientes etapas: 1) la formación de la agenda; 2) las decisiones (o no decisiones) de políticas; 3) la implementación de un nuevo programa o la modificación de una política pública existente y 4) la evaluación crítica y las evaluaciones formales.

Todas estas fases forman un flujo que integra el curso de acción dirigido a definir las políticas públicas de un Estado y que están permeadas por un feedback constante e intermitente que permite incluir nuevos temas en la agenda o replantear aquellos que ya fueron incorporados al proceso. A su vez, como recuerdan los autores citados, todo en este ciclo está

\footnotetext{
5 Raúl Velásquez Gavilanes, "Hacia una nueva definición del concepto 'política pública". Desafíos 20 (2010): 156.

6 Agustín Ferraro, Reinventando el Estado. Por una administración pública democrática y profesional en Iberoamérica (Madrid: Instituto Nacional de Administración Pública, 2009).
} 
decididamente influenciado por el entorno político. ${ }^{7}$ Dicho lo anterior, y habiendo definido prima facie que la construcción de paz es una política pública, resulta interesante analizar cómo sucedieron estas fases que han sido categorizadas por la doctrina.

El punto central del análisis que proponemos hará énfasis en la participación ciudadana como estrategia que persigue la incorporación de la sociedad en la definición de los asuntos públicos, no desde el punto de vista discursivo, sino desde la generación de acciones efectivas que colaboran en la mejor elaboración de una política pública. Existen estudios teóricos que proponen la democratización de la gestión pública y evidencian, con meridiana certeza, que el rol que adquiere la participación ciudadana en el ciclo de las políticas públicas es un elemento crucial. ${ }^{8}$ Partiendo de esta afirmación, haremos el recorrido del proceso que se siguió adelante desde la negociación hasta la puesta en marcha del Acuerdo Final firmado por las FARC y el Gobierno, observando el componente de la participación ciudadana.

\subsection{La paz como tema de la agenda de las políticas públicas}

En cuanto a la formación de la agenda podemos encontrar que, dadas las características esenciales de los procesos de paz, cuyo propósito es poner de acuerdo a dos contendores políticos y militares, esta fase, además de esencial, se debe llevar a cabo con el mayor hermetismo y celo posible. ${ }^{9} \mathrm{La}$ negociación entre el Gobierno y las FARC no fue diferente pues respondió a la necesidad de mantener en secreto la decisión de encarar una agenda de acuerdos. Después de una serie de acercamientos informales para medir la voluntad de negociación de cada una de las partes y, concretamente, de algunos encuentros exploratorios llevados a cabo en La Habana entre el

\footnotetext{
7 Shafritz, Russell y Borick, Introducing public administration.

8 En relación con este tema, podemos citar los trabajos de Nuria Cunill Grau, "La rearticulación de las relaciones Estado-sociedad: en búsqueda de nuevos sentidos". Revista del CLAD Reforma $y$ democracia, n. ${ }^{\circ} 4$ (1995): 25-58; Jean L. Cohen, y Andrew Arato, Civil society and political theory (Cambridge: мiт Press, 1995). Más cerca en el tiempo, Joan Subirats, Otra sociedad. ¿̇Otra politica? Del "no nos representan" a la democracia de lo común (Barcelona: Icaria, 2011); Wayne Parsons, Politicas públicas: una introducción a la teoría y la práctica del análisis de politicas públicas (México: Flacso Mexico, 2013).

9 Vincenç Fisas, "Introducción a los Procesos de Paz". Quaderns de Construció de Pau. El proceso de paz en Colombia, n. 17 (febrero, 2010).
} 
23 y el 26 de agosto del 2012, las partes lograron sentar seis puntos como ejes esenciales para la consecución de un acuerdo para poner fin al conflicto armado que los enfrenta. Tales puntos, como es de público conocimiento, fueron la política de desarrollo agrario integral, la participación en política, el fin del conflicto, la solución al problema de las drogas ilícitas, la reparación de las víctimas, y lo relacionado con implementación, verificación y refrendación.

Es decir, las FARC y el Gobierno nacional sellaron una agenda compartida sobre la cual trabajarían para crear un acuerdo tendiente a la construcción de la paz. Ahora bien, dicha agenda tuvo como característica principal la de no ser una hoja de ruta para simplemente callar los fusiles, sino además para generar condiciones de convivencia pacífica y erradicar las causas del conflicto. Esto significa que se construyó sobre un concepto de paz positiva que, por definición, busca un alcance mayor a la simple cesación de las hostilidades. ${ }^{10}$ En suma, la formación de la agenda para el caso de la política pública de paz ha tenido como embrión el consenso alcanzado por dos partes enfrentadas en un conflicto armado, que hallaron en el abordaje de un itinerario de asuntos sustantivos la fórmula para construir un acuerdo para finalizar el conflicto y emprender una ruta de construcción de paz.

En este escenario, es preciso reflexionar sobre el lugar que ocupó la ciudadanía para influir en la definición de la agenda. En la etapa de formación de la agenda de las políticas públicas, se difunden las ideas o asuntos por medio de diversos canales de comunicación, hasta terminar siendo considerados por una institución pública, como pueden ser una legislatura, el poder ejecutivo, una agencia independiente de gobierno o un tribunal. Es interesante resaltar que, desde esta óptica, la formación de la agenda no está restringida a los políticos, sino que muchas personas pueden participar, existiendo determinados grupos, llamados agenda setters, que tienden a tener mayor influencia y ejercerla con mayor frecuencia. ${ }^{11}$

La participación de los ciudadanos y sus organizaciones para generar las políticas públicas "desde abajo"12 tiene la virtud de hacer visibles ciertos

10 Johan Galtung, "Violence, peace, and peace research". Journal of Peace Research 6, n. 3 (1969).

11 Ferraro, Reinventando el Estado.

12 Manuel Canto Chac, "Gobernanza y participación ciudadana en las políticas públicas frente al reto del desarrollo”. Política y cultura, n. 30 (2008). 
temas, ampliar los derechos, generar sentimientos de pertenencia social y garantizar el derecho a una buena administración. ${ }^{13}$ Esta modalidad responde a la reconfiguración que se ha dado en las relaciones entre Estado y sociedad, que constata que el Estado ha dejado de ser el centro y el eje del poder público, y la sociedad le ha ganado protagonismo en la detentación de ese poder. ${ }^{14}$ Atrás quedaron los modelos lineales de política pública, según los cuales esta se transmite desde el Gobierno como oferta hacia la sociedad para que la acepte como ordenación de sus intereses. Por ello, se propone "trascender una noción relacionada puramente con la delegación y la representación de la democracia, en favor de canales múltiples de consulta, participación, diálogo y concertación social (...)" ${ }^{15}$ En concreto, esto significa que la ciudadanía se encuentra indudablemente implicada en la articulación de las políticas, utilizando los mecanismos que proporciona el sistema democrático y exigiéndole al Estado que evacúe sus demandas.

En el marco del análisis propuesto, podríamos aseverar que esta etapa de formación de la agenda fue mediada por instituciones que les daban garantías a las partes, como la Universidad Nacional a través del Centro de Pensamiento y Seguimiento al Proceso de Paz y el sistema de Naciones Unidas en Colombia. Precisamente a ellos se les encargó, por parte de la mesa negociadora, la realización de una serie de foros regionales y nacionales para abordar las principales temáticas de la agenda de paz. ${ }^{16}$ En esta

13 Este derecho, reconocido expresamente en la Carta Europea de Derechos Humanos, se concibe como un conjunto de valores a través de los cuales la ciudadanía juzga hoy la legitimidad de las administraciones públicas (Agustí Cerrillo i Martínez, La gobernanza hoy: 10 textos de referencia [Madrid: Instituto Nacional de Administración Pública, 2005]). Según se afirma, "La buena administración está muy relacionada con la autoexigencia administrativa de calidad en los servicios públicos, aunque va más allá de ella, pues aporta un elemento externo configurado por los ciudadanos que ejercen un derecho y presionan para el impulso de dicha calidad".Joan Prats, "Políticas de buena administración para la Administración General del Estado en España. Un enfoque de gobernanza democrática”, en Gobernanza democrática y fiscalidad (España: Tecnos, 2010).

14 José Esteve Pardo, La nueva relación entre Estado y sociedad (Madrid: Marcial Pons, 2013).

15 Comisión Económica para América Latina y el Caribe (Cepal), Cohesión social: inclusión y sentido de pertenencia en América Latina y el Caribe (Santiago de Chile: Cepal, 2007).

16 Cfr. Informe preliminar Foro Nacional de Víctimas, http://www.co.undp.org/content/dam/colombia/docs/Paz/undp-co-informefinalFNV-2014.pdf; Informe y Balance General Foro de Desarrollo Agrario Integral (enfoque territorial), https://www.dropbox.com/s/c0c7o8uousr1w3c/informe_y_balance_general.pdf; Informe y Balance General Foro Participación Política, https://www.dropbox. com/s/h5cias1duo1vtib/Participaci\%C3\%B3n \%20pol\%C3\%ADtica-\%20Informe\%20general.pdf; 
misma fase se identifica la puesta a disposición de la ciudadanía de una herramienta virtual para el envío de propuestas relacionadas con la agenda de negociación, la cual canalizó aproximadamente 16.820 comentarios, propuestas y observaciones. ${ }^{17}$

Por otra parte, la cobertura mediática del proceso ha tenido una influencia poderosa en la instalación del tema en la sociedad y en la percepción social del asunto. La teoría de la agenda setting se ocupa, precisamente, de estas dos dimensiones de influencia ${ }^{18}$ y es claro que la prensa tradicional, como la radio, los periódicos o la televisión, así como los medios que han surgido con el avance tecnológico a través de Internet y la telefonía inteligente, son responsables del posicionamiento de los temas en la agenda pública y de difundir las labores que se adelantan a favor de la paz. No desconocemos que la información es un elemento muy valioso en los procesos de construcción de paz, pues el éxito de estos depende en gran medida de la capacidad para transmitir la realidad del conflicto que, para algunos, se presenta en un contexto alejado de su propia realidad. Pero tampoco es posible soslayar el hecho concreto de que la sociedad civil no participó directamente, a través de la deliberación y la discusión colectiva, en la fijación de la agenda. Incluso se puede colegir que el revés plebiscitario del 2 de octubre, así como los obstáculos que se deberán afrontar en la implementación programática del Acuerdo de Paz, se encuentran fundados, entre otras razones, en este déficit de participación. ${ }^{19}$

Informe y Balance General Foro Nacional y Regional sobre la solución al problema de las drogas ilícitas, https://www.dropbox.com/s/ird4tt9uvah0ky1/INFORME\%20Y\%20BALANCE\%20GENERAL\%20DROGAS\%20ILICITAS.pdf

17 Esta herramienta se encuentra contenida en la página web www.mesadeconversaciones. com.co. En el siguiente vínculo se encuentra la relación de las propuestas: Mesa de Conversaciones para la Terminación del Conflicto y la Construcción de una Paz Estable y Duradera en Colombia, https://www.mesadeconversaciones.com.co/estado-propuestas?field_consecutivo_db_opt_value=

18 Maxwell McCombs y Dixie Evatt, “Los temas y los aspectos: explorando una nueva dimensión de la agenda setting". Comunicación y Sociedad 8, n. ${ }^{\circ} 1$ (1995).

19 Somos conscientes de que el voto mayoritariamente negativo obedeció a un grupo de factores de variada índole: la contienda política que rodeó al Acuerdo sometido a votación, la (des)información en torno al contenido del Acuerdo, las preferencias de los votantes, la cultura de la abstención electoral, e incluso el factor climático a raíz del impacto que se atribuye al huracán Matthew en la afectación de la concurrencia electoral. Todos estos elementos y otros que quedan en el tintero merecen un tratamiento particularizado que excede el objeto de este artículo. En consecuencia, aclaramos 
Nadie puede dudar que la construcción bilateral y consensuada de la agenda de paz es la principal medida de confianza entre las partes inmersas en un conflicto armado. Observamos que esa obra de arquitectura tan delicada debió contemplar la generación de espacios de participación real de los ciudadanos, lo que hubiera contribuido a la apropiación del acuerdo, y a que la ciudadanía efectuara control político y administrativo en una etapa clave como lo es la definición de los temas de la agenda. Desde este punto de partida, sostenemos que la implementación del Acuerdo Final deberá afrontarse a la opinión pública y someterse a sus justas críticas, lo cual no es desdeñable, pero la apertura democrática temprana evidentemente hubiera nutrido de compromiso ciudadano activo al diseño de la política pública de paz.

\subsection{La decisión de la política pública de paz}

La segunda etapa identificada en el esquema propuesto por Shafritz, Russell y Borick es la del momento decisorio de la política pública, es decir, aquel donde se define el curso a seguir de conformidad con la agenda planteada para el logro del objetivo previsto, para el caso que nos ocupa, la construcción de paz. Conscientes de la carencia democrática de los procesos de negociación, pues estos involucran en su dinámica exclusivamente a las partes en conflicto, el Gobierno y las FARC acordaron que en la mesa de negociación se diseñarían las líneas gruesas de desarrollo de la agenda, pero que, en todo caso, ello debía ser adoptado mediante los mecanismos contemplados por la Constitución de 1991. Lo anterior se traduce en que la operatividad en el ordenamiento jurídico interno del Acuerdo Final, en sus contenidos sustantivos y procedimentales, si bien serían formulados en la mesa de negociación, dependería del ejercicio de las competencias atribuidas por la Constitución en cada materia al órgano legislativo y al ejecutivo, siempre y cuando el poder electoral refrendara lo acordado. Ello se deduce, además de en el contenido del Acto Legislativo para la paz (1 del 2016), en el Acuerdo del 12 de mayo del 2016 alcanzado por las partes. ${ }^{20}$

que, siendo la variable explicativa de este trabajo el tema de la participación en la elaboración y construcción de la política pública de paz, solo nos concentramos en el análisis de este factor.

20 Mesa de Conversaciones para la Terminación del Conflicto y la Construcción de una Paz Estable y Duradera en Colombia, “Comunicado Conjunto \#69" (La Habana, Cuba, 12 de mayo 
Dejando de lado por el momento los aspectos formales que rodearon las negociaciones y el Acuerdo alcanzado, no es posible eludir en esta etapa de análisis que los actores que lideran el proceso de paz en Colombia representan, sin lugar a dudas, diversos intereses e ideologías, lo que se traduce en una pluralidad de soluciones posibles para tratar o resolver el conflicto. Además de las autoridades públicas implicadas, hay actores políticos, organizaciones intermedias, entre las que se cuentan organizaciones de la sociedad civil, sindicatos y movimientos sociales, y una porción importante de la sociedad que clama verse reflejada y reconocida en los programas y cursos de acción a seguir. Esta multiplicidad de intereses y actores explica por qué las decisiones no son siempre las más racionales o las más coherentes, pues son el resultado de la confrontación y la negociación. Pero justamente la riqueza de estos procesos deliberativos radica en que su resultado emana de una pluralidad de discursos a partir de los cuales se establece una voluntad común.

El Acuerdo alcanzado por el Gobierno y las FARC fue el producto de un largo y complejo proceso que poco tiene que ver con el esquema clásico de la perspectiva de la decisión racional, propuesta originalmente por Laswell para explicar el proceso común a toda decisión de política pública adoptada en forma racional. ${ }^{21}$ Por el contrario, subyace en este proceso la teoría crítica de esa perspectiva lineal que propone que las alternativas de solución posibles compiten en una clara concepción pluralista que predomina en las relaciones en los procesos de toma de decisiones y de la distribución del poder en la sociedad. Este modelo, llamado de perspectiva incremental, explica de un modo más realista que las decisiones de política pública son mediadas por el autointerés. Es decir, son influidas por la lucha entre actores políticos que actúan en defensa de sus propios intereses o ideologías y ganan terreno en la medida en que se van imponiendo unas sobre otras. ${ }^{22}$

de 2016), https://www.mesadeconversaciones.com.co/comunicados/comunicado-conjunto-69-lahabana-cuba-12-de-mayo-de-2016

${ }^{21}$ Harold D. Lasswell, “The decision process: seven categories of functional analysis”, Bureau of Governmental Research, College of Business and Public Administration, University of Maryland, 1956.

22 Charles E. T. Lindblom, "The science of muddling through". Public Administration Review 19, n. 2 (1959). 
Según el planteamiento de la visión incremental, como teoría que busca explicar los mecanismos de producción de las decisiones de políticas públicas, los diferentes grupos tienen capacidad para defender sus intereses y para que ninguno sea ignorado, resolviéndose el conflicto a través del proceso de ajuste mutuo. ${ }^{23} \mathrm{Si}$ bien esta teoría ha sido objeto de críticas, vinculadas, por ejemplo, con la existencia de una desigual distribución del poder que impide esa dinámica de conciliación equitativa, ${ }^{24}$ lo cierto es que hay algo innegable en el planteamiento y es que la formación e implementación de una política pública es, inevitablemente, el resultado de la interacción entre actores diversos, con intereses, metas y estrategias disímiles. En el caso, el proceso que condujo a la formulación del Acuerdo Final en su primera versión respondió a la lógica de la negociación y el debate, en el que pugnaron las partes intervinientes hasta alcanzar un nivel óptimo de satisfacción que se sometió al escrutinio de la ciudadanía.

Sin embargo, es posible precisar que en esa etapa decisoria, inicialmente, no se promovió con intensidad un diálogo inclusivo de todos los potencialmente afectados, pues la decisión cerrada desde el ejecutivo fue sometida a consulta pública en la recta final. Recién, luego de haber sido rechazado ese Acuerdo por la mayoría de los ciudadanos que confluyeron en las urnas, se consuma en un nuevo Acuerdo la participación de los sectores de la sociedad y se anuncia que este será sometido a un procedimiento de refrendación, mediante sistemas de participación ciudadana que no se limitan al plebiscito. ${ }^{25}$

Precisamente, la Corte Constitucional, en Sentencia C-699 del 2016, tuvo oportunidad de pronunciarse al respecto. A propósito de una acción pública de inconstitucionalidad presentada contra el Acto Legislativo para la Paz (01 del 2016), este Tribunal estudió cuál era la interpretación constitucionalmente adecuada del término "refrendación popular", toda vez que la vigencia de las medidas del procedimiento conocido como fast

23 Francesc Pallarés Porta, "Las políticas públicas: el sistema político en acción”. Revista de Estudios Políticos (1988).

${ }^{24}$ Joan Subirats, "E1 análisis de las políticas públicas". Gaceta Sanitaria: Organo oficial de la Sociedad Española de Salud Pública y Administración Sanitaria 15, n. ${ }^{\circ} 3$ (2001).

25 Mesa de Conversaciones para la Terminación del Conflicto y la Construcción de una Paz Estable y Duradera en Colombia, "Acuerdo final". 
track se encontraban supeditadas a que se refrendara popularmente el Acuerdo Final. La Corte se preguntó si el proceso refrendatorio concluía con el pronunciamiento del pueblo mediante un mecanismo directo de participación ciudadana o si existían otros factores a considerar, máxime cuando del resultado del plebiscito del 2 de octubre no era posible colegir un rechazo absoluto y mandatorio a la consolidación de una política pública de construcción de paz. ${ }^{26}$ En este sentido, lo primero que expresa la Corte Constitucional en la sentencia es que la participación ciudadana, esta vez mediante plebiscito, si bien hace referencia a la forma como se tenía contemplado cumplir con el mandato constitucional de garantizar el orden público, proveer la defensa y la seguridad nacional y darle vigencia al derecho constitucional a la paz (artículos 22, 189.3 y 189.4), su resultado negativo no podía significar una prohibición de cumplir estas obligaciones de imperioso acatamiento constitucional.

Es decir, la Corte Constitucional destacó que, no obstante el pronunciamiento plebiscitario negativo, el deber del presidente de la República de garantizar el orden público, proveer a la defensa y la seguridad nacional y celebrar acuerdos de paz se debía mantener incólume. Además de dicha consideración, el segundo prisma a través del cual la Corte analizó el problema jurídico fue el de sus propias competencias. En el criterio del Tribunal, este no podía atribuirse la facultad de determinar si el acuerdo había sido refrendado popularmente, por cuanto ello tenía que ser objeto de la valoración política más acreditada democráticamente que, para el caso colombiano, la encarna el Congreso de la República. Ello, a juicio de la Corte, significa que el "proceso de refrendación popular por consulta previa de la ciudadanía solo es tal, si los resultados del mecanismo previo de participación ciudadana son interpretados, respetados y desarrollados de buena fe, en un escenario de búsqueda de mayores consensos". Quiere decir, en concreto, que para la Corte Constitucional la refrendación popular del Acuerdo Final era en realidad un proceso incremental en el que el pronunciamiento plebiscitario era una de tantas etapas que debían dirigirse a la

26 De hecho, los sectores más representativos opositores a la implementación del Acuerdo de Paz suscrito en Cartagena, con posterioridad a la contienda plebiscitaria, se manifestaron a favor de buscar consensos políticos que viabilizaran la implementación de un acuerdo tendiente a concretar una salida dialogada al conflicto armado. 
construcción de un consenso político y social sobre cómo hacer efectivos los compromisos constitucionales frente al orden público y la paz.

\subsection{La puesta en práctica y la evaluación del Acuerdo de Paz}

Cuando hablamos de la evaluación de las políticas públicas, no nos estamos refiriendo únicamente a la fiscalización que podría hacerse en la etapa última de su implementación para verificar los resultados de la ejecución. En rigor, también aludimos a la valoración que debe realizarse a lo largo de todo el ciclo, desde el mismo diseño y elaboración de la política pública. En este sentido, se entiende que la evaluación consiste en "aportar elementos al proceso de toma de decisiones (reformulación), que permitan mejorar los efectos de la actividad evaluada y contribuyan a la rendición de cuentas y a la generación de ciudadanía". ${ }^{27}$ La evaluación equivale, en esos términos, a una instancia para reflexionar sobre el camino adoptado, monitorear el impacto que puede tener la política pública decidida y proponer ajustes o cambios. Habida cuenta de que el ejercicio de evaluación debe realizarse durante todo el proceso, ${ }^{28}$ se torna necesario aprender de la experiencia que ha dejado el resultado del plebiscito celebrado el 2 de octubre en la tarea de encontrar caminos que permitan reencauzar el proceso de paz colombiano.

Desde la disciplina de estudio de la administración pública se han propuesto varios enfoques que representan modelos de implementación de políticas públicas. ${ }^{29}$ Los más recientes involucran como aspecto clave la negociación entre actores y hacen énfasis en modelos deliberativos y participativos, respondiendo así a los postulados de las reformas administrativas afines al enfoque de la gobernanza. ${ }^{30}$ Estos modelos, "fundados en la recuperación de la confianza y legitimidad de la acción pública, y buscando contar con la ciudadanía como centro y protagonista de su pro-

\footnotetext{
27 Myriam Cardozo Brum, "De la evaluación a la reformulación de políticas públicas”. Política y Cultura (2013).

28 Joan Subirats, "El análisis de las políticas públicas". Gaceta Sanitaria: Órgano oficial de la Sociedad Española de Salud Pública y Administración Sanitaria (2001).

29 Ferraro, Reinventando el Estado.

30 Canto Chac, "Gobernanza y participación”. En la misma orientación, José Juan Sánchez González, "La participación ciudadana como instrumento de gobierno abierto". Espacios Públicos (2015): 18, http://www.redalyc.org/articulo.oa?id=67642415003
} 
pio desarrollo", ${ }^{31}$ se alejan del esquema tradicional conforme al cual las decisiones de políticas públicas emanan jerárquicamente del Estado como centro del poder político. ${ }^{32}$

En esta visión, la arquitectura estatal exige hoy en día una mayor interacción entre Estado y sociedad en la ejecución de las políticas públicas. Precisamente esta garantía de participación se contempla en el Acuerdo Final, tanto en su versión original como en la nueva, al proclamar que

La participación ciudadana es el fundamento de todos los acuerdos que constituyen el Acuerdo Final. Participación en general de la sociedad en la construcción de la paz y participación en particular en la planeación, la ejecución y el seguimiento a los planes y programas en los territorios, que es además una garantía de transparencia. ${ }^{33}$

Por añadidura, el tema de la participación ciudadana se hace presente en varios pasajes del Acuerdo adquiriendo un protagonismo destacable en el texto.

De manera pues que podríamos afirmar que, al momento de la implementación de este Acuerdo, existirán muchas herramientas que pondrán a prueba la capacidad institucional y la madurez de la sociedad para articular los espacios de diálogo y deliberación que están contemplados. El gran reto, en lo que se viene, será generar dicha capacidad institucional a

31 Cfr. "Preámbulo", Carta Iberoamericana de Gobierno Abierto, Aprobada por la XVII Conferencia Iberoamericana de Ministras y Ministros de Administración Pública y Reforma del Estado (Bogotá, 7 y 8 de julio del 2016).

32 Más allá de la lectura crítica que podría hacerse del concepto de gobernanza, lo cierto es que hay un consenso básico respecto de que el modelo representa un cambio en el sentido y en el proceso de gobernar que desplaza del centro de la escena al Gobierno. En efecto, no podemos eludir que, cuando se habla de participación ciudadana en el marco de las políticas públicas, se aborda indefectiblemente el asunto de la gobernanza que, como es sabido, logró amplia difusión cuando el Banco Mundial y otros organismos internacionales promotores de políticas de desarrollo anunciaron la llamada crisis in governance. En palabras de Mayntz, "actualmente se recurre a governance sobre todo para indicar un nuevo estilo de gobierno, distinto del modelo del control jerárquico y caracterizado por un mayor grado de cooperación y por la interacción entre el Estado y los actores no estatales al interior de redes decisionales mixtas entre lo público y lo privado". Renate Mayntz, "Nuevos desafíos de la teoría del governance". Instituciones y Desarrollo (2000).

33 Mesa de Conversaciones para la Terminación del Conflicto y la Construcción de una Paz Estable y Duradera en Colombia, "Acuerdo final”, 6-7. 
nivel nacional pero también en el ámbito territorial, para no solo incluir a la ciudadanía en la ejecución del Acuerdo Final, sino también para que ese involucramiento sea efectivo, y no se traduzca en un escenario ficticio de participación y en un dispendio innecesario y excesivo de gasto público.

Ahora bien, retomando el análisis planteado en esta sección, observamos que la intervención de la ciudadanía no se aprovechó en la etapa de diálogos exploratorios para construir la agenda de paz ni tampoco en la definición de los puntos centrales del Acuerdo. Más allá de una plataforma virtual en la que los ciudadanos podían realizar propuestas, evidentemente la realidad demostró que era fundamental una discusión e interlocución más profunda con los sectores de la sociedad civil, para enriquecer las negociaciones de la mesa y robustecer la legitimidad de los Acuerdos.

También ha evidenciado la realidad de que el mecanismo del plebiscito, al limitar la definición de una política de semejante trascendencia a una decisión binaria, no convenció a la ciudadanía para inclinarse mayoritariamente a aceptar el Acuerdo. Esta circunstancia, desde el punto de vista del ciclo de las políticas públicas, plantea un escenario de forzosa retroalimentación o feedback que conduzca a replantear el camino seguido. Este reto ha sido encarado desde el triunfo del No en el plebiscito con la premura que exigió no perder el impulso negociador de las partes, a través del intercambio de argumentos con sectores que se consideraban aplazados, con el fin de construir colectivamente un Acuerdo más integrador que contemplara los ajustes y precisiones que estos sectores reclamaron.

Por lo visto hasta aquí, el análisis teórico del ciclo de las políticas públicas nos permite visualizar que la participación ciudadana es vital en todas las etapas de esta clase de procesos. ${ }^{34} \mathrm{Al}$ respecto, en el Informe de Desarrollo Humano: Callejón con salida del PNud para Colombia del 2003, se advertía que el Estado debía mostrarse más abierto y menos desconfiado en las iniciativas de la sociedad civil y que, a su turno, la sociedad civil no debía olvidar "que es un poder, que el poder existe para ser usado y que usarlo

$34 \mathrm{Al}$ respecto, se ha sostenido que "la participación ciudadana en los asuntos públicos es un elemento fundamental de las nuevas formas de gobernar (lo que en estos días se conoce como gobernanza), y es central para el funcionamiento de cualquier democracia”. Mónica Tapia Álvarez, Beatriz Campillo Carrete, Susana Cruickshank Soria y Giovanna Morales Sotomayor, Manual de incidencia en políticas públicas (México: Alternativas y Capacidades, 2010). 
bien es jugarse a la paz" ${ }^{35}$ Cabe insistir en que la participación no es solo predicable respecto de momentos puntuales en la toma de decisiones, sino que el ideal democrático exige que la ciudadanía tome su lugar a lo largo de todo el ciclo. Esto no significa que se prescinda de la institucionalidad pública, pues en esta visión la sociedad civil carece de autoridad para tomar por su cuenta decisiones de política pública, sino que su tarea puede consistir en proveer información, ejercer presión e influir activamente en el diagnóstico, la programación, la ejecución y la evaluación de las políticas públicas. ${ }^{36}$

\section{La legitimación democrática de la política pública de paz}

Mucho se ha escrito sobre la participación ciudadana en los últimos años, incluso por parte de quienes cuestionan seriamente su funcionamiento. ${ }^{37}$ En esta oportunidad, nos interesa dejar trazadas solo unas líneas generales que servirán de marco para observar el funcionamiento que ha tenido en la práctica el mecanismo de refrendación utilizado para legitimar el Acuerdo de Paz. Por ello, partimos de la base de que, si bien el fenómeno participativo es discutible, por las flaquezas que se demuestran en el plano empírico y que, podríamos arriesgarnos a asegurar, son congénitas a todo espacio de apertura democrática en que puedan desarrollarse, sostenemos que los diagnósticos negativos no deben ser motivo de resignación. En todo caso, la balanza debe siempre inclinarse a favor de estas prácticas porque al menos acercan las preferencias de los ciudadanos a los representantes, fortaleciendo el vínculo de confianza entre ambos.

Existe consenso acerca de que el fenómeno de la participación de la ciudadanía en la gestión pública ha sido el producto de un nuevo paradigma que ha desembocado en la resignificación del papel del Estado y de la sociedad en la construcción de las políticas públicas. En el proceso

35 Programa de las Naciones Unidas para el Desarrollo — PNUD-. Informe Nacional de Desarrollo Humano para Colombia 2003: El conflicto, callejón con salida (Bogotá: PNUD, 2003), 459.

36 Germán Valencia Agudelo, "Incidencia de la sociedad civil en el ciclo de las políticas públicas". Papel Político 17, n. ${ }^{\circ} 2$ (2012).

37 Pilar Arcidiacono, "El protagonismo de la sociedad civil en las políticas públicas: entre el 'deber ser' de la participación y la necesidad política”. Revista Reforma y Democracia, n.o 51 (2011), http://www.redalyc.org/toc.oa?id=3575\&numero=33683; Johnatan Fox, "Sociedad civil y políticas de rendición de cuentas”. Perfiles Latinoamericanos, n. ${ }^{\circ} 27$ (enero-julio 2006): 33-68. 
que analizamos, tanto en la construcción como en la reconstrucción del Acuerdo Final, que es la plataforma sobre la cual se está contruyendo el proceso de paz, queda en evidencia que el ejercicio del diálogo es el motor que legitimará la política a implementarse. Ahora bien, en este diseño político-institucional que tiene por objeto que los ciudadanos se hagan parte de las decisiones públicas fundamentales que son de su interés, exponiendo sus preferencias y las razones que justifican su opción, se propone una mejora institucional al modelo de la democracia participativa, asentada en el pensamiento republicano de Rousseau. ${ }^{38}$

Según esta óptica, la democracia participativa adquiere dos variantes. Una es la forma directa, defendida por Rousseau, que se caracteriza por la introducción de mecanismos institucionales que garanticen la participación de la ciudadanía en la vida pública, a través de instrumentos como los referéndums, la iniciativa popular de ley, la revocatoria del mandato, entre otros. La otra es la forma deliberativa de la regulación democrática participativa, sustentada en la teoría comunicativa de Habermas, que se define a partir del contenido del proceso decisional, el cual, con el propósito de lograr decisiones justificadas, integra en un diálogo inclusivo a todas las partes afectadas por la decisión que, ante un desacuerdo, se debe tomar. ${ }^{39}$ Así, en un intercambio de razones y argumentos, tanto ciudadanos como representantes construyen de manera cooperativa y consensuada la decisión tendiente a la resolución del desacuerdo.

Esta fórmula deliberativa de la democracia se presenta como el ideal regulativo ${ }^{40}$ en razón de la imparcialidad de su resultado. $\mathrm{O}$, dicho en otros

38 Jean-Jacques Rousseau, “E1 contrato social”, en Escritos de combate (Madrid: Alfaguara, 1979).

39 Robert Gargarella, "El nuevo constitucionalismo dialógico, frente al sistema de los frenos y contrapesos”. Revista Argentina de Teoría Jurídica (2013): 1-32, http://www.utdt.edu/ver_contenido. php?id_contenido=9173\&id_item_menu=5858

40 Véase, entre otros, Bruce Ackerman, La política del diálogo liberal (1998); Ronald Dworkin, Los derechos en serio (1989); Owen Fiss, Between supremacy and exclusivity (2006); Roberto Gargarella, El nuevo constitucionalismo dialógico frente al sistema de los frenos y los contrapesos (2013), El ideal de la democracia deliberativa en el análisis del sistema representativo. Algunas notas teóricas y una mirada sobre el caso de la Argentina (1995), Los fundamentos legales de la desigualdad: el constitucionalismo en América (1776-1860) (2005), La justicia frente al gobierno. Sobre el caracter contramayoritario del poder judicial (1996); Stephen Holmes, El precompromiso y la paradoja de la democracia (1999); Robert Post y Reva Siegel, Constitucionalismo democrático. Por una reconciliación entre Constitución y pueblo (2013); Rodrigo Uprimny, La judicialización de la política en Colombia: casos, potencialidades y riesgos (2007); Joshua 
términos, como lo explica Nino al referirse al valor epistémico de la democracia:
(...) la concepción deliberativa de la democracia ve a esta última como profundamente interrelacionada con la moral y se apoya sobre su poder para transformar preferencias moralmente aceptables (...) el consenso alcanzado después de un ejercicio de discusión colectiva debe ser de algún modo confiable en el proceso de conocimiento de asuntos morales. ${ }^{41}$

En esta vertiente deliberativa, la democracia se traduce en una herramienta procedimental que permite a los intervinientes del debate público exponer sus puntos de vista con el propósito de persuadir a sus interlocutores pero, al mismo tiempo, les da la oportunidad de atender a estos últimos para permitirles ser persuadidos ante los argumentos del resto de intervinientes.

Holmes, con mayor precisión, apunta que en esta concepción la democracia es el "gobierno por discusión pública” y no solo la imposición de la voluntad mayoritaria. Así, afirma que será democrática la decisión que haya tenido ocasión de ser discutida a profundidad contemplando todos los puntos de vista posibles incluyendo, especialmente, a los más críticos. En tal sentido, un diseño institucional que profundice la deliberación incluyente y participativa garantizaría en su criterio que la adopción de decisiones de gobierno provenga de debates ricos y con información completa y, consecuentemente, desprovista de arbitrariedades. De manera pues que la deliberación no es solo una garantía para proteger a la minoría sino también un instrumento para asegurar que la mayoría corrija e instruya su decisión. ${ }^{42}$

En el marco señalado, podemos observar que en la aprobación e implementación de la política de paz en el caso colombiano, el mecanismo de democracia participativa directa ha tenido que ser complementado con un ejercicio de democracia deliberativa. En efecto, luego de la realización

Cohen, Deliberation and democratic legitimacy (2003); Carlos F. Rosenkrantz, La teoría episistémica de la democracia revisitada (2004); Albert Calsamiglia Blancafort, Constitucionalismo y democracia.

41 Carlos Nino, La Constitución de la democracia deliberativa (Barcelona: Gedisa, 1997).

42 Stephen Holmes, "El precompromiso y la paradoja de la democracia", en Constitucionalismo y democracia, de Jon Elster y Rune Slagstad (México D.F.: Fondo de Cultura Económica, 1999). 
del plebiscito, en un claro contexto de feedback, los sectores de la sociedad que se consideraron apartados del debate o que no encontraron suficiente representación en el Acuerdo exigieron al Gobierno que se prolongara la discusión y les concediera la oportunidad de expresar sus intereses para poder aceptar lo que se estaba proponiendo desde la institucionalidad. Esto demuestra que, si bien es válida la adopción de cualquier sistema derivado de uno u otro modelo de democracia participativa, la poca discusión previa y la simplificación de un sistema que permite votar por Sí o por No, en el caso de una decisión tan relevante, el mecanismo del plebiscito quedó pequeño. Lo anterior no quiere decir que la opción de refrendar el Acuerdo Final mediante un mecanismo de participación directa como el plebiscito haya sido desatinada. Lo que parece haber sido un error es que el proceso en sí mismo no haya estado acompañado de espacios constantes, periódicos e institucionalizados de discusión con todos los sectores de la sociedad, especialmente los más críticos del Acuerdo.

Indudablemente, son las condiciones de tiempo, modo y lugar de cada sociedad las que aconsejan la adopción de uno u otro modelo de democracia participativa y la profundización en una u otra concepción de regulación democrática. Tampoco puede negarse que, al final, la deliberación y el intercambio argumentativo entre los ciudadanos y las instituciones contribuyen a reforzar el ideal democrático, pues el diálogo institucional, por sí solo, a veces no alcanza a efectos de la democratización de la deliberación pues excluye de la dinámica dialógica a los ciudadanos que son, precisamente, quienes legitiman la resolución de los desacuerdos en una sociedad.

Por tal motivo, el poder potencial que tienen los ciudadanos al participar a través del diálogo en la construcción del Acuerdo de Paz será determinante para legitimar democráticamente el resultado que pueda arrojar su implementación. Que la ciudadanía tenga la posibilidad de persuadir y ser persuadida sobre una lectura específica del Acuerdo es lo que subsana el déficit democrático que podría atribuirse a una política pública impuesta por los poderes públicos. Tal consideración nos pone de presente que una decisión legitimada democráticamente no solo depende de quien propone sino de quien tiene la posibilidad de hacer oír su voz.

Los hechos nos demostraron que, dada la fragilidad del cese al fuego de hostilidades bilateral y definitivo por cuenta del resultado plebiscitario, la refrendación del Acuerdo Final con sus modificaciones se llevó a cabo 
mediante la intervención del Congreso de la República, como fue sugerido por la propia Corte Constitucional en la precitada Sentencia C-699 del 2016. Ello, por supuesto, volvió más estrechos los escenarios de deliberación democrática, plural, abierta e incluyente. No obstante, el reto que actualmente atraviesa la sociedad y el Estado colombiano es el de imbuirse en un diálogo sincero, amplio y leal, sobre todos y cada uno de los puntos sobre los cuales las FARC y el Gobierno se han puesto de acuerdo para callar los fusiles pero, especialmente, eliminar las condiciones por las cuales el conflicto emergió y perduró por tantos años.

Lo anterior, sin contar con que el 7 de febrero de 2017 se instalaron formalmente los diálogos de paz con la guerrilla del ELN, que resultan más desafiantes en materia de participación ciudadana pues, según la hoja de ruta trazada, la apertura democrática no es solamente un objetivo de la negociación sino el medio que tienen contemplado para llegar a consensos sobre el fin del conflicto armado entre ambas partes.

\section{Conclusiones}

A partir de lo expuesto hasta aquí, la primera reflexión que surge es que, siendo la paz una política pública del Estado colombiano, esta se constituye en un objetivo transversal de planeación gubernamental. Efectivamente, la paz se ha incorporado en la agenda de gobierno, pero observamos a partir del análisis propuesto que no se ha incorporado decididamente al ciudadano en el diseño de esta política pública en todas sus fases.

Como observadores del proceso, advertimos que el involucramiento de la ciudadanía ha pasado por al menos tres fases: una primera, de absoluto distanciamiento signado por el hermetismo de la mesa de negociación, bien por encontrarse el proceso en etapa exploratoria, o bien porque los primeros meses de negociación las partes estaban concentradas en consolidar la confianza que requerían para emprender la etapa formal de negociación; una segunda etapa, en la que la participación ciudadana fue agenciada por instituciones que les daban garantías a las partes, como la Universidad Nacional a través del Centro de Pensamiento y Seguimiento al Proceso de Paz y el sistema de Naciones Unidas en Colombia; y, finalmente, se puede identificar una tercera etapa de pleno involucramiento de la sociedad, que está signado por la definición del plebiscito como mecanismo de refrendación. 
Es decir, el momento de participación institucionalizada en el proceso tuvo lugar recién en el momento de la celebración del plebiscito y, luego, en la etapa posterior a la jornada plebiscitaria, cuando es posible evidenciar una presencia activa de los más diversos sectores políticos, económicos y sociales del país en el curso del proceso de paz, que es el curso de la política pública al final de cuentas.

A partir de esta conclusión general, las reflexiones particulares que nos surgen son las que siguen:

- Somos partícipes de la idea de que la terminación de un conflicto armado por la vía dialogada demanda un compromiso fuerte del Gobierno en la elaboración de estrategias robustas para poner en marcha una política pública centrada en el concepto de paz positiva.

- Dicho proceso tiene como antesala necesaria diversos grupos implicados y gran parte de la sociedad interesada en resolver un conflicto en el que los intereses son distantes, antagónicos y enfrentados. En esa medida, las decisiones que se adopten afectarán en adelante la vida de la Nación y por ello es absolutamente imprescindible un involucramiento profundo de todos los sectores, para que el fin del conflicto se enmarque en un escenario de legitimidad política.

- La democracia directa, aunque deseable e imperiosa constitucionalmente, puede ser limitada para dotar de legitimidad política a un proceso de paz. La legitimidad reposa, desde nuestra óptica, en que en las etapas previas a la refrendación del acuerdo todos los sectores sociales, pero especialmente los contradictores, tengan espacios amplios, plurales e institucionalizados para transmitir sus reclamos.

- La esperanza reposa en el hecho de que la apertura democrática que se evidencie en la etapa de implementación del Acuerdo Final tendrá un efecto legitimador porque es la única manera de que la ciudadanía ejerza una función de vigilancia para que se cumpla lo acordado.

\section{Bibliografía}

"Preámbulo". Carta Iberoamericana de Gobierno Abierto, Aprobada por la XVII Conferencia Iberoamericana de Ministras y Ministros de 
Administración Pública y Reforma del Estado. Bogotá, 7 y 8 de julio del 2016.

Arcidiacono, Pilar. "El protagonismo de la sociedad civil en las políticas públicas: entre el 'deber ser' de la participación y la necesidad política”. Revista Reforma y Democracia, n. ${ }^{o} 51$ (2011), http://www.redalyc. org/toc.oa?id $=3575 \&$ numero $=33683$

Mesa de Conversaciones para la Terminación del Conflicto y la Construcción de una Paz Estable y Duradera en Colombia. "Acuerdo final para la terminación del conflicto y la construcción de una paz estable y duradera”, 12 de noviembre de 2016, suscrito entre el Gobierno nacional de la República de Colombia y las FARC EP, https://www. mesadeconversaciones.com.co/sites/default/files/12-1479102292.111479102292.2016nuevoacuerdofinal-1479102292.pdf

Canto Chac, Manuel. “Gobernanza y participación ciudadana en las políticas públicas frente al reto del desarrollo". Politica y cultura, n. ${ }^{\circ} 30$ (2008): 9-37.

Cardozo Brum, Myriam. "De la evaluación a la reformulación de políticas públicas”. Politica y Cultura (2013): 123-149.

Comisión Económica para América Latina y el Caribe (Cepal). Cohesión social: inclusión y sentido de pertenencia en América Latina y el Caribe. Santiago de Chile: Cepal, 2007.

Cerrillo i Martínez, Agustí. La gobernanza hoy: 10 textos de referencia. Madrid: Instituto Nacional de Administración Pública, 2005.

Cohen, Jean L. y Andrew Arato. Civil society and political theory. Cambridge: Miт Press, 1995.

Cunill Grau, Nuria. "La rearticulación de las relaciones Estado-sociedad: en búsqueda de nuevos sentidos". Revista del CLAD Reforma y democracia, n. ${ }^{\circ} 4$ (1995): 25-58.

Esteve Pardo, José. La nueva relación entre Estado y sociedad. Madrid: Marcial Pons, 2013.

Ferraro, Agustín. Reinventando el Estado. Por una administración pública democrática y profesional en Iberoamérica. Madrid: Instituto Nacional de Administración Pública, 2009.

Fisas, Vincenç. "Introducción a los Procesos de Paz". Quaderns de Construció de Pau. El proceso de paz en Colombia, n. 17 (febrero, 2010): 5-22. 
Fox, Johnatan. "Sociedad civil y políticas de rendición de cuentas". Perfiles Latinoamericanos, n. ${ }^{\circ} 27$ (enero-julio 2006): 33-68.

Galtung, Johan. "Violence, peace, and peace research". Journal of Peace Research (1969) 6, n. ${ }^{\circ}$ 3: 167-191.

Gargarella, Robert. "El nuevo constitucionalismo dialógico, frente al sistema de los frenos y contrapesos". Revista Argentina de Teoría Jurídica (2013): 1-32, http://www.utdt.edu/ver_contenido.php?id_ contenido=9173\&id_item_menu $=5858$

Holmes, Stephen. "El precompromiso y la paradoja de la democracia", en Constitucionalismo y democracia, de Jon Elster y Rune Slagstad, 217262. México D.F.: Fondo de Cultura Económica, 1999.

Informe preliminar Foro Nacional de Víctimas, http://www.co.undp.org/content/dam/colombia/docs/Paz/undp-co-informefinalFNV-2014.pdf

Informe y Balance General Foro de Desarrollo Agrario Integral (enfoque territorial), https://www.dropbox.com/s/c0c7o8uousr1w3c/ informe_y_balance_general.pdf

Informe y Balance General Foro Participación Política, https://www.dropbox. $\mathrm{com} / \mathrm{s} / \mathrm{h} 5$ cias1duo1vtib/Participaci $\% \mathrm{C} 3 \% \mathrm{~B} 3 \mathrm{n} \% 20 \mathrm{pol} \% \mathrm{C} 3 \% \mathrm{AD}-$ tica-\%20Informe\%20general.pdf

Informe y Balance General Foro Nacional y Regional sobre la solución al problema de las drogas ilícitas, https://www.dropbox.com/s/ird4tt9uvah0ky1/INFORME \%20Y\%20BALANCE\%20GENERAL\%20 DROGAS \%20ILICITAS.pdf

Lasswell, Harold D. "The decision process: seven categories of functional analysis". Bureau of Governmental Research, College of Business and Public Administration, University of Maryland, 1956.

Ley 1753 del 2015, 9 de junio. Por la cual se expide el Plan Nacional de Desarrollo 20142018 “Todos por un nuevo país”. Diario Oficial 49.538.

Lindblom, Charles E. T. “The science of muddling through”. Public Administration Review 19, n.o 2 (1959): 79-88.

Mayntz, Renate. “Nuevos desafíos de la teoría del governance”. Instituciones y Desarrollo (2000): 35-52.

McCombs, Maxwell y Dixie Evatt. "Los temas y los aspectos: explorando una nueva dimensión de la agenda setting". Comunicación y sociedad 8, n. ${ }^{\circ 1}$ (1995): 1-20. 
Mesa de Conversaciones para la Terminación del Conflicto y la Construcción de una Paz Estable y Duradera en Colombia, https://www. mesadeconversaciones.com.co/estado-propuestas?field_consecutivo_db_opt_value=

Mesa de Conversaciones para la Terminación del Conflicto y la Construcción de una Paz Estable y Duradera en Colombia. "Comunicado Conjunto \#69”. La Habana, Cuba, 12 de mayo de 2016, https:// www.mesadeconversaciones.com.co/comunicados/comunicadoconjunto-69-la-habana-cuba-12-de-mayo-de-2016

Nino, Carlos. La Constitución de la democracia deliberativa. Barcelona: Gedisa, 1997.

Parsons, Wayne. Politicas públicas: una introducción a la teoría y la práctica del análisis de políticas públicas. México: Flacso Mexico, 2013.

Porta, Francesc Pallarés. "Las políticas públicas: el sistema político en acción”. Revista de Estudios Políticos (1988): 141-162.

Prats,Joan. "Políticas de buena administración para la Administración General del Estado en España. Un enfoque de gobernanza democrática”, en Gobernanza democrática y fiscalidad, 25-55. España:Tecnos, 2010.

Programa de las Naciones Unidas para el Desarrollo - PNUD-. Informe Nacional de Desarrollo Humano para Colombia 2003: "El conflicto, callejón con salida”. Bogotá: PNUD, 2003.

Rousseau,Jean-Jacques. “El contrato social”, en Escritos de combate, 393-526. Madrid: Alfaguara, 1979.

Sánchez González, José Juan. "La participación ciudadana como instrumento de gobierno abierto”. Espacios Públicos (2015): 51-73, http://www. redalyc.org/articulo.oa?id=67642415003

Shafritz, Jay M., E. W. Russell y Christopher Borick. Introducing public administration. Nueva York: Routledge, 2015.

Sentencia C-379 del 2016, 18 de julio. MP: Luis Ernesto Vargas Silva.

Subirats, Joan. "El análisis de las políticas públicas". Gaceta Sanitaria: Órgano oficial de la Sociedad Española de Salud Pública y Administración Sanitaria 15, n. 3 (2001): 259-264.

Subirats, Joan. "El análisis de las políticas públicas”. Gaceta Sanitaria: Órgano oficial de la Sociedad Española de Salud Pública y Administración Sanitaria 15, n. ${ }^{\circ}$ 3, (2001): 259-264. 
Subirats, Joan. Otra sociedad. ¿Otra politica? Del "no nos representan" a la democracia de lo común. Barcelona: Icaria, 2011.

Tapia Álvarez, Mónica, Beatriz Campillo Carrete, Susana Cruickshank Soria y Giovanna Morales Sotomayor. Manual de incidencia en políticas públicas. México: Alternativas y Capacidades, 2010.

Valencia Agudelo, Germán. "Incidencia de la sociedad civil en el ciclo de las políticas públicas". Papel Político 17, n. 2 (2012): 469-496.

Velásquez Gavilanes, Raúl. "Hacia una nueva definición del concepto 'política pública”. Desafíos 20 (2010): 149-187. 



\title{
A propósito de la refrendación popular del Acuerdo suscrito entre el Gobierno de Colombia y las FARC y las lecciones aprendidas de la Ley de la Claridad de Canadá y su aplicabilidad al caso colombiano*
}

\author{
Manuel Alberto Restrepo Medina**
}

\section{Introducción}

Dada la estrechez del resultado del plebiscito, que negó por un margen menor al 1\% entre las dos opciones la aprobación del acuerdo negociado entre los representantes del Gobierno nacional de Colombia y los de las FARC-EP, ha surgido la pregunta de cómo resolver de otra manera la aprobación o negación de cuestiones constitucionales relevantes, que por su trascendencia deban ser consultadas directamente a los ciudadanos.

Llama la atención que, ni antes de haberse pactado por parte de los negociadores que la implementación del acuerdo producto de la negociación bilateral quedaría sujeta a refrendación popular (punto 6.6 del Acuerdo),

* La idea que inspira el presente escrito no es original de su autor. Corresponde a una sugerencia del profesor Ricardo Rivero Ortega, decano de la Facultad de Derecho de la Universidad de Salamanca, expuesta al responder una pregunta de una participante en el coloquio del Doctorado en Derecho de la Facultad de Jurisprudencia de la Universidad del Rosario que lo tuvo a él como conferencista invitado, quien nos invitó a reflexionar sobre la posibilidad que señala el título.

** Abogado. Especialista en Legislación Financiera. Magíster en Estudios Políticos. Magíster en Derecho Administrativo. DEA en Derecho Procesal. Doctor en Derecho. Director de la Escuela Doctoral de la Facultad de Jurisprudencia de la Universidad del Rosario. Correo electrónico: manuel.restrepo@urosario.edu.co 
p. 192) ${ }^{1}$ ni después del resultado del plebiscito, se hubiera realizado ninguna reflexión sobre la solución hallada en Canadá al tema de la secesión de Quebec y su eventual aplicación al caso colombiano.

En tal sentido, y como lección aprendida de lo acontecido en el caso colombiano, el presente escrito se ocupará de presentar las características del caso canadiense y de qué manera las cuestiones esenciales que dieron lugar tanto al pronunciamiento de la Corte Suprema de ese país como a la expedición de la Clarity Act/Loi de Clarification podrían haber servido para prevenir las consecuencias de un resultado como el que se presentó o tenerlas en cuenta para situaciones similares en el futuro.

Para entender la dimensión de los cambios constitucionales que requieren un tratamiento especial cuando son sometidos a refrendación popular, es adecuado tener en cuenta la siguiente reflexión contenida en el preámbulo de la mencionada ley:

El hecho de descartar la posibilidad de entablar una negociación sobre la secesión a menos que esta cuente con el apoyo de una mayoría clara, y no incierta y frágil, pone de manifiesto que la secesión se considera un acto grave y probablemente irreversible, que afecta a las generaciones futuras y que tiene consecuencias muy importantes para todos los ciudadanos del país que, de ese modo, quedaría escindido. La pregunta formulada en el referéndum también debe ser clara, ya que es evidente que solo una pregunta que aborde verdaderamente la secesión permitiría saber si los ciudadanos la desean realmente.

Así, frente a un acto grave y probablemente irreversible, que afecte a las generaciones futuras y que tenga consecuencias muy importantes para el país, la pregunta que se le formule al pueblo debe ser lo suficientemente clara como para permitir saber si los ciudadanos desean realmente su aprobación,

\footnotetext{
1 “6.6 Acuerdo sobre 'Refrendación'. El Gobierno de Colombia y las FARC-EP, para zanjar las diferencias surgidas hasta la fecha sobre el tema aludido, en desarrollo de la agenda del Acuerdo General para la terminación del conflicto, hemos convenido acoger como fórmula de convergencia la decisión que profiere la Corte Constitucional sobre los alcances del Proyecto de Ley Estatutaria 156 Cámara del 2015, 94 del 2015 Senado, en el espíritu hasta ahora anunciado, y en esa medida aceptamos el mecanismo de participación popular que la Corte indique y en los términos que este alto tribunal señale".
} 
y, como se verá más adelante, la respuesta no solamente debe ser positiva, como es lo apenas obvio, sino que además tiene que ser contundente.

Un acto tanto o más trascendental que una secesión es un acuerdo para poner fin a un conflicto armado interno de más de cinco décadas de duración que ha producido más de 220.000 homicidios, más de 45.000 desapariciones forzadas, al menos 30.000 secuestros, no menos de 13.000 víctimas de agresiones sexuales y 11.000 de minas antipersona, así como más de 6,7 millones de personas desplazadas. ${ }^{2}$ Por tanto, la definición de las reglas para su aprobación, empleando un mecanismo de refrendación popular, debería considerar experiencias para decisiones de esta naturaleza en otras jurisdiciones, como las que muestra el caso canadiense sobre la eventual secesión de la provincia de Quebec.

\section{El caso canadiense}

Para poner en contexto lo que aquí se llamará la solución canadiense, baste recordar, para no remontarse tan atrás, que en 1995 hubo un referendo sometido a consideración de los ciudadanos quebequenses, cuyo resultado fue favorablemente leve al No como respuesta a la pregunta que les fue formulada, por un margen de 50,58\% a 49,42\%, porcentajes que podrían ser muy semejantes a los del resultado del plebiscito colombiano.

La pregunta del referendo resultó controvertida por su redacción ambigua: “¿Está usted de acuerdo en que Quebec debería convertirse en soberano después de haber hecho una oferta formal a Canadá para una nueva asociación económica y política en el ámbito de aplicación del proyecto de ley sobre el futuro de Quebec y del acuerdo firmado el 12 de junio de 1995?”.

A la luz tanto del resultado como del texto con que se consultó al pueblo, el Gobierno nacional, presidido por el primer ministro Jean Chrétien, por conducto de Stéphane Dion como ministro de Asuntos Intergubernamentales, puso en tela de juicio el criterio de los soberanistas quebequenses acerca de la validez jurídica del referendo, negando que una declaración unilateral de independencia fuera compatible con el derecho internacional, que una mayoría del $50 \%$ más uno fuera un umbral suficiente para aprobar

2 Cifras tomadas del documento publicado por la Oficina del Alto Comisionado para la Paz, titulado "Proceso de Paz. Acuerdo sobre las víctimas del conflicto"(2016), 2. 
la secesión y que el derecho internacional protegería la integridad territorial de Quebec después de la secesión. ${ }^{3}$

De las afirmaciones de Dion, para los efectos del presente escrito, resulta pertinente detenerse en la segunda, en relación con la cual el ministro indicaba que una mayoría por diferencia escasa, que podría desaparecer rápidamente en medio de cualquier dificultad, sería insuficiente para dar legitimidad política al proyecto soberanista, habida cuenta de los cambios trascendentales que se derivarían de la secesión para la vida de los quebequenses.

En función de los reparos expuestos, el Gobierno de Canadá solicitó a la Corte Suprema de Canadá que se pronunciara sobre las siguientes cuestiones: ${ }^{4}$

1. Según la Constitución de Canadá, ¿puede la Asamblea Nacional, legislatura o el Gobierno de Quebec efectuar la secesión de Quebec de Canadá unilateralmente?

2. ¿Tiene la Asamblea Nacional, la legislatura o el Gobierno de Quebec el derecho a efectuar la secesión de Quebec de Canadá unilateralmente según el derecho internacional?

3. En caso de conflicto entre la legislación nacional y la internacional sobre el derecho de la Asamblea Nacional, la legislatura o el Gobierno de Quebec a efectuar la secesión de Quebec de Canadá de manera unilateral, ¿cuál de las legislaciones tendría preferencia en Canadá, la nacional o la internacional?

Casi dos años después de formulada la consulta, la Corte Suprema concluyó lo siguiente en su pronunciamiento del 20 de agosto de 1998:5

- Quebec no tiene el derecho a separarse unilateralmente, ni por la legislación canadiense, ni por la internacional. Sin embargo,

3 Stéphane Dion, La política de la claridad. Discursos y escritos sobre la unidad canadiense, traducido por María Dolores Torres París (Alianza Editorial, 2005), https://sites.google.com/site/textosdereferencia/st\%C3\%A9phanedion\%3Alapol\%C3\%ADticadelaclaridad.disc

4 Canadian Law, Canadian Clarity Act, http://www.canadianlawsite.ca/clarity-act.htm

5 Canadian Law, Canadian Clarity Act, http://www.canadianlawsite.ca/clarity-act.htm 
el Gobierno de Canadá tendría que entrar en negociaciones con el Gobierno de Quebec si los quebequenses expresaran una clara voluntad de separarse.

- El Parlamento de Canadá tendría la facultad de determinar si la pregunta del referéndum sería lo suficientemente clara para provocar dichas negociaciones.

- La Constitución de Canadá permanecería en vigor hasta que los términos de la secesión fueren acordados por todas las partes involucradas, y estos términos deberán respetar los principios de la democracia, los derechos de las minorías y los individuos, como se indica en la constitución canadiense.

En España, donde la cuestión de la secesión ha estado muy presente en la opinión pública por los nacionalismos separatistas, especialmente el catalán, se ha seguido con especial interés la solución canadiense. Allí se consideró que el concepto de la Corte Suprema de Canadá acoge la doctrina internacional clásica respecto al derecho de autodeterminación, que legitima una declaración unilateral de independencia en casos perfectamente tasados, como las situaciones coloniales, alejados todos ellos del quebequés, sin que atributos particulares de un grupo de ciudadanos, como la lengua, la cultura o la religión, atribuyan un derecho unilateral a la secesión en un Estado democrático. ${ }^{6}$

Sin embargo, por aplicación de los principios constitucionales, si el Gobierno de Quebec, en un nuevo proyecto por su independencia, somete a referéndum de su población una pregunta clara (requisito no cumplido en los dos referéndums anteriores) a la que respondiera favorablemente una mayoría evidente de quebequenses, existiría una obligación constitucional de negociar las reformas legales que permitieran abrir ese camino.

En todo caso, ese resultado debería conseguirse a través de un proceso de negociación basado en la buena fe, y el respeto a la democracia y al Estado de derecho. Y tal negociación tendría que comprender cuestiones sumamente difíciles y complejas, entre otras, una posible nueva definición

6 Hay Derecho, "El derecho de secesión y sus límites. El ejemplo canadiense”, 14 de septiembre del 2012, http://hayderecho.com/2012/09/14/el-derecho-de-secesion-y-sus-limites-el-ejemplocanadiense/ 
de las fronteras. En el caso de que determinadas poblaciones concentradas territorialmente en Quebec solicitaran claramente seguir formando parte de Canadá, debería preverse para ello la divisibilidad del territorio quebequés con el mismo espíritu de apertura con el que se aceptaba la divisibilidad del territorio canadiense.

A raíz del pronunciamiento judicial, Dion ${ }^{7}$ criticó al primer ministro de Quebec por aceptar algunos aspectos de la sentencia de la Corte Suprema sobre la secesión (como la obligación política para el Gobierno de Canadá de negociar la secesión tras una clara expresión de la voluntad del pueblo de Quebec) y no otros (por ejemplo, la necesidad de una clara mayoría con una pregunta clara y la inconstitucionalidad de una declaración unilateral de independencia), y enfatizó en tres aspectos que luego serían definitivos en la redacción de la Ley de Claridad:

- El Gobierno federal tiene un papel en la selección de la pregunta y el nivel de apoyo necesario para que se considere aprobada.

- La secesión solo puede lograrse a través de la negociación en lugar de una declaración "unilateral de independencia".

- Los términos de la negociación no pueden ser decididos exclusivamente por el Gobierno de Quebec.

Como resultado de los debates suscitados con posterioridad al resultado del referendo de 1995 y al pronunciamiento de la Corte Suprema, el 13 de diciembre de 1999 fue presentado el proyecto de ley a consideración del Parlamento canadiense, el cual fue aprobado por la Cámara de los Comunes el 15 de marzo del 2000 y por el Senado el 29 de junio del 2000. Los siguientes son los puntos clave de la ley:

- La Cámara de los Comunes de Canadá tiene el poder de decidir si la pregunta del referéndum de un hipotético proceso de secesión es clara antes de ser sometida a votación. En concreto se indica que cualquier pregunta no referida únicamente a la secesión debe ser considerada poco clara.

7 Dion, La política de la claridad. 
- La Cámara de los Comunes tendría la facultad de determinar si una clara mayoría se habría producido en un referéndum, lo que implicaría que algún tipo de mayoría reforzada sería necesaria para considerar que el resultado del referéndum habría sido favorable a la secesión.

- Todas las provincias y las primeras naciones (entidades políticas formadas por aborígenes americanos reconocidas en el sistema político canadiense) deben tomar parte en las negociaciones.

- La Cámara de los Comunes tiene el poder de anular una decisión alcanzada en referéndum si estima que se ha violado alguno de los principios de la Ley de Claridad.

- La secesión de una provincia de Canadá requeriría una enmienda a la Constitución de Canadá.

La ong Hay Derecho destaca ${ }^{8}$ que esta ley convierte a Canadá en el primer gran Estado democrático que admite expresamente por ley la posibilidad de su propia divisibilidad. La ley, recogiendo las conclusiones de la sentencia, precisa las circunstancias en las que el Gobierno de Canadá podría entablar una negociación sobre la secesión de una de las provincias. Además, prohíbe entablarla a menos que la Cámara de los Comunes haya comprobado que la pregunta del referéndum aborda claramente la cuestión de la secesión y que el resultado ha sido obtenido por una mayoría también clara.

En el evento en que esas dos situaciones se concreten, la Ley sobre la Claridad precisa qué elementos deben figurar necesariamente en la agenda de negociación: repartición de activo y pasivo, modificaciones de la frontera del territorio que se separa y protección de los intereses de las minorías, entre otros.

Las tensiones entre el interés del Gobierno nacional por mantener la integridad del Estado y el de un determinado Gobierno provincial por alcanzar su autonomía se tendrían que resolver con una negociación de buena fe entre las partes, posterior al pronunciamiento democrático que de manera clara y contundente expresara su decisión de optar por el segundo camino.

8 Hay Derecho, "El derecho de secesión". 


\section{Aplicabilidad del caso canadiense al caso colombiano}

Tanto de los contenidos del concepto de la Corte Suprema de Justicia de Canadá como de lo establecido en The Clarity Act, se pueden extractar algunos elementos:

1. La legitimidad y validez de recurrir a la refrendación popular como mecanismo para decidir cuestiones de la mayor gravedad constitucional.

2. La necesidad de que el resultado de la votación popular refleje de manera inequívoca una clara mayoría y una clara intención.

3. La necesidad de que la decisión de esa mayoría se concrete en una negociación de buena fe que respete la democracia, el Estado de derecho y los derechos de las minorías.

Trasladadas estas consideraciones al caso colombiano, se podrían formular las siguientes premisas:

Según el régimen constitucional colombiano y con las normas del derecho internacional humanitario, no es necesario que para suscribir y poder aplicar un acuerdo para la terminación de un conflicto armado interno se requiera de su refrendación popular para que lo convenido entre las partes tenga eficacia jurídica.

No obstante, si las partes, con el fin de darle legitimidad política al acuerdo, deciden someter su texto a la refrendación popular, el resultado será vinculante solamente si la pregunta es clara y si la decisión sobre la misma también lo es.

En Canadá, The Clarity Act confirió al Parlamento Nacional la potestad de establecer la claridad de la pregunta y de determinar el porcentaje de votantes y el umbral de participación requerido para entender que también la mayoría es clara.

En el caso colombiano, con el régimen vigente, la claridad de la pregunta solamente tendría la posibilidad de un control judicial posterior de carácter rogado, en cabeza de la Corte Constitucional, dado que por haberse tratado de un plebiscito y no de un referendo, no está previsto el control previo y automático de su constitucionalidad. Por su parte, la definición de la mayoría tuvo establecida una regla especial para este caso, de un voto 
más que el contrario, siempre que la participación excediera el 13\% del censo electoral.

Con el fin de garantizar que se cumplan los dos primeros supuestos de la solución canadiense, aun si el mecanismo de refrendación popular se cataloga como político (plebiscito) y no como jurídico (referendo), la claridad de la pregunta debería tener un control ex ante que así lo garantizara y que, conforme al diseño institucional colombiano, debería recaer en la Corte Constitucional.

De esta forma, se evitaría que la intención expresada democráticamente pudiera ser cuestionada o ser en sí misma cuestionable por falta de claridad en la formulación de la consulta, que fue lo que aconteció con el plebiscito y la pregunta sometida a la refrendación popular: “¿apoya usted el acuerdo final para terminar el conflicto y construir una paz estable y duradera?".

En efecto, expertos sin un interés directo en el resultado de la consulta manifestaron sus reservas sobre la claridad de la pregunta y cuestionaron que su lenguaje no fuera neutro, por la inclusión de la expresión "paz estable y duradera" (Thom Brooks, profesor de Derecho y Gobierno de la Universidad de Durham) y además que no incluyera al Gobierno y las FARC como actores (Marcos Criado de Diego, profesor de Derecho Constitucional de la Universidad de Extremadura). En cambio, la utilización del vocablo apoyar en lugar de aprobar fue entendida como apropiada por tratarse de una consulta de índole política y no de carácter jurídico. ${ }^{9}$

En ese orden de ideas, una pregunta más precisa, directa y concreta en su redacción, del estilo: "¿apoya usted el acuerdo de paz firmado entre el Gobierno de Colombia y la guerrilla de las FARC?", que no se hubiera prestado a objeciones por parte de los opositores a su aprobación y cuya certificación de claridad se garantizara previamente a la votación por el órgano de cierre del sistema jurídico, habría facilitado un mejor entendimiento por parte de la población y hubiera incrementado las posibilidades de una decisión mayoritaria basada en un conocimiento informado y no en prejuicios ni en tergiversaciones.

La segunda cuestión atinente al aprendizaje de la solución canadiense indica que en lugar de haberse reducido el umbral mínimo de participación

9 Natalio Cosoy, “¿Es tendenciosa la pregunta del plebiscito en Colombia sobre los acuerdos de paz con las FARC?”. BBC Mundo, http://www.bbc.com/mundo/noticias-america-latina-37239265 
para que el resultado fuera vinculante, no solamente se tendría que haber mantenido, sino que probablemente se tendría que haber incrementado, poniéndolo, por ejemplo, al nivel de lo exigido para convocar una asamblea constituyente, y estableciendo que para que la decisión fuera vinculante la opción ganadora debería obtener más que la mitad más uno de los votos.

Una determinación razonable de la claridad de la decisión podría ser una diferencia superior a los 10 puntos entre las dos opciones, como acontece en algunos sistemas para definir la necesidad de una segunda vuelta presidencial, en los cuales si la opción más votada supera el $40 \%$ de los votos y su ventaja es de más de 10 puntos sobre la siguiente alternativa, se la declara como ganadora.

De esta manera, si el pronunciamiento popular es por la negativa con ese margen, el Gobierno no tendría alternativa distinta que la de desistir de su propósito y, dada la contundencia del resultado, ello muy probablemente lo debería llevar a dimitir, en tanto que si la decisión democrática es por la afirmativa, tal margen le daría toda la legitimidad para implementar la cuestión consultada.

En función de lo anterior, un resultado por un margen menor, aun si la mitad más uno estuviera a favor de la aprobación de lo consultado, obligaría a realizar una negociación de buena fe entre los representantes de las dos posturas, con una veeduría que verificara su disposición a encontrar una posición conciliada que se sometiera de nuevo, dentro de un plazo razonable, al pronunciamiento democrático.

Parte de lo que se hizo para la recomposición del Acuerdo tras el resultado electoral del plebiscito se basó en la ausencia de una victoria contundente de alguna de las dos opciones, dando paso a que los promotores de una y otra realizaran una negociación que, a su turno, condujo a una renegociación del acuerdo inicial firmado con las FARC y a la suscripción de un nuevo acuerdo, que fue ratificado por el Congreso.

Sin embargo, en la negociación entre los partidarios de la aprobación y los de la negativa al acuerdo inicial, no hubo una exigencia explícita de que lo tuvieran que haber hecho de buena fe, no existió un mecanismo de veeduría y ni siquiera de acompañamiento para garantizar que la negociación avanzara, no estaba contemplado un plazo determinado o determinable para cerrar la negociación y, a pesar de haberse podido renegociar el acuerdo 
inicial con las FARC, el mecanismo de refrendación del nuevo acuerdo no fue, o al menos no lo ha sido hasta ahora, la consulta directa a la ciudadanía.

Estas carencias ponen en entredicho la legitimidad del acuerdo refrendado por el Congreso, y tanto las dificultades presentadas a raíz del resultado del plebiscito como las que se pueden suscitar para la implementación del nuevo acuerdo se habrían podido evitar o se prevendrían si, aprendiendo de las lecciones como las que deja el caso canadiense, se hubieran contemplado reglas especiales en el ordenamiento jurídico nacional para la refrendación popular de asuntos de especial trascendencia constitucional.

Visto el resultado del plebiscito y lo sucedido en las siguientes semanas hasta llegar a la suscripción de un nuevo acuerdo y a su refrendación por parte del Congreso, se hace evidente la necesidad de contar con un mecanismo para tal finalidad. Aprender de las experiencias exitosas de otros, como aquí se ha propuesto, puede ayudar a ese propósito, y aun si ya es tarde para aplicar los aprendizajes a la refrendación del Acuerdo de Paz suscrito por el Gobierno nacional con las FARC, puede considerarse para otras cuestiones de especial trascendencia constitucional que siguen pendientes de ser resueltas.

\section{Conclusiones}

$\mathrm{El}$ aprendizaje que el caso canadiense deja para Colombia, visto lo acontecido con el resultado la refrendación plebiscitaria del Acuerdo firmado por el Gobierno nacional con las FARC, es la necesidad y la conveniencia de adicionar la Ley Estatutaria de Participación Ciudadana con un mecanismo particular de refrendación democrática y popular para asuntos de especial trascendencia constitucional, que la propia ley defina o establezca los parámetros para hacerlo.

En la regulación de dicho mecanismo se tendrían que incorporar los aspectos clave que la experiencia canadiense enseña: la verificación de la claridad de la pregunta objeto de la consulta, la determinación de la mayoría requerida para la aprobación o negación definitiva de lo consultado y las reglas de una negociación de buena fe cuando ninguna de las dos opciones obtenga la mayoría requerida para una aprobación o negación definitiva de lo consultado.

Contar con un mecanismo de esas características evitaría la incertidumbre que frente a un tema tan delicado como el de la refrendación de 
un acuerdo de paz generó el resultado del plebiscito, enviaría un mensaje diáfano a otros procesos encaminados al mismo objetivo y allanaría el camino para encontrar una solución democrática a otras cuestiones de trascendencia constitucional que siguen pendientes, como el ordenamiento territorial o la administración de justicia, que no han podido ser resueltas por el constituyente derivado.

Un mecanismo refrendatario como el que se propone, cuyo resultado reflejara en forma clara y contundente la voluntad mayoritaria de la población, y en esa medida proveyera al Gobierno de la legitimidad para obrar en consecuencia con lo decidido popular y democráticamente, podría ser útil para lograr impulsar ciertas reformas indispensables para mejorar el sistema político y el funcionamiento del aparato estatal, como a las que antes se ha hecho mención, y que no se han podido llevar a cabo porque las propias instituciones se han encargado de bloquearlas.

\section{Bibliografía}

Canadian Law. Canadian Clarity Act, http://www.canadianlawsite.ca/ clarity-act.htm

Cosoy, Natalio. “¿Es tendenciosa la pregunta del plebiscito en Colombia sobre los acuerdos de paz con las FARc?”. BBC Mundo, http://www. bbc.com/mundo/noticias-america-latina-37239265

Dion, Stéphane. La politica de la claridad. Discursos y escritos sobre la unidad canadiense, traducido por María Dolores Torres París. Alianza Editorial, 2005. https://sites.google.com/site/textosdereferencia/ st \%C3\%A9phanedion \%3Alapol \%C3\%ADticadelaclaridad.disc

Hay Derecho. "El derecho de secesión y sus límites. El ejemplo canadiense", 14 de septiembre del 2012, http://hayderecho.com/2012/09/14/elderecho-de-secesion-y-sus-limites-el-ejemplo-canadiense/ 


\title{
Acuerdo General y los acuerdos temáticos para la terminación del conflicto y la construcción de una paz estable y duradera: ¿acuerdo especial?*
}

\author{
Ligia Galvis Ortiz \\ Beatriz Londoño-Toro \\ Soraya Pérez Portillo \\ Nicolás Felipe Mendoza Cerquera* \\ Héctor Peña Díaz
}

* Este artículo se construyó con los elementos centrales del amicus curiae presentado por los autores ante la Corte Constitucional colombiana en el caso de la demanda de inconstitucionalidad presentada por el doctor Eduardo Montealegre Lynnett frente a la Resolución 339 del 2012 (Instalación Mesa de diálogo de La Habana).

** Abogada de la Universidad Externado de Colombia. Doctora en Filosofía de la Universidad Católica de Lovaina. Docente y consultora en derechos humanos y derecho internacional humanitario. Correo electrónico: ligiagal@gmail.com

*** Abogada de la upв. Doctora en Derecho de la Universidad Complutense de Madrid. Profesora titular de la Universidad del Rosario. Directora del Área de Derechos Humanos. Correo electrónico: beatriz.londono@urosario.edu.co

**** Abogada de la Universidad Externado de Colombia. Candidata a Doctorado en Estudios Políticos de la Universidad Externado. Correo electrónico: soraya.perez@uexternado.edu.co

***** Asistente de investigación del Grupo de Derechos Humanos de la Universidad del Rosario. Correo electrónico: nicolas.fmc@gmail.com

****** Abogado de la Universidad Santo Tomás. Especialista en Derechos Humanos y Derecho Internacional Humanitario de la Universidad Complutense de Madrid. Correo electrónico: veramar1@yahoo.com 


\section{Introducción}

El problema jurídico al que intentaremos dar respuesta en este capítulo es el siguiente: ¿cuáles son las características del Acuerdo Final que integra el acuerdo general y los acuerdos temáticos, para la terminación del conflicto y la construcción de una paz estable y duradera en Colombia, que permiten que se le considere un acuerdo especial en el marco del artículo $3^{\circ}$ común a los Convenios de Ginebra de 1949?

Nuestra contribución se expresa en argumentos relacionados con las funciones presidenciales previstas en la Constitución Política colombiana respecto a la garantía de los derechos humanos en el orden interno, y de las obligaciones que, como jefe de Estado, le corresponden en cumplimiento de los tratados internacionales de derechos humanos y del derecho internacional humanitario - DIH - ratificados por Colombia. Nos proponemos desarrollar los siguientes temas: 1) el Acuerdo Final "Acuerdo final para la terminación del conflicto y la construcción de una paz estable y duradera”, celebrado entre el Gobierno y las FARC-EP, contiene obligaciones que responden a la garantía de las condiciones de ejercicio de los derechos humanos consagrados en la Constitución Política colombiana y en los tratados internacionales de derechos humanos; 2) la obligación de aplicar los tratados internacionales de derechos humanos y del DIH en el territorio nacional; 3) El Acuerdo Final desarrolla el DIH, especialmente lo establecido en el artículo 3 común y en el Protocolo Adicional II, por consiguiente, es un acuerdo especial; 4) la responsabilidad del Estado en la aplicación de los tratados internacionales de derechos humanos y del DIH y los efectos que tiene el Acuerdo General, los acuerdos temáticos y el Acuerdo Final para alcanzar la paz estable y duradera, en el desarrollo de esta responsabilidad.

\section{El Acuerdo Final y las garantías de los derechos humanos}

Un recuento somero del título segundo de nuestra Constitución Política nos permite enunciar los derechos cuya realización se hace efectiva mediante la aplicación inmediata del Acuerdo Final para la terminación del conflicto y la construcción de una paz estable y duradera. Enunciamos los siguientes: artículos 11 derecho a la vida; 12 derecho a no ser sometido a desaparición forzada, a torturas ni a tratos o penas crueles, inhumanos o degradantes; 13 derechos a la libertad y la igualdad; 22 derecho a la paz; 24 circulación por el territorio nacional; 25 derecho al trabajo; 40 derecho 
a la participación; 43 igualdad de derechos y oportunidades entre hombres y mujeres y protección a las mujeres cabeza de familia; 44 derechos de los niños y las niñas, corresponsabilidad entre la familia, la sociedad y el Estado en la garantía de los derechos de la infancia y prevalencia de los derechos de los niños y niñas sobre los derechos de los demás; 45 protección y formación integral de los y las adolescentes; 60 acceso a la propiedad; y 64 acceso progresivo a la propiedad de la tierra de los trabajadores agrarios, en forma individual o asociativa.

El Acuerdo Final para la terminación del conflicto y la construcción de una paz estable y duradera tiene características especiales que garantizan el goce y el restablecimiento de estos derechos: la declaración expresa de la aplicación del enfoque de los derechos humanos, ${ }^{1}$ el enfoque de género ${ }^{2}$ y el enfoque territorial. ${ }^{3}$ Estos principios aseguran el reconocimiento de la igualdad en la titularidad de los derechos de todas las personas (hombres y mujeres, habitantes rurales y urbanos, niñas, niños, adolescentes, jóvenes, adultos y viejos) y la igualdad de oportunidades para que todos puedan desarrollar sus proyectos de vida individuales y colectivos con autonomía y libertad. Los intentos por garantizar estos derechos y así superar los estados de desigualdad recurrentes en el país no han sido lo suficientemente

1 "La implementación de todos los acuerdos alcanzados debe contribuir a la protección y la garantía del goce efectivo de los derechos de todos y todas. Los derechos humanos son inherentes a todos los seres humanos por igual, lo que significa que les pertenecen por el hecho de serlo, y en consecuencia su reconocimiento no es una concesión, ya que son universales, imperativos indivisibles e interdependientes y deben ser considerados en forma global y de manera justa y equitativa". Mesa de Conversaciones, "Acuerdo final para la terminación del conflicto y la construcción de una paz estable y duradera”, 24 de noviembre del 2016, 193https://www.mesadeconversaciones.com.co/ sites/default/files/24-1480106030.11-1480106030.2016nuevoacuerdofinal-1480106030.pdf

2 "En el presente Acuerdo el enfoque de género significa el reconocimiento de la igualdad de derechos entre hombres y mujeres y de las circunstancias especiales de cada uno, especialmente de las mujeres independientemente de su estado civil, ciclo vital y relación familiar y comunitaria, como sujeto de derechos y de especial protección constitucional. Implica en particular la necesidad de garantizar medidas afirmativas para promover esa igualdad, la participación activa de las mujeres y sus organizaciones en la construcción de la paz y el reconocimiento de la victimización de la mujer por causa del conflicto". Mesa de Conversaciones, "Acuerdo final", 193.

3 "El enfoque territorial del Acuerdo supone reconocer y tener en cuenta las necesidades, características y particularidades económicas, culturales y sociales de los territorios y las comunidades, garantizando la sostenibilidad socio-ambiental; y procurar implementar las diferentes medidas de manera integral y coordinada, con la participación activa de la ciudadanía”. Mesa de Conversaciones, "Acuerdo final", 6. 
eficaces, ${ }^{4}$ por eso este acuerdo adquiere relevancia para cumplir con los postulados del Estado social de derecho establecidos en el artículo $1^{\circ}$ de la Carta Fundamental. Es obligación del Estado reconocer, respetar, promover, proteger, defender y restablecer los derechos conculcados. Es obligación del presidente de la República garantizar los derechos y orientar las políticas públicas para la realización de los mandatos que le impone la Constitución y los tratados internacionales de derechos humanos y del DiH que han sido ratificados por Colombia.

\section{Obligación de aplicar los tratados internacionales de derechos humanos y los convenios de Ginebra de 1949 y sus protocolos adicionales - DIH - en el territorio nacional \\ En Colombia,}

Las normas de derecho internacional pueden ser integradas al sistema jurídico colombiano de tres maneras: (i) con rango constitucional; (ii) con rango supralegal; o (iii) con rango de ley. La regla general es que el derecho internacional adquiere el rango de ley en el sistema jurídico colombiano, a menos de que la Constitución disponga lo contrario. $^{5}$

Según lo anterior, los tratados internacionales ratificados por Colombia, en este caso los instrumentos internacionales de derechos humanos y del DiH, se aplican en el territorio nacional porque, en virtud de su aprobación por el Congreso de la República, se convierten en leyes internas. Para el caso que nos ocupa, el pacto de derechos civiles y políticos y el pacto de derechos económicos, sociales y culturales entraron en vigor para Colombia mediante la Ley 74 de 1968. Los convenios de Ginebra lo hicieron a través de la Ley 5 de 1960 y el protocolo II adicional a los convenios de Ginebra entró en vigor en virtud de la Ley 171 de 1994.

4 Hernán Darío Martínez Hincapié y Juan Carlos Marín Castillo, "Protección de los derechos económicos, sociales y culturales en el ordenamiento jurídico colombiano - el papel de los jueces”. Justicia Juris $11, \mathrm{n} .^{\circ} 1$ (2015).

5 María Angélica Prada, "La integración del derecho internacional en el sistema colombiano", en Protección multinivel de derechos (Barcelona: Universitat Pompeu Fabra, 2013), https://www.upf. edu/dhes-alfa/materiales/res/pmdh_pdf/PMDH_Manual.365-392.pdf 
La figura del bloque de constitucionalidad, entendida como la concepción según la cual la Constitución en calidad de norma jurídica suprema no se reduce a su estricto articulado, es una idea que ha sido ampliamente difundida en el constitucionalismo contemporáneo, mediante el cual se considera que las constituciones no son catálogos cerrados, por ende, se pretende sistematizar jurídicamente los derechos o principios que no están directamente en el texto constitucional pero que deben tenerse en cuenta al momento de resolver un asunto de constitucionalidad. ${ }^{6}$

Por vía jurisprudencial se ha desarrollado la figura del bloque de constitucionalidad con fundamento en los artículos 9, 53, 93, 94 y 214, de la Carta Fundamental.

Según la Corte Constitucional, en la Sentencia C-225 de 1995:

El bloque de constitucionalidad está compuesto por aquellas normas y principios que, sin aparecer formalmente en el articulado del texto constitucional, son utilizados como parámetros del control de constitucionalidad de las leyes, por cuanto han sido normativamente integrados a la Constitución, por diversas vías y por mandato de la propia Constitución. Son pues verdaderos principios y reglas de valor constitucional, esto es, son normas situadas en el nivel constitucional, a pesar de que puedan a veces contener mecanismos de reforma diversos al de las normas del articulado constitucional stricto sensu. ${ }^{7}$

De igual forma, la Sentencia C-582 de 1999 manifiesta, de conformidad con el artículo 93 de la Carta Política, que no todos los tratados internacionales son per se parte del bloque, pues

Solo constituyen parámetros de control constitucional aquellos tratados y convenios internacionales que reconocen derechos humanos y que prohíben su limitación en los estados de excepción. Es por ello que integran el bloque de constitucionalidad, entre otros,

6 Diego Mauricio Higuera, "Relectura estructural del bloque de constitucionalidad en Colombia: elementos críticos para aplicación del Control de Constitucionalidad”. Revista Principia Iuris, n. ${ }^{\circ} 15$ (2011): 99.

7 Sentencia C-225 de 1995, 18 de mayo. MP: Alejandro Martínez Caballero. 
los tratados de derecho internacional humanitario, tales como los Convenios de Ginebra, los Protocolos I y II y ciertas normas del Pacto de San José de Costa Rica. ${ }^{8}$

Este es el punto de partida para conformar el bloque de constitucionalidad y es la manera como los tratados internacionales de derechos humanos y DIH adquieren el rango de principios aplicables en el control de constitucionalidad. Al respecto la Sentencia C-067 del 2003 señala:

La incorporación en la doctrina jurídica nacional de una institución como el bloque de constitucionalidad surgió entonces del reconocimiento de la prevalencia de los tratados internacionales de derechos humanos sobre el orden interno pero también, y de manera específica, de la necesidad de armonizar dicho principio con la ya tradicional preceptiva constitucional que erige a la Carta Política en el estatuto de mayor jerarquía dentro del ordenamiento jurídico nacional. ${ }^{9}$

Los tratados internacionales de derechos humanos y el DiH también hacen parte del bloque de constitucionalidad en sentido estricto, según lo ha expresado la Corte a través de la Sentencia C-191 de 1998:

Resulta posible distinguir dos sentidos del concepto de bloque de constitucionalidad. En un primer sentido de la noción, que podría denominarse bloque de constitucionalidad strictu sensu, se ha considerado que se encuentra conformado por aquellos principios y normas de valor constitucional, los que se reducen al texto de la Constitución propiamente dicha y a los tratados internacionales que consagren derechos humanos cuya limitación se encuentre prohibida durante los estados de excepción y las normas de Derecho Internacional Humanitario (art. 93). Por otro lado, la noción latu sensu del bloque de constitucionalidad, según la cual, aquel estaría compuesto por todas aquellas normas, de diversa jerarquía que sirven

\footnotetext{
8 Sentencia C-582 de 1999, 11 de agosto. MP: Alejandro Martínez Caballero.

9 Sentencia C-067 del 2003, 4 de febrero. MP: Marco Gerardo Monroy Cabra.
} 
como parámetro para llevar a cabo el control de constitucionalidad de la legislación. ${ }^{10}$

Tenemos, en consecuencia, dos formas de aplicar los tratados internacionales de derechos humanos, por una parte desde su valor equiparable a la Constitución Política para resolver el dilema entre Constitución y tratados internacionales, y como leyes de la república, especialmente en su utilización como fuente legal en las decisiones de las autoridades judiciales y administrativas que resuelven conflictos sobre los derechos humanos. Por ende, la figura del bloque de constitucionalidad en Colombia ha permitido que los tratados de derechos humanos y de DIH adquieran fuerza práctica en el derecho nacional. ${ }^{11}$

Este aspecto se refleja en la expedición del Acto Legislativo 02 del 2017, que en su artículo $1^{\circ}$ establece:

\begin{abstract}
Artículo 1. La Constitución Política tendrá un nuevo artículo transitorio así: Artículo transitorio xx. En desarrollo del derecho a la paz, los contenidos del Acuerdo Final para la terminación del conflicto y la construcción de una paz estable y duradera, firmado el día 24 de noviembre de 2016, que correspondan a normas de derecho internacional humanitario o derechos fundamentales definidos en la Constitución Política y aquellos conexos con los anteriores, serán obligatoriamente parámetros de interpretación y referente de desarrollo y validez de las normas y las leyes de implementación y desarrollo del Acuerdo Final, con sujeción a las disposiciones constitucionales. $^{12}$
\end{abstract}

Estas vías le permiten al Estado colombiano dar cumplimiento a su obligación de aplicar los tratados internacionales de derechos humanos y

10 Sentencia C-191 de 1998, 6 de mayo. MP: Eduardo Cifuentes Muñoz.

11 Vanessa Suelt-Cock, "El bloque de constitucionalidad como mecanismo de interpretación constitucional. Aproximación a los contenidos del bloque en derechos en Colombia”. Vniversitas 133 (2016): 334.

12 Congreso de Colombia. Artículo 1. Acto Legislativo 02 del 2017. 
el DIH en todo el territorio nacional. El hecho de que estos se conviertan en leyes y que formen parte del bloque de constitucionalidad ${ }^{13}$ implica que
(...) las instituciones y autoridades del Estado tienen la obligación de cumplir de buena fe con lo establecido en el Acuerdo Final. En consecuencia, las actuaciones de todos los órganos y autoridades del Estado, los desarrollos normativos del Acuerdo Final y su interpre- tación y aplicación deberán guardar coherencia e integralidad con lo acordado, preservando los contenidos, los compromisos, el espíritu y los principios del Acuerdo Final. ${ }^{14}$

Un tema de especial relevancia que ha asumido la Corte Constitucional es el de la naturaleza jurídica de los acuerdos especiales, frente a lo cual ha dicho:
(...) el artículo $3^{\circ}$ común señala que las partes en conflicto podrán realizar acuerdos especiales con el fin de vigorizar la aplicación de las normas humanitarias. Tales acuerdos no son, en sentido estricto, tratados, puesto que no se establecen entre sujetos de derecho in- ternacional público sino entre las partes enfrentadas en un conflicto interno, esto es, entre sujetos de derecho internacional humanita- rio (...). Sin embargo, tales acuerdos responden a una pretensión política perfectamente razonable, puesto que la vigencia práctica y efectiva del derecho internacional humanitario depende, en gran medida, de que exista una voluntad y un compromiso reales de las partes por respetarlo.

El Acuerdo Final celebrado entre el Gobierno nacional y las FARC-EP contiene compromisos específicos que permiten desarrollar acciones para procurar tanto el acceso a la tierra de manera individual y colectiva, como el desarrollo integral de la población campesina, para así disminuir en

13 En relación con el tema de la implementación del derecho internacional humanitario, véase Johannes Chan, "Implementation of International Humanitarian Law". Asia Pacific Law Review 8 (2000): 211-228.

14 Congreso de Colombia. Inciso 2, artículo 1 del Acto Legislativo 02 del 2017. 
buena medida las desigualdades que endémicamente están instaladas entre el campo y la ciudad y entre grandes propietarios de tierras y campesinos desposeídos o desplazados por el conflicto que azotó al país durante más de medio siglo. Comprende, además, la obligación de garantizar la igualdad de los géneros y el respeto a todas las personas sin distinciones por razones de sexo, opciones sexuales, edad, ubicación territorial o pertenencia a pueblos indígenas, pueblos rom o afrocolombianos. Propone también la ampliación de la democracia desde el punto de vista de la participación de todos los colombianos en los diferentes campos de interés y en particular de quienes dejan las armas para incorporarse a la vida civil.

Es pertinente insistir en que la dejación de las armas propuesta en el Acuerdo tiene un propósito específico que es la incorporación a la vida social, económica, cultural y política del país. Como colombianos que son tienen el derecho de participar en las diferentes manifestaciones de la vida social de la nación. No se puede alimentar la marginalidad de quienes se integran, en primer lugar, porque se estarían incrementando y estimulando violaciones a los derechos humanos de las personas y se estaría propiciando la criminalidad, como ha sucedido en otros procesos de paz en los cuales no se han tomado las medidas adecuadas para que la dejación de las armas tenga estímulos de integración y regreso a la vida social, como corresponde a los seres humanos que somos y a la cosmovisión integral propuesta en el artículo $1^{\circ}$ de la Declaración Universal de los Derechos Humanos: "todos los seres humanos nacen libres e iguales en dignidad y derechos”.

El Acuerdo garantiza los derechos de las víctimas a la verdad, la justicia, la reparación y la no repetición; contempla las medidas que deben ser expeditas para que se cumplan y se restablezcan los derechos de las víctimas. En nuestro parecer, no puede haber acuerdo entre un Estado que por acción u omisión no ha podido garantizar la tranquilidad y el bienestar de la población, por más de medio siglo, para solo considerar el último periodo de las violencias políticas que han azotado el país desde los inicios de la era republicana, y un grupo armado que, con sus acciones bélicas, ha generado tantas víctimas, tanto dolor y sufrimiento a millones de colombianos, sin que esas víctimas estén en el centro de la consideración para que sean restablecidos todos sus derechos, incluso el derecho a que los actores les pidan perdón. 
Las víctimas nos han dado ejemplo de entendimiento y de comprensión, y nos han enseñado a anteponer el interés general de la sociedad que necesita vivir en paz, a su dolor, a su ira y a su derecho al rencor. Las víctimas no quieren más víctimas y nosotros debemos seguirlas, estamos obligados a hacerlo, en este propósito. Gracias a su nobleza, hoy podemos pensar que la puesta en marcha de este Acuerdo permitirá construir un país que pueda vivir en dignidad y formar parte de las naciones que para dirimir sus diferencias y sus conflictos usan los mecanismos democráticos y ejercen la política a través del discurso argumentado en los foros y demás escenarios públicos. El Acuerdo Final, comprensivo de todos los temas que integran el Acuerdo General que orientó la mesa de negociaciones, es un medio para construir un país en donde la sociedad en su conjunto tendrá los elementos para vivir mejor y para hacer de la paz el modo de vida que le da razón de ser a la democracia que le heredaremos a las próximas generaciones.

\section{El Acuerdo Final para la terminación del conflicto y la construcción de una paz estable y duradera es un acuerdo especial, en el marco del artículo 3 común a los convenios de Ginebra y del Protocolo Adicional II}

El DiH, que hace parte del ius cogens ${ }^{15}$ y la Convención de Viena, ${ }^{16}$ señala que las normas humanitarias son “(...) obligatorias para los Estados y las partes en conflicto, incluso si estos no han aprobado los tratados respectivos, por cuanto la imperatividad de esta normatividad no deriva del consentimiento de los Estados sino de su carácter consuetudinario". ${ }^{17}$

De los convenios de Ginebra y de sus protocolos adicionales, se desprenden obligaciones para los Estados, una de las cuales es la de buscar acuerdos especiales para resolver situaciones particulares relacionadas con la protección de los combatientes, de la población civil y de los bienes públicos. Los cuatro convenios contemplan, en especial el artículo 3 común,

15 Elizabeth Salmón, “Introducción al Derecho Internacional Humanitario”. cIcr, Lima, 2012, http://idehpucp.pucp.edu.pe/wp-content/uploads/2012/10/Introducci \%C3\%B3n-al-DerechoInternacional-Humanitario-2012-3.pdf

16 "Convención de Viena, sobre el derecho de los tratados entre Estados y Organizaciones Internacionales o entre Organizaciones Internacionales”, 28 de abril de 1988, http://www.ordenjuridico. gob.mx/TratInt/I2.pdf

17 Ibid. 
la posibilidad de acuerdos especiales para la aplicación de los convenios y de los protocolos adicionales.

Es pertinente recordar la relación entre el DIH y los derechos humanos y la necesidad de proteger a las víctimas del conflicto, que se establece en el preámbulo del Protocolo Adicional II. Afirma este instrumento: "recordando, así mismo, que los instrumentos internacionales relativos a los derechos humanos ofrecen a la persona humana una protección fundamental. Subrayando la necesidad de garantizar una mejor protección a las víctimas del conflicto armado". Esta relación es un llamado imperativo a las partes actoras del conflicto a minimizar los efectos de la guerra, pero también a ponerle fin al conflicto, puesto que esta es la protección por excelencia que se le puede brindar a la población civil.

En relación con el artículo 3 común a los convenios de Ginebra, en el que se establece que "las partes en conflicto harán lo posible por poner en vigor, mediante acuerdos especiales, la totalidad o parte de las otras disposiciones del presente Convenio", el documento más reciente de interpretación por parte del $\mathrm{CICR}^{18}$ señala que:

- En dicho concepto se pueden incluir los acuerdos de paz, acuerdos de cese de hostilidades u otros similares "si contienen cláusulas para crear otras obligaciones derivadas de los Convenios de Ginebra y/o sus Protocolos adicionales". ${ }^{19}$

- De igual forma señala que "un acuerdo puede contener obligaciones derivadas del derecho de los derechos humanos y ayudar a aplicar el derecho humanitario", ${ }^{20}$

- En su contenido pueden "proveer una relación sencilla del derecho aplicable al contexto, o bien una extensa lista de las disposiciones del DIH diferentes del derecho ya aplicable, y lograr un compromiso claro de las partes de acatar este derecho". ${ }^{21}$

18 Comité Internacional de la Cruz Roja — CICR—, “¿Qué dice el DiH sobre los acuerdos especiales en el marco de un proceso de paz?”, https://www.icrc.org/es/document/acuerdos-especialesacuerdos-de-paz-dih-colombia-comentarios-convenios-de-ginebra

19 Ibid.

20 Ibid., punto 11.

${ }^{21}$ Ibid., punto 2. 
- En relación con el contenido,

(...) los acuerdos pueden ser de carácter meramente declaratorio, en el sentido de que pueden reconocer obligaciones del derecho convencional o consuetudinario que ya sean aplicables, o bien pueden establecer disposiciones más detalladas para aplicar obligaciones existentes o nuevas. Lo que importa es que las disposiciones que se pongan en vigor entre las partes sirvan para proteger a las víctimas del conflicto armado. ${ }^{22}$

- En conclusión, "toda disposición incluida en un acuerdo para aplicar o poner en vigor el derecho humanitario puede constituir un acuerdo especial a los fines del artículo 3 común”.

La finalidad de esta disposición es alentar a las partes en un conflicto armado a acordar un conjunto de normas más amplio para proteger a las personas que no participan o que han dejado de participar en las hostilidades. Los acuerdos especiales que dispongan la aplicación del derecho internacional humanitario consuetudinario, o que prevean un conjunto de normas más amplio que el que establecen los convenios de Ginebra, en particular las del Protocolo Adicional I, pueden considerarse acuerdos especiales conforme al artículo 3 común. ${ }^{23}$

De igual forma, el cIcr ha realizado unas aclaraciones respecto a los acuerdos de paz, los acuerdos especiales y el DiH, a saber. ${ }^{24}$

1) Los acuerdos especiales son una figura del derecho internacional que le permite a las partes en un conflicto armado interno acordar obligaciones más amplias o detalladas de las que ya están contempladas en los convenios de Ginebra, con el fin de proteger a la población civil. ${ }^{25}$

${ }^{22}$ Ibid., punto 7.

23 Ibid.

${ }^{24}$ Comité Internacional de la Cruz Roja — CICR—, "Colombia: 10 preguntas sobre acuerdos de paz, acuerdos especiales y DIH”, https://www.icrc.org/es/document/colombia-10-preguntas-sobreacuerdos-de-paz-acuerdos-especiales-y-dih

25 Ibid. 
2) Un acuerdo de paz o de cese de hostilidades puede ser un acuerdo especial siempre y cuando incluya obligaciones derivadas del DIH. ${ }^{26}$

3) A veces las normas del DiH y las leyes nacionales no son suficientes para regular aspectos muy específicos de las obligaciones. Las partes firman, entonces, acuerdos especiales para ampliar sus deberes con fines humanitarios o definir mecanismos para poner en marcha ciertas obligaciones. $^{27}$

4) La posibilidad de suscribir acuerdos especiales está prevista en el artículo 3 común referido. ${ }^{28}$

5) Quienes hacen parte de los acuerdos especiales son quienes firman el acuerdo. En algunos casos, las partes pueden pedir la participación de un tercero para implementar los acuerdos, como una organización humanitaria, sin que sea parte de dichos acuerdos. También existen acuerdos tripartitos que incluyen como parte del acuerdo a alguna organización internacional. ${ }^{29}$

6) La firma de un acuerdo especial no afecta de manera alguna el estatus jurídico de los grupos armados no estatales y tampoco implica un reconocimiento de beligerancia. El cumplimiento del DIH es obligación de todas las partes, independientemente de su rol político o jurídico. $^{30}$

7) No hay trámite previsto para que un acuerdo de paz se convierta en un acuerdo especial, ni en el derecho internacional ni en el derecho interno.

8) Las partes firmantes del acuerdo deben garantizar que el acuerdo tendrá cambios reales en la vida de las víctimas. Es posible que no exista un ente que obligue el cumplimiento de un acuerdo especial, a menos que el acuerdo incluya a un organismo de verificación. ${ }^{31}$

9) No existen mecanismos específicos que regulen las consecuencias del incumplimiento de un acuerdo especial. Sin embargo, así 
como las partes se comprometen con nuevas obligaciones, también pueden prever mecanismos de verificación y cumplimiento que se consignen en el mismo acuerdo. De todos modos, el hecho de que se haya firmado un acuerdo especial no exime a las partes a acatar las normas del derecho internacional o el derecho interno. ${ }^{32}$

El fin del conflicto con las FARC-EP en Colombia se ha concertado en las conversaciones de La Habana (Cuba) y se ha plasmado en el Acuerdo Final cuya naturaleza se analiza. Este tiene que considerarse un acuerdo integral que incorpora el Acuerdo General de agenda, que es su punto de partida, los acuerdos temáticos y el Acuerdo Final que los incorpora y los anexos.

Este Acuerdo cumple con los imperativos consagrados en el preámbulo del Protocolo Adicional II que fueron citados, es decir, crea obligaciones derivadas del derecho internacional humanitario y del derecho internacional de los derechos humanos, tiene en cuenta el enfoque de los derechos humanos y protege especialmente los derechos de las víctimas. Por consiguiente, es un acuerdo especial que pone en práctica el mandato del artículo 3 común. Además, es pertinente recordar lo establecido en el artículo 80 del Protocolo Adicional I que establece que "las Partes en conflicto adoptarán sin demora todas las medidas necesarias para cumplir las obligaciones que les incumben en virtud de los convenios y del presente protocolo". ${ }^{33}$

El Acuerdo Final en su estructura, en sus contenidos y en las obligaciones que establece desarrolla los convenios de Ginebra en lo relativo al artículo 3 común y su posterior desarrollo consagrado en el Protocolo Adicional II que rige en Colombia a partir de la expedición de la Ley 171 de 1994. Estas disposiciones del DIH y su relación con los derechos humanos están desarrolladas en el Acuerdo Final y, por ello, es pertinente su declaración como acuerdo especial en el marco de lo establecido en el artículo 3 común a los cuatro convenios de Ginebra de 1949. La tabla 1 ejemplifica esta función del Acuerdo Final.

\footnotetext{
32 Ibid.

33 Véase Gretty Pavlovich Jiménez, "El acuerdo especial humanitario frente al derecho internacional humanitario". Justicia Juris 9, n. 1 (enero-junio, 2013): 48, https://goo.gl/ulS1kx
} 
Tabla 1. Síntesis de las obligaciones que hacen del "Acuerdo Final para la terminación del conflicto y la construcción de una paz estable y duradera" un acuerdo especial

\begin{tabular}{|c|c|}
\hline $\begin{array}{l}\text { Puntos del } \\
\text { Acuerdo FARC- } \\
\text { EP y Gobierno } \\
\text { colombiano }\end{array}$ & Consideraciones sobre su categoría de "acuerdo especial" \\
\hline $\begin{array}{l}\text { 1. Hacia un } \\
\text { nuevo campo } \\
\text { colombiano: } \\
\text { Reforma Rural } \\
\text { Integral }^{34}\end{array}$ & 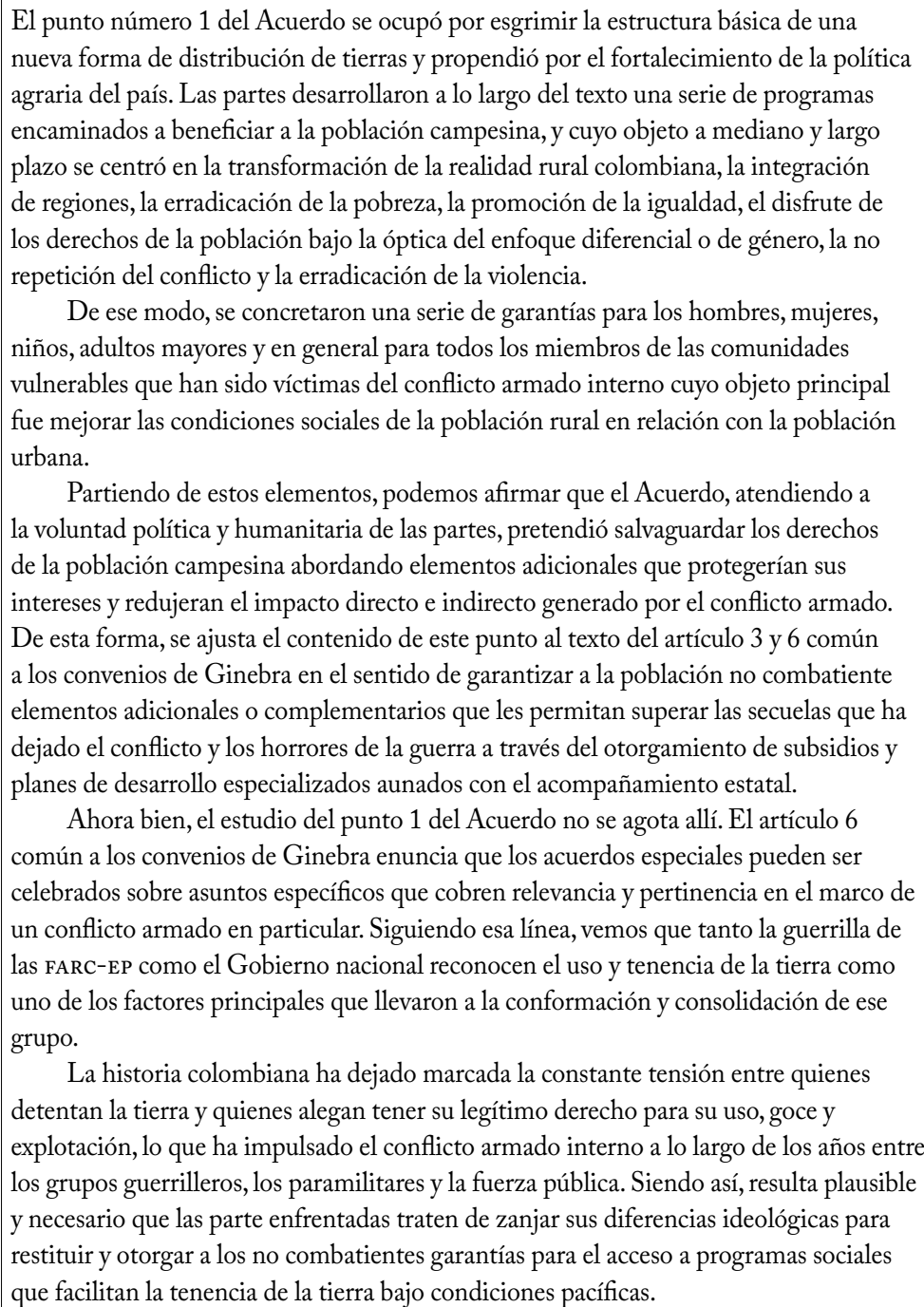 \\
\hline
\end{tabular}

Continúa

34 Véase Decreto Ley 902 del 2017, 29 de mayo. Por el cual se adoptan medidas para facilitar la implementación de la Reforma Rural Integral contemplada en el Acuerdo Final en materia de tierras, específicamente el procedimiento para el acceso y formalización y el Fondo de Tierras. 


\begin{tabular}{|c|c|}
\hline $\begin{array}{l}\text { Puntos del } \\
\text { Acuerdo FARC- } \\
\text { EP y Gobierno }\end{array}$ & Consideraciones sobre su categoría de "acuerdo especial" \\
\hline & $\begin{array}{l}\text { En armonía con lo anterior, y siguiendo los parámetro de la tipología del acuerdo } \\
\text { especial, se puede entender que las partes crearon nuevas obligaciones que desbordaron } \\
\text { los límites del dir y robustecieron la situación social y cultural de las víctimas. } \\
\text { Planteando así diversas propuestas y alternativas a la problemática del uso de la tierra, } \\
\text { que otrora fue relevante como causa del conflicto, se amparó la población rural de } \\
\text { las secuelas de la guerra en el posconflicto, y, a su vez, contrario a lo que se entendió } \\
\text { en un momento, se fortaleció el concepto de la propiedad privada y su función social } \\
\text { y ecológica como elemento esencial de los derechos fundamentales y sociales de las } \\
\text { poblaciones afectadas por el conflicto. }\end{array}$ \\
\hline $\begin{array}{l}\text { 2. Participación } \\
\text { en política: } \\
\text { apertura } \\
\text { democrática } \\
\text { para construir } \\
\text { la paz }\end{array}$ & 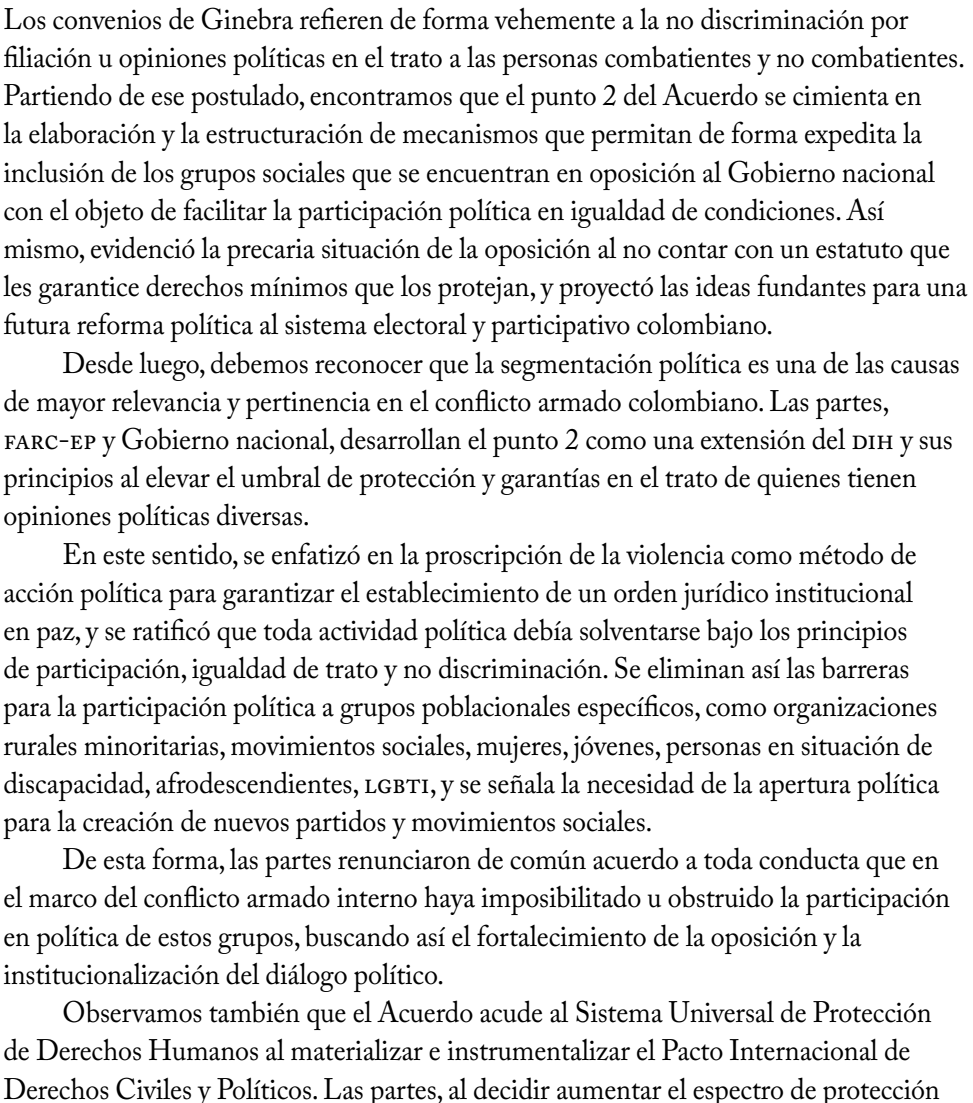 \\
\hline
\end{tabular}

Continúa

35 Véase Acto Legislativo 03 de 2017. Por medio del cual se regula parcialmente el componente de reincorporación política del acuerdo final para la terminación del conflicto y la construcción de una paz estable y duradera. 


\begin{tabular}{|c|c|}
\hline $\begin{array}{c}\text { Puntos del } \\
\text { Acuerdo FARC- } \\
\text { EP y Gobierno }\end{array}$ & Consideraciones sobre su categoría de "acuerdo especial" \\
\hline & $\begin{array}{l}\text { de las garantías necesarias para el ejercicio de los derechos políticos, lograron otorgar } \\
\text { mayores niveles de accesibilidad a las poblaciones marginales, rurales y específicamente } \\
\text { a las disidentes, permitiendo la visibilización y promoción de programas políticos } \\
\text { diversos en el escenario social. } \\
\text { Entonces, la participación política es una norma de ius cogens introducida en el } \\
\text { Acuerdo, que permite la ejecución de principios y directrices aún más amplios que } \\
\text { los señalados por el DiH. Estas estipulaciones, por su naturaleza y en armonía con los } \\
\text { preceptos constitucionales, no pueden ser ni limitadas ni transadas al ser parte del } \\
\text { núcleo de los derecho fundamentales que le asisten a toda persona. } \\
\text { En relación con lo anterior, destacamos que la participación en política de los } \\
\text { miembros del partido que se conforme una vez haya sucedido el tránsito de las FARC- } \\
\text { EP a la vida civil se encuentra restringida en el sentido de no permitir la inscripción } \\
\text { de candidatos en las zonas afectadas por los actos criminales de las FARC-EP. Esta } \\
\text { prohibición se convierte en un elemento crucial para las víctimas al garantizar que } \\
\text { no habrá lugar a la revictimización, que los perpetradores de graves violaciones a los } \\
\text { DDHH y al DiH no sean elegibles en esas zonas y, consecuencialmente, que no se afecten } \\
\text { los procesos judiciales en contra de los miembros de las FARC-EP. Esto favorecerá los } \\
\text { principios de justicia, verdad, reparación y garantías de repetición propios de nuestro } \\
\text { Sistema Regional de Protección de Derechos Humanos. }\end{array}$ \\
\hline $\begin{array}{l}\text { 3. Fin del } \\
\text { Conflicto }^{36}\end{array}$ & $\begin{array}{l}\text { Los convenios propenden para la solución pacífica de las controversias al fijar unas } \\
\text { reglas mínimas de respeto por la dignidad humana y los derechos de las partes en } \\
\text { conflicto (humanización de la guerra), así como procuran la protección de las personas } \\
\text { no combatientes que de una u otra forma resultaron afectadas por el conflicto armado. } \\
\text { En efecto, este punto del Acuerdo pretende extender la aplicación del DiH para } \\
\text { cimentar las bases del fin del conflicto y la construcción de una paz estable y duradera. } \\
\text { A su vez, se incluyen los compromisos acordados entre las FARC-EP y el Gobierno } \\
\text { nacional para dar por terminado el conflicto, superar las causas estructurales de la } \\
\text { guerra e implementar programas para la reintegración de víctimas y excombatientes a la } \\
\text { vida civil. Así expuesto, el fin del conflicto conlleva la creación de un nuevo andamiaje } \\
\text { de obligaciones y programas (socioeconómicos) que involucran a diversos actores de } \\
\text { la realidad política del país, entre ellos a las autoridades nacionales, las comunidades } \\
\text { locales, las víctimas del conflicto, los excombatientes y la comunidad internacional. } \\
\text { Conforme a lo dicho, el Acuerdo proscribe de forma implícita todo trato que vaya } \\
\text { en contra de las disposiciones del DiH, las acciones de represalias, la toma de rehenes y } \\
\text { se procura el trato con humanidad no solo con las víctimas del conflicto armado sino } \\
\text { también con los excombatientes de las FARC-EP. }\end{array}$ \\
\hline
\end{tabular}

Continúa

36 Véase Decreto Ley 885 del 2017, 26 de mayo. Por medio del cual se modifica la Ley 434 de 1998 y se crea el Consejo Nacional de Paz, Reconciliación y Convivencia; Decreto Ley 897 del 2017, 29 de mayo. Por el cual se modifica la estructura de la Agencia Colombiana para la Reintegración de Personas y Grupos Alzados en Armas y se dictan otras disposiciones. 


\begin{tabular}{|c|c|}
\hline $\begin{array}{c}\text { Puntos del } \\
\text { Acuerdo FARC- } \\
\text { PP y Gobierno }\end{array}$ & Consideraciones sobre su categoría de "acuerdo especial" \\
\hline & $\begin{array}{l}\text { Lo anterior se circunscribe bajo la categoría de "acuerdo especial" entre los } \\
\text { negociadores del Gobierno nacional y la guerrilla de las FARC-EP porque (motu proprio) } \\
\text { se implementan herramientas para concertar la paz, fortalecer las instituciones del } \\
\text { Estado y dar continuidad al tránsito hacia la legalidad de los excombatientes. } \\
\quad \text { Por las razones expuestas, consideramos que el punto } 3 \text { del Acuerdo Final se ajusta } \\
\text { a las características del acuerdo especial a la luz de los Convenios de Ginebra, y, como } \\
\text { tal, debe ser incluido en el bloque de constitucionalidad bajo la categoría de acuerdo } \\
\text { especial en el marco del DIH. }\end{array}$ \\
\hline $\begin{array}{l}\text { 4. Solución al } \\
\text { problema de } \\
\text { drogas ilícitas }^{37}\end{array}$ & $\begin{array}{l}\text { Las FARC-EP y el Gobierno nacional en el punto } 4 \text { del Acuerdo reconocen que la } \\
\text { problemática de las drogas y su comercialización es un asunto transversal y social que } \\
\text { requiere encontrar una solución consensuada en la sociedad. Así mismo, identifican } \\
\text { que el narcotráfico ha servido para financiar el conflicto armado interno, y que, en el } \\
\text { posconflicto, se deben adoptar mecanismos para desestimar esta actividad, sin llegar } \\
\text { a desconocer con ello el uso licito, médico, cultural o tradicional de algunas sustancias } \\
\text { psicoactivas. } \\
\quad \text { En otras palabras, el Acuerdo plasma la voluntad del Gobierno en conjunto } \\
\text { con las FARC-EP al evaluar y reconocer que el narcotráfico es un problema estructural } \\
\text { dentro de la guerra y que, con el fin de llegar al posconflicto, resulta necesario que sea } \\
\text { erradicado. Este es un asunto que consideramos se enmarca dentro del artículo } 6 \text { común } \\
\text { a los convenios de Ginebra, ya que las partes encuentran el narcotráfico como una de } \\
\text { las causas coyunturales de la guerra, y proponen herramientas de común acuerdo para } \\
\text { abandonarlo y superarlo, evitando que sus nocivos efectos continúen afectando los } \\
\text { derechos de la población civil, excombatientes y no combatientes. } \\
\quad \text { Visto de otra forma, las partes buscaron culminar una de las prácticas más } \\
\text { reprochables ejecutadas por las FARC-EP, acogiéndose a las peticiones generalizadas de la } \\
\text { comunidad internacional y fortaleciendo la dinámica entre los derechos de propiedad, } \\
\text { uso de la tierra,la convivencia social y las actividades de desminado humanitario. }\end{array}$ \\
\hline $\begin{array}{l}\text { 5. Acuerdo } \\
\text { sobre las } \\
\text { Víctimas del } \\
\text { Conflicto: } \\
\text { "Sistema } \\
\text { Integral de } \\
\text { Verdad, Justicia, } \\
\text { Reparación y } \\
\text { No Repetición", } \\
\text { incluyendo la }\end{array}$ & $\begin{array}{l}\text { Los convenios de Ginebra fueron concebidos para aliviar la suerte de los combatientes y } \\
\text { no combatientes en el marco de situaciones de guerra. Por eso, al buscarse la protección } \\
\text { de las víctimas y no combatientes mediante acuerdos especiales se reafirmó la confianza } \\
\text { recíproca entre las FARC-EP y el Gobierno nacional para buscar la paz. } \\
\text { El Acuerdo se estructuró alrededor de un conjunto de disposiciones que engloban } \\
\text { no solo elementos del DiH, sino que, en su núcleo, condensan normas de DDHH, las } \\
\text { cuales funcionen como una herramienta para lograr la eficacia del DiH. Este capítulo } \\
\text { es el centro del Acuerdo, incluye el trazado de derechos universales que asiste a toda } \\
\text { persona víctima del conflicto armado interno y sus mecanismos para implementarlos, } \\
\text { de forma que sea posible alcanzar la construcción de la paz. }\end{array}$ \\
\hline
\end{tabular}

Continúa

37 Véase Decreto Ley 896 de 2017,29 de mayo. Por el cual se crea el Programa Nacional Integral de Sustitución de cultivos de uso ilícito - PNIs-. 


\begin{tabular}{|c|c|}
\hline $\begin{array}{l}\text { Puntos del } \\
\text { Acuerdo FARc- } \\
\text { EP y Gobierno } \\
\text { colombiano }\end{array}$ & Consideraciones sobre su categoría de "acuerdo especial" \\
\hline $\begin{array}{l}\text { Jurisdicción } \\
\text { Especial para } \\
\text { la Paz y el } \\
\text { Compromiso } \\
\text { sobre Derechos } \\
\text { Humanos }^{38}\end{array}$ & 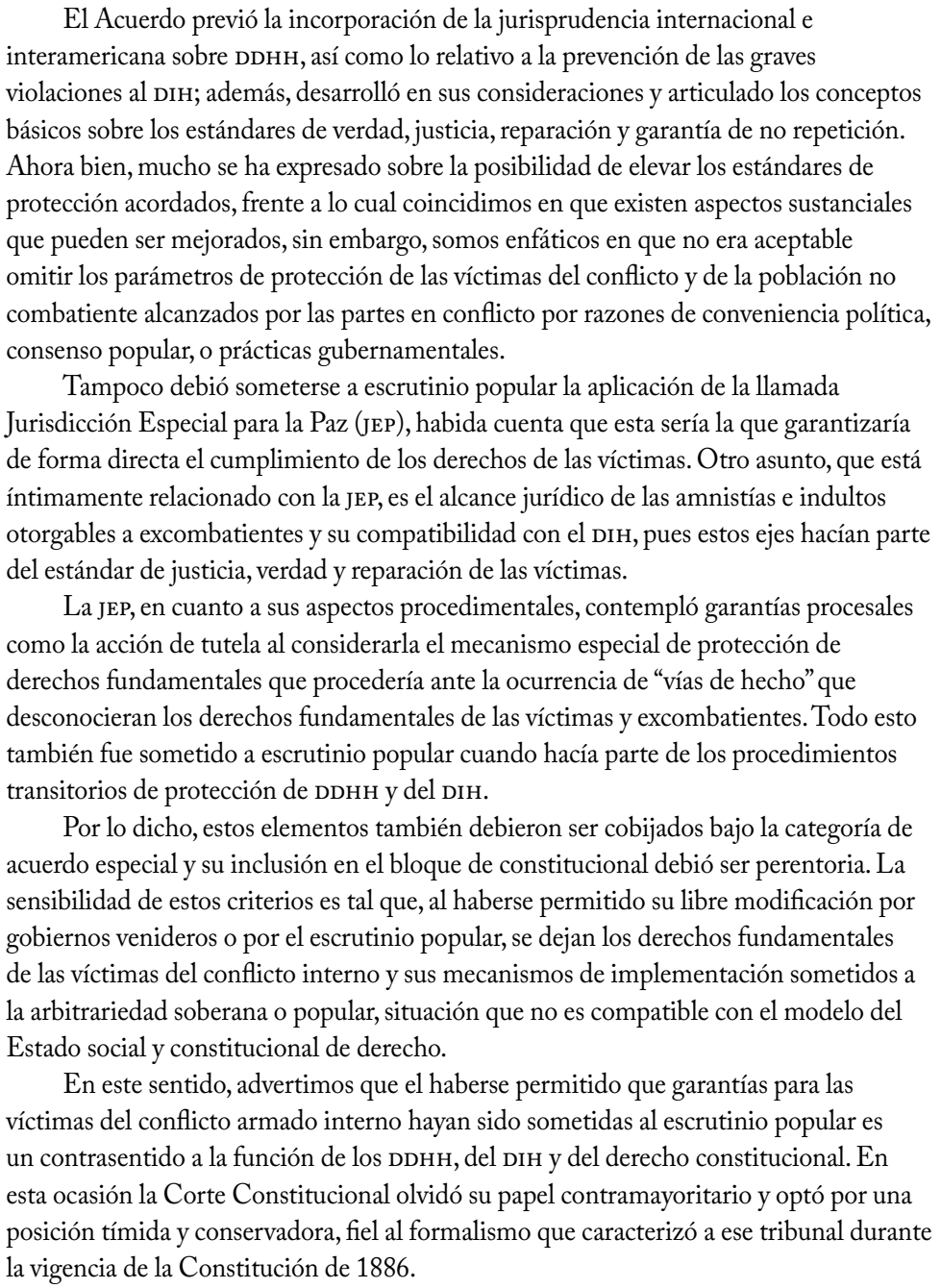 \\
\hline
\end{tabular}

Continúa

38 Véase Acto Legislativo 01 del 2017. Por medio del cual se crea un título de disposiciones transitorias de la constitución para la terminación del conflicto armado y la construcción de una paz estable y duradera y se dictan otras disposiciones; Decreto Ley 587 del 2017, 5 de abril. Por el cual se conforma el Comité de Escogencia para la selección de unos miembros del Sistema Integral de Verdad, Justicia, Reparación y No Repetición (sIvjRnR); Decreto Ley 900 del 2017, 29 de mayo. Por el cual se adiciona el artículo 8 de la Ley 418 de 1997, a su vez modificado por el artículo 1 de la Ley 1779 de 2016 y se dictan otras disposiciones. 


\begin{tabular}{|c|c|}
\hline $\begin{array}{c}\text { Puntos del } \\
\text { Acuerdo FARC- } \\
\text { EP y Gobierno } \\
\text { colombiano }\end{array}$ & Consideraciones sobre su categoría de "acuerdo especial" \\
\hline $\begin{array}{l}\text { 6. Implemen- } \\
\text { tación, verifica- } \\
\text { ción y refrenda- } \\
\text { ción }^{39}\end{array}$ & $\begin{array}{l}\text { Finalmente, encontramos que el articulado de los convenios de Ginebra propende por } \\
\text { la cooperación internacional para la salvaguarda de la dignidad de las personas a partir } \\
\text { de la implementación del diH durante la etapa de conflicto y de posconflicto. Como } \\
\text { es posible identificar, en el texto del Acuerdo se acude en diversas ocasiones al control, } \\
\text { el apoyo y la supervisión de organizaciones internacionales para la implementación, } \\
\text { ejecución y seguimiento del Acuerdo, generando así obligaciones internacionales } \\
\text { encaminadas a la protección de los derechos de las víctimas y no combatientes. } \\
\text { En este punto se pactaron obligaciones consensuadas por los negociadores que } \\
\text { blindaron con la supervisión internacional el proceso de desmovilización. El Estado } \\
\text { colombiano ha invitado a diversos sujetos de derecho internacional* a servir como } \\
\text { garantes del proceso de paz; estos actores han expresado su intención de acompañar el } \\
\text { proceso de desarme, desmovilización y reintegración (DDR), apoyando y verificando el } \\
\text { cumplimiento de estándares mínimos prescritos por los DDHH y el DiH. } \\
\text { Este punto del Acuerdo se reviste de especial importancia al contener las } \\
\text { prioridades y el cronograma de implementación normativa que señala los asuntos que, } \\
\text { por su sensibilidad, requieren especial atención. En razón a ello, el Gobierno nacional se } \\
\text { comprometió a desplegar las reformas legales y constitucionales necesarias para adaptar } \\
\text { el ordenamiento interno a lo pactado en el Acuerdo Final conforme a lo establecido en } \\
\text { el Acto Legislativo } 01 \text { del } 2016 \text {. } \\
\text { Dicho esto, se concluye que el Acuerdo Final se centra de forma clara y precisa } \\
\text { en estructurar los mecanismos de implementación normativa, y de verificación y } \\
\text { seguimiento necesarios para la ejecución y protección de los estándares acordados. }\end{array}$ \\
\hline
\end{tabular}

* Punto 6.3.2 del Acuerdo.

Fuente: elaboración por el equipo del amicus curiae, 2016, a partir de Mesa de Conversaciones, "Acuerdo Final”.

La tabla muestra cómo cada uno de los capítulos del Acuerdo Final integra elementos que corresponden al contenido de un acuerdo especial al aumentar el umbral de protección de las víctimas y personas no combatientes, entre otras temáticas. En palabras de la Corte, estos acuerdos buscan asegurar

\begin{abstract}
una mayor aplicación progresiva de las normas humanitarias del protocolo II. En tal contexto, la realización de los acuerdos especiales puede fortalecer esos compromisos entre las partes y favorecer
\end{abstract}

39 En relación con el uso da las Facultades Presidenciales para la Paz, contenidas en el artículo 2ºl Acto Legislativo 01 del 2016, el presidente de la República ligó cada uno de los decretos leyes expedido con uno de los asuntos señalados en los literales del punto 6.1.10 del Acuerdo Final para blindarlos con los criterios constitucionales de finalidad, conexidad y estricta necesidad. 
la puesta en marcha de mecanismos de verificación, que logren, en la práctica, un creciente cumplimiento de las obligaciones humanitarias por las partes enfrentadas. Por ello, la Corte Constitucional coincide con el Ministerio Público en que el Gobierno, quien es el responsable de la preservación del orden público (CP. Art 189 numerales $3^{\circ}$ y $4^{\circ}$ ), puede efectuar tales acuerdos especiales, con el fin de hacer más efectiva la aplicación del derecho internacional humanitario y su cumplimiento real por las partes enfrentadas. En efecto, esos acuerdos especiales son no solo una clara posibilidad jurídica contemplada expresamente por el artículo $3^{\circ}$ común, cuya vigencia no se discute, sino que, además, como lo señala el Ministerio Público, son útiles para aliviar la suerte de las víctimas de la guerra, favorecer consensos y acrecentar la confianza recíproca entre los enemigos para la búsqueda de la paz. ${ }^{40}$

En la reciente Sentencia C-171 del 2017, ${ }^{41}$ se observa que la Corte eludió el problema central planteado en lugar de hacer un pronunciamiento histórico que marcara la pauta para este y futuros procesos de paz:
(...) decidió declararse INHIBIDA para emitir un pronunciamiento de fondo respecto de la demanda de inconstitucionalidad presentada contra la expresión "acuerdo", contenida en el acuerdo general para la terminación del conflicto y la construcción de una paz estable y duradera, alcanzado en La Habana (Cuba) el 26 de agosto de 2012, por ineptitud sustantiva de la demanda y falta de competencia de la Corte para emitir un pronunciamiento de fondo. ${ }^{42}$

Consideramos importante hacer referencia a los argumentos que sintetiza la Corte en dicha sentencia:

1. La Corte asume un criterio formalista para analizar los acuerdos y concluye que

\footnotetext{
40 Sentencia C-225 de 1995, 18 de mayo. MP: Alejandro Martínez Caballero.

41 Sentencia C-171 del 2017, 22 de marzo. MP: Iván Escurecía Mayolo.

42 Ibid.
} 
(...) la acusación se dirige contra una expresión que no está contenida en un acto que tenga fuerza material de ley (...) la Corte no tiene competencia para conocer y decidir sobre la demanda, de conformidad con las funciones que le confiere el artículo 241 de la Carta Política. Para la Corte, la anterior conclusión encuentra soporte en el hecho de que ya esta Corporación, en la sentencia en la cual se pronunció sobre la ley estatutaria que regula el plebiscito especial para la paz, estableció que los acuerdos que se celebran en desarrollo de un proceso de paz no tienen valor normativo y que su naturaleza es eminentemente política. ${ }^{43}$

Puede observarse cómo la Corte elude con su decisión inhibitoria un tema central para el futuro de la paz en Colombia: la naturaleza jurídica y la vinculatoriedad de los Acuerdos de Paz, no solo el celebrado con las FARC-EP, sino los acuerdos futuros con el ELN.

2. Debemos resaltar los aportes de los dos salvamentos de voto que presentaron los magistrados Alberto Rojas Ríos e Iván Escrucería Mayolo, porque encontramos coincidencias conceptuales con nuestra propuesta: 1) en relación con el examen de los acuerdos firmados y los acuerdos especiales a la luz del DiH y especialmente con una mirada desde los derechos de las víctimas; 2) la importancia de examinar la naturaleza y el alcance de estos acuerdos en el marco del bloque de constitucionalidad; 3) importancia de un pronunciamiento sobre el valor normativo de los acuerdos.

Algunos de los argumentos centrales de estos salvamentos y aclaraciones fueron:

a. El doctor Alberto Rojas en síntesis consideró

(...) que se planteaba una acusación apta contra un contenido prescriptivo que permitía a la Corte realizar un examen de fondo sobre una interpretación del término acusado, conforme a las normas su-

43 Ibid., consideración jurídica n. ${ }^{\circ} 3$. 
periores y a los parámetros del Derecho Internacional Humanitario. En su criterio, el término acuerdo contenido en el Acuerdo General para la terminación del conflicto y la construcción de una paz estable y duradera, comprendía elementos previstos en el artículo $3^{\circ}$ común de los Convenios de Ginebra concernientes al cese al fuego, dejación de armas y a las normas que buscan proteger a las víctimas y personas que no participen directamente en las hostilidades originadas en un conflicto armado interno. Por consiguiente, la acusación formulada contra la expresión normativa acuerdo admitía un estudio sobre su alcance y naturaleza frente al bloque de constitucionalidad acorde con lo regulado en el artículo $3^{\circ}$ común de los Convenios de Ginebra. ${ }^{44}$

b. El magistrado Iván Humberto Escrucería Mayolo aclaró su voto en el siguiente sentido:

(...) por cuanto la demanda no satisfacía los presupuestos de una pretensión de inconstitucionalidad (...): (i) en virtud del principio pro actione, la Corte ha debido avanzar en determinar el valor normativo del acuerdo de paz, en el entendido que este es una decisión política como lo estableció la Sentencia C-379 de 2016, pero en su opinión con vocación normativa, es decir, un derecho en formación que requiere de actos y leyes de implementación al constituirse como un acto complejo. (ii) El análisis efectuado en la Sentencia C-379 de 2016, no tuvo como parámetro de control de constitucionalidad el artículo $3^{\circ}$ común a los Convenios de Ginebra, con lo cual la Corte, en esta ocasión, pudo haber analizado la naturaleza del Acuerdo a la luz del Derecho Internacional Humanitario, en lo relacionado con materias de la mayor importancia para las víctimas de un conflicto armado interno, tales como el cese del fuego, dejación de armas, derecho a la verdad, justicia, reparación y no repetición, entrega de menores reclutados, descontaminación de minas antipersonas y búsqueda de personas desaparecidas, entre otras. ${ }^{45}$

\footnotetext{
44 Ibid.

45 Ibid.
} 


\section{La responsabilidad del Estado y el cumplimiento del Acuerdo de Paz}

En el orden interno, la Constitución Política establece que es deber del Estado prevenir los conflictos y, cuando estos existen, buscar las salidas institucionales que permitan el restablecimiento del orden público y el regreso a la tranquilidad. También habilita al primer mandatario para buscar caminos, procedimientos y tomar medidas que pongan fin al enfrentamiento armado interno y sus consecuencias adversas, como el desplazamiento forzado, las masacres y demás violencia indiscriminada, en desarrollo de los principios constitucionales y en ejercicio del bloque de constitucionalidad.

Ante las instancias internacionales de derechos humanos y del derecho internacional humanitario, el Estado es el agente responsable de su reconocimiento, promoción, protección y defensa en todo el territorio nacional. ${ }^{46}$ Esta responsabilidad no es transferible. Lo que sí puede el Estado es ordenar el respeto y la garantía de los derechos a otros actores mediante el principio de corresponsabilidad, para cumplir con sus obligaciones como garante de los derechos humanos y para poner en marcha el DiH. Un claro ejemplo de esta gestión corresponsable de los derechos humanos se encuentra en el artículo 44 de la Constitución Política que establece los tres agentes corresponsables en la vigencia de los derechos de los niños y las niñas, que son: la familia, la sociedad y el Estado. El principio de corresponsabilidad es un mecanismo que le permite al Estado hacer operativa su responsabilidad, sin renunciar a ella, ni depositarla en otros agentes de manera definitiva. Nada exculpa al Estado de la responsabilidad que tiene de poner en marcha los instrumentos internacionales de derechos humanos y del derecho internacional humanitario. El Estado está obligado a garantizar el ejercicio de los derechos humanos en todo tiempo y lugar, y, para ello, tiene que poner en marcha las disposiciones del DIH mientras dure el conflicto armado; además, ante todo tiene la obligación de tomar las medidas pertinentes para ponerle fin a los conflictos que perturban el ejercicio de los derechos y, en particular, el goce del derecho a la paz.

El cicr encontró que en las últimas décadas se ha dado una práctica general en los Estados orientada a promover el respeto y la aplicación del

46 Jiménez, "El acuerdo especial". 
DIH en los conflictos armados internos, que se ha consolidado en un cuerpo de DIH consuetudinario. ${ }^{47}$

Para ello, los instrumentos internacionales de derechos humanos establecen salvaguardias especiales para asegurar el cumplimiento de las obligaciones de los Estados, como la establecida en el artículo 30 de la Declaración Universal de los Derechos Humanos (reiterada en el artículo 5 común al PDCP y al PDESC); esta disposición dice:

Nada en la presente Declaración podrá interpretarse en el sentido de que contiene derecho alguno al Estado, a un grupo o a una persona, para emprender y desarrollar actividades o realizar acciones tendientes a la supresión de cualquiera de los derechos y libertades proclamadas en esta Declaración.

Este principio es la clave para evitar la exención de responsabilidad del Estado en la vigencia de los derechos humanos.

Cuando el Gobierno acude a los mecanismos constitucionales de participación ciudadana (artículo 104, Constitución Política) para legitimar ciertas acciones o decisiones con la población y estos resultan violatorios de los derechos humanos, el Estado no está obligado a cumplir sus resultados porque de hacerlo así estaría violando estos derechos. Como la decisión de la Corte Constitucional se produce después de realizado el plebiscito de legitimación el 2 de octubre del 2016, esta corporación debe tener en cuenta en su decisión dichos resultados para que su fallo no contribuya a la violación de los derechos contemplados en nuestra Carta Fundamental y en los tratados internacionales.

Así lo expresa la Corte cuando afirma que

(...) el contenido del mandato popular expresado mediante dicho instrumento es de índole política, no normativa. Por este mismo motivo, a través del plebiscito no pueden someterse a refrendación popular el contenido y alcance de los derechos fundamentales, pues estos tienen raigambre normativa superior $y$, a su vez, de estos se

47 Caterina Heyck, "DIH y conflicto armado interno”, en Derecho Internacional, Acuerdo Humanitario y resolución pacifica del secuestro (Bogotá: Universidad del Rosario, 2011), 245. 
predica una naturaleza contra mayoritaria, incompatible con el sometimiento de su vigencia a la voluntad política de la mayoría de los ciudadanos. ${ }^{48}$

\section{Conclusión}

En conclusión, consideramos que el Acuerdo Final para la terminación del conflicto y la construcción de una paz estable y duradera, firmado por el presidente de la República y las FARC-EP el 24 de noviembre del 2016, es un acuerdo integral que incorpora los acuerdos precedentes, y tiene el carácter de un acuerdo especial en el marco del artículo 3 común a los convenios de Ginebra de 1949 y el Protocolo Adicional II que desarrolla esta disposición, para poner en marcha los convenios en los que tiene relación con el conflicto armado no internacional que ha vivido el país durante más de cincuenta años. Este desarrolla el DIH con el fin de restablecer derechos humanos conculcados por el conflicto, en particular los derechos de las víctimas y el derecho a la paz para todo el pueblo colombiano. En consecuencia, es responsabilidad del Estado hacerlo cumplir y ponerlo en marcha, porque su desarrollo es base fundamental para la realización de los derechos humanos señalados, en particular el derecho a la paz.

El pronunciamiento inhibitorio de la Corte Constitucional en la Sentencia C-271 del 2017 deja abierto el debate y permite a futuro que este tema se aborde nuevamente y ojalá sea resuelto teniendo en cuenta su importancia decisiva para el futuro de la paz, las normas del DIH, los derechos de las víctimas, el bloque de constitucionalidad, el principio pro actione y el valor no solo político sino normativo de los acuerdos especiales.

\section{Bibliografía}

"Convención de Viena, sobre el derecho de los tratados entre Estados y Organizaciones Internacionales o entre Organizaciones Internacionales", 28 de abril de 1988, http://www.ordenjuridico.gob.mx/ TratInt/I2.pdf

Acto Legislativo 01 del 2017. Por medio del cual se crea un título de disposiciones transitorias de la constitución para la terminación del

\footnotetext{
48 Sentencia C-379 del 2016, 18 de julio. MP: Luis Ernesto Vargas Silva.
} 
conflicto armado y la construcción de una paz estable y duradera y se dictan otras disposiciones.

Acto Legislativo 03 de 2017. Por medio del cual se regula parcialmente el componente de reincorporación política del acuerdo final para la terminación del conflicto y la construcción de una paz estable y duradera.

Comité Internacional de la Cruz Roja - CICR-. "¿Qué dice el DIH sobre los acuerdos especiales en el marco de un proceso de paz?”, https://www.icrc.org/es/document/acuerdos-especiales-acuerdosde-paz-dih-colombia-comentarios-convenios-de-ginebra

Comité Internacional de la Cruz Roja — CICR—. "Colombia: 10 preguntas sobre acuerdos de paz, acuerdos especiales y DIH”, https://www.icrc. org/es/document/colombia-10-preguntas-sobre-acuerdos-de-pazacuerdos-especiales-y-dih

Chan, Johannes. "Implementation of International Humanitarian Law". Asia Pacific Law Review 8 (2000): 211-228.

Decreto Ley 587 del 2017, 5 de abril. Por el cual se conforma el Comité de Escogencia para la selección de unos miembros del Sistema Integral de Verdad, Justicia, Reparación y No Repetición (sivjRnr).

Decreto Ley 885 de 2017, 26 de mayo. Por medio del cual se modifica la Ley 434 de 1998 y se crea el Consejo Nacional de Paz, Reconciliación y Convivencia.

Decreto Ley 896 de 2017, 29 de mayo. Por el cual se crea el Programa Nacional Integral de Sustitución de cultivos de uso ilícito - PNIs-.

Decreto Ley 897 de 2017, 29 de mayo. Por el cual se modifica la estructura de la Agencia Colombiana para la Reintegración de Personas y Grupos Alzados en Armas y se dictan otras disposiciones.

Decreto Ley 900 del 2017, 29 de mayo. Por el cual se adiciona el artículo 8 de la Ley 418 de 1997, a su vez modificado por el artículo 1 de la Ley 1779 de 2016 y se dictan otras disposiciones.

Decreto Ley 902 del 2017, 29 de mayo. Por el cual se adoptan medidas para facilitar la implementación de la Reforma Rural Integral contemplada en el Acuerdo Final en materia de tierras, específicamente el procedimiento para el acceso y formalización y el Fondo de Tierras. 
Heyck, Caterina. "DIH y conflicto armado interno", en Derecho Internacional, Acuerdo Humanitario y resolución pacifica del secuestro, 203-268. Bogotá: Universidad del Rosario, 2011.

Higuera, Diego Mauricio. "Relectura estructural del bloque de constitucionalidad en Colombia: elementos críticos para aplicación del Control de Constitucionalidad”. Revista Principia Iuris, n. 15 (2011): 99.

Jiménez, Gretty Pavlovich. "El acuerdo especial humanitario frente al derecho internacional humanitario". Justicia Juris 9, n. ${ }^{\circ} 1$ (enero-junio, 2013): 48-55, https://goo.g1/ulS1kx

Ley 5 de 1960, 26 de agosto. Por la cual se aprueba el Acta Final y los Convenios suscritos por la Conferencia Diplomática de Ginebra del 12 de agosto de 1949. Diario Oficial 30.318.

Ley 74 de 1968, 26 de diciembre. Por la cual se aprueban los Pactos Internacionales de Derechos Económicos, Sociales y Culturales, de Derechos Civiles y Políticos, así como el Protocolo Facultativo de este último, aprobados por la Asamblea General de las Naciones Unidas en votación unánime, en Nueva York, el 16 de diciembre de 1966. Diario Oficial 32.682.

Ley 171 de 1994, 16 de diciembre. Por medio de la cual se aprueba el "Protocolo Adicional a los Convenios de Ginebra del 12 de agosto de 1949, relativo a la protección de las víctimas de los conflictos armados sin carácter internacional (Protocolo II)", hecho en Ginebra el 8 de junio de 1977. Diario Oficial 41.640.

Martínez Hincapié, Hernán Darío y Juan Carlos Marín Castillo. "Protección de los derechos económicos, sociales y culturales en el ordenamiento jurídico colombiano - el papel de los jueces”. Justicia Juris 11, n. ${ }^{\circ}$ (2015): 13-25.

Mesa de Conversaciones. "Acuerdo final para la terminación del conflicto y la construcción de una paz estable y duradera”, 24 de noviembre del 2016, https://www.mesadeconversaciones.com.co/sites/ default/files/24-1480106030.11-1480106030.2016nuevoacuerdof inal-1480106030.pdf

Prada, María Angélica. "La integración del derecho internacional en el sistema colombiano", en Protección multinivel de derechos. Barcelona: Universitat Pompeu Fabra, 2013, 365, https://www.upf.edu/dhesalfa/materiales/res/pmdh_pdf/PMDH_Manual.365-392.pdf 
Salmón, Elizabeth. "Introducción al Derecho Internacional Humanitario”. cIcr, Lima, 2012, http://idehpucp.pucp.edu.pe/wp-content/ uploads/2012/10/Introducci\%C3\%B3n-al-Derecho-InternacionalHumanitario-2012-3.pdf

Sentencia C-225 de 1995, 18 de mayo. MP: Alejandro Martínez Caballero. Sentencia C-191 de 1998, 6 de mayo. MP: Eduardo Cifuentes Muñoz. Sentencia C-582 de 1999, 11 de agosto. MP: Alejandro Martínez Caballero. Sentencia C-067 del 2003, 4 de febrero. MP: Marco Gerardo Monroy Cabra. Sentencia C-379 del 2016, 18 de julio. MP: Luis Ernesto Vargas Silva. Sentencia C-171 del 2017, 22 de marzo. MP: Iván Escurecía Mayolo. Suelt-Cock, Vanessa. "El bloque de constitucionalidad como mecanismo de interpretación constitucional. Aproximación a los contenidos del bloque en derechos en Colombia”. Vniversitas 133 (2016): 334. 



\title{
Sobre la idoneidad de los procesos penales y las comisiones de la verdad para abordar situaciones de crímenes internacionales de ius cogens. Especial referencia a la Jurisdicción Especial para la Paz y la Comisión para el Esclarecimiento de la Verdad, la Convivencia y la No Repetición en Colombia*
}

\author{
Héctor Olasolo Alonso
}

\footnotetext{
* El presente trabajo hace parte de los siguientes proyectos de investigación: 1) "La función de los órganos judiciales y arbitrales internacionales en la ejecución de un evento al Acuerdo de Paz en Colombia fruto de la renegociación resultante del Referéndum del 2 de octubre de 2016" y 2) "Principios de armonización entre la función y alcance de la justicia y las demandas surgidas en los procesos políticos de transición”. Ambos proyectos se encuentran adscritos a la línea de investigación Crítica al derecho internacional desde fundamentos filosóficos, del Grupo de Investigación de Derecho Internacional de la Facultad de Jurisprudencia de la Universidad del Rosario, Bogotá, Colombia Los proyectos son financiados por la Dirección de Investigación e Innovación de la Universidad del Rosario y su Facultad de Jurisprudencia. El autor agradece a Daniela Pedraza-Moreno, Jannluck Canosa y Lucía Carcano por su inestimable ayuda en la edición de este artículo.

** Licenciado y doctor en Derecho de la Universidad de Salamanca, España. Maestría en Derecho de la Universidad de Columbia, Estados Unidos. Es actualmente profesor titular de la carrera de Derecho Internacional en la Universidad del Rosario, Colombia, donde dirige su Clínica Jurídica Internacional y el Anuario Ibero-Americano de Derecho Internacional Penal (Anidip). Es profesor ad hoc de la Universidad de La Haya para las Ciencias Aplicadas, Holanda, y preside desde el $2011 \mathrm{el}$ Instituto Iberoamericano de La Haya para la Paz, los Derechos Humanos y la Justicia Internacional, Holanda. El profesor Olasolo Alonso se ha desempeñado también como catedrático de Derecho Internacional Penal en la Universidad de Utrecht (Holanda, 2010-2012), magistrado auxiliar de la Corte Penal Internacional (2004-2010), miembro de la Fiscalía del Tribunal Internacional Penal para la ex Yugoslavia (2002-2004) y asesor jurídico de la delegación española en la Comisión Preparatoria de la Corte Penal Internacional (1999-2002). Ha sido también asesor externo del Tribunal Especial para el Líbano, miembro del Roster de Juristas de Reconocido Prestigio de la Organización de las Naciones Unidas para el Nombramiento de Magistrados Internacionales en las Salas Especiales de los Tribunales de Camboya, perito ante la Corte Interamericana de Derechos Humanos. Correo electrónico: hectorolasolo@gmail.com
} 


\section{Introducción}

E1 50,2\% de los votantes en el referendo realizado el 2 de octubre del 2016 por el Gobierno de Colombia para ratificar el Acuerdo de Paz firmado el 26 de septiembre del 2016 con las Fuerzas Armadas Revolucionarias de Colombia-Ejército del Pueblo — FARC-EP — ${ }^{1}$ rechazó, de manera inesperada, su contenido (en adelante, "acuerdo del 26 de septiembre”). Entre las diversas razones esgrimidas por los defensores del No destaca la relativa a la impunidad de los dirigentes de las FARC-EP. ${ }^{2}$ Esta era la consecuencia, en su opinión, de establecer un régimen de penas alternativas significativamente distinto al previsto en la Ley 975 de Justicia y Paz (5 a 8 años de reclusión, más cuatro años adicionales de libertad condicional) para los responsables de genocidio, crímenes de lesa humanidad y crímenes de guerra, que reconocieran su responsabilidad, colaboraran con la justicia y pidiesen perdón a las víctimas. ${ }^{3}$ En aplicación de este, los defensores del No entendieron que los dirigentes de las FARC-EP (así como los de las fuerzas gubernamentales) terminarían haciendo frente a su responsabilidad por crímenes de ius cogens ${ }^{4}$ mediante restricciones de derechos (consistentes, entre otras cosas, en el desarrollo de trabajos comunitarios durante 5 a 8 años) o restricciones de libertad que les impedirían salir de una determinada región geográfica (por ejemplo, un municipio) por ese mismo espacio de tiempo, sin que ello, además, conllevara automáticamente la inhabilitación automática para formar parte de órganos de representación popular, como el Congreso de la República o desarrollar actividades de naturaleza política. ${ }^{5}$

1 Mesa de Conversaciones, "Acuerdo final para la terminación del conflicto de una paz estable y duradera”, 26 de septiembre del 2016, https://www.mesadeconversaciones.com.co/sites/default/fi les/24_08_2016acuerdofinalfinalfinal-1472094587.pdf

2 Boris Miranda, "Las razones por las que el "No" se impuso en el plebiscito en Colombia", $B B C$ Mundo, 3 de octubre del 2016, http://www.bbc.com/mundo/noticias-america-latina-37537629

3 Ley 975 del 2005, 25 de julio. Por la cual se dictan disposiciones para la reincorporación de miembros de grupos armados organizados al margen de la ley, que contribuyan de manera efectiva a la consecución de la paz nacional y se dictan otras disposiciones para acuerdos humanitarios. Diario Oficial 45.980 .

4 A los efectos del presente trabajo, cuando nos referimos a crímenes de ius cogens, nos estamos refiriendo a aquellos crímenes sobre los que los tribunales internacionales penales creados a partir de la década de 1990 tienen jurisdicción: genocidio, crímenes de lesa humanidad y crímenes de guerra.

5 Mesa de Conversaciones, “Acuerdo final”, 147-148. 
Días después del referendo, llegaron las primeras propuestas de renegociación del contenido del acuerdo del 26 de septiembre por parte de los defensores del No, iniciándose así una serie de rondas de consultas entre estos últimos y el Gobierno, por una parte, y el propio Gobierno y las FARC-EP por otra, que llevaron a la firma el 12 de noviembre del 2016 de un nuevo acuerdo de paz entre el Gobierno y las FARC-EP. ${ }^{6} \mathrm{~A}$ pesar de que a los pocos días los principales defensores del No en el referendo del 2 de octubre rechazaron el nuevo acuerdo por insuficiente, ${ }^{7}$ el Gobierno decidió recurrir a sus mayorías parlamentarias para obtener su aprobación en un tiempo récord, de manera que para el $1^{\circ}$ de diciembre el Congreso y el Senado ya lo habían aprobado. Esto llevó a que los miembros del principal grupo de la oposición, el Centro Democrático, mostraran su más profunda disconformidad con lo que estaba acaeciendo, saliendo de la cámara en el momento en que se producía la última votación en el Congreso. ${ }^{8}$

Es en el marco de esta desafortunada situación de gran incertidumbre política y profunda división social que el presente capítulo reflexiona tanto sobre las fortalezas y las debilidades de los procesos penales y las comisiones extrajudiciales de la verdad, como sobre la medida en que estas últimas pueden ser superadas mediante una utilización conjunta de los procesos penales. Con ello, se adentra en un debate de lege ferenda para determinar si es aconsejable introducir modificaciones en el actual marco jurídico normativo internacional (lege lata). ${ }^{9}$ Así mismo, en el marco de este debate se

6 Mesa de Conversaciones, "Acuerdo final para la terminación del conflicto de una paz estable y duradera", 12 de noviembre del 2016, https://www.mesadeconversaciones.com.co/sites/default/ files/12-1479102292.11-1479102292.2016nuevoacuerdofinal-1479102292.pdf

7 "Colombia: la oposición rechaza el nuevo acuerdo del paz y pide una reunión con las FARc", Clarin, 22 de noviembre del 2016, http://www.clarin.com/mundo/Colombia-oposicion-acuerdoreunion-FARC_0_1691830848.html

8 Nicholas Casey, "El gobierno de Colombia aprueba nuevo acuerdo de paz para las FArc". The New York Times. Edición América, 1 de diciembre del 2016, http://www.nytimes.com/es/2016/12/01/ el-congreso-de-colombia-aprueba-nuevo-acuerdo-de-paz-con-las-farc/

9 En consecuencia, a diferencia de trabajos anteriores, el presente capítulo no se dirige a analizar el marco normativo vigente en el derecho internacional para los crímenes de ius cogens, que, como explicamos en su momento, exige a los Estados que investiguen, enjuicien y sancionen penalmente a sus responsables (particularmente, a los máximos responsables), y reparen íntegramente a las víctimas, reconociendo al mismo tiempo a estas últimas los derechos a la verdad, 
analizan ciertos aspectos que convendría revisar de la regulación que los acuerdos de paz del 26 de septiembre y del 12 de noviembre realizan de la Comisión para el Esclarecimiento de la Verdad, la Convivencia y la No Repetición, y la Jurisdicción Especial para la Paz —JEP-, en cuanto que componentes del Sistema Integral de Verdad, Justicia, Reparación y NoRepetición - SIVJRNR - previsto en dichos acuerdos.

Para ello, en la sección 1 analizamos el alcance y las limitaciones de los procesos penales a la luz del fin de prevención general positiva que resulta central en el derecho internacional penal y de su énfasis en los "máximos responsables". A continuación, en la sección 2 estudiamos el alcance y las limitaciones de las comisiones de la verdad. Sobre esta base, abordamos en la sección 3 la cuestión relativa a si es posible superar las limitaciones presentadas por los procesos penales y las comisiones de la verdad recurriendo a estas conjuntamente. Finalmente, en la sección de conclusiones responderemos a la pregunta sobre si de lo que se trata es de elegir entre procesos penales y comisiones extrajudiciales de la verdad, de combinarlos o de no recurrir, en ocasiones, a ninguno de ellos, atendiendo a las características particulares de las comunidades victimizadas.

la justicia y la reparación. Tampoco se dirige a estudiar cómo, con el fin de declarar y ejecutar la responsabilidad internacional penal derivada de estos delitos, una de las consecuencias del actual régimen jurídico internacional es la exigencia de que se desarrollen procesos penales ante jurisdicciones nacionales o ante tribunales internacionales penales. Sobre estas cuestiones, véase Héctor Olasolo, Andrea Mateus y Andrés Contreras, "La naturaleza imperativa del principio 'no hay paz sin justicia' respecto a los máximos responsables del fenómeno de la lesa humanidad y sus consecuencias para el ámbito de actuación de la llamada 'justicia de transición”. Boletin Mexicano de Derecho Comparado, n. ${ }^{\circ} 145$ (2016); Héctor Olasolo, "El principio 'no hay paz sin justicia' como principio rector del fenómeno de la lesa humanidad por el Derecho internacional y su impacto en los procesos de paz: particular atención al caso colombiano", en Introducción al derecho internacional penal (Valencia: Tirant lo Blanch, Editorial de la Universidad del Rosario \& IнH, 2014). Para una interpretación contraria, véase Diego Acosta, René Buchan y Russelly Ureña, "Beyond justice, beyond peace? Colombia, the interests of justice, and the limits of international criminal law". Criminal Law Forum 26, n. ${ }^{\circ} 2$ (2015); Ezequiel Malarino, "Transición, derecho penal y amnistía. Reflexiones sobre la utilización del derecho penal en procesos de transición”. Revista de Derecho Penal y Criminología, n. 9 (2003); y Louise Mallinder, Amnesty human rights and political transitions: bridging the peace and justice divide (Oxford: Hart, 2008). 


\section{Alcance y limitaciones de los procesos penales. Especial referencia a la Jurisdicción Especial para la Paz en Colombia}

\subsection{Los procesos penales como instrumento para declarar y ejecutar la responsabilidad internacional individual por crímenes de ius cogens: el debate en torno a la prevención especial positiva y al énfasis en los máximos responsables}

Hafner et al., ${ }^{10} \mathrm{O}^{\prime} \mathrm{Connor}^{11}$ y Scharf ${ }^{12}$ nos ofrecen un buen número de razones de política criminal que justifican la necesidad de recurrir a procesos penales para declarar y ejecutar la responsabilidad internacional individual por crímenes de ius cogens. Para estos autores, las actuaciones judiciales son irremplazables porque consideran que 1) las comisiones de la verdad no dirimen las responsabilidades civiles y penales derivadas de los delitos cometidos, incumpliendo así lo que exige el derecho internacional de los derechos humanos, el derecho internacional humanitario y el derecho internacional penal; 2) dejan sin castigo a los máximos responsables de los crímenes más graves para la sociedad internacional, lo que promueve la desconfianza en el Estado de derecho y el desdén por el sistema político en su conjunto; 3) los nuevos sistemas democráticos necesitan de una credibilidad y legitimidad que solo pueden adquirir mediante actuaciones judiciales justas y trasparentes a través de las que pueda establecerse qué sucedió y quiénes son responsables por lo sucedido, y esto solo se puede conseguir a través de una verdad judicial que ofrece mayores garantías y legitimidad sobre las responsabilidades individuales, porque es resultado de un proceso contradictorio con todas las garantías en el que se aplican normas estrictas sobre admisión de prueba en las actuaciones judiciales, los derechos de la

10 Gerhard Hafner, Hafner, Gerhard, Kristen Boon, Anne Rübesame y Jonathan Huston, "A response to the American view as presented by Ruth Wedgwood”. European Journal of International Law 10 (1999).

11 Gerhard O'Connor, “The pursuit of justice and accountability: why the United states should support the establishment of an international criminal court”. Hofstra Law Review 27 (1999): 929.

12 Michael Scharf, “The amnesty exception to the jurisdiction of the International Criminal Court”. Cornell International Law Journal 32 (1999): 512. 
defensa, el principio de presunción de inocencia y el estándar probatorio "más allá de toda duda razonable". ${ }^{13}$

A pesar del mérito de los argumentos esgrimidos por estos autores, el carácter irremplazable de los procesos penales ante jurisdicciones nacionales o ante tribunales internacionales penales choca contra la realidad de las limitaciones materiales de las actuaciones judiciales a través de las que se declara y ejecuta la responsabilidad internacional penal por crímenes de ius cogens. Es a esto a lo que se refiere Minow cuando califica como simbólicas y poco efectivas a las jurisdicciones regionales e internacionales establecidas por el derecho internacional de los derechos humanos, el derecho internacional humanitario y el derecho internacional penal, en particular la Corte Penal Internacional. ${ }^{14}$

En este sentido, conviene subrayar que, desde mediados de la década de 1990 hasta la fecha, los tribunales internacionales penales no han podido desarrollar más de trescientos casos, ${ }^{15}$ cifra inferior a la recogida en cual-

13 La antigua Comisión de Derechos Humanos de la Organización de las Naciones Unidas y la Subcomisión para la Prevención de la Discriminación y la Protección de los Menores han afirmado también que la impunidad es una de las razones principales de las violaciones continuadas de derechos humanos en todo el mundo. Véase a este respecto Comisión de Derechos Humanos (Naciones Unidas), Report on the consequences of impunity, un Doc. E/CN.4/1990/13 (1990).

14 Martha Minow, "Making history or making peace: when prosecutions should give way to truth commissions and peace negotiations", en Law in Transition. Human Rights, Development and Transitional Justice, editado por Ruth Buchanan y Peer Zumbasen (Oxford: Hart Publishing, 2014), 208.

15 ElTribunal Internacional Penal para la ex Yugoslavia informaba en su último informe semestral que entre 1994 y el 2015 sus actuaciones frente a las 161 personas imputadas habían concluido en noviembre del 2015, a excepción de tres procesos de apelación relativos a diez personas y cuatro enjuiciamientos de primera instancia que permanecían pendientes. Véase Tribunal Internacional Penal para la Ex-Yugoslavia, Assessment and report of Judge Theodor Meron, President of the International Tribunal for the Former Yugoslavia, provided to the Security Council pursuant to paragraph 6 of Security Council resolution 1534 (2004) covering the period from 16 May 2015 to 16 November 2015 (16 de noviembre del 2015), http://www.securitycouncilreport.org/atf/cf/\%7B65BFCF9B-6D27-4E9C8CD3-CF6E4FF96FF9\%7D/s_2015_874.pdf. Por su parte, el Tribunal Internacional Penal para Ruanda, en su informe final del 17 de noviembre del 2015, señalaba que entre 1995 y el 2015 había finalizado su trabajo de primera instancia en relación con las 93 personas imputadas, así como con respecto a 55 procesos de apelación, esperando completar la última apelación pendiente en diciembre del 2015. Véase Tribunal Internacional Penal para Ruanda, Report on the completion of the Mandate of the International Criminal Tribunal for Rwanda as at 15 November 2015 (17 de noviembre del 2015), p. 4, http://www.securitycouncilreport.org/atf/cf/\%7B65BFCF9B-6D27-4E9C-8CD3-CF6E4FF96FF9\%7D/s_2015_884.pdf. Otros tribunales internacionalizados presentan una situación 
quiera de las jurisdicciones nacionales (Argentina, Bosnia-Herzegovina, Colombia o Ruanda), en las que durante ese mismo periodo de tiempo se han desarrollados procesos por crímenes de ius cogens con cierta consistencia. De esta manera, las estadísticas existentes parecen dar la razón a quienes piensan como Minow, excepto en lo que se refiere a la mayor ineficacia de la Corte Penal Internacional, puesto que, en términos de investigaciones y enjuiciamientos, la eficacia de esta última ${ }^{16}$ no parece ser significativamente

similar. Así, la Corte Especial de Sierra Leona señaló en su informe final que entre el 2003 y el 2013 había completado cuatro casos relativos a diez máximos responsables. Véase Corte Especial para Sierra Leona, Eleventh and final report of the President of the Special Court for Sierra Leone (31 de diciembre del 2013), http://www.rscsl.org/Documents/AnRpt11.pdf. Por su parte, las Salas Especiales de las Cortes de Camboya han concluido entre el 2004 y el 2015 el caso contra Kaing Guek Eav, alias Duch, al que hay que sumar tres casos adicionales contra máximos responsables del régimen de la República de Kampuchea (1975-1977) que se siguen tramitando en estos momentos. Véase Salas Extraordinarias de las Cortes de Camboya, The Court Report of the Extraordinary Chambers in the Courts of Cambodia, n. 94 (febrero del 2016), febrero del 2016, http://www.eccc.gov.kh/sites/default/files/publications/ Court \%20Report\%20on \%20February\%202016.pdf. Con anterioridad, el Tribunal Militar Internacional de Núremberg - TMI-, establecido por Estados Unidos, Francia, Gran Bretaña y la Unión Soviética a través del Tratado de Londres del 8 de agosto de 1945, juzgó entre el 20 de noviembre de 1946 y el 1º de octubre de 1946 a los 24 principales dirigentes políticos, militares, económicos e ideológicos del régimen nacional-socialista que gobernó en Alemania entre 1933 y 1945, que habían sobrevivido a la Segunda Guerra Mundial y habían sido capturados por los Aliados. Tambien fueron enjuiciadas por TMI varias de sus principales organizaciones. Véase Tribunal de Núremberg, Judgment of the International Military Tribunal for the Trial of German Major War Criminals (30 de septiembre y 1 de octubre de 1946), http://avalon.law.yale.edu/imt/judgen.asp. Por su parte, el Tribunal Militar Internacional para el Lejano Oriente, establecido mediante decreto administrativo del comandante supremo de las Fuerzas Aliadas en el Pacífico (general Douglas McArthur), el 19 de enero de 1946, juzgó entre el 3 de mayo de 1946 y el 12 de noviembre de 1948 al primer ministro de Japón, Hideki Tojo, y a otros 24 miembros del Gobierno japonés y altos oficiales de las fuerzas armadas japonesas (si bien, con el fin de facilitar la transición en Japón, el general McArthur, así como la Fiscalía y las propias defensas de los imputados, protegieron al emperador Hirohito, jefe del Estado Imperial Japonés, que ni tan siquiera fue llamado a declarar). Véase a este respecto, Shunzo Majima, "Just military occupation? A case study of the American occupation in Japan", en Ius Post Bellum and Transitional Justice, editado por Larry May y Elizabeth Edenberg (Cambridge: Cambridge University Press, 2015).

16 Entre el 2003 y el 2016, la cPI: 1) ha recibido 11.568 comunicaciones; 2) ha concluido los exámenes preliminares en relación con 13 situaciones (diez con decisión de apertura de investigación: Costa de Marfil, Darfur-Sudán, República Democrática del Congo, Georgia, Libia, Kenia, Mali, República Centro-Africana I y II, y Uganda, y tres con decisión de no apertura de investigación: Honduras, República de Corea y Venezuela); 3) mantiene abiertos los exámenes preliminares con respecto a otras diez situaciones (Afganistán, Burundi, Colombia, Flotilla Humanitaria [Comoros, Grecia y Camboya], Gabón, Guinea, Iraq, Nigeria, Palestina y Ucrania); 4) desarrolla investigaciones con respecto a las diez situaciones cuyo examen preliminar finalizó con decisión de apertura de investigación; 5) ha iniciado procesos penales en relación con 18 casos relativos a 8 situaciones, de los que 
menor que la de otros tribunales internacionales penales con jurisdicción sobre una única situación de crisis (ex Yugoslavia, Ruanda o Sierra Leona).

Quienes defienden el carácter irrenunciable de los procesos penales responden afirmando que la declaración y ejecución de la responsabilidad internacional penal por crímenes de ius cogens no se limita a los órganos jurisdiccionales internacionales, sino que se extiende a las jurisdicciones nacionales, ${ }^{17}$ en particular a los Estados en cuya jurisdicción se comenten graves violaciones del derecho internacional de los derechos humanos y del derecho internacional humanitario, constitutivas de genocidio, crímenes de lesa humanidad y crímenes de guerra. ${ }^{18}$ Además, los principios de nacionalidad activa, nacionalidad pasiva y justicia universal permiten, y en ocasiones obligan, a las jurisdicciones nacionales a perseguir penalmente los crímenes de ius cogens. ${ }^{19}$

Si tomamos las estadísticas desde mediados de la década de los noventa, ${ }^{20}$ el número de procesos penales por crímenes de ius cogens ade-

cuatro se encuentran en actuaciones previas a la confirmación de cargos (Barara, Huseein, Al-Bashir, y Harum y Kushayb); dos han concluido con decisión de no confirmación de cargos (Mbarushimana y Abu Garda); dos se encuentran en la fase de preparación del juicio oral una vez confirmados los cargos (Banda y Ongwen); uno ha finalizado con el retiro de los cargos por la Fiscalía antes del inicio del juicio oral y una vez confirmados los cargos (Kenyatta); tres se encuentran en juicio oral (Gbagbo y Blé Goudé, Bemba et al. y Ntaganda); uno ha finalizado por insuficiencia de las pruebas presentadas por la Fiscalía (caso Ruto y Sang); uno ha finalizado con sentencia absolutoria en primera instancia y apelación (Ngudjolo); uno se encuentra en fase de apelación después de sentencia absolutoria en primera instancia (Bemba); dos se encuentran en fase de reparación tras sentencias condenatorias en primera instancia que no fueron apeladas (Katanga y Al-Mahdi); y uno se encuentra en fase de reparación tras sentencia condenatoria en primera instancia y apelación. Véase la página web de la Corte Penal Internacional (CPI), https://www.icc-cpi.int/, menú “investigations and cases".

17 M. Cherif Bassiouni, "Estudio histórico: 1914-1998", en CPI ratificación y legislación nacional de actuación (Toulouse: Nouvelles Études Pénales, Association Internationale de Droit Pénal, Érès, 1999).

18 Olasolo, Mateus y Contreras, "La naturaleza imperativa”, 136-168.

19 Bassiouni, "Estudio histórico".

20 Con anterioridad a 1995, se encuentran principalmente los aproximadamente 900 casos juzgados en Alemania en relación con los crímenes cometidos durante el régimen nacional socialista (entre estos se incluirían los procesos desarrollados entre 1946 y 1951 por los tribunales de ocupación británicos, franceses, norteamericanos y rusos en aplicación de la Ley 10 del Consejo de Control Aliado). Sin embargo, llama la atención la tenacidad con la que los tribunales nacionales de la República Federal Alemana, a diferencia de los de la República Democrática Alemana, se opusieron sistemáticamente a las imputaciones por crímenes de lesa humanidad, incluso en los casos de exterminio más flagrantes, como consecuencia de una interpretación extraordinariamente rígida del principio de legalidad. Véase 


\section{lantados ante las jurisdicciones nacionales es notablemente superior al de los que han tenido lugar ante tribunales internacionales penales, como lo muestran, entre otros, los casos de Argentina, ${ }^{21}$ Bosnia-Herzegovina, ${ }^{22}$}

a este respecto la excelente exposición de Lawrence Douglas, "Was damals Recht war... Nulla Poena and the Prosecution of Crimes against Humanity in Occupied Germany", en Ius Post Bellum and Transitional Justice, editado por Larry May y Elizabeth Edenberg (Cambridge: Cambridge University Press, 2015). La situación fue muy distinta en Japón, donde tras la sentencia del Tribunal Militar Internacional para el Lejano Oriente no se desarrollarían procesos penales ante los tribunales nacionales japoneses (si bien en terceros países ocupados por Japón durante la Segunda Guerra Mundial se desarrollaron algunos procesos penales contra las autoridades de ocupación, como es el caso del desarrollo por una Comisión Militar norteamericana contra el comandante en jefe de las fuerzas de ocupación japonesas en las Filipinas, el general Tomoyuki Yamashita). Por su parte, en Italia fueron muy pocos los procesos penales relativos a autoridades civiles y militares del régimen fascista que Mussolini estableció en Italia entre 1922 y 1943, denegándose, así mismo, las solicitudes de extradición por crímenes internacionales provenientes de terceros países en África y Europa. Como Carlos Nino ha subrayado: "En última instancia, el cargo de alto comisionado fue abolido y el Ministro de Justicia aprobó una ley de amnistía, convirtiendo en una parodia los intentos de procesamiento criminal. Solo un número reducido de torturas 'extremadamente crueles' quedó excluido de la ley de amnistía. A la mayor parte de los funcionarios públicos que habían sido exonerados se les reincorporó a sus cargos y se puso término abruptamente a la confiscación de ganancias económicas obtenidas durante el régimen fascista". Véase Carlos Nino, "El castigo como una respuesta a las violaciones de Derechos Humanos. Una perspectiva global”, traducido por el Instituto de Derechos Humanos de la Universidad de Chile, en Radical evil on trial (New Haven y Londres: Yale University Press, 1996).

21 Desde la Sentencia de la Corte Suprema de Argentina en el caso Simón, dictada el 14 de julio del 2005, y en la que se declara la inconstitucionalidad de las Leyes de Obediencia Debida y Punto Final de 1986, un total de 2354 personas (entre ellas 70 civiles) han sido imputadas por delitos de lesa humanidad en Argentina, de las que 669 han sido condenadas en las 156 causas finalizadas, sobre un total de 526 abiertas. Entre los condenados, el exjefe del III Cuerpo del Ejército, Luciano Benjamín Menéndez, acumula 12 condenas, diez de las cuales son a cadena perpetua. En cuanto a los civiles, de los más de 70 acusados, hasta el momento han sido condenados cuatro: los empresarios Emilio Felipe y Juan Manuel Méndez y los exfuncionarios judiciales Víctor Brusa (en la céntrica provincia de Santa Fe) y Manlio Martínez (en la norteña de Tucumán). Para el 2016, hay 13 juicios en marcha, entre los que destacan 1) el que juzga los supuestos crímenes perpetrados en los centros clandestinos de detención de la Escuela Superior Mecánica de la Armada — Esma - en Buenos Aires (donde son juzgadas 59 personas por haber presuntamente cometido 789 secuestros, torturas y homicidios en la ESMA, entre las que figuran ocho pilotos acusados por los denominados "vuelos de la muerte", en los que arrojaban a detenidos al Río de La Plata para deshacerse de sus cuerpos); 2) en lo relativo al centro clandestino de detención de La Perla, Córdoba (con 52 imputados y 417 víctimas); y 3) el desarrollado con respecto al Plan Cóndor, conforme al que las dictaduras suramericanas se coordinaron para intercambiar información y trasladar prisioneros). Véase "A 40 años del golpe de Estado en Argentina, los juicios en cifras”, El Pais, 24 de marzo del 2016, http://internacional.elpais.com/ internacional/2016/03/24/argentina/1458840802_572867.html

22 Para finales del 2015, más de 500 personas han sido formalmente imputadas en Bosnia y Herzegovina por crímenes de guerra cometidos durante el conflicto que asoló el país entre 1992 y 1995. 


\section{Colombia ${ }^{23}$ y Ruanda. ${ }^{24}$ Esto ha permitido que, junto con las actuaciones desarrolladas por los tribunales internacionales penales, un buen número de jefes de Estado y de Gobierno hayan podido ser objeto de investigación, enjuiciamiento o sanción penal durante este periodo. ${ }^{25}$}

De estas, 140 han sido ya condenadas. Véase Balkan Transitional Justice, Over 500 Indicted for War Crimes in Bosnia, 7 de octubre del 2015, http://www.balkaninsight.com/en/article/state-prosecution500-accusations-of-war-crimes-235-indictments-10-06-2015

23 En Colombia más de 600 miembros del Ejército y la Fuerza Pública han sido condenados y varios miles están siendo investigados por las ejecuciones extrajudiciales sistemáticas de al menos 3000 civiles cometidas por varias brigadas del Ejército colombiano a lo largo del país entre el 2002 y el 2008. Véase: Human Rights Watch, Acuerdo con las FARC es jaque mate para la justicia colombiana, 27 de marzo del 2016, http://www.eltiempo.com/mundo/ee-uu-y-canada/human-right-watch-criticaacuerdo-con-las-farc-por-falsos-positivos/16547551; y "Más de cinco mil agentes del Estado son investigados por falsos positivos: Fiscalía”, El País, 25 de junio del 2015, http://www.elpais.com.co/ elpais/judicial/noticias/cinco-mil-agentes-estado-son-investigados-por-falsos-positivos-fiscalia. Así mismo, entre el 2005 y el 2015, la jurisdicción nacional colombiana: 1) ha condenado a entre 50 y 60 senadores y congresistas y 15 gobernadores, por vínculos con el paramilitarismo; 2) ha condenado o procesado a 43 de los 46 más altos líderes paramilitares vivos; 3) se encuentra procesando, a través de la Jurisdicción Especial de Justicia y Paz, a cerca de 3000 mil paramilitares desmovilizados; 4) ha proferido numerosas sentencias contra integrantes de las dos principales guerrillas del país (FARC y ELN), incluyendo a quienes forman parte de sus respectivos secretariados. Véase Fiscalía de la Corte Penal Internacional, "Situación en Colombia, Reporte Intermedio", 12 de noviembre del 2012, http:// www.icc-cpi.int/en_menus/icc/structure\%20of\%20the\%20court/office \%20of\%20the\%20prosecutor/ comm\%20and\%20ref/colombia/Pages/Situation-in-Colombia-Interim-Report.aspx. Véase también, Héctor Olasolo, "Los exámenes preliminares de la Corte Penal Internacional en América Latina: el caso colombiano y su impacto sobre futuras negociaciones de paz en la región”. Anuario de Derechos Humanos Universidad de Chile 10 (2014).

24 En Ruanda, alrededor de 1300 procesos por genocidio tuvieron lugar entre 1996 y el 2001, antes de recurrir a la justicia comunitaria de las gacaca. Véase: Lynne Tirrell, "Transitional justice in post-conflict rwanda: an integrative approach”, en Theorizing transitional justice, editado por Claudio Corradetti, Nir Eisikovits y Jack Volpe Rotondi (Surrey: Ashgate, 2014), 243.

25 Sin ánimo de exhaustividad, solamente en América Latina se han adelantado, a nivel nacional, procesos penales contra los miembros de las cuatro juntas militares argentinas que gobernaron el país entre 1976 y 1983, Juan María Bordaberry (Uruguay), Augusto Pinochet (Chile), Alberto Fujimori (Perú) y Efraín Ríos Montt (Guatemala). Por su parte, los Tribunales Internacionales para la antigua Yugoslavia y Ruanda y la Corte Especial para Sierra Leona han desarrollado procesos penales contra Slobodan Milošević, Jean Kambanda y Charles Taylor, mientras que el Tribunal Especial para Iraq enjuició a Saddam Hussein. Así mismo, desde el 2009, la cPI ha abierto actuaciones penales contra los siguientes jefes de Estado o de Gobierno: Omar Al-Bashir (Sudán), Muammar E1 Gaddafi (Libia), Said Al Islam Gaddafi (Libia), Urumu Kenyatta (Kenia) y Laurent Ggagbo (Costa de Marfil). Véase a este respecto, Ellen Lutz y Caitlin Reiger (eds.), Prosecuting heads of states (Cambridge: Cambridge University Press, 2009). 
Sin embargo, no es menos cierto que incluso en aquellas jurisdicciones nacionales que han estado más activas el número de personas investigadas y enjuiciadas por genocidio, crímenes de lesa humanidad y crímenes de guerra apenas llega al $1 \%$ del total de presuntos responsables. Así, por ejemplo, en el caso de Ruanda, Tirrell nos recuerda que, de los 130.000 detenidos en 1994, 93 casos fueron completados por el Tribunal Internacional Penal para Ruanda, 1300 por los tribunales penales ruandeses y 128.700 fueron enviados a la justicia comunitaria de las gacaca. ${ }^{26}$ Argentina, Bosnia-Herzegovina y Colombia constituyen otros ejemplos en este sentido. ${ }^{27}$

Ante esta situación, una buena parte de la doctrina sitúa el fin central del régimen jurídico internacional de los crímenes de ius cogens en la transmisión del mensaje de que no se tolerará la impunidad de sus máximos responsables (prevención general positiva), ${ }^{28}$ lo que se ve reflejado en

26 Tirrell nos recuerda en relación con Ruanda que los casos procesados por los tribunales penales apenas llegan al $1 \%$ de los 130.000 detenidos que tuvieron que ser reenviados a la justicia comunitaria de las gacaca para evitar un colapso en el aparato de justicia. Véase Tirrell, "Transitional justice”, 243.

27 Las 140 personas condenadas y 500 imputadas ante la Sala de Crímenes de Guerra de Bonia y Herzegovina solo constituyen una mínima fracción de los responsables del desplazamiento forzado entre 1992 y 1995 de la mitad de su población (alrededor de dos de sus cuatro millones de habitantes). Del mismo modo, en Colombia, donde existen alrededor de siete millones de desplazados, y decenas de miles de casos de violencia sexual, solo se ha proferido hasta el momento unas cuantas decenas de condenas por este tipo de delito. Véase Fiscalía de la Corte Pena Internacional, "Situación en Colombia". Estas concusiones se reafirman en los sucesivos informes preliminares de la Fiscalía de la cPI en relación con el examen preliminar de la situación en Colombia. En cuanto a los crímenes internacionales cometidos durante la Segunda Guerra Mundial, Douglas nos recuerda que los casos juzgados en Alemania no llegan ni mucho menos al 1\% de las 500.000 personas que eran parte del Partido Nacional Socialista en los años cuarenta. Véase Douglas, "Was damals", 44-73. En consecuencia, quizá sea el caso de Argentina, aquel en el que, teniendo en cuenta el alto número de procesamientos, y siendo el número de víctimas considerablemente inferior al de las otras situaciones, se ha llevado ante la justicia un porcentaje superior de los presuntos responsables.

28 Véase en este sentido, Ambos Kai, "Crímenes de lesa humanidad y la Corte Penal Internacional”, en Cuadernos de derecho penal (Bogotá: Universidad Sergio Arboleda, 2013): 71; Robert Cryer, Prosecuting international crimes: selectivity and the international criminal law regime (Cambridge: Cambridge University Press, 2005), 191; Mirjan Damaška, "What is the point of international criminal justice?”. Chicago-Kent Law Review 83 (2008); Mark Drumbl, “Collective violence and individual punishment: the criminality of mass atrocity". Northwestern University Law Review 99 (2005): 173; Anthony Duff, "Can we punish the perpetrators of atrocities?", en The religious in responses to mass atrocity, editado por Thomas Brudman y Thomas Chushman (Cambridge: Cambridge University Press, 2008); Carsten Stahn, "Between faith and facts: by what standards should we assess international criminal justice?”. Leiden Journal of International Law 25 (2012): 251; y Pablo Eiroa, Políticas del castigo y derecho internacional para una concepción minimalista de la justicia penal (Buenos Aires: 
dos aspectos: 1) el énfasis que los tribunales internacionales penales han puesto en la investigación, enjuiciamiento y sanción penal de aquel grupo de dirigentes, que según las resoluciones 1503 del 2003 y 1534 del 2004 del Consejo de Seguridad de las Naciones Unidas ${ }^{29}$ y los documentos de política criminal de la Fiscalía de la Corte Penal Internacional - $\mathrm{CPI}$ - ${ }^{30}$ conforman la categoría de los "máximos responsables"31; y 2) la práctica constante y uniforme de los tribunales internacionales e internacionalizados

Ad Hoc, 2009). Para un mayor desarrollo sobre la relevancia de la prevención general positiva entre los fines del derecho internacional penal, véase Héctor Olasolo, Derecho internacional penal, justicia transicional y delitos transnacionales (Valencia: Tirant lo Blanch \& Instituto Iberoamericano de La Haya para la Paz, los Derechos Humanos y la Justicia Internacional, 2017).

29 Consejo de Seguridad de las Naciones Unidas, Resolución 1534 sobre el Tribunal Internacional Penal para la ex Yugoslavia y el Tribunal Internacional Penal para Ruanda, un. Doc. S/RES/1534 (26 de marzo del 2004), párr. 5 y 6, http://www.un.org/en/ga/search/view_doc.asp?symbol=S/RES/1534(2004). En esta resolución, el Consejo de Seguridad, entre otras cosas: 1) “insta a cada uno de los Tribunales a que, al examinar y confirmar las acusaciones nuevas, se aseguren de que concentran la labor en el procesamiento de los más altos dirigentes de quienes se sospeche que les cabe la mayor responsabilidad respecto de los delitos que sean de competencia del Tribunal de que se trate, según se establece en la resolución 1503 (2003)"; y 2) "pide a cada uno de los Tribunales que proporcionen al Consejo, a más tardar el 31 de mayo de 2004 y semestralmente después de esa fecha, evaluaciones realizadas por su Presidente y su Fiscal en que se expongan en detalle los progresos logrados en la aplicación de su estrategia de conclusión, se expliquen las medidas adoptadas y pendientes de aplicación, incluida la remisión de las causas relativas a inculpados de rango medio o inferior a jurisdicciones nacionales competentes, y expresa la intención del Consejo de reunirse con el Presidente y el Fiscal de cada Tribunal para examinar esas evaluaciones". Véase también a este respecto, Consejo de Seguridad de las Naciones Unidas, Resolución 1503 sobre el Tribunal Internacional Penal para la ex Yugoslavia (TIPY) y el Tribunal Internacional Penal para Ruanda, un. Doc. S/RES/1503 (28 de agosto del 2003).

30 Fiscalía de la Corte Penal Internacional, Policy Paper (1 de septiembre del 2003), https://www. icc-cpi.int//Pages/item.aspx?name=otp-policy-paper-2003; Fiscalía de la Corte Penal Internacional, Policy Paper on the Interests of Justice (1 de septiembre del 2007), https://www.icc-cpi.int//Pages/item. aspx?name=otp-policy-int-just; Fiscalía de la Corte Penal Internacional, Policy Paper on Preliminary Examinations (1 de noviembre del 2013), https://www.icc-cpi.int//Pages/item.aspx?name=otppolicy-pe-11_2013; Fiscalía de la Corte Penal Internacional, Draft policy paper on case selection and prioritisation (29 de abril del 2016), https://www.icc-cpi.int//Pages/item.aspx?name=Draft-PolicyPaper-on-Case-Selection-and-Prioritisation; y Fiscalía de la Corte Penal Internacional, Policy Paper on Case Selection and Prioritisaton (15 de septiembre del 2016), https://www.icc-cpi.int//Pages/item. aspx?name=policy-paper-on-case-selection-and-prioritisation

31 Además del caso contra el exjefe de Estado de Liberia, Charles Taylor, la Corte Especial para Sierra Leona limitó también sus actuaciones contra los principales líderes políticos y militares supervivientes de los tres grupos enfrentados en la guerra civil que tuvo lugar en la década de 1990 en Sierra Leona: Revolutionary United Front — RUF—, Civil Defense Forces — CDF- y Armed Forces Revolutionary Council — AFrC—. Véase: Mecanismo Residual de la Corte Especial para Sierra Leona, Sección de casos, http://www.rscsl.org/ 
de carácter penal establecidos desde la Segunda Guerra Mundial de imponer penas de reclusión proporcionales a la gravedad de los delitos cometidos y al grado de participación en estos de quienes resultan condenados. ${ }^{32}$

Ahora bien, no es menos cierto que el énfasis que los tribunales internacionales penales han puesto en los máximos responsables no resulta ni mucho menos pacífico. Así, autores como Zolo, ${ }^{33}$ Margalit ${ }^{34}$ y Jeangène Vilmer ${ }^{35}$ muestran su profunda preocupación ante esta práctica, dada su vulnerabilidad a la instrumentalización política por algunos de los Estados más influyentes de la sociedad internacional. A este respecto, Zolo se muestra particularmente receloso de la función unidireccional jugada por los tribunales de Núremberg y Tokio, y sospecha que algo similar puede estar ocurriendo con la nueva ola de tribunales internacionales penales surgidos desde 1993, sobre todo en un contexto de primado político-militar de una única superpotencia y de sus más cercanos aliados de la Alianza del Tratado del Atlántico Norte — OTAN—. ${ }^{36}$ Por su parte, Jeangène Vilmer aporta una significativa documentación, incluyendo numerosas referencias a las declaraciones de la exfiscal del Tribunal Internacional Penal para la ex Yugoslavia y del Tribunal Internacional Penal para Ruanda, Carla del

32 La pena de reclusión ha sido la pena central de los tribunales de Núremberg y Tokio tras la Segunda Guerra Mundial, así como de aquellos creados a partir de 1990, como son el Tribunal Internacional para la ex Yugoslavia, el Tribunal Internacional para Ruanda, la Corte Especial para Sierra Leona, las Salas Especiales de los Tribunales de Camboya o el Tribunal Especial para el Líbano. Igualmente, el artículo 77 del Estatuto de la Corte Penal Internacional establece como pena principal la reclusión en centro penitenciario hasta un máximo de treinta años, con la posibilidad de su extensión a la cadena perpetua revisable en caso de que concurran dos circunstancias agravantes. Según esta disposición, las penas de multa y decomiso pueden imponerse de manera complementaria a la pena de reclusión, pero nunca de manera alternativa a esta. Véase Silvia D'Ascoli, Sentencing in international criminal law: the approach of the two un ad hoc tribunals and future perspectives for the International Criminal Court (Oxford: Hart Publishing Ltd., 2011).

33 Danilo Zolo, La justicia de los vencedores: de Núremberg a Bagdag (Madrid: Ed. Trotta, 2007).

34 Avishai Margalit, On compromise and rotten compromises (Princeton: Princeton University Press, 2010).

35 Jean-Baptiste Jeangène Vilmer, Pas de paix sans justice? Le dilemme de la paix et de la justice en sortie de conflicto armé (París: SciencesPo Les Presses, 2011).

36 En apoyo de esta afirmación, se presenta la excesiva focalización del Tribunal Internacional Penal para la ex Yugoslavia en los delitos cometidos por los serbios y los serbo-bosnios, así como el olvido de la sociedad internacional frente a las decenas, sino cientos de miles, de víctimas del Frente Patriótico Ruandés a su entrada en Ruanda en julio de 1994. Véase Zolo, La justicia. 
Ponte, ${ }^{37}$ sobre la dependencia de los tribunales internacionales penales de los Estados (en particular, de los pertenecientes a la OTAN) para poder llevar a cabo sus funciones, al no poder operar sin su cooperación. ${ }^{38}$

A esta situación hay que sumar la crítica planteada por autores como Guembe y Olea, ${ }^{39} \mathrm{o}$ incluso por el propio primer fiscal de la CPI, Luis Moreno Ocampo, ${ }^{40}$ con base en los casos de Colombia y Uganda, al subrayar las dificultades para concluir con éxito las negociaciones de paz entre actores armados que no han sido derrotados militarmente, si lo que espera a sus dirigentes es su enjuiciamiento y castigo penal por los crímenes de ius cogens cometidos de manera sistemática o generalizada a través de sus subordinados. $^{41}$

\subsection{Reflexiones sobre el alcance y las limitaciones de la Jurisdicción Especial para la Paz en Colombia}

El Acuerdo General para la Terminación del Conflicto firmado por el Gobierno de Colombia y las FARC-EP el 26 de agosto del 2012 incluyó en la agenda de negociación para los siguientes años el estudio de los derechos de las víctimas y los mecanismos de esclarecimiento de la verdad, ${ }^{42}$ guardando, sin embargo, absoluto silencio sobre las cuestiones relativas a la justicia. ${ }^{43}$

\footnotetext{
37 Carla del Ponte, La Traque, les Criminels de guerre et Moi: autobiografie (París: Edition H. d'Ormesson, 2009).

38 Jeangène Vilmer, Pas de paix, 99-109.

39 María José Guembe y Helena Olea, "No justice, no peace: discussion of a legal framework regarding the demobilization of non-state armed groups in Colombia", en Transitional justice in the Twenty-First Century: beyond truth versus justice, coordinado por Roth Arriaza, y Mariezcurrena (Cambridge: Cambridge University Press, 2006).

40 Luis Moreno Ocampo, "Pursuing human dignity, facing history and ourselves", Conferencia dada en Harvard Law School (Boston, 4 de noviembre del 2005).

41 Véase también en este sentido, Adam Branch, "The role of ICC in Northern Uganda", en Peacemaking: from practice to theory, editado por Susan Allen Nan, Zachariah Cherian Mampilly y Andrea Bartoli, Vol. 1 (2011).

42 Mesa de Conversaciones, "Acuerdo general para la terminación del conflicto y la construcción de una paz estable y duradera" (La Habana, 26 de agosto del 2012), punto 5 de la agenda de negociación, https://www.mesadeconversaciones.com.co/sites/default/files/AcuerdoGeneralTerminacionConflicto.pdf

43 En este sentido, véase Human Rights Watch, "Colombia: Los derechos de las víctimas deben ser centrales en las negociaciones de paz -La paz sin justicia no es sostenible”, 16 de octubre del
} 
Apenas un par de meses después, el Congreso de Colombia, por iniciativa del Gobierno, aprobaba el Acto Legislativo 01 del 2012, ${ }^{44}$ conocido como el Marco Jurídico para la Paz, que introducía en la Constitución colombiana los artículos 66 bis y 67 bis, en los que se establecía la creación de una comisión de la verdad y se adoptaban toda una serie de medidas que, si bien pretendían asegurar el cumplimiento de los deberes del Estado de investigar y sancionar los crímenes de ius cogens, lo cierto es que no despejaban las dudas sobre la insuficiencia del tratamiento del componente de justicia. ${ }^{45}$ De hecho, como Uprimny, Sánchez y Sánchez ${ }^{46}$ han señalado, el Marco Jurídico para la Paz, fruto de una iniciativa unilateral del Gobierno no apoyada por las FARC-EP, no hacía sino reflejar las grandes dificultades existentes en la mesa de negociación: por un lado, las FARC-EP no estaban dispuestas a aceptar la justicia del Estado; ${ }^{47}$ por otro lado, existía una gran resistencia a que se sometieran a la acción de la justicia aquellos agentes del Estado que estuvieran involucrados en crímenes de ius cogens en el marco del conflicto armado. ${ }^{48}$

Habría que esperar hasta el comunicado conjunto del Gobierno de Colombia y las FARC-EP, de 23 de septiembre del 2015, para conocer que las partes negociadoras habían alcanzado un acuerdo para la creación de una Jurisdicción Especial para la Paz. En este, junto con la aceptación de someterse a esta nueva jurisdicción y de reparar íntegramente a las víctimas, se preveía el otorgamiento de amnistías e indultos para los delitos no constitutivos de genocidio, crímenes de lesa humanidad y crímenes de guerra para los miembros de las FARC-EP y otras medidas equivalentes para

2012, https:/www.hrw.org/es/news/2012/10/16/colombia-los-derechos-de-las-victimas-deben-sercentrales-en-las-negociaciones-de.

${ }^{44}$ Acto Legislativo 01 del 2012,31 de julio. Por medio del cual se establecen instrumentos jurídicos de justicia transicional en el marco del artículo 22 de la Constitución Política y se dictan otras medidas.

45 Para un mayor desarrollo de esta cuestión, véase Olasolo, "Los exámenes preliminares", 35-56.

46 Rodrigo Uprimny Yepes, Luz María Sánchez Duque y Nelson Camilo Sánchez León, Justicia para la paz. Crimenes atroces, derecho a la justicia y paz negociada (Bogotá: Centro de Estudios de Derecho, Justicia y Sociedad, Dejusticia, 2014), 147.

47 FARC-EP, Comunicado del 6 de agosto del 2013, Sobre un Marco Jurídico fuera de contexto (Primera reflexión) (La Habana, Cuba).

48 Uprimny Yepes, Sánchez Duque y Sánchez León, Justicia para la paz, 147. 
los agentes del Estado, y se establecía un sistema comprehensivo de penas alternativas a las de carácter ordinario. ${ }^{49}$

De esta manera, con la creación de la JEP se ha pretendido limitar las resistencias, arriba mencionadas, de las FARC-EP y de una parte importante de las Fuerzas Armadas y otros agentes del Estado mediante: 1) el establecimiento de una jurisdicción de carácter especial y autónoma; 2) la provisión de un sistema de amnistía e indultos que recogiera la demanda de las FARC-EP del reconocimiento del delito político para quienes fueron capturados y juzgados por delitos como el de rebelión; y 3) la provisión de un trato especial a los agentes del Estado, que pretende ser "equilibrado y equitativo" con el tratamiento ofrecido a los miembros de las FARC-EP. ${ }^{50}$

Sin embargo, desde la perspectiva de la eficacia de la prevención general positiva del régimen jurídico internacional de los crímenes de ius cogens, del énfasis de los tribunales internacionales penales en la investigación, enjuiciamiento y sanción penal de los "máximos responsables", y de la práctica constante y uniforme de los tribunales internacionales e internacionalizados de carácter penal de imponer penas de reclusión proporcionales a la gravedad de los delitos cometidos y al grado de participación en estos de quienes resultan condenados, ${ }^{51}$ conviene subrayar que varios aspectos de la JEP, recogidos en el acuerdo del 26 de septiembre del 2016 entre el Gobierno de Colombia y las FARC-EP, y ratificados en el nuevo acuerdo del 12 de noviembre del 2016, son particularmente preocupantes.

En primer lugar, se encuentra la inclusión dentro de los posibles delitos amnistiables y, por lo tanto, su exclusión del ámbito de aplicación de la JEP de los crímenes de guerra que sean considerados "no graves". ${ }^{52} \mathrm{La}$ distinción entre crímenes de guerra "graves" y "no graves" no tiene ningún sustento jurídico ni en el derecho internacional humanitario, en el que todos los crímenes de guerra constituyen infracciones graves de este y no

49 Gobierno de Colombia y FARC-EP, Comunicado conjunto \# 60 sobre el Acuerdo de creación de una Jurisdicción Especial para la Paz La Habana, Cuba, 23 de septiembre del 2015.

50 Mesa de Conversaciones, "Acuerdo final", 143-ss; FARC-EP, Jurisdicción especial para la paz, amnistía e indulto. Cartilla para prisioneras y prisioneros politicos, http://www.farc-ep.co/pdf/CartillaJurisdiccion-Especial-para-la-Paz-para-Prisioneras-y-Prisioneros-Politicos.pdf.

51 Véase la nota al pie 32.

52 Mesa de Conversaciones, "Acuerdo final”, 151. 
son amnistiables, ${ }^{53}$ ni en el derecho internacional de los derechos humanos o el derecho internacional penal, considerando este último, en particular, a todos los crímenes de guerra, sin distinción alguna, como parte de los "crímenes más graves de transcendencia para la comunidad internacional en su conjunto". ${ }^{4}$

En segundo lugar, se observa la distinción, a efectos de la determinación de la pena alternativa, entre el genocidio, los crímenes de lesa humanidad y los crímenes de guerra calificados como "muy graves" y aquellos que no merezcan dicha calificación (esta distinción tampoco tiene ningún asidero jurídico en el derecho internacional de los derechos humanos, el derecho internacional humanitario o el derecho internacional penal). ${ }^{55}$

En tercer lugar, se encuentra la expresa extensión del fuero del que disfrutan ante la jurisdicción ordinaria quienes han ejercido la Presidencia de la República, ${ }^{56}$ lo que, dada la práctica de la Comisión de Acusaciones del Congreso, supone, en realidad, una garantía de que no responderán ante la JEP. ${ }^{57}$ En este sentido, como hemos visto, uno de los principales fines del régimen jurídico internacional de los crímenes de ius cogens es "hablarle directamente al poder", con el fin, como subraya Luban, de recordarle la existencia de una serie de normas jurídicas que regulan su conducta de una forma totalmente diferente a los consejos maquiavélicos del pasado. ${ }^{58}$ Este mensaje se debilita profundamente con medidas como la aquí mencionada,

53 Véase artículos 49 y 50 de la Convención I de Ginebra (1949), artículos 50 y 51 de la Convención II de Ginebra (1949), artículos 129 y 130 de la Convención III de Ginebra (1949), artículos 146 y 147 de la Convención IV de Ginebra (1949), y artículo 85 del Protocolo Adicional I a dichas Convenciones (1977). Tampoco hace distinción alguna en este sentido el artículo 6(5) del Protocolo Adicional II, que, como ya hemos explicado en otros trabajos, excluye de su ámbito de aplicación todos aquellos comportamientos constitutivos de crímenes de guerra por tratarse de graves infracciones del derecho internacional humanitario aplicables a los conflictos armados de carácter no internacional. Véase a este respecto, Héctor Olasolo, "Dignidad humana, derecho internacional penal y justicia transicional”. Revista de Estudios Socio-Jurídicos 16 (2014).

54 Estatuto de Roma de la Corte Penal Internacional, preámbulo y artículo 5.

55 Mesa de Conversaciones, "Acuerdo final”, 164-165.

56 Constitución Política de Colombia, artículo 174.

57 Mesa de Conversaciones, “Acuerdo final”, 149.

58 David Luban, "After the honeymoon: reflections on the current state of international criminal justice". J Int Criminal Justice 11, n. ${ }^{\circ} 3$ (2013): 509. 
que actúan como una amnistía de facto frente a los crímenes de ius cogens ${ }^{59}$ en favor de los más altos representantes del Gobierno de Colombia (una de las partes en el conflicto y en el proceso de negociación). Además, el hecho de que las partes hayan acordado no extenderla expresamente a los más altos representantes de la contraparte (las FARC-EP) refleja su carácter superfluo e innecesario con respecto a la superación de las dificultades arriba mencionadas por Guembe y Olea,${ }^{60}$ y Moreno Ocampo ${ }^{61}$ para la conclusión con éxito de este tipo de negociaciones de paz entre actores armados que no han sido derrotados militarmente.

En cuarto lugar, a diferencia de lo que ocurría en la Ley de Justicia y Paz -en cuyas actuaciones las víctimas tenían el derecho a realizar preguntas durante las versiones libres realizadas por la Fiscalía, y les era reconocida una posición procesal en las actuaciones ante los magistrados de garantías y conocimiento (ejercida a través de la Defensoría Pública en cuanto que sus representantes legales de oficio) —,${ }^{62}$ las víctimas no tienen reconocida ninguna posición procesal propia en las actuaciones ante las Salas y Tribunal de la JeP. ${ }^{63}$

En quinto lugar, existe la limitación a un máximo de 20 años de reclusión para los máximos responsables de estos crímenes que no cumplan con ninguno de los presupuestos de la justicia transicional (y, por lo tanto, no puedan ser acreedores de una pena alternativa), al no reconocer su responsabilidad, no colaborar con la justicia, no pedir perdón a las víctimas, no entregar bienes para la reparación y ser declarados culpables solamente tras un proceso penal contradictorio. ${ }^{64}$

En sexto lugar, se observa el establecimiento para los máximos responsables que sí cumplan con dichos presupuestos y admitan su responsabilidad

59 Ibid, 514. En el mismo sentido, Stef Vandeginste, "Bypassing the prohibition of amnesty for human rights crimes under international law: lessons learned from the Burundi Peace Process". Netherlands Quarterly Of Human Rights 29, n. ${ }^{\circ} 2$ (2011): 198-199.

60 Guembe y Olea, "No justice”.

61 Moreno Ocampo, "Pursuing human dignity".

62 Esto no significa que no hayan presentado problemas importantes en la aplicación en la práctica de la participación de las víctimas en las actuaciones procesales desarrolladas ante los magistrados de justicia y paz.

63 Mesa de Conversaciones, "Acuerdo final", 143-175.

64 Ibid., 165. 
antes del inicio del juicio ora ${ }^{65}$ de penas alternativas (restricción de derechos como la realización de trabajos comunitarios o la prohibición de salir de ciertas regiones geográficas durante 5 a 8 años). ${ }^{66}$ Esto, contrariamente a la práctica constante y uniforme de los tribunales internacionales e internacionalizados de carácter penal establecidos desde la Segunda Guerra Mundial ${ }^{67}$ y al fin central del régimen jurídico de los crímenes de ius cogens de enviar el mensaje de que no se tolerará la impunidad de los máximos responsables de dichos delitos (prevención general positiva), ${ }^{68}$ excluye la pena de reclusión (algo que no sucede con la Ley de Justicia y Paz del 2005). ${ }^{69}$

Esta situación se agrava, sin duda, al dejarse abierta la posibilidad de que las FARC-EP puedan nombrar a algunos de los máximos responsables de crímenes de ius cogens para ocupar, inmediatamente después de la aprobación de la correspondiente legislación de desarrollo del acuerdo, asientos parlamentarios en el Congreso de la República, lo que, además, parece que impediría en la práctica que pudieran cumplir las penas alternativas de restricción de libertad que les fuera eventualmente impuestas por la JEP. ${ }^{70}$ Así mismo, ni el acuerdo del 26 de septiembre, ni el del 12 de noviembre abordan con la suficiente claridad el régimen aplicable al cumplimiento de las penas alternativas por los miembros del Gobierno de Colombia y los agentes del Estado (incluidos los máximos responsables) que se encuentren involucrados en la comisión de genocidio, crímenes de lesa humanidad y crímenes de guerra, y reconozcan su responsabilidad ante la JEP. ${ }^{71}$

El nuevo acuerdo alcanzado el 12 de noviembre del 2016 entre el Gobierno de Colombia y las FARC trata de dar respuesta a algunos de los problemas identificados en el acuerdo del 26 de septiembre, si bien deja sin abordar la mayor parte de estos e introduce dificultades adicionales nada despreciables. Así, entre sus elementos novedosos, recoge la limitación a

65 Aquellos que admitan su responsabilidad después de la apertura del juicio oral y antes de que se dicte sentencia serán acreedores a una pena de reclusión de 5 a 8 años. Ibid., 165.

66 Ibid., 164-165 y 172-174.

67 Véase pie de página 32.

68 Véase pie de página 29.

69 Ley 975 del 2005, 25 de julio, artículos 10, 11 y 29.

70 Mesa de Conversaciones, "Acuerdo final", 70-71.

71 Ibid., 164-174. 
“zonas veredales transitorias de normalización” la extensión de las regiones geográficas a las que se verán confinados los condenados por aquellos crímenes de ius cogens que sean considerados "muy graves", y el establecimiento de una reglamentación más detallada del régimen en que se cumplirá este tipo de pena alternativa. ${ }^{72}$

En segundo lugar, se prevé también de manera expresa (el acuerdo del 26 de septiembre lo recogía solo implícitamente) la obligación de entrega de bienes por parte de las FARC a los efectos de la reparación y la sanción de pérdida de la pena alternativa para quien pretenda ocultarlos. ${ }^{73}$

Finalmente, se pretende, a priori, corregir el elemento objetivo de la definición de la responsabilidad de mando, de manera que parece abandonarse el requerimiento del control efectivo del superior sobre la conducta punible de sus subordinados (previsto en el acuerdo del 26 de septiembre), para, conforme a lo establecido por el artículo 28 del Estatuto de la CPI, limitarse a exigir la capacidad del superior para: 1) prevenir la comisión de los delitos; o, una vez cometidos, 2) reprimirlos, poniéndoles fin, castigando a sus subordinados, o, cuando esto último exceda el ámbito de sus competencias, enviando la cuestión a las autoridades competentes para su investigación y enjuiciamiento. ${ }^{74}$ Sin embargo, la ausencia de toda referencia expresa al artículo 28 del Estatuto de la CPI en el Acto Legislativo de la JEP, aprobado el 14 de marzo del 2017, genera, como se debatió recientemente en las audiencias del 20 y 21 de marzo del 2017 ante la Comisión Interamericana de Derechos Humanos, serias dudas sobre la aplicación efectiva de la figura de la responsabilidad de mando por la JEP.

Ahora bien, los avances que suponen estos nuevos aspectos del régimen de penas se ven ciertamente empañados por la introducción de varias de las propuestas más preocupantes presentadas por algunos de los defensores del No en el referendo del 2 de octubre. Entre ellas, y a modo de ejemplo, cabe citar la expresa extensión del ámbito de aplicación de la JEP a los casos de falsos positivos (cuya investigación, enjuiciamiento y sanción se ha

\footnotetext{
72 Ibid., 151 y $165-166$.

73 Ibid., 186.

74 Ibid., 152. Véase, en este sentido, Human Rights Watch, Carta al presidente Santos sobre el nuevo acuerdo de paz con las FARC, 23 de noviembre del 2016, https://www.hrw.org/es/news/2016/11/23/ carta-al-presidente-santos-sobre-el-nuevo-acuerdo-de-paz-con-las-farc
} 
convertido, desde el informe del 12 de noviembre del 2012, en la principal exigencia de la Fiscalía de la Corte Penal Internacional en relación con los crímenes de lesa humanidad y de guerra cometidos por los agentes del Estado colombiano), o la expresa imposición de plazos máximos para que la Fiscalía General de la Nación envíe sus informes de investigación a las salas de la JEP (dos años, prorrogables a un máximo de tres). ${ }^{75}$

Esta última cuestión tiene muy notables repercusiones dada la ausencia de poderes de investigación de la Sala de reconocimiento de verdad, de responsabilidad y de determinación de hechos y conductas de la JEP. Esto, junto con la prohibición expresa de realizar solicitudes de información a la Comisión para el Esclarecimiento de la Verdad, la Convivencia y la No Repetición, ${ }^{76}$ y la mencionada limitación temporal a las actividades de investigación que pueda realizar la Fiscalía General de la Nación a petición de dicha Sala, priva a esta, en gran medida, de los mecanismos necesarios para realizar eficazmente su función de verificación de la información que aporten quienes comparezcan voluntariamente. ${ }^{77}$

\section{Alcance y limitaciones de las comisiones de la verdad. Especial atención a las situaciones en Colombia, España e Irlanda del Norte}

Akhavan, ${ }^{78}$ Hayner ${ }^{79}$ Wiebelhauss-Brahm ${ }^{80}$ y Tamarit ${ }^{81}$ consideran que las comisiones de la verdad, además de ser una alternativa a los procesos judiciales (ya sean penales o civiles, nacionales o internacionales) para expresar

75 Mesa de Conversaciones, “Acuerdo final”,153. También se establecen límites temporales para que las distintas salas de la JEP desempeñen sus funciones. Véase Mesa de Conversaciones, "Acuerdo final", 145 .

76 Ibid., 133-134.

77 Ibid., 133-134, 152-153 y 172-174.

78 Payam Akhavan, "The Yugoslav Tribunal at a crossroads: the Dayton Peace Agreement and beyond”. Human Rights Quarterly 18 (1996): 271.

79 Priscilla Hayner, Unspeakable trutbs: confronting state terror and atrocity (Nueva York: Routedge, 2001).

80 Eric Wiebelhauss-Brahm, Truth commissions and transitional societies: the impact on human rights and democracy (Oxon y Nueva York: Routledge, 2010).

81 Josep María Tamarit, "Los límites de la justicia transicional penal: la experiencia del caso español”. Política Criminal 7, n. o 13 (julio, 2012). 
la condena de la sociedad a los crímenes de ius cogens, ofrecen una serie de ventajas en los siguientes aspectos: 1) el nombramiento de los victimarios; 2) el papel preponderante atribuido a las víctimas mediante la escucha del relato de sus historias, el amplio reconocimiento de su sufrimiento y la búsqueda de la restauración de su dignidad; 3) la promoción de reparaciones individuales y colectivas, de naturaleza monetaria y simbólica, así como de programas educativos, memoriales y proyectos que fortalecen las instituciones democráticas; 4) la determinación de una visión más amplia de los patrones sociales, políticos y económicos que contribuyeron a la degradación social en la que se cometieron los crímenes internacionales de ius cogens; y 5) la promoción de una memoria colectiva y un compromiso cultural que condene dichos crímenes. ${ }^{82}$

Para Minow ${ }^{83}$ y Nagy, ${ }^{84}$ las comisiones de la verdad también se encuentran mejor equipadas que los procesos penales, puesto que, además de poner a las víctimas en el centro del proceso, facilitan una mirada más amplia de las causas de la violencia, sin constituir una amenaza tan latente para los máximos dirigentes de las partes en conflicto.

Sin embargo, Lawther, ${ }^{85}$ y Rotondi y Eisikovits ${ }^{86}$ nos recuerdan que algunas de las ventajas manifestadas por estos autores no son necesariamente ciertas, puesto que, con frecuencia, las comisiones de la verdad evitan analizar de manera comprehensiva el pasado. Además, no disipan entre los dirigentes de las partes implicadas la amenaza latente que su actuación puede generar a su posición. ${ }^{87}$

82 Naomi Roht-Arriaza, "Punishment, redress and pardon: Theoretical and psychological approaches", en International law and practice, editado por Naomi Roht-Arriaza (Nueva York: Oxford University Press, 1995).

83 Minow, "Making history", 208-211.

84 Rosemary Nagy, “Transitional justice as global project: critical reflexions”, en Law in transition. Human rights, development and transitional justice, editado por Ruth Buchanan y Peer Zumbasen (Oxford: Hart Publishing, 2014), 223.

85 Cheryl Lawther, "Peace without the past? Truth, transition and the Northern Ireland case", en Theorizing transitional justice, editado por Claudio Corradetti, Nir Eisikovits y Jack Volpe Rotondi (Surrey: Ashgate, 2014), 29-37.

86 Nir Eisikovits y Jack Rotondi, "Forgetting after the war: a qualified defense", en Theorizing transitional justice, editado por Claudio Corradetti, Nir Eisikovits y Jack Volpe Rotondi (Barrington: Ashgate, 2014).

87 Ibid. 
Con respecto a la primera objeción, Jolly, ${ }^{88}$ y Rehn y Sirleaf ${ }^{89}$ subrayan que muchas comisiones de la verdad no abordan los patrones de injusticia estructural, en particular en lo que se refiere a: 1 ) el eje diferencial de género; ${ }^{90}$ y 2) los efectos socioeconómicos de la violencia y su "legalización" a través de procesos de transición que dejan dichos efectos ocultos en un segundo plano (los procesos de transición raramente revierten las adquisiciones sistemáticas y a gran escala de propiedad a través de actos de violencia, o aprovechado la situación generada por esta). ${ }^{91}$ Para Mamdani, ${ }^{92}$ la Comisión de la Verdad y Reconciliación de Sudáfrica constituye, en este sentido, un ejemplo paradigmático de autorrestricción en el análisis, al tratar en todo momento de limitar la cuestión racial mediante un tratamiento superficial del apartheid como un simple telón de fondo en el marco del cual se produjeron los actos de violencia individuales que fueron presentados como los auténticos delitos. ${ }^{93}$

Incluso en aquellos casos en que se abordan estos aspectos, son muy pocas las comisiones de la verdad que, como sucedió con la de Timor Oriental en relación con su ocupación por Indonesia desde 1974 hasta 1999, y el apoyo a esta última de Australia, Estados Unidos, Japón y Reino Unido,

88 Rosemary Jolly, "Desiring good(s) in the face of marginalized subjects: South Africa's Truth and Reconciliation Commission in a global context”. South Atlantic Quaterly 100, n. ${ }^{\circ} 3$ (2001): 623.

89 Elisabeth Rehn y Ellen Sirleaf, Women, war and peace: The independent expert's assessment on the impact of armed conflict on women's role in peace building (Nueva York: UNDP, 2002).

90 Como recalca Nagy, la Comisión de Reconciliación y Verdad de Sierra Leona ha sido la excepción, pues ha enfrentado la violencia de género de una manera usual y sistemática. Véase Nagy, “Transitional justice", 224-225. Véase también Sierra Leone Truth and Reconciliation Commission, Witness to truth: final report of the TRC, http://www.sierraleonetrc.org/index.php/view-the-final-report

91 Una versión similar se sostiene en Héctor Olasolo, "La inseguridad jurídica de los acuerdos de paz a la luz del régimen jurídico internacional de los crímenes de ius cogens y la justicia de transición". Política Criminal 12, n. ${ }^{\circ} 23$ (2017): 78-102.

92 Mahmood Mamdani, "Reconciliation without justice". South African Review of Books 46 (1996).

93 Llegan a esta conclusión reconociendo incluso los aspectos positivos de las audiencias sectoriales ejercidas por el TRC en el marco de comunidades negociadoras, médicas, legales, religiosas y carcelarias. El valor de dichas audiencias ha sido resaltado por David Dyzenhaus, Judging the judges: judging ourselves (Oxford: Hart Publishing, 1998); Alex Boraine, A country unmasked: inside South Africa's truth and reconciliation commission (Nueva York: Oxford University Press, 2000); y Bill Rolston, "Assembling the Jigsaw: truth, justice and transition in the North of Ireland". Race and Class 44 (2002). 
describen el papel fundamental de terceros Estados. ${ }^{94}$ De hecho, de las más de cuarenta comisiones extrajudiciales de la verdad que han desarrollado sus trabajos en los últimos veinticinco años, ${ }^{95}$ Hayner ${ }^{96}$ y Nagy ${ }^{97}$ nos advierten que se pueden contar con los dedos de la mano aquellas que, como las de Chad, Chile, E1 Salvador, Guatemala y Timor Oriental, han analizado el papel esencial jugado por terceros Estados (en particular, aquellos más influyentes en la sociedad internacional) en la injusticia estructural (social, política, económica, étnica, religiosa o de género) que fue el caldo de cultivo de los crímenes de ius cogens allí cometidos. ${ }^{98}$

Desde esta perspectiva, es ciertamente preocupante la limitación a un plazo máximo de tres años del funcionamiento de la Comisión para el Esclarecimiento de la Verdad, la Convivencia y la No Repetición (CEVCNR), recogida en el acuerdo del 26 de septiembre del 2016 entre el Gobierno de Colombia y las FARC-EP, ${ }^{99}$ y reiterada en el nuevo acuerdo del 12 de noviembre. ${ }^{100}$ Teniendo en cuenta la excepcionalmente larga duración del conflicto armado en Colombia, el amplio número de actores involucrados, la extensión del actuar de los actores armados a la casi totalidad del territorio nacional, la magnitud de la violencia empleada, los cerca de ocho millones de víctimas que la sufrieron, y la amplitud de la ley de amnistía prevista en el Acuerdo (que solo excluye expresamente de su ámbito de aplicación el genocidio, los crímenes de lesa humanidad y los graves crímenes de guerra), dicho plazo de tres años parece ciertamente insuficiente. En este tiempo se debe abordar desde un enfoque territorial (ámbitos local, regional y nacional), de género (especiales características de la violencia sufrida por niñas, adolescentes y mujeres adultas) y diferencial (particularidades de la violencia

94 Nagy, “Transitional justice”, 223. Véase tambien Comissao de Acolhimento, Verdade e Reconciliacao de Timor-Leste, Chega! The Report of the Commission for the Reception, Truth and Reconciliation for Timor-Leste (CAVR) (2005), http://www.cavr-timorleste.org/en/chegaReport.htm

95 Un recuento histórico de las decenas de comisiones de la verdad establecidas desde 1990 puede encontrarse en Jorge Ibañez Najar, Justicia de transición y las comisiones de la verdad (Madrid: Berg Institute, 2014).
96 Hayner, Unspeakable truths, 75-76.
97 Nagy, “Transitional justice”, 224-226.
98 Hayner, Unspeakable truths, 75-76.
99 Mesa de Conversaciones, "Acuerdo final”, 125.
${ }^{100}$ Mesa de Conversaciones, "Acuerdo final”, 138. 
sufrida por numerosos grupos y comunidades en Colombia con identidad propia, como niños, adultos de tercera edad, personas con discapacidades, grupos étnicos, afrocolombianos, población gitana, población LGTBI, comunidades de campesinos, defensores de derechos humanos, sindicalistas o periodistas, por solo poner algunos ejemplos) los patrones de injusticia estructural e intervención de terceros Estados que, según la mitad de los informes publicados en el 2015 por la Comisión para la Historia del Conflicto y de las Víctimas en Colombia, ${ }^{101}$ han caracterizado el conflicto armado en este país. ${ }^{102}$ De hecho, teniendo en cuenta la diversidad de las visiones que sobre las razones y características del conflicto armado han tenido la oportunidad de aflorar en los informes de esta última Comisión, ${ }^{103}$ existe un riesgo cierto de que la CEVCNR se convierta en un escenario de lucha por la memoria, a través de la cual se trate de "homogeneizar" la pluralidad de perspectivas existentes.

La insuficiencia de este plazo de tres años se pone, si cabe, más de manifiesto cuando se analizan los tres fines principales de la CEVCNR. En primer lugar, se afirma que se dirige a “(...) ofrecer una explicación amplia de

${ }^{101}$ En esta Comisión participaron catorce académicos nombrados de común acuerdo por el Gobierno de Colombia y las FARC-EP. El informe final de esta contiene 12 informes, cada uno elaborado por uno de los miembros de la Comisión, y dos relatorías escritas respectivamente por Eduardo Pizarro León-Gómez ("Una lectura múltiple y pluralista de la historia”) y Víctor Manuel Moncayo Cruz ("Hacia la verdad del conflicto: insurgencia guerrillera y orden social vigente").

102 Mesa de Conversaciones, “Acuerdo final”, 134-138.

${ }^{103}$ Comisión Histórica del Conflicto y sus Víctimas, Contribución al entendimiento del conflicto armado en Colombia (febrero del 2015). De los 12 informes presentados, los conceptos de violencia o injusticia estructural se recogen en los siguientes 6 informes de De Zubiría, Dimensiones politicas y culturales en el conflicto colombiano; Estrada Álvarez (2015), Acumulación capitalista, dominación de clase y rebelión armada; Fajardo, Estudio sobre los orígenes del conficto social armado, razones de su persistencia y sus efectos más profundos en la sociedad colombiana; Giraldo, Aportes sobre el origen del conflicto armado en Colombia, su persistencia y sus impactos; Pecault, Un conflicto armado al servicio del status quo social y político; Vega, Injerencia de los Estados Unidos, contrainsurgencia y terrorismo de Estado; y la relatoría de Moncayo Cruz, Hacia la verdad del conflicto: insurgencia guerrillera y orden social vigente. Los conceptos de violencia o injusticia estructural no se recogen, sin embargo, en los otros 6 informes, ni en la relatoría de Pinzón Leongómez Una lectura múltiple y pluralista de la historia. Véase en este sentido los informes de Duncan, Exclusión, insurrección y crimen; Jorge Giraldo, Politica y guerra sin compasión; Gutiérrez, $\dot{\zeta}$ Una historia simple?; A. Molano, Fragmentos de la historia del conflicto armado (1920-2010); Torrijos, Cartografía del conflicto:pautas interpretativas sobre la evolución del conflicto irregular colombiano; y Wills, Los tres nudos de la guerra colombiana. Así mismo, tampoco hace referencia expresa o implícita estos conceptos la relatoría de Pinzón Leongómez, Una lectura múltiple y pluralista de la bistoria. 
la complejidad del conflicto, de tal forma que se promueva un entendimiento compartido en la sociedad, en especial de los aspectos menos conocidos del conflicto, como el impacto del conflicto". ${ }^{104}$ En segundo lugar, se subraya que la CEVCNR se dirige también a promover "el reconocimiento de las víctimas como ciudadanos y ciudadanas que vieron sus derechos vulnerados y como sujetos políticos de importancia para la transformación del país”. ${ }^{105}$ Finalmente, se señala que la CEVCNR

\begin{abstract}
deberá promover la convivencia en los territorios, en el entendido de que la convivencia no consiste en el simple compartir de un mismo espacio social y político, sino en la creación de un ambiente transformador que permita la resolución pacífica de los conflictos y la construcción de la más amplia cultura de respeto y tolerancia en democracia. ${ }^{106}$
\end{abstract}

De esta manera, mientras que el primero de los objetivos de la CEVCNR parece ir dirigido a proveer una verdad técnica sobre los patrones generales de atrocidades sufridas por la sociedad colombiana durante el conflicto armado, el segundo objetivo pone el énfasis en la necesidad de escuchar las historias de las víctimas como forma de reconocerlas y empoderarlas en cuanto ciudadanos y actores políticos (lo cual es también visto como una forma de reparación). ${ }^{107}$ La tensión entre estos dos fines se vivió de manera particularmente intensa en la Comisión para la Verdad y la Reconciliación en Sudáfrica, lo que llevó a que quienes abogaron por la primacía del ofrecimiento a la sociedad sudafricana de una verdad técnica sobre los patrones generales de atrocidades sufridas calificaran los trabajos de la Comisión como absolutamente insuficientes, ${ }^{108}$ mientras que quienes consideraron

\footnotetext{
${ }^{104}$ Mesa de Conversaciones, "Acuerdo final", 131.

105 Ibid.

${ }^{106}$ Ibid., 132.

107 Ibid., 182.

108 Audrey R. Chapman y Patrick Ball, "Levels of truth: macro-truth and the Trc", en Truth and reconciliation commission in South Africa: did the TRC deliver?, editado por Audrey R. Chapman y Hugo van der Merwe (Filadelfia: University of Pennsylvania Press, 2008). Véase también Mamdani, "Reconciliation without justice", 46-ss.
} 
que la principal función de la Comisión era reconocer y empoderar a las víctimas como paso previo hacia la reconciliación reflejaron una visión mucho más positiva de dichos trabajos. ${ }^{109}$ Los notables problemas generados por esta tensión en Sudáfrica no parecen, sin embargo, haber sido tenidos en cuenta por el Gobierno de Colombia y las FARC, puesto que ni el tercer fin de la CEVCNR, ni los enfoques territorial, de género y diferencial que la CEVCNR ha de seguir ofrecen criterio alguno para abordarla. ${ }^{110}$

Con respecto a la segunda objeción, Lawther, ${ }^{111}$ y Rotondi y Eisikovits, ${ }^{112}$ a la luz de las situaciones en España, Irlanda del Norte y Mozambique, rechazan la proposición de que las comisiones de la verdad faciliten una mirada al pasado sin constituir una amenaza latente para los máximos dirigentes de las partes en conflicto. Si bien reconocen la falta de estudios que analicen la correlación entre la sistematicidad de la información revelada por las comisiones de la verdad y el grado de amenaza experimentado por los principales actores en las negociaciones en las que se diseñan los modelos de transición, subrayan que no deja de ser una poderosa intuición el hecho de que el incremento del grado de amenaza sea proporcional al nivel de sistematicidad y profundidad con que los informes de las comisiones de la verdad analizan: 1) el tratamiento de la injusticia estructural que generó la degradación social en la que se cometieron los crímenes de ius cogens; 2) los efectos socioeconómicos de la violencia y su "legalización" a través de los diseños transicionales; y 3) el papel fundamental de los Estados más influyentes en la sociedad internacional. ${ }^{113}$

${ }^{109}$ Stephane Leman-Langlois y Clifford Shearing, "Transition, forgiveness and citizenship: the TRC and the social construction of forgiveness", en Justice and reconciliation in post-apartheid South Africa, editado por Francois du Bois y Antje du Bois-Pedain (Cambridge: Cambridge University Press, 2008). Véase también Boraine, A country unmasked, 357-358.

${ }^{110}$ Héctor Olasolo, Joel Ramírez y Antonio Varón, "Have the Colombian Government and the FARC learnt the lessons of the South African Truth and Reconciliation Commission as to the need to clearly define and prioritize the main goals of the truth commission?". Harvard Human Rights Online Journal 58 (2017) (en prensa).

${ }^{111}$ Lawther, "Peace without the past?", 29-37.

112 Eisikovits y Rotondi, "Forgetting after the war", 13-25.

${ }^{113}$ Lawther, "Peace without the past?", 29-37; Eisikovits y Rotondi, "Forgetting after the war", 13-25. 
Hamber, ${ }^{114}$ Lundy ${ }^{115}$ y Lawther ${ }^{116}$ subrayan los extensos y controvertidos debates sostenidos tanto dentro de las propias instituciones de la transición (Comité de Asuntos de Irlanda del Norte ${ }^{117}$ y Grupo de Consulta sobre el Pasado), ${ }^{118}$ como al interior de la sociedad civil sobre la necesidad, o no, de establecer un mecanismo general de búsqueda de la verdad para superar la violencia política vivida en Irlanda del Norte desde finales de la década de $1960 .{ }^{119}$ Si tenemos en cuenta que en Irlanda del Norte actores con gran influencia sociopolítica mantienen visiones completamente distintas de las causas, culpabilidades y responsabilidades de la violencia, no es de extrañar que el proceso de recuperación de la verdad se vea más como un escenario de batalla sectaria por la memoria, que como un instrumento de reconciliación con el pasado. ${ }^{120}$

Los procesos políticos de transición en Irlanda del Norte ${ }^{121}$ y España ${ }^{122}$ ilustran también con particular intensidad la fuerte oposición a reconocer las "verdades oscuras" del accionar de las estructuras estatales y de los grupos paraestatales promovidos por estas. Así, en España, la suspensión, tras el intento de golpe de estado militar del 23 de febrero de 1981, de las exhumaciones de cadáveres enterrados sin identificar en fosas comunes durante el periodo 1936-1975 (las exhumaciones habían comenzado por iniciativa

${ }^{114}$ Brandon Hamber, "Remembering to forget: issues to consider when establishing structures for dealing with the past", en Past imperfect: dealing with the past in Northern Ireland and South Africa, editado por Brandon Hamber (Londonberry: Incore/University of Ulster, 1998).

115 Patricia Lundy, “Commissioning the past in Northern Ireland”. Review of International Affairs 60, n. ${ }^{\circ} 1138-1139$ (2010).

116 Lawther, "Peace without the past?", 29-37.

117 Northern Ireland Affairs Committee, Ways of dealing with Northern Ireland's past: Interim Report - Victims and Survivors (Londres: The Stationary Office, 2005).

118 Consultative Group on the Past, Report of the Consultative Group on the Past (Belfast, 2009).

119 Véase también Healing Through Remembering, Making peace with the past: options for truth recovery regarding the conflict in and about Northern Ireland (Belfast, octubre del 2006).

120 Cheryl Lawther, Truth, denial and transition: Northern Ireland and the contested past (Londres: Routledge, 2014).

${ }^{121}$ Robin Eames y Denis Bradley, "Eames: the speech in full”, Belfast Telegraph, 29 de mayo del 2008, http://www.belfasttelegraph.co.uk/news/eames-the-speech-in-full-28390171.html

122 Paloma Aguilar, "Justice, politics and memory in the Spanish transition", en The politics of memory: transitional justice in democratizing societies, editado por Alexandra Barahona de Brito y Carmen González Enríquez (Oxford: Oxford University Press, 2001). 
privada de los familiares de las víctimas en 1979) es un claro exponente de este fenómeno. ${ }^{123}$ Las exhumaciones solo se reanudaron, de nuevo por iniciativa privada, casi veinte años después, y a pesar de la elaboración, a raíz de la aprobación de la Ley 52 del 2007 de Memoria Histórica, de un Mapa de Fosas, que hasta el momento ha identificado 2387 fosas comunes, lo cierto es que hasta el 2016 se han abierto únicamente unas $500 .{ }^{124}$ Esta situación —así como el hecho de que las exhumaciones se hayan dejado a la iniciativa privada (fenómeno conocido como la "privatización" de las exhumaciones), lo que genera la indiferencia de las instituciones del Estado, provoca que las autoridades judiciales españolas ni tan siquiera se apersonen al denunciarse el descubrimiento de una fosa, e impide la existencia de registros oficiales de las exhumaciones - ${ }^{125}$ es, sin duda, sorprendente si tenemos en cuenta que, según el último informe sobre España del Grupo de Trabajo sobre Desapariciones Forzadas o Involuntarias de las Naciones Unidas,

En España se cometieron graves y masivas violaciones a los derechos humanos durante la Guerra Civil (1936-1939) y la dictadura (1939-1975). Hasta la fecha no existe una cifra oficial del número de personas desaparecidas, ya que España no cuenta con una base de datos centralizada al respecto. De acuerdo con la instrucción penal efectuada por el Juzgado de Instrucción Penal $\mathrm{N}^{\circ} 5$ de la $\mathrm{Au}-$ diencia Nacional, el número de víctimas de desapariciones forzadas del 17 de julio de 1936 a diciembre de 1951 ascendería a 114.226. Dado que dicha instrucción penal fue, a todos los efectos prácticos, paralizada o disgregada, el número tampoco pudo ser determinado fehacientemente por una investigación judicial. ${ }^{126}$

\footnotetext{
${ }^{123}$ Carlos Farran y Samuel Amago, Unearthing Franco's legacy: mass graves and the recovery of historical memory in Spain (París: University of Notre Dame Press, 2010).

${ }^{124}$ Pablo de Greiff, Informe del relator especial sobre la promoción de la verdad, la justicia, la reparación y las garantías de no repetición, 22 de julio del 2014, párrs. 61-65, A/HRC/27/56/Add.1.

${ }^{125}$ Ibid., párr. 66.

${ }^{126}$ Working Group on Enforced or Involuntary Disapperances, Report of the Working Group on Enforced or Involuntary Disappearances: Mission to Spain, un. Doc., A/HRC/27/49/Add., 2 de julio del 2014, http://www.ohchr.org/EN/Countries/ENACARegion/Pages/ESIndex.aspx. En este sentido, el periódico Nueva España reportó que la acusación criminal presentada a la Audiencia Nacional el 16 de octubre del 2008 incluía información relativa al entierro de 114.266 personas en fosas comunes
} 
La gravedad de esta situación es evidente si se compara con las 46.657 desapariciones contabilizadas por el Registro Único de Víctimas desde la década de 1960 en el conflicto armado colombiano, ${ }^{127}$ los entre 10.000 y 30.000 desaparecidos en Argentina entre 1976 y $1983^{128}$ y los 3500 desparecidos en Chile durante la dictadura del general Augusto Pinochet entre 1973 y $1989 .{ }^{129}$ De hecho, según las denuncias presentadas en el marco de la mencionada instrucción penal del Juzgado de Instrucción Penal n.o 5 de la Audiencia Nacional, en algunas comunidades autónomas españolas, como La Rioja, el número de presuntos desaparecidos por cada cien mil habitantes (643) es seis veces y media superior que la media en Colombia (97).

Es en este contexto en el que se entiende mejor la posición de Leebaw al afirmar que la tensión entre el objetivo de acabar con la negación y exponer el alcance de la complicidad, por un lado, y la importancia de proteger el compromiso político, por otro, es inherente a la justicia transicional. ${ }^{130}$ En el mismo sentido, Lawther hace un recuento de las razones de índole política, sociológica y práctica que justifican la oposición a los procesos de recuperación de la verdad, subrayando "las versiones contrapuestas

(32.289 en Andalucía, 10.178 en Aragón, 1246 en Asturias, 1777 en las Islas Baleares, 262 en las Islas Canarias, 850 en Cantabria, 7067 en Castilla-La Mancha, 12.979 en Castilla y León, 2400 en Cataluña, 4345 en Valencia, 9459 en País Vasco, 10.266 en Extremadura, 4396 en Galicia, 2007 en La Rioja, 2995 en Madrid, 855 en Murcia, 3431 en Navarra, 464 en Ceuta, Melilla y los territorios del norte de África, y 7000 en otros territorios. Véase "Hubo 114.266 desaparecidos entre 1936 y 1951 según el auto del juez Garzón”. Nueva España, octubre 2008, http://www.Ine.es/espana/2008/10/16/ espana-hubo-114266-desaparecidos-1936-1951-auto-juez-garzon/686147.html. Posteriormente, debido a multitud de reclamaciones, se corregiría esta figura y el número de desapariciones denunciadas subiría a 143.353 (traducción del autor).

127 Véase la página web del Registro Único de Víctimas del Gobierno de Colombia, http://rni. unidadvictimas.gov.co/RUV. Véase también Centro de Memoria Histórica, ;Basta Ya!: Colombia Memorias de Guerra y Dignidad, coordinado por Gonzalo Sánchez, 2013, http://www.centrodememoriahistorica.gov.co/micrositios/informeGeneral/descargas.html

${ }^{128}$ Comisión Nacional sobre la Desaparición de Personas (Conadep), Reporte de la Comisión Nacional sobre la Desaparición de 1984, septiembre de 1984, http://web.archive.org/web/20031004074316/ nuncamas.org/english/library/nevagain/nevagain_001.htm

${ }^{129}$ Comisión Nacional Chilena de Verdad y Reconciliación, Report of the Chilean National Commission on Truth and Reconciliation, 1991, http://www.usip.org/sites/default/files/resources/collections/ truth_commissions/Chile90-Report/Chile90-Report.pdf

${ }^{130}$ Bronwyn Leebaw, “The irreconcilable goals of transitional justice”. Human Rights Quaterly 30 (2008). 
del concepto de víctima; la importancia de honrar los sacrificios pasados; y desde la perspectiva práctica de realización de la paz, la necesidad de mantener la estabilidad política y social". ${ }^{131}$ Por ello, Roth-Arriaza sostiene que las comisiones de la verdad están mucho mejor diseñadas para recopilar lo sucedido que para generar entendimiento común, reconciliación o cambio social. ${ }^{132}$

\section{3. ¿Es posible superar las limitaciones de los procesos penales y las comisiones de la verdad recurriendo a ambos conjuntamente?}

Ante las limitaciones presentadas por los procesos penales y las comisiones de la verdad, surge la pregunta sobre si el recurso a ambos tipos de mecanismos permitiría resolver algunas de las dificultades descritas en las secciones anteriores. Tejan-Cole, ${ }^{133}$ Schabas, ${ }^{134}$ Horowitz, ${ }^{135}$ Burgess, ${ }^{136}$ Cueva, ${ }^{137}$ Lutz $^{138}$ y Minow ${ }^{139}$ responden a esta pregunta afirmativamente.

${ }^{131}$ Lawther, "Peace without the past?", 29-37.

${ }^{132}$ Naomi Roht Arriaza, "The new landscape of transitional justice”, en Transitional justice in the Twenty-First Century: beyond truth versus justice, editado por Roht Arriaza y Mariezurrena (Cambridge: Cambdrige University Press, 2006).

${ }^{133}$ Abdul Tejan-Cole, "The complementarity and conflicting relationship between the Special Court for Sierra Leone and the Truth and Reconciliation Commission". Yale Human Rights and Development Law Journal 6 (2003): 139.

${ }^{134}$ William Schabas, “The Sierra Leone Truth and Reconciliation Commission”, en Transitional justice in the Twenty-First Century: beyond truth versus justice, editado por Roht Arriaza y Mariezurrena (Cambridge: Cambdrige University Press, 2006), 38-40.

135 Sigall Horowitz, "Transitional criminal justice in Sierra Leone”, en Transitional justice in the Twenty-First Century: beyond truth versus justice, editado por Roht Arriaza y Mariezurrena (Cambridge: Cambdrige University Press, 2006), 54-55.

136 Patrick Burgess, "A new approach to Restorative Justice-East Timor's Community Reconciliation Process", en Transitional justice in the Twenty-First Century: beyond truth versus justice, editado por Roht Arriaza y Mariezurrena (Cambridge: Cambdrige University Press, 2006).

${ }^{137}$ Eduardo Cueva, "The Peruvian Truth and Reconciliation Commission and the challenge of impunity", en Transitional justice in the Twenty-First Century: Beyond truth versus justice, editado por Roht Arriaza y Mariezurrena (Cambridge: Cambdrige University Press, 2006).

${ }^{138}$ Ellen Lutz, "Transitional justice: lessons learned and the road ahead", en Transitional justice in the Twenty-First Century: beyond truth versus justice, editado por Roht Arriaza y Mariezurrena (Cambridge: Cambdrige University Press, 2006), 325-327.

${ }^{139}$ Minow, "Making history", 210-211. 
Subrayan que esta combinación puede facilitar la restauración de la dignidad de las víctimas; contribuir a evitar el incumplimiento de la normativa internacional en materia de derecho internacional de los derechos humanos, derecho internacional humanitario y derecho internacional penal; $y$ fomentar la complementariedad entre una verdad judicial que ofrezca mayores garantías sobre las responsabilidades individuales, y una verdad histórica y contextual significativamente más amplia sobre las causas de los crímenes de ius cogens. Ahora bien, para que se generen estos efectos beneficiosos es necesario, según estos autores, coordinar adecuadamente los objetivos, actuaciones y procedimientos para el intercambio de información entre los procesos penales y las comisiones de la verdad.

A este respecto, el caso de Perú muestra que los procesos penales y las comisiones de la verdad pueden articularse mediante su sucesión en el tiempo, de manera que las segundas recopilen documentación que pueda posteriormente ser utilizada en los primeros. ${ }^{140}$ Pero también es posible que ambos mecanismos actúen simultáneamente, reservando, como en Sierra Leona, las actuaciones relativas a los máximos responsables a los procesos penales, ${ }^{141}$ o estableciendo, como en Timor Oriental, una clara demarcación entre las funciones de declaración y ejecución de la responsabilidad penal propias de los procesos penales, y los objetivos de la comisión de la verdad de promover la restauración de la dignidad de las víctimas y fomentar la reconciliación a través de una mayor articulación de las causas sociales, políticas, económicas y culturales de los crímenes internacionales de ius cogens. ${ }^{142}$

Desde esta perspectiva, la regulación prevista en los acuerdos del 26 de septiembre y del 12 de noviembre del 2016 de la CEVCNR y la JEP en Colombia no resuelve adecuadamente la cuestión relativa a la coordinación de los objetivos, actuaciones y procedimientos de intercambio de información entre ambos mecanismos. De hecho, lo que se hace es establecer una separación absoluta entre los trabajos de la CEVCNR y la JEP, sin que se establezca una clara división de funciones entre ambos, estipulando que

\footnotetext{
${ }^{140}$ Cueva, "The Peruvian Truth".

${ }^{141}$ Horowitz, "Transitional criminal justice”, 54-55.

${ }^{142}$ Burgess, “A new approach”, 200-201.
} 
"[1]a información que reciba o produzca la Comisión no podrá ser trasladada por esta a autoridades judiciales para ser utilizada con el fin de atribuir responsabilidades en procesos judiciales o para tener valor probatorio; ni las autoridades judiciales podrán requerírsela”. ${ }^{143}$ Además, se deja sin resolver la cuestión relativa a si los archivos creados por la CEVNR durante su excesivamente limitado periodo de mandato de tres años estarán a disposición de la JEP al término de este. ${ }^{144}$

Un segundo grupo de autores subrayan que el recurso conjunto a los procesos penales y las comisiones de la verdad no permite superar las limitaciones mostradas por ambos mecanismos. En primer lugar, Freeman, ${ }^{145}$ Maculan y Pastor, ${ }^{146}$ Gil Gil, ${ }^{147}$ y Nesbitt ${ }^{148}$ afirman que, para el adecuado funcionamiento de los procesos penales y las comisiones de la verdad, es necesario evitar la transmisión de la información obtenida por las segundas a los primeros, porque nadie prestará declaración ante las comisiones de la verdad si considera que esta puede ser utilizada en su contra ante los tribunales de justicia. Así mismo, para estos autores, la utilización en procesos penales de la información obtenida ante las comisiones de la verdad afectaría los derechos y garantías de la defensa.

${ }^{143}$ Mesa de Conversaciones, "Acuerdo final", 26 de septiembre, 121. Véase también Mesa de Conversaciones, "Acuerdo final", 12 de noviembre, 133.

${ }^{144}$ Mesa de Conversaciones, “Acuerdo final”, 26 de septiembre, 118-126. Véase también Mesa de Conversaciones, “Acuerdo final”, 12 de noviembre, 130-139.

145 Mark Freeman, Truth commissions and procedural fairness (Cambridge: Cambridge University Press, 2006).

${ }^{146}$ Elena Maculan y Daniel Pastor, El derecho a la verdad y su realización por medio del proceso penal (Buenos Aires: Hammurabi, 2013), 19-143.

${ }^{147}$ Alicia Gil Gil, "El tratamiento jurídico de los crímenes cometidos en el conflicto armado colombiano. La problemática jurídica en el marco de la dicotomía paz-justicia”, en Semana Iberoamericana, editado por Sonia Alda Mejías y Susana de Sousa Ferreira (Madrid: Instituto Universitario Gutiérrez Mellado, 2017).

${ }^{148}$ Michael Nesbit, "Lessons from the Sam Hinga Norman Decision of the Special Court for Sierra Leone: how trials and truth commissions can co-exist". German Law Journal 8, n. ${ }^{\circ} 10$ (2007): 977-1014. 
De esta manera, si para Tejan-Cole, ${ }^{149}$ Schabas, ${ }^{150}$ Horowitz, ${ }^{151}$ Burgess, ${ }^{152}$ Cueva, ${ }^{153}$ Lutz $^{154}$ y Minow ${ }^{155}$ el recurso conjunto a los procesos penales y las comisiones de la verdad permite superar algunas de sus limitaciones, siempre y cuando se coordinen adecuadamente sus objetivos, actuaciones y procedimientos con el fin de favorecer un adecuado intercambio de información entre estos, para Freeman, ${ }^{156}$ Maculan y Pastor, ${ }^{157}$ Gil, ${ }^{158}$ y Nesbitt, ${ }^{159}$ dicho intercambio de información acabaría inevitablemente con tales mecanismos.

En segundo lugar, Lawther, ${ }^{160}$ Rotondi y Eisikovits, ${ }^{161}$ Hamber ${ }^{162}$ y Lundy ${ }^{163}$ subrayan que el recurso conjunto a los procesos penales y las comisiones de la verdad no permite siempre superar la principal limitación mostrada por ambos mecanismos: las resistencias generadas en influyentes actores sociales, políticos y económicos de los procesos de transición (en particular, los máximos dirigentes de las partes implicadas en crímenes internacionales de ius cogens), que ven en el análisis del pasado una considerable amenaza a su posición.

Así mismo, la combinación de procesos penales y comisiones de la verdad tampoco aborda las objeciones presentadas por Hayner ${ }^{164}$ y Nagy $^{165}$

\footnotetext{
149 Tejan-Cole, “The complementarity”, 139.

${ }^{150}$ Schabas, "The Sierra Leone”, 38-40.

${ }^{151}$ Horowitz, "Transitional criminal justice”, 54-55.

152 Burgess, “A new approach”, 200-201.

${ }^{153}$ Cueva, "The Peruvian truth".

${ }^{154}$ Lutz, "Transitional justice”, 325-327.

155 Minow, “Making history”, 210-211.

${ }^{156}$ Freeman, Truth commissions, 104.

157 Maculan y Pastor, El derecho a la verdad, 19-143.

${ }^{158}$ Gil Gil, "E1 tratamiento jurídico".

159 Nesbit, “Lessons”, 977-1014.

${ }^{160}$ Lawther, "Peace without the past?", 29-37.

${ }^{161}$ Eisikovits y Rotondi, "Forgetting after the war", 13-25.

${ }^{162}$ Hamber, "Remembering to forget", 56-78.

${ }^{163}$ Lundy, "Commissioning the past", 101-133.

${ }^{164}$ Hayner, Unspeakable truths, 75-76.

165 Nagy, “Transitional justice”, 224-226.
} 
sobre el inadecuado tratamiento en las actividades de recuperación de la verdad de: 1) la injusticia estructural que genera la degradación social en la que se cometen los crímenes internacionales de ius cogens; 2) los efectos socioeconómicos de la violencia y su "legalización" a través de los modelos transicionales; y 3) el papel jugado por los Estados más influyentes en la sociedad internacional. De hecho, si bien el enjuiciamiento de los elementos contextuales de los crímenes de lesa humanidad (existencia de un ataque sistemático o generalizado contra una población civil en ejecución de la política de un Estado o de una organización) y de los crímenes de guerra (vinculación con la existencia de un conflicto armado de carácter interno o internacional) podría ofrecer, en principio, una buena oportunidad para superar dichas limitaciones a través de la presentación de la prueba relativa a estos, lo cierto es que, como afirma Minow, el tipo de prueba documental o pericial que se practica en los procesos penales nacionales e internacionales no aporta nada nuevo a la información que se puede obtener en el ámbito de las comisiones de la verdad. ${ }^{166}$

En consecuencia, a la hora de buscar una verdad histórico-contextual más amplia, los procesos penales servirán a lo sumo de "paliativo" en aquellos casos en los que o bien no se creen comisiones de la verdad - como fue el caso de la Ley 975 de Justicia y Paz en Colombia (2005)_, o bien estas se resistan a desarrollar con la debida profundidad el tipo de análisis histórico-contextual para el que se encuentran mejor equipadas. Además, al menos en lo que se refiere al papel jugado en los crímenes de ius cogens por los Estados más influyentes de la sociedad internacional, es cuestionable la aportación que pueda esperarse desde la aplicación del derecho internacional penal por los tribunales internacionales penales a la luz de las preocupaciones expuestas por Zolo, ${ }^{167}$ Margalit ${ }^{168}$ y Jeangène Vilmer ${ }^{169}$ sobre los riesgos de su instrumentalización por dichos Estados.

\footnotetext{
166 Minow, “Making history”, 208-211.

${ }^{167}$ Zolo, La justicia.

${ }^{168}$ Margalit, On compromise.

${ }^{169}$ Jeangène Vilmer, Pas de paix.
} 


\section{Conclusión}

Ante el marco normativo vigente en el derecho internacional para los crímenes de ius cogens, el debate sobre procesos penales y comisiones de la verdad ha de tener una naturaleza de lege ferenda, como paso previo a la revisión de dicho marco normativo, para tratar de armonizarlo en la medida de lo posible con las exigencias derivadas de la necesidad de articular procesos políticos de transición que permitan superar las situaciones en que se cometen este tipo de delitos.

$\mathrm{El}$ análisis realizado muestra que tanto los procesos penales como las comisiones de la verdad presentan fortalezas y debilidades, y que no se trata, por tanto, de elegir entre ellos, sino de entender su verdadero alcance y limitaciones, y utilizarlos conjuntamente, coordinando con cuidado los objetivos, actuaciones y procedimientos para el intercambio de información entre ambos mecanismos. De esta manera, se favorece la restauración de la dignidad de las víctimas, se contribuye a evitar el incumplimiento del régimen jurídico internacional vigente de los crímenes de ius cogens y se fomenta la complementariedad entre una verdad judicial que ofrezca mayores garantías sobre las responsabilidades individuales, y una verdad histórica y contextual más amplia sobre las causas de la violencia.

Sin embargo, el presente trabajo muestra también que el recurso conjunto a los procesos penales y las comisiones de la verdad no permite siempre disipar las resistencias generadas en influyentes actores sociales, políticos y económicos de los procesos de transición (en particular, los máximos dirigentes de las partes implicadas en crímenes de ius cogens), que ven en el análisis del pasado una considerable amenaza a su posición. Así mismo, tampoco permite, necesariamente, superar los problemas relativos al inadecuado tratamiento en los mecanismos de recuperación de la verdad de: 1) la injusticia estructural que genera la degradación social en la que se cometen los crímenes de ius cogens; 2) los efectos socioeconómicos de la violencia y su "legalización" a través de los modelos transicionales; y 3) el papel jugado por los Estados más influyentes en la sociedad internacional.

A los efectos de limitar el alcance de estos problemas en la situación en Colombia, son varios los aspectos que convendría revisar de la regulación finalmente recogida en el acuerdo del 12 de noviembre del 2016 (aprobado el $1^{\circ}$ de diciembre por las dos cámaras parlamentarias), con respecto a la CEVCNR y la JEP. En primer lugar, se debería extender el mandato de la 
primera más allá de los tres años recogidos en el acuerdo. En segundo lugar, se deberían coordinar de manera más clara los objetivos, actuaciones y procedimientos de intercambio de información entre ambos mecanismos, y especificar, en este marco, si los archivos creados por la Comisión estarán a disposición de la JEP al término de sus actividades. Finalmente, se deberían revisar los diversos aspectos analizados en la sección 2 de este capítulo que constituyen un obstáculo muy importante para que se pueda transmitir de manera efectiva el mensaje de que no se tolerará la impunidad de los máximos responsables de genocidio, crímenes de lesa humanidad y crímenes de guerra cometidos por los distintos actores en el conflicto armado, en cuanto que es considerado, mayoritariamente, el fin central del actual régimen jurídico internacional de los crímenes de ius cogens.

\section{Bibliografía}

"A 40 años del golpe de Estado en Argentina, los juicios en cifras". El País, 24 de marzo del 2016, http://internacional.elpais.com/internacional/2016/03/24/argentina/1458840802_572867.html

"Colombia: la oposición rechaza el nuevo acuerdo del paz y pide una reunión con las FARC". Clarín, 22 de noviembre del 2016, http://www.clarin.com/mundo/Colombia-oposicion-acuerdo-reunion-FARC_0_1691830848.html

"Hubo 114.266 desaparecidos entre 1936 y 1951 según el auto del juez Garzón”. Nueva España, octubre 2008, http://www.lne.es/espana/2008/10/16/espana-hubo-114266-desaparecidos-1936-1951-auto-juez-garzon/686147.html

"Más de cinco mil agentes del Estado son investigados por falsos positivos: Fiscalía”. El País, 25 de junio del 2015, http://www.elpais.com.co/ elpais/judicial/noticias/cinco-mil-agentes-estado-son-investigadospor-falsos-positivos-fiscalia

Acosta, Diego, René Buchan y Russelly Ureña. "Beyond justice, beyond peace? Colombia, the interests of justice, and the limits of international criminal law". Criminal Law Forum 26, n. 2 (2015): 291-318.

Acto Legislativo 01 del 2012, 31 de julio. Por medio del cual se establecen instrumentos jurídicos de justicia transicional en el marco del artículo 22 de la Constitución Política y se dictan otras medidas. 
Aguilar, Paloma. "Justice, politics and memory in the Spanish transition", en The politics of memory: transitional justice in democratizing societies, editado por Alexandra Barahona de Brito y Carmen González Enríquez, 92-118. Oxford: Oxford University Press, 2001.

Akhavan, Payam. "The Yugoslav Tribunal at a crossroads: the Dayton Peace Agreement and beyond”. Human Rights Quarterly 18 (1996): 501-510. Balkan Transitional Justice. Over 500 Indicted for War Crimes in Bosnia, 7 de octubre del 2015, http://www.balkaninsight.com/en/article/state-prosecution-500-accusations-of-war-crimes-235-indictments-10-06-2015

Bassiouni, M. Cherif. “Estudio histórico: 1914-1998”, en CPI ratificación y legislación nacional de actuación, 1-44. Toulouse: Nouvelles Études Pénales, Association Internationale de Droit Pénal, Érès, 1999.

Boraine, Alex. A country unmasked: inside South Africa's truth and reconciliation commission. Nueva York: Oxford University Press, 2000.

Branch, Adam. "The role of ICC in Northern Uganda", en Peacemaking: from practice to theory, editado por Susan Allen Nan, Zachariah Cherian Mampilly y Andrea Bartoli, Vol. 1, 122-134, 2011.

Burgess, Patrick. "A new approach to Restorative Justice-East Timor's Community Reconciliation Process", en Transitional justice in the Twenty-First Century: beyond truth versus justice, editado por Roht Arriaza y Mariezurrena, 176-196. Cambridge: Cambdrige University Press, 2006.

Casey, Nicholas. "El gobierno de Colombia aprueba nuevo acuerdo de paz para las FARc". New York Times. Edición América, 1 de diciembre del 2016, http://www.nytimes.com/es/2016/12/01/el-congreso-decolombia-aprueba-nuevo-acuerdo-de-paz-con-las-farc/

Centro de Memoria Histórica. ;Basta Ya!: Colombia Memorias de Guerra y Dignidad, coordinado por Gonzalo Sánchez, 2013, http://www. centrodememoriahistorica.gov.co/micrositios/informeGeneral/descargas.html

Chapman, Audrey R. y Patrick Ball. "Levels of truth: macro-truth and the TRC", en Truth and reconciliation commission in South Africa: did the TRC deliver?, editado por Audrey R. Chapman y Hugo van der Merwe, 158-167. Filadelfia: University of Pennsylvania Press, 2008. 
Comisión de Derechos Humanos (Naciones Unidas). Report on the consequences of impunity, un Doc. E/CN.4/1990/13, 1990.

Comisión Histórica del Conflicto y sus Víctimas. Contribución al entendimiento del conflicto armado en Colombia, febrero del 2015.

Comisión Nacional Chilena de Verdad y Reconciliación. Report of the Chilean National Commission on Truth and Reconciliation, 1991, http://www. usip.org/sites/default/files/resources/collections/truth_commissions/ Chile90-Report/Chile90-Report.pdf

Comisión Nacional sobre la Desaparición de Personas (Conadep). Reporte de la Comisión Nacional sobre la Desaparición de 1984, septiembre de 1984, http://web.archive.org/web/20031004074316/nuncamas.org/ english/library/nevagain/nevagain_001.htm

Comissao de Acolhimento, Verdade e Reconciliacao de Timor-Leste, Chega! The Report of the Commission for the Reception, Truth and Reconciliation for Timor-Leste (CAVR), 2005, http://www.cavr-timorleste.org/ en/chegaReport.htm

Consejo de Seguridad de las Naciones Unidas. Resolución 1503 sobre el Tribunal Internacional Penal para la ex Yugoslavia (TIPY) y el Tribunal Internacional Penal para Ruanda, un. Doc. S/RES/1503, 28 de agosto del 2003.

Consejo de Seguridad de las Naciones Unidas. Resolución 1534 sobre el Tribunal Internacional Penal para la ex Yugoslavia y el Tribunal Internacional Penal para Ruanda, un. Doc. S/RES/1534, 26 de marzo del 2004, http://www.un.org/en/ga/search/view_doc.asp?symbol=S/ RES/1534(2004)

Consultative Group on the Past. Report of the Consultative Group on the Past. Belfast, 2009.

Corte Especial para Sierra Leona. Eleventh and final report of the President of the Special Court for Sierra Leone, 31 de diciembre del 2013, http:// www.rscsl.org/Documents/AnRpt11.pdf

Corte Penal Internacional (CPI). https://www.icc-cpi.int/

Cryer, Robert. Prosecuting international crimes: selectivity and the international criminal law regime. Cambridge: Cambridge University Press, 2005.

Cueva, Eduardo. “The Peruvian Truth and Reconciliation Commission and the challenge of impunity", en Transitional justice in the Twenty-First 
Century: Beyond truth versus justice, editado por Roht Arriaza y Mariezurrena, 85-89. Cambridge: Cambdrige University Press, 2006. D'Ascoli, Silvia. Sentencing in international criminal law: the approach of the two UN ad hoc tribunals and future perspectives for the International Criminal Court. Oxford: Hart Publishing Ltd., 2011.

Damaška, Mirjan. "What is the point of international criminal justice?". Chicago-Kent Law Review 83 (2008): 329-331.

De Greiff, Pablo. Informe del relator especial sobre la promoción de la verdad, la justicia, la reparación y las garantias de no repetición, 22 de julio del 2014, A/HRC/27/56/Add.1, 2014.

Del Ponte, Carla. La Traque, les Criminels de guerre et Moi: autobiografie. París: Edition H. d'Ormesson, 2009.

Douglas, Lawrence, "Was damals Recht war... Nulla Poena and the Prosecution of Crimes against Humanity in Occupied Germany", en Ius Post Bellum and Transitional Justice, editado por Larry May y Elizabeth Edenberg, 44-73. Cambridge: Cambridge University Press, 2015.

Drumbl, Mark. "Collective violence and individual punishment: the criminality of mass atrocity". Northwestern University Law Review 99 (2005): 101-179.

Duff, Anthony. "Can we punish the perpetrators of atrocities?", en The religious in responses to mass atrocity, editado por Thomas Brudman y Thomas Chushman, 85-100. Cambridge: Cambridge University Press, 2008.

Dyzenhaus, David. Judging the judges: judging ourselves. Oxford: Hart $\mathrm{Pu}$ blishing, 1998.

Eames, Robin y Denis Bradley. "Eames: the speech in full”. Belfast Telegraph, 29 de mayo del 2008, http://www.belfasttelegraph.co.uk/ news/eames-the-speech-in-full-28390171.html

Eiroa, Pablo. Políticas del castigo y derecho internacional para una concepción minimalista de la justicia penal. Buenos Aires: Ad Hoc, 2009.

Eisikovits, Nir y Jack Volpe Rotondi. "Forgetting after the war: a qualified defense", en Theorizing transitional justice, editado por Claudio Corradetti, Nir Eisikovits y Jack Volpe Rotondi, 29-37. Barrington: Ashgate, 2014.

FARC-EP. Comunicado del 6 de agosto del 2013, Sobre un Marco Jurídico fuera de contexto (Primera reflexión). La Habana, Cuba. 
FARC-EP. Jurisdicción especial para la paz, amnistia e indulto. Cartilla para prisioneras y prisioneros politicos, http://www.farc-ep.co/pdf/CartillaJurisdiccion-Especial-para-la-Paz-para-Prisioneras-y-PrisionerosPoliticos.pdf

Farran, Carlos y Samuel Amago. Unearthing Franco's legacy: mass graves and the recovery of historical memory in Spain. París: University of Notre Dame Press, 2010.

Fiscalía de la Corte Penal Internacional. Draft policy paper on case selection and prioritisation, 29 de abril del 2016, https://www.icc-cpi.int// Pages/item.aspx? name=Draft-Policy-Paper-on-Case-Selectionand-Prioritisation

Fiscalía de la Corte Penal Internacional. Policy Paper on Case Selection and Prioritisaton, 15 de septiembre de 2016, https://www.icc-cpi. int//Pages/item.aspx?name=policy-paper-on-case-selection-andprioritisation

Fiscalía de la Corte Penal Internacional. Policy Paper on Preliminary Examinations, 1 de noviembre del 2013, https://www.icc-cpi.int//Pages/ item.aspx? name $=$ otp - policy-pe-11_2013

Fiscalía de la Corte Penal Internacional. Policy Paper on the Interests of Justice, 1 de septiembre del 2007, https://www.icc-cpi.int//Pages/item. aspx? name $=$ otp-policy-int-just

Fiscalía de la Corte Penal Internacional. Policy Paper, 1 de septiembre del 2003, https://www.icc-cpi.int//Pages/item.aspx?name=otp-policypaper-2003

Fiscalía de la Corte Penal Internacional. "Situación en Colombia, Reporte Intermedio", 12 de noviembre del 2012, http://www.icc-cpi.int/ en_menus/icc/structure \%20of \%20the \%20court/office \%20of\%20 the \%20prosecutor/comm \%20and \%20ref/colombia/Pages/Situation-in-Colombia-Interim-Report.aspx

Freeman, Mark. Truth commissions and procedural fairness. Cambridge: Cambridge University Press, 2006.

Gil Gil, Alicia. "El tratamiento jurídico de los crímenes cometidos en el conflicto armado colombiano. La problemática jurídica en el marco de la dicotomía paz-justicia”, en Semana Iberoamericana, editado por Sonia Alda Mejías y Susana de Sousa Ferreira, 21-52. Madrid: Instituto Universitario Gutiérrez Mellado, 2017. 
Gobierno de Colombia y FARC-EP. Comunicado conjunto \# 60 sobre el Acuerdo de creación de una Jurisdicción Especial para la Paz La Habana, Cuba, 23 de septiembre del 2015.

Guembe, María José y Helena Olea. "No justice, no peace: discussion of a legal framework regarding the demobilization of non-state armed groups in Colombia", en Transitional justice in the Twenty-First Century: beyond truth versus justice, coordinado por Roth Arriaza, y Mariezcurrena. Cambridge: Cambridge University Press, 2006.

Hafner, Gerhard, Kristen Boon, Anne Rübesame y Jonathan Huston. "A response to the American view as presented by Ruth Wedgwood". European Journal of International Law 10 (1999): 108-123.

Hamber, Brandon. "Remembering to forget: issues to consider when establishing structures for dealing with the past", en Past imperfect: dealing with the past in Northern Ireland and South Africa, editado por Brandon Hamber, 56-78. Londonberry: Incore/University of Ulster, 1998.

Hayner, Priscilla. Unspeakable truths: confronting state terror and atrocity. Nueva York: Routedge, 2001.

Healing Through Remembering. Making peace with the past: options for truth recovery regarding the conflict in and about Northern Ireland. Belfast, octubre del 2006.

Horowitz, Sigall. "Transitional criminal justice in Sierra Leone", en Transitional justice in the Twenty-First Century: beyond truth versus justice, editado por Roht Arriaza y Mariezurrena, 43-69. Cambridge: Cambdrige University Press, 2006.

Human Rights Watch. Acuerdo con las FARC es jaque mate para la justicia colombiana,27 de marzo del 2016, http://www.eltiempo.com/mundo/ ee-uu-y-canada/human-right-watch-critica-acuerdo-con-las-farcpor-falsos-positivos/16547551

Human Rights Watch. "Colombia: Los derechos de las víctimas deben ser centrales en las negociaciones de paz - La paz sin justicia no es sostenible", 16 de octubre de 2012, https://www.hrw.org/es/ news/2012/10/16/colombia-los-derechos-de-las-victimas-debenser-centrales-en-las-negociaciones-de

Human Rights Watch. Carta al presidente Santos sobre el nuevo acuerdo de paz con las FARC, 23 de noviembre del 2016, https://www.hrw.org/ 
es/news/2016/11/23/carta-al-presidente-santos-sobre-el-nuevoacuerdo-de-paz-con-las-farc

Ibañez Najar,Jorge. Justicia de transición y las comisiones de la verdad. Madrid: Berg Institute, 2014.

Jeangène Vilmer, Jean-Baptiste. Pas de paix sans justice? Le dilemme de la paix et de la justice en sortie de conflicto armé. París: SciencesPo Les Presses, 2011.

Jolly, Rosemary. "Desiring good(s) in the face of marginalized subjects: South Africa's Truth and Reconciliation Commission in a global context". South Atlantic Quaterly 100, n. 3 (2001): 693-715.

Kai, Ambos. "Crímenes de lesa humanidad y la Corte Penal Internacional", en Cuadernos de derecho penal, 95-140. Bogotá: Universidad Sergio Arboleda, 2013.

Lawther, Cheryl. "Peace without the past? Truth, transition and the Northern Ireland case", en Theorizing transitional justice, editado por Claudio Corradetti, Nir Eisikovits y Jack Volpe Rotondi, 29-41. Surrey: Ashgate.

Lawther, Cheryl. Truth, denial and transition: Northern Ireland and the contested past. Londres: Routledge, 2014.

Leebaw, Bronwyn. "The irreconcilable goals of transitional justice”. Human Rights Quaterly 30 (2008): 95-118.

Leman-Langlois, Stephane y Clifford Shearing. "Transition, forgiveness and citizenship: the TRC and the social construction of forgiveness", en Justice and reconciliation in post-apartheid South Africa, editado por Francois du Bois y Antje du Bois-Pedain, 211-222. Cambridge: Cambridge University Press, 2008.

Ley 975 del 2005, 25 de julio. Por la cual se dictan disposiciones para la reincorporación de miembros de grupos armados organizados al margen de la ley, que contribuyan de manera efectiva a la consecución de la paz nacional y se dictan otras disposiciones para acuerdos humanitarios. Diario Oficial 45.980.

Luban, David. "After the honeymoon: reflections on the current state of international criminal justice". J Int Criminal Justice 11, n. ${ }^{\circ} 3$ (2013): 505-515.

Lundy, Patricia. "Commissioning the past in Northern Ireland". Review of International Affairs 60, n. ${ }^{\circ} 1138-1139$ (2010): 101-133. 
Lutz, Ellen y Caitlin Reiger (eds.). Prosecuting heads of states. Cambridge: Cambridge University Press, 2009.

Lutz, Ellen. "Transitional justice: lessons learned and the road ahead", en Transitional justice in the Twenty-First Century: beyond truth versus justice, editado por Roht Arriaza y Mariezurrena, 325-341. Cambridge: Cambdrige University Press, 2006.

Maculan, Elena y Daniel Pastor. El derecho a la verdad y su realización por medio del proceso penal. Buenos Aires: Hammurabi, 2013.

Majima, Shunzo. "Just military occupation? A case study of the American occupation in Japan", en Ius Post Bellum and Transitional Justice, editado por Larry May y Elizabeth Edenberg, 36-42. Cambridge: Cambridge University Press, 2015.

Malarino, Ezequiel."Transición, derecho penal y amnistía. Reflexiones sobre la utilización del derecho penal en procesos de transición”. Revista de Derecho Penal y Criminología, n. 9 (2003): 205-222.

Mallinder, Louise. Amnesty human rights and political transitions: bridging the peace and justice divide. Oxford: Hart, 2008.

Mamdani, Mahmood. "Reconciliation without justice". South African Review of Books 46 (1996): 3-5.

Margalit, Avishai. On compromise and rotten compromises. Princeton: Princeton University Press, 2010.

Mecanismo Residual de la Corte Especial para Sierra Leona. Sección de casos, http://www.rscsl.org/

Mesa de Conversaciones. "Acuerdo general para la terminación del conflicto y la construcción de una paz estable y duradera". La Habana, 26 de agosto del 2012, https://www.mesadeconversaciones.com.co/sites/ default/files/AcuerdoGeneralTerminacionConflicto.pdf

Mesa de Conversaciones. "Acuerdo final para la terminación del conflicto de una paz estable y duradera", 26 de septiembre del 2016, https:// www.mesadeconversaciones.com.co/sites/default/files/24_08_201 6acuerdofinalfinalfinal-1472094587.pdf

Mesa de Conversaciones. "Acuerdo final para la terminación del conflicto de una paz estable y duradera", 12 de noviembre del 2016, https://www. mesadeconversaciones.com.co/sites/default/files/12-1479102292.111479102292.2016nuevoacuerdofinal-1479102292.pdf 
Minow, Martha. "Making history or making peace: when prosecutions should give way to truth commissions and peace negotiations", en Law in Transition. Human Rights, Development and Transitional Justice, editado por Ruth Buchanan y Peer Zumbasen, 203-214. Oxford: Hart Publishing, 2014.

Miranda, Boris. "Las razones por las que el "No" se impuso en el plebiscito en Colombia”. BBC Mundo, 3 de octubre del 2016, http://www.bbc. com/mundo/noticias-america-latina-37537629

Moreno Ocampo, Luis. "Pursuing human dignity, facing history and ourselves”, Conferencia dada en Harvard Law School, Boston, 4 de noviembre del 2005.

Nagy, Rosemary. “Transitional justice as global project: critical reflexions”, en Law in transition. Human rights, development and transitional justice, editado por Ruth Buchanan y Peer Zumbasen, 215-226. Oxford: Hart Publishing, 2014.

Nesbit, Michael. "Lessons from the Sam Hinga Norman Decision of the Special Court for Sierra Leone: how trials and truth commissions can co-exist". German Law Journal 8, n. 10 (2007): 977-1014.

Nino, Carlos. "El castigo como una respuesta a las violaciones de Derechos Humanos. Una perspectiva global", traducido por el Instituto de Derechos Humanos de la Universidad de Chile, en Radical evil on trial, 3-40. New Haven y Londres: Yale University Press, 1996.

Northern Ireland Affairs Committee. Ways of dealing with Northern Ireland's past: Interim Report-Victims and Survivors. Londres: The Stationary Office, 2005.

O'Connor, Gerhard. “The pursuit of justice and accountability: why the United States should support the establishment of an international criminal court”. Hofstra Law Review 27 (1999): 927-977.

Olasolo, Héctor. Derecho internacional penal, justicia transicional y delitos transnacionales. Valencia: Tirant lo Blanch \& Instituto Iberoamericano de La Haya para la Paz, los Derechos Humanos y la Justicia Internacional, 2017.

Olasolo, Héctor. "El principio 'no hay paz sin justicia' como principio rector del fenómeno de la lesa humanidad por el Derecho internacional y su impacto en los procesos de paz: particular atención al caso colombiano", en Introducción al derecho internacional penal, 53-80. 
Valencia: Tirant lo Blanch, Editorial de la Universidad del Rosario \& IнH, 2014.

Olasolo, Héctor. "Los exámenes preliminares de la Corte Penal Internacional en América Latina: el caso colombiano y su impacto sobre futuras negociaciones de paz en la región". Anuario de Derechos Humanos Universidad de Chile 10 (2014): 35-56.

Olasolo, Héctor. "Dignidad humana, derecho internacional penal y justicia transicional”. Revista de Estudios Socio-Jurídicos 16 (2014): 7-22.

Olasolo, Héctor. "La inseguridad jurídica de los acuerdos de paz a la luz del régimen jurídico internacional de los crímenes de ius cogens y la justicia de transición”. Política Criminal 12, n. ${ }^{\circ} 23$ (2017): 78-102.

Olasolo, Héctor, Andrea Mateus y Andrés Contreras. "La naturaleza imperativa del principio 'no hay paz sin justicia' respecto a los máximos responsables del fenómeno de la lesa humanidad y sus consecuencias para el ámbito de actuación de la llamada 'justicia de transición”. Boletin Mexicano de Derecho Comparado, n. ${ }^{\circ} 145$ (2016): 136-168.

Olasolo, Héctor, Joel Ramírez y Antonio Varón. "Have the Colombian Government and the FARC learnt the lessons of the South African Truth and Reconciliation Commission as to the need to clearly define and prioritize the main goals of the truth commission?". Harvard Human Rights Online Journal 58 (2017) (en prensa).

Registro Único de Víctimas del Gobierno de Colombia, http://rni.unidadvictimas.gov.co/RUV

Rehn, Elisabeth y Ellen Sirleaf. Women, war and peace: The independent expert's assessment on the impact of armed conflict on women's role in peace building. Nueva York: undP, 2002.

Roht-Arriaza, Naomi. "The new landscape of transitional justice”, en Transitional justice in the Twenty-First Century: beyond truth versus justice, editado por Roht Arriaza y Mariezurrena, 1-16. Cambridge: Cambdrige University Press, 2006.

Roht-Arriaza, Naomi. "Punishment, redress and pardon: Theoretical and psychological approaches", en International law and practice, editado por Naomi Roht-Arriaza, 13-23. Nueva York: Oxford University Press, 1995.

Rolston, Bill. "Assembling the Jigsaw: truth, justice and transition in the North of Ireland". Race and Class 44 (2002). 
Salas Extraordinarias de las Cortes de Camboya. The Court Report of the Extraordinary Chambers in the Courts of Cambodia, n. ${ }^{\circ}$ 94, febrero del 2016, http://www.ecc.gov.kh/sites/default/files/publications/ Court\%20Report\%20on\%20February\%202016.pdf

Schabas, William. "The Sierra Leone Truth and Reconciliation Commission”, en Transitional justice in the Twenty-First Century: beyond truth versus justice, editado por Roht Arriaza y Mariezurrena, 21-42. Cambridge: Cambdrige University Press, 2006.

Scharf, Michael. "The amnesty exception to the jurisdiction of the International Criminal Court". Cornell International Law Journal 32 (1999): 507-527.

Sierra Leone Truth and Reconciliation Commission. Witness to truth: final report of the TRC, http://www.sierraleonetrc.org/index.php/viewthe-final-report

Stahn, Carsten. "Between faith and facts: by what standards should we assess international criminal justice?”. Leiden Journal of International Law 25 (2012): 251-282.

Tamarit, Josep María. "Los límites de la justicia transicional penal: la experiencia del caso español”. Politica Criminal 7, n. ${ }^{\circ} 13$ (julio, 2012): 74-93.

Tejan-Cole, Abdul. "The complementarity and conflicting relationship between the Special Court for Sierra Leone and the Truth and Reconciliation Commission". Yale Human Rights and Development Law Journal 6 (2003): 139-159.

Tirrell, Lynne. "Transitional justice in post-conflict rwanda: an integrative approach", en Theorizing transitional justice, editado por Claudio Corradetti, Nir Eisikovits y Jack Volpe Rotondi, 237-250. Surrey: Ashgate, 2014.

Tribunal de Núremberg. Judgment of the International Military Tribunal for the Trial of German Major War Criminals, 30 de septiembre y 1 de octubre de 1946, http://avalon.law.yale.edu/imt/judgen.asp

Tribunal Internacional Penal para la Ex Yugoslavia. Assessment and report of Judge Theodor Meron, President of the International Tribunal for the Former Yugoslavia, provided to the Security Council pursuant to paragraph 6 of Security Council resolution 1534 (2004) covering the period from 16 May 2015 to 16 November 2015, 16 de noviembre del 2015, 
http://www.securitycouncilreport.org/atf/cf/ \%7 B65BFCF9B-6D27-4E9C-8CD3-CF6E4FF96FF9\%7D/s_2015_874. pdf

Tribunal Internacional Penal para Ruanda. Report on the completion of the Mandate of the International Criminal Tribunal for Rwanda as at 15 November 2015, 17 de noviembre del 2015, http://www.securitycouncilreport.org/atf/cf/\%7B65BFCF9B-6D27-4E9C-8CD3CF6E4FF96FF9\%7D/s_2015_884.pdf

Uprimny Yepes, Rodrigo, Luz Marina Sánchez Duque y Nelson Camilo Sánchez León.Justicia para la paz. Crimenes atroces, derecho a la justicia y paz negociada. Bogotá: Centro de Estudios de Derecho, Justicia y Sociedad, Dejusticia, 2014.

Vandeginste, Stef. "Bypassing the prohibition of amnesty for human rights crimes under international law: lessons learned from the Burundi Peace Process". Netherlands Quarterly Of Human Rights 29, n. 2 (2011): 189-211.

Wiebelhauss-Brahm, Eric. Truth commissions and transitional societies: the impact on human rights and democracy. Oxon y Nueva York: Routledge, 2010.

Working Group on Enforced or Involuntary Disapperances. Report of the Working Group on Enforced or Involuntary Disappearances: Mission to Spain, un. Doc., A/HRC/27/49/Add., 2 de julio del 2014, http:// www.ohchr.org/EN/Countries/ENACARegion/Pages/ESIndex.aspx Zolo, Danilo. La justicia de los vencedores: de Núremberg a Bagdag. Madrid: Ed. Trotta, 2007. 


\title{
Derecho de la inversión extranjera y acuerdos de paz: tensiones y soluciones
}

\author{
René Urueña* \\ Enrique Prieto-Rios ${ }^{* * *}$
}

\section{Introducción}

Desde el inicio de las conversaciones de paz con las Farc, el Gobierno colombiano ha querido enfatizar que el "modelo económico" del país no está sujeto a negociación. ${ }^{1}$ En términos generales, la experiencia de Venezuela y el impresionante fracaso de sus medidas económicas alimentaron esa posición y la legitimaron. Sea lo que fuere que saliera de la conversación debería integrarse en el marco de una economía de libre mercado, en la que se respetaría la propiedad privada y, sobre todo, las inversiones extranjeras. $^{2}$

* Abogado, LL. M., Ph. D. (eximia cum laude). Profesor asociado, director del área de Derecho Internacional y del Centro de Investigaciones Sociojurídicas (cijus) de la Facultad de Derecho de la Universidad de los Andes. Presidente de la Academia Colombiana de Derecho Internacional (ACCOLDI). Correo electrónico: rf.uruena21@uniandes.edu.co

** Abogado, ma Derecho Internacional y Ph. D. en proceso de grado (tesis y defensa aprobada mayo 2017, fecha de grado noviembre 2017). Profesor principal, investigador del Grupo de Investigación en Derecho Internacional de la Facultad de Jurisprudencia de la Universidad del Rosario. Correo electrónico: enrique.prieto@urosario.edu.co

1 “Aquí no venimos a negociar el modelo de desarrollo del país': Humberto de La Calle", El Pais, 18 de octubre del 2012.

2 Rubido Bieito, “Juan Manuel Santos: 'Gestionar la paz es más difícil que hacer la guerra”, El País, 6 de mayo del 2016. 
A pesar de que el Acuerdo de Paz entre las farc y el Gobierno no pone en riesgo el modelo económico capitalista, algo que es evidente es que hizo promesas que lo ponen en una trayectoria de colisión con las obligaciones de Colombia con sus inversionistas extranjeros, protegidas por una red de tratados bilaterales de inversión - Тв - - tratados de libre comercio - TLC - En este sentido, este texto argumenta que es probable que surjan estos conflictos, particularmente en relación con las inversiones extranjeras en la minería y la agroindustria, y hace recomendaciones sobre la manera en que el Gobierno colombiano y los tribunales de arbitraje de inversión podrían abordarlas: el primero, emitiendo la señal en el sentido de que el Acuerdo de Paz es necesario para proteger la seguridad esencial de Colombia; y los segundos, adoptando una posición deferente, que reconozca la dimensión humanitaria de su responsabilidad como verdaderas autoridades judiciales internacionales.

\section{Arbitraje como mecanismo de solución de controversias entre inversionistas extranjeros y Estados}

Desde el siglo xx han existido tratados que han generado un cierto grado de protección a la propiedad de extranjeros en el exterior, como sucedió con los tratados de amistad, comercio y navegación - TACN- A pesar de estos primeros avances, solamente fue hasta la segunda mitad del siglo $\mathrm{xx}$, como respuesta a los procesos de descolonización, que se consolidó una estructura legal internacional dirigida específicamente a proteger la propiedad privada y, en general, los intereses económicos de los inversionistas, siendo el primer тві moderno aquel firmado en 1959 entre la República Alemana y Pakistán. ${ }^{3}$

A pesar de lo anterior, los тві solo tomaron fuerza a nivel mundial consolidándose como una red mundial de tratados a partir de los ochenta, debido a la expansión de una ideología neoliberal, la imposición de ciertas políticas por parte de instituciones financieras internacionales que favorecían la creación de un ambiente amigable a los inversionistas extranjeros, la privatización de empresas estatales y la hegemonización del discurso

3 Véase Andrei Gómez Suárez, Nicolás M. Perrone, Enrique Prieto-Rios, "Foreign investors and the Colombian Peace Process". International Community Law Review 18, n. 3-4 (2016): 223. 
desarrollista, donde la inversión extranjera es presentada como parte fundamental en el camino al desarrollo. ${ }^{4}$

Ahora bien, la relevancia geopolítica de este sistema solo se evidenció en los últimos 17 años ${ }^{5}$ debido al incremento en el número de demandas presentadas por inversionistas extranjeros en contra de países receptores de inversión extranjera. Así, por ejemplo, entre el periodo comprendido entre 1965 y el 2000 solo se presentaron 66 demandas ante el Centro Internacional de Arreglo de Controversias Relativas a la Inversión - CIADI-, comparado con 300 nuevas disputas entre el 2000 y el 2011. ${ }^{6}$ Lo anterior permitió evidenciar las limitaciones que el sistema impone a la capacidad regulatoria de los Estados, la facilidad del inversionista extranjero de no acudir a cortes locales y usar directamente el arbitraje de inversión como un mecanismo de solución de controversias, y el hecho de que varios sectores estratégicos para la economía de los países, como la infraestructura y los servicios públicos, fueron colocados bajo la lupa del derecho de inversiones. ${ }^{7}$

En términos generales, los тв otorgan protección a los inversionistas en cuatro áreas: 1) acceso a mercados, 2) tratamiento del inversionista, 3) expropiación, y 4) solución de disputas. La garantía de acceso a mercados le asegura al inversionista extranjero la entrada y establecimiento en el mercado del Estado receptor. Tal garantía, a su vez, sería irrelevante si el inversionista pudiera ser discriminado por el Estado receptor de la inversión. En consecuencia, una segunda protección otorgada a los inversionistas hace referencia al trato que deberán recibir de los Estados receptores. Tales garantías de tratamiento se subdividen, a su vez, en dos: garantía de nodiscriminación (en especial, trato de nación más favorecida y trato nacional) y estándares mínimos de tratamiento (en especial, trato justo y equitativo, y el estándar de "protección y seguridad").

\footnotetext{
4 Véase Enrique Prieto-Rios, "Neoliberal market rationality: the driver of International Investment Law”. Birkbeck Law Review 3, n. ${ }^{\circ} 1$ (2015): 55.

5 Véase José E. Álvarez, The Public International Law Regime GoVéasening International Investment, Recueil Des Cours, 2009 (La Haya: Hague Academy of International Law, 2011).

6 Rahim Baghban y Mahin Sajedi, "An introduction to international investment and investment disputes”. Savant Journal of Social Sciences and Humanity 1, n. ${ }^{\circ}$ (2015): 7.

7 José E. Álvarez y Kathryn Khamsi, "Argentine crisis and foreign investors: a glimpse into the heart of the investment regime", en The Yearbook on International Investment Law and Policy, editado por Karl P. Sauvant y Lisa Sachs (Nueva York: Oxford UniVéasesity Press, 2008).
} 
Un tercer grupo de garantías, íntimamente relacionadas con las anteriores, hace referencia a la expropiación. Los тві ofrecen protección respecto a dos tipos de expropiación: la directa, que implica la transferencia al Estado de la propiedad del activo expropiado, y la indirecta, en la cual no hay transferencia formal de propiedad. En esta última, el Estado receptor adopta medidas que interfieren en el giro ordinario de la inversión o con el aprovechamiento de los beneficios derivados de forma tal que los derechos de propiedad relacionados con ella devienen, en la práctica, sin valor.

Es importante anotar que los тв no prohíben ninguno de estos tipos de expropiación. Sin embargo, solo la permiten si se cumplen cuatro condiciones incluidas en la mayoría de tratados: objetivo público legítimo de la medida expropiatoria, no discriminación, debido proceso y justa compensación. Estos requisitos son acumulativos, al menos, en principio. En consecuencia, es viable argumentar que la medida de un Estado receptor que afecte de manera grave una inversión deberá ser compensada, aun si es tomada con un objetivo público legítimo, de manera no discriminatoria y con sujeción al debido proceso.

Finalmente, el cuarto pilar de los тві define los mecanismos de solución de controversias. Los tratados usualmente reconocen jurisdicción y competencia a dos tipos de tribunales de arbitramento. El primero es el arbitraje Estado-Estado, para solucionar las controversias relativas a la interpretación y aplicación del tratado. Usualmente, estos tribunales son ad hoc, y su funcionamiento y derecho aplicable es muy similar al de los tribunales conformados con ocasión de conflictos soberanos y a los conflictos resueltos en virtud de un comprimis especial por la Corte Internacional de Justicia.

El segundo tipo de mecanismo de solución de disputas es el arbitramento inversionista-Estado. En ejercicio de este, el inversionista está en capacidad de iniciar un trámite arbitral en contra del Estado receptor si considera que las protecciones sustantivas explicadas con anterioridad no han sido respetadas en relación con una inversión específica. Es común que el тві reconozca al inversionista la opción de escoger entre llevar su controversia a los tribunales nacionales o solicitar la conformación de un tribunal internacional de arbitramento inversionista-Estado.

El arbitraje de inversión inversionista-Estado fue diseñado como mecanismo para solucionar las controversias entre los inversionistas y el Estado receptor, retirando el problema del conocimiento de cortes locales. 
En el arbitraje de inversión los países renuncian parcialmente a su soberanía para que no sean las cortes de su país las que decidan el conflicto, sino un tribunal de arbitramento internacional no permanente el que lo haga. ${ }^{8}$

Entre las diferentes razones detrás de sacar del conocimiento de las cortes locales los conflictos entre inversionistas y Estado se encuentra una lógica de superioridad epistémica fundada en el origen colonial del sistema del DIEE, que se estructuró originalmente en un marco de relaciones norte-sur. ${ }^{9}$ Otra razón constantemente presentada para el uso del arbitraje de inversión está relacionada con la búsqueda de la despolitización de la protección de la inversión extranjera, debido a que el uso de la protección diplomática como mecanismo de protección de los derechos de los inversionistas implicaba costos políticos altos en las relaciones bilaterales y multilaterales entre países.

En caso de que el inversionista escoja la alternativa de llevar su controversia ante un tribunal internacional de arbitramento inversionista-Estado, y no ante los tribunales nacionales, la conformación del tribunal estará guiada por alguno de los tres principales grupos de normas procedimentales para la conformación y el funcionamiento del tribunal.

El primero son las normas del ciAdi previstas/consagradas en la Convención de Washington de 1965. ciadi es una organización internacional independiente que forma parte del Grupo del Banco Mundial. En caso de que una de las partes del твi no sea parte de la Convención de Washington, el тві se referirá comúnmente al mecanismo adicional de cIADI, que difiere del mecanismo tradicional, entre otros aspectos, en que los laudos adoptados en el primero deben ser objeto exequatur en el Estado receptor, mientras que los del segundo no requieren de tal procedimiento.

El segundo grupo de normas procedimentales corresponde a la Cámara de Comercio Internacional de París (ICC, por sus siglas en inglés). El tercer grupo de procedimientos aplicables son las normas de arbitraje adoptadas

8 Liseth Colen y Andrea Guariso, "What type of foreign direct investment is attracted by bilateral investment treaties?", en Foreign direct investment and human development: the law and economics of international agreements, editado por Oli Véase de Schuteer, Johan Swinnen y Jan Wouters (Londres y Nueva York: Routledge, 2013), 138.

9 Gómez Suárez, Perrone y Prieto-Rios, "Foreign investors". 
en 1976 por la Comisión de las Naciones Unidas para el Derecho Mercantil Internacional (CNUDMi o Uncitral, por sus siglas en inglés).

Una vez constituido el tribunal de arbitramento de conformidad con la regla aplicable, este decidirá, con arreglo a las normas internacionales de los tratados internacionales a los que hace parte el Estado receptor de la inversión (nunca de acuerdo con el derecho nacional del Estado receptor), si el Estado receptor en efecto vulneró los estándares aplicables. De ser ese el caso, el Estado puede ser condenado a indemnizar al inversionista afectado. Sin embargo, el tribunal no tiene la competencia formal de anular decisiones regulatorias adoptadas por el Estado receptor.

\section{Acuerdos de inversión en las negociaciones de paz colombianas}

Las negociaciones de paz en Colombia no presionaron al Gobierno para que cambiara la estrategia de integración a los mercados globales que se persigue en el país desde los años noventa. ${ }^{10}$ Esa estrategia ha implicado centrarse en la inversión extranjera como la clave para el desarrollo económico, utilizando acuerdos comerciales para señalar la estabilidad jurídica a los inversionistas extranjeros y favoreciendo a las industrias extractivas y a la gran agroindustria como sectores clave para el desarrollo. ${ }^{11}$

Colombia tiene en la actualidad 13 acuerdos de inversión vigentes, incluyendo acuerdos con Estados Unidos, la Unión Europea, Canadá, China y el Reino Unido. Durante el periodo de negociaciones en La Habana, el Gobierno de Colombia firmó cuatro nuevos TBi y seis nuevos TLC, que incluyen disposiciones de protección de inversiones. A pesar de que las FARC han manifestado públicamente su oposición a la inversión extranjera y a los тLC у тві en general, ${ }^{12}$ y durante la negociación presentaron una propuesta

10 Véase Enrique Prieto-Rios, “вітs y la Constitución de 1991: internacionalización de la economía dentro de un Estado social de derecho”. Estudios Socio Jurídicos 13, n. 1 (2011): 109.

11 Véase cifras en Portal Oficial de Inversión de Colombia, http://inviertaencolombia.com.co/

12 Véase "FARC piden revisar TLC que afecten soberanía alimentaria de Colombia”, ElTiempo, 24 de enero del 2013, http://www.eltiempo.com/archivo/documento/CMS-12545062 y "FARC envían carta al ministro de agricultura criticando inversión extranjera”, Vanguardia Colombia, 18 de enero del 2013, http://www.vanguardia.com/actualidad/colombia/191996-farc-envian-carta-al-ministrode-agricultura-criticando-inversion-extranj 
para denunciar los acuerdos comerciales y exigir la resolución interna de controversias relacionadas con la inversión extranjera, ${ }^{13}$ no presentaron una resistencia fuerte a la negociación de esos tratados.

En este contexto, el Acuerdo de Paz (versión con los cambios posplebiscito) no hizo referencia expresa a la protección de la inversión extranjera a los тві о тLC. Los autores de este texto desconocen las razones por las cuales este tema no se incluyó en la mesa de negociación; una razón podría ser el desconocimiento que se tiene sobre este sistema de derecho internacional. A pesar de lo anterior, el texto del Acuerdo menciona que el desarrollo rural integral se adelantará en un contexto de globalización y de políticas de inserción en un mercado globalizado. ${ }^{14}$ De igual forma, el texto expresa que en el desarrollo integral del campo se debe promover, entre otros aspectos, la agroindustria, la agricultura comercial de escala y la inversión en el campo con una visión empresarial. ${ }^{15}$

Excepcionalmente, y como respuesta a algunas inquietudes de las FARC en cuanto a la garantía progresiva del derecho a la alimentación, el Acuerdo menciona que se crearán las condiciones e incentivos para la producción y comercialización de los productos locales con el fin de que en la economía campesina, familiar y comunitaria se eviten o minimicen los impactos negativos que supongan la internacionalización de la economía y la liberalización del comercio. ${ }^{16}$ Sin embargo, en los documentos disponibles al público, tanto de minutas como de acuerdos entre las partes, no hay una mención que explícitamente señale que hay una intención de denunciar o renegociar los тLC о тві existentes o dejar de negociar futuros tratados de este tipo.

13 Fuerzas Armadas Revolucionarias de Colombia-Ejército del Pueblo — FARC-EP-, "Desarrollo rural y agrario para la democratización y la paz con justicia social en Colombia: 100 propuestas mínimas", febrero del 2014, http://www.pazfarc-ep.org/pdf/100-PROPUESTAS-MINIMAS1-PUNTO-AGRARIO.pdf

14 Véase Mesa de Conversaciones, "Acuerdo final para la terminación del conflicto y la construcción de una paz estable y duradera”, 12 de noviembre del 2016 https://www.mesadeconversaciones. com.co/sites/default/files/12-1479102292.11-1479102292.2016nuevoacuerdofinal-1479102292.pdf

15 Véase Mesa de Conversaciones, “Acuerdo final”, principios y 4.1.3.6. Componentes de los planes integrales de sustitución.

16 Véase Mesa de Conversaciones, “Acuerdo final”, 1.3.4. Sistema para la garantía progresiva del derecho a la alimentación. 


\section{Una política de tierras contradictoria}

La opción de mantener la paz y la protección de la inversión en vías separadas significa que el Acuerdo posplebiscito se implementará en un espacio regulatorio donde la inversión extranjera está fuertemente protegida, lo cual es particularmente relevante con respecto a la tenencia de la tierra cuando esta se encuentre en manos de un inversionista extranjero. Históricamente, la tierra ha estado en el centro del conflicto armado colombiano; ${ }^{17}$ la violencia y el desplazamiento interno se han relacionado con la tenencia de la tierra, con el 79\% de las personas desplazadas dejando atrás algún tipo de título inmobiliario. ${ }^{18}$

Según el reporte del 2013 ; Basta Ya! producido por el Centro Nacional de Memoria Histórica, 8,3 millones de hectáreas han sido apropiadas de forma ilegal, ${ }^{19}$ y según el Registro Nacional de Víctimas, aproximadamente 6,4 millones de personas han sido desplazadas. ${ }^{20}$ Más grave aún, Colombia se caracteriza por la alta concentración de la propiedad de la tierra: casi el $78 \%$ de la tierra rural en Colombia es propiedad del 13,7\% de los propietarios y el coeficiente de Gini para la tierra es de 0,88 , uno de los peores del mundo. ${ }^{21}$

Como lo dejan ver las cifras mencionadas, la búsqueda de una verdadera paz implicaba algún tipo de acuerdo sobre reforma agraria y restitución. En este contexto, el Acuerdo de Paz se esforzó por crear una "reforma agraria integral” para revertir la concentración de la tierra redistribuyéndola,

17 Alejandro Reyes Posada, Guerreros y campesinos: el despojo de la tierra en Colombia (Buenos Aires: Editorial Norma, 2009).

18 Procuraduría General de la Nación, Control preventivo y seguimiento a las politicas públicas en materia de reinserción y desmovilización (Bogotá: Procuraduría General de la Nación, 2006), 185.

19 Vease Centro Nacional de Memoria Histórica. ;Basta Ya! Colombia: Memorias de Guerra y Dignidad, 2013, http://www.centrodememoriahistorica.gov.co/descargas/informes2013/bastaYa/ basta-ya-colombia-memorias-de-guerra-y-dignidad-2016.pdf y Luis Jorge Garay y Fernando Barberi, "Decimo primer informe. Cuantificación y valoración de las tierras y los bienes abandonados o despojados a la población desplazada en Colombia. Bases para el desarrollo de procesos de reparación”. Comisión de Seguimiento a la Política Pública sobre Desplazamiento Forzado (19 de enero del 2009), 10.

20 Para el Registro Único de Víctimas véase: http://rni.unidadvictimas.gov.co/RUV

21 Ana María Ibáñez Londoño, "La persistencia de la concentración de la tierra en Colombia: ¿qué pasó entre 2000 y 2010?”, en Distributive justice in transitions, editado por Morten Bergsmo (Oslo: Torkel Opsahl Academic Publisher, 2010). 
al entender que la concentración es una causa estructural del conflicto, y favorecer la agricultura de tamaño pequeño y mediano.

El centro de este esfuerzo fue la creación de un "fondo de tierras" de tres millones de hectáreas, el cual estará compuesto de terrenos baldíos recuperados: tierras cuyos títulos de propiedad están extinguidos administrativamente porque "no cumplían con la función social y ecológica de la propiedad" y, finalmente, tierras formalmente expropiadas para fines públicos, con "la compensación correspondiente", entre otras fuentes. ${ }^{22}$ Además, el Acuerdo de Paz fortalece los esfuerzos en curso de restitución de tierras a las víctimas del conflicto armado, un programa ambicioso que continuará independientemente del estatus del Acuerdo. ${ }^{23}$

Este novedoso mecanismo de transición entrará a funcionar en un espacio de política pública que ya está muy regulado en el contexto de una política de desarrollo rural centrada en incentivar las industrias extractivas y la agroindustria intensiva en capital. En efecto, durante las últimas décadas, Colombia ha otorgado generosas exenciones fiscales a las empresas mineras ${ }^{24} \mathrm{y}$ ha facilitado la adquisición de licencias de extracción. ${ }^{25}$ Además, desde el 2007, el Gobierno ha impulsado una serie de leyes para facilitar el establecimiento de grandes áreas de tierras rurales dedicadas a la agroindustria intensiva en capital, más recientemente mediante la creación de las zonas de interés de desarrollo rural —Zidres-. ${ }^{26}$

22 Mesa de Conversaciones, "Acuerdo Final”, 1.1.1. Fondo de Tierras para la Reforma Rural Integral.

23 Véase Ley 1448 del 2011,10 de junio. Por la cual se dictan medidas de atención, asistencia y reparación integral a las víctimas del conflicto armado interno y se dictan otras disposiciones. Diario Oficial 48.096.

${ }^{24}$ Guillermo Rudas Lleras y Jorge Enrique Espitia Zamora, "Participación del Estado y la sociedad en la renta minera", en Minería en Colombia: derechos, políticas públicas y gobernanza, editado por Luis Jorge Garay (Bogotá: Contraloría General de la República, 2013), 147.

25 Camilo González Posso, La renta minera y el plan de desarrollo (Bogotá: Indepaz, 2011), 33-34.

26 Primero fue la Ley 1152 del 2007 (artículos 90 y 91) (declarada inconstitucional en la Sentencia C-175 del 2009); luego vino la Ley 1450 del 2011 (artículos 61-62) (declarada inconstitucional en la Sentencia C-644 del 2012); luego un proyecto del 2013 para crear "zonas de interés especial", que fracasó en el Congreso en el 2013 (Proyecto de Ley 162 del 2013, Cámara) y un proyecto del 2013 para regular la inversión extranjera en tierras (Proyecto de Ley 164 del 2013, Senado), que fracasó en el Congreso en el 2014. 
Este marco paralelo de desarrollo rural puede entrar en conflicto con el tipo de reforma agraria que el Acuerdo propone. Si bien el acuerdo expresamente menciona que es importante promover industrias y tener una aproximación empresarial en el desarrollo del agro, el texto del Acuerdo también menciona la importancia de democratizar el acceso a la tierra, apoyar a los pequeños campesinos y restituir tierras a las víctimas. ${ }^{27}$

Una de las posibles aristas de los conflictos que se pueden originar tiene que ver con el hecho de que estos programas de desarrollo agroindustrial requieren la concentración de la tierra y de gran capital para tener éxito. La inversión extranjera generalmente aporta ese capital tan necesario. En el 2010, el $48 \%$ de toda la inversión extranjera directa en Colombia se destinó a las industrias extractivas, y en el 2015, fue alrededor del $25 \%$, debido al menor precio del petróleo. ${ }^{28}$ Mientras que las cifras son fluctuantes, es posible discernir una clara tendencia: una parte considerable de la inversión extranjera en Colombia va a industrias cuyo marco legal se basa en un modelo de desarrollo rural que es lo opuesto al previsto en los Acuerdos de Paz.

\section{Protección de la inversión frente al Acuerdo de Paz}

Esta situación pone al Acuerdo de Paz en un rumbo de colisión con los inversionistas extranjeros, particularmente si un arbitraje es provocado por políticas de la transición relacionadas con el componente de tierras en el Acuerdo. Específicamente, los casos de inversión podrían surgir también de procesos de expropiación de terrenos para la conformación del fondo de tierras gratuito cuando se generen dichos procesos de terrenos que son actualmente propiedad de inversionistas extranjeros, o, en el caso de baldíos, cuando los poseedores son inversionistas extranjeros.

Ya es posible ver algunas de estas tensiones. Por ejemplo, desde el 2008, Anglo Gold Ashanti, el tercer productor de oro del mundo, y otras empresas más pequeñas recibieron concesiones para la minería de oro en la reserva de los emberá, una comunidad indígena en el Pacífico colombiano.

27 Véase Mesa de Conversaciones, “Acuerdo Final”, 1.1.1.1. Hacia un Nuevo Campo Colombiano: Reforma Rural Integral.

28 Cálculos propios, basados en datos del Banco de la República, https://www.banrep.gov.co/ inversion-directa 
El área había sido centro de intensos combates entre las FARC y el Ejército, y este último bombardeó parte de la reserva, obligando a miles de emberá a desplazarse. Un par de años más tarde, la comunidad buscó que sus tierras fueran restituidas bajo el mecanismo de justicia transicional creado para ese efecto, pero Anglo Gold se opuso a la restitución, argumentando que la concesión minera otorgada por el Gobierno cumplió con los requisitos dispuestos en la ley vigente. El juez decidió contra Anglo Gold y restituyó la tierra a los emberá, considerando que la comunidad no había sido consultada cuando se otorgaron las concesiones. ${ }^{29}$

El caso emberá es un buen ejemplo del tipo de casos de inversión que un Acuerdo de Paz colombiano puede desencadenar. Anglo Gold, o cualquier inversor en su situación, podría tratar de obtener una indemnización en virtud de un tratado de inversión aplicable, argumentando que la orden de restitución del juez colombiano es una medida equivalente a la expropiación ${ }^{30}$ o que viola la norma de tratamiento justo y equitativo. ${ }^{31}$

Por ejemplo, según Oxfam, Cargill (el mayor comerciante de productos agrícolas del mundo) pudo haber evadido ciertas restricciones aplicables en Colombia respecto a la posibilidad de adquirir tierras previamente propiedad del Estado destinadas a la agricultura familiar al comprar 50.000 hectáreas de parcelas previamente vacantes. ${ }^{32}$ Si esta acusación resulta ser verdadera y el Gobierno colombiano decide revertir las adquisiciones e incluir estas parcelas en el fondo de tierras, Cargill podría solicitar una compensación bajo el TLc Colombia-Estados Unidos. ¿Prevalecería? Por supuesto, es imposible saberlo. Cargill siempre ha dicho que siguió escrupulosamente la ley

29 Véase: Tribunal Superior de Antioquia. Sala Civil Especializada en Restitución de Tierras, "Resguardo Indígena Emberá-Katío del Alto Andágueda v. Continental Gold Ltd. Sucursal Colombia y otros". Sentencia del 23 de septiembre del 2014.

30 Véase Caroline Henckels, "Indirect expropriation and the right to regulate: revisiting proportionality analysis and the standard of review in investor-state arbitration". Journal of International Economic Law 15, n. 1 (2012).

31 Véase Roland Kläger, Fair and equitable treatment in International Investment Law (Cambridge: Cambridge: Cambridge University Press, 2011).

32 Oxfam, "Divide and purchase: how land ownership is being concentrated in Colombia", Oxfam GB, 2013, https://www.oxfamamerica.org/static/media/files/rr-divide-and-purchase-landconcentration-colombia-211013-en.pdf 
colombiana. ${ }^{33}$ Sin embargo, el riesgo de compensación seguramente pesará en la decisión colombiana de incluir ciertos baldíos en el fondo de tierras.

Es importante aclarar que el derecho internacional de la inversión extranjera no protege la ilegalidad. Sin embargo, la situación frente a la tierra en Colombia es tan compleja que el tener un título de propiedad no significa necesariamente que la propiedad de ese terreno esté libre de disputa sobre su legalidad, entre otros factores por actos de corrupción. ${ }^{34} \mathrm{Lo}$ anterior puede generar choques de tipo probatorio y legal sobre la buena fe por parte de inversionistas al adquirir un terreno, y la valoración que se haga en el proceso doméstico probablemente no sea la misma que se haga de los hechos por parte de un tribunal de arbitramento de inversión, debido a que los estándares internacionales son más exigentes en cuanto a la protección de la inversión extranjera y al cálculo de la indemnización.

También resulta importante señalar que la inversión extranjera no es, en sí misma, antitética al Acuerdo de Paz y que, de la forma como se ha estructurado la política de inversión extranjera por parte del Gobierno colombiano, sí puede generar complicaciones al momento de poner en marcha las medidas transicionales de distribución de tierras. De igual forma, es importante señalar que si bien hay en teoría suficiente tierra en Colombia para fomentar la agroindustria y para implementar iniciativas de paz, la realidad de la falta de infraestructura de transporte es tan grave que, como un problema de asignación de recursos, este es un juego de suma cero, en tanto que de un lado la tierra utilizada para minería o para la agroindustria intensiva en capital es probable que no sea usada dentro de las políticas de paz relacionadas con tierra debido a los intereses e incentivos económicos en torno a esta. En ese sentido, si las tierras usadas son aquellas ubicadas en lugares con difícil acceso debido a la pobre infraestructura de transporte, no se cumpliría en ningún momento con la finalidad de los temas de tierras en el Acuerdo de Paz.

33 Cargill, “Cargill's response to Oxfam's 'Smallholders at Risk' and 'Divide and Purchase' reports”, 2014, http://www.cargill.com/news/company-statements/cargill-response-oxfam-smallholders-riskand-divide-and-purchase-reports/index.jsp

34 Por ejemplo, el caso del 2011 donde se encontró que dentro de la Superintendencia de Notariado y Registro un grupo de funcionarios otorgaban títulos fraudulentos sobre terrenos que habían sido despojados. 
En este contexto, el régimen de solución de disputas relacionadas con inversión se vuelve crucial. Su gran efectividad en hacer cumplir las obligaciones internacionales de protección al inversionista mueve la balanza a favor de mantener la tierra en la minería y la agroindustria en Colombia, no porque el régimen de inversión esté sesgado a favor de estas industrias en sí mismo, sino porque los inversores extranjeros en Colombia tienen preferencia por estas. Así, el peso del régimen jurídico internacional respalda a esos inversionistas y se convierte, por esa vía, en un incentivo en contra de asignar tierras a iniciativas transicionales. Como resultado, se hace más difícil reasignar tierras de estas industrias a iniciativas de transición, o, por lo menos, el régimen de inversión puede terminar dando una justificación política y jurídica para no hacerlo.

\section{Protección del Acuerdo de Paz frente a la inversión}

Los negociadores colombianos no han considerado seriamente la protección de la inversión como parte de los límites que el derecho internacional puede imponer a la implementación de un acuerdo de paz (a diferencia, por ejemplo, de los derechos humanos o del derecho penal internacional). En nuestro criterio, esta posición genera graves riesgos jurídicos para el Acuerdo de Paz y debe ser reconsiderada. En concreto, opinamos que el Gobierno colombiano debería manifestar de manera formal que el Acuerdo y sus políticas de reforma agraria son necesarios para proteger la seguridad esencial de Colombia - una medida que podría sentar las bases para una eventual defensa colombiana en un futuro arbitraje. ${ }^{35}$

Ahora bien, tal aproximación puede ser interpretada como "not selfjudging”, en el sentido de que no recae en el Estado que la alega, sino en los árbitros el decidir si esta interpretación unilateral se ajusta a las excepciones planteadas por los тві у los TLC firmados por Colombia. ${ }^{36}$ Se abre

35 Véase William W. Burke-White y Andreas von Staden, "Investment protection in extraordinary times: the interpretation and application of non-precluded measures provisions in bilateral investment treaties". Virginia Journal of International Law 48 (2008): 307. En contra, véase: Álvarez y Khamsi, "Argentine crisis".

36 Véase cms Transmission Co.v. Argentina, icsid Case n. ${ }^{\circ}$ ARB/01/8, Award, para. 373 (12 de mayo del 2005); LG\&E Energy Corp. v. Argentina, Icsid Case n. ${ }^{\circ}$ Arb/02/1, Decision on Liability, paras. 214, 257 (3 de octubre del 2006); Enron Corp., Ponderosa Assets, L.P.v. Argentina, Icsid Case n. ${ }^{\circ}$ Arb/01/3, Award, para. 332 (22 de mayo del 2007); Sempra Energy Int'lv. Argentina, Icsid Case 
así un amplio margen de interpretación arbitral. ¿Cómo deben los árbitros de inversiones abordar las disputas que surgen del Acuerdo de $\mathrm{Paz}$ colombiano? Los pocos precedentes disponibles dan escasa orientación con respecto a medidas transicionales en el contexto de las controversias sobre inversiones. Por ejemplo, en Piero Foresti, un grupo de demandantes italianos argumentó que sus acciones en una empresa de explotación minera habían sido expropiadas, ya que la ley minera posapartheid de Sudáfrica exigía el $26 \%$ de propiedad de los sudafricanos históricamente desfavorecidos. La disputa, sin embargo, fue conciliada y el caso se interrumpió. ${ }^{37}$

Más importante fue Funnekotter. ${ }^{38}$ Este caso involucró a un grupo de terratenientes holandeses que fueron privados de sus tierras por las controvertidas reformas de Mugabe, que buscaban redistribuir la tierra de los propietarios blancos a la población negra. Zimbabue argumentó, en primer lugar, que su reforma agraria era "de interés público y con arreglo a las debidas garantías procesales” y, por consiguiente, no exigía ninguna compensación. Adicionalmente, arguyó que la reforma se adoptó por necesidad. El tribunal rechazó ambos argumentos y decidió a favor de los demandantes, otorgando la mayor parte de la indemnización. Curiosamente, al debatir el monto de la compensación, Zimbabue sostuvo que, en casos de nacionalizaciones a gran escala, debe hacerse un descuento del valor de mercado de los activos. ${ }^{39} \mathrm{El}$ tribunal, sin embargo, rechazó el argumento: el valor del activo debe calcularse independientemente "del número y objetivo de las expropiaciones hechas".

Esta discusión tiene alta relevancia para el caso colombiano. En nuestro contexto, la pregunta central es si un tribunal de inversión debe considerar el contexto de transición que enmarca la política de tierras en el país y el derecho a la paz que es parte esencial de la autodeterminación de los

n. ${ }^{\circ}$ Arb/02/16, Award, para. 385 (28 de septiembre del 2007); Continental Casualty Co. v. Argentina, ICsid Case n. ${ }^{\circ}$ ARB/03/9, Award, para. 182 (5 de septiembre del 2008); Sempra Energy Int'1 v. Argentina, Icsid Case n. ${ }^{\circ}$ Arb 02/16, Annulment, para. 175 (29 de junio del 2010).

37 Piero Foresti v. South Africa, Icsid Case n. ${ }^{\circ}$ ARB(AF)/07/01, Award (4 de agosto del 2010).

38 Bernardus Henricus Funnekotter v. Zimbabwe, icsid Case n. ${ }^{\circ}$ ARB/05/6, Award (15 de abril del 2009).

39 Bernardus Henricus Funnekotter v. Zimbabwe, icsid Case n. ${ }^{\circ}$ ARB/05/6, Award (15 de abril del 2009). 
pueblos. ${ }^{40} \mathrm{Si}$ bien los precedentes no son alentadores, en nuestro criterio el proceso de justicia transicional debería tener peso, así como el derecho a la paz del pueblo colombiano y la posibilidad de resolver un conflicto armado de más de cincuenta años.

El componente territorial del Acuerdo de Paz será la piedra angular en la reparación de los abusos contra los derechos humanos ocurridos durante el conflicto armado y es crucial para prevenir más violencia. Como criterio general, entonces, los árbitros deben reconocer la dimensión humanitaria de su responsabilidad como adjudicadores y de implicaciones superiores, como respetar la autodeterminación para poner fin a un conflicto, en lugar de centrarse en los estándares de inversión aislados de su contexto. En este sentido, también es relevante mencionar que los árbitros deben tener presente aspectos como la relación que puede existir entre los principios rectores sobre las empresas, y los derechos humanos de las Naciones Unidas y el arbitraje de inversión. ${ }^{41}$

Este enfoque no implica negar a los inversionistas la protección prevista en los tratados, en tanto que Colombia adoptó obligaciones que deben ser mantenidas según los estándares y principios del derecho internacional. Sin embargo, las normas de inversión y los procedimientos arbitrales abren un espacio para que los árbitros consideren todas las implicaciones de su decisión y hagan una interpretación sistemática. Un ejemplo reciente de una interpretación amplia y sistemática que puede servir como un precedente alentador para los retos que Colombia tiene que afrontar es la reciente decisión de Uruguay contra Philip Morris, en la que los árbitros hicieron una interpretación teniendo en el cuenta contexto. Específicamente en el caso de Philip Morris contra Uruguay, el tribunal de inversión le dio un espaldarazo a la posibilidad de los Estados de regular en temas de salud pública

40 Véase Gómez Suárez, Perrone y Prieto-Rios, "Foreign investors".

41 Sobre la discusión y la relación entre los principios rectores sobre las empresas y los derechos humanos de las Naciones Unidas y el arbitraje de inversión, véase: Enrique Prieto-Ríos y Álvaro Amaya, "Los principios rectores sobre empresas y derechos humanos y la práctica legal en el arbitraje de inversión respecto del derecho internacional de los derechos humanos", en Derechos humanos y empresas: reflexiones desde América Latina, Humberto Cantú Rivera (Instituto Interamericano de Derechos Humanos, 2017). 
cuando las medidas se adopten de buena fe. ${ }^{42}$ También fue importante que el tribunal aplicó la interpretación del margen de apreciación señalando que este no está limitado únicamente a la Convención Europea de Derechos Humanos y que, por el contrario, puede ser aplicado a TBI о TLC (capítulo de inversión) cuando se necesita interpretar si una medida adoptada por un Estado está relacionada con objetivos de salud pública. ${ }^{43}$ Por último, en la interpretación sistemática adoptada por este tribunal, el laudo ratificó la importancia del Convenio Marco de la Organización Mundial de la Salud para el Control del Tabaco. ${ }^{44}$

En el caso colombiano, el hecho de que los árbitros adopten una interpretación amplia, teniendo en cuenta el contexto de transición y fin del conflicto, tendría ciertas consecuencias procedimentales y sustanciales. Procedimentalmente, implicaría permitir a las organizaciones de la sociedad civil, y en particular a las organizaciones colombianas de víctimas, participar en el proceso de arbitraje de inversiones, tener acceso a las reclamaciones y ser oídas por el tribunal. ${ }^{45}$ Además, al juzgar las políticas de tierras derivadas del Acuerdo de Paz, un árbitro que tenga en cuenta las implicaciones humanitarias del litigio de inversión en el contexto colombiano también podría adoptar un criterio de examen (un standard of review) más deferente. ${ }^{46}$ Cuando llegue el caso adecuado, los tribunales de arbitraje de inversión estarán en condiciones de revisar la arquitectura legal interna y la implementación de un acuerdo de paz. ${ }^{47}$ Deberían adoptar

${ }^{42}$ Philip Morris Brands Sàrl, Philip Morris Products S.A. y Abal Hermanos S.A. v. Oriental Republic of Uruguay, Icsid Case n. ${ }^{\circ}$ ARB/10/7 (actualmente FTr Holding SA, Philip Morris Products S.A. y Abal Hermanos S.A. v. Oriental Republic of Uruguay).

43 Ibid.

${ }^{44}$ Ibid.

45 Véase René Urueña, No citizens here: global subjects and participation in international law (Leiden/Boston: Martinus Nijhoff Publishers, 2012), 189-211.

46 Véase René Urueña, "Subsidiarity and the public-private distinction in investment treaty arbitration". Law and Contemporary Problems 79, n. 2 (2016).

47 Gus van Harten y Martin Loughlin, "Investment treaty arbitration as a species of global administrative law". European Journal of International Law 17, n. ${ }^{\circ} 1$ (2006); Daniel Kalderimis, "Investment treaty arbitration as global administrative law: what this might mean in practice", en Evolution in investment treaty law and arbitration, editado por Kate Miles y Chester Brown (Cambridge/Nueva York: Cambridge University Press, 2011). 
una norma deferente, dando en principio mucho peso a las decisiones de los tribunales colombianos y solo excepcionalmente decidir las cuestiones de reforma agraria de nuevo. ${ }^{48}$

Doctrinalmente, este enfoque podría implicar un estándar más estricto para la diligencia del inversionista. Si alguien decidió invertir en tierra en Colombia, atraído por los generosos incentivos de la minería o la agroindustria, ese inversionista debería haber considerado también que la tenencia de la tierra en Colombia siempre ha sido un elemento central del conflicto, lo que hace razonable esperar que será también un elemento central de un acuerdo de paz, como lo han sugerido algunos laudos reconociendo la dimensión del principio de caveat emptor.

En el caso de Hassan Awdi, el tribunal arbitral discutió la restitución de un edificio histórico que había sido confiscado por los comunistas rumanos en la década de 1950, luego privatizado y vendido a inversionistas extranjeros en los años noventa. En su razonamiento, el tribunal se tomó en serio el programa de restitución de bienes de Rumania y constató que no se había producido ninguna expropiación, ya que los reclamantes sabían que la restitución era una posibilidad cuando hacían la inversión. ${ }^{49} \mathrm{El} \mathrm{com-}$ ponente de tierras y el proceso de restitución son también una posibilidad clara en Colombia y los tribunales arbitrales deben considerar razonable exigir a los inversionistas que lo sepan.

Este enfoque también podría influir en el cálculo de la compensación a los inversores. Exigir cantidades significativas de dinero de un Estado que está implementando un ambicioso programa de transición podría tener efectos humanitarios desastrosos y puede no estar justificado bajo principios básicos de justicia. ${ }^{50}$ En su opinión separada en $C M E$, Ian Brownlie consideró relevantes los efectos desastrosos que el laudo tendría sobre la República

48 Caroline Henckels, "Balancing investment protection and the public interest: the role of the standard of review and the importance of deference in investor-state arbitration". Journal of International Dispute Settlement 4, n. 1 (2013).

49 Mr. Hassan Awdi, Enterprise Business Consultants, Inc. and Alfa El Corporation v. Romania, ICsid Case n. ${ }^{\circ}$ ARB/10/13, Award, paras. 438-442 (2 de marzo del 2015).

50 Larry May, "Jus post bellum, grotius and meionexia", en Jus post bellum: mapping the normative foundations, editado por Carsten Stahn, Jennifer S. Easterday y Jens Iverson (Oxford: Oxford University Press, 2014), 18. 
Checa. ${ }^{51}$ Igualmente, tanto en Sempra como en $C M S$ los tribunales dijeron que la crisis argentina tenía que ser considerada al calcular las reparaciones: "la crisis no puede ser ignorada y tiene consecuencias específicas sobre la cuestión de la reparación”. ${ }^{52}$ Tales circunstancias particulares deben considerarse también en el caso colombiano.

Por último, los árbitros de inversiones que se acercan a un caso colombiano deben conocer las obligaciones de ese Estado en virtud de la Convención Americana de Derechos Humanos. El régimen interamericano de protección de los derechos humanos y de la inversión ya ha interactuado, en particular cuando Paraguay trató de utilizar sus obligaciones bajo el тв Alemania-Paraguay para eludir la restitución de las tierras tradicionales de la comunidad indígena sawhoyamaxa. ${ }^{53} \mathrm{~A}$ pesar de que el Tribunal Interamericano rechazó el argumento, el caso puso de manifiesto que los vasos de comunicación entre los regímenes son cruciales para una situación como la de Colombia: un Estado que tiene estrictas obligaciones bajo el sistema regional de derechos humanos, que puede implicar, como hemos visto, la restitución de tierras. El derecho de las inversiones extranjeras no debe ser un obstáculo para que Colombia cumpla con sus obligaciones internacionales, particularmente cuando, según la Corte Interamericana, los derechos a un debido proceso han alcanzado el estatus de ius cogens. ${ }^{54}$

\section{Conclusiones}

Como se planteó de forma breve en este artículo, el proceso de transición que implica la implementación del Acuerdo Final para la terminación del conflicto y la construcción de una paz estable y duradera generará conflictos entre el derecho internacional para la protección y promoción de la inversión

51 сме, Czech Republic B.V.v. The Czech Republic; Separate Opinion of Professor Brownlie, paras. 75-80 (14 de marzo del 2003).

52 cms Transmission Co.v. Argentina, icsid Case n. ${ }^{\circ}$ ARB/01/8, Award, para. 373 (12 de mayo del 2005); Sempra Energy Int'1 v. Argentina, Icsid Case n. ${ }^{\circ}$ Arb/02/16, Award, para. 385 (28 de septiembre del 2007).

53 Comunidad Indígena Sawhoyamaxa v. Paraguay, Merits, Reparations and Costs, Judgment, Inter-Am. Ct. H.R. (ser. C) n.o 146 (29 de marzo del 2006).

54 Goiburú y otros v. Paraguay, Merits, Reparations and Costs, Judgment, Inter-Am. Ct. H.R. (ser. C) n. ${ }^{o} 153$ (22 de septiembre del 2006). 
extranjera (тві у тLC) y los compromisos expresados en el Acuerdo Final. Estos conflictos van a surgir de manera específica en cuanto a la aplicación del primer punto del Acuerdo, que propone una reforma rural integral que implica adoptar medidas que buscan la redistribución y restitución de tierras, entre ellas la creación de un fondo de tierras de distribución gratuita.

El conflicto surgirá debido a que tanto los TBI como los TLC ofrecen una protección amplia y mejorada a los inversionistas extranjeros, lo que implica que cualquier medida adoptada por Colombia, inclusive aquellas que tienen que ver con el proceso de transición, que afecte los intereses económicos de los inversionistas faculta al inversionista a llevar la controversia ante un Tribunal de Arbitramento de Inversión, el cual está limitado por los términos del тві o del TLC. Experiencias pasadas de otros países, como los casos de Suráfrica o Zimbabue, demuestran que en situaciones de transición los inversionistas ante todo buscan la protección de sus intereses económicos y es probable que el país receptor de la inversión tenga que pagar una indemnización.

En este sentido, nuestras dos propuestas para enfrentar este panorama tan oscuro se centran, de un lado, en proponer que el Gobierno colombiano se manifieste de manera formal, señalando que el Acuerdo y sus políticas de reforma agraria son necesarios para proteger la seguridad esencial de $\mathrm{Co}_{-}$ lombia - una medida que podría sentar las bases para una eventual defensa colombiana en un futuro arbitraje- La segunda propuesta se centra en que el país argumente que el proceso de justicia transicional debería tener peso, así como el derecho a la paz del pueblo colombiano y la posibilidad de resolver un conflicto armado de más de cincuenta años. En este contexto, se busca que los árbitros al momento de interpretar los tratados realicen una interpretación sistemática más amplia, lo cual puede inclusive implicar algunos ajustes procedimentales al proceso arbitral.

Como queda en evidencia de la lectura planteada en este artículo (y en este libro, en general), la implementación del Acuerdo tendrá varios retos que pueden llegar a limitar su aplicación. Entonces, es importante que el Gobierno se prepare de forma tal que pueda prever los diversos escenarios donde puedan surgir conflictos, con el fin de adoptar una política de prevención que evite los arbitrajes o que fortalezca la posición de Colombia, garantizando la efectividad del Acuerdo. 


\section{Bibliografía}

“Aquí no venimos a negociar el modelo de desarrollo del país': Humberto de La Calle". El País, 18 de octubre del 2012.

"FARC envían carta al ministro de agricultura criticando inversión extranjera". Vanguardia Colombia, 18 de enero del 2013, http://www.vanguardia. com/actualidad/colombia/191996-farc-envian-carta-al-ministrode-agricultura-criticando-inversion-extranj

"FARC piden revisar TLC que afecten soberanía alimentaria de Colombia". ElTiempo, 24 de enero del 2013, http://www.eltiempo.com/archivo/ documento/CMS-12545062

Álvarez,José E. The Public International Law Regime GoVéasening International Investment, Recueil Des Cours, 2009. La Haya: Hague Academy of International Law, 2011.

Álvarez,José E.y Kathryn Khamsi. "Argentine crisis and foreign investors: a glimpse into the heart of the investment regime", en The Yearbook on International Investment Law and Policy, editado por Karl P. Sauvant y Lisa Sachs, 379-479. Nueva York: Oxford UniVéasesity Press, 2008. Baghban, Rahim y Mahin Sajedi. "An introduction to international investment and investment disputes". Savant Journal of Social Sciences and Humanity 1, n. ${ }^{\circ} 1$ (2015): 7-14.

Banco de la República, https://www.banrep.gov.co/inversion-directa

Bernardus Henricus Funnekotter v. Zimbabwe, icsid Case n. ${ }^{\circ}$ ARB/05/6, Award, 15 de abril del 2009.

Bieito, Rubido. “Juan Manuel Santos: 'Gestionar la paz es más difícil que hacer la guerra”. El País, 6 de mayo del 2016.

Burke-White, William W. y Andreas von Staden. "Investment protection in extraordinary times: the interpretation and application of nonprecluded measures provisions in bilateral investment treaties". Virginia Journal of International Law 48 (2008): 307-409.

Cargill. "Cargill's response to Oxfam's 'Smallholders at Risk' and 'Divide and Purchase' reports”, 2014, http://www.cargill.com/news/companystatements/cargill-response-oxfam-smallholders-risk-and-divideand-purchase-reports/index.jsp

Centro Nacional de Memoria Histórica. ;Basta Ya! Colombia: Memorias de Guerra y Dignidad,2013, http://www.centrodememoriahistorica.gov. 
co/descargas/informes2013/bastaYa/basta-ya-colombia-memoriasde-guerra-y-dignidad-2016.pdf

CME, Czech Republic B.V. v. The Czech Republic; Separate Opinion of Professor Brownlie, paras. 75-80, 14 de marzo del 2003.

CMs Transmission Co.v. Argentina, ICsid Case n. ${ }^{\circ}$ ARB/01/8, Award, para. 373, 12 de mayo del 2005.

Colen, Liseth y Andrea Guariso. "What type of foreign direct investment is attracted by bilateral investment treaties?", en Foreign direct investment and human development: the law and economics of international agreements, editado por Oli Véase de Schuteer, Johan Swinnen y Jan Wouters, 138-156. Londres y Nueva York: Routledge.

Comunidad Indígena Sawhoyamaxa v. Paraguay, Merits, Reparations and Costs, Judgment, Inter-Am. Ct. H.R. (ser. C) n.o 146, 29 de marzo del 2006.

Continental Casualty Co.v. Argentina, ICsid Case n. ${ }^{\circ}$ ARB/03/9, Award, para. 182, 5 de septiembre del 2008.

Enron Corp., Ponderosa Assets, L.P.v. Argentina, Icsid Case n. ${ }^{\circ}$ Arb/01/3, Award, para. 332, 22 de mayo del 2007.

Fuerzas Armadas Revolucionarias de Colombia-Ejército del Pueblo — FARCEP-. "Desarrollo rural y agrario para la democratización y la paz con justicia social en Colombia: 100 propuestas mínimas”, febrero del 2014, 71-74, http://www.pazfarc-ep.org/pdf/100-PROPUESTASMINIMAS-1-PUNTO-AGRARIO.pdf

Garay, Luis Jorge y Fernando Barberi. “Decimo primer informe. Cuantificación y valoración de las tierras y los bienes abandonados o despojados a la población desplazada en Colombia. Bases para el desarrollo de procesos de reparación”. Comisión de Seguimiento a la Política Pública sobre Desplazamiento Forzado, 19 de enero del 2009.

Goiburú y otros v. Paraguay, Merits, Reparations and Costs, Judgment, Inter-Am. Ct. H.R. (ser. C) n.o 153, 22 de septiembre del 2006.

Gómez Suárez, Andrei, Nicolás M.Perrone y Enrique Prieto-Rios. "Foreign investors and the Colombian Peace Process". International Community Law Review 18, n. ${ }^{\circ}$ 3-4 (2016): 223-247.

González Posso, Camilo. La renta minera y el plan de desarrollo. Bogotá: Indepaz, 2011. 
Henckels, Caroline. "Balancing investment protection and the public interest: the role of the standard of review and the importance of deference in investor-state arbitration". Journal of International Dispute Settlement 4, n. ${ }^{\circ} 1$ (2013): 197-215.

Henckels, Caroline. "Indirect expropriation and the right to regulate: revisiting proportionality analysis and the standard of review in investor-state arbitration". Journal of International Economic Law 15, n. 1 (2012): 223-255.

Ibáñez Londoño, Ana María. "La persistencia de la concentración de la tierra en Colombia: ¿qué pasó entre 2000 y 2010?”, en Distributive justice in transitions, editado por Morten Bergsmo, 279-309. Oslo: Torkel Opsahl Academic Publisher, 2010.

Kalderimis, Daniel. "Investment treaty arbitration as global administrative law: what this might mean in practice", en Evolution in investment treaty law and arbitration, editado por Kate Miles y Chester Brown, 145-160. Cambridge/Nueva York: Cambridge University Press, 2011.

Kläger, Roland. Fair and equitable treatment in International Investment Law. Cambridge: Cambridge University Press, 2011.

Ley 1152 del 2007, 25 de julio. Por la cual se dicta el Estatuto de Desarrollo Rural, se reforma el Instituto Colombiano de Desarrollo Rural, Incoder, y se dictan otras disposiciones. Diario Oficial 46.700.

Ley 1448 del 2011, 10 de junio. Por la cual se dictan medidas de atención, asistencia y reparación integral a las víctimas del conflicto armado interno y se dictan otras disposiciones. Diario Oficial 48.096.

Ley 1450 del 2011, 16 de junio. Por la cual se expide el Plan Nacional de Desarrollo, 2010-2014. Diario Oficial 48.102.

LG\&E Energy Corp. v. Argentina, ICsid Case n. ${ }^{\circ}$ Arb/02/1, Decision on Liability, paras. 214, 257, 3 de octubre del 2006.

May, Larry. "Jus post bellum, grotius and meionexia", en Jus post bellum: mapping the normative foundations, editado por Carsten Stahn, Jennifer S. Easterday y Jens Iverson, 15-25. Oxford: Oxford University Press, 2014.

Mesa de Conversaciones. "Acuerdo final para la terminación del conflicto y la construcción de una paz estable y duradera”, 12 de noviembre del 2016 https://www.mesadeconversaciones.com.co/sites/de- 
fault/files/12-1479102292.11-1479102292.2016nuevoacuerdofin al-1479102292.pdf

Mr. Hassan Awdi, Enterprise Business Consultants, Inc. and Alfa El Corporation v. Romania, ICsid Case n. ${ }^{\circ} \mathrm{ARB} / 10 / 13$, Award, paras. 438-442, 2 de marzo del 2015.

Oxfam. "Divide and purchase: how land ownership is being concentrated in Colombia”. Oxfam GB, 2013, https://www.oxfamamerica.org/static/ media/files/rr-divide-and-purchase-land-concentration-colombia211013-en.pdf

Philip Morris Brands Sàrl, Philip Morris Products S.A.y Abal Hermanos S.A. v. Oriental Republic of Uruguay, Icsid Case n. ${ }^{\circ} \mathrm{ARB} / 10 / 7$ (actualmente Ftr Holding SA, Philip Morris Products S.A.y Abal Hermanos S.A.v. Oriental Republic of Uruguay).

Piero Foresti v. South Africa, Icsid Case n. ${ }^{\circ}$ ARB(AF)/07/01, Award, 4 de agosto del 2010.

Portal Oficial de Inversión de Colombia, http://inviertaencolombia.com.co/. Prieto-Rios, Enrique. "вIтs y la Constitución de 1991: internacionalización de la economía dentro de un Estado social de derecho". Estudios Socio Jurídicos 13, n.o 1 (2011): 109-143.

Prieto-Rios, Enrique y Álvaro Amaya. "Los principios rectores sobre empresas y derechos humanos y la práctica legal en el arbitraje de inversión respecto del derecho internacional de los derechos humanos", en Derechos humanos y empresas: reflexiones desde América Latina, Humberto Cantú Rivera, 405-422. San José de Costa Rica: Instituto Interamericano de Derechos Humanos, 2017.

Prieto-Rios, Enrique. "Neoliberal market rationality: the driver of International Investment Law”. Birkbeck Law Review 3, n. ${ }^{\circ} 1$ (2015): 55-76.

Procuraduría General de la Nación. Control preventivo y seguimiento a las politicas públicas en materia de reinserción y desmovilización. Bogotá: Procuraduría General de la Nación, 2006.

Proyecto de Ley 162 del 2013, Cámara.

Proyecto de Ley 164 del 2013, Senado.

Registro Único de Víctimas, http://rni.unidadvictimas.gov.co/RUV

Reyes Posada, Alejandro. Guerreros y campesinos: el despojo de la tierra en Colombia. Buenos Aires: Editorial Norma, 2009. 
Rudas Lleras, Guillermo y Jorge Enrique Espitia Zamora. "Participación del Estado y la sociedad en la renta minera”, en Minería en Colombia: derechos, politicas públicas y gobernanza, editado por Luis Jorge Garay, 125-176. Bogotá: Contraloría General de la República, 2013. Sentencia C-175 del 2009, 18 de marzo. MP: Luis Ernesto Vargas Silva. Sentencia C-644 del 2012,23 de agosto. MP: Adriana Marín Guillen Arango. Sempra Energy Int'l v. Argentina, ICsid Case n. ${ }^{\circ}$ Arb 02/16, Annulment, para. 175, 29 de junio del 2010.

Sempra Energy Int'l v. Argentina, ICsid Case n. ${ }^{\circ}$ Arb/02/16, Award, para. 385, 28 de septiembre del 2007.

Tribunal Superior de Antioquia. Sala Civil Especializada en Restitución de Tierras. "Resguardo Indígena Emberá-Katío del Alto Andágueda v. Continental Gold Ltd. Sucursal Colombia y otros”. Sentencia del 23 de septiembre del 2014.

Urueña, René. "Subsidiarity and the public-private distinction in investment treaty arbitration". Law and Contemporary Problems 79, n. 2 (2016): 99-121.

Urueña, René. No citizens here: global subjects and participation in international law. Leiden/Boston: Martinus Nijhoff Publishers, 2012.

van Harten, Gus y Martin Loughlin. "Investment treaty arbitration as a species of global administrative law". European Journal of International Law 17, n. 1 (2006): 121-150. 


\title{
Las medidas de reparación integral establecidas en el Acuerdo Final para la terminación del conflicto y la construcción de una paz estable y duradera
}

\author{
Hugo Andrés Arenas Mendoza*
}

\section{Introducción}

El resultado del diálogo de paz iniciado en el 2012 entre el Gobierno colombiano y la guerrilla de las FARC fue el "Acuerdo final para la terminación del conflicto y la construcción de una paz estable y duradera"; este texto fue sometido a plebiscito el 2 de octubre del 2016 y el resultado fue la no aprobación del Acuerdo por parte del pueblo colombiano, concretamente con el 50,21\% de la votación.

Uno de los puntos centrales del Acuerdo es la reparación a las víctimas del conflicto armado colombiano, tema al que se hace referencia en varias partes de este, principalmente en el punto 5, titulado "Acuerdo sobre las víctimas del conflicto: 'Sistema Integral de Verdad, Justicia, Reparación y No Repetición, incluyendo la Jurisdicción Especial para la Paz; y Compromiso sobre Derechos Humanos', que se subdivide en: una parte introductoria; 5.1. Sistema integral de Verdad, Justicia, Reparación y no Repetición; 5.2. Compromiso con la promoción, el respeto y la garantía de los derechos humanos y 5.3. Acuerdo complementario sobre el "Sistema Integral de Verdad, Justicia, Reparación y No Repetición”.

* Abogado, sociólogo y maestro en Derecho Administrativo de la Universidad del Rosario. Doctor en Derecho de la Universidad de Salamanca. Profesor principal de Derecho Administrativo de la Universidad del Rosario. Correo electrónico: hugo.arenas@urosario.edu.co 
Existen diversos enfoques para responsabilizar a los actores de los daños causados dentro del conflicto armado que permiten saber si se pretende castigar a los infractores, prevenir daños o proteger a las víctimas.

En este sentido se debe destacar que las partes eligieron incluir en el texto del Acuerdo la noción de reparación integral como un criterio fundamental para la indemnización de las víctimas y para la materialización de las medidas tanto individuales como colectivas contenidas en el texto definitivo. Esta decisión se ajusta a la finalidad general del Acuerdo, porque concede a la víctima un papel central, que garantiza que todos los daños sufridos sean reparados.

Este capítulo destaca que el Acuerdo hace una referencia muy general a las medidas de reparación individual al punto de solo mencionarlas, sin explicar su contenido y, al contrario, le da un gran protagonismo a las medidas de reparación colectiva, desarrollándolas ampliamente. De este modo, es aconsejable darle un mayor contenido a las indemnizaciones individuales para que realmente las víctimas tengan acceso a una verdadera reparación integral y que, una vez sea garantizada, se piense en realizar resarcimientos colectivos.

En este orden de ideas, el presente texto será dividido en los siguientes cuatro puntos: 1) enfoques que se le pueden asignar a la responsabilidad patrimonial por los daños causados en el conflicto armado; 2) principios del Acuerdo; 3) la reparación integral en el Acuerdo; y 4) las medidas de reparación integral para la construcción de la paz.

\section{Enfoques que se le pueden asignar a la responsabilidad patrimonial por los daños causados en el conflicto armado}

Una parte esencial del Acuerdo consistía en elegir el enfoque teórico que sirviera de fundamento para la reparación de los daños, evitar la ocurrencia de hechos similares y encontrar la manera en que se iba a castigar a los infractores patrimonialmente. Con base en esto, se han desarrollado tesis basadas en cuestiones de justicia, económicas, de control social, sancionatorias, de reparación integral, etcétera.

El "Acuerdo para la terminación del conflicto y la construcción de una paz estable y duradera" hace referencia en varias ocasiones a la noción de reparación integral, estableciéndola como una directriz para la indemnización a las víctimas.

Antes de concentrarse en el Acuerdo, es preciso presentar los diversos enfoques que se le pueden asignar a la responsabilidad por los daños 
cometidos, puesto que de esto dependerá la manera en que se indemnice a las víctimas del conflicto armado, se castigue a los infractores y se evite la ocurrencia de hechos similares. En este orden de ideas, se debe hacer referencia a las funciones punitiva, control social, económica, solidaridad, reparadora, preventiva, reparación integral y transformadora:

- Punitiva: esta procede del derecho norteamericano, tomando una visión proveniente del derecho penal que permite que la lesión sea indemnizada por encima del detrimento sufrido. ${ }^{1}$ Se basa en la reparación como castigo ${ }^{2}$ y tiene la finalidad de que se disuada a las personas de repetir el comportamiento. ${ }^{3}$

- Control social: el Estado tiene que realizar unas funciones que le han sido atribuidas constitucionalmente; para materializarlas debe realizar actuaciones $u$ omisiones, que pueden causar daños a los asociados. Por esto, alguna parte de la doctrina ha entendido que la responsabilidad tiene una función de control social, es decir, sirve como mecanismo para evaluar el comportamiento de las instituciones, ${ }^{4}$ y también una función marcadamente pedagógica. ${ }^{5}$

1 "Esta regla de oro del derecho de daños no opera, sin embargo, en países de corte anglosajón, en los cuales el concepto de 'daño punitivo' - punitive, exemplary, punitory, vindicative damagespermite sobrepasar sin problema la regla en estudio en favor de la víctima." Juan Henao, El daño. Análisis comparativo de la responsabilidad extracontractual del Estado en el derecho colombiano y en el francés (Bogotá: Universidad Externado de Colombia, 2007), 45.

2 "La idea central era la reparación como castigo, ya que si a todos los hombres en la sociedad se los presentaba formalmente como libres e iguales, el daño aparecía como un conducta desviada que debía ser reencausada por medio de la sanción del agente dañador, y muy especialmente haciendo hincapié en el aspecto patrimonialista de la problemática." Carlos Ghersi, Teoría de la reparación de daños (Buenos Aires: Editorial Astrea, 2013), 32.

3 "A la responsabilidad se le atribuía una función disuasiva: era concebida como la sanción impuesta para quien, trasgrediendo el precepto del neminem laedere, hubiese causado perjuicio al derecho de otros." Francesco Galgano, I fatti illecitti (Padua: Casa Edirtice Dott. Abtonio Millani, 2008), 15.

4 "La institución de la responsabilidad civil de la Administración puede y debe servir para controlar el buen funcionamiento de los servicios públicos. Esta es una función que no se debe malograr y que conviene potencializar." Oriol Mir, La responsabilidad de la adminsitración: Hacia un nuevo sistema (Madrid: Civitas ediciones, 2002), 147-148.

5 "Esa función pedagógica supone que la Administración aprenda a cómo debe actuar en el futuro para evitar ser condenada." Luis Rebollo, Responsabilidad patrimonial de las entidades locales (Madrid: Editorial Iustel, 2005), 221. 
- Económica: la visión económica del derecho de daños, iniciada por Guido Calabresi, ${ }^{6}$ considera que las personas son racionales en sus decisiones, calculando los costos de sus actuaciones y, por esto, si el daño causado es mayor que el beneficio obtenido, las personas lo evitarán. Como lo explica Coleman: "Esta característica podría resumirse en que la responsabilidad extracontractual articula un marco de permisos y precios, de juicios sobre lo que pueden hacer los individuos y los precios que deben pagar para hacerlo". ${ }^{7}$

- Solidaridad: la solidaridad que se predica inherente a los Estados sociales de derecho es otra función que se le ha atribuido a la responsabilidad estatal. ${ }^{8}$ La tesis de la redistribución de riqueza ha sido fuertemente criticada por la doctrina, al entender que la naturaleza de la responsabilidad es muy diversa a la de otras figuras, como los fondos, las subvenciones u otros tipos de medidas asistenciales desarrolladas por el Estado. ${ }^{9}$

- Reparadora: la función reparadora o de garantía se basa en la justicia correctiva y busca la reparación de los daños causados por el Estado a los particulares. ${ }^{10} \mathrm{Al}$ sufrir un daño a su patrimonio, por afectación a sus bienes materiales o inmateriales, lo que se busca

6 "Guido Calabresi fue el primer autor en hacer en hacer un estudio sistemático, aunque sin valerse de modelos formales, de los objetivos económicos del derecho de daños." Diego Papayannis, Comprensión y justificación de la responsabilidad extracontractual (Madrid: Marcial Pons, 2014), 39.

7 Jules Coleman, Riesgos y daños (Madrid: Marcial Pons, 2010), 92.

8 "De allí que la solidaridad no puede ser entendida única y exclusivamente como expresión de la justicia distributiva aristotélica, sino que, por el contrario, puede llegar a expresar — desde el plano de la responsabilidad - un sustento filosófico y jurídico para determinar cuándo alguien está compelido a indemnizar el perjuicio causado." Enrique Gil, La constitucionalización del derecho de daños (Bogotá: Editorial Temis, 2014), 21.

9 "El derecho de la responsabilidad patrimonial es ajeno por completo a cualquier finalidad asistencial, sin que los mecanismos jurídicos de la beneficencia tengan nada que ver con él. La responsabilidad patrimonial no es obra jurídica de misericordia; y cualesquiera medidas de signo asistencial que compensen los daños sufridos (al margen del responsable) rebasan sus límites intrínsecos, insertándose en el seno de un Estado Social, como reacción tuitiva frente a la insalvable insuficiencia de su regulación." Luis Medina, "La responsabilidad patrimonial de las Adminsitraciones Públicas", en Lecciones y materiales para el estudio del derecho administrativo (Madrid: Iustel, 2009), 54.

10 "No cabe en efecto, concebir una responsabilidad administrativa que no tenga como objetivo prioritario que la compensación de daños, la indemnización a las víctimas.” Mir, La responsabilidad, 144. 
es que la persona no vea disminuida las condiciones en las que se encontraba antes de la ocurrencia del hecho. Así, como lo expresa Juan Henao, "El daño es la causa de la reparación y la reparación es la finalidad última de la responsabilidad civil". ${ }^{11}$

- Preventiva: pretende influenciar en el comportamiento de los agentes que pueden generar la responsabilidad, con el fin de evitar la ocurrencia de otros daños. ${ }^{12}$ Así, la función preventiva tiene como objetivo primordial cambiar la motivación de los agentes ${ }^{13}$ al mostrarles el impacto negativo de su conducta (demasiado oneroso, fuertes sanciones o grave deterioro medioambiental) y, con esto, poder evitar que se cometan nuevos daños.

- Reparación integral: el desarrollo de las ideas sobre reparación integral surgió de la necesidad de perfilar mejor la función reparadora de la responsabilidad estatal. Con esto, los operadores jurídicos pretenden hacer aplicable en la práctica una reparación que realmente pueda indemnizar todos los aspectos del patrimonio de la víctima, es decir, tanto los daños materiales como los inmateriales que haya sufrido.

- Transformadora: una reciente propuesta creada para ser utilizada en situaciones posconflicto o donde se han producido violaciones a derechos humanos es la función transformadora. ${ }^{14}$ La justicia transformadora que se aplica en casos puntuales de sociedades

11 Henao, El daño, 37.

12 "Las reglas de la responsabilidad civil pueden así cumplir una benéfica función preventiva. Adecuadamente configurada, pueden inducir a todos los sujetos implicados a tomar medidas eficientes de precaución contra el riesgo de que ciertos bienes jurídicos resulten lesionados." Gabriel Doménech, "El principio de responsabilidad patrimonial de los poderes públicos, en Los principios jurídicos del derecho administrativo (Madrid: Editorial la Ley, 2010), 667.

13 "El correcto y completo despliegue de esta función preventiva exige que la responsabilidad civil (y el estímulo que representa) alcance no solo a la Administración, como organización, sino también a las concretas personas físicas que la integran y actúan a su servicio." Mir, La responsabilidad, 145.

14 "Así pues, de cara a las violaciones masivas y protuberantes de los derechos en Colombia, exponen la necesidad de apreciar la reparación no solo como una forma de justicia correctiva, sino como un modo de impulsar transformaciones democráticas en la sociedad."Juan Henao, "Las formas de reparación en la responsabilidad del Estado: hacia su unificación sustancial en todas las acciones contra el Estado", en La responsabilidad extracontractual del Estado (Bogotá: Universidad Externado de Colombia, 2015), 110. 
desiguales busca armonizar las nociones clásicas de justicia correctiva y distributiva, y se materializa en programas de reparación. ${ }^{15}$

\section{Principios del Acuerdo}

Como se explicó en la introducción de este libro, el "Acuerdo final para la terminación del conflicto y la construcción de una paz estable y duradera" está compuesto por un preámbulo, una introducción y seis puntos que son: 1) hacia un nuevo campo colombiano: Reforma Rural Integral; 2) participación política: apertura democrática para construir la paz; 3) fin del conflicto; 4) solución al problema de las drogas ilícitas; 5) acuerdo sobre las víctimas del conflicto: "Sistema Integral de Verdad, Justicia, Reparación y No Repetición”, incluyendo la Jurisdicción Especial para la Paz; y Compromiso sobre Derechos Humanos; y 6) implementación, verificación y refrendación. Además, el texto presenta al final un acápite sobre protocolos y anexos.

En la parte introductoria del Acuerdo se encuentra la "Declaración de principios" del 7 de junio del 2014, donde se establecen los siguientes diez principios: reconocimiento de las víctimas; reconocimiento de la responsabilidad; satisfacción de los derechos de las víctimas; participación de las víctimas; esclarecimiento de la verdad; reparación de las víctimas; garantías de protección y seguridad; garantía de no repetición; principio de reconciliación; y enfoque de derechos. ${ }^{16}$ A continuación se analizará cada uno de estos principios, lo cual resulta relevante para la línea argumentativa seguida en este texto.

- Reconocimiento de las víctimas: "Es necesario reconocer a todas las víctimas del conflicto, no solo en su condición de víctimas,

15 “Por ello, hemos desarrollado el concepto de 'reparaciones transformadoras', o reparaciones dirigidas a promover la transformación democrática, como un esfuerzo por articular la justicia correctiva y la justicia distributiva en el diseño e implementación de los programas de reparación.” Rodrigo Uprimny y Diana Guzman, "En la búsqueda de un concepto transformador y participativo para las repraraciones en contextos transicionales". Revista colombiana de derecho intenacional, n. ${ }^{\circ} 17$ (2010): 252.

16 Véase Mesa de Conversaciones, "Acuerdo final para la terminación del conflicto y la construcción de una paz estable y duradera”, 24 de noviembre del 2016, 124-125, https://www.mesadeconversaciones.com.co/sites/default/files/24-1480106030.11 1480106030.2016nuevoacuerdofinal-1480106030.pdf 
sino también y principalmente, en su condición de ciudadanos con derechos". ${ }^{17}$ Este principio consagra la centralidad de la víctima en el Acuerdo, lo que se traduce en hacer prevalecer los derechos de las personas afectadas por el conflicto por encima de intereses políticos o conveniencias de otros sujetos participantes o no en la guerra.

- Reconocimiento de la responsabilidad: "Cualquier discusión de este punto debe partir del reconocimiento de responsabilidad frente a las víctimas del conflicto. No vamos a intercambiar impunidades". ${ }^{18}$ La responsabilidad por los hechos cometidos durante el conflicto armado deberá ser asumida siempre, el proceso de paz no puede servir de instrumento para evitar que los victimarios puedan eludir sus compromisos por los daños causados a los damnificados.

- Satisfacción de los derechos de las víctimas: "Los derechos de las víctimas del conflicto no son negociables; se trata de ponernos de acuerdo acerca de cómo deberán ser satisfechos de la mejor manera en el marco del fin del conflicto". ${ }^{19}$ Nuevamente, se destaca el enfoque sobre la protección de los derechos de la víctima, precisando que no son renunciables o negociables. Lo único que se busca es que sean respetados e indemnizados de la manera más favorable posible.

- Participación de las victimas:

La discusión sobre la satisfacción de los derechos de las víctimas de graves violaciones de derechos humanos e infracciones al Derecho Internacional Humanitario con ocasión del conflicto, requiere necesariamente de la participación de las víctimas, por diferentes medios y en diferentes momentos. ${ }^{20}$

Para lograr la verdadera garantía de la satisfacción de los derechos de las víctimas de violaciones de derechos humanos e infracciones al DIH, se requiere una participación activa de las víctimas durante todo el procedimiento y no en un momento concreto.

\footnotetext{
17 Ibid., 124.

18 Ibid., 124.

19 Ibid., 124.

20 Ibid., 124.
} 
- Esclarecimiento de la verdad:

Esclarecer lo sucedido a lo largo del conflicto, incluyendo sus múltiples causas, orígenes y sus efectos, es parte fundamental de la satisfacción de los derechos de las víctimas, y de la sociedad en general. La reconstrucción de la confianza depende del esclarecimiento pleno y del reconocimiento de la verdad. ${ }^{21}$

El derecho a conocer la verdad es una de las metas del proceso de paz, puesto que permite reconstruir la confianza entre los intervinientes y, sobre todo, en el Estado colombiano. Así mismo, permite identificar los hechos, las causas y los efectos de la guerra, para poder conocer sus alcances, reparar la totalidad de los daños y evitar la ocurrencia de hechos similares.

- Reparación de las víctimas:

Las víctimas tienen derecho a ser resarcidas por los daños que sufrieron a causa del conflicto. Restablecer los derechos de las víctimas y transformar sus condiciones de vida en el marco del fin del conflicto es parte fundamental de la construcción de la paz estable y duradera. ${ }^{22}$

La reparación de las víctimas debe ser integral, indemnizando tanto los daños materiales como los inmateriales que hayan padecido por la guerra. Del mismo modo, se debe buscar que los afectados vivan en condiciones de paz que les garanticen la protección de sus derechos.

- Garantías de protección y seguridad: "Proteger la vida y la integridad personal de las víctimas es el primer paso para la satisfacción de sus demás derechos”. ${ }^{23}$ En este apartado se destaca la necesidad de proteger la vida y la integridad de las personas, para que no queden en la situación de vulnerabilidad en la que se encontraban durante la existencia del conflicto armado.

\footnotetext{
21 Ibid., 124.

22 Ibid., 124.

23 Ibid., 125.
} 
- Garantía de no repetición:

El fin del conflicto y la implementación de las reformas que surjan del Acuerdo Final, constituyen la principal garantía de no repetición y la forma de asegurar que no surjan nuevas generaciones de víctimas. Las medidas que se adopten tanto en el punto 5 como en los demás puntos de la Agenda deben apuntar a garantizar la no repetición de manera que ningún colombiano vuelva a ser puesto en condición de víctima o en riesgo de serlo. ${ }^{24}$

Para que los colombianos podamos vivir en paz, es necesario que los daños que se produjeron a las personas durante la guerra no se repitan y que los hechos queden en la memoria colectiva para que los ciudadanos nunca más estén en condición de víctima o en riesgo de serlo.

- Principio de reconciliación: "Uno de los objetivos de la satisfacción de los derechos de las víctimas es la reconciliación de toda la ciudadanía colombiana para transitar caminos de civilidad y convivencia". ${ }^{25} \mathrm{Se}$ debe tener presente que para que haya una verdadera reconciliación entre los intervinientes en el conflicto con sus víctimas es necesario que se satisfagan todos los derechos de las víctimas y, a partir de esto, se empiece a vivir civilizadamente y en convivencia en Colombia.

- Enfoque de derechos:

Todos los acuerdos a los que lleguemos sobre los puntos de la Agenda y en particular sobre el punto 5 "Víctimas" deben contribuir a la protección y la garantía del goce efectivo de los derechos de todos $\mathrm{y}$ todas. Los derechos humanos son inherentes a todos los seres humanos por igual, lo que significa que les pertenecen por el hecho de serlo, y en consecuencia su reconocimiento no es una concesión, son universales, indivisibles e interdependientes y deben ser considerados en forma global y de manera justa y equitativa. En consecuencia,

\footnotetext{
24 Ibid., 125.

25 Ibid., 125.
} 
el Estado tiene el deber de promover y proteger todos los derechos y las libertades fundamentales, y todos los ciudadanos el deber de no violar los derechos humanos de sus conciudadanos. Atendiendo los principios de universalidad, igualdad y progresividad y para efectos de resarcimiento, se tendrán en cuenta las vulneraciones que en razón del conflicto hubieran tenido los derechos económicos, sociales y culturales. ${ }^{26}$

Este principio reivindica la importancia de los derechos humanos que tienen todas las personas y busca el compromiso tanto del Estado como de los particulares para que cesen las violaciones a los derechos humanos en nuestro país.

Concretamente, en el tema de reparación patrimonial, los anteriores principios son importantes en la medida en que indican los parámetros generales que serán utilizados por los actores para lograr la reparación de las víctimas, incentivar el reconocimiento de los derechos humanos, evitar que se repitan estas situaciones, que exista el perdón entre los implicados, se conozca la verdad y para que los colombianos puedan vivir pacíficamente.

De la lectura de los principios mencionados, se puede concluir que el Acuerdo busca la reparación integral a las víctimas, hasta el punto de mencionarla textualmente en el "Principio a la reparación de las víctimas". Adicionalmente, se puede percibir otro interés en las partes contratantes en evitar que se presenten nuevos daños tanto para las víctimas actuales como las futuras, supuesto en el que cobra vigencia la función preventiva.

Finalmente, se debe tener presente que estos principios son de obligatorio cumplimiento, por lo que deben ser acatados tanto por el Estado como por los miembros de las FARC, y que se aplican a todas las actuaciones e indemnizaciones que se realicen desde el momento de la firma del Acuerdo.

\section{La reparación integral en el Acuerdo}

En el Acuerdo Final se hace recurrente referencia a la noción de reparación integral, que, como se observó, es tan solo una posibilidad entre otras para

\footnotetext{
26 Ibid., 125.
} 
determinar las condiciones en las que se realizará la reparación de los daños. Como se verá a continuación, la noción de reparación integral desarrollada en el Acuerdo ha sido acogida mayoritariamente por la doctrina, la legislación y la jurisprudencia nacional.

La reparación integral surgió de la necesidad de perfilar mejor la función reparadora, buscando que se logre un resarcimiento que realmente deje a la víctima en las condiciones en que se hallaba antes de producirse el perjuicio. Siguiendo a García de Enterría y a Tomás Ramón Fernández:

El principio general era (y es), por lo demás muy claro: la indemnización debe dejar "indemne" a la víctima del daño injusto, debe procurar una reparación integral del detrimento que dicho daño ha supuesto para su patrimonio, debe restituir este en su pleno valor anterior al suceso dañoso, debe cubrir; por tanto, todos los "daños y perjuicios" sufridos, "en cualquiera de sus bienes o derechos" (...). ${ }^{27}$

Aunque es evidente la gran acogida que tiene la noción de reparación integral en el derecho colombiano, es pertinente advertir que hay parte de la doctrina que considera que no se deberían seguir sus parámetros, sino los establecidos por la reparación transformadora, por tratarse de un caso tan complejo como el del conflicto interno del país.

Con base en lo anterior, es necesario desarrollar tres puntos fundamentales sobre el tema de la reparación integral que son: 3.1 ) la reparación integral en la doctrina administrativista; 3.2) sus principales críticas desde el punto de vista de la doctrina de la reparación transformadora; y 3.3) la consagración de la reparación integral en el ordenamiento jurídico.

\subsection{La reparación integral en la doctrina administrativista colombiana}

La doctrina colombiana ha reconocido la vigencia del principio de reparación integral, entre quienes se destacan Javier Tamayo, ${ }^{28}$ Libardo Rodríguez, ${ }^{29}$

27 Eduardo García de Enterría y Tomás Fernádez, Curso de derecho administrativo II (Navarra: Editorial Civitas, 2015), 419-420.

28 Javier Tamayo, Tratado de responsabilidad civil II (Bogotá: Legis, 2011), 543.

29 Libardo Rodríguez, Derecho administrativo. General y colombiano (Bogotá: Temis, 2015), 656. 
Juan Henao, ${ }^{30}$ Ramiro Saavedra, ${ }^{31}$ Enrique Gil,,${ }^{32}$ Orlando Santofimio ${ }^{33}$ y Hugo Arenas. ${ }^{34}$

Según la doctrina más autorizada, para una verdadera reparación integral es necesario indemnizar tanto los daños materiales ${ }^{35}$ como los inmateriales ${ }^{36}$ causados a la víctima dentro del conflicto armado. Así mismo, para que se produzca una efectiva reparación es necesario que se actualice el valor de la condena al momento de ser pagada al afectado o de lo contrario se producirán sanciones meramente simbólicas, que no permitan resarcir adecuadamente el daño percibido. ${ }^{37}$

En todo caso, es recomendable hacer uso de una noción más profunda de reparación integral, como la proporcionada por Orlando Santofimio, quien le otorga un carácter jurídico, político y sociológico, sustentando que

En este sentido es mucho y materialmente más que un simple concepto indemnizatorio, al involucrar ideas de reconstrucción y reivindicación del ser humano en la sociedad. Luego el concepto de reparación conlleva cargas de individualismo pero también de responsabilidad colectiva. Desde una perspectiva estrictamente

30 Henao, El daño, 45.

31 Ramiro Saavedra, La responsabilidad extracontractual de la administración pública (Bogotá: Editorial Ibáñez, 2003), 605.

32 Gil, La constitucionalización, 47.

33 Alán Brewer-Carías y Jaime Santofimio, Control de convencionalidad y responsabilidad del Estado (Bogotá: Universidad Externado de Colombia, 2013), 239.

34 Hugo Arenas, El régimen de responsabilidad objetivo (Bogotá: Editorial Legis, 2013), 145.

35 "En cuanto a la cobertura de los daños baste señalar que la indemnización debe cubrir el daño emergente y el lucro cesante, en orden a procurar una reparación integral del daño." Francisco de Ahumada, La responsabilidad patrimonial de las Administraciones Públicas (Pamplona: Aranzadi, 2009), 197.

36 "Con base al principio de la integra reparación del daño, de hecho, no debe ser ignorado el aspecto no patrimonial de las lesiones ocasionadas por la administración. No tendría ningún sentido limitar tan solo al daño patrimonial la protección ofrecida al privado." Alessio Liberati, La responsabilità della pubblica ammninistrazione ed il risarcimento del danno (Padova: Cedam, 2009), 180.

37 "El principio de reparación integral exige que se valore el daño atendiendo a la fecha en que se produjo (surgiendo, en consecuencia, la obligación resarcitoria), pero actualizando la cantidad a la fecha de la sentencia." Medina, "La responsabilidad patrimonial", 78. 
jurídica, es un derecho de toda víctima, sustentado en las ideas de verdad y justicia. ${ }^{38}$

En la reparación integral el agente central es la víctima, entonces es en torno a ella que deben orientarse las actuaciones realizadas por las partes. Para esto, es necesario entender que el patrimonio de las personas incluye bienes materiales e inmateriales y, por esto, la reparación integral no debe ser solo económica, sino que implica entender la situación particular del individuo, abordando, por ejemplo, cuestiones psicológicas, físicas, sociológicas y simbólicas.

\subsection{Sus principales críticas desde el punto de vista de la doctrina de la reparación transformadora}

Aunque la función de la reparación integral es la que mayor acogida tiene en la actualidad, no quiere decir que exista unanimidad en el derecho nacional, sino que ha sido objeto de fuertes críticas. En este momento, se hará referencia a las cuatro objeciones más importantes formuladas por sus principales detractores, quienes consideran que para el caso del conflicto armado colombiano sería mucho más viable recurrir a una reparación trasformadora.

- La imposibilidad de retornar a la situación inicial: el principio de reparación resulta inaplicable en ciertas ocasiones en que es imposible regresar a la situación original:

En general, frente a las violaciones más graves de los derechos humanos, como una ejecución extrajudicial o una desaparición forzosa, el principio de restitutio in integrum resulta inaplicable pues no es posible retornar a la víctima a la situación en la cual se encontraba antes de que ocurriera la atrocidad. ${ }^{39}$

- La reparación integral solo aplica para perjuicios materiales: en los casos de perjuicios inmateriales no es real hablar de la aplicación de una verdadera reparación integral, quedando de lado el daño

\footnotetext{
38 Brewer-Carías y Santofimio, Control de convencionalidad, 239.

39 Uprimny y Guzman, “En la búsqueda”, 240.
} 
moral, daño corporal y las afectaciones a los bienes constitucional o convencionalmente protegidos. En palabras de Milagros Koteich:

Por el contrario, cuando se trata de los perjuicios no económicos o de carácter personal, tal afirmación puede resultar poco "realista" (...), pues, por carecer de precio el bien o interés lesionado, no es posible, si se nos permite la expresión, ir a la plaza o mercado — con la cantidad concedida - a "readquirir" la integridad psicofísica vulnerada en forma permanente a la dignidad ofendida; como sí lo es en cambio cuando se trata de la lesión a un bien de carácter económico, por lo que puede sostenerse que cuando se trata del perjuicio extrapatrimonial o personal, no es posible, sin incurrir en un artificio, hablar de verdadera "reparación integral" (....). ${ }^{40}$

- La reparación integral no funciona para situaciones como el conflicto armado interno colombiano: la reparación integral está pensada para situaciones de normalidad en que, por regla general, no se violan derechos humanos: "Así, el principio la reparación integral genera paradojas y dilemas difíciles en sociedades que intentan saldar cuentas frente a violaciones graves y masivas a los derechos humanos, ocurridas en regímenes autoritarios o durante conflictos armados". ${ }^{41}$

- La reparación integral no está pensada para situaciones de responsabilidad colectiva: a las anteriores tres críticas se ha de agregar que no es la misma aproximación jurídica que se debe aplicar en caso de que se trate de pocas víctimas o cuando se trate de colectividades. La reparación trasformadora lograría un mejor resultado de la utilización de los recursos públicos al realizar un programa común que favorezca al conjunto de afectados y no tratar de indemnizar mínimamente a cada uno de los afectados.

40 Milagros Koteich, La reparación del daño como mecanismo de tutela de la persona (Bogotá: Unviersidad Externado de Colombia, 2012), 326-327.

41 Uprimny y Guzman, "En la búsqueda”, 235. 


\title{
3.3. La consagración de la reparación integral en el ordenamiento jurídico colombiano
}

En Colombia, a partir de la Ley 446 de 1998, se estableció normativamente la reparación integral del daño, explicando que:

\begin{abstract}
Art. 16. Dentro de cualquier proceso que se surta ante la Administración de Justicia, la valoración de los daños irrogados a las personas y a las cosas, atenderá los principios de reparación integral y equidad y observará los criterios técnicos actuariales.
\end{abstract}

En ocasiones, se ha pretendido desdibujar el contenido de la reparación integral, diciendo que lo que pretendía el legislador era utilizar o una reparación integral o, en otras, una reparación en equidad. Afortunadamente, se ha aclarado que la reparación integral se debe llevar a su máxima expresión sin tener en consideración cuestiones presupuestales para bajar los montos de la condena a las víctimas.

Posteriormente, la reparación integral se ha mantenido en las leyes 975 del 2005, 1448 del 2011 y 1592 del 2012, las cuales están encaminadas a situaciones relativas a los daños producidos en el marco del conflicto armado interno colombiano. Esta normatividad incluyó las nuevas formas de reparación integral, que superan las tradicionales formas de indemnización dineraria o por especie.

Se debe tener presente que la jurisprudencia colombiana ha consagrado la noción de reparación integral; tanto la Corte Constitucional (ver sentencias C-228 del 2002, C-370 del 2006, C-575 del 2006, C-1199 del 2008, C-029 del 2009 y C-286 del 2014), como el Consejo de Estado (por ejemplo, en las sentencias de unificación del 28 de agosto del 2014, exps. 28804, $31172,36149,27709,26251,28832,32988$ y 31170$)$ se puede apreciar que se “(...) ha ampliado sustancialmente la reparación por fuera de aquella monetaria, es otra muestra del esfuerzo del juez en una interpretación más favorable a los administrados sustentada en normas constitucionales y en general en el bloque de constitucionalidad". ${ }^{42}$

42 Juan Henao, "Estado social y derecho administrativo", en La constitucionalización del derecho administrativo (Bogotá: Universidad Externado de Colombia, 2014), 197. 


\title{
3.4. La reparación integral en el Acuerdo Final para la terminación del conflicto y la construcción de una paz estable y duradera
}

El Acuerdo Final hace referencia en más de diez ocasiones a la noción de reparación integral, estableciendo que es un criterio orientador fundamental para la defensa de los derechos de las víctimas. En el tema concreto, de las medidas de reparación integral para la construcción de la paz establece:

\begin{abstract}
Medidas de reparación integral para la construcción de la paz: Se trata de medidas que buscan asegurar la reparación integral de las víctimas, incluyendo los derechos a la restitución, la indemnización, la rehabilitación, la satisfacción y la no repetición; y la reparación colectiva de los territorios, las poblaciones y los colectivos más afectados por el conflicto y más vulnerables, en el marco de la implementación de los demás acuerdos. Con este fin, se fortalecerán los mecanismos existentes, se adoptarán nuevas medidas, y se promoverá el compromiso de todos con la reparación del daño causado. ${ }^{43}$
\end{abstract}

De la lectura del anterior párrafo, se puede derivar que el enfoque de la reparación integral ha sido el elegido por las partes contratantes para reparar los daños causados, dentro del conflicto armado interno, siendo el más acorde con los lineamientos del ordenamiento jurídico colombiano $y$, en consecuencia, con el bloque tanto de constitucionalidad como el de convencionalidad.

Las medidas enunciadas son las más benéficas para las víctimas, con lo que se logra que cada uno de los daños reales sufridos por los afectados sea reconocido e indemnizado de la manera más adecuada. Así, la reparación integral permite discriminar cada una de las lesiones y elegir si se debe reparar volviendo a la situación anterior al daño o se debe recurrir a otras formas de reparación como la material o la simbólica.

Además, se establece la posibilidad de utilizar medidas de reparación integral tanto individuales como colectivas. Por una parte, las tradicionales medidas individuales de reparación son las de restitución, indemnización, rehabilitación, satisfacción y no repetición, y por la otra, las medidas

43 Véase Mesa de Conversaciones, "Acuerdo final”, 129-130. 
de reparación colectivas, que se estarán fortaleciendo según la aplicación del Acuerdo.

Se debe tener presente que de la lectura conjunta del Acuerdo se desprende que los daños serán reparados integralmente, en primera medida por sus causantes, y el Estado concurrirá subsidiariamente a la reparación cuando los causantes no tengan dinero para pagarlos.

\section{Las medidas de reparación integral para la construcción de la paz}

La reparación integral busca que la víctima sea resarcida en cada uno de los ámbitos en que fue lesionada, por esto se deben indemnizar los daños psicológicos, físicos y económicos. En el derecho se permite la compensación de diferentes clases o tipologías de daños, las cuales varían dependiendo del lugar y del momento al que se haga referencia.

En la actualidad en Colombia se reconoce la satisfacción tanto de los daños materiales como los inmateriales. Los primeros se clasifican en daño emergente y lucro cesantes, mientras que los segundos se subdividen en daño moral, daño a la salud y la vulneración a bienes constitucional o convencionalmente protegidos. ${ }^{44}$

Siguiendo los lineamientos del derecho internacional público, que han sido aplicados por las cortes colombianas en sus sentencias, ${ }^{45}$ el texto del Acuerdo nombra las medidas alternativas individuales establecidas de reparación integral para la construcción de la paz que buscan que se reparen tanto los daños materiales como los inmateriales que ha padecido la víctima.

\subsection{Las medidas individuales de reparación integral para la construcción de la paz incorporadas en el Acuerdo}

Las medidas individuales de reparación integral son mecanismos encaminados a satisfacer a la víctima de una manera particular; se busca que el individuo sea resarcido en cada uno de los daños sufridos, bien sean psicológicos, físicos, económicos o a su dignidad. El Acuerdo hace referencia, aunque solo las menciona, a las siguientes medidas individuales de

${ }^{44}$ Hugo Arenas, Un siglo de jurisprudencia del Consejo de Estado en materia de responsabilidad extracontractual (Bogotá: Ibáñez, 2015), 263-275.

45 Sobre el tema véase Brewer-Carías y Santofimio, Control de convencionalidad, 316-347. 
reparación integral: restituir, indemnizar, rehabilitar, satisfacer y no repetir. Adicionalmente, debido al énfasis especial que se hace sobre el tema en el Acuerdo, se debe hacer mención puntual a la recuperación emocional.

- Restituir: la restitución se puede definir como las actuaciones enfocadas a regresar a la víctima a la situación anterior a la comisión de los hechos, por ejemplo, que se le permita retornar al lugar del que fue desplazado o devolverle sus bienes tanto materiales como inmateriales.

- Indemnizar: la indemnización se puede entender como la compensación monetaria de un perjuicio, que debe corresponder con el monto del detrimento patrimonial sufrido; por esto, es necesario que se indemnice tanto el daño material como el inmaterial y se debe actualizar la suma al presente.

- Rehabilitar: por rehabilitación se puede entender el conjunto de actuaciones realizadas hacia el bienestar de la víctima, tratando de recuperarla de las lesiones tanto psicológicas o físicas que haya padecido. Algunos ejemplos de medidas de rehabilitación serían la terapia física parar lograr la movilidad de alguna parte del cuerpo que haya sido afectada, o la psicológica, para lograr superar algún recuerdo o sentimiento causado por el conflicto armado.

- Satisfacer: para lograr la satisfacción de la víctima se pueden utilizar otras medidas simbólicas, con las que se busca lograr reparar algunos daños que pueden afectar otros derechos como la dignidad o el buen nombre de las personas. En este sentido, se puede ordenar, entre otras posibilidades, que se erija un monumento, se reconozca que actuaron inadecuadamente o se presenten disculpas públicas a los afectados.

- Garantías de no repetición: las garantías de no repetición buscan que las personas que hayan sufrido un daño no lo vuelvan a padecer. Para esto, se debe establecer las causas que originaron el daño y asegurar especial protección a las víctimas, para que no vayan a quedar de nuevo en situaciones de vulnerabilidad. Este tema es desarrollado con mayor profundidad en el punto 5.1.4. del Acuerdo.

- Recuperación emocional: el Acuerdo desarrolla textualmente las medidas de recuperación emocional a nivel individual, estableciendo: 
En el marco del fin del conflicto, y con el fin de atender y contribuir a aliviar el sufrimiento de las víctimas, el Gobierno Nacional y las FARC-EP hemos acordado que el Gobierno Nacional, en desarrollo de este Acuerdo, se compromete a ampliar la cobertura pública y despliegue territorial, y mejorar la calidad de la atención psico-social para la recuperación emocional de las víctimas de acuerdo al daño específico que hayan padecido, entre ellas las afectaciones particulares de las víctimas de violencia sexual. Para ello se multiplicarán los centros locales de atención a las víctimas y se impulsarán estrategias móviles para llegar a los lugares más apartados.

Así mismo, en cumplimiento de los acuerdos alcanzados el Gobierno Nacional fortalecerá el acceso y los servicios de salud mental para las víctimas que así lo requieran. ${ }^{46}$

Este apartado desarrolla medidas de reparación tanto colectivas como individuales, pero no queda duda de que la recuperación emocional a nivel individual y el mejoramiento en la cobertura de los servicios de salud mental para las víctimas que lo requieran es un mecanismo que contribuirá a facilitar la reparación integral de los afectados.

\subsection{Las medidas colectivas de reparación integral para la construcción de la paz establecidas en el Acuerdo}

Al lado de las medidas de reparación integral individual, el Acuerdo incorpora las medidas de reparación integral colectivas. Estas buscan tutelar los derechos de varias víctimas que hayan sufrido daños similares, como consecuencia de unos hechos parecidos; también se puede tratar de colectivos o grupos de personas que han sufrido de daños conjuntos. ${ }^{47}$ En todo caso, deben quedar completamente reparadas todas las lesiones padecidas, tanto los perjuicios materiales como los inmateriales.

46 Véase Mesa de Conversaciones, “Acuerdo final”, 181.

47 "Es decir, se refiere al caso de que haya una multiplicidad de sujetos afectados individualmente, todos ellos identificados o identificables, caso en el cual por vía doctrinal se sostiene que estamos ante un daño masivo o grupal, que no es más que una manera de identificar la multiplicidad de daños individuales." Orlando Santofimio, "La cláusula constitucional de la responsabilidad del Estado: estructura, régimen y el principio de convencionalidad como pilar de su construcción dogmática”, en Estudios sobre el control de convencionalidad (Caracas: Editorial Jurídico venezolana, 2015), 370. 
Las medidas colectivas son desarrolladas en el punto "Reparación: medidas de reparación integral para la construcción de paz", en el que se explica cada uno de los diversos mecanismos, a diferencia de las individuales a las que simplemente menciona. De este modo, hace referencia a: actos tempranos de reconocimiento de responsabilidad colectiva; acciones concretas de contribución a la reparación; reparación colectiva en el fin del conflicto; rehabilitación psicosocial; procesos colectivos de retornos de personas en situación de desplazamiento y reparación de víctimas en el exterior; medidas sobre restitución de tierras; y adecuación y fortalecimiento participativo de la política de atención y reparación integral a víctimas en el marco del fin del conflicto, y contribución a su reparación material.

- Actos tempranos de reconocimiento de responsabilidad colectiva: se trata de actos por parte de los responsables de los daños causados durante el conflicto para que reconozcan su responsabilidad colectiva y pidan perdón a las víctimas. Estos actos deberán ser formales, públicos y solemnes, y se llevarán a cabo tanto en el ámbito nacional como en el territorial. ${ }^{48}$

- Acciones concretas de contribución a la reparación: es la posibilidad que tienen las partes que causaron los daños para que puedan realizar operaciones concretas de reparación a las víctimas. El Gobierno nacional se compromete a tomar medidas para garantizar la participación en las distintas medidas de reparación y las FARC se obligan, por ejemplo, a reincorporarse a la vida civil y a realizar acciones para reparar los daños causados (reparación de infraestructura, recolección de minas antipersonales, destrucción de municiones, sustitución de cultivos, ubicación de restos de personas, búsquedas de desaparecidos y reparación del daño ambiental). ${ }^{49}$

- Reparación colectiva en el fin del conflicto: busca fortalecer los procesos de reparación colectiva, manteniendo el enfoque reparador en sus planes y programas de la reforma rural integral. El Acuerdo diferencia entre estos tres lineamientos: 1) carácter reparador de los planes de desarrollo rural con enfoque territorial, 2) planes

\footnotetext{
48 Véase Mesa de Conversaciones, "Acuerdo final”, 178.

49 Véase Mesa de Conversaciones, “Acuerdo final”, 178-179.
} 
de reparación colectiva con enfoque territorial y 3) planes nacionales de reparación colectiva. ${ }^{50}$

- Rebabilitación psicosocial: un importante punto en el Acuerdo es la reparación de las víctimas en cada uno de los daños sufridos y, por ende, se le da un tratamiento especial al tema de los efectos que pueden producir los hechos ocurridos en la mente de las personas. El Acuerdo se subdivide en medidas de recuperación a nivel individual (tema que se trató en el apartado anterior) y el plan de rehabilitación psicosocial para la convivencia y no repetición, con el que se busca aumentar la rehabilitación comunitaria, para la reconstrucción del tejido social y, en general, la recuperación de la confianza, la convivencia y la paz. ${ }^{51}$

- Procesos colectivos de retornos de personas en situación de desplazamiento y reparación de victimas en el exterior: son unos programas colectivos específicos de retorno y reubicación de víctimas, tanto para desplazados internos como para los que se encuentren en el exterior, que buscan la seguridad, la dignidad y la voluntariedad. Estos procesos colectivos deben tener en cuenta los elementos de identificación de territorios, la coordinación interinstitucional, la seguridad en los territorios para el retorno y el fortalecimiento de los defensores comunitarios. $^{52}$

- Medidas sobre restitución de tierras: son mecanismos tendientes a fortalecer y dinamizar los procesos de restitución de tierras. Entre sus lineamientos se destacan la utilización de expertos, de criterios técnicos, la construcción de infraestructura, el acceso a los servicios públicos, programas de reconstrucción de sus vidas, de generación de ingresos, sustitución de cultivos ilícitos, reconstrucción del tejido social y la construcción de memoria para la reconciliación. ${ }^{53}$

- Adecuación y fortalecimiento participativo de la politica de atención y reparación integral a víctimas en el marco del fin del conflicto y contribución a la reparación material de las victimas: las partes del Acuerdo

\footnotetext{
50 Véase Mesa de Conversaciones, “Acuerdo final”, 179-181.

51 Véase Mesa de Conversaciones, “Acuerdo final”, 181-182.

52 Véase Mesa de Conversaciones, "Acuerdo final”, 182-183.

53 Véase Mesa de Conversaciones, “Acuerdo final”, 184.
} 
consideran la necesidad de fortalecer la política de atención y reparación integral a la víctimas, logrando la mayor cobertura posible. Para esto, es necesaria la participación de las víctimas, organizaciones de víctimas, expertos académicos, entidades internacionales, organizaciones especializadas y defensores de derechos humanos. A partir de estas opiniones, el Gobierno debe adecuar sus políticas y su ordenamiento jurídico, y, en general, facilitar los mecanismos necesarios para su ejecución. ${ }^{54}$

Con el acogimiento del enfoque de reparación integral, las partes contratantes han acertado al aceptar el modelo más favorable para las víctimas, permitiendo que se pueda llegar a las necesidades tanto personales como colectivas de las personas, porque en muchas ocasiones se trata de grupos muy extensos de personas, lo que hace posible la utilización de medidas encaminadas a solventar necesidades conjuntas y no solo a dar indemnizaciones monetarias.

\section{Conclusiones}

Existen varios enfoques o funciones que se le pueden atribuir a la responsabilidad patrimonial por las reparaciones que se realizan con base en los daños producidos en los conflictos armados, por ejemplo, punitiva, preventiva, control social, económica, solidaria, reparadora, transformadora y reparación integral. El Acuerdo de Paz colombiano ha incorporado los lineamientos tendientes a la realización de la reparación integral, siguiendo los parámetros imperantes en la doctrina, la legislación y la jurisprudencia colombiana, aunque existen fuertes críticas por parte de los defensores de la reparación trasformadora.

El tema de las reparaciones integrales a las víctimas de los daños causados dentro del conflicto armado interno está desarrollado principalmente en el quinto apartado del Acuerdo, que se titula "Sistema Integral de Verdad, Justicia, Reparación y No Repetición”. El Acuerdo, siguiendo parámetros del derecho internacional y de la propia jurisprudencia colombiana, ha

\footnotetext{
54 Véase Mesa de Conversaciones, “Acuerdo final”, 184-186.
} 
establecido medidas de reparación integral para la construcción de la paz, clasificándolas en individuales y colectivas.

Las medidas individuales de reparación integral son mecanismos encaminados a satisfacer a la víctima de una manera particular. Se busca que el individuo sea resarcido totalmente en cada uno de los daños sufridos, bien sean psicológicos, físicos, económicos o a su dignidad. El Acuerdo establece como medidas individuales de reparación integral para la construcción de la paz las de restituir, indemnizar, rehabilitar, satisfacer, no repetir y la recuperación emocional. Desafortunadamente, no profundiza en cada una de las anteriores nociones; tampoco, hace referencia a los tipos de daños que reconocerá y no es clara sobre la actualización de los valores de las condenas.

Las reparaciones colectivas integrales buscan tutelar los derechos de varias víctimas que han sufrido daños similares como consecuencia de unos hechos parecidos; también se puede tratar de colectivos o grupos de personas que han padecido de daños conjuntos. En todo caso, deben quedar completamente reparadas todas las lesiones padecidas, tanto los perjuicios materiales como los inmateriales. Las medidas colectivas de reparación contenidas en el Acuerdo son: los actos tempranos de reconocimiento de responsabilidad colectiva; las acciones concretas de contribución a la reparación; la reparación colectiva en el fin del conflicto; la rehabilitación psicosocial; los procesos colectivos de retornos de personas en situación de desplazamiento y reparación de víctimas en el exterior; las medidas sobre restitución de tierras; y la adecuación y el fortalecimiento participativo de la política de atención y reparación integral a víctimas en el marco del fin del conflicto y contribución a su reparación material.

Las medidas de reparación individual y colectiva no son excluyentes entre sí; sin embargo, primero, se debe recurrir a las individuales y solamente si no se logra una reparación total es conveniente acudir a las segundas. Esto garantiza que todos los daños sean efectivamente solventados, puesto que las reparaciones colectivas en ocasiones no llegan a todas las víctimas o se pueden destinar recursos a otros beneficios que no produzcan el resultado esperado.

El objetivo de la reparación integral patrimonial del daño fijado en el Acuerdo es que se indemnice totalmente a la víctima, para esto es necesario reconocer tanto los daños materiales como los inmateriales y que se actualicen los montos a los precios actuales. Se puede utilizar cualquier 
mecanismo individual o colectivo, lo importante es que no se indemnice dos veces por el mismo concepto.

El enfoque de reparación integral elegido en el Acuerdo es una visión que concibe a la víctima como eje central de las reparaciones y que, como ser humano, debe ser indemnizado en cada uno de los aspectos que fueron vulnerados. Del mismo modo, las ideas plasmadas en el Acuerdo logran superar las cuatro principales críticas provenientes de la reparación transformadora, puesto que: 1) a pesar de que en ocasiones no se puede retornar a la situación previa al daño, prevé la posibilidad de mecanismos alternativos para reparar el daño; 2) reconoce la necesidad de solventar los daños tanto materiales como morales; 3) su aplicación está en perfecta consonancia con la finalización del conflicto interno colombiano y 4) logra abordar eficientemente las hipótesis en que se deben reparar daños colectivos.

\section{Bibliografía}

Arenas Mendoza, Hugo. El régimen de responsabilidad objetivo. Bogotá: Legis, 2013.

Arenas, Hugo. Un siglo de jurisprudencia del Consejo de Estado en materia de responsabilidad extracontractual. Bogotá: Ibáñez, 2015.

Brewer-Carías, Alán y Orlando Santofimio. Control de convencionalidad y responsabilidad del Estado. Bogotá: Universidad Externado de Colombia, 2013.

Coleman, Jules. Riesgos y daños. Madrid: Marcial Pons, 2010.

De Ahumada, Francisco. La responsabilidad patrimonial de las administraciones públicas. Pamplona: Aranzadi, 2009.

Doménech, Gabriel. "El principio de responsabilidad patrimonial de los poderes públicos”, en Los principios jurídicos del derecho administrativo, 664-697. Madrid: Editorial la Ley, 2010.

Galgano, Francesco. I fatti illecitti. Padua: Casa Edirtice Dott. Antonio Millani, 2008.

García de Enterría, Eduardo y Tomás Fernádez. Curso de derecho administrativo II, Navarra: Editorial Civitas, 2015.

Ghersi, Carlos. Teoría de la reparación de daños. Buenos Aires: Editorial Astrea, 2013.

Gil, Enrique. La constitucionalización del derecho de daños. Bogotá: Editorial Temis, 2014. 
Henao, Juan. El daño. Análisis comparativo de la responsabilidad extracontractual del Estado en el derecho colombiano y en el francés. Bogotá: Universidad Externado de Colombia, 2007.

Henao, Juan. "Estado social y derecho administrativo", en La constitucionalización del derecho administrativo, 145-201. Bogotá: Universidad Externado de Colombia, 2014.

Henao, Juan. "Las formas de reparación en la responsabilidad del Estado: hacia su unificación sustancial en todas las acciones contra el Estado", en La responsabilidad extracontractual del Estado, 32-117. Bogotá: Universidad Externado, 2015.

Koteich, Milagros. La reparación del daño como mecanismo de tutela de la persona. Bogotá: Universidad Externado de Colombia, 2012.

Ley 446 de 1998, 7 de julio. Por la cual se adoptan como legislación permanente algunas normas del Decreto 2651 de 1991, se modifican algunas del Código de Procedimiento Civil, se derogan otras de la Ley 23 de 1991 y del Decreto 2279 de 1989, se modifican y expiden normas del Código Contencioso Administrativo y se dictan otras disposiciones sobre descongestión, eficiencia y acceso a la justicia. Diario Oficial 43.335.

Ley 975 del 2005, 25 de julio. Por la cual se dictan disposiciones para la reincorporación de miembros de grupos armados organizados al margen de la ley, que contribuyan de manera efectiva a la consecución de la paz nacional y se dictan otras disposiciones para acuerdos humanitarios. Diario Oficial 45.980.

Ley 448 del 2011, 10 de junio. Por la cual se dictan medidas de atención, asistencia y reparación integral a las víctimas del conflicto armado interno y se dictan otras disposiciones. Diario Oficial 48.096.

Ley 1592 del 2012, 3 de diciembre. Por medio de la cual se introducen modificaciones a la Ley 975 de 2005 "por la cual se dictan disposiciones para la reincorporación de miembros de grupos armados organizados al margen de la ley, que contribuyan de manera efectiva a la consecución de la paz nacional y se dictan otras disposiciones para acuerdos humanitarios" y se dictan otras disposiciones. Diario Oficial 48.633.

Liberati, Alessio. La responsabilità della pubblica ammninistrazione ed il risarcimento del danno. Padova: Cedam, 2009. 
Medina, Luis. "La responsabilidad patrimonial de las adminsitraciones públicas", en Lecciones y materiales para el estudio del derecho administrativo, 69-116. Madrid: Iustel, 2009.

Mesa de Conversaciones. "Acuerdo final para la terminación del conflicto y la construcción de una paz estable y duradera”, 24 de noviembre del 2016, https:/www.mesadeconversaciones.com.co/sites/ default/files/24-1480106030.11 1480106030.2016nuevoacuerdofinal-1480106030.pdf

Mir, Oriol. La responsabilidad de la adminsitración: Hacia un nuevo sistema. Madrid: Civitas ediciones, 2002.

Papayannis, Diego. Comprensión y justificación de la responsabilidad extracontractual. Madrid: Marcial Pons, 2014.

Rebollo, Luis. Responsabilidad patrimonial de las entidades locales. Madrid: Editorial Iustel, 2005.

Rodríguez, Libardo. Derecho administrativo. General y colombiano. Bogotá: Temis, 2015.

Saavedra, Ramiro. La responsabilidad extracontractual de la administración pública. Bogotá: Editorial Ibáñez, 2003.

Santofimio, Orlando. "La cláusula constitucional de la responsabilidad del Estado: estructura, régimen y el principio de convencionalidad como pilar de su construcción dogmática”, en Estudios sobre el control de convencionalidad, 167-426. Caracas: Editorial Jurídico venezolana, 2015.

Sentencia C-228 del 2002, 3 de abril. MP: Manuel José Cepeda Espinosa y Eduardo Montealegre Lynett.

Sentencia C-370 del 2006, 18 de mayo. MP: Manuel José Cepeda Espinosa, Jaime Córdoba Triviño, Rodrigo Escobar Gil, Marco Gerardo Monroy Cabra, Álvaro Tafur Galvis, Clara Inés Vargas Hernández.

Sentencia C-575 del 2006, 25 de julio. MP: Álvaro Tafur Galvis.

Sentencia C-1199 del 2008, 4 de diciembre. MP: Nilson Pinilla Pinilla. Sentencia C-029 del 2009, 28 de enero. MP: Rodrigo Escobar Gil.

Sentencia C-286 del 2014, 20 de mayo. MP: Luis Ernesto Vargas Silva.

Sentencia de Unificación del 28 de agosto del 2014. Exp. 28804.

Sentencia de Unificación del 28 de agosto del 2014. Exp. 31172.

Sentencia de Unificación del 28 de agosto de 2014. Exp. 36149.

Sentencia de Unificación del 28 de agosto de 2014. Exp. 27709. 
Sentencia de Unificación del 28 de agosto de 2014. Exp. 26251.

Sentencia de Unificación del 28 de agosto de 2014. Exp. 28832.

Sentencia de Unificación del 28 de agosto de 2014. Exp. 32988.

Sentencia de Unificación del 28 de agosto de 2014. Exp. 31170.

Tamayo, Javier. Tratado de responsabilidad civil II. Bogotá: Legis, 2011.

Uprimny, Rodrigo y Diana Guzmán. "En la búsqueda de un concepto transformador y participativo para las repraraciones en contextos transicionales". Revista colombiana de derecho intenacional, n. ${ }^{\circ} 17$ (2010), 232-286. 



\title{
El debate por la propiedad de la tierra, el punto por donde debe comenzar una pedagogía de la paz
}

\author{
Sergio Latorre Restrepo*
}

\section{Introducción}

E1 2 de octubre del 2016, a las 4:45 pm, cuando la Registraduría Nacional del Estado Civil expidió el boletín número 8 de los resultados del plebiscito por la paz, el panorama político de Colombia cambió drásticamente. El boletín indicaba que el porcentaje de votos por el No superaba el anticipado y mayoritario voto por el Sí en algo menos que 25.000 votos; eventualmente el No superaría la votación del Sí por 53.894. ${ }^{1}$ Este inesperado bandazo de la ya imprevisible vida política nacional nos ponía de cara a buscar explicaciones de los nuevos acontecimientos, explicaciones post-facto que desde la academia y la sociedad civil hemos venido desarrollando para explicar con argumentos más o menos convincentes lo que pasó.

Resulta cada vez más cierto que el miedo, la desconfianza y, en algunos casos, el odio y el resentimiento fueron factores importantes que incidieron en el fracaso de la refrendación del plebiscito. Sn embargo, al enfocarnos

* Doctor en Ciencias Jurídicas (S. J. D.) de la Universidad de Cornell. Profesor del área de Derecho Civil de la Universidad del Norte, Barranquilla. Miembro del Grupo de Investigación en Derecho y Ciencia Política - Gidep - y del grupo de investigación Conflictos y postconflictos desde la región Caribe. Este trabajo es fruto de la investigación "La propiedad de la transición de la paz-los retos de la teoría de la propiedad en Colombia".

1 Página web Registraduría Nacional del Estado Civil, http://plebiscito.registraduria.gov. co/99PL/DPL 
en este tipo de explicaciones invisibilizamos la discusión sobre cada uno de los puntos de la agenda y las posiciones adoptadas por la sociedad en torno a los puntos de la negociación. Más allá de la negociación política derivada del rechazo al plebiscito y que ha llevado a adelantar nuevas negociaciones entre los sectores representativos del No y el Gobierno nacional, lo realmente significativo del momento actual es la oportunidad tanto de seguir profundizando en los contenidos del Acuerdo como de discutir sobre cada uno de los puntos y sobre otros temas que no se incluyen en este pero que son necesarios para sentar las bases para la paz.

Una decisión sobre el Acuerdo "en bloque", como la que planteó el plebiscito, no alcanza a revelar matices sobre la posición del electorado en torno a cada uno de los puntos. ${ }^{2}$ Resulta claro que individualmente considerados no todos estos tenían el mismo nivel de rechazo por la mayoría. Ciertamente el punto dos, sobre la participación política, y el punto cinco, en lo concerniente a la jurisdicción especial para la paz, han sido aquellos que más resquemor y resistencia explícita y masiva despertaron dentro del electorado. Sin embargo, el tema de la reforma rural integral amerita un análisis particularmente complejo, pues si bien las críticas explícitas de la

2 La Corte, en la Sentencia C-379 del 2016, revisando la legalidad del plebiscito y comparándolo con otras fórmulas como el referendo multitemático, estableció que el plebiscito debería tener una sola pregunta. Al respecto la Corte consideró que: "En el caso analizado, el Acuerdo Final ha sido comprendido en esta sentencia como la definición de una política pública de un proceso de negociación entre el Gobierno y un grupo armado ilegal, lo cual dista de ser un articulado concreto. El Acuerdo Final, en tanto decisión política, debe ser entendido como un todo, integrado por asuntos transversales, no separables. De allí que resulte justificado que la integralidad del Acuerdo Final y no sus componentes particulares, sean sometidos al escrutinio del Pueblo. Si se aceptara que la votación pudiese hacerse de manera seccionada, entonces ello generaría irresolubles problemas, debido a que si el Acuerdo Final es parcialmente aprobado, no solo generaría su desarticulación, sino también obligaría a una renegociación del mismo, a pesar que la competencia exclusiva para ello la tiene el Presidente. Por ende, en tanto el Acuerdo Final corresponde a una decisión política del Presidente, según se ha explicado insistentemente en este fallo, al Pueblo convocado en plebiscito le corresponde aprobar o improbar dicho Acuerdo. En consecuencia, si el elector está parcialmente en desacuerdo con la agenda de acción política fruto de la negociación del Gobierno, deberá ponderar dicho desacuerdo frente a una visión integral sobre los contenidos del Acuerdo Final, a fin de decidir si opta por apoyarlo o rechazarlo. (...) En suma, la Corte encuentra que el plebiscito especial contenido en el pLE no puede ser jurídicamente considerado como un referendo, por una razón simple: lo que se está sometiendo a la consideración del Pueblo no es un articulado que se inserte autónoma y directamente en el orden jurídico, sino una política objeto de implementación normativa posterior". 
oposición en torno a este fueron pocas y muchas de ellas mal informadas, ${ }^{3}$ fue el punto de tierras uno de los que recibió más propuestas de modificación por parte de los promotores del No en el periodo posplebiscitario. ${ }^{4}$

¿Qué revela la presentación de una agenda de tantas propuestas de modificación ${ }^{5}$ para un punto que en principio no despertaba tanta resistencia popular? Este capítulo parte del supuesto de que el tema de la tierra permite ver, tal vez como ningún otro, una división entre la discusión electoral que se llevó a cabo durante la época preplebiscitaria y una discusión real sobre la propiedad en el campo, que subyace como uno de los puntos de mayor tensión en la base de la negociación.

Lo cierto es que para las élites rurales y los grandes propietarios de tierra del país, la tierra y el desarrollo agrario representan uno de los puntos más sensibles del posacuerdo más allá de los falsos fantasmas de la expropiación y la amenaza a la propiedad privada. La democratización del acceso a la tierra y la transformación de las estructuras de poder en el campo que pudiese conseguir el Acuerdo representan un riesgo para estas ya consolidadas élites en términos de su configuración histórica, económica y social. De igual forma, la transformación del campo viene a ser uno de los puntos de importancia histórica para las Fuerzas Armadas Revolucionarias de

3 Véase, por ejemplo, Luis Guillermo Echeverri Vélez, "En defensa de la legalidad: los tales principios para la paz", Primero Colombia, 18 de diciembre del 2015, http://www.primerocolombia. com/sites/default/files/en_defensa_de_la_legalidad.pdf

4 Véase, por ejemplo, "En las cinco primeras propuestas de Uribe no están las víctimas", Revista Semana, 9 de octubre del 2016, http://www.semana.com/nacion/articulo/alvaro-uribe-presentasus-propuestas-para-el-acuerdo-de-paz/498437; "Las propuestas de Marta Lucía Ramírez para renegociar con las Fuerzas Armadas Revolucionarias de Colombia (farc)", W Radio, 10 de octubre del 2016, http://www.bluradio.com/nacion/reforma-la-justicia-y-proteccion-la-familia-propuestasde-martha-lucia-ramirez-119045; "Las cinco propuestas de los del 'No' en el plebiscito", El Tiempo, 16 de octubre del 2016, http://www.eltiempo.com/politica/proceso-de-paz/propuestas-de-los-delno-en-el-plebiscito/16727272

5 Se propusieron temas que estaban más allá de lo pactado como, por ejemplo, derogar la Ley 1448 del 2011, en cuanto a la inversión de la carga de la prueba para opositores a predios inscritos en el registro de predios despojados. La inversión en la carga de la prueba, que establece que aquel que se oponga a un proceso de restitución debe entrar a probar su buena fe calificada al momento de la transacción, es para muchos uno de los elementos más importantes de la ley de víctimas y restitución de tierras. Véase "Propuestas del Centro Democrático: ¿realistas o para dilatar?", El Espectador, 14 de octubre del 2016, http://www.elespectador.com/noticias/politica/propuestas-realistas-o-dilatararticulo-660359 
Colombia (FARC), cuyo origen campesino se encuentra fuertemente atado a las demandas por una reforma rural profunda y al acceso a la tierra.

No obstante lo anterior, es interesante resaltar que este punto que simboliza conflictos de poder históricos fue también uno donde, primero, se alcanzaron acuerdos entre el Gobierno y la guerrilla, y donde hasta cierto punto se han logrado consensos con los promotores del No. En este aparte la guerrilla ha cedido en algunas de sus posiciones más ambiciosas de cara a alcanzar el acuerdo en lo referente a la distribución de la propiedad rural y a la protección de la agricultura campesina. Igualmente, luego de las modificaciones al Acuerdo, se incluye un nuevo principio: el desarrollo integral del campo, en el que se establece que este "depende de un adecuado balance entre las diferentes formas de producción existentes — agricultura familiar, agroindustria, turismo, agricultura comercial de escala”.

Si bien la consagración de este principio que ha aceptado la coexistencia entre la agricultura rural y la agroindustria ayuda a superar el escollo de las negociaciones, todavía no es claro cómo se pueden acomodar dos modelos y visiones tan diferentes sobre el campo. Aunque el Estado siga apostándole de manera paralela a dos modelos de desarrollo para el campo, es precisamente la imposibilidad de superar varias de las contradicciones derivadas de estos modelos lo que ha hecho al mundo rural el escenario más propicio para la violencia. De hecho, este tipo de solución política al punto de la tierra, por lo menos la discusión poselectoral, concluida con la incorporación del principio de desarrollo integral en el nuevo acuerdo, genera grandes incertidumbres y puntos sin resolver que ponen de manifiesto la compleja y profunda discusión que todavía subsiste sobre el campo. La solución propuesta en lugar de superar esas contradicciones las mantiene.

Es por eso que es vital utilizar lo acordado y debatido en La Habana para propiciar una reflexión sobre la tierra, el agro y cómo se ha abordado el ordenamiento de sus complejas relaciones de poder desde lo jurídico, político e institucional. Este es precisamente uno de los puntos más cruciales y sensibles para consolidar la paz real en el país.

En este sentido, este capítulo tiene como objetivo presentar una descripción y análisis de los contenidos del Acuerdo de Reforma Rural Integral y sus recientes modificaciones, en el contexto del estado actual del campo colombiano. Con base en lo anterior, propone algunos puntos que no se recogen en las negociaciones pero que serán de vital importancia considerar 
de cara a lograr consolidar en el campo un ambiente de bienestar y equidad necesarios para consolidar la paz.

Esta discusión no resulta sino siendo un paso o, si se quiere, un medio más, mediante el cual se puede reactivar dicho debate sobre lo rural y sus connotaciones históricas, políticas y jurídicas más importantes, tal vez para que en un futuro dicho debate sea realizado con más profundidad y pese más sobre la forma en que el electorado toma sus decisiones.

\section{El estado del campo}

El campo ha sido el epicentro del conflicto colombiano. Contrario a lo que se presumía como una aguda transformación de la Colombia rural a la Colombia urbana en la segunda mitad del siglo xx y un paulatino abandono del campo hacia las ciudades, estudios como la Misión para la Transformación del Campo (Misión Rural), ${ }^{6}$ realizado en el 2013, nos muestran cómo la vida rural sigue teniendo un peso muy elevado en el país: "cerca del $60 \%$ de los municipios que tiene Colombia deben considerarse rurales y existe, además, una población rural dispersa en el resto de municipios, con lo cual la población rural representa poco más de $30 \%$ de la población del país”. El estudio enfatiza además que muchas de nuestras ciudades intermedias e incluso grandes siguen teniendo una relación muy estrecha con las actividades agropecuarias.

En ese sentido, el campo en Colombia, como lo sostiene el PNUD en su informe Colombia rural. Razones para la esperanza, ${ }^{7}$ se ha mantenido como un espacio rezagado al proceso de modernización, en parte porque "el modelo de desarrollo y la modernización han ignorado y desvalorizado lo rural, porque han visto a los conglomerados urbanos como la opción más viable para alcanzar el progreso y lograr mejores niveles de vida”. Según este informe, esa opción por lo urbano y por la industrialización llevó al país a "darle la espalda a la sociedad rural dejando el problema agrario sin

6 José Antonio Ocampo, Misión para la Transformación del Campo. Marco conceptual de la Misión para la Transformación del Campo (Bogotá: Departamento Nacional de Planeación, octubre 2014), 4.

7 Programa de las Naciones Unidas para el Desarrollo — PNuD-. Colombia rural: Razones para la esperanza. Informe Nacional de Desarrollo Humano (Bogotá: INDH/PNUD, 2011), 30, https://www. dane.gov.co/files/CensoAgropecuario/avanceCNA/CNA_agosto_2015_new_present.pdf 
solución, agudizando la pobreza y la desigualdad, generando conflictos y, con ello, disminuyendo las oportunidades de sus pobladores". ${ }^{8}$

Hoy la principal justificación para la negociación de un acuerdo de paz es precisamente la crítica situación en la que se encuentra el campo colombiano. Así, los datos de la Misión Rural revelan que "[e]1 89\% de la población rural es pobre o vulnerable, es decir con alta probabilidad de caer en pobreza". Si bien se aclara en el informe que se han realizado avances para reducir la pobreza en términos amplios (multidimensional), en donde se incluyen también las políticas sociales a nivel de educación, vivienda y salud, lo cierto es que la pobreza a nivel de ingresos ha aumentado. El informe revela cómo la política social ha hecho mucho más por mejorar la situación de la población rural que las oportunidades económicas y la generación de ingresos en el campo, que "han sido muy limitadas para los habitantes pobres del campo". 9

Aun así, si se compararan con el sector urbano, el desempeño en muchos de estos servicios muestra los grandes rezagos del sector rural. El bajo logro educativo en las zonas rurales es notorio. Mientras que la población urbana de 15 años y más tiene al menos los 9 años de educación obligatoria, la población en zona rural tiene tan solo primaria completa (5,1 años). Según la Encuesta de Calidad de Vida del 2012, citada en el informe de la Misión para la Transformación del Campo o Misión Rural, ${ }^{10}$ mientras que la cobertura en acueducto en la zona rural es de $53 \%$ y en alcantarillado es de $16 \%$, la de la zona urbana es de $97 \%$ y $92 \%$, respectivamente.

En cuanto a la dimensión de salud, si bien ya no hay brechas significativas en afiliación a seguridad social entre la zona rural y urbana, el informe Misión Rural ${ }^{11}$ ilustra que existen grandes diferencias en acceso, uso y calidad de los servicios entre cabeceras y población dispersa. Igualmente, el informe menciona cómo muchos asalariados del campo carecen de los mecanismos de protección social:

\footnotetext{
PNUD, Colombia rural, 30.

PNUD, Colombia rural, 9.

10 Ocampo, Misión para la Transformación.

11 Ibid.
} 
Este hecho y, aún más, el predominio de prácticas informales de trabajo, implica que algunos mecanismos de protección social (el sistema pensional) casi no existen en las zonas rurales y otros tienen un desarrollo precario (acceso a los servicios de las Cajas de Compensación) o están caracterizados por serios problemas de calidad. ${ }^{12}$

En relación con la distribución de tierras, el diagnóstico es igualmente preocupante, pues la desigualdad en la distribución de la propiedad rural es elevadísima en Colombia (coeficientes de Gini del orden de 0,8-0,9, según la medida específica utilizada), según el informe. ${ }^{13}$ Esta situación se ha mantenido a pesar de los sucesivos esfuerzos de reforma agraria. En este mismo sentido, el Censo Nacional Agrario realizado en el 2014 encontró que el 69,9\% de unidades de producción agrícolas tienen menos de 5 hectáreas y ocupan menos del $5 \%$ del área censada, mientras que el 0,4\% de unidades en Colombia tienen 500 o más hectáreas y ocupan el 41,1\% del área censada. Así mismo, el censo revela que en los últimos 55 años se incrementó la proporción de las unidades de menos de 5 hectáreas en todo el territorio nacional. ${ }^{14}$ Esto nos habla con claridad de que a la par de los problemas de concentración de la tierra, el problema de la fragmentación improductiva de la tierra no solo se mantiene sino que se ha acrecentado, ilustrando ambas dinámicas de concentración y fragmentación no como opuestas, sino mutuamente dependientes e interrelacionadas.

Igualmente, la producción agropecuaria sigue estando insuficientemente diversificada y desarrollada. Sin embargo, aunque las actividades agropecuaria y piscícola hoy están subdesarrolladas, hay una creciente actividad minera que ha entrado en conflictos por recursos, como el agua y la tierra, con las actividades agropecuarias en muchas zonas del país. Se observa el surgimiento de servicios de diferente naturaleza que se prestan desde los núcleos poblados y en algunas zonas se ha desarrollado un importante turismo rural. El informe destaca en particular que la actividad del sector agropecuario muestra en el último cuarto de siglo un comportamiento

\footnotetext{
12 Ibid., 8.

13 PNud, Colombia rural.

14 PNUD, Colombia rural.
} 
decepcionante, de hecho uno de los más decepcionantes de América Latina. En este mismo sentido, el Censo Nacional Agropecuario del 2014 encontró que solo un $18 \%$ de los productores agropecuarios tiene acceso a sistemas de riego, $10 \%$ a la asistencia técnica y solo un $9 \%$ a créditos formales.

En relación con el uso del suelo, el informe de Misión Rural ${ }^{15}$ afirma que este no corresponde siempre con su vocación y, en particular, hay todavía muchos terrenos planos con vocación agrícola que se utilizan para ganadería extensiva, en tanto que la agricultura familiar con vocación agrícola se tiende a localizar en las laderas, en condiciones que presentan desafíos para su desarrollo, y sostenibilidad económica y ambiental. También menciona el estudio que hay "un conflicto creciente en el uso del agua y la tierra y serios problemas asociados a la ocupación de humedales e insuficiente regulación de corrientes que genera problemas de inundaciones en épocas de lluvias". ${ }^{16}$

Finalmente, se menciona como último factor de la crisis del campo la persistente debilidad institucional. La red institucional de los años cincuenta y sesenta con la cual se buscó implementar la Reforma Agraria del gobierno Lleras Restrepo, que servía relativamente bien en las tareas rurales aunque con deficiencias, fue desarticulada. A partir de los noventa y principios del nuevo milenio las funciones y competencias de por lo menos cuatro instituciones para el sector rural con tradiciones totalmente diferentes buscaron reorganizarse a través de una sola, el Instituto Colombiano de Desarrollo Rural - Incoder - lo que a la postre terminó por deteriorar a cada una de sus misiones. Frente al marcado deterioro de la institucionalidad del sector, el gasto se fue concentrando en el Ministerio de Agricultura y Desarrollo Rural, en programas como el cuestionado Agro Ingreso Seguro y algunos otros con mejores proyecciones, como las iniciativas derivadas del Pacto Agrario.

Aunque las funciones principales del Ministerio deben ser la planeación, el diseño de la política sectorial y la orientación de sus empresas e institutos adscritos para que sean estos quienes ejecuten los programas de gasto diseñados desde el Ministerio, hoy se mantiene el rol excluyente del

\footnotetext{
15 Ocampo, Misión para la Transformación.

16 Ibid., 16.
} 
Ministerio mientras se somete al sector a un rediseño y reestructuración. Los resultados de dicho proceso de rediseño tanto para acomodar algunos de los puntos del Acuerdo, como para incorporar algunas de las recomendaciones de la misión rural aún son demasiado prematuros para determinar si ellos podrán generar las condiciones necesarias para una real y eficaz presencia institucional en el sector rural.

\section{Lo que propone el Acuerdo en cuanto a la política de desarrollo agrario integral}

\subsection{Generalidades}

El desarrollo rural ha sido uno de los temas centrales en las negociaciones llevadas a cabo entre el Gobierno nacional y las Fuerzas Armadas Revolucionarias de Colombia-Ejército del Pueblo (FARC-EP). El primer punto del Acuerdo General para la terminación del conflicto y la construcción de una paz estable y duradera, llamado "Hacia un nuevo campo colombiano: Reforma Rural Integral”, fue acordado el 26 de mayo del 2013 como el primero de los puntos del Acuerdo, ${ }^{17}$ aunque posteriormente se fueron incorporando algunos elementos adicionales hasta la última versión del Acuerdo del 12 de noviembre del 2016 (el nuevo acuerdo). ${ }^{18}$

En términos conceptuales, el acuerdo sobre el desarrollo rural se puede caracterizar en tres sentidos: primero, mantiene intacto el andamiaje jurídico bajo el cual se conceptualizan las relaciones de propiedad sobre la tierra y se regula su acceso y uso, enfatizando en los mecanismos de formalización

17 El grueso del punto sobre desarrollo rural fue el primer tema acordado el 26 de mayo del 2013. Sin embargo, innumerables veces las partes mantuvieron la posición de que ninguno de los puntos estaba acordado hasta que todo estuviera acordado.

18 Durante la negociación, en el tema agrario la mesa ha publicado diferentes versiones sobre este punto: cuatro documentos centrales constatan los cambios y modificaciones que se realizaron: el “Acuerdo General, Informe Conjunto de la Mesa”, sobre el punto 1, publicado en enero del 2014; el "Borrador Conjunto: Política de desarrollo agrario integral" publicado el 24 de septiembre del 2014; el Primer Acuerdo Final en su integridad del 24 de agosto del 2016; y finalmente el Segundo Acuerdo Final publicado el 12 de noviembre del 2016 (ajustado finalmente el 24 de noviembre del 2016), sobre el cual se centra nuestro análisis en este capítulo. Véase Mesa de Conversaciones, "Acuerdo sobre política de desarrollo rural integral”, 2016, punto 1 de la agenda, https://www.mesadeconversaciones. com.co/sites/default/files/24-1480106030.11-1480106030.2016nuevoacuerdofinal-1480106030.pdf 
y organización del territorio rural; segundo, plantea, aunque de manera general, un enfoque de desarrollo territorial; y tercero, actualiza una política de reforma agraria a las nuevas circunstancias de una economía mundial y a la liberalización del comercio en temas como acceso a servicios, nuevas tecnologías, seguridad alimentaria y la promoción de la agricultura orgánica.

Por lo demás, se destacan en los acuerdos la creación de múltiples espacios de concertación y participación activa de las comunidades en la definición de políticas y planes de implementación en diferentes aspectos (educación, comercialización, manejo medioambiental, entre otros), así como el desarrollo de políticas en torno al reconocimiento de la mujer rural. No obstante lo anterior, el Acuerdo plantea una coexistencia problemática entre modelos de desarrollo opuestos, como el modelo de la agricultura familiar campesina y el de desarrollo agroindustrial en el sector rural. De esta manera, genera inquietudes respecto a las posibilidades reales de lograr un desarrollo coherente y armónico de ambos modelos en contexto de desigualdad social, política y económica, y ante la frágil presencia institucional en las zonas rurales.

Los acuerdos sobre desarrollo rural están organizados en tres temas centrales: acceso y uso de tierras, programa de desarrollo con enfoque territorial —PDET-, y planes nacionales para la reforma rural integral; este último se desarrolla a partir de una elaboración de planes nacionales sobre temas como infraestructura rural, salud y educación rural, entre otros. En dicho documento, ambas partes dejan explícitamente consignado que lograr los acuerdos sobre este punto es determinante para impulsar la integración de las regiones, y el desarrollo social y económico equitativo del país. El territorio rural se concibe, por lo demás, como un escenario con diversidad social y cultural, en donde hombres y mujeres desempeñan su papel en la definición del mejoramiento de sus condiciones de vida y en la definición del desarrollo del país dentro de una visión de integración urbano-rural.

A continuación procederé a explicar cada uno de los tres temas centrales que se desarrollan en el punto 1, Reforma Rural Integral. 


\subsection{Acceso y uso de la tierra ${ }^{19}$}

En lo que se refiere a la política de acceso y uso de tierras, el Acuerdo mantiene la estructura jurídica según la cual se ha intentado organizar la tenencia de la tierra rural en Colombia. ${ }^{20} \mathrm{El}$ Acuerdo es claro en que no se establece modificación alguna al régimen de la propiedad consolidada sobre predios rurales. En varias ocasiones el Gobierno manifestó que el régimen de propiedad privada no es materia de revisión o negociación y que no hacía parte de los puntos de la agenda. Posteriormente, en el nuevo Acuerdo de Paz presentado posplebiscito se hace mención explícita a ello:

$19 \mathrm{Al}$ momento de realizar las revisiones finales de este capítulo se había expedido ya el Decreto 902 del 2017, 29 de mayo. Por el cual se adoptan medidas para facilitar la implementación de la Reforma Rural Integral contemplada en el Acuerdo Final en materia de tierras, específicamente el procedimiento para el acceso y formalización y el Fondo de Tierras. Dicho decreto, expedido a tan solo unas horas de que vencieran las facultades extraordinarias otorgadas al ejecutivo por el Acto Legislativo 01 de 2016 (Acto Legislativo para la Paz), junto con otras medidas sobre diferentes temas del Acuerdo, se constituyó en el desabrido desenlace de la discusión sobre el proyecto de decreto con fuerza de ley para el Ordenamiento Social de la Propiedad y Tierras Rurales que promovió el Gobierno meses antes y que generó tanta resistencia y críticas por diferentes sectores del país.

Desde diferentes orillas se criticaron multiplicidad de aspectos del proyecto de decreto con fuerza de ley, como el poder excesivo otorgado a la Agencia Nacional de Tierras en lo relacionado con la negociación directa o expropiación de predios para dar cumplimiento a los Acuerdos de Paz que podía lesionar la seguridad jurídica de la propiedad, o el reconocimiento como beneficiarios a título oneroso de aquellas personas naturales o jurídicas cuyo patrimonio neto fuese superior a los 500 salarios mínimos y a quienes se les otorgaba la posibilidad de que recibiesen predios rurales para su uso o explotación, solo por mencionar algunas de las muchas objeciones.

De esta manera, dicho proyecto de decreto con fuerza de ley, que buscaba constituirse en la piedra angular de lo que sería la reglamentación del punto uno sobre Reforma Rural Integral acordado en La Habana y organizaría de una buena vez la propiedad de la tierra en el campo, quedó diluido en diferentes componentes. Se estableció que temas de gran resistencia, como la expropiación o el reconocimiento de derechos de uso y explotación, o el derecho real de superficie, deberían ser objeto de una discusión más amplia en el seno del Congreso de la República, y aquellos temas menos controversiales, como la constitución del Fondo de Tierras, las normas para la adjudicación directa y asignación del subsidio integral, y las disposiciones relacionadas con la formalización de la propiedad y la creación de un procedimiento único que permita dar mayor agilidad a estos procesos, quedó reglamentada por el Decreto 902 del 2017. Aquí valga la pena llamar la atención al lector sobre los cuestionamientos que se harán en este capítulo precisamente sobre aquellos aspectos considerados como menos controvertidos, como es el caso de la formalización.

20 El Acuerdo en su punto de desarrollo rural mantiene la estructura diseñada a partir del ordenamiento jurídico en materia agraria. Se incluye dentro de esta estructura la Ley 160 de 1994, hoy vigente, y se rescatan algunas disposiciones y enfoques propuestos por otras leyes de reformas agrarias anteriores en el país, como la Ley 135 de 1961 y la Ley 200 de 1936. 
"Nada de lo establecido en el Acuerdo debe afectar el derecho constitucional a la propiedad privada". ${ }^{21}$

Los puntos concernientes al acceso y uso de la tierra se han desarrollado a partir de tres temas clave: dotación y acceso a la tierra, formalización, registro e información de la propiedad rural,y organización del territorio rural.

Para efectos de este documento haremos referencias específicas a cada uno de estos tres puntos sustanciales por considerarlos de vital importancia tanto por los desafíos que plantean, como por las oportunidades que abren para la discusión y la posibilidad de generar algunas propuestas. ${ }^{22}$

\subsubsection{Dotación y acceso a tierras}

En consonancia con las normas civiles y agrarias vigentes, el Acuerdo especifica las fuentes de la dotación de tierras para el fondo y la forma como se llevará a cabo la correspondiente asignación de tierras a campesinos. En particular dicho fondo se constituye de: tierras provenientes de la extinción judicial de dominio a favor de la Nación (Ley 793 del 2002 y Ley 1708 del 2014); baldíos indebidamente apropiados (Ley 160 de 1994 y Decreto 1465 del 2013); tierras provenientes de la actualización, delimitación y fortalecimiento de la reserva forestal; tierras inexplotadas mediante la aplicación del actual procedimiento de extinción administrativa de dominio (Ley 160 de 1994 y Decreto 1465 del 2013); tierras adquiridas o expropiadas por motivos de interés social o de utilidad pública con la correspondiente indemnización (art. 58 CP, Ley 160 de 1994, art. 31); finalmente, las tierras donadas al fondo de tierras.

Adicionalmente, frente a las objeciones planteadas por los opositores, se incluyó en la versión de noviembre un párrafo adicional que ratifica que el aprovisionamiento para las tierras del fondo se realizará según la Constitución y siguiendo las normas legales, de forma que

${ }^{21}$ Mesa de Conversaciones. "Acuerdo final para la terminación del conflicto y la construcción de una paz estable y duradera entre el Gobierno de Colombia y las FARC-EP" (2016), 13.

22 De los 10 subpuntos establecidos en el Acuerdo para este numeral, se tratarán con mayor énfasis algunos de ellos, aunque se recogen comentarios generales sobre aspectos como la actualización del catastro e impuesto predial rural, la creación de una nueva jurisdicción agraria para la resolución de conflictos de tenencia, y el cierre de la frontera agrícola y zonificación ambiental. 
los procedimientos de expropiación administrativa por motivos de interés social y utilidad pública y la extinción administrativa del derecho de dominio por no explotación (extinción del dominio sobre tierras incultas) se aplicarán de conformidad con la Constitución y siguiendo los criterios establecidos en las leyes vigentes.

A partir de allí, el Acuerdo dispone un modelo de distribución gratuita a favor de "trabajadores y trabajadoras con vocación agraria sin tierra o con tierra insuficiente, priorizando a la población rural victimizadas", los cuales recibirán tierras que tendrán las limitaciones de inalienables e inembargables por periodo de 7 años, para evitar la concentración, a la vieja usanza, de la dotación directa de tierras prevista en la Ley 135 de 1961, y que fue posteriormente reformada con la Ley 160 de 1994; esta modificó dicho modelo estableciendo mecanismos para promover la demanda y la negociación voluntaria de tierras entre campesinos y propietarios mediante subsidios, en contraposición a la entrega directa de tierra.

Sin embargo, el Acuerdo continúa manteniendo aspectos del modelo de demanda al establecer "otros mecanismos" para promover el acceso a tierras, como los subsidios para la compra de tierras y créditos especiales. El Acuerdo consagra como beneficiarios de dichas medidas a "trabajadores con vocación agraria”, priorizando a la mujer cabeza de familia y a la población desplazada, como lo disponen ya las leyes de reforma agraria y otras disposiciones sobre población vulnerable hoy vigentes (Ley 387 de 1997, Ley 1448 del 2011, Ley 1232 del 2008).

La dificultad principal con esta serie de medidas tendientes a dotar y garantizar el acceso a tierras a la población campesina no es, como caricaturescamente se presentó a la opinión, una nueva irrupción del "castrochavismo" en Colombia; según esta, se evocaban imágenes de Hugo Chávez en algún lugar recóndito de la llanura venezolana o en el palacio de Miraflores durante su alocución en el programa Aló Presidente anunciando la expropiación de fincas, edificios privados, bancos, empresas, con la temida frase: “¡Exprópiese!” y a continuación la seguidilla de aplausos de una audiencia enardecida. Por el contrario, si algo queda claro del Acuerdo es que en nada modifica la normatividad vigente. Antes bien, su principal problema en este punto es que hereda muchos de los viejos vicios de las políticas de reforma agraria ya implementadas en el país. 
En primer lugar, no se anticipan cambios sustanciales en la figura de la expropiación por motivos de interés social o utilidad pública con indemnización previa, como se encuentra hoy reconocida constitucional y legalmente (art. 58 CP y la Ley 160 de 1994, art. 31), y que poco ha hecho como mecanismo de distribución equitativa de la tierra. Igualmente, la figura de la extinción de dominio, hoy regulada por la Ley 1708 del 2014, no termina de ser una medida eficiente que permite recuperar los bienes mediante un proceso expedito y que permite rápidamente ponerlos a disposición de los beneficiarios de programas de reforma rural.

Por otro lado, sobre los baldíos que alimentarían dicho fondo subsisten por lo menos dos problemas estructurales. Por un lado, hoy se tiene poca claridad sobre la extensión de tierras baldías con que cuenta el Estado; ni los censos de baldíos, ${ }^{23}$ ni los mecanismos de clarificación de la propiedad para determinar si han salido de la propiedad del Estado han sido efectivos para saber cuáles son las tierras baldías con que cuenta el Estado para adelantar programas de reforma rural.

23 En relación con los baldíos, Mauricio Rengifo explica cómo fue la transición de las tierras realengas de la Corona a los baldíos de la nación, y cómo desde ese momento no se han podido superar varios de los vacíos en su regulación. Sobre el particular, Rengifo afirma: "El siglo xIX estuvo marcado por importantes fenómenos de colonización. El dominio eminente sobre las tierras realengas pasó de la Corona a la nación. En adelante las tierras realengas recibieron el nombre genérico de baldíos. La política de colonización de los baldíos fue organizada por Bolívar durante los primeros años de la república. La primera medida conocida consistió en elaborar un inventario de los baldíos de la nación, que quedó a cargo de las juntas provinciales de agricultura y comercio (decreto de mayo 21 de 1820)". Sin embargo, la política de colonización de baldíos quedó truncada por diferentes razones, entre las que se cuentan la guerra de independencia y la falta de inmigración de ciudadanos europeos; por ello los baldíos se utilizaron para atender diferentes obligaciones que de otra forma el Gobierno no podía cumplir: "Por ejemplo, los militares que habían participado en las guerras de independencia recibieron en compensación por sus servicios un número significativo de hectáreas. Lo mismo sucedió con las viudas y las familias de los caídos en combate (...) lo cierto es que la política de baldíos, inicialmente concebida para dotar de propiedades a una población desposeída, se había desvirtuado en la práctica". Ya para finales del siglo xıx y "pese a la expedición del Código Civil, la estructura de tenencia de la tierra siguió siendo prácticamente la misma”. Según Rengifo “el régimen de baldíos tardó mucho tiempo en recibir la orientación necesaria para atender las demandas de tierra. Dicho régimen fue desde siempre de carácter excepcional, ya que el derecho civil permaneció en silencio sobre el verdadero modo originario de adquisición de la propiedad (...). En otras palabras: el derecho civil jamás reguló verdaderamente este importante proceso, ni estableció pautas para la distribución equitativa de la tierra". Mauricio Rengifo, Teoría general de la propiedad (Bogotá: Editorial Temis, 2011), 25-26. 
En relación con este punto, como lo sugiere Reyes, el criterio para recuperar baldíos indebidamente apropiados debe prevalecer cuando, por ejemplo, se han despojado en conflicto con ocupantes campesinos que tenían mejor derecho, cuando se los han apropiado para capturar rentas de la tierra sin cumplir la función social y ambiental, o cuando la apropiación ha afectado las reservas ambientales como ciénagas y playones, rondas de los ríos, páramos y sabanas comunales. ${ }^{24}$

No obstante lo anterior, la indebida apropiación de baldíos se relaciona con un problema estructural que se remonta a nuestro pasado colonial y a los primeros años de vida como república, pues desde entonces se ha discutido la legalidad de muchos títulos de propiedad privada. ${ }^{25}$ Hoy las condiciones políticas del Acuerdo no permiten poner en tela de juicio la propiedad de gran parte del territorio, aunque algunos de esos títulos pueden ser disputados por el Estado como baldíos indebidamente apropiados y dicha propiedad podría revertir al Estado para alimentar el Fondo. ${ }^{26}$

Un segundo problema derivado de la falta de un inventario sobre los baldíos disponibles es que parece que son pocos los que no se encuentran ocupados por campesinos o empresarios del campo, y que, en consecuencia, no tengan la expectativa de titulación a su favor. Por lo anterior, no solo se está frente a un problema de aclarar la propiedad de aquellos baldíos indebidamente apropiados, sino también resolver aquellas situaciones en las que existen expectativas de adjudicación de baldíos que llevan siendo ocupados de hecho de tiempo atrás.

En relación con la dotación para el Fondo de Tierras para la Paz, este plantea también algunos interrogantes derivados de la forma como se implementaron o se han venido implementando otros fondos similares, como

24 Alejandro Reyes, “La reversión del acuerdo agrario”, El Espectador, 22 de octubre del 2016, http://www.elespectador.com/opinion/reversion-del-acuerdo-agrario

25 Véase, por ejemplo, Rengifo, Teoría general, 70-80 y Lina Céspedes, Rocío Peña-Huertas, Daniel Cabana y Santiago Zuleta-Ríos, "Who owns the land? Litigants, justices, colonos, and titleholders' struggle to define the origins of private property in Colombia". Global Jurist, n. ${ }^{\circ} 3$ (2015).

26 De hecho si se revisaran las cadenas de transacciones, muchas de las propiedades de mayor extensión derivan sus títulos o partes de ellos de baldíos indebidamente ocupados. Es el caso, por ejemplo, de sentencias de pertenencia sobre bienes baldíos del Estado que se otorgaron en el pasado, a los cuales su naturaleza de baldíos los hacía imprescriptibles y, por lo tanto, imposibles de reclamar por vía judicial. 
el Fondo Nacional Agrario (Ley 160 de 1994), el Fondo para la Reparación de Tierras, previsto en la Ley de Justicia y Paz (Ley 975 del 2005) y el Fondo de la Unidad de Tierras para la Restitución (Ley 1448 del 2011).

Como ha sucedido con otros fondos creados con fines parecidos, las tierras que alimentarán el Fondo de Tierras para la Paz pueden presentar problemas respecto a la falta de información confiable de los predios $\mathrm{y}$ varios de los bienes que los integran se puedan encontrar inmersos en complejos procesos administrativos o judiciales. Adicionalmente, la falta de coordinación entre las diferentes disposiciones de política pública para dotación de tierras diseñadas para campesinos sin tierra y aquellas específicas para víctimas de la violencia plantean un entramado jurídico complejo que puede generar conflictos entre diferentes políticas y derivar en serios trastornos y retrasos en cuanto a la implementación de la política de dotación de tierras del Acuerdo.

Finalmente, cabe mencionar que el Acuerdo mantiene una política mixta de dotación de tierras, en la que las medidas de entrega de estas se complementan con la política de acceso a tierras a través de la demanda de subsidios y créditos por parte de campesinos para la compra, como "herramienta alternativa que contribuya a solucionar problemas puntuales de acceso". Dicho mecanismo de subsidios y créditos, que era desarrollado con la Ley 160 de 1994, modificado recientemente en el plan de desarrollo actual (art. 101 de la Ley 1753 del 2015) como subsidios integrales a la Reforma Agraria, ha mostrado un pobre desempeño en modificar las condiciones de inequidad estructural en el campo, así como resultó sumamente laborioso para los campesinos pobres sin tierra participar de dicho proceso por la gran cantidad de requisitos solicitados.

\subsubsection{Formalización, registro e información}

En relación con la formalización y la consolidación de la propiedad rural, el Acuerdo plantea una serie de medidas ambiciosas para regular y proteger los derechos de la pequeña y mediana propiedad, estableciendo programas de formalización masiva de siete millones de hectáreas, con lo cual se garantiza la gratuidad de los procedimientos, se acompaña tanto el proceso de adjudicación de baldíos como el de saneamiento de la propiedad, y se diseña un nueva jurisdicción agraria que permita resolver los conflictos sobre la tenencia de la tierra de manera ágil y expedita. 
Igualmente, plantea la construcción de un Sistema General de Información Catastral multipropósito con el fin de actualizar y armonizar la información sobre la propiedad rural consagrada en el registro inmobiliario con la información actualizada del catastro rural en un plazo máximo de siete años. También contempla el diseño de un sistema para que los municipios liquiden, cobren y recauden efectivamente el impuesto predial, en desarrollo del principio de progresividad, con el fin de incentivar la inversión social y la desconcentración de la propiedad rural improductiva, y garantizar la transparencia en la propiedad de la tierra.

Si bien este punto representa un avance positivo respecto a los deficientes mecanismos de formalización, registro e información de la propiedad rural en el país, no es claro el efecto que este tipo de medidas por sí mismas puedan tener de cara a consolidar la transformación que necesita el campo y lograr cumplir con los principios del punto de reforma rural, en especial el principio de buen vivir ${ }^{27}$ que consagra el punto uno del Acuerdo.

La formalización de la propiedad propuesta en el Acuerdo se inserta dentro de las medidas en materia de desarrollo y política pública promovidas por instituciones como el Banco Mundial y el Instituto para la Libertad y Democracia del economista Hernando de Soto como medida para luchar contra la pobreza. Su tesis principal sugiere que el elemento que falta para que el desarrollo despegue en el tercer mundo es la falta de arreglos institucionales que, como la formalización de la propiedad, ayuden a crear el capital necesario para potenciar el crecimiento económico y el bienestar de la sociedad. En este sentido, la normalización de las diversas relaciones de tenencia a través de títulos de propiedad es la forma de reconocer "el capital muerto", ${ }^{28}$ y su reconocimiento formal permite que se pueda extraer su valor a través, por ejemplo, de la utilización de la propiedad formal sobre la tierra como garantía para créditos financieros. De esta manera, el reconocimiento formal de la propiedad puede hacer despegar ciclos económicos virtuales que dinamicen la economía.

\footnotetext{
27 Mesa de Conversaciones, "Acuerdo final”, 12.

28 Véase Hernando de Soto, The mystery of capital: why capitalism triumphs in the west and fails everywhere else (Nueva York: Basic Books, 2000).
} 
Esta política ha recibido innumerables críticas, especialmente porque no es claro el efecto que este tipo de medidas por sí mismas puedan tener para mejorar el nivel de prosperidad de todos aquellos nuevos propietarios, y consolidar la transformación que necesita el campo para lograr cumplir con el punto 1 de la reforma rural del Acuerdo.

Tradicionalmente una reforma rural real que busque de manera sostenible fomentar la transformación en el campo hace que se necesiten mecanismos que permitan desarrollar el otro eje fundamental de este tipo de reformas: la redistribución. Sobre este punto en particular el Acuerdo no contempla ninguna medida específica. El tema de la distribución equitativa de la tierra, que es sustancialmente diferente a la redistribución, se establece en las consideraciones generales del Acuerdo y en la consagración del Fondo de Tierras para la Paz, a cuyas dificultades y retos ya nos hemos referido en este capítulo.

Mencionaré dos puntos ciegos que no se resuelven con la formalización y que, antes bien, parecen profundizarse a la par que se formaliza la propiedad de la tierra, lo cual acarrea consecuencias negativas a aquellos habitantes rurales más pobres. En primer lugar, existe un vacío o zona gris entre la visión formalizadora de las relaciones de tenencia en el territorio lograda a través de la entrega del título y las prácticas cotidianas, muchas de ellas espontáneas, que suceden en el mismo territorio. Me refiero, por ejemplo, a que hoy los campesinos y sus familias beneficiarias de programas de parcelación según reformas rurales anteriores se ven expuestos a innumerables problemas para registrar aquellos actos de disposición que han realizado por las vías de hecho desde hace ya varios años, en muchos de los casos forzados por la necesidad o las circunstancias (i.e. la venta de una porción de su parcela o la subdivisión realizada en vida a sus herederos). Todos aquellos actos llevados a cabo pese a las restricciones legales que prohibían la venta de una unidad agrícola familiar - UAF- sin autorización previa del Incora (art. 39) o la subdivisión improductiva de la propiedad, a riesgo de perder su vocación agrícola (art. 44), hoy son un constante inconveniente para los habitantes rurales pobres.

Cada vez es más claro que la realidad para los campesinos en el territorio se mantiene en constante cambio y transformación por diferentes razones, entre ellas, el alto índice de movilidad de las familias, lo porosa que resulta la identificación del núcleo familiar, que a veces puede incluir 
familia extensa $u$ otras personas que no son parientes pero que tienen relación con la familia, y las vicisitudes propias de coexistir en un estado de precariedad. Dicha realidad rápidamente lleva a que los incipientes intentos por formalizar y actualizar las relaciones de tenencia de la propiedad fracasen frente a la cambiante realidad rural. Este constante atraso entre lo inscrito y lo formalizado y la multiplicidad de relaciones que se suceden espontáneamente en el territorio termina por afectar negativamente a las familias campesinas pobres beneficiaras directas del Acuerdo. ${ }^{29}$

Adicionalmente, con la formalización de la propiedad se presenta un segundo problema que termina por afectar directamente a los campesinos pobres, ya que uno de los principales efectos de formalizar la tierra es que esta se convierte en un recurso finito, pues una vez formalizada la propiedad se tiene certeza de que una parcela es asignada formalmente a una persona o a una familia. ${ }^{30}$ Una vez convertido en un recurso delimitado y finito, la tierra se vuelve un recurso escaso, en la medida en que, una vez reconocida la propiedad a alguien, otras personas no podrán entrar a participar de la propiedad sobre esta. Por lo tanto, formalizar la propiedad también puede significar que las disputas por obtener la propiedad de la tierra entre campesinos se acrecienten, por ejemplo, entre potenciales asignatarios de terrenos baldíos, o como opositores frente a minorías, disputando el reconocimiento de su propiedad frente al derecho de los indígenas sobre tierras de resguardo, o frente a comunidades afrodescendientes y las tierras reconocidas mediante títulos colectivos; todos estos grupos, quienes se encuentran en un alto nivel de precariedad, ahora resultan siendo competidores entre sí, disputándose la asignación de este recurso escaso.

En ocasiones incluso la formalización de la propiedad termina por restringir el acceso a la tierra a campesinos pobres cuando el Estado decide destinar porciones de esta a otros usos o proyectos de su interés, como zonas ecológicamente protegidas, proyectos forestales, mineros o agroindustriales.

29 A manera de ejemplo, piénsese en todas las situaciones atípicas que surgen de las fallas en el sistema notarial y registral hoy, y cómo el juez de tierras ha tenido que hacer frente a estos vacíos en las situaciones de despojo.

30 Véase Sergio Latorre, "The making of land ownership: land titling in rural Colombia - A reply to Hernando de Soto". Third World Quarterly 35, n. 8 (2015). 
Finalmente, al formalizar la propiedad de la tierra y reconocer una cosa como bien susceptible de apropiación y sobre el cual recaiga el derecho real de dominio, a la par que permite la creación de un activo en el mundo económico, también está propiciando, a largo plazo, fenómenos de concentración o de fragmentación de la propiedad física de la tierra. Ambos, la fragmentación de la propiedad y la concentración, aunque fenómenos que van en direcciones opuestas, comparten el mismo origen, a saber, el momento que se formaliza la propiedad (como parte de este acto, entre otras acciones, se identifica al propietario y al bien susceptible de apropiación a partir de la demarcación de sus límites, lo que en la escritura pública se conoce como definición de cabidas y linderos). De los antecedentes directos en la historia agraria del país podemos percibir cómo, dependiendo de variables propias del contexto, se presenta uno u otro fenómeno. En ambos ejemplos los fenómenos de concentración o fragmentación suceden a partir del reconocimiento formal de la propiedad a favor de campesinos.

En cuanto a la concentración de la tierra, se ha documentado cómo durante el periodo del 2006 al 2009 en los Montes de María se llevó a cabo una estrategia de despojo y de concentración de la propiedad que consistía en la compra de pequeñas parcelas de tierra, adjudicadas inicialmente por el Incora, y que en muchos casos tenían deudas. En estas circunstancias, bajo una operación orquestada por compradores foráneos a través de intermediarios, solo se compraban las parcelas saneadas o se saneaban previamente, pactando que dentro de la operación de compra se incluía el dinero para saldar las deudas que tenía el campesino. Una vez saneadas, se iniciaba el proceso para transferir el derecho de dominio al nuevo comprador, luego se englobaban varias de estas parcelas para conformar un predio más grande y así destinarlas a actividades agroindustriales. ${ }^{31}$

31 "Muchas de las acciones de compra masiva en esta región están asociadas, aunque no exclusivamente, a la Corporación Amigos de Montes de María la cual reúne un amplio grupo de individuos y sociedades empresariales dedicadas a actividades agropecuarias industriales y constituidas desde la filosofía de integración en cadena, es decir desde la producción de materia prima, hasta su procesamiento y comercialización. Las compras masivas suelen seguir un esquema de compra de varios predios de una gran variedad de extensiones (entre 10 y 200 has., pero con predominancia de un tamaño alrededor de 20) que luego se engloban (...). En la región se habla de compraventas de más de 100.000 has. Lo que se ha podido comprobar, solo para el año 2008 y 2009 y solo a través de una oficina de registro, es la compra de más de 15.000 has. En total se compraron 257 predios individuales y 133 predios colectivos (es decir de reforma agraria, con sus respectivas resoluciones de adjudicación del 
Bajo un fenómeno opuesto como el de fragmentación, desde 1996 el Centro de Estudios Ganaderos y Agrícolas — CEgA— de la Universidad Nacional ha documentado cómo se presenta un acelerado incremento del minifundio y microfundio en el centro oriente del país en departamentos como Boyacá, Cundinamarca y Santander, particularmente en zonas en donde no se presentaron fenómenos de despojos masivos por causa de la violencia armada. Dicho estudio reporta que el problema de la fragmentación improductiva se ha venido acrecentado en las tierras de pequeños propietarios o minifundista, y que dicha fragmentación de la propiedad está relacionada con los procesos de herencia y con el deterioro típico de las zonas de minifundio, donde la pobreza no permite a los pobladores rurales

Incoder), distribuidos por los municipios". El documento igualmente afirma que se han encontrado tres estrategias o circunstancias interrelacionadas que posibilitan las compras masivas de tierras que pertenecían a los campesinos: "la imposibilidad de retornar; ser parcelero del Incora/Incoder; y por endeudamiento". Prosigue el texto estableciendo que "En efecto, las compras masivas de tierras se realizan en su mayoría aunque no exclusivamente por empresarios foráneos, predominantemente antioqueños, conocidos en el lenguaje popular de la costa como 'los cachacos' o 'los paisas'. Para ellos, los antecedentes de la violencia y el abandono de tierras han constituido una 'ventana de oportunidades' para realizar sus negocios. Se ha podido documentar una pequeña parte de esos procesos de compras masivas en Montes de María, que demuestran que la mitad de esas tierras proceden de antiguas parcelaciones de reforma agraria. (...) La compra masiva de predios, efectuada especialmente en dos periodos (2006 y 2009), y el posterior englobe de ellos en propiedades de tamaño mayor, contribuye a un nuevo proceso de concentración de la tierra, precisamente en una zona, los Montes de María, que había sido objeto de reforma agraria. Con ello, los mínimos y precarios resultados de las políticas redistributivas del pasado quedaron aniquilados definitivamente. Los aspectos aparentemente legales de esas compras, y su orientación hacia una explotación de alta competitividad fomentada desde el Gobierno, constituyen un desafío para su eventual restitución, dado que los límites entre acciones de buena y de mala fe quedan borrosos. (...) Enmarcada dentro de la compra masiva de tierras y combinada con otras modalidades como la venta forzada, a bajo precio, con sobreprecio y en algunas ocasiones con el desalojo de los ocupantes mediante la ejecución de sentencias judiciales, las parcelas del Incora han sido compradas y vendidas principalmente en el departamento de Bolívar, pero también se conocen casos en Córdoba y Sucre. Para la adquisición de estas parcelas el comprador de manera directa o con la participación de un intermediario busca al adjudicatario para establecer los términos del 'negocio', el precio de compra y los trámites necesarios para transferir los derechos de dominio; adicionalmente estas parcelaciones adjudicadas por el Incora a lo largo del periodo analizado, exigen una serie de trámites y requisitos específicos para ser comercializadas en el mercado, muchos de los cuales han sido vulnerados a través de diversos mecanismos, generando la percepción entre los y las campesinas de que los trámites de compraventa son auspiciados por procedimientos fraudulentos o elementos de corrupción". Centro Nacional de Memoria Histórica - $\mathrm{CNMH}$ - La tierra en disputa. Memorias del despojo y resistencias campesinas en la Costa Caribe: 1960-2010 (Bogotá: Centro Nacional de Memoria Histórica, 2010), 169 y 175. 
adquirir explotaciones más extensas, manteniendo la estructura de la gran propiedad casi inmutable. ${ }^{32}$

En ambos ejemplos, tanto de concentración como de fragmentación de la propiedad, estos dos fenómenos son perceptibles una vez se ha reconocido la propiedad formal del campesino; los dos ejemplos tratan sobre tierras formalmente reconocidas como propiedad del campesino, o bien porque fueron adjudicadas en procesos de parcelación anteriores o porque fueron objeto de compraventas directas. Sin embargo, en ambos ejemplos resulta claro que no basta con la formalización de la propiedad para impulsar un proyecto de reforma rural ambicioso, como plasma el Acuerdo. A la par que se formaliza la propiedad se deben encontrar soluciones viables a la forma como estos fenómenos terminan impactando negativamente

32 Según Absalón Machado, comparando la estructura de la propiedad entre 1984 y 1996, "en la frontera agropecuaria incorporada, el número de pequeños propietarios en 1996 ascendió a 2.982.216, el de medianos a 276.789 y el de grandes a 43.524 —incluidos los resguardos indígenas-. Entre 1984 y 1996 todos los estratos de tamaño crecieron en términos absolutos - excepto el número de predios grandes-, lo que indica una expansión predial significativa —en algunos casos se trata de mejoras en los registros catastrales-. La pequeña propiedad creció en superficie más que la mediana, y la grande más que ambas. (...) Por regiones se observan los siguientes cambios: (...) En el centrooriente del país se presentó una atenuación de la concentración con una fuerte fragmentación predial que tipifica un minifundio intenso en Cundinamarca, Boyacá y Santander muy influido por fincas de recreo; la mediana propiedad se estabilizó y la grande se deterioró”. Sobre este dinámica, Machado afirma que "El problema agrario en Colombia se ha vinculado siempre con la estructura de la tenencia de la tierra, la cual se considera como la fuente principal de las dificultades del sector para alcanzar un proceso de desarrollo estable y eficiente, liberado de conflictos y con una alta contribución a la construcción de democracia. Ello se ha fundamentado en la concentración de las mejores tierras en manos de unos pocos propietarios, en la proliferación del minifundio y el microfundio que constituyen grandes cinturones de pobreza y miseria en el campo. (...) Los índices de concentración de la propiedad rural se mantienen altos y en algunas regiones han aumentado, mientras la fragmentación de la pequeña propiedad sigue avanzando con lo que se multiplica el minifundio y la pobreza en el sector rural. (...) La información permite concluir que mientras en los años sesenta se presentó una tendencia a la concentración de la propiedad, durante 1970 y 1984 se registró una descomposición de la gran propiedad y la consolidación de la mediana, 'pero sin que se reduzca la desigualdad rural debido a la fragmentación de la pequeña propiedad' (CEGA, 1985). Esta subdivisión de la pequeña propiedad está relacionada con los procesos de herencia y el deterioro típico de las zonas de minifundio donde la pobreza no permite a los pobladores rurales adquirir explotaciones más extensas. Esta situación es crítica en departamentos minifundistas como Cauca y Nariño. Pero igualmente, fue reforzada por la política del Incora de ocuparse solo de la división de la gran propiedad sin atender la recomposición del minifundio a través de políticas específicas que evitaran su deterioro". Absalón Machado, Tenencia de tierras, problema agrario y conflicto en La reforma rural, una deuda social y política (Bogotá: cID-Universidad Nacional de Colombia, 2009), 119 y 122. 
a los campesinos. La solución, como resulta obvio, no debe ser dejar de reconocer la propiedad formal de la tierra a quienes así la reclamen como beneficiarios de la política de desarrollo rural, pero sí identificar los puntos ciegos y límites de dicha política, para saber cómo prevenir las consecuencias negativas que dicha formalización trae, y que nos muestra una lectura crítica de nuestra propia historia agraria.

Por último, es menester aclarar que las soluciones concretas a algunos de los puntos que he mencionado no pueden pasar por una consagración formal y jurídica estableciendo nuevas cuotas o limitaciones al dominio, como lo han intentado hacer normas anteriores (Ley 160 de 1994, o el mismo acuerdo declarando la limitación de venta por 7 años). Si algo queda claro a lo largo de la historia agraria en el país es que la sola consagración normativa no ayuda a resolver los problemas derivados del reconocimiento de la propiedad en el campo, más aún cuando en muchos de estos casos las normas legales tienen un carácter ambivalente, pues en algunos contextos se desconocen o son recibidas con desconfianza, o incluso son abiertamente rechazadas.

\subsubsection{Organización del territorio rural}

Como tercer tema central sobre acceso y uso de la tierra, el Acuerdo establece una serie de disposiciones entorno a la reorganización del territorio rural, entre las que se encuentran medidas para delimitar y cerrar la frontera agrícola, mecanismos para actualizar los sistemas de información sobre la propiedad y la tenencia rural, así como incentivos para prevenir e impulsar soluciones a los conflictos entre la vocación de la tierra y su uso real.

El respaldo que da el Acuerdo al organizar el territorio rural es uno de los puntos sobresalientes en relación con la discusión sobre desarrollo agrario integral. El Acuerdo establece planes de zonificación ambiental que permiten ampliar el inventario y la caracterización de las áreas que deben tener un manejo ambiental especial (zonas de reserva forestal, zonas de alta biodiversidad, entre otras), y promueve las zonas de reserva campesina, consagradas en la Ley 160 de 1994, atendiendo a los campesinos que quieran adelantar procesos de constitución y haciendo efectivo el apoyo a los planes de desarrollo de las zonas constituidas.

De esta manera, quedan enmarcados ciertos rasgos de la política pública para la organización territorial de este sector agrario que emanan del 
Acuerdo, como son la protección del medio ambiente y la promoción de territorios campesinos que contribuyan a la construcción de paz.

Sin embargo, resulta difícil comprender cómo este tipo de orientación de la política pública para organizar el territorio rural se compagina o complementa con el principio recientemente incluido en el Acuerdo sobre desarrollo integral del campo, que permite el desarrollo de otras formas de producción, como la agroindustria o agricultura comercial de escala, y fomenta otras iniciativas del Gobierno que tienen una incidencia directa sobre la reorganización del territorio y que en ocasiones pueden ir en contravía de lo propuesto en el Acuerdo.

A manera de ejemplo me refiero a las zonas de interés de desarrollo rural, económico y social (Zidres) (Ley 1776 del 2016), que impulsan un modelo, para muchos, en abierta contradicción al impulsado inicialmente en el Acuerdo. Igualmente, preocupa el impacto que puedan tener sobre la organización del territorio rural aquellas zonas que se encuentren incluidas dentro de proyectos (proyectos de interés nacional y estratégicos - PINE-) desarrollados a partir del actual plan de desarrollo, y en particular la imposibilidad que establece la ley (Ley 1753 del 2015, art. 50) para que dichas tierras puedan ser objeto de restitución.

Finalmente, las zonas de reserva campesina - $\mathrm{ZRC}-$, tanto aquellas ya conformadas como aquellas que puedan constituirse, ameritan una reflexión crítica. Si bien se encuentran definidas en la ley (art. 80 y siguientes de la Ley 160 de 1994) y en el Acuerdo como zonas que deben contribuir a la construcción de paz, garantizar los derechos políticos, económicos, sociales y culturales de los campesinos, y asegurar su desarrollo con sostenibilidad socioambiental y alimentaria, esta consagración no da suficientemente cuenta de su potencial real para potenciar la transformación del campo.

En ese sentido, es importante que la consagración de zonas de reserva no este circunscrita al reconocimiento único y exclusivo de su relación económica y productiva con la tierra como "trabajadores con vocación agraria”, ni que se establezcan con el único objetivo de controlar la expansión inadecuada de la frontera agropecuaria del país.

Aunque hoy las ZRC se establecen con base en UAF adjudicadas o reconocidas directamente por el Estado, el impulso a estas zonas a través del Acuerdo debería coadyuvar para adelantar la discusión seria e informada sobre la posibilidad de reconocer las ZRC como una nueva forma de 
propiedad colectiva y comunitaria de consagración constitucional, tomando como propias algunas de las características que hoy tienen los territorios indígenas (art. 63 y 329 Constitución Política), y los títulos colectivos reconocidos a las comunidades afrodescendientes (art. 55 transitorio Constitución Política, Ley 70 de 1993). Así, por lo menos se permitiría garantizar la inembargabilidad, inalienabilidad e imprescriptibilidad de dichos territorios y, de esta manera, se les brinda protección frente a la desintegración física, social y económica a la que actualmente se ven sometidos aquellos territorios de extracción campesina. ${ }^{33}$

Además, estas zonas deben partir del reconocimiento de los campesinos y campesinas como sujetos de derechos y de reconocimiento diferencial, teniendo en cuenta tanto su complejo ethos cultural y social, como la coexistencia entre identidades campesinas y étnicas (por ejemplo, indígenas y afrocampesinas).

\subsection{Programas de desarrollo con enfoque territorial}

El segundo punto establecido en el Acuerdo en el tema de desarrollo rural son los programas de desarrollo con enfoque territorial, cuyo objetivo es el de operativizar las acciones necesarias para llevar a cabo la transformación estructural del campo, con lo cual se aseguran el bienestar y el buen vivir de la población rural, se protege la riqueza pluriétnica y multicultural, se incentiva tanto el desarrollo de la economía campesina y familiar, como el desarrollo y la integración de las regiones más abandonadas y golpeadas por el conflicto, entre otros propósitos.

33 En esta dirección parece ir el decreto que las regula, en cuyo artículo 2 se establece que la constitución y delimitación de zonas de reserva campesina tiene los siguientes objetivos: 1) controlar la expansión inadecuada de la frontera agropecuaria del país; 2) evitar corregir los fenómenos de inequitativa concentración, o fragmentación antieconómica de la propiedad rústica; 3) crear las condiciones para la adecuada consolidación y desarrollo sostenible de la economía campesina y de los colonos en las zonas respectivas; 4) regular la ocupación y aprovechamiento de las tierras baldías, dando preferencia en su adjudicación a los campesinos o colonos de escasos recursos; 5) crear y constituir una propuesta integral de desarrollo humano sostenible, de ordenamiento territorial y de gestión política; 6) facilitar la ejecución integral de las políticas de desarrollo rural; 7) fortalecer los espacios de concertación social, política, ambiental y cultural entre el Estado y las comunidades rurales, garantizando su adecuada participación en las instancias de planificación y decisión local y regional (Decreto 1777 de 1996). 
Los programas seguirán criterios específicos, en los que si bien se busca cobijar la totalidad de las zonas rurales del país, se priorizarán las zonas más necesitadas y urgidas según criterios como los niveles de pobreza, el grado de afectación derivado del conflicto, la debilidad institucional y la presencia de cultivos ilícitos en la región, con el objetivo de implementar con mayor celeridad y recursos los respectivos proyectos. El Acuerdo precisa que los programas de desarrollo con enfoque territorial serán la forma como se ejecutarán los planes nacionales que se deriven del Acuerdo (ej. vías, riego, etc. y que serán mencionados más adelante como tercer punto del Acuerdo sobre reforma rural) en las zonas priorizadas.

Para adelantar dichos programas en cada zona priorizada se elaborarán de manera participativa planes de acción para la transformación regional que incluyan todos los niveles del ordenamiento territorial y que sean concertados entre las autoridades locales y las comunidades. En estos planes se busca fomentar la participación activa de las comunidades - hombres y mujeres- en conjunto con las autoridades de las entidades territoriales, para lo cual se garantizarán la participación ciudadana en los distintos niveles territoriales, incluyendo la participación de las mujeres rurales, y el acompañamiento de los órganos de control. La participación de la comunidad será determinante tanto para definir prioridades en la implementación de los planes nacionales a nivel local, como para asegurar la ejecución de obras y su mantenimiento, y desarrollar los mecanismos de seguimiento y de veeduría de proyectos.

De los programas con enfoque territorial se destaca la premisa de que la consolidación de la paz debe pasar por una paz territorial. Sin embargo, es importante alertar sobre los peligros en que se puede incurrir al tener tan pocas claridades sobre los aspectos operativos de este tipo de enfoque. Los vacíos acerca de cómo, dónde y cuándo se debe materializar dicha política de desarrollo territorial pueden degenerar en la implementación de una paz territorial pensada en las regiones desde el centro, o produciendo una creciente burocratización que termine por invisibilizar las iniciativas locales y regionales.

Dichas "instancias de planeación participativa de abajo hacia arriba", como se ha denominado la orientación de dichos programas por los ne- 
gociadores del Acuerdo, ${ }^{34}$ deben vincular no solo estructuras organizativas locales de tipo formal, como juntas de acción comunal o asociaciones, sino también la participación de líderes regionales o de instancias municipales o departamentales a través de asambleas o concejos; tampoco deben realizar el seguimiento de sus planes y acciones únicamente mediante comités especiales de seguimiento o veeduría.

La experiencia en cuanto al diseño institucional para promover la participación de políticas públicas por la propia comunidad y "desde abajo", en especial en temas como atención a comunidades desplazadas y víctimas de la violencia, demuestra cómo muchos de estos espacios terminan burocratizándose, o la voz de las comunidades termina reducida a la de unas pocas personas que se abrogan la representación de estas. Incluso en muchas ocasiones los líderes representantes terminan replicando cierto tipo de lógica institucional poco representativa dentro de sus propios entornos.

Es por esto que la dirección de estos programas con enfoque territorial debe promover también la participación en otros espacios informales en donde transcurre gran parte de la vida en zonas rurales, como las dinámicas derivadas de las relaciones intraveredales o intrafamiliares, que no necesariamente pasan por los espacios de participación formal. Dicho enfoque debe desarrollar estrategias que integren otros espacios informales de discusión sobre la construcción de la paz en los territorios.

\subsection{Planes nacionales para la Reforma Rural Integral}

Finalmente, este documento considera que es precisamente en el último punto de la política rural en donde los Acuerdos plantean más elementos innovadores, en cuanto a la elaboración y puesta en marcha de diferentes planes para alcanzar una Reforma Rural Integral que permita tanto la superación de la pobreza y la desigualdad, como la integración y el cierre de la brecha entre campo y ciudad, con una meta tangible de reducir la pobreza rural en un $50 \%$ en un periodo de 15 años.

El Acuerdo consagra la adopción de diferentes planes: en infraestructura (Plan Nacional de Vías Terciarias, Riego y Drenaje, Electrificación y

34 Sergio Jaramillo, "La paz territorial". Conferencia dictada en la Universidad de Harvard. Oficina del Alto Comisionado para la Paz, 13 de marzo del 2014, http://www.interaktive-demokratie. org/files/downloads/La-Paz-Territorial.pdf 
Conectividad Rural); salud (Plan Nacional de Salud Rural); educación (Plan Especial de Educación Rural); vivienda y agua potable (Plan Nacional de Construcción y Mejoramiento de la Vivienda Social Rural); economía solidaria y cooperativa (Plan Nacional de Fomento a la Economía Solidaria y Cooperativa Rural); asistencia técnica e investigación (Plan Nacional de Asistencia Integral Técnica, Tecnológica y de Impulso a la Investigación); subsidios, generación de ingresos y crédito (Plan para Apoyar y Consolidar la Generación de Ingresos de la Economía Campesina, Familiar y Comunitaria); mercadeo (Plan Nacional para la Promoción de la Comercialización de la Producción de la Economía Campesina, Familiar y Comunitaria); y formalización laboral rural y protección social (Plan Progresivo de Protección Social y de Garantía de Derechos de los Trabajadores). Finalmente, propone que todos los planes nacionales cumplan de manera transversal con los objetivos de la política alimentaria y nutricional en las zonas rurales basadas en el incremento progresivo de la producción de alimentos, la generación de ingresos y, en general, la creación de condiciones de bienestar en el campo.

Dichos planes, desde luego, no pretenden cambiar el enfoque bajo el cual entendemos las relaciones en el campo, sino que prenden profundizar algunos aspectos clave en la política de Reforma Agraria Integral en los que se busca saldar una deuda histórica que han dejado inconclusa anteriores intentos de reforma agraria en el país; además, busca resolver aspectos estructurales clave que impactan la política rural, en temas como educación e infraestructura, e introducir nuevos temas, como la difusión de nuevas tecnologías en el sector rural y el interés por garantizar el derecho humano a la alimentación sana, nutritiva y culturalmente apropiada, contextualizándolos a los nuevos retos y circunstancias de un mundo globalizado.

Adicionalmente, el nuevo Acuerdo, una vez introducidas las modificaciones luego de la victoria del No en el plebiscito, y en concordancia con el principio de desarrollo integral, establece que el Gobierno promoverá la asociatividad, los encadenamientos y las alianzas productivas entre pequeños, medianos y grandes productores, y procesadores, comercializadores y exportadores, con el fin de garantizar una producción a escala y competitiva e insertada en cadenas de valor agregado que contribuyan a mejorar las condiciones de vida de los habitantes del campo, en general, y de los pequeños productores, en particular. Para ello el Gobierno se compromete 
en el Acuerdo a brindar asistencia técnica, jurídica y económica (crédito o financiamiento) a los pequeños productores con el fin de garantizar proyectos de economía familiar y asociativos equilibrados y sostenibles.

Como se adelantó en diferentes apartes de este capítulo, respecto a la introducción del principio de desarrollo integral y ahora respecto a los encadenamientos y alianzas productivas entre pequeños productores y la agricultura familiar, y los grandes productores y la agricultura comercial o la agroindustria, las experiencias son variadas y en muchos casos controversiales. Mientras desde algunos sectores, en especial gremios como Fedepalma, se presentan las alianzas productivas como una contribución exitosa de los gremios al posconflicto, en donde los pequeños productores aliados al modelo muestran grados de satisfacción importantes, especialmente en cuanto al acceso a crédito, ${ }^{35}$ para otros las alianzas mantienen la jerarquía en las relaciones de trabajo y la generación de riqueza en el campo; en estas los pequeños y medianos productores se encuentran frecuentemente sometidos a las reglas establecidas por los grandes productores, en relación tanto con el precio de compra de la producción, los insumos para el cultivo y el control de la producción, como con utilizar la tierra como garantía de la inversión. ${ }^{36}$ Igualmente, dicho modelo representa para los campesinos el abandono de las prácticas de la agricultura tradicional frente al rápido avance de la agricultura industrial y a gran escala. ${ }^{37}$

35 Federación Nacional de Cultivadores de Palma de Aceite - Fedepalma - y Agencia de Estados Unidos para el Desarrollo Internacional —Usaid—, 2010, citados en Centro Nacional de Memoria Histórica, Tierras y conflictos rurales. Historia, politicas agrarias y protagonistas (Bogotá: Centro Nacional de Memoria Histórica, 2016), 615.

36 Por ejemplo, en el 2013 el senador Jorge Robledo denunció el modelo de alianzas productivas en el caso específico de la cooperativa Coopsabana I (Sabana de Torres, Santander, en convenio con Indupalma), al denunciar el malestar de las personas asociadas para quienes esta alianza es poco benéfica: los frutos deben ser vendidos únicamente a Indupalma y, según ellas, los precios de compra son bajos en comparación con otras empresas que cuentan con una planta procesadora del fruto. Sumado a ello, las comisiones que cobra Indupalma como ejecutora del proyecto al parecer son excesivas, aunque la inversión de base haya sido puesta por los campesinos asociados y sean ellos los únicos responsables del pago de préstamos para la producción ante los bancos. Senador Jorge Enrique Robledo, Unidad de Trabajo Legislativo, 2013, citado en Centro Nacional de Memoria Histórica, Tierras y conflictos.

37 Las alianzas productivas y el encadenamiento no son una estrategia nueva propuesta por los gremios, ya que ya se debatía en el país frente a las modificaciones de la Ley 160, en la que se proponía ampliar las alianzas a toda la canasta agropecuaria del país. Véase este debate en Rocío Rubio, “Actores políticos frente al agro colombiano", en Cuadernos Tierra y Justicia n. ${ }^{\circ}$ (Bogotá: ILSA, 2003). 
Hasta aquí he buscado explicar de manera sistemática los grandes temas del Acuerdo en relación con el primer punto sobre la Reforma Rural Integral, abarcando tanto su contenido como algunas de las dudas y vacíos que aún quedan por resolver respecto a estos temas. En la conclusión de este capítulo me concentraré en retomar tres problemáticas centrales que se tocaron en diferentes momentos del análisis y que quiero retomar y dejarlos abiertos para la discusión.

\section{A manera de conclusión}

Si bien el Acuerdo en el punto sobre desarrollo rural integral abre una ventana de esperanza y un renovado interés por resolver los problemas estructurales del campo en Colombia, sus contenidos específicos no alteran sustancialmente el enfoque bajo el cual se comprenden las diversas relaciones entre el territorio y sus habitantes, y que da cuenta de aquello que constituye lo rural, desaprovechando con ello una oportunidad única que consolide una real transformación del campo colombiano.

En primer lugar, aunque es un aliciente para la revisión juiciosa y sistemática de nuestro régimen civil sobre la propiedad de bienes inmuebles rurales, y aunque podría contextualizar dicho régimen a las condiciones y situaciones particulares del sector rural y a los campesinos pobres, el Acuerdo más bien parece hacer uso de la normativa civil y agraria para la consecución de otros fines.

El Acuerdo añade en su nueva versión la disposición según la cual en un plazo no mayor a tres meses se hagan recomendaciones de reformas normativas y de política pública necesarias para una adecuada definición y protección de los derechos de propiedad si se quiere lograr el tránsito hacia un sociedad que cuente con reglas claras para transar y acceder a la propiedad sobre la tierra. Con ese propósito se conformará un grupo de tres expertos en el tema de tierras que pueda hacer recomendaciones para: regularizar los derechos de propiedad de los propietarios, ocupantes y poseedores de buena fe, siempre que no haya despojo o mala fe; garantizar la función social y ecológica de la propiedad; facilitar el acceso a los trabajadores sin tierra o con tierra insuficiente; y promover el uso productivo de la tierra.

En este sentido, el enfoque y los temas desarrollados en el Acuerdo no revisan los mecanismos según los cuales se consolida la propiedad, sino cómo dichos mecanismos pueden generar o proteger otro tipo de intereses 
como el acceso, la función social y ecológica, o la regularización de la posesión de buena fe, entre otros. Es por esto que sería importante revisar los problemas técnico jurídicos relativos a las normas de propiedad como tal, en particular en cuanto a la normativa civil y agraria hoy vigente.

Innumerables problemas técnicos jurídicos subsisten hoy en el ordenamiento civil y agrario que hacen particularmente difícil la aplicación del sistema de propiedad vigente en el contexto rural. Uno de ellos es la doble instancia de formalización dispuesta por nuestro ordenamiento civil, con especial repercusión en zonas rurales, y que se constituye como causa de relevancia al explicar la situación de inequidad e informalidad en la tenencia rural.

Según la normativa civil, el artículo 756 establece esta doble instancia para formalizar el derecho real de dominio sobre bienes inmuebles. ${ }^{38} \mathrm{De}$ esta manera, por ejemplo, para entender consolidado el derecho de propiedad en cabeza de una persona, el título (por ejemplo, en el caso de una compraventa el contrato de compraventa elevado a escritura pública, o la resolución de adjudicación de un bien baldío por parte del Incoder) deberá registrarse en el folio de matrícula inmobiliaria para entender transmitido el derecho de dominio.

Este proceso de doble instancia ha sido particularmente problemático para campesinos que, por ejemplo, entienden que la consolidación del derecho de propiedad radica en el título o escritura pública, y no en la inscripción del título en la oficina de instrumentos públicos. Muchos campesinos reciben las escrituras, más nunca las registran, lo que termina por generarles problemas para acreditar su titularidad frente a terceros y volverse sujetos a crédito. Consideraciones similares pueden hacerse frente otros instrumentos técnico-jurídicos del régimen civil y agrario, en cuanto a, por ejemplo, el carácter de tenedor o poseedor, cuya comprensión y recepción resulta particularmente problemática para comunidades campesinas pobres, o las limitaciones en cuanto a la disposición de bienes adjudicados, como las unidades agrícolas familiares.

En segundo lugar, el Acuerdo y en particular la inclusión del principio de desarrollo integral y los puntos relativos a la asociatividad entre pequeños

38 Reza el artículo 756 en su inciso 1 del Código Civil: "Se efectuará la tradición del dominio de los bienes raíces por la inscripción del título en la oficina de registro de instrumentos públicos”. 
y grandes productores introducidos posrreferendo siguen manteniendo una tendencia, si se quiere, bipolar respecto a la política pública sobre el campo, que históricamente ha resultado gravosa especialmente para el campesino pobre. La disyuntiva, varias veces mencionada por expertos en el tema, radica en la indefinición sobre cuál es el modelo de desarrollo para el campo, si una política que incentive la economía tradicional campesina, o la visión agroempresarial y a gran escala, en la que se privilegia el desarrollo por la vía de las alianzas estratégicas y las cadenas productivas.

En ese sentido, el Estado ha actuado con ingenuidad o miopía respecto a las contradicciones irreconciliables de ambos modelos, pretendiendo adelantar ambas políticas simultáneamente. Si históricamente esta bipolaridad fue practicada y en muchos casos promovida por gobiernos que buscaron la expansión de la frontera agrícola en ciertas regiones del país, lo cierto es que hoy, conforme se plantea el cierre de la frontera agropecuaria del país, el conflicto que surge entre la destinación de tierras para avanzar en uno y otro modelo de desarrollo es cada vez más polémico. El ejemplo referido en este capítulo respecto a los baldíos destinados para el Fondo de Tierras y la posibilidad de integrar terrenos baldíos, o incluso impulsar su adjudicación y formalización si estos se encuentran asociados con proyectos dentro de las Zidres (Ley 1776 del 2016, art. 3 Par. 3; art. 16 y 17), ayuda a ilustrar dicha controversia. ${ }^{39}$

En el Acuerdo la pugna sigue latente, y más bien este parece evidenciar la inexistencia de un consenso sobre qué modelo de desarrollo se debe impulsar en este contexto. Lo cierto es que dicha indefinición en la política pública ha resultado particularmente negativa para el campesino y pequeño propietario. Aunque el Acuerdo no define dicha contradicción y antes, por el contrario, parece ponerla una vez más de manifiesto, sí se espera que el paquete de medidas que hemos descrito en este capítulo ayude a revertir la tendencia negativa del sector rural y de empobrecimiento paulatino del campesino, ofrezca mayores garantías para la protección y defensa de sus derechos, y amplíe las oportunidades para su participación y la ejecución de políticas para el sector rural.

39 Recordar casos como el de Carimagua. Véase "El escándalo de Carimagua”, El Espectador, 11 de marzo del 2008, http://www.elespectador.com/noticias/politica/articulo-minagricultura-afrontadebate-carimagua 
Finalmente, si se toman en consideración los análisis realizados en este capítulo respecto al andamiaje jurídico y de formalización que adelanta el Acuerdo, la persistente indefinición de la política de desarrollo del campo, así como otros temas, o la ausencia de ellos, como la redistribución o la prevalencia de la visión productivista, podemos llegar a la conclusión de que el Acuerdo no modifica estructuralmente las relaciones en el espacio rural y entre sus pobladores. En ese sentido, y retomando una de nuestras hipótesis iniciales, tal vez es precisamente por lo que no modifica y las discusiones que deja abiertas que el punto 1 sobre desarrollo rural fue precisamente aquel sobre el que más rápido se llegó a un conceso político posplebiscito.

\section{Bibliografía}

Mesa de Conversaciones. "Acuerdo final para la terminación del conflicto y la construcción de una paz estable y duradera entre el Gobierno de Colombia y las FARC-EP", 2016.

"El escándalo de Carimagua”. El Espectador, 11 de marzo del 2008, http://www.elespectador.com/noticias/politica/articulo-minagricultura-afronta-debate-carimagua

“En las cinco primeras propuestas de Uribe no están las víctimas". Semana, 9 de octubre del 2016, http://www.semana.com/nacion/articulo/alvarouribe-presenta-sus-propuestas-para-el-acuerdo-de-paz/498437

“Las cinco propuestas de los del 'No' en el plebiscito”. El Tiempo, 16 de octubre del 2016, http://www.eltiempo.com/politica/proceso-de-paz/ propuestas-de-los-del-no-en-el-plebiscito/16727272

"Las propuestas de Marta Lucía Ramírez para renegociar con las FARC". $W$ Radio, 10 de octubre del 2016, http:/www.bluradio.com/nacion/ reforma-la-justicia-y-proteccion-la-familia-propuestas-de-marthalucia-ramirez-119045

"Propuestas del Centro Democrático: ¿realistas o para dilatar?". El Espectador, 14 de octubre del 2016, http://www.elespectador.com/noticias/ politica/propuestas-realistas-o-dilatar-articulo-660359

Centro Nacional de Memoria Histórica - $\mathrm{CNMH}$ - La tierra en disputa. Memorias del despojo y resistencias campesinas en la Costa Caribe: 19602010. Bogotá: Centro Nacional de Memoria Histórica, 2010. 
Centro Nacional de Memoria Histórica. Tierras y conflictos rurales. Historia, politicas agrarias y protagonistas. Bogotá: Centro Nacional de Memoria Histórica, 2016.

Céspedes, Lina, Rocío Peña-Huertas, Daniel Cabana y Santiago ZuletaRíos. "Who owns the land? Litigants, justices, colonos, and titleholders' struggle to define the origins of private property in Colombia". Global Jurist, n. 3 (2015): 329-459.

De Soto, Hernando. The mystery of capital: why capitalism triumphs in the west and fails everywhere else. Nueva York: Basic Books, 2000.

Decreto 1777 de 1996,1 de octubre. Por el cual se reglamenta parcialmente el Capítulo X11l de la Ley 160 de 1994, en lo relativo a las Zonas de Reserva Campesina. Diario Oficial 42.892.

Decreto 1465 del 2013, 10 de julio. Por el cual se reglamentan los capítulos X, XI y XII de la Ley 160 de 1994, relacionados con los procedimientos administrativos especiales agrarios de clasificación de la propiedad, deslimitación o deslinde de las tierras de la Nación, extinción del derecho de dominio, recuperación de baldíos indebidamente ocupados o apropiados, reversión de baldíos adjudicados y se dictan otras disposiciones. Diario Oficial 48.847.

Decreto 902 del 2017, 29 de mayo. Por el cual se adoptan medidas para facilitar la implementación de la Reforma Rural Integral contemplada en el Acuerdo Final en materia de tierras, específicamente el procedimiento para el acceso y formalización y el Fondo de Tierras. Echeverri Vélez, Luis Guillermo. "En defensa de la legalidad: los tales principios para la paz”. Primero Colombia, 18 de diciembre del 2015, http://www.primerocolombia.com/sites/default/files/en_defensa_de_la_legalidad.pdf

Jaramillo, Sergio. "La paz territorial”. Conferencia dictada en la Universidad de Harvard. Oficina del Alto Comisionado para la Paz, 13 de marzo del 2014, http:/www.interaktive- demokratie.org/files/downloads/ La-Paz-Territorial.pdf

Latorre, Sergio. "The making of land ownership: land titling in rural Colombia - A reply to Hernando de Soto”. Third World Quarterly 35, n. ${ }^{\circ} 8$ (2015): 1546-1569

Ley 200 de 1936, 16 de diciembre. Sobre régimen de tierras. 
Ley 135 de 1961, 13 de diciembre. Sobre reforma social agraria. Diario Oficial 30.691.

Ley 70 de 1993, 27 de agosto. Por la cual se desarrolla el artículo transitorio 55 de la Constitución Política. Diario Oficial 41.013.

Ley 160 de 1994, 3 de agosto. Por la cual se crea el Sistema Nacional de Reforma Agraria y Desarrollo Rural Campesino, se establece un subsidio para la adquisición de tierras, se reforma el Instituto Colombiano de la Reforma Agraria y se dictan otras disposiciones. Diario Oficial 41.479.

Ley 387 de 1997, 18 de julio. Por la cual se adoptan medidas para la prevención del desplazamiento forzado; la atención, protección, consolidación y esta estabilización socioeconómica de los desplazados internos por la violencia en la República de Colombia.

Ley 793 del 2002, 27 de diciembre. Por la cual se deroga la Ley 333 de 1996

y se establecen las reglas que gobiernan la extinción de dominio. Diario Oficial 45.046.

Ley 975 del 2005, 25 de julio. Por la cual se dictan disposiciones para la reincorporación de miembros de grupos armados organizados al margen de la ley, que contribuyan de manera efectiva a la consecución de la paz nacional y se dictan otras disposiciones para acuerdos humanitarios. Diario Oficial 45.980.

Ley 1232 del 2008, 17 de julio. Por la cual se modifica la Ley 82 de 1993,

Ley Mujer Cabeza de Familia y se dictan otras disposiciones. Diario Oficial 47.053.

Ley 1448 del 2011, 10 de junio. Por la cual se dictan medidas de atención, asistencia y reparación integral a las víctimas del conflicto armado interno y se dictan otras disposiciones. Diario Oficial 48.096.

Ley 1708 del 2014, 20 de enero. Por medio de la cual se expide el Código de Extinción de Dominio. Diario Oficial 49.039.

Ley 1753 del 2015, 9 de junio. Por la cual se expide el Plan Nacional de Desarrollo 2014-2018 “Todos por un nuevo país”. Diario Oficial 49.538.

Ley 1776 del 2016, 29 de enero. Por la cual se crean y se desarrollan las zonas de Interés de desarrollo rural, económico y social, Zidres. Diario Oficial 49.770. 
Machado, Absalón. Tenencia de tierras, problema agrario y conflicto en La reforma rural, una deuda social y politica. Bogotá: ciD-Universidad Nacional de Colombia, 2009.

Mesa de Conversaciones. "Acuerdo sobre política de desarrollo rural integral", 2016, punto 1 de la agenda, https://www.mesadeconversaciones.com. co/sites/default/files/24-1480106030.11-1480106030.2016nuevoa cuerdofinal-1480106030.pdf

Ocampo, José Antonio. Misión para la Transformación del Campo. Marco conceptual de la Misión para la Transformación del Campo. Bogotá: Departamento Nacional de Planeación, octubre 2014.

Programa de las Naciones Unidas para el Desarrollo - PNUD-. Colombia rural: Razones para la esperanza. Informe Nacional de Desarrollo Humano. Bogotá: INDH/PNUD, 2011, https://www.dane.gov.co/files/CensoAgropecuario/avanceCNA/CNA_agosto_2015_new_present.pdf

Registraduría Nacional del Estado Civil, http://plebiscito.registraduria. gov.co/99PL/DPL

Rengifo, Mauricio. Teoría general de la propiedad. Bogotá: Editorial Temis, 2011.

Reyes, Alejandro. “La reversión del acuerdo agrario”. El Espectador, 22 de octubre del 2016, http://www.elespectador.com/opinion/reversiondel-acuerdo-agrario

Rubio, Rocío. "Actores políticos frente al agro colombiano", en Cuadernos Tierra y Justicia n. ${ }^{\circ}$ 8, 1-55. Bogotá: ILSA, 2003.

Sentencia C-379 del 2016, 18 de julio. MP: Luis Ernesto Vargas Silva. 


\title{
La visión del Acuerdo de Paz sobre el abastecimiento de agua en el medio rural
}

\author{
Andrés Gómez-Rey* \\ Gloria Amparo Rodríguez
}

\section{Introducción}

El presente artículo pretende analizar si el Acuerdo de Paz suscrito el 26 de agosto del 2016 entre el Gobierno nacional y las Fuerzas Armadas Revolucionarias de Colombia-Ejército del Pueblo — FARC-EP-, junto con su reformulación en la versión del 12 de noviembre del 2016, ${ }^{1}$ contribuye a la concreción del derecho humano al agua y representa una oportunidad en la mejora de su garantía en las zonas rurales del país, entendiendo la paz como un medio para la garantía de derechos.

De esta forma, el texto busca comprender si el Acuerdo de Paz está construido a partir de la realidad del campo colombiano (medio rural) para buscar su desarrollo y no como históricamente ha ocurrido, desde "el deber ser de las cosas". Para lograrlo, se presentan a continuación los contenidos del Acuerdo de Paz, y se analizará si posibilitan la satisfacción

* Abogado de la Universidad de La Sabana. Especialista en Derecho Ambiental y magíster en Derecho Administrativo de la Universidad del Rosario. Profesor de la Universidad del Rosario. Correo electrónico: andres.gomez@urosario.edu.co

* Abogada. Ph. D. en Sociología Jurídica e Instituciones Políticas. Actualmente se desempeña como profesora titular de carrera de la Facultad de Jurisprudencia de la Universidad del Rosario, donde además es directora de la especialización y de la línea de investigación en Derecho Ambiental. Correos electrónicos: gloria.rodriguez@urosario.edu.co, http://gloriamparodriguez.blogspot.com

1 Sobre este punto es importante aclarar que los textos son similares, en lo tocante al tema de este artículo en donde únicamente cambia la inclusión de unas mayúsculas y la eliminación de la expresión "equidad de género". 
de las necesidades relacionadas con el abastecimiento de agua de la zona rural y los correlativos derechos, en relación con los distritos de riego y los servicios públicos domiciliarios.

Comencemos estableciendo que por medio rural

se entiende, hoy en día, como una entidad socioeconómica y un espacio geográfico, compuesto por un territorio, una población, un conjunto de asentamientos y un conjunto de instituciones públicas y privadas. Es un conjunto de regiones o zonas en las que se asientan pueblos, aldeas, pequeñas ciudades y centros regionales, espacios naturales y cultivados y en donde se desarrolla una gran diversidad de actividades como la agricultura, la industria pequeña y mediana, el comercio, los servicios, la ganadería, la pesca, la minería, el turismo y la extracción de recursos naturales. ${ }^{2}$

La anterior definición propone la existencia de una zona territorial compleja, en donde su tejido social y actores son diversos, las actividades económicas variadas y existe una presencia difusa por parte del Estado. La ruralidad colombiana es importante para el país por ser la fábrica de los alimentos que son consumidos en los cascos urbanos y los centros poblados (seguridad alimentaria) $)^{3}$ y porque contiene la biodiversidad que caracteriza al territorio colombiano. ${ }^{4}$ Lo anterior, sin olvidar que representa el equilibrio territorial, la fuente primordial de territorios con vocación de esparcimiento, recreación, usos agroindustriales, manufactureros, entre otros.

A través de las "Bases del Plan Nacional de Desarrollo", 5 el Gobierno nacional ha mencionado que el campo colombiano contribuye de manera

2 María Adelaida Farah Q.y Edelmira Pérez C., "Mujeres rurales y nueva ruralidad en Colombia”, en II Congreso Iberoamericano de Estudios de Género, en la mesa de trabajo sobre Mujeres rurales y organización. Salta, Argentina, 24-26 de julio del 2003 (Bogotá: Cuadernos de Desarrollo Rural, 2004), 51.

3 Véase, entre otros, Organización de las Naciones Unidas para la Alimentación y la Agricultura, Alimentos para la ciudades, http://www.fao.org/3/a-ak824s/

4 Diana Patricia Ramírez, Olga Lucia Trespalacios, Febe Lucía Ruiz y Javier Otero García, Oportunidades para la conservación de la biodiversidad local, conectividad ecológica en la zona urbano-rural (Bogotá: Instituto de Investigación de Recursos Biológicos Alexander von Humboldt, 2008).

5 Departamento Nacional de Planeación, Bases del Plan Nacional de Desarrollo 2014-2018 “Todos por un nuevo país" (Bogotá: DNP, 2014), 376. 
importante al desarrollo económico y social del país. En efecto, el 84,7\% del territorio colombiano está conformado por municipios totalmente rurales, y según la Misión para la Transformación del Campo, el 30,4\% de la población colombiana vive en zonas rurales. Por su parte, el sector agropecuario aporta en promedio 6,1\% del producto interno bruto - PIB - total y genera el 16,3\% del empleo del país. Además, el campo cuenta con más de 42 millones de hectáreas aptas para las actividades agropecuarias y forestales, y es la fuente de los recursos naturales que ofrecen ventajas comparativas para Colombia, como los hidrocarburos, los minerales y la biodiversidad.

Sin embargo, se destaca que en Colombia el 30\% de la población rural no tiene acceso a una fuente de agua mejorada, el $31 \%$ no tiene un sistema sanitario y el $84 \%$ carece de servicio de alcantarillado o eliminación de excretas. ${ }^{6}$ La situación termina siendo tan compleja que la Comisión Económica para América Latina y el Caribe - Cepal— realizó un estudio sobre los bienes y servicios públicos sociales en la zona rural de Colombia, en el cual señaló, al referirse al tema de los déficits y las brechas en acceso a los servicios públicos de acueducto y alcantarillado, que son muy altas y que no se han reducido recientemente. Según este estudio, la cobertura de acueducto en la zona rural es de 53,3\% y en alcantarillado es de apenas $15,6 \%$. Asegura también que la cobertura de hogares rurales con mecanismos alternativos de eliminación de excretas presenta una tendencia de crecimiento del 2,8\% anual, que, de mantenerse, significará alcanzar cobertura del $100 \%$ de los hogares en la zona rural en el $2022 .^{7}$

Lo anterior significa que el medio rural colombiano no ha sido un especial foco de atención por parte del Estado, lo que ha conllevado a la generación de dinámicas propias y a la "autogestión" ${ }^{8}$ de las necesidades básicas de sus habitantes, quienes están principalmente representados en comunidades campesinas, afrocolombianas e indígenas. Unido a lo anterior, está el hecho de que la población rural ha sido la principal víctima

\footnotetext{
6 Ibid., 309.

7 Juan Carlos Ramírez J., Renata Pardo, Olga Lucía Acosta y Luis Javier Uribe, Naciones Unidas, Bienes y servicios públicos sociales en la zona rural de Colombia. Brechas y políticas públicas (Santiago: Cepal, 2016), 30.

8 Se plantea para el presente texto como "autogestión" la solución autónoma a sus necesidades básicas que sin apoyo del Estado han desarrollado las comunidades que habitan el medio rural del país.
} 
del conflicto armado, siendo objeto de desplazamiento, confinamiento y violación de sus derechos humanos.

Producto de la "autogestión" de sus necesidades relacionadas con el abastecimiento de agua, los habitantes del medio rural colombiano han establecido relaciones especiales en torno a los recursos naturales renovables. Entre ellas encontramos que toda forma o sistema creado por las comunidades (refiriéndonos con ello a la infraestructura) ha buscado satisfacer los “usos múltiples del agua", ${ }^{9}$ como el consumo humano y domestico, ${ }^{10} \mathrm{el}$ uso pecuario (bovinos y aves) y el riego. ${ }^{11}$

De otra parte, también encontramos que estas comunidades, al realizar grandes esfuerzos financieros y técnicos en relación con el recurso hídrico, han afianzado sus tejidos sociales, creando modelos comunitarios de abastecimiento y respetando sus conocimientos tradicionales, lo cual se traduce en construcciones populares, ${ }^{12}$ lo que genera sus propias reglas de conducta. ${ }^{13}$

Adicionalmente, estas comunidades rurales han tenido que asumir grandes retos para lograr la garantía de los derechos que dependen del recurso hídrico, dada la ausencia de presencia estatal, lo cual posee dos acepciones: de una parte, superar los aspectos técnicos del abastecimiento de agua por los bajos índices de cobertura del servicio público domiciliario de acueducto ${ }^{14} \mathrm{y}$ distritos de riego dada la dispersión de las viviendas; ${ }^{15} \mathrm{y}$, de otra parte, obtener y cumplir los engorrosos y, en algunos casos, innecesarios requisitos

9 Las principales actividades de sustento en la ruralidad son consideradas primarias al versar sobre pesca, cultivos, minería de subsistencia, productos del bosque (incluida su extracción) y otras similares.

10 Tal y como lo puede ser la preparación de alimentos, aseo personal, aseo del domicilio y vestuario.

11 Véase Inés Restrepo Tarquino, Usos múltiples del agua, como estrategia para la reducción de la pobreza (Santiago de Cali: Programa Editorial Universidad del Valle, 2010).

12 Hernán Darío Correa C., Acueductos comunitarios, patrimonio público y movimientos sociales (Bogotá: Corpenca, 2006), 11, http://www.corpenca.org/images/stories/documentos/acueductoscomunitariospatrimoniopublicomovimientossociales.pdf

13 Reglas que incluyen las conductas populares como procesos de reproche ante su inobservancia.

14 Organización Mundial de la Salud, Fondo de las Naciones Unidas para la Infancia, Progresos en materia de saneamiento y agua potable: informe de actualización (2010), http://www.wssinfo.org/ fileadmin/user_upload/resources/JMPreport_Spanish.pdf

15 Defensoría del Pueblo, La gestión comunitaria del pueblo (Bogotá: Imprenta Nacional, 2013), 126. 
y exigencias normativas ${ }^{16}$ que el Estado ha diseñado para garantizar dicho abastecimiento. Estos retos además han venido siendo solucionados a través de la autogestión, a pesar de los bajos niveles de escolaridad, que dificultan la gestión administrativa u operativa en sus actividades. ${ }^{17}$

Superar las dificultades que poseen las comunidades rurales y lograr un desarrollo integral del campo implica no solo que estas tengan acceso a la tierra, sino también al agua y al saneamiento básico. ${ }^{18}$ De esta forma es posible contribuir en el proceso de alcanzar una Colombia en paz y lograr el cierre de brechas sociales, económicas y territoriales como base de las transformaciones sociales que requiere el país. ${ }^{19}$

Producto de estas problemáticas, la Corte Constitucional ha señalado que "las personas que habitan en el sector rural y tienen limitados recursos económicos, tienen derecho a ser protegidas especialmente, asegurándoles que no sean 'los últimos de la fila' en acceder al agua potable”, ${ }^{20}$ por las deficiencias que aún subsisten en torno a la materia.

La estrategia metodológica utilizada parte del estudio de las fuentes del derecho - norma ius fundamental, ley, doctrina, jurisprudencia y, en general, el ordenamiento jurídico relacionado-, en observancia del aspecto sociológico de la implementación de la norma. En consecuencia, es nuestra intensión aportar al debate y realizar propuestas que permitan incidir en el camino hacia el logro de la paz.

16 A manera de ejemplo, la exigencia de la micromedición en el sector de servicios públicos es compleja de cumplir ya que las aguas rurales poseen materiales particulados (como tierra), lo cual tapona el instrumento tecnológico, situación que implica un gasto innecesario por parte de los suscriptores.

17 Ministerio de Educación de Colombia, Sistema Nacional de Indicadores Educativos para los Niveles de Preescolar, Básica y Media en Colombia (Bogotá: Men, 2014), 20.

18 De conformidad con lo dispuesto en el artículo 14, numeral 19 de la Ley 142 de 1994, se entiende por saneamiento básico "las actividades propias del conjunto de los servicios domiciliarios de alcantarillado y aseo".

19 Departamento Nacional de Planeación, Bases del Plan, 44.

20 Sentencia T-418 del 2010, 25 de mayo. MP: María Victoria Calle Correa. Igualmente, se seguirá en este aparte el documento construido por uno de los autores para la Defensoría del Pueblo llamado Acciones para el impulso del derecho humano al agua en Colombia. Una mirada critica al sector de agua potable y saneamiento básico (Bogotá: Imprenta Nacional, 2014), http://www.defensoria.gov.co/ es/public/Informesdefensoriales/739/ACCIONES-PARA-EL-IMPULSO-DEL-DERECHOHUMANO-AL-AGUA-EN-COLOMBIA-Una-mirada-cr\%C3\%ADtica-al-sector-de-aguapotable-y-saneamiento-b \%C3\%A1sico-Informes-defensoriales---Agua.htm 


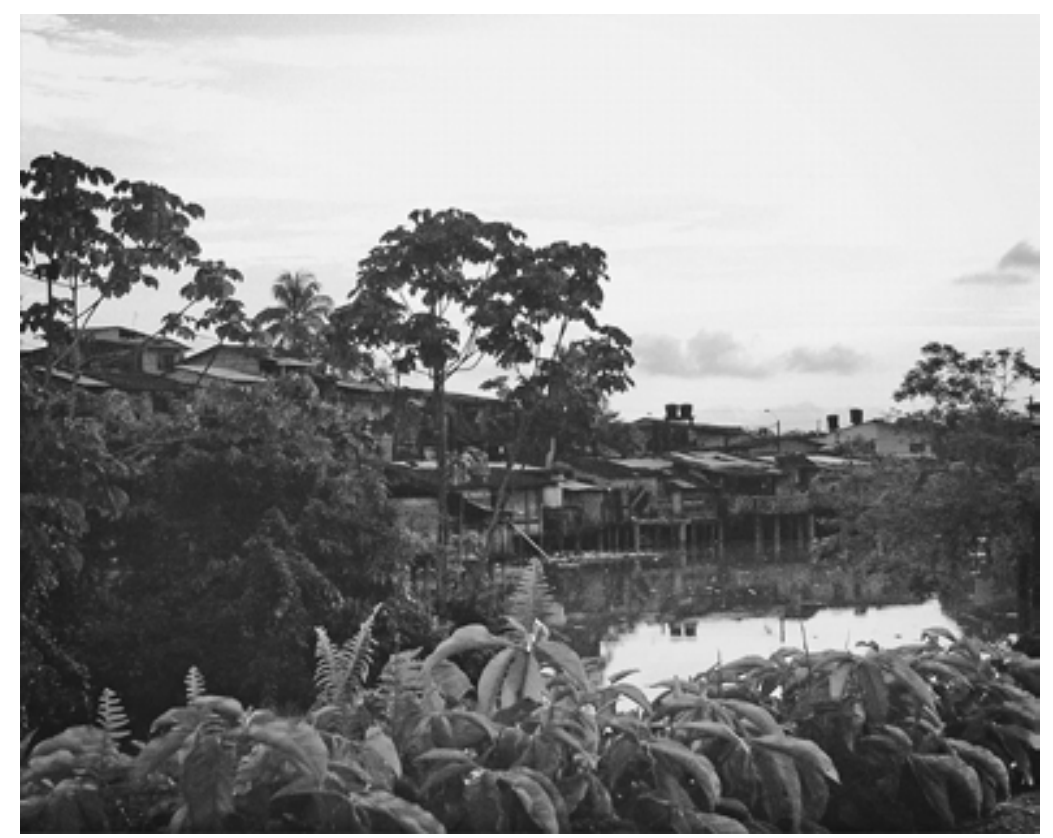

Fotografía 1. Zona rural del municipio de Quibdó, Chocó

Fuente: tomada por Andrés Gómez-Rey

\section{El agua en el Acuerdo de Paz}

El Acuerdo de Paz suscrito el 26 de agosto del 2016 y su reformulación del 12 de noviembre del 2016 incluyen elementos relacionados con el abastecimiento de agua de las zonas rurales, poniendo de presente la existencia de una problemática a nivel nacional sobre el acceso y abastecimiento de agua. Así las cosas, hemos dividido el análisis del acceso al agua en relación con el Acuerdo de Paz en cuatro ítems: comenzamos con los distritos de riego; luego abordamos el tema del servicio público domiciliario de acueducto; así pasamos a los estímulos a la economía solidaria y cooperativa; y terminando con un especial planteamiento del principio de desarrollo sostenible.

Pese a lo dicho, es importante recordar que el Acuerdo de Paz contiene seis puntos (así fue dividido por sus autores), en donde el primero recoge los aspectos necesarios para una reforma rural integral que, en palabras de dicho documento,

(...) contribuirá a la transformación estructural del campo, cerrando las brechas entre el campo y la ciudad y creando condiciones de 
bienestar y buen vivir para la población rural. La "Reforma Rural Integral" debe integrar las regiones, contribuir a erradicar la pobreza, promover la igualdad y asegurar el pleno disfrute de los derechos de la ciudadanía (...).

Expresan que los principales rezagos que existen en la garantía de derechos en relación con el agua se presentan en el medio rural colombiano. Por esto, los tópicos que veremos están inmersos en este punto 1 del Acuerdo, en el cual se llama la atención sobre la necesidad de solucionar y garantizar la igualdad de oportunidades, la propiedad, el acceso y la concentración sobre la tierra, la provisión de bienes y servicios públicos como educación, salud, recreación, infraestructura, asistencia técnica, alimentación y nutrición, entre otros, que brinden bienestar y buen vivir a la población rural.

Entonces, los distritos de riego, los servicios públicos y los estímulos a la economía solidaria y cooperativa son los principales retos en conexidad con el agua a través de una visión especial del desarrollo sostenible, lo que nos lleva a realizar las siguientes reflexiones.

\subsection{Los distritos de riego}

Teniendo en cuenta que la demanda de agua en Colombia está representada en el sector agrícola e industrial en un 73,2\% del volumen total, mientras que el consumo humano y doméstico representa el $17,8 \%,{ }^{21}$ se vio la necesidad de elaborar una política pública que impulsara el riego de las zonas agrícolas del país. Entre 1960 y 1990 el riego creció a una media anual de 15.000 ha, con una proporción de 2 a 1, dos tercios de inversión privada y el restante de pública. ${ }^{22}$

En los años sesenta fue impulsado el riego con la creación del Instituto Colombiano de la Reforma Agraria - Incora- y en los setenta con el Instituto Colombiano de Hidrología, Meteorología y Adecuación de Tierras

21 Instituto de Hidrología, Meteorología y Estudios Ambientales de Colombia - Ideam-, Estudio Nacional del Agua (Bogotá: Imprenta Nacional, 2015), 151.

22 Ariel Dinar y Andrew Keck, Private irrigation investment in Colombia: effects of violence, macroeconomics policy and environmental conditions (World Bank, 1996), 1-6, http://nersp.osg.ufl.edu/ vecy/ LitSurvey/Dinar.97.pdf 
- Himat- Sin embargo, no fue sino hasta 1993, con la Ley $41,{ }^{23}$ y los decretos reglamentarios 1278 y 2135, que se logró un alcance del riego en aproximadamente unas 950 mil hectáreas. ${ }^{24}$ En dicha ley, se planteó la creación de distritos de riego como estrategia del Gobierno, los cuales son "un área geográfica en donde se proporciona el servicio permanente de irrigación y drenaje, mediante obras de infraestructura hidroagrícola, como vaso de almacenamiento, derivaciones directas, plantas de bombeo, pozos, canales y caminos que en su conjunto manejan el sistema", ${ }^{25}$ que tienen como fin surtir de agua a cultivos agrícolas a cambio de un costo no tarifario sino de inversión, llamado canon. ${ }^{26}$

Como su nombre lo indica, el distrito de riego posee como fin la distribución para actividades agrícolas, empresariales en mayor medida, excluyendo el uso del agua para la agricultura de subsistencia y para consumo humano directo. Sin embargo, la política pública en relación con el riego ha carecido del impacto necesario en los habitantes del campo, ya que la inversión en ellos se ha visto focalizada en la industria agrícola del país, más no en su población primaria.

Teniendo en cuenta estos antecedentes, este tema se trató en el Acuerdo de Paz en el título 1.3. "Planes Nacionales para la Reforma Rural Integral", subtítulo 1.3.1.2. "Infraestructura y adecuación de tierras", así:

Infraestructura de riego: con el propósito de impulsar la producción agrícola familiar y la economía campesina en general, garantizando el acceso democrático y ambientalmente sostenible al agua, el gobierno nacional creará e implementará el Plan Nacional de Riego y Drenaje para la economía campesina, familiar y comunitaria. Para el desarrollo del Plan se tendrán en cuenta los siguientes criterios: La promoción y aplicación de soluciones tecnológicas apropiadas de

23 Por la cual se organiza el subsector de adecuación de tierras y se establecen sus funciones.

24 Dinar y Keck, Private irrigation.

25 Corporación Autónoma Regional de Cundinamarca, CARta Ambiental n. 25 (Bogotá: Corporación Autónoma Regional de Cundinamarca, 2010), 3.

26 Entre los costos se encuentran: 1) los beneficiarios de obras públicas realizadas por el Gobierno, que deben cancelar un cargo por revalorización de la tierra; 2) los costos de operación y mantenimiento, que se traducen en un cargo fijo por el agua y uno variable por el volumen de agua suministrado. 
riego y drenaje para la economía campesina, familiar y comunitaria, de acuerdo con las particularidades de las zonas, del proyecto productivo y de las comunidades (...). El acompañamiento a las asociaciones de usuarios y usuarias en el diseño y formulación de los proyectos de riego y drenaje (...). La asistencia técnica y la promoción de las capacidades organizativas de las comunidades para garantizar el mantenimiento, la administración y la sostenibilidad económica y ambiental de los proyectos de riego y drenaje (...).

Nótese cómo, aunque estamos en el marco del abastecimiento de agua para riego, el Acuerdo de Paz pretende la creación de un plan que permita el desarrollo de la "economía campesina, familiar y comunitaria", histórico rezago de la ruralidad colombiana. Recordemos que el factor de pobreza es creador de dinámicas especiales; según la Misión para el Diseño de una Estrategia para la Reducción de la Pobreza y la Desigualdad —MERPD— ${ }^{27}$ en el 2005, el 62\% de la población rural se encontraba en estado de pobreza, lo cual presenta un panorama complejo en la nación ya que esto involucra también baja productividad y precarias condiciones de trabajo, seguridad social, educación y salud. ${ }^{28} \mathrm{El}$ porcentaje restante no ostenta condiciones óptimas, sino que simplemente no se encuentra en pobreza, pero sí es una población vulnerable de otra manera, al no contar con altos niveles de escolaridad que les ofrezcan grandes ventajas comparativas. Por tanto, en las condiciones actuales, es un sector que no tiene posibilidades de crecimiento por fuera de su tradicional desenvolvimiento en la "sociedad moderna".

Ahora bien, el alto grado de pobreza de la zona rural, teniendo en cuenta que "las familias más pobres desarrollan actividades productivas en su sitio de alojamiento", ${ }^{29}$ implica que la economía campesina, por el momento, se desarrolla al interior del hogar o residencia y no por fuera de esta, por lo cual es indispensable contar con agua para su crecimiento.

\footnotetext{
27 Jorge Enrique Torres Ramírez, Misión para el diseño de una estrategia de reducción de la pobreza y la desigualdad. Contrato de Consultoría no. 192-04, (2005), http://www.javeriana.edu.co/arquidis/ injaviu/coloquio/2008/documents/MISIONPARAELDISENODEUNAESTARTEGIADEREDUCCIONDELAPOBREZAYLADESIGUALDAD.pdf

28 Restrepo Tarquino, Usos múltiples del agua, 14.

29 Ibid., 16.
} 
Así, según el Censo 2005, el $73 \%$ de las viviendas rurales desarrolla actividades económicas en su hogar como bien lo pueden ser las agropecuarias. Más aún, esta economía rural está llamada a la producción para la supervivencia propia y sistemas económicos de menor escala, como bien lo puede ser el riego de pequeños cultivos y la cría de animales como cerdos, vacas y gallinas. ${ }^{30}$

En este sentido, encontramos que el acuerdo suscrito comprende un gran avance ya que aborda la realidad de la economía campesina y solidaria, buscando así su impulso y garantizando los derechos. Recordemos que es la desigualdad el fundamento propio de nuestro conflicto.

\subsection{Del servicio público domiciliario de acueducto}

$\mathrm{El}$ acueducto $^{31}$ es "la distribución municipal de agua apta para el consumo humano, incluida su conexión y medición", actividad que posee una serie de reglas técnicas ${ }^{32}$ para su puesta en marcha. Entre las principales características del servicio está el hecho de que la distribución debe ser de carácter municipal y que el agua sea para consumo humano, lo cual tiene una doble connotación: de un lado, que el agua esté en condiciones de potabilidad o salubridad, permitiendo con ello que no afecte la salud y vida de las personas, y, de otro lado, que la destinación final que se le otorgue al agua sea la ingesta humana, excluyendo así la distribución de agua para riego, uso pecuario y otras actividades. Igualmente, se requiere que el servicio sea ofrecido en forma general o masiva, ${ }^{33}$ que posea un "punto terminal" denominado suscriptor o usuario y que implique como contraprestación el pago de una suma de dinero por el servicio prestado.

En este escenario se destaca que la zona rural colombiana no se enmarca fácilmente en las características del servicio antes citadas. Por ello,

\footnotetext{
30 Véase como soporte de esta afirmación tanto el contenido del Censo en cita como Ibid., 50.

31 Según el artículo 14 numeral 14.22 de la Ley 142 de 1994.

32 Principalmente contenidas en el Reglamento Técnico del Sector de Agua Potable y Saneamiento Básico — RAs - (2000), http://www.minvivienda.gov.co/viceministerios/viceministerio-deagua/reglamento-tecnico-del-sector/reglamento-tecnico-del-sector-de-agua-potable

33 Esto por cuanto el artículo 366 constitucional plantea que la finalidad de los servicios domiciliarios es ofrecer de forma masiva bienes o actividades que propendan por el bienestar general y el mejoramiento de la calidad de vida de la población, mediante la solución de necesidades básicas insatisfechas.
} 
el Acuerdo de Paz en el punto 1.3.2.3 expresa la necesidad de elaborar un documento que coadyuve en la satisfacción de las necesidades relacionadas con el agua y los principios que deberán ser tenidos en cuenta, así:

Vivienda y agua potable: con el propósito de garantizar condiciones de vida digna a las personas que habitan en el campo, el Gobierno Nacional creará e implementará el Plan nacional de construcción y mejoramiento de la vivienda social rural. Para el desarrollo del Plan se tendrán en cuenta los siguientes criterios: (...). La promoción y aplicación de soluciones tecnológicas apropiadas (acueductos veredales y soluciones individuales) para garantizar el acceso al agua potable y el manejo de aguas residuales (...). La asistencia técnica y la promoción de las capacidades organizativas de las comunidades para garantizar el mantenimiento, la operación y la sostenibilidad de las soluciones de acceso al agua y manejo de aguas residuales (...). Promover prácticas adecuadas para el uso del agua potable (...).

De la lectura del contenido del Acuerdo se puede observar el llamado de atención sobre la necesidad de contar con un plan o ruta metodológica que gire en torno a tres aspectos principales que históricamente han sido las dificultades o retos del sector en la zona rural: soluciones tecnológicas apropiadas, asistencia técnica y prácticas adecuadas para el uso del agua potable.

La consagración de las "soluciones tecnológicas apropiadas" constituiría un gran avance en la garantía del abastecimiento de agua. Empero, para el medio rural, aun siendo un llamado de atención que proviene de la imposibilidad de prestar el servicio de forma tradicional, ${ }^{34}$ implicaría un cambio de visión en la cual se estructura el servicio público. Por ello, se requeriría de una modificación normativa e institucional sobre la materia, dado que dicha prestación presenta graves dificultades debido, como se ha mencionado, a la dispersión de las viviendas y a los bajos niveles de escolaridad allí presentes.

34 Es decir que una persona jurídica realice las actividades de captación de agua, aducción, tratamiento, almacenamiento, conducción, comercialización, transporte o distribución de agua, mediante una red o sistemas con puntos terminales en el domicilio de las personas. 
En consecuencia, una política que comprenda el abastecimiento del agua a través de soluciones individuales o sistemas alternativos en la prestación es una necesidad que debe atenderse para garantizar el derecho humano al agua, ${ }^{35}$ lo cual implica que se debe contar con este recurso en las condiciones y cantidades suficientes para satisfacer las necesidades básicas o elementales del ser humano. Este derecho es indispensable para vivir dignamente y es condición previa para la realización de otros derechos humanos, lo que termina reflejando una realidad innegable: "sin agua, no hay vida". ${ }^{36}$

Para la generación de medios alternativos para el abastecimiento de agua o la prestación a través de redes (en donde sea posible), ${ }^{37}$ se requiere sin lugar a dudas de un conocimiento de la actividad para que se realice de manera eficiente y efectiva, lo cual es precisamente el segundo pilar del acuerdo: "la asistencia técnica" necesaria para realizar de manera correcta la tarea.

Ahora bien, el tercer pilar de este título expresa la necesidad de realizar prácticas adecuadas para el uso del agua potable, lo cual se enmarca en que el

35 Siguiendo a la Corte Constitucional Colombiana. Sentencia T-418 del 2010, 25 de mayo. MP: María Victoria Calle Correa: “(...) el Comité de Derechos Económicos, Sociales y Culturales, en su Observación General No. 15, indicó que respecto al derecho al agua se predican ciertas obligaciones específicas como son: (i) la disponibilidad, (ii) la accesibilidad y (iii) la calidad (...). La disponibilidad hace referencia a la cantidad suficiente del líquido vital necesario para la supervivencia humana; a la regularidad en el suministro o distribución del recurso hídrico; y a la sostenibilidad del mismo. En palabras del Comité de Derechos Económicos esta obligación implica que 'el abastecimiento de agua de cada persona debe ser continuo y suficiente para los usos personales y domésticos' (...). La accesibilidad implica que 'el agua y las instalaciones y servicios de agua deben ser accesibles para todos, sin discriminación alguna, dentro de la jurisdicción del Estado Parte' (...). La calidad significa que el agua necesaria para cada uso personal o doméstico debe ser salubre, y por lo tanto no ha de contener microorganismos o sustancias químicas o radiactivas que puedan constituir una amenaza para la salud de las personas (...)".

36 Andrés Gómez-Rey y Gloria Amparo Rodríguez, El derecho fundamental al agua. Desde el derecho ambiental y los servicios públicos domiciliarios (Bogotá: Universidad del Rosario/Legis, 2013).

37 Sobre este punto, véase el Título “j” del Reglamento Técnico para el Sector de Agua Potable y Saneamiento Básico — RAs - denominado "Alternativas Tecnológicas en Agua y Saneamiento para el Sector Rural”, donde el numeral "1.1. Alcance y Campo de Aplicación” plantea la diferencia de dos tipos de asentamientos: "i) los centros poblados o población nucleada concentrada en caseríos o conjuntos de por lo menos 20 viviendas, separadas por paredes, muros, cercas o huertas y ii) fincas y viviendas dispersas separadas por áreas cultivadas, prados, bosques, potreros, carreteras o caminos".

La densidad de población promedio del país según el Censo DANE 2005 es de 40,7 hab/ $\mathrm{km}^{2}$ (cerca de 10 familias $/ \mathrm{km}^{2}$ ). 
agua tratada sea utilizada tanto para consumo humano, como para actividades no humanas pero de subsistencia, como bien lo pueden ser las actividades agropecuarias, por ejemplo, el mantenimiento de una cabeza de ganado, de un cerdo, unas cuantas gallinas y una pequeña huerta, entre otros.

La mencionada situación comprende un gran avance al interior del régimen legal sobre la prestación de este servicio, ya que este prohíbe el uso diferente al consumo humano, ${ }^{38}$ lo cual en la realidad no se cumple debido a que en los cascos urbanos es también utilizada para el mantenimiento estético de vehículos y otros usos alejados del legalmente establecido.

\subsection{Estímulos a la economía solidaria y cooperativa}

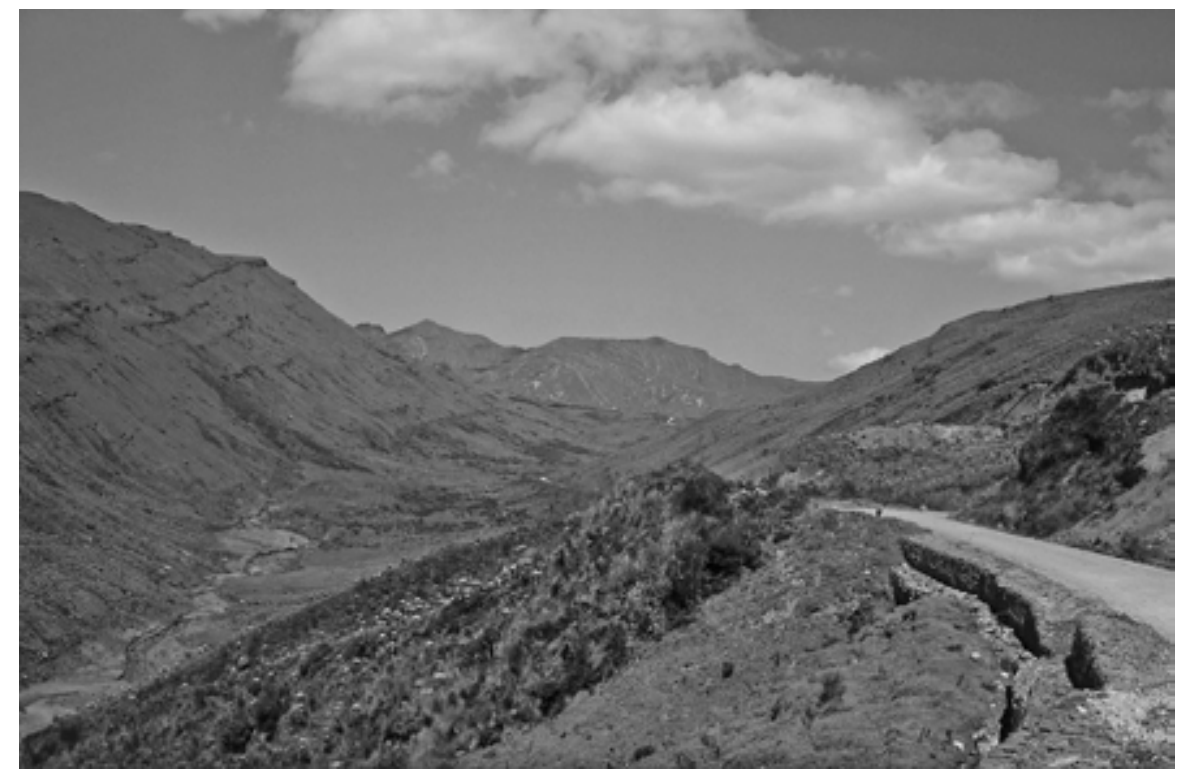

Fotografía 2. Zona rural de la localidad de Sumapáz del Distrito Capital de Bogotá

Fuente: tomada por Andrés Gómez-Rey

38 "El agua para consumo humano es aquella que por cumplir las características físicas, químicas y microbiológicas, en las condiciones señaladas en el presente decreto y demás normas que la reglamenten, es apta para consumo humano. Se utiliza en bebida directa, en la preparación de alimentos o en la higiene personal", es decir agua salubre que al ser ingerida por los seres humanos no afecte de ninguna manera su salud o su vida (artículo 2 del Decreto 1575 del 2007). 
Teniendo en cuenta lo anterior, el Acuerdo de Paz plantea además algunos estímulos a la economía solidaria y cooperativa. ${ }^{39}$ Así, el Acuerdo posee un punto de vital importancia para el impulso del real y efectivo cumplimiento del derecho humano al agua: el fortalecimiento de las formas asociativas comunitarias que asumieron esta importante tarea, a través de un plan que comprende además un enfoque de género, ${ }^{40}$ basado en la solidaridad y la cooperación, que promueva la capacidad de los productores de bienes y servicios rurales. El Acuerdo establece:

Estímulos a la economía solidaria y cooperativa: con el propósito de estimular diferentes formas asociativas de trabajo de o entre pequeños y medianos productores y productoras, basadas en la solidaridad y la cooperación, y que promuevan, ${ }^{41}$ la autonomía económica y la capacidad organizativa en especial de las mujeres rurales, y fortalezcan la capacidad de los pequeños productores y productoras de acceder a bienes y servicios, comercializar sus productos y en general mejorar sus condiciones de vida, de trabajo y de producción, el Gobierno Nacional creará e implementará el Plan nacional de fomento a la economía solidaria y cooperativa rural.

Para el desarrollo del Plan se tendrán en cuenta los siguientes criterios: (...). El acompañamiento, apoyo técnico y financiero a las comunidades rurales $(\ldots)$ en la creación y fortalecimiento de cooperativas, asociaciones y organizaciones solidarias y comunitarias (...). El apoyo con medidas diferenciales a las organizaciones comunitarias y asociaciones para contribuir a la gestión de proyectos de infraestructura y equipamiento (vías, vivienda, salud, educación, agua y saneamiento básico, riego y drenaje) (...).

39 Tal y como se afirmó con anterioridad, la ruralidad colombiana posee un especial tejido social en el cual las reglas construidas por las comunidades son aquellas que rigen el comportamiento del conglomerado social. Así las cosas, la economía también es permeada por esta variable y es considerada comunitaria, solidaria y cooperativa, al comprender particularidades públicas y otras privadas.

40 Aunque el presente artículo no posee como fin la exposición del enfoque de género de los acuerdos, sí es interesante contemplar que esta relación entre la mujer y el agua hoy en día posee un gran desarrollo conceptual. Véase a manera de ejemplo Women for Water Partnership, www.womenforwater.org

41 El acuerdo suscrito en agosto del 2016 contenía la siguiente expresión que fue eliminada “(...) y la cooperación, y que promuevan la equidad de género, la autonomía económica (...)”. 
Con el fin de apoyar la economía campesina y superar las problemáticas planteadas, se debe partir del conocimiento de las particularidades del medio rural para así lograr soluciones efectivas que atiendan las necesidades y expectativas de sus habitantes. A manera de ejemplo (además de los ya citados, como los usos múltiples del agua, la dispersión de las viviendas, la ausencia de grados de escolaridad), veamos algunas de las problemáticas a las cuales constantemente se enfrentan estas asociaciones encargadas de realizar el abastecimiento del agua en el medio rural: ${ }^{42}$

a) Dados los aspectos de pobreza de estos sectores, se requiere que el abastecimiento de agua sea asequible, es decir, que las personas puedan disfrutarla según la capacidad económica propia de estas regiones, lo cual implica condiciones de calidad del agua especiales y una estructura tarifaria acorde a las dinámicas rurales.

b) La violencia y existencia de grupos al margen de la ley que producen inseguridad, ausentamiento de la juventud, desplazamiento, tráfico de personas, de drogas, de armas y otros, impiden un libre acceso al recurso hídrico, por cuanto la propiedad o tenencia tanto de los predios de interés de las organizaciones comunitarias que distribuyen las aguas como de los nacimientos y la propiedad de las redes que componen el sistema de abastecimiento están siendo controlados por las fuerzas propias de la guerra. ${ }^{43} \mathrm{El}$ punto anterior posee dos connotaciones: de un lado, que en caso de no avanzar en la paz del país, las asociaciones relacionadas con el agua deben acceder a ella en sectores lejanos que no estén contralados por grupos al margen de la ley; y, de otro, en el caso de comenzar la construcción de la paz, se debe trabajar para evitar la restricción al acceso de este recurso.

\footnotetext{
42 Esto, sin referirnos a los trámites administrativos y exigencias legales que no están siendo cumplidos por las organizaciones, como: reporte de información al Sistema Único de Información — suIque administra la Superintendencia de Servicios Públicos Domiciliarios; los permisos, concesiones y autorizaciones para el uso de los recursos naturales; los reportes de calidad de agua (concertación, materialización, toma de muestras y reporte de IRCA); análisis de índices de agua no contabilizada; estudios de costos y tarifas; cumplimiento de normas tributarias y laborales, entre muchos otros.

43 Sin olvidar también que en algunas ocasiones los entes territoriales u otros prestadores de mayor tamaño administrativo desean tomar posesión de los prestadores menores o pequeños prestadores.
} 
El fortalecimiento de estas organizaciones y su empoderamiento social debe presentarse a través del desarrollo de la gobernanza del agua, que implica un sistema participativo en torno a las cuestiones rurales de dicho recurso, el cual, además, es indispensable para la garantía del derecho humano al agua en la ruralidad colombiana. En consecuencia, también se les debe garantizar el acceso al agua potable y el saneamiento básico, lo que implica fomentar la estructuración de esquemas sostenibles de acceso y saneamiento, al igual que realizar inversiones en infraestructura en las zonas rurales que habitan, como se ha planteado en el Plan Nacional de Desarrollo. ${ }^{44}$

La realidad rural colombiana ha sido construida en el ordenamiento jurídico a través de un enfoque centralista, sin embargo, al no observarse las dinámicas propias de la ruralidad colombiana, no se generó un mayor bienestar a sus habitantes. Lo anterior puede verse en el hecho de que cada régimen jurídico de abastecimiento, como servicios públicos, distritos de riego y hasta el tema ambiental, más que un impulso, impone límites o dificultades al ejercicio del derecho humano al agua, ${ }^{45}$ por lo cual pensar en reformular la política del campo es una necesidad y obligación del Estado.

En consecuencia, concordamos con la $\mathrm{Cepal}^{46}$ en que la inclusión de pobladores y territorios rurales se debe lograr con propósitos y reglas públicas claras, para que la Nación asegure que sus habitantes en territorios rurales tengan los mismos derechos sociales que el conjunto de la población nacional, de modo que las brechas se reduzcan hasta desaparecer, lo que permite mejores condiciones de vida de los pobladores rurales y condiciones de desarrollo para ser cada vez más autónomos.

\subsection{Un especial planteamiento del principio de desarrollo sostenible} Producto de los puntos anteriores, el Acuerdo de Paz "Hacia un Nuevo Campo Colombiano: Reforma Rural Integral” establece el desarrollo sostenible como uno de sus principios orientadores y su implementación, con una redacción que difiere sustancialmente de la contenida en la Comisión

44 Departamento Nacional de Planeación, Bases del Plan, 149.

45 A manera de ejemplo el cobro del servicio de evaluación para la garantía del derecho humano al agua para consumo afecta la asequibilidad de este. El régimen de servicios públicos exige la capacidad jurídica para contratar, lo cual excluye la garantía del derecho para aquellos que no la poseen.

46 Ramírez J. et al. Bienes y servicios, 8. 
Mundial del Medio Ambiente y del Desarrollo de la onu, cuyo texto lo define así: "el desarrollo sostenible como la satisfacción de las necesidades de la generación presente sin comprometer la capacidad de las generaciones futuras para satisfacer sus propias necesidades". ${ }^{47}$

Por su parte, el Acuerdo de Paz define el principio de desarrollo sostenible de la siguiente forma: "Es decir, es ambiental y socialmente sostenible y requiere de la protección y promoción del acceso al agua, dentro de una concepción ordenada del territorio (...)”. Este concepto incluye de manera directa otro enfoque al dado al principio de desarrollo sostenible. Con este nuevo planteamiento se está buscando que la actividad de "desarrollo" comprenda dos aspectos que la califiquen: lo ambiental y lo social, y la necesidad latente de hacer partícipe a la sociedad en las decisiones de desarrollo que se adopten y la protección de los recursos naturales renovables, lo cual, en últimas, conlleva la necesidad de avanzar en la gobernanza, para este caso, del agua.

Ahora bien, lo curioso en la consagración del principio es que se incluye como elemento principal de dicha sostenibilidad ambiental y social del desarrollo el agua, a través de dos visiones: el agua como derecho, al establecer la necesidad de contar con su acceso, ${ }^{48}$ y como un criterio que permita el orden del territorio a través del mencionado recurso, constituyéndose así en un principio de desarrollo sostenible "especial" para la coyuntura del país del logro y la consolidación de la paz.

El acceso al agua en condiciones de disponibilidad, accesibilidad y calidad para el medio rural, conllevaría el desarrollo integral de las personas y la población rural, al permitir que posean condiciones que superen la satisfacción

47 Organización de las Naciones Unidas, Asamblea General, Informe "Nuestro futuro común", Comisión Mundial sobre el Medio Ambiente y el Desarrollo (1987).

48 Acceso que se presenta bien sea por: 1) contar con las redes del servicio público domiciliario de acueducto o 2) por tener la fuente de agua en la cercanía y contar con las autorizaciones ambientales exigidas para su utilización. Sobre este punto recordemos que para poder captar las aguas de dominio público y, de esta manera, adelantar acciones del servicio de acueducto o de los distritos de riego se requiere obtener ante la autoridad ambiental: concesión de aguas superficiales que permite el uso de los depósitos y corrientes no marítimas o continentales; permiso para la construcción de obras hidráulicas, que permite la instalación de la infraestructura necesaria para la extracción de las aguas superficiales (o estar inmerso en una reglamentación de corrientes); permiso de prospección y exploración de aguas subterráneas y su consecuente concesión, que son dos autorizaciones por medio de las cuales se otorga el derecho de construir un pozo profundo y de extraer de este el agua que se encuentra en depósitos y corrientes subterráneas. 
de sus necesidades básicas, es decir que sus preocupaciones no versen sobre el agua y la alimentación diaria, sino que permitan proyectarse hacia actividades diferentes tales como la educación, el desarrollo y la tecnología.

Sobre este particular, las "Bases del Plan Nacional de Desarrollo 20142018" establecieron que

(...) el acceso al agua potable y saneamiento básico son factores determinantes para mejorar las condiciones de habitabilidad de las viviendas, impactar en la situación de pobreza y salud de la población e incrementar los índices de competitividad y crecimiento del país. Sin embargo, se identifican las siguientes dificultades: 1) deficientes procesos de planeación sectorial, en algunas zonas del país, que no permiten la adecuada focalización de las inversiones; 2) esquemas de prestación de los servicios de acueducto, alcantarillado y aseo, en algunos municipios, que no son sostenibles económica, financiera, ambiental y socialmente, lo que impide mejorar los indicadores de cobertura, calidad y continuidad; y 3) riesgos en la prestación de los servicios de agua potable y saneamiento básico asociados a la sostenibilidad ambiental del recurso hídrico. ${ }^{49}$

Ahora bien, teniendo en cuenta que la Ley 99 de 1993 establece que el proceso de desarrollo económico y social del país se orientará según los principios universales y del desarrollo sostenible, es válido preguntarse sobre las falencias de implementación que este principio está teniendo en el ordenamiento jurídico interno, por las problemáticas ambientales que actualmente se presentan en el país y la especial consagración en el Acuerdo de Paz, cuyo contenido es ampliado de manera significativa en el orden social.

Seguramente el cambio de visión entre el principio consagrado en la Ley 99 de 1993 y el Acuerdo de Paz obedece a las necesidades y retos constantes en relación con la contaminación y degradación del recurso hídrico, lo cual ha sido reconocido por el Estado colombiano. A manera de ejemplo encontramos que el Conpes 3343 del $2005^{50}$ estableció que

\footnotetext{
49 Departamento Nacional de Planeación, Bases del Plan.

50 Departamento Nacional de Planeación, Documento Conpes 3344, lineamientos y estrategias de desarrollo sostenible para los sectores de agua, ambiente y desarrollo territorial (Bogotá: DNP, 2005), 1.
} 
Colombia enfrenta retos importantes en términos de degradación ambiental que comprometen su desarrollo económico sostenible. Estudios preliminares sobre los costos de degradación ambiental en Colombia, indican que los impactos más considerables están asociados con la contaminación del agua (...), las inadecuadas condiciones del agua, el saneamiento y la higiene (...) se ha encontrado que la degradación ambiental afecta significativamente la salud de niños y adultos mayores, la población más pobre y grupos más vulnerables.

La mencionada situación de deterioro del recurso muestra la necesidad de reformular tanto las políticas existentes como su implementación, y qué mejor oportunidad que el momento histórico en el que Colombia se encuentra, en relación con la revisión del Acuerdo de Paz, para comenzar con un principio de desarrollo sostenible acorde a las necesidades de todos los colombianos.

Consideramos lo anterior pertinente, sobre todo si tenemos en cuenta que los objetivos de desarrollo sostenible de las Naciones Unidas, ${ }^{51}$ en especial el sexto objetivo, versan sobre la necesidad de lograr el acceso universal y equitativo al agua potable, a un precio asequible para todos, incluyendo el saneamiento e higiene; aumentar sustancialmente la utilización eficiente de los recursos hídricos en todos los sectores y asegurar la sostenibilidad de la extracción y el abastecimiento de agua dulce para hacer frente a la escasez de agua y reducir sustancialmente el número de personas que sufren de escasez de agua; poner en práctica la gestión integrada de los recursos hídricos a todos los niveles, incluso mediante la cooperación transfronteriza; proteger y restablecer los ecosistemas relacionados con el agua, incluidos los bosques, las montañas, los humedales, los ríos, los acuíferos y los lagos; ampliar la cooperación internacional y el apoyo prestado a los países en desarrollo para la creación de capacidad en actividades y programas relativos al agua y el saneamiento, incluidos el acopio y el almacenamiento de agua, la desalinización, el aprovechamiento eficiente de los recursos hídricos, el tratamiento de aguas residuales y las tecnologías de reciclaje y reutilización;

51 Las Naciones Unidas ha establecido los objetivos de desarrollo sostenible —oDs—, también conocidos como objetivos mundiales, que son un llamado universal a la adopción de medidas para poner fin a la pobreza, proteger el planeta y garantizar que todas las personas gocen de paz y prosperidad. 
apoyar y fortalecer la participación de las comunidades locales en la mejora de la gestión del agua y el saneamiento. ${ }^{52}$

De igual manera, es oportuno tener en cuenta también lo que plantea la $\mathrm{Cepa}^{53}$ en el sentido de que las políticas deben reconocer los positivos y necesarios encadenamientos y las sinergias entre temas para hacer más integral y sostenible el desarrollo. Por ejemplo, son bien conocidas las relaciones entre el acceso al agua potable y al saneamiento con las condiciones de salud; la asociación que existe entre la infraestructura para agua y para riego; entre los beneficios de mediano plazo de la educación, y los ingresos de los hogares y la salud; y entre los programas de cuidado social y la autonomía de las mujeres. Esta formulación plantea retos a la mejor secuencia de los programas públicos. En realidad, lo más sinérgico será el tejido que se crea y se activa, que se puede dar de muchas maneras.

\section{Conclusiones}

\section{Según Harold Lockwood,}

(...) existe también un peligro real en la incapacidad de reconocer que la gestión comunitaria tiene sus límites. Cada año, en América Latina los gobiernos centrales y las agencias donantes internacionales invierten millones de dólares en la construcción de nuevos proyectos de servicios de agua potable y saneamiento manejados por las comunidades, pero muchos de estos proyectos no lograrán mantener los beneficios previstos a largo plazo. Esta situación representa un alto costo, tanto en términos de inversión de capital original como en otros términos, que son más difíciles de cuantificar, en áreas como los costos asociados con la incapacidad de aumentar al máximo los beneficios potenciales para la salud, la disminución de oportunidades para ganarse el sustento y conflictos sociales dentro de las comunidades, causados por los sistemas fracasados. ${ }^{54}$

52 Véase en la página web del Programa de las Naciones Unidas para el Desarrollo. Específicamente en el link: http://www.undp.org/content/undp/es/home/sustainable-development-goals.html

53 Ramírez J., et al., Bienes y servicios, 44.

54 Harold Lockwood, "Mecanismos de apoyo institucional para los sistemas rurales de agua potable y saneamiento manejados por las comunidades en América Latina", Oficina para América latina y el Caribe Usaid, Environmental Health Project (2002). 
Más allá de la reflexión propuesta y de realizar la recopilación in genere de lo expuesto, se desea llamar la atención sobre la oportunidad que presenta el momento histórico que está viviendo Colombia, con el fin de generar propuestas que permitan la construcción de una paz a través de la identificación y atención de necesidades particulares de la población. Con lo dicho entonces tenemos que la realidad de la ruralidad colombiana respecto del abastecimiento de agua y, por ende, la garantía del derecho humano al agua se constituye en una necesidad impostergable que debe asumirse y garantizarse a través de acciones concretas que deben adoptarse de manera urgente. No se puede desconocer que en la actualidad el acceso al agua rural se presenta por fuera de los regímenes jurídicos de distribución del líquido diseñados por el Estado: los servicios públicos domiciliarios, los distritos de riego y el derecho ambiental; es más, es una mezcla de los tres o un punto intermedio entre estos. Tal y como se pudo observar en el texto, el agua en la zona rural se requiere para usos agrícolas, consumo humano, entre otros, lo cual hace que las necesidades de abastecimiento requieran de un cuerpo normativo propio.

Por ello, consideramos que se requiere de una política pública que contemple el suministro de agua en el medio rural con una visión integral, basada en la realidad y no en la tendencia ideal o deontológica que se tenga de la ruralidad. Es de vital importancia que Colombia avance en implementar acciones encaminadas a mejorar las condiciones de vida de las comunidades, en la construcción de un cuerpo normativo y la elaboración de políticas públicas especiales que tengan en cuenta las particularidades de la zona rural del país. ${ }^{55}$

Por ello, lo dispuesto en el Acuerdo de Paz y su reformulación, si bien se constituye un avance en la materia, a través del presente capítulo nos permitimos proponer como desarrollo en los avances de este la creación, diseño, concertación, promulgación y evaluación de políticas públicas, normas

55 Así pues, se pueden generar avances primordiales si se contara con los siguientes aspectos: una política unificada tanto para la protección del recurso, como para su acceso en la zona rural; la implementación de tecnologías apropiadas y alternativas que permitan el acceso al agua, así como las normas necesarias para que esto sea posible; la creación de un sistema de subsidios apropiado a la realidad de la zona rural, lo cual confirma sin lugar a dudas la necesidad de contar con un cuerpo normativo e institucional que esté avocado única y exclusivamente a las particularidades de la zona rural colombiana. 
y reglamentación que tengan en cuenta las necesidades de la ruralidad, no dentro de los esquemas de servicios públicos, distritos de riego o el derecho ambiental, sino uno nuevo.

Esta nueva perspectiva debe, además de los anteriores elementos, como mínimo establecer que los sistemas de distribución sean viables o factibles desde el punto de vista financiero, técnico y operativo para satisfacer las necesidades de las personas que se encuentran a grandes distancias. Adicionalmente, la distribución del agua debe poseer unos costos acordes a los ingresos per cápita de los habitantes de la zona rural, en cuyo caso, la intervención del Estado se debe generar a partir del respeto de las condiciones tradicionales y culturales de la zona en cuestión, para lo cual es indispensable que los sistemas de abastecimiento estén acorde con las capacidades técnicas de los habitantes. Es importante entonces un nuevo cuerpo jurídico que posibilite los usos múltiples del agua, es decir, "tecnología multipropósito", ${ }^{56}$ como pueden ser captación de aguas lluvia, ${ }^{57}$ subterránea y superficial sectorizada por necesidad, ${ }^{58}$ entre otros.

El Estado colombiano debe emprender acciones orientadas a asegurar mejores condiciones de vida para la población rural, superando así la pobreza, los problemas de salud, las necesidades de servicios públicos y el acceso adecuado al recurso hídrico necesario para mejorar sus condiciones y promover el desarrollo integral del campo. Por ello, entonces, el abastecimiento de agua en el contexto del Acuerdo de Paz, además de garantizar varios derechos, como el derecho humano al agua, representa un aporte al logro de condiciones que garanticen la paz estable y duradera para Colombia.

56 Temática importante a definir por cuanto las particularidades de cada sector deben ser evaluadas en una nueva opción normativa que recoja el abastecimiento de agua de la zona rural, por ejemplo las obligaciones de micromedición, las estructuras tarifarias, la facturación, las desviaciones significativas, los índices de agua no contabilizada, entre muchos otros.

57 Desafortunadamente en Colombia se ha considerado que el uso de aguas lluvias está asociado a poblaciones atrasadas y por ende ha venido al desuso. No obstante, es una muy buena opción para la solución de los usos múltiples.

58 Hay que llamar la atención en que el RAs 2000 relaciona el nivel de complejidad de los sistemas de distribución según el tamaño de la población atendida o su capacidad económica y no por su grado o nivel tecnológico, como la necesidad de abarcar grandes áreas dispersas y usos múltiples del agua. 
A manera de ejemplo, Loockwood plantea como principales modelos que permitan tanto el apoyo de las comunidades, como un ejercicio de competencias técnicas por parte del Estado, los siguientes:

- Un modelo centralizado, a través de una agencia o ministerio que opere desde el punto nacional, pero que trabaje directamente con las estructuras de gestión comunitaria rurales, propiciado por la transferencia de tecnología y conocimiento (servicios de apoyo).

- Un modelo desconcentrado, mediante una agencia gubernamental nacional con autonomía que, a través de oficinas regionales o departamentales, proporcione a las comunidades sistemas necesarios para la satisfacción de sus necesidades.

- Un modelo delegado en una agencia gubernamental central o local que entrega la responsabilidad de la provisión de servicios de apoyo a una tercera entidad, que podría ser una ONG o una empresa del sector privado, que atienda las necesidades de la población según sus condiciones culturales.

Dichos modelos lógicamente estarán dispuestos a la generación de sistemas de uso múltiple, como se hizo referencia en el primer aparte de esta publicación.

\section{Bibliografía}

Corporación Autónoma Regional de Cundinamarca. CARta Ambientaln. ${ }^{\circ} 25$.

Bogotá: Corporación Autónoma Regional de Cundinamarca, 2010.

Correa C., Hernán Darío. Acueductos comunitarios, patrimonio público y movimientos sociales. Bogotá: Corpenca, 2006, http://www.corpenca. org/images/stories/documentos/acueductoscomunitariospatrimoniopublicomovimientossociales.pdf

Decreto 1575 del 2007, 9 de mayo. Por el cual se establece el Sistema para la Protección y Control de la Calidad del Agua para Consumo Humano. Defensoría del Pueblo. La gestión comunitaria del pueblo. Bogotá: Imprenta Nacional, 2013.

Defensoría del Pueblo. Acciones para el impulso del derecho humano al agua en Colombia. Una mirada critica al sector de agua potable y saneamiento básico. Bogotá: Imprenta Nacional, 2014, http://www.defensoria.gov. 
co/es/public/Informesdefensoriales/739/ACCIONES-PARA-ELIMPULSO-DEL-DERECHO-HUMANO-AL-AGUA-ENCOLOMBIA-Una-mirada-cr\%C3\%ADtica-al-sector-de-aguapotable-y-saneamiento-b\%C3\%A1sico-Informes-defensoriales--Agua.htm

Departamento Nacional de Planeación. Bases del Plan Nacional de Desarrollo 2014-2018 "Todos por un nuevo país”. Bogotá: DNP, 2014.

Departamento Nacional de Planeación. Documento Conpes 3344, lineamientos y estrategias de desarrollo sostenible para los sectores de agua, ambiente y desarrollo territorial. Bogotá: DNP, 2005.

Dinar, Ariel y Andrew Keck. Private irrigation investment in Colombia: effects of violence, macroeconomics policiy and environmental conditions. World Bank, 1996, http://nersp.osg.ufl.edu/ vecy/LitSurvey/Dinar.97.pdf Farah Q. María Adelaida y Edelmira Pérez C. "Mujeres rurales y nueva ruralidad en Colombia”, en II Congreso Iberoamericano de Estudios de Género, en la mesa de trabajo sobre Mujeres rurales y organización. Salta, Argentina, 24-26 de julio del 2003. Bogotá: Cuadernos de Desarrollo Rural, 2004.

Gómez Rey, Andrés y Gloria Amparo Rodríguez. El derecho fundamental al agua. Desde el derecho ambiental y los servicios públicos domiciliarios. Bogotá: Universidad del Rosario/Legis, 2013.

Instituto de Hidrología, Meteorología y Estudios Ambientales de Colombia -Ideam - Estudio Nacional del Agua. Bogotá: Imprenta Nacional, 2015.

Ley 142 de 1994, 11 de julio. Por la cual se establece el régimen de los servicios públicos domiciliarios y se dictan otras disposiciones. Diario Oficial 41.433.

Lockwood, Harold. "Mecanismos de apoyo institucional para los sistemas rurales de agua potable y saneamiento manejados por las comunidades en América Latina”. Oficina para América Latina y el Caribe Usaid, Environmental Health Project, 2002.

Ministerio de Educación de Colombia. Sistema Nacional de Indicadores Educativos para los Niveles de Preescolar, Básica y Media en Colombia. Bogotá: MEN, 2014.

Organización Mundial de la Salud, Fondo de las Naciones Unidas para la Infancia. Progresos en materia de saneamiento y agua potable: informe de 
actualización,2010,http://www.wssinfo.org/fileadmin/user_upload/ resources/JMPreport_Spanish.pdf

Organización de las Naciones Unidas, Asamblea General. Informe "Nuestro futuro común”, Comisión Mundial sobre el Medio Ambiente y el Desarrollo, 1987.

Organización de las Naciones Unidas para la Alimentación y la Agricultura. Alimentos para la ciudades, http://www.fao.org/3/a-ak824s/

Programa de las Naciones Unidas para el Desarrollo, http://www.undp. org/content/undp/es/home/sustainable-development-goals.html

Ramírez J., Juan Carlos, Renata Pardo, Olga Lucía Acosta y Luis Javier Uribe, Naciones Unidas. Bienes y servicios públicos sociales en la zona rural de Colombia. Brechas y politicas públicas. Santiago: Cepal, 2016. Ramírez, Diana Patricia, Olga Lucía Trespalacios, Febe Lucía Ruiz y Javier Otero García. Oportunidades para la conservación de la biodiversidad local, conectividad ecológica en la zona urbano-rural. Bogotá: Instituto de Investigación de Recursos Biológicos Alexander von Humboldt, 2008.

Reglamento Técnico del Sector de Agua Potable y Saneamiento Básico —RAs—, 2000, http://www.minvivienda.gov.co/viceministerios/ viceministerio-de-agua/reglamento-tecnico-del-sector/reglamentotecnico-del-sector-de-agua-potable

Restrepo Tarquino, Inés. Usos múltiples del agua, como estrategia para la reducción de la pobreza. Santiago de Cali: Programa Editorial Universidad del Valle, 2010.

Sentencia T-418 del 2010, 25 de mayo. MP: María Victoria Calle Correa. Torres Ramírez, Jorge Enrique. Misión para el diseño de una estrategia de reducción de la pobreza y la desigualdad. Contrato de Consultoría n. ${ }^{\circ} 192-04$, 2005, http://www.javeriana.edu.co/arquidis/injaviu/coloquio/2008/ documents/MISIoNPARAELDISEnODEUNAESTARTEGIADEREDUCCIONDELAPOBREZAYLADESIGUALDAD.pdf

Women for Water Partnership, www.womenforwater.org 



\title{
Bioprospección y el Acuerdo de Paz*
}

\author{
Diana Rocío Bernal-Camargo* \\ Leonardo Güiza-Suárez \\ Paola Moreno Latorre \\ Enrique Prieto-Rios
}

\section{Introducción}

Hacer referencia a las actividades de bioprospección implica necesariamente acudir al concepto de biodiversidad, que ha sido abordado tanto desde la literatura científica como en la normatividad internacional y nacional, por ejemplo, el caso del Convenio de Diversidad Biológica de 1992. En términos generales, la biodiversidad se entiende como la variedad de vida, diversidad de ecosistemas, especies y variedad genética que se encuentran en

* Las opiniones expresadas en este documento son personales, de exclusiva responsabilidad de la autora y no representan la opinión o posición del Gobierno de Colombia o de la Cancillería.

** Abogada. Ph. D. en Bioética y Biojurídica. Profesora asociada, investigadora del Grupo de Investigación en Derechos Humanos de la Facultad de Jurisprudencia de la Universidad del Rosario. Correo electrónico:diana.bernalc@urosario.edu.co

*** Abogado y biólogo. Msc en Derechos Humanos de la Universidad de Alcalá y Msc en Derecho Ambiental Industrial de la Universidad de Poitiers. Profesor principal de la Facultad de Jurisprudencia de la Universidad del Rosario. Correo electrónico: leonardo.guiza@urosario.edu.co

**** Abogada. Especialista en Organizaciones, Desarrollo y Responsabilidad Social y especialista en Derechos de Autor, Propiedad Industrial y Nuevas Tecnologías. Asesora en propiedad intelectual en el Ministerio de Relaciones Exteriores. Correo electrónico: paola.moreno@cancilleria.gov.co

***** Abogado, ma Derecho Internacional y Ph. D. en proceso de grado (tesis y defensa aprobada mayo 2017, fecha de grado noviembre 2017). Profesor principal, investigador del Grupo de Investigación en Derecho Internacional de la Facultad de Jurisprudencia de la Universidad del Rosario. Correo electrónico: enrique.prieto@urosario.edu.co 
un territorio o el planeta, ${ }^{1} \mathrm{y}$ acorde con esta distribución se habla de países ricos y países pobres en biodiversidad. En esta clasificación, Colombia, por su ubicación geográfica, se ubica en el primer grupo, es decir hace parte de los 14 países con mayor índice de biodiversidad en el mundo, incluida una gran variedad de material genético. ${ }^{2}$ Esto facilita la oferta de muchos servicios basados en la diversidad biológica, entre ellos las actividades de bioprospección, entendida como la investigación de unidades de herencia funcional, y procesos biológicos y moleculares que tienen valor comercial para aportar a las diferentes industrias y al desarrollo de la ciencia y la tecnología.

Para el caso nacional, es posible encontrar una relación entre el conflicto armado y las prácticas de investigación científica en diversas zonas ricas en biodiversidad. ${ }^{3}$ Por ello ha de analizarse si en el contexto de los acuerdos de paz, la cesación de actividades bélicas por parte de las Fuerzas Armadas Revolucionarias de Colombia — FARC - en diversos lugares del país, especialmente en lugares abundantes en biodiversidad, ${ }^{4}$ puede incidir favorablemente en actividades de investigación científica y acceso a recursos genéticos, tanto con fines académicos como comerciales, y, en consecuencia, crear una oportunidad económica para el país.

Lo anterior permitirá la exploración y el estudio científico de organismos y sustancias con posibles usos para beneficio del ser humano que pueden tener un valor comercial significativo en diversos sectores, como el industrial, alimentario, cosmético y farmacéutico, en zonas donde antes investigadores y compañías nacionales y extranjeras se abstenían de

1 Jane Guyer y Paul Richards, “The invention of biodiversity: social perspectives on the management of biological variety in Africa". Africa: Journal of the International African Institute 66, n. 1 (1996), http://www.jstor.org/stable/1161508

2 Véase Instituto de Investigación de Recursos Biológicos Alexander von Humboldt, "La biodiversidad y los servicios ecosistémicos", http://www.humboldt.org.co/es/biodiversidad/que-esla-biodiversidad

3 Colciencias, "Colombia Bio",http://www.colciencias.gov.co/sites/default/files/upload/paginas/ resena-colombiabio-2016.pdf

4 Véase Jimena Puyana y Sandra Aristizábal (Coord.), "Consideraciones ambientales para la construcción de una paz territorial estable, duradera y sostenible en Colombia" (Naciones Unidas Colombia - Cooperación Alemana, 2014); Andia Chaves Fonnegra, "Carrera con obstáculos para el estudio y conservación de la biodiversidad en Colombia” Biogenic (2016), http://www.biogeniccolombia. org/nuestros-artiacuteculos-de-temporada 
ingresar por el temor a la seguridad y a las amenazas del grupo armado. ${ }^{5}$ Si bien dichas amenazas no desparecen totalmente por la presencia de otros actores, como el Ejército de Liberación Nacional — ELN-, acorde con la cartografía que se presenta en este artículo, la coincidencia entre zonas de actividades de bioprospección y zonas que ocupaban las FARC y zonas transitorias de dejación de armas es mayor a la coincidencia con zonas de otros grupos armados.

Por lo anterior, este punto, entendido como uno de los retos del posconflicto, fue discutido en la mesa de conversaciones y fue tratado en el primer informe conjunto, en el que se reconoció la necesidad de garantizar un desarrollo sostenible con especial atención a la protección y preservación del agua y el medio ambiente. ${ }^{6}$

En este contexto, el presente capítulo analiza la bioprospección desde la óptica de los Acuerdos y los retos que implicará en el posconflicto. Para lo anterior, es necesario considerar la relación entre medio ambiente y conflicto armado teniendo en cuenta que tanto la industria nacional como la extranjera puede ver en el posconflicto nuevas oportunidades de aprovechamiento de los recursos genéticos y biológicos para aplicaciones industriales o farmacéuticas.

El análisis de este capítulo se hará desde la óptica del "Acuerdo final para la terminación del conflicto y la construcción de una paz estable y duradera" aprobado por el Congreso el 1 ${ }^{\circ}$ de diciembre del 2016. ${ }^{7}$ Parte de la argumentación presentada aquí incluye comparaciones cartográficas de territorios que este grupo ha ocupado, el estudio de las licencias de acceso a recursos genéticos otorgadas en los últimos años y las zonas transitorias para la dejación de armas de las FARC.

5 Véase Puyana y Aristizábal, “Consideraciones ambientales”; Jeffrey A.McNeely, “Biodiversity, conflict and tropical forests” (International Institute of Sustainable Development, 2002), https://www.iisd.org/pdf/2002/envsec_conserving_overview.pdf

6 Mesa de Conversaciones, "Primero Informe Conjunto. Mesa de Conversaciones" (La Habana, 21 de junio del 2013), https://www.mesadeconversaciones.com.co/comunicados/1er-informeconjunto-mesa-de-conversaciones-la-habana-21-de-junio-de-2013

7 Mesa de Conversaciones para la terminación del Conflicto y la Construcción de una Paz Estable y Duradera en Colombia, "Comunicado Conjunto \#8 Bogotá, 1 de diciembre de 2016", https:// www.mesadeconversaciones.com.co/comunicados/comunicado-conjunto-8-bogot\%C3\%A1-1-dediciembre-de-2016 
La estructura de este capítulo se presenta en cuatro puntos: primero, una conceptualización sobre la bioprospección; segundo, una referencia a la regulación del tema; tercero, un análisis de la bioprospección en el marco de los Acuerdos de Paz; cuarto, un contraste de los contratos de acceso a recursos genéticos; $y$, finalmente, plantear, a modo de conclusión, lo que se espera en el marco del posconflicto.

\section{Acerca de la bioprospección}

En el proceso de aprovechamiento del recurso natural encontramos que la biodiversidad ofrece servicios para la satisfacción de necesidades humanas básicas. En este contexto, y con el desarrollo de la ciencia y la tecnología, aparece la biotecnología como disciplina que busca caracterizar las plantas y los animales con el propósito de estudiar su ácido desoxirribonucleico — ADN - recombinante, proceso celular y moléculas, identificando sus funciones y procesos biológicos para la investigación y uso comercial en las diferentes industrias del mundo. ${ }^{8}$

Con la incorporación del concepto de biodiversidad en el Convenio de Diversidad Biológica de las Naciones Unidas de 1992 adoptado en la Cumbre de la Tierra, los países reconocieron la potencialidad que tiene la diversidad biológica y genética en términos de valor comercial. ${ }^{9}$ Uno de los elementos más importantes para los países megadiversos como Colombia en el Convenio de Diversidad Biológica - $\mathrm{CDB}$ - fue el reconocimiento de la soberanía sobre sus recursos biológicos y genéticos, pasando de una noción de patrimonio común o dominio público a patrimonio propio de cada Estado.

Lo anterior es muy importante porque le permitió al país regular el acceso sobre los recursos que se encuentran dentro de su territorio. Por otro lado, el CDв permitió que se visibilizaran los intereses de los países megadiversos, usualmente países en desarrollo, a través de la participación

\footnotetext{
8 Christopher L. Plein, “Popularizing biotechnology: the influence of issue definition”. Science, Technology, \& Human Values 16, n.o 4 (1991), http://www.jstor.org/stable/689804

9 Véase Convenio sobre la Diversidad Biológica — $\mathrm{CDB}$ - http://www.un.org/es/events/biodiversityday/convention.shtml
} 
y determinación del uso de su biodiversidad y la definición de las políticas para obtener la distribución de los beneficios. ${ }^{10}$

Es importante resaltar que la participación por parte de los países biodiversos fue resultado de las constantes críticas por la explotación de sus recursos biológicos y apropiación de los conocimientos tradicionales de sus comunidades locales basadas en invenciones, por parte de multinacionales en la mayoría de casos de países desarrollados, sin obtener ninguna retribución o contraprestación, reforzando la brecha de pobreza existente entre los países en desarrollo y los desarrollados. ${ }^{11}$

Inicialmente, había una política hecha por países desarrollados para explorar los países biodiversos con el propósito de realizar investigación de determinados recursos y semillas que impactarían la producción de la agricultura, la industria cosmetológica y la farmacéutica. Dentro de esa política, se establecía un sistema de compensación a los países que participan en el suministro de recursos o conocimientos a través de la distribución de beneficios económicos, fortalecimiento de capacidades, transferencia de tecnología, entre otros, los cuales se han entendido por algunos autores como la justicia de intercambio. ${ }^{12}$

Ahora bien, es importante entender la biodiversidad en el caso colombiano desde la bioculturalidad. Si bien podríamos referirnos a la biodiversidad desde una perspectiva ajena a la intervención humana, en la mayoría de casos no podríamos hacerlo, especialmente en la biodiversidad colombiana cuya interacción del ecosistema con las poblaciones es inevitable. Frecuentemente podemos encontrar variedad de comunidades indígenas, afrodescendientes, campesinos, rom y locales quienes han desarrollado prácticas y estilos de vida estableciendo conexión con el lugar geográfico para el aprovechamiento de los recursos, la conservación de los ecosistemas y el desarrollo de conocimientos a partir de la relación con el medio ambiente. ${ }^{13}$

10 Katy Moran, Steven R. King y Thomas J. Carlson, "Biodiversity prospecting: lessons and prospects”. Annual Review of Anthropology 30 (2001), http://www.jstor.org/stable/3069226

11 Véase Convention on Biological Diversity, "History of the Convention", https://www.cbd. int/history/

12 Doris Schroeder y Thomas Pogge, "Justice and the Convention on Biological Diversity”. Ethics E International Affairs 23, n. 3 (septiembre, 2009).

13 Véase Daniel J. Hruschka, Daniel H. Lende y Carol M. Worthman, "Biocultural dialogues: biology and culture in psychological anthropology". Ethos 33, n.o 1 (2005): 1; Kenneth A. Bennett, 
Asignarle valor al enfoque biocultural como aportación de las dinámicas del ser humanos en la conservación y determinación de los ecosistemas, como lo señala Nemoga ${ }^{14}$ implica la comprensión de que las personas y las comunidades no son un elemento separado de la biodiversidad, sino que existe una interdependencia directa para la supervivencia y se convierten en custodios de la biodiversidad al promoverla con sus estilos de vida.

Con el desarrollo de la ciencia y la tecnología, la actividad de investigación de unidades de herencia funcional, y procesos biológicos y moleculares que tenían valor comercial para aportar a las diferentes industrias se conoció como bioprospección. Esta puede tener diferentes aproximaciones dependiendo del contexto en que sea aplicada, como indica Melgarejo:
algunos desde un enfoque restrictivo se refieren a las actividades de investigación de los componentes, los genes, las proteínas que tienen un valor comercial. $Y$ desde un enfoque más amplio incluye los conocimientos tradicionales en los procesos de investigación que caracterizan recursos genéticos biológicos y componentes químicos para determinar sus funciones biológicas permitiendo el desarrollo de productos, su protección a través de los Derechos de Propiedad Intelectual y la participación de los diferentes grupos de interés en las múltiples etapas. ${ }^{15}$

Dicha perspectiva amplia de bioprospección debe tomarse en cuenta en relación con los retos que estos avances biotecnológicos implican, entre ellos: la importancia de salvaguardar la riqueza de los países biodiversos a través de la inclusión de modelos ecológicos; la coexistencia de mercados verdes tradicionales provenientes de las comunidades; la adopción de modelos que mitiguen la desertificación; el uso de semillas que no afecten las dinámicas

Richard H. Osborne y Robert J. Miller, "Biocultural ecology". Annual Review of Anthropology 4 (1975); Andreas Grotewold, "World exports of non-mineral primary products". The American Journal of Economic and Sociology 25, n. 3 (1966).

${ }^{14}$ Gabriel Ricardo Nemogá, "Diversidad biocultural: innovando en investigación para la conservación”. Acta Biológica Colombiana 21, n. 1 (2016).

15 Luz Marina Melgarejo, "Bioprospecting as a possible development mechanism for Colombia". Acta Biologica Colombiana 18, n.o 1 (enero, 2013): 20. 
ecosistémicas. En este contexto, lograr estrategias de compatibilidad entre modelos tradicionales, por ejemplo de cultivos, y la inclusión de nuevas tecnologías a partir de actividades de bioprospección, implica incentivar y estructurar programas dirigidos a las comunidades que rescatan la conservación y promueven el uso sostenible de la biodiversidad.

\section{Regulación de la bioprospección}

Es importante revisar de forma breve la regulación actual en materia de bioprospección a nivel tanto doméstico como internacional. En el ordenamiento jurídico colombiano, el material genético se considera patrimonio de la Nación, su ingreso y salida es regulado y se debe buscar siempre la protección del interés del país. ${ }^{16}$ Específicamente encontramos el artículo 81 de la Constitución Política de Colombia.

Adicionalmente, se cuenta con el Conpes 3697 del 2011 sobre "Política para el desarrollo comercial de la biotecnología a partir del uso sostenible de la biodiversidad". Si bien este documento busca clarificar la política colombiana sobre la bioprospección, no incorpora la participación de las comunidades en el desarrollo de las actividades de bioprospección y se enfoca desde la perspectiva de creación de productos de valor agregado para su comercialización, como si se tratara de un componente exclusivamente económico.

El Conpes 3697 establece la creación de condiciones para la generación de productos de valor agregado basada en el uso sostenible de la biodiversidad y reconoce la bioprospección como identificación de recursos biológicos, genéticos y derivados para la creación de productos con valor agregado que puedan ser comercializados. Sin embargo, como señala Melgarejo, esta aproximación es restrictiva y abandona a los diferentes grupos de interés y procesos que permiten y conciben la bioprospección como mecanismo de desarrollo.

A nivel internacional, y como se mencionaba en la sección anterior, el tema se encuentra regulado por el Convenio de las Naciones Unidas sobre la Diversidad Biológica de 1994, que en Colombia fue adoptado por medio

16 Martha Isabel Gómez Lee, "El Tlc y el acceso a los recursos genéticos”, Ponencia presentada en la Audiencia Pública del TLC (14 de febrero del 2006, Bogotá, Colombia), http://portal.uexternado. edu.co/pdf/5_boletinDerechoVida/Boletin_DER_Y_VID_49.pdf 
de la Ley 165 de 1994. Este Convenio reconoce el derecho que tienen los países soberanos para controlar su biodiversidad y genera un control restringido al acceso a material genético en tanto que no son considerados patrimonio de la humanidad. Es importante señalar que los beneficios de este Convenio solo podrán ser efectivos a través de la ratificación del Protocolo de Nagoya por parte de Colombia, lo cual no se ha logrado aún porque este debe pasar por consulta previa de las comunidades. ${ }^{17}$

También se encuentran las decisiones 391 y 486 de la Comunidad Andina de Naciones — CAN-. Es importante señalar que la decisión 391 de la can establece que los recursos genéticos son inalienables, imprescriptibles e inembargables, razón por la cual la explotación comercial de estos recursos requiere la firma de contratos de acceso que debe ser tramitada frente a las autoridades medio ambientales, en este caso el Ministerio del Medio Ambiente. ${ }^{18}$

Adicional a lo anterior, la bioprospección también está regulada por los tratados de libre comercio - TLC - firmados con varios países. En el caso del TLC con Estados Unidos, acoge criterios de patentabilidad de dicho país que son diferentes, por ejemplo, a los criterios de patentabilidad de la Comunidad Andina de Naciones. La patente se puede solicitar sobre material genético o conocimiento tradicional sin que se requiera consentimiento de las comunidades locales o indígenas. El punto de partida de la discusión es que no hay una normativa clara y unificada sobre el acceso al material genético en Colombia, ${ }^{19}$ además es un sistema normativo estricto, lo que puede incentivar la biopiratería.

\section{La bioprospección en los Acuerdos de Paz}

Para avanzar en la investigación de la biodiversidad en Colombia para el aprovechamiento de sus recursos de manera sostenible, es importante trabajar en: 1) integrar, restaurar y promover las comunidades indígenas y locales del país con sus conocimientos tradicionales; 2) trazar los lineamientos políticos y normativos a largo plazo que faciliten la actividad de

\footnotetext{
17 Véase Diana Lorena Rojas Blanco, “Vicisitudes del Protocolo de Nagoya en Colombia”. Revista Gestión y Ambiente 16, n.o 3 (2013).

18 Óscar Duarte Torres, "La bioprospección en Colombia”. Expedito 7 (2011): 17.

19 Gómez Lee, "El TLC".
} 
la bioprospección de manera sostenible; y 3) establecer un modelo que promueva el desarrollo económico sostenible desde el punto de vista ecológico, en el que Colombia también aproveche los recursos naturales para su desarrollo científico y tecnológico, evitando ser únicamente un país proveedor o exportador de su diversidad.

Las preocupaciones por la preservación de la biodiversidad deben ser comprendidas no solo desde la conservación de los ecosistemas y las especies que la componen, sino desde el enfoque biocultural (véase sección 1 de este capítulo), teniendo en cuenta el rol determinante que tienen las comunidades para que se sigan produciendo las dinámicas y los diferentes modos de vida. ${ }^{20}$ Sin embargo, para promover la participación de las diferentes comunidades y la preservación de sus conocimientos tradicionales se hace prioritaria la recuperación de los resguardos y de las tierras que son la base fundamental de las comunidades para su subsistencia y desarrollo. El desplazamiento forzado producido por el conflicto armado ha significado una amenaza para su patrimonio e identidad cultural, generando la pérdida de la cohesión como comunidad, y su sometimiento a situaciones de pobreza y condiciones difíciles de subsistencia. ${ }^{21}$

Por otro lado, los lineamientos políticos y la normatividad del país encuentran un escenario de inoperancia por la presencia de organizaciones armadas ilegales, lo que disminuye el control institucional en las regiones y territorios del país. La participación de las poblaciones y su interacción con el Gobierno se ve amenazada por la presencia de los grupos armados, lo que impide la estructuración de soluciones efectivas para gobernabilidad en las zonas de conflicto. ${ }^{22}$

En este contexto, tanto el acuerdo de Cartagena como la nueva versión del Acuerdo aprobada el $1^{\circ}$ de diciembre por el Congreso de la República ${ }^{23}$ marcan una línea de interés hacia la protección del medio ambiente y la

20 Nemogá, "Diversidad biocultural".

21 Silvia Catalina Quintero Torres y Laura Natalia Vargas Mora, "Indígenas en la ciudad. Construcción y mantenimiento de la identidad en contextos urbanos a partir del desplazamiento forzado". Revista de Derecho Público 31 (2013): 1-28, https://derechopublico.uniandes.edu.co/components/ com_revista/archivos/derechopub/pub383.pdf

22 Armando Borrero, Mansilla, "El conflicto armado interno, los cultivos ilícitos y la gobernabilidad local”. Revista Opera, n. ${ }^{\circ} 004$ (2004): 285.

23 Mesa de Conversaciones, "Comunicado Conjunto \#8”. 
biodiversidad en general. De esta forma, se encuentra que la protección al medio ambiente en los términos del Acuerdo y de su implementación se debe enmarcar dentro de un enfoque de desarrollo ambiental sostenible, protegiendo los intereses socioambientales. ${ }^{24}$ Así, por ejemplo, el preámbulo del Acuerdo Final señala que debe existir una visión de país que promueva la "protección del medio ambiente, en el respeto a la naturaleza, sus recursos renovables y no renovables y su biodiversidad". 25

Varios de los aspectos relacionados con la protección al medio ambiente en general se encuentran en el primer punto del Acuerdo ("hacia un nuevo campo colombiano: Reforma Rural Integral”). Conforme a los términos del Acuerdo, la transformación estructural del campo debe propender por un ordenamiento socioambiental sostenible. ${ }^{26}$

De igual forma, en el primer capítulo se señala que en el diseño de los lineamientos generales para el uso de la tierra se deberá tener en cuenta la sostenibilidad socioambiental y la conservación de la biodiversidad, ${ }^{27}$ buscando un equilibrio entre el medio ambiente, el bienestar y el buen vivir, según los principios de participación de las comunidades rurales y de desarrollo sostenible. ${ }^{28}$ De igual forma, el Acuerdo señala que se debe dar un manejo especial a las zonas de alta biodiversidad, incluyendo la protección de organismos genéticos. ${ }^{29}$ Para este fin establece la necesidad de crear un Plan de Zonificación Ambiental para, entre otros propósitos, caracterizar las zonas de alta biodiversidad, junto con un Plan de Asistencia Integral Técnica, Tecnológica y de Impulso a la Investigación, que debe estar dirigido, entre otros objetivos, a "salvaguardar el patrimonio genético y la biodiversidad como recursos soberanos de la nación”. ${ }^{30}$

24 Véase Mesa de Conversaciones. "Acuerdo final para la terminación del conflicto y la construcción de una paz estable y duradera", 12 de noviembre del 2016, https://www.mesadeconversaciones. com.co/sites/default/files/12-1479102292.11-1479102292.2016nuevoacuerdofinal-1479102292.pdf

25 Ibid.

26 Ibid.

27 Ibid., "1.1.8. Algunos mecanismos de resolución de conflictos de tendencia y uso y de fortalecimiento de la producción alimentaria".

28 Ibid., "1.1.10. Cierre de la frontera agrícola y protección de zonas de reserva".

29 Ibid.

30 Ibid., "1.3.3.2. Asistencia técnica". 
Adicionalmente, el punto tres del Acuerdo (sobre el fin del conflicto), señala que se "identificarán los planes o programas necesarios para la atención de recuperación del medio ambiente", lo cual implica la reparación en los lugares donde se haya generado un daño. En el punto cuatro del Acuerdo (relacionado con los asuntos de drogas ilícitas), se menciona la necesidad de proteger el medio ambiente durante la erradicación de cultivos ilícitos, ${ }^{31}$ incluyendo que los componentes de los planes de sustitución deben propiciar la recuperación ambiental. ${ }^{32}$ Por último, en el punto cinco del Acuerdo (sobre víctimas) se menciona la importancia de materializar durante el posconflicto la protección efectiva del medio ambiente.

De forma particular, en relación con la bioprospección, el Acuerdo habla de la necesidad de proteger la biodiversidad, especialmente los organismos genéticos como recursos soberanos de la nación. ${ }^{33}$ Esta mención específica refleja el hecho de que varias zonas de alta presencia de grupos al margen de la ley, como las FARC, coinciden con lugares de alta biodiversidad y donde existen recursos genéticos importantes (explicado con mayor detalle en la siguiente sección de este capítulo). Esto posiblemente implicará que con el fin de las operaciones de las FARC en estas áreas el espacio quedará abierto a la investigación y uso del material genético con fines comerciales, aunque el Estado deberá buscar las medidas y estrategias para garantizar que otros grupos al margen de la ley no ocupen estas zona de gran posibilidad de desarrollo.

Como se evidencia, el Acuerdo se encuentra permeado por una aproximación protectora al medio ambiente, sin embargo, y como lo mencionábamos al inicio de esta sección, esta protección se enmarca dentro de un desarrollo sostenible, lo cual implica que el interés económico juega un papel relevante en la interpretación y aplicación de los acuerdos en materia medio ambiental. Si bien el Acuerdo evidencia una preocupación por la protección de la biodiversidad y del material genético, no es lo suficientemente claro y específico en el punto. Así, no señala la forma como se deberá promover el uso sostenible del material genético (por ejemplo) sin que esto implique

\footnotetext{
31 Ibid., “4.1.3.2. Acuerdos con las comunidades”.

32 Ibid., “4.1.3.6. Componentes de los planes integrales de sustitución”.

33 Ibid., numerales 1.1 .10 y 1.3.3.2.
} 
de un lado la promoción de biopiratería, y, de otra parte, que no afecte los derechos y las formas de vivir de las comunidades.

Pese a lo anterior, es importante señalar que en esta construcción del desarrollo sostenible y protección del medio ambiente no se incluye de forma expresa que las comunidades indígenas y locales participarán en la definición de estas políticas, aunque, de conformidad con los estándares internacionales, se cuenta con el mecanismo de la consulta previa, que se extiende a las comunidades campesinas locales para el caso de las actividades de bioprospección.

Sin embargo, a pesar de la obligación que con la aplicación del Acuerdo surja en relación con la consulta previa, lo cierto es que su texto en sí mismo - en relación con la bioprospección y actividades afines- no tiene un enfoque biocultural que promueva la salvaguarda de los estilos de vida de las comunidades y sus conocimientos tradicionales. En este sentido, no es suficiente que se mencione que se tendrá en cuenta la participación de las comunidades rurales, sino que efectivamente se haya contado con los retos y preocupaciones de las comunidades para integrarlas desde el principio al Acuerdo de Paz.

\section{Los contratos de acceso a recursos genéticos y el conflicto armado en Colombia}

La relación entre diversidad biológica y conflicto armado en Colombia se puede ver entendiendo "la alta fragilidad de los ecosistemas presentes en escenarios de conflicto armado y en aquellos donde se materializan sus posibles soluciones". ${ }^{34}$ Así, tanto el Acuerdo de Paz, como la reglamentación que se derive, definirán, en gran medida, "la posibilidad de un desarrollo sostenible en estas regiones y afectarán la estabilidad de los acuerdos".

En el marco del conflicto armado colombiano, se han generado importantes impactos sobre el medio ambiente, como lo son: 1) la ampliación de frontera agrícola para la siembra de cultivos ilícitos; 2) la contaminación de fuentes hídricas y suelos por la voladura de oleoductos, y el establecimiento de campamentos y laboratorios de estupefacientes; 3) las fumigaciones con

34 Lorena Franco Vidal y Juan Pablo Ruíz, V Informe Nacional de biodiversidad de Colombia ante el Convenio de Diversidad Biológica (Bogotá: Instituto de Investigaciones de Recursos Biológicos Alexander von Humboldt, 2014), 8. 
glifosato, entre otros. ${ }^{35}$ Sin embargo, es importante reconocer aquí que en ciertas zonas de ocupación de las FARC este grupo ha logrado, bien sea de manera directa o indirecta, mantener intactos territorios de gran importancia desde el punto de vista ecológico. Así por ejemplo, la entrada de aserradores, la construcción de vías, la realización de actividades mineras formales, la caza furtiva y la entrada de investigadores a estudiar la biodiversidad de las zonas.

Teniendo en cuenta esa relación entre medio ambiente y conflicto armado, conviene tener una perspectiva de afectación y oportunidad que poco o nada ha sido documentada desde la visión de acceso a recursos genéticos. En este sentido, y con el fin de hacer una aproximación a esta temática, se revisó la localización geográfica por departamentos de los contratos de acceso a recursos genéticos - $\mathrm{CARG}$ - que a la fecha se han concedido, conforme al trámite pertinente, en el Ministerio del Medio Ambiente y Desarrollo Sostenible.

Para tal fin, se revisaron las 106 solicitudes de contratos que reporta el Ministerio de Ambiente en su sitio web, una más desde el 2013 acorde con la revisión reportada por Güiza y Bernal, ${ }^{36}$ y se encontró que los departamentos en los que se encuentra la mayoría de los procedimientos de colecta de especímenes en el marco de estos contratos son Antioquia, Cundinamarca, Magdalena, Valle del Cauca, Meta y Boyacá. En un segundo lugar se encuentran Tolima, Santander, Cauca, Bolívar, Risaralda, Quindío, Chocó, San Andrés y Caldas. Finalmente, se puede evidenciar que los departamentos con menos contratos son Amazonas, Caquetá, Huila, Casanare, Nariño, César, Norte de Santander, Córdoba, Sucre, Guaviare, Guainía, Putumayo, atlántico y Guajira (mapa 1).

Como se observa, las zonas menos afectadas por la presencia del grupo armado de las FARC (mapa 2) son aquellas en las que se registra mayor número de contratos de acceso a recursos genéticos. En departamentos como Vichada es evidente la prevalencia de este grupo, en donde no logró encontrarse siquiera un contrato de acceso a recursos genéticos. Así mismo,

35 María C. Londoño y Leidy J. Martínez A., El medio ambiente, otra víctima del conflicto armado colombiano actual (Manizales: Universidad de Manizales, 2015).

36 Leonardo Güiza y Diana Bernal, “Bioprospecting in Colombia”. Universitas Scientiarum 18, n. ${ }^{\circ} 2$ (2013): 153-164. 
Colciencias, en su documento "Colombia Bio", reconoce el conflicto armado como uno de los factores que han influido en que "una amplia porción del país aún no se conozca, ni siquiera en el ámbito académico”. ${ }^{37}$ En la misma línea se pueden encontrar los informes de instituciones públicas y privadas que han visto el conflicto armado como un factor que ha tenido estas actividades de bioprospección en el país, ${ }^{38}$ por lo que puede inferirse una relación entre la presencia de este grupo armado, o de otros, y el número de contratos de acceso a recursos genéticos en el país.

Es importante resaltar que, si bien ninguno de los contratos de acceso a recursos genéticos persigue fines comerciales, en por lo menos tres de ellos se hace evidente la posibilidad de derivar en un futuro contrato comercial, en tanto que implican nuevos usos, especialmente medicinales, de la flora, lo que evidentemente conlleva a nuevas oportunidades bioeconómicas para el país, la población campesina y, por supuesto, los futuros guerrilleros desmovilizados. En este sentido, una de las grandes posibilidades en relación con las actividades de bioprospección es el mercado de medicamentos biológicos y biosimilares, cuyo principio activo se obtiene a partir de organismos vivos, y en el caso de países ricos en biodiversidad, como Colombia, este desarrollo puede estar asociado al conocimiento tradicional de comunidades ancestrales, situación que puede ser de interés tanto para la industria nacional como la extranjera.

En este sentido, las zonas transitorias para la dejación de armas por parte de las FARC (mapa 3) pueden abrir una oportunidad como corredor para la bioprospección.

37 Colciencias, "Colombia Bio".

38 Luz Marina Melgarejo, Jimena Sánchez, Carmen Reyes, Federico Newmark y Marisol SantosAcevedo, Plan Nacional en Bioprospección Continental y Marina (Propuesta Técnica) (Bogotá: Invemar, Ministerio del Medio Ambiente, Universidad Nacional de Colombia, Banco Interamericano de Desarrollo, 2013). 


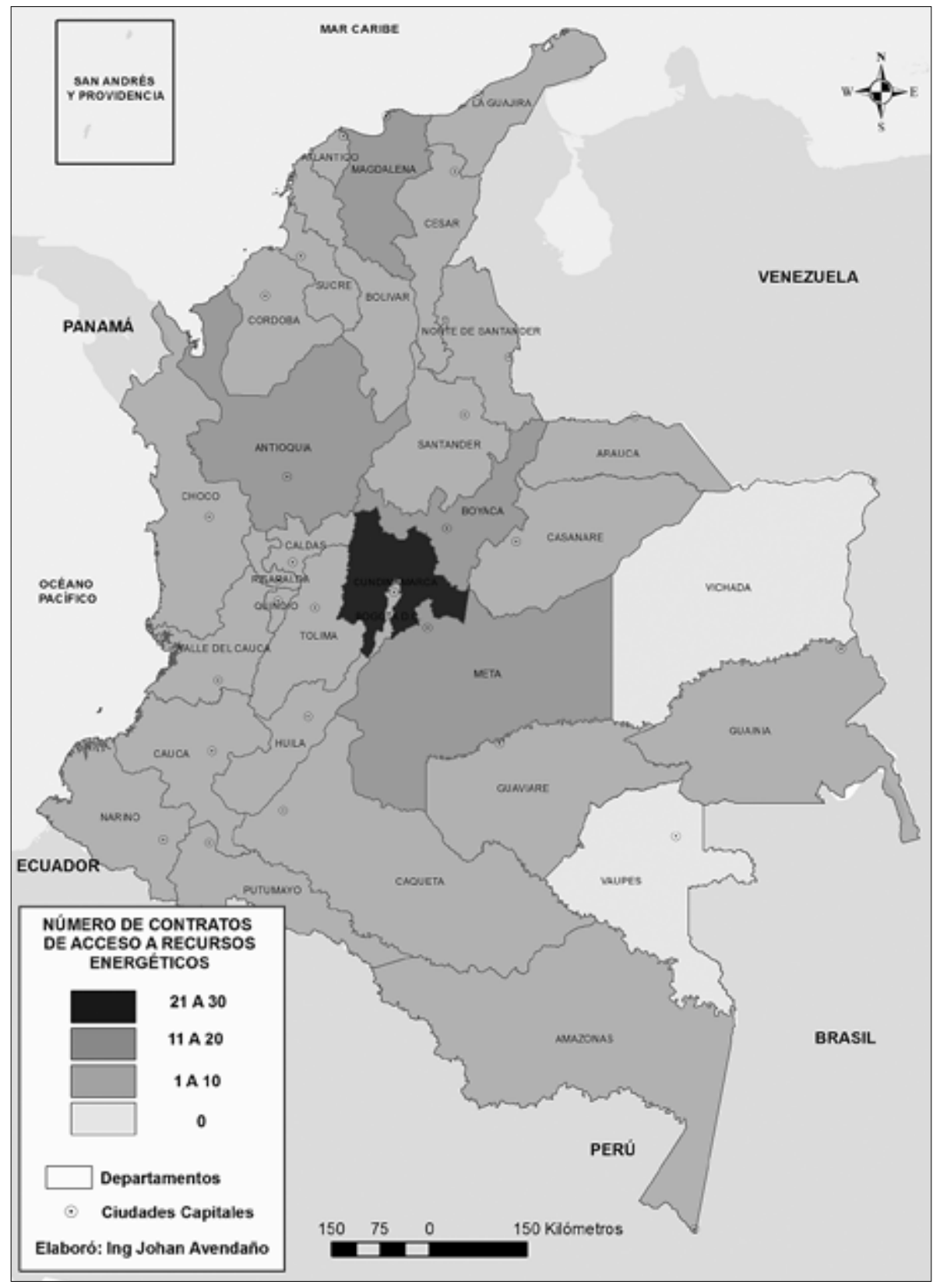

Mapa 1. Bioprospección y posconflicto a nivel departamental

Fuente: elaboración propia a partir de la información reportada en el sitio web del Ministerio del Medio Ambiente y Desarrollo Sostenible. 


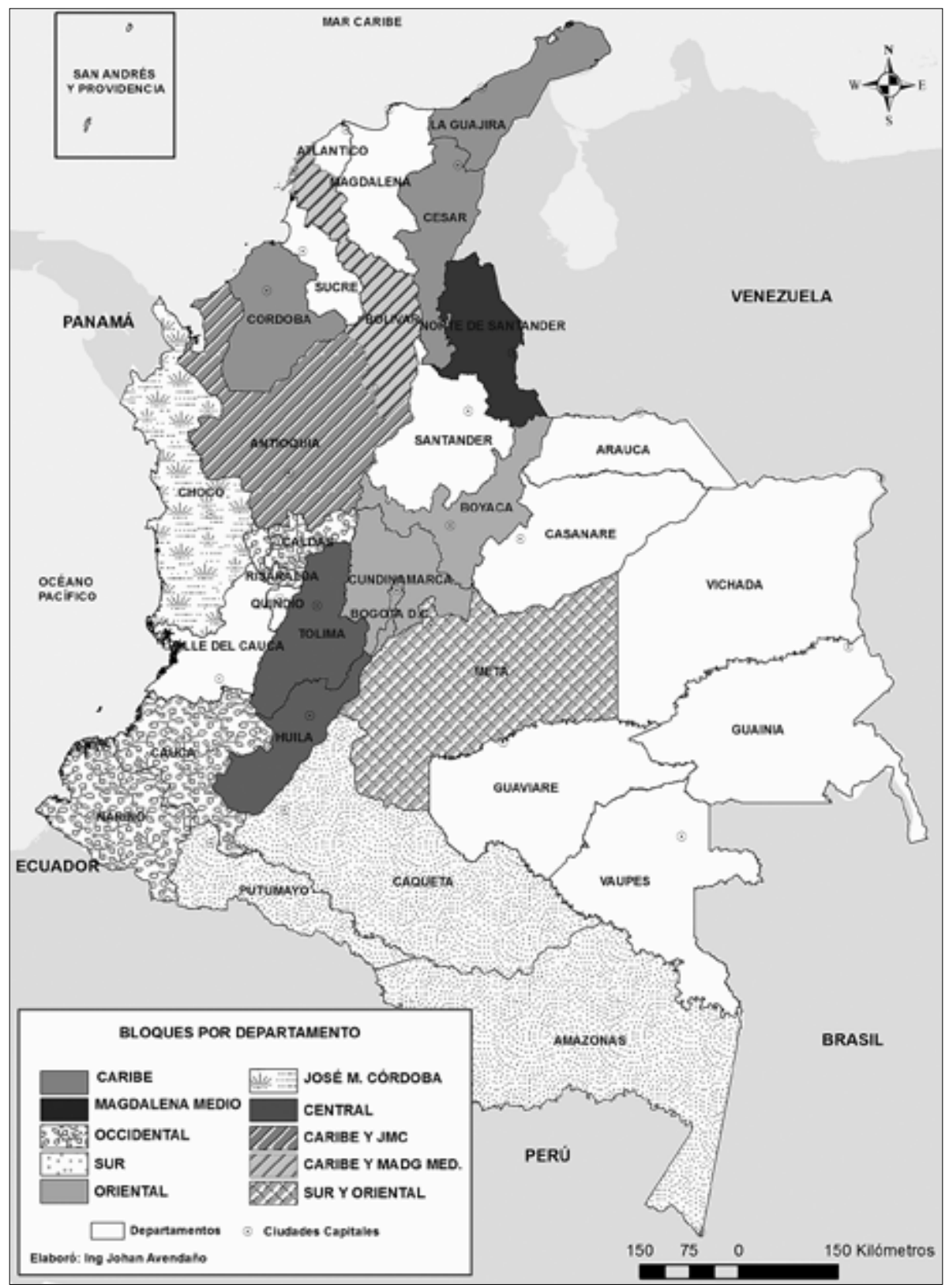

Mapa 2. Ubicación territorial de las FARC-EP por Bloques 2016

Fuente: elaboración propia a partir de información reportada en medios de comunicación (El Espectador, El Tiempo, Semana). 


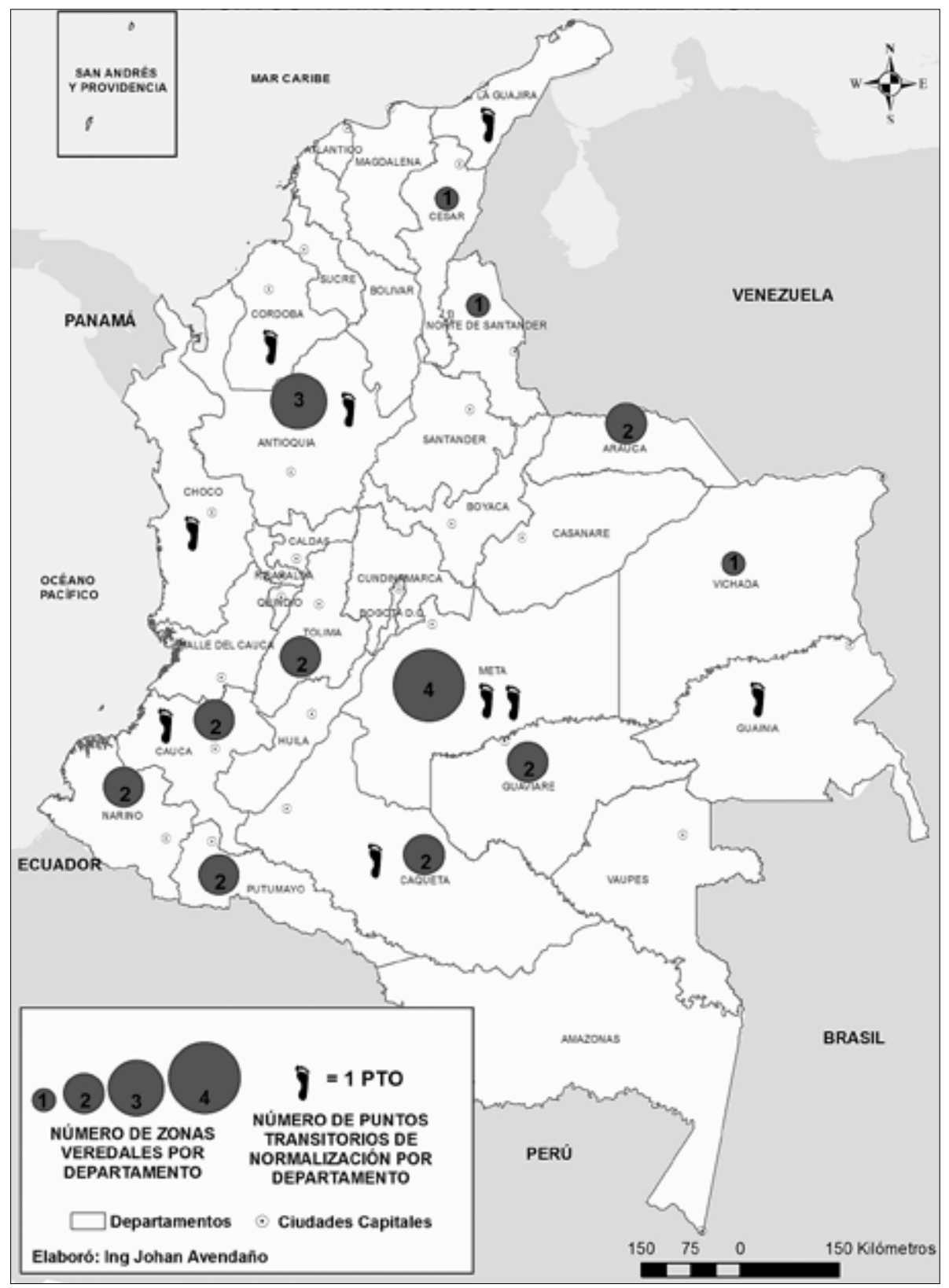

Mapa 3. Zonas veredales transitorias de normalización y puntos transitorios de normalización

Fuente: elaboración propia a partir de los Decretos Presidenciales de 2016. 
Conforme a lo anterior, es un desafío que las zonas ricas en biodiversidad tengan condiciones de seguridad y acceso para llevar a cabo actividades de bioprospección.

\section{Conclusiones}

Comprender la bioprospección en su sentido amplio, como lo aborda Melgarejo, implica incluir las diferentes dimensiones económicas, sociales y ambientales, para convertirla en un mecanismo de ventaja competitiva y de desarrollo que respondería a necesidades específicas del país y del mundo, promoviendo la conservación de la biodiversidad.

Debe existir un cambio de paradigma en el cual Colombia no sea únicamente país proveedor de recursos biológicos para corporaciones internacionales y otros países, sino, por el contrario, que sus recursos sean aprovechados por el país y los investigadores nacionales de manera sostenible para el desarrollo de la ciencia y biotecnología colombiana, lo que permite su explotación económica a través de los derechos de propiedad intelectual y cuyos rendimientos sean reinvertidos en la conservación de los ecosistemas.

Dentro de un escenario de posconflicto es necesario recuperar la gobernabilidad y la presencia institucional en las zonas afectadas, e incorporar los actores sociales que participan en el proceso de bioprospección y conservación de la biodiversidad, incluyendo las comunidades y entidades del Gobierno, para que sean ellas beneficiarias de la defensa del territorio y los recursos naturales en estos corredores, para garantizar que en efecto se logre su acceso.

Es importante el desarrollo de un comercio sostenible o biocomercio con métodos eficaces que permitan el control de bienes y servicios que afecten el medio ambiente y la salubridad, a través de marcas o sellos de certificación para las industrias que preservan la biodiversidad y cumplen con la normatividad en el acceso a recursos biológicos y genéticos.

Como parte de la preservación de la biodiversidad, se hace necesario la creación tanto de estándares nacionales uniformes que dialoguen de manera articulada con las entidades nacionales e internacionales, del orden público y privado, para fortalecer la normatividad en la investigación, el uso comercial o no de los recursos biológicos, la biotecnología y la bioseguridad, 
como medidas estrictas en el transporte nacional y transfronterizo de los recursos biológicos que representen la pérdida de la biodiversidad. Se recomienda la creación de programas que prohíban la colonización, ocupación de territorios, el uso indiscriminado de plaguicidas, la expansión de actividades agrícolas, el establecimiento de cultivos ilícitos y otros que transforman los hábitats y ecosistemas naturales generando la pérdida de la biodiversidad.

Destacamos la priorización de programas que devuelvan los territorios a las comunidades indígenas, afrodescendientes, rom y campesinas, que propendan por la restauración de la identidad cultural de las comunidades, el respeto del consentimiento informado previo o consulta previa para los asuntos que las afecten, y la preservación de sus conocimientos tradicionales a través de mecanismos sui generis como instrumentos de cooperación que tiendan hacia restaurar la identidad cultural de las comunidades y actividades dirigidas al empoderamiento para la toma de decisiones.

El desarrollo de una política de ciencia, tecnología e innovación sistémica que articule la academia, el sector público, privado, el medio ambiente, las comunidades indígenas y locales, y los grupos armados ilegales se hace menester para cumplir con un modelo económico basado en la competitividad y la productividad en biotecnología, y para diversificar fuentes de empleo e ingresos, cuyo fin sea reducir la pobreza y ofrecer oportunidades de reinserción a los guerrilleros y el mantenimiento de los estilos de vida tradicionales que preservan la biodiversidad.

La bioprospección sostenible como instrumento de política pública puede apoyar el desarrollo del país en aspectos como el ordenamiento territorial y los mecanismos para el acceso a las zonas más biodiversas del país. Lo anterior permite trazar las formas de utilización del territorio, los recursos naturales y genéticos, el diálogo con las comunidades indígenas y locales, la generación de empleo para los grupos armados y, finalmente, el desarrollo económico sostenible a través del biocomercio y del impulso de la ciencia, la tecnología y la innovación.

Estas medidas deben ser tomadas en el corto plazo, dado que las zonas en las que ha tenido históricamente ocupación territorial las FARC, y en las cuales ha dejado de actuar militarmente en el marco del proceso de paz, pueden generar nuevas dinámicas de ocupación por parte de nuevos 
colonos o de otros grupos al margen de la ley, lo que puede aumentaría los índices de biopiratería o de bioprospección ilegal en estas. ${ }^{39}$

\section{Bibliografía}

“ONU advierte sobre aparición de 'posparamilitares' en zonas dejadas por las FARC”. El Paí, 17 de noviembre 17 del 2016, http://www.elpais.com. co/elpais/colombia/proceso-paz/noticias/onu-advierte-aparicionposparamilitares-zonas-estan-dejando-farc

Borrero Mansilla, Armando. "El conflicto armado interno, los cultivos ilícitos y la gobernabilidad local”. Revista Opera, n. ${ }^{\circ} 004$ (2004): 285-316. Bennett, Kenneth A., Richard H. Osborne y Robert J. Miller. "Biocultural ecology”. Annual Review of Anthropology 4 (1975): 163-181.

Chaves Fonnegra, Andia. "Carrera con obstáculos para el estudio y conservación de la biodiversidad en Colombia”. Biogenic, 2016, http://www.biogeniccolombia.org/nuestros-artiacuteculos-de-temporada

Colciencias. "Colombia Bio", http://www.colciencias.gov.co/sites/default/ files/upload/paginas/resena-colombiabio-2016.pdf

Convenio sobre la Diversidad Biológica — $\mathrm{CDB}$ - http://www.un.org/es/ events/biodiversityday/convention.shtml

Convention on Biological Diversity. "History of the Convention", https:// www.cbd.int/history/

Duarte Torres, Óscar. “La bioprospección en Colombia”. Expedito 7 (2011): 17-25.

Franco Vidal, Lorena y Juan Pablo Ruíz. V Informe Nacional de biodiversidad de Colombia ante el Convenio de Diversidad Biológica. Bogotá: Instituto de Investigaciones de Recursos Biológicos Alexander von Humboldt, 2014.

$39 \mathrm{Al}$ respecto, recientemente la Oficina del Alto Comisionado de las Naciones Unidas para los Derechos Humanos en Colombia expresó su preocupación por la situación de violencia que se está registrando en las regiones de las que están saliendo las FARC, y que están siendo copadas por grupos "posparamilitares" dedicados al negocio del narcotráfico. "onu advierte sobre aparición de 'posparamilitares' en zonas dejadas por las FArc", El País, 17 de noviembre 17 del 2016, http://www.elpais. com.co/elpais/colombia/proceso-paz/noticias/onu-advierte-aparicion-posparamilitares-zonas-estandejando-farc 
Gómez Lee, Martha Isabel. "El TLC y el acceso a los recursos genéticos". Ponencia presentada en la Audiencia Pública del TLc, 14 de febrero del 2006, Bogotá, Colombia, http://portal.uexternado.edu.co/ pdf/5_boletinDerechoVida/Boletin_DER_Y_VID_49.pdf

Grotewold, Andreas. "World exports of non-mineral primary products". The American Journal of Economic and Sociology 25, n. 3 (1966): 321-334.

Güiza, Leonardo y Diana Bernal. “Bioprospecting in Colombia”. Universitas Scientiarum 18, n. 2 (2013): 153-164.

Guyer, Jane y Paul Richards. "The invention of biodiversity: social perspectives on the management of biological variety in Africa". Africa: Journal of the International African Institute 66, n. ${ }^{\circ} 1$ (1996): 1-13. http://www.jstor.org/stable/1161508

Hruschka, Daniel J., Daniel H. Lende y Carol M. Worthman. "Biocultural dialogues: biology and culture in psychological anthropology". Ethos 33, n. ${ }^{\circ} 1$ (2005): 1-19.

Instituto de Investigación de Recursos Biológicos Alexander von Humboldt. "La biodiversidad y los servicios ecosistémicos", http://www. humboldt.org.co/es/biodiversidad/que-es-la-biodiversidad

Londoño H., María C. y Martínez A., Leidy J. El medio ambiente, otra víctima del conflicto armado colombiano actual. Manizales: Universidad de Manizales, 2015.

McNeely,Jeffrey A. "Biodiversity, conflict and tropical forests". International Institute of Sustainable Development, 2002, https://www.iisd.org/ pdf/2002/envsec_conserving_overview.pdf

Melgarejo, Luz Marina. "Bioprospecting as a possible development mechanism for Colombia”. Acta Biologica Colombiana 18, n. ${ }^{\circ} 1$ (enero, 2013): 19-30.

Mesa de Conversaciones. "Primer Informe Conjunto. Mesa de Conversaciones”. La Habana, 21 de junio del 2013, https://www.mesadeconversaciones.com.co/comunicados/1er-informe-conjunto-mesa-deconversaciones-la-habana-21-de-junio-de-2013

Mesa de Conversaciones para la terminación del Conflicto y la Construcción de una Paz Estable y Duradera en Colombia. "Comunicado Conjunto \#8 Bogotá, 1 de diciembre de 2016”, https://www.mesadeconversaciones.com.co/comunicados/comunicado-conjunto8-bogot \%C3\%A1-1-de-diciembre-de-2016 
Mesa de Conversaciones. "Acuerdo final para la terminación del conflicto y la construcción de una paz estable y duradera", 12 de noviembre del 2016, https://www.mesadeconversaciones.com.co/sites/ default/files/12-1479102292.11-1479102292.2016nuevoacuerdof inal-1479102292.pdf

Melgarejo, Luz Marina, Carmen Reyes Jimena Sánchez, Federico Newmark y Marisol Santos-Acevedo. Plan Nacional en Bioprospección Continental y Marina (Propuesta Técnica). Bogotá: Invemar, Ministerio del Medio Ambiente, Universidad Nacional de Colombia, Banco Interamericano de Desarrollo, 2013.

Moran, Katy, Steven R. King y Thomas J. Carlson. "Biodiversity prospecting: lessons and prospects". Annual Review of Anthropology 30 (2001): 505-526, http://www.jstor.org/stable/3069226

Nemogá, Gabriel Ricardo. "Diversidad biocultural: innovando en investigación para la conservación”. Acta Biológica Colombiana 21, n. ${ }^{\circ} 1$ (2016): 311-319.

Plein, Christopher L. "Popularizing biotechnology: the influence of issue definition”. Science, Technology, E Human Values 16, n. 4 (1991): 474-490, http://www.jstor.org/stable/689804

Puyana, Jimena y Sandra Aristizábal (Coord.). "Consideraciones ambientales para la construcción de una paz territorial estable, duradera y sostenible en Colombia”. Naciones Unidas Colombia - Cooperación Alemana, 2014.

Quintero Torres, Silvia Catalina y Laura Natalia Vargas Mora. "Indígenas en la ciudad. Construcción y mantenimiento de la identidad en contextos urbanos a partir del desplazamiento forzado". Revista de Derecho Público 31 (2013): 1-28, https://derechopublico.uniandes. edu.co/components/com_revista/archivos/derechopub/pub383.pdf Rojas Blanco, Diana Lorena. "Vicisitudes del Protocolo de Nagoya en Colombia”. Revista Gestión y Ambiente 16, n. 3 (2013): 17-23.

Schroeder, Doris y Thomas Pogge. "Justice and the Convention on Biological Diversity”. Ethics E International Affairs 23, n. 3 (septiembre, 2009): 267-280. 


\title{
En los confines de lo posible: inclusión del enfoque de género en el Acuerdo de La Habana
}

\author{
Lina M. Céspedes-Báez
}

La verdad sale más pronto del error que de la confusión (...).

Francis Bacon, Novum Organum

El Acuerdo de Paz de La Habana firmado por el Gobierno nacional colombiano y las Fuerzas Armadas Revolucionarias de Colombia - FARCfue rechazado en las urnas por múltiples razones. Entre ellas vale la pena destacar el papel preponderante de la categoría género en la movilización en su contra y la consecuente preminencia que hoy en día parece ocupar en los términos de la renegociación de lo pactado. Aunque mucho se ha dicho sobre las distorsiones y manipulaciones que sufrió esta materia en manos de los opositores del Acuerdo y se ha recalcado que este texto no hace más que recoger una cuestión evidente -el impacto de género del conflicto

* Abogada de la Universidad del Rosario, con especialización en Derecho Tributario de la misma Universidad. Maestría en Estudios de Género de la Universidad Nacional de Colombia, LL. M. con concentración en Derecho Internacional de Cardozo School of Law (Nueva York) y doctorado en Derecho de Temple University (Filadelfia). Becaria Fulbright 2012-2014 y Residential Fellow del Institute for Global Law and Policy — IGLP-) de la Facultad de Derecho de la Universidad de Harvard 2014-2015. Actualmente es la vicedecana de la Facultad de Jurisprudencia de la Universidad del Rosario. Correo electrónico: linam.cespedes@urosario.edu.co 
armado interno - el debate no ha ahondado en qué fue lo que permitió que se construyera una narrativa del pánico alrededor de este asunto. ${ }^{1}$

Los esfuerzos del Gobierno nacional y de otros grupos de interés, como activistas de derechos humanos, académicos y organizaciones no gubernamentales - ONG-, por salvaguardar el Acuerdo de La Habana, han redundado en la domesticación de la perspectiva y los estudios de género. Así, estos actores han presentado a la opinión pública una lectura aséptica del significado de incluir la categoría género en la comprensión de la guerra y sus consecuencias, como si ello fuera un mandato del sentido común y no una movida teórica que hunde sus raíces en un cuerpo de conocimiento elaborado a través de décadas de investigación académica feminista. Por su parte, los opositores del Acuerdo han optado por demonizar los usos del género en este contexto. El llamar "ideología de género" a la integración de una perspectiva que permite introducir el sexo y la sexualidad como categorías relevantes para comprender el conflicto armado les permite negar la seriedad y la relevancia teórica de esta propuesta y mostrarla como un proyecto subversivo carente de fundamento. ${ }^{2}$

1 Véase Lina M. Céspedes-Báez, "Gender panic and the failure of a peace agreement". American Journal of International Law Unbound 183 (2016), https://www.asil.org/blogs/symposiumcolombian-peace-talks-and-international-law-gender-panic-and-failure-peace-agreement; "Ideología de género, el caballo de batalla del No al plebiscito, Semana, 9 de septiembre del 2016, http:// www.semana.com/nacion/articulo/ideologia-de-genero-el-caballo-de-batalla-del-no-al-plebiscito/493093; José Alberto Mojica Patiño, "La suma al clamor por un acuerdo ya", El Tiempo, 16 de octubre del 2016, http://www.eltiempo.com/estilo-de-vida/gente/iglesia-pide-acuerdo-en-proceso-depaz/16727642; Humberto de la Calle Lombana,."Enfoque de género", ElTiempo, 16 de octubre del 2016, http://www.eltiempo.com/opinion/columnistas/enfoque-de-genero-humberto-de-la-calle-columnista-el-tiempo/16727692; “Proceso de Paz: ¿dónde están las mujeres?”, Semana, 14 de octubre del 2016, http://www.semana.com/nacion/articulo/proceso-de-paz-criticas-por-ausencia-de-mujeresen-negociaciones-del-plebiscito/499082; "Es una ironía que los hombres decidan si el enfoque de género se saca de los acuerdos", Semana, 17 de octubre del 2016, http://www.semana.com/nacion/articulo/plebiscito-monica-roa-habla-del-enfoque-de-genero-en-los-acuerdos-de-la-habana/499367; Colombia 2020, “¿Ideología o enfoque de género?”, El Espectador, 14 de octubre del 2016, http://colombia2020.elespectador.com/pais/ideologia-o-enfoque-de-genero

2 El término "ideología” es plurívoco y sirve varios fines. En este caso específico su uso busca darles una connotación negativa a los estudios de género y negar sus fundamentos académicos. Para ahondar en el uso de la palabra "ideología", véase Terry Eagleton, Ideology: an introduction (Nueva York: Verso, 1991). Para ver el uso que le ha dado la Iglesia Católica, véase "Synod15. Final Relatio of the Synod of Bishops to the Holy Father, Francis, 24th October, 2015”. Diócesis de Lancaster - Inglaterra, http://www.lancasterdiocese.org.uk/wp-content/uploads/2015/11/FinalRelatio15-Final.pdf 
Ninguna de esas aproximaciones permite comprender el proceso por medio del cual se situó el género en el conflicto armado colombiano, los supuestos en los cuales se basa y lo que esto significa para otros grupos que buscan reconocimientos diferenciados en este contexto, especialmente para la población gay, lesbiana, bisexual y transgenerista — LGBT-. Así, esta discusión ha contribuido a hacer invisibles los términos en los cuales ha sido planteado el nexo entre género y guerra en el país, y lo que ello implica en cuanto a retos y limitaciones. Por ejemplo, nada se ha dicho del papel que jugó el feminismo legal y el derecho internacional en esta materia, ni del fortalecimiento de un feminismo criollo netamente anclado en lo jurídico para proveer una lectura específica del sexo y la sexualidad en medio de la violencia. Una controversia planteada desde la domesticación/demonización facilita que la supervivencia del enfoque de género en el Acuerdo de La Habana y los debates políticos que están por venir se hagan al precio de catalogar como meramente descriptiva a la categoría de género y se la desligue de un proyecto más amplio que propenda por la inclusión efectiva de ordenaciones diversas del sexo y la sexualidad en la sociedad colombiana.

La manera en que se construyó y consolidó en los últimos quince años una interpretación de género del conflicto armado sin duda contribuyó indirectamente a la generación de un pánico de género, el cual fue hábilmente movilizado para sustentar el rechazo de lo negociado por el Gobierno y las FARC. Mientras que para las feministas criollas ${ }^{3}$ el Acuerdo de La Habana era un sitio de compendio y reiteración de más de una década de trabajo, para la comunidad LGBT era una oportunidad de apropiación y reinvención de un término que había sido utilizado por estas para situar a las mujeres en el conflicto armado como víctimas primordialmente de violencia sexual heterosexual.

3 Desde hace unos cuantos años he decidido llamar al conocimiento feminista producido en Colombia "feminismo criollo" y a las feministas que lo producen "feministas criollas". Con ello quiero resaltar dos cosas: 1) el hecho de que las feministas nacionales crean conocimiento a partir de la mixtura y transformación de teorías importadas de otros sitios de producción de conocimiento que casi siempre coinciden con el norte global; y 2) que sus elecciones al respecto son en su mayoría estratégicas, cuestión que les permite adoptar un sincretismo que las posiciona como expertas e interlocutoras válidas en el contexto público colombiano e internacional. Para el efecto, véase Lina M. Céspedes-Báez, "Conflicto armado colombiano y feminismo radical criollo: una aproximación preliminar a las lecciones aprendidas”, en Aristas del Conflicto Colombiano editado por María Victoria Uribe y Ana María Forero (Bogotá: Editorial Universidad del Rosario, 2014). 
La particular manera en que se incorporó el género a la situación colombiana y sus fundamentos teóricos permitieron no solo hacer una incidencia efectiva para implementar acciones positivas para las mujeres en este contexto, sino consolidar una lectura bastante conservadora y dicotómica del sexo y la sexualidad. Este marco epistemológico daba poca cabida a una interpretación independiente y sistemática de la violencia en contra de la población LGBT en el escenario de la guerra. La mesa de negociación de La Habana, entonces, representaba para la comunidad LGBT una ocasión única para hacer una intervención en los significados del género y ampliar las aristas de su aplicación. Sin embargo, como los fundamentos de la ordenación de los sexos y la sexualidad no habían sido tocados sino superficialmente por más de una década de reflexión feminista sobre el conflicto, la apuesta de la comunidad LGBT se tornó en algo más que subversivo, en algo difícilmente inteligible.

Este artículo ofrece un breve análisis de las estrategias jurídicas que fueron cruciales para promover, sostener y convertir en sentido común una cierta lectura de género del conflicto armado y cómo esta produjo una identidad legal particular para las mujeres y no para la comunidad LGBT. Así mismo, explora de manera preliminar y hace un llamado a ahondar en cómo esta particular argumentación feminista criolla estrechaba los espacios para que otros grupos recurrieran a la categoría género para estructurar otras narrativas que les permitieran avanzar su agenda de derechos. Para el efecto, me centraré en responder las siguientes preguntas: 1) ¿cuál es el entendimiento común y aceptado por la sociedad colombiana frente al impacto de género del conflicto armado?; 2) ¿cuáles son las bases jurídicofeministas que dan sustento a ese entendimiento?; 3) ¿cómo se reflejó ese entendimiento en los Acuerdos de La Habana?

El género ha permitido que podamos señalar lugares insospechados de producción y reproducción de la discriminación basada en el sexo y la sexualidad, así que no es el momento de domesticar ni demonizar su significado, sino de comprender en qué enriquece nuestra comprensión de ciertos fenómenos sociales y cuándo se puede convertir en un lente que los simplifique demasiado. ${ }^{4}$ En últimas, mi pretensión es brindar una (mi)

4 Esta reflexión se conecta con la que en su momento iniciaron las profesoras Helena Alviar e Isabel Cristina Jaramillo. Para el efecto, véase Helena Alviar García y Cristina Jaramillo Sierra, 
lectura ordenada del posicionamiento del género como término relevante para la comprensión del conflicto, porque "la verdad sale más pronto del error que de la confusión". ${ }^{5}$

Este documento está organizado en cuatro secciones. En la primera, se exponen las líneas teóricas generales del feminismo radical que impactó el sistema jurídico internacional en la década de 1990 y definió la manera en que se iba a introducir la lectura de género del conflicto armado colombiano. La segunda explica con más detalle de qué manera fue trasplantado el feminismo radical al país y cómo alrededor de este surgió una élite de letradas ${ }^{6}$ feministas que logró convertir su narrativa de género del conflicto en un sentido común a través del uso de la letra de la ley. La tercera se ocupa de cómo logra posicionarse el tema de género en las conversaciones de La Habana y en la cuarta se analiza su materialización en la letra del Acuerdo.

\section{El feminismo radical o feminismo de la guerra contra las mujeres}

No todos los feminismos son iguales, por eso no todas las feministas lo son. Aunque su objetivo primordial puede ser el mismo, esto es, eliminar la discriminación y violencia en contra de las mujeres, sus puntos de partida son tan diversos que sus maneras de lograr esa meta varían considerablemente. ${ }^{7}$ Eso es apenas lógico: si las explicaciones de las causas de esta situación precaria de las mujeres cambian, los modos de enfrentarla y modificarla también. Si el proyecto feminista ubica el problema en la desvalorización social de las diferencias existentes entre hombres y mujeres, las soluciones ofrecidas por este girarán alrededor de lograr el posicionamiento positivo de esas características típicamente femeninas. Eso sucede con el feminismo cultural y su interés en darle relevancia a la ética del cuidado. En cambio,

Feminismo y crítica jurídica. El análisis distributivo como alternativa crítica al legalismo liberal (Bogotá: Siglo del Hombre Editores/Universidad de los Andes, 2012), 139-174.

5 Francis Bacon, The new organon or: true directions concerning the interpretation of nature, 66, http://www.earlymoderntexts.com/assets/pdfs/bacon1620.pdf

6 Ángel Rama y y John Charles Chasteen, The lettered city (Durham: Duke University Press, 1996). Para una explicación más detallada del término letradas ver pie de página 20 de este capítulo.

7 Para un excelente análisis de los feminismos, sus puntos comunes y disidencias, véase Janet Halley, Split decisions. How and why take a break from feminism (Princeton: Princeton University Press, 2006). 
si el punto de partida es la igualdad entre hombres y mujeres, la cual ha sido distorsionada por el ordenamiento jurídico, las líneas de acción estarán encaminadas a borrar esa diferencia artificial por medio de intervenciones en el derecho. Esta corresponde a una versión simplificada de los supuestos del feminismo liberal. ${ }^{8}$

Desde mediados de 1970, el objetivo primordial del feminismo dejó de ser un contradiscurso ${ }^{9}$ insular para ser integrado gradualmente en el derecho internacional como una aspiración y un estándar de producción normativa. La Conferencia Mundial sobre la Mujer, celebrada en Ciudad de México en 1975, marcó un hito en este proceso de integración de las temáticas feministas en los debates jurídicos internacionales. La caída de la cortina de hierro, por su parte, allanó el camino para que ciertos feminismos se afianzaran en este escenario, mientras otros perdían protagonismo debido al cierre de los debates respecto del modelo económico. Fue así cómo los feminismos socialistas, que ubicaban el tema de la subordinación de la mujer en el campo de la política económica, fueron pasando a un segundo plano y aquellos que más bien centraban su explicación de la situación de la mujer en el nivel del reconocimiento de derechos fueron ganando terreno. ${ }^{10}$

El feminismo radical encontró en este nuevo escenario internacional una oportunidad para florecer e influenciar los movimientos normativos

8 Véase Céspedes-Báez, “Conflicto armado colombiano”; Lina M. Céspedes-Báez, "Far beyond what is measured: governance feminism and indicators in Colombia". International Law Revista Colombiana de Derecho Internacional, n. 25 (2014).

9 La formación de opiniones públicas depende de la circulación de discursos y contradiscursos. Los primeros son aquellos que son producidos por cuerpos deliberantes hegemónicos que, por tales, gozan de un nivel de aceptación y circulación alto. Los segundos nacen en cuerpos deliberantes subalternos, razón por la cual sus contenidos son del todo ignorados o considerados subversivos. Para ahondar en esta cuestión, véase las nociones de públicos débiles, públicos fuertes y contrapúblicos de Nancy Fraser, "Rethinking the public sphere. A contribution to the critique of actually existing democracy", en Justice interruptus: critical reflections on the postsocialist condition (Nueva York: Routledge, 1997).

10 Véase Carol Harrington, "Resolution 1325 and post-cold war feminist politics". International Feminist Journal of Politics 13, n. 4 (2011); Celia Donert, “Whose utopia? Gender, ideology, and human rights' at the 1975 World Congress of Women in East Berlin", en The breakthrough. Human rights in the 1970s, editado por Jan Eckel y Samuel Moyn (Filadelfia: University of Pennsylvania Press, 2013). El dilema de la redistribución versus el reconocimiento es tratado, entre otras, por Nancy Fraser, Iustitia interrupta. Reflexiones críticas desde la posición "postsocialista" (Bogotá: Universidad de los Andes/Siglo del Hombre Editores, 1997), 17-54. 
más importantes del derecho internacional público de la década de $1990 .{ }^{11}$ Sus elaboraciones respecto a las causas y consecuencias de la discriminación de las mujeres fueron diseñadas con la idea de ofrecer una teoría totalizante que, por medio de la identificación y crítica de las limitaciones de los feminismos liberal y cultural, propusiera una explicación universal de las vicisitudes de los sujetos femeninos en el juego social.

Catharine MacKinnon, una de las representantes más visibles del feminismo radical, sentó las bases para estructurar una línea de pensamiento sumamente poderosa fundamentada en la refutación de que la discriminación entre hombres y mujeres estuviera anclada en la diferencia natural (feminismo cultural) o artificial (feminismo liberal). Para ello, MacKinnon eliminó la distinción entre sexo y género. Además de afirmar que eran sinónimos, determinó que eran construcciones sociales que establecían jerarquías a través de una particular y obligatoria ordenación de la sexualidad: la heterosexualidad. Estas premisas le permitieron aseverar que la producción del género convertía a lo masculino en dominante y a lo femenino en dominado, y que el desarrollo de la sexualidad en esta matriz desembocaba fatalmente en la violación sexual. Si el género es jerarquía y la heterosexualidad es imperativa, toda relación sexual entraña falta de autonomía de lo femenino. ${ }^{12}$

Una estructura del sexo y la sexualidad construida en estos términos representaba una oportunidad para hacer intervenciones jurídicas a nivel de creación de normas y litigio en lo atinente a la violación y la violencia sexual en general. En la medida en que el género era creado por una sexualidad heterosexual dominante, un ejercicio jurídico estratégico en este campo constituía una táctica plausible para socavar la ordenación de los

11 Catharine MacKinnon acuñó el nombre "feminismo radical" para su propuesta feminista. Su punto de partida no fue solo hacer una crítica a los feminismos liberales y socialistas de la época, sino el de diseñar una teoría estructural y totalista de la discriminación y violencia en contra de las mujeres que pudiera brindar una explicación única para esta situación. Véase Catharine A. MacKinnon, "Feminism, marxism, method, and the State: toward feminist jurisprudence". Signs: Journal of Women in Culture and Society 8, n. 4 (1983): 639-640.

12 Véase MacKinnon, "Feminism, marxism, Method", 635-658; Catharine A. MacKinnon, Feminism unmodified: discourses on life and law (Cambridge, Mass. Harvard University Press, 1987), 3, 5-10 y 40-45; Catharine A. MacKinnon, Toward a feminist theory of the state (Cambridge, Mass.: Harvard University Press, 1991), capítulos 6 y 7. 
sexos. En la década de 1990, las feministas radicales se dieron a la tarea de demostrarlo con el posicionamiento de la violencia en contra de las mujeres como una cuestión de derecho internacional y con el litigio asociado al conflicto armado. Esto conllevó a que sus intervenciones se centraran en: 1) introducir el concepto de violencia en la Convención para la Eliminación de Todas las Formas de Discriminación Contra la Mujer - Cedaw-, y 2) posicionar el tema de violencia sexual en los tribunales internacionales ad hoc para la antigua Yugoslavia y Ruanda, y luego en la redacción del Estatuto de Roma. ${ }^{13}$ No es una coincidencia que en estos momentos jurídicos se consolidaran especiales reglas de procedimiento y prueba que facilitaban el establecimiento de la ocurrencia de estos crímenes, sobre todo en lo que atañe a la fuerza y el consentimiento. Si la sexualidad es jerarquía, el consentimiento y el despliegue de fuerza en estos crímenes debían ser examinados en consecuencia. ${ }^{14}$

A finales de 1990, las feministas colombianas vieron en la propuesta de las feministas radicales una manera de ajustar sus líneas de acción frente al escalamiento del conflicto armado interno. Las lecciones aprendidas durante su movilización para incidir en la redacción de la Constitución de 1991 las preparó para hacer frente y aprovechar en su beneficio la creciente juridificación $^{15}$ de los espacios de formación de opinión pública y de incidencia que se abrieron con la nueva carta política y con la propagación y popularización del derecho internacional público. ${ }^{16}$ Sin embargo, su particular agenda, trazada con base en una mezcla de feminismo liberal y cultural con algunos toques del socialista, les impedía hacer una lectura de género

13 Janet Halley, "Rape at Rome: feminist interventions in the criminalization of sex-related violence in positive international criminal law". Michigan Journal of International Law 30, n. 1 (2008); Alice M. Miller, "Sexuality, violence against women, and human rights. Women make demands and ladies get protection". Health and Human Rights Journal 7, n. ${ }^{\circ} 2$ (2004).

14 Véase International Criminal Court, Rules of procedure and evidence, https://www.icc-cpi.int/ iccdocs/pids/legal-texts/rulesprocedureevidenceeng.pdf

15 Gunther Teubner, "Juridification. Concepts, aspects, limits, solutions", en Juridification of social spheres. A comparative analysis in the areas of labor, corporate, antitrust and social welfare law, editado por Gunther Teubner (Berlín: Walter De Gruyter, 1987).

16 Julieta Lemaitre, El derecho como conjuro. Fetichismo legal, violencia y movimientos sociales (Bogotá: Siglo del Hombre Editores/Universidad de los Andes, 2009), 207-214; Ugo Mattei, “A theory of imperial law: a study on U.S. hegemony and the Latin resistence". Indiana Journal of Global Legal Studies 10, n. $^{\circ} 1$ (2003). 
contundente de la experiencia de las mujeres en medio de la guerra. ${ }^{17} \mathrm{La}$ violencia que desencadenaba el conflicto en contra de las mujeres no se podía explicar por una distorsión de la igualdad entre hombres y mujeres causada por dispositivos sociales, ni por una falla de estos en el reconocimiento y valoración de sus diferencias. Aunado a esto, esta violencia no parecía tener una lectura obvia de género, pues en su conjunto no parecía estar dirigida exclusivamente hacia las mujeres por el hecho de ser mujeres. El feminismo radical prometía una salida a través de una interpretación de la subordinación de las mujeres que enfatizaba la universalidad y ubicuidad de esta experiencia y utilizaba la sexualidad como marcador diferenciador de las vicisitudes de hombres y mujeres en el conflicto armado. Este era un feminismo que les permitía convertir una guerra sin aristas evidentes de género en una guerra en contra de las mujeres. Así fue como nació el feminismo radical criollo.

\section{MacKinnon en Bogotá ${ }^{18}$}

El proceso de la Asamblea Nacional Constituyente de 1991 allanó el terreno para la conformación de unas élites jurídicas dentro del movimiento feminista. El nuevo panorama inaugurado por la naciente Constitución hizo del manejo de la letra de ley una habilidad necesaria para reclamar experticia en distintos campos relacionados con el activismo. El nicho de los derechos de las mujeres no fue la excepción. Esto permitió que un selecto

17 Las propuestas hechas desde el movimiento feminista para el proceso de la Asamblea Nacional Constituyente de 1991 dejan ver los ejes centrales de ese movimiento para comienzos de esa década. Para el efecto, véase Beatriz Quintero, "Las mujeres colombianas y la Asamblea Nacional Constituyente de 1991 - Participación e impactos, 21, 22 y 23 de febrero del 2005”. Cepal, http://www.cepal.org/mujer/reuniones/Bolivia/Beatriz_Quintero.pdf

18 Con este subtítulo quiero parafrasear a Diego Eduardo López Medina y el aparte de su libro La teoría impura del derecho llamado "Kelsen en Bogotá: lecturas y usos locales de la teoría pura del derecho". Sin embargo, quiero variar en alguna medida su significado. Mi intención es enfatizar que nuestra teoría jurídica también ha estado atravesada por las selecciones de los movimientos sociales en su lucha por el reconocimiento y la garantía de derechos. Es decir, la escogencia de a quiénes leemos y cómo los integramos en nuestro panorama jurídico también está mediada por actores sociales no académicos y poco interesados, en principio, en impactar la teoría del derecho. Aunque la teoría del derecho tiene un tinte claramente académico, la presencia del movimiento social la abre a influencias insospechadas. De ahí la importancia de entender cómo y por qué razón MacKinnon "llegó”a Bogotá. Diego Eduardo López Medina, Teoría impura del derecho. La transformación de la cultura jurídica latinoamericana (Bogotá: Legis Editores, 2004), 341-398. 
grupo de mujeres, que luego se organizaría primordialmente en ONG, emergiera para asumir el rol protagónico en esta causa. ${ }^{19}$ Estas letradas ${ }^{20}$ fueron las encargadas de traer a MacKinnon a Bogotá a través del uso estratégico del derecho internacional penal y de los derechos humanos.

Desde finales de la década de 1990 y principios del 2000, el conflicto armado colombiano fue monitoreado y analizado básicamente a través del desplazamiento forzado. El primer esfuerzo sistemático por atender a sus víctimas se llevó a cabo alrededor de este delito. ${ }^{21} \mathrm{La}$ crisis humanitaria que planteaba el hecho de que miles de personas tuvieran que dejar sus lugares de residencia se convirtió en la imagen evidente del conflicto. A esto se sumaba la presión de la comunidad internacional, pues el desplazamiento encarnaba la potencialidad de convertirse en un problema de refugiados. ${ }^{22}$ El desplazamiento forzado, entonces, fue la única vía por más de una década para demandar del Estado protección en medio de la violencia y de entablar un diálogo con los organismos internacionales en busca de respaldo. ${ }^{23}$

19 Estas mujeres de la élite feminista se organizaron básicamente en ong como Casa de la Mujer, Corporación Sisma Mujer y Corporación Humanas.

20 Angel Rama, en su libro La ciudad letrada, explica cómo el Imperio Español uso la fundación de ciudades para establecer y consolidar su poder. La importancia de las ciudades radicaba en que no solo eran un lugar geográfico, sino un epicentro de producción de conocimiento y experticia. Dentro de esa empresa colonial, el papel de la regulación legal y de un grupo de letrados capaz de manejarla con maestría fue determinante. Dentro de este se contaba no solo a los abogados, sino a las jerarquías religiosas, los funcionarios administrativos y profesionales, entre otros. Letradas, entonces, se refiere a una élite de mujeres que surgió del movimiento social colombiano y que se especializó y posicionó por medio del manejo de la letra de la ley. Rama y Chasteen, The lettered city.

21 Tal vez la primera ley que procuró ofrecer una salida jurídica a las víctimas del conflicto fue la Ley 387 de 1997, "por la cual se adoptan medidas para la prevención del desplazamiento forzado; la atención, protección, consolidación y estabilización socioeconómica de los desplazados internos por la violencia en la República de Colombia".

22 Véase Céspedes-Báez, "Far beyond".

23 La Corte Constitucional también participó en fomentar esta lectura del conflicto armado. La Sentencia T-025 del 2004, por medio de la cual esta Corte declaró una falla estructural en la realización de los derechos fundamentales de la población desplazada, se convertiría en uno de los hitos jurídicos del conflicto armado. Debido a que el incumplimiento del Estado no era puntual sino sistémico, el estado de cosas inconstitucional fue declarado. Esto le permitió a la Corte no perder competencia sobre el cumplimiento de sus órdenes y la facultó para seguir expidiendo providencias judiciales para forzar al Estado a cumplir con sus obligaciones. Los autos 092 del 2008, 098 del 2013 y 009 del 2015, por medio de los cuales la mirada letrada del conflicto se convirtió también en la mirada de la institucionalidad, nacieron de este proceso de seguimiento. 
Los retos que representaba un conflicto armado traducido en el debate público en términos de desplazamiento forzado eran evidentes para el movimiento de mujeres. No existía una manera obvia de introducir el género como categoría determinante en la comprensión de ese fenómeno, mucho menos cuando las agendas feministas colombianas estaban delineadas tomando como base el feminismo liberal y cultural. El dilema primordial estaba en que este delito no podía ser caracterizado como violencia basada en género, por cuanto no era posible identificar un ataque a las mujeres por el hecho de ser mujeres. Más bien, lo que sucedía era que las mujeres eran un grupo más afectado por el desplazamiento que quizá podía tener más alta representatividad por cuestiones ajenas al género: la alta incidencia del homicidio en los hombres. A esto se sumaba que el monitoreo del desplazamiento fue por años deficiente y controvertido, de manera que las cifras no arrojaban un dato que pudiera ser completamente confiable. ${ }^{24}$ Esto no les permitía recurrir con tranquilidad al argumento cuantitativo para decir que el número de mujeres desplazadas era más alto, por cuanto las cifras estaban constantemente en disputa.

La incorporación de las elaboraciones teóricas del feminismo radical en el derecho internacional permitió convertir el desplazamiento forzado en violencia basada en género a través de un argumento jurídico que resumo bajo la rúbrica del código de la desproporción. Para ello, las feministas criollas se valieron de la Recomendación General n. 19 del Comité para la Eliminación de la Discriminación contra la Mujer de 1992. Esta interpretación autorizada de la Cedaw era una herramienta útil por la sencilla razón de que había introducido en el cuerpo de este tratado el concepto de violencia. Para ello, el Comité amplió la noción de discriminación del artículo $1^{\circ}$ con el fin de incluir un entendimiento expansivo de la violencia basada en género. Así, determinó que el concepto de discriminación incluye el de violencia y que este último comprende no solo la "violencia dirigida a la mujer porque es mujer [sino también la que] la afecta en forma desproporcionada”. ${ }^{25}$

${ }^{24}$ Juan Carlos Guataquí, “¿Cómo medir la magnitud del problema? La dimensión del desplazamiento en Colombia: la problemática del sistema de registro y caracterización de la población desplazada", en Más allá del desplazamiento. Políticas, derechos y superación del desplazamiento forzado en Colombia, editado por César Rodríguez Garavito (Bogotá: Universidad de los Andes, 2010).

25 Comité para la Eliminación de la Discriminación contra la Mujer, Recomendación General No. 19, http://www.ipu.org/splz-e/cuenca10/cedaw_19.pdf 
La contribución de la Recomendación General n. ${ }^{\circ} 19$ finalmente permitió incluir a nivel mundial la violencia en contra de las mujeres dentro de la narrativa de los derechos humanos y a nivel doméstico armar una interpretación de género del desplazamiento forzado. ${ }^{26}$ Para ello, las letradas debieron demostrar que el desplazamiento forzado imponía un efecto desproporcionado sobre las mujeres. Como la consecución sistemática de datos implicaba una inversión significativa de tiempo y recursos, las letradas optaron por seleccionar y mapear un impacto que permitiera ser leído como primordialmente femenino, a pesar de los problemas metodológicos de su levantamiento: la violencia sexual. ${ }^{27}$

Para el 2001, la Confluencia Nacional de Mujeres y la Corporación Sisma Mujer elaboraron un marco conceptual en el cual sentaron las bases del código de la desproporción, por medio del cual se posicionaría el delito de violencia sexual como típicamente femenino y se introduciría el enfoque de género en el conflicto armado colombiano. ${ }^{28} \mathrm{Su}$ contenido básico, que luego sería replicado no solo por el movimiento social sino por el Estado, tuvo como punto de partida las siguientes premisas: 1) la discriminación de las mujeres proviene esencialmente de la dominación masculina; 2) esta discriminación se hace operativa a través de la violencia, en particular aquella que se ejerce sobre y a través de la sexualidad; 3) la violencia proveniente de la dominación masculina es una experiencia común a todas las mujeres; y 4) en contextos de conflicto armado/desplazamiento forzado esa discriminación es la misma, lo que varía es la intensidad (desproporción). ${ }^{29}$

Esta aproximación teórica permitía concluir que, aunque las mujeres siempre son las perdedoras del juego social, en el contexto del conflicto armado el desbalance incrementaba y las exponía aún más a ser víctimas de esa clase de violencia típicamente masculina, es decir, aquella asociada a la sexualidad. Como el desplazamiento forzado era la faceta más evidente del

26 Miller, "Sexuality, violence against women", 24.

27 Françoise Roth, Tamy Guberek y Amelia Hoover Green, "Using quantative data to assess conflict-related sexual violence in Colombia: challenges and opportunities”, Corporación Punto de Vista, 2011, https://hrdag.org/content/colombia/SV-report_2011-04-26.pdf

28 Pilar Rueda, Documento Marco Conceptual, 2001, http://pmayobre.webs.uvigo.es/textos/cecilia/ documento_marco_conceptual.pdf

29 Este concepto lo he trabajado también en: Céspedes-Báez, "Conflicto armado colombiano"; Céspedes-Báez, "Far beyond". 
conflicto interno, la introducción de una mirada de género tenía que pasar por una conexión estrecha entre ese delito y la dominación masculina, algo que pudo realizarse con éxito a través del énfasis en la violencia sexual. A pesar de que el documento insistía en que sexo y género eran diferentes y se esforzó en introducir visos del feminismo cultural, la lectura de la discriminación de las mujeres como una cuestión íntimamente ligada a la jerarquía del género ejercida básicamente a través de la sexualidad las alineaba más con el feminismo radical que con cualquier otra expresión feminista.

Esta aproximación a la violencia en contra de las mujeres implicaba no solo hacerla ahistórica y ubicua, sino situar su nicho de producción en una dinámica heterosexual. La Mesa de Mujer y Conflicto Armado, una coalición de activistas, académicas y ong de derechos humanos y mixtas de la cual la Corporación Sisma Mujer hacía parte, se apropió de este marco conceptual. En su tercer informe publicado en el 2003 ya es posible observar un trabajo significativo de refinación y abstracción del argumento con miras a consolidar una narrativa jurídica y política en la que la violencia sexual se convertía en el crimen de género paradigmático del conflicto y en el mecanismo básico de producción y reproducción de la subordinación femenina. ${ }^{30}$

La aprobación de la Ley 975 del 2005, más conocida como Ley de Justicia y Paz, por medio de la cual se pretendió facilitar la desmovilización paramilitar en el país, contribuyó a consolidar el código de la desproporción en la medida en que obligó a las letradas a enfrentarse a los retos del litigio. Esta ley representaba una oportunidad única de llevar a la práctica lo delineado en años previos de incidencia y documentación de violencia en contra de las mujeres en el conflicto. Su implementación permitía poner a prueba al derecho como herramienta útil para el desmonte de la dominación masculina. En concordancia con el proyecto del feminismo radical y con el marco conceptual trazado en años anteriores, el litigio en violencia sexual se convirtió en el eje central de su agenda. ${ }^{31}$ Las letradas importaron y se apropiaron del derecho penal internacional para el efecto y desarrollaron

30 Mesa de Trabajo Mujer y Conflicto Armado, III informe sobre violencia sociopolitica contra mujeres, jóvenes y niñas en Colombia (Bogotá: Ediciones Ántropos, 2003).

31 MacKinnon, Toward a feminist theory, 237-249; Catharine MacKinnon, "Rape, genocide, and women's human rights", en Mass rape. The war against women in Bosnia-Herzegovina, editado por Alexandra Stiglmayer (Londres: University of Nebraska Press, 1994). 
una experticia alrededor de los casos emblemáticos de violencia sexual de los tribunales ad hoc internacionales y del Estatuto de Roma. ${ }^{32}$ Litigar o trabajar en pro del litigio de estos casos intensificó la juridificación del tema de las mujeres en el conflicto y robusteció una mirada de género anclada en la heterosexualidad obligatoria y dominante. Así, gradualmente se comenzó a confundir mujer en conflicto con violencia sexual, hasta convertir en sentido común la idea de que ser mujer en ese contexto significaba la exposición desproporcionada a este crimen.

La Corte Constitucional, a través de su Auto 092 del 2008, fue determinante en darle presencia jurídica oficial al código de la desproporción y en fortalecer su capacidad de dispositivo para expandir esa particular lectura de género a todas las manifestaciones del conflicto. A pesar de que esa providencia procuró enumerar otras violaciones de derechos humanos que afectaban a las mujeres, como la persecución y el homicidio, la violencia sexual dominó la narrativa de la Corte a lo largo de sus más de doscientas páginas. Ningún otro crimen mereció un análisis tan detallado por la Corporación como este. Prueba de ello es que solo en materia de violencia sexual la Corte: 1) habló de la generalidad y sistematicidad del delito, sugiriendo que este constituía crimen de lesa humanidad; 2) creó su propia categorización de sus usos estratégicos; y 3) recogió todos los testimonios y hechos documentados que le fueron facilitados en un anexo reservado del cual dio traslado a la Fiscalía General de la Nación para su investigación. ${ }^{33}$

El uso totalista del código se hizo evidente en dos escenarios: el abandono y despojo de tierras, y la participación política. La Ley 975 puso de nuevo sobre la mesa el tema de la pérdida de la propiedad inmueble, especialmente en la Colombia rural, y su relación con los fenómenos de desplazamiento. ${ }^{34}$ En este escenario, la violencia sexual fue, de nuevo, una forma de situar a las mujeres en el centro de esa discusión. Si esta violencia contra las

32 Corporación Humanas Colombia, Guía para llevar casos de violencia sexual. Propuestas de argumentación para enjuiciar crimenes de violencia sexual cometidos cometidos en el marco del conflicto armado colombiano (Bogotá: Ediciones Ántropos, 2009); Corporación Sisma Mujer, Violencia sexual, conflicto armado y justicia en Colombia (Bogotá: Corporación Sisma Mujer, 2007).

33 Auto 092 de 2008, 14 de abril. MP: Manuel José Cepeda.

${ }^{34}$ Comisión Nacional de Reparación y Reconciliación - Grupo de Memoria Histórica, La tierra en disputa. Memorias del despojo y resistencias campesinas en la Costa Caribe 1960-2010 (Bogotá: Editorial Tauros, 2010), 13-17. 
mujeres funcionaba como un dispositivo para causar el desplazamiento, ya fuera como violencia masculina actual o potencial, el resultado del desplazamiento - la pérdida de la propiedad inmueble - en la lógica feminista radical debía estar conectada a sus causas. De esta manera, la dominación masculina lograba ubicarse en la base de otra de las violaciones de derechos de las mujeres en este contexto y convertirla en violencia basada en género.

Aunque este argumento resultaba impecable, su prueba presentó dificultades. Una cosa era aplicar la matriz feminista radical que, con su visión totalista, permitía explicar cualquier experiencia negativa de las mujeres a partir de la dominación masculina y elaborar argumentos jurídicos coherentes, y otra era encontrar las pruebas para sustentarlos. Sin embargo, la contundencia del argumento era de tal calibre que conllevó, por ejemplo, a que un estudio realizado por la Defensoría del Pueblo, en el cual fueron entrevistados 1630 mujeres y 414 hombres en situación de desplazamiento forzado y en el cual se halló que el 17,7\% de estas personas identificaron como causa para dejar sus lugares de residencia la violencia sexual en contra de ellas o sus familiares, se integrara a una retórica feminista radical que borró la presencia de la población masculina del grupo entrevistado. ${ }^{35}$ Así, el trabajo de la Defensoría se convirtió en un hito que estableció, a través de su reinterpretación, la correlación fuerte entre violencia sexual en contra de las mujeres y el desplazamiento. Esto permitió que la Mesa de Mujer y Conflicto, por ejemplo, adelantara el argumento de que la violencia sexual tenía una "relación estrecha" con el despojo y abandono de tierras y lo ilustrara con la documentación de 27 casos en los que las mujeres víctimas manifestaron que ese delito fue la causa directa de su desplazamiento. ${ }^{36}$

En el 2010, cuando llegó el momento de discutir en el Congreso la Ley 1448 del 2011, o más comúnmente conocida como Ley de Víctimas

35 Donny Meertens y Margarita Zambrano, "Citizenship deferred: the politics of victimhood, land restitution and gender justice in the Colombian (post?) conflict". The International Journal of Transitional Justice 4 (2010): 194; Julissa Mantilla Falcón y Rodrigo Uprimny Yepes, "Violencia de Género y Justicia Constitucional en Colombia”, en ¿̇justicia desigual? Género y derechos de las víctimas en Colombia (Bogotá: Fondo de Desarrollo de las Naciones Unidas para la Mujer -Unifem-, 2009), 119.

36 Mesa de Trabajo Mujer y Conflicto Armado, VIII informe sobre violencia sociopolitica contra mujeres, jóvenes y niñas en Colombia (Bogotá: Ediciones Ántropos, 2008), 46-47. Mesa de Trabajo Mujer y Conflicto Armado, LX informe sobre violencia sociopolitica contra mujeres, jóvenes y niñas en Colombia (Bogotá: Ediciones Ántropos, 2009), 63-64. 
y Restitución de Tierras, la interpretación de las letradas con respecto al género en el conflicto era dominante y considerada parte del sentido común o conocimiento común acumulado en años de estudio de la situación colombiana. Esta ley, entonces, incorporó una lectura de género acerca de la victimización del conflicto armado basada en el feminismo radical criollo de las letradas. A pesar de que hubo un reconocimiento a las parejas del mismo sexo como víctimas y el enfoque diferencial incorporó la orientación sexual, la parte operativa de la regulación demostró que las mujeres víctimas de violencia sexual seguían siendo el sujeto de género predominante en lo jurídico.

Así, las medidas para facilitar el juzgamiento de la violencia sexual constituyeron el núcleo duro en lo referente al género. En abierto contraste, las normas para facilitar la recuperación de tierras en el caso de las mujeres se caracterizaron por ser formalistas e inofensivas o dependientes de la interpretación de los jueces de restitución de tierras. Mientras la Ley 1448 se extendió en la traducción de los Principios de Procedimiento y Prueba del Estatuto de Roma para los casos de violencia sexual, apenas ordenó que las solicitudes de restitución de tierras de las mujeres tuvieran prelación en el trámite o reiteró la lógica de la Ley 30 de 1988 por medio del mandato de titular conjuntamente la propiedad para cónyuges o compañeros que hubieran sufrido el desplazamiento. ${ }^{37}$

También, la Corte Constitucional se encargó de movilizar los usos expansivos del código de la desproporción para establecer una diferenciación basada en el género respecto a la persecución de defensores de derechos humanos y líderes de la población en situación de desplazamiento. En el Auto 098 del 2013, esta Corporación indicó que las mujeres que asumen estas posiciones de liderazgo enfrentan riesgos más altos que los hombres por su condición de género. Según su lectura feminista radical, esto se explica por cuanto las mujeres están expuestas a una violencia estructural que se exacerba en el contexto del conflicto. A pesar de que la Corte hizo el esfuerzo de tratar otro tipo de daños y conductas delictivas, su retórica, fuertemente condicionada por la del Auto 092 del 2008, terminó recurriendo a la violencia sexual no solo para ejemplarizar la desproporción

37 Véase artículo 12 de la Ley 30 de 1988. 
sino para hacerla su manifestación paradigmática y el dispositivo básico de la violencia estructural de género.

MacKinnon llegó a Colombia patrocinada por el derecho internacional e invitada por las letradas. Su teoría no fue sustancialmente modificada cuando fue implementada in situ y todo su potencial quedó en evidencia en la naturaleza expansiva del código de la desproporción. El feminismo radical criollo constituiría, entonces, el entorno académico y político en que se discutirían las cuestiones de género en La Habana. Durante más de una década las letradas habían trabajado para construir una episteme que vendría a definir los confines de lo posible y lo transgresor, lo inteligible y lo ininteligible, en la negociación con las FARC.

\section{Las letradas en La Habana}

Los diálogos de La Habana comenzaron sin las letradas y sin ninguna agenda clara en cuestiones de género. ${ }^{38}$ En el 2013, como respuesta a esta situación, algunas de ellas organizaron la Cumbre Nacional de Mujeres y Paz. Este espacio convocó por tres días a casi quinientas mujeres en Bogotá - la ciudad de las letradas - con el fin de delinear su posición frente a los puntos objeto de negociación y de insistir en la importancia de integrar a las mujeres en conversaciones. ${ }^{39} \mathrm{E} 1 \mathrm{mismo}$ año, como respuesta a la presión, el Gobierno nombró como plenipotenciarias a María Paulina Riveros y a Nigeria Rentería. Al año siguiente, las partes convinieron en crear la Subcomisión de Género. ${ }^{40}$ Este órgano paritario de hasta diez miembros fue establecido con el mandato de ofrecer recomendaciones en este tema para aquellos puntos que ya habían sido negociados para el momento de su establecimiento — política de desarrollo agrario integral, participación política y solución al problema de las drogas ilícitas-y para los que estaban

38 "Si en La Habana hubiera más mujeres la negociación iría más rápido", Verdad Abierta, 8 de mayo del 2015, http://www.verdadabierta.com/procesos-de-paz/farc/5752-si-en-la-mesa-hubieramas-mujeres-iria-mas-rapido

39 Cumbre Nacional de Mujeres y Paz, Sistematización, http://www.humanas.org.co/archivos/ Sistematizacumbre_mujeres_y_paz.pdf

40 Colombia 2020, "Los logros de la Subcomisión de Género en tres acuerdos de La Habana", El Espectador, 23 de julio del 2016, http://colombia2020.elespectador.com/politica/los-logros-dela-subcomision-de-genero-en-tres-acuerdos-de-la-habana 
por ser serlo — fin del conflicto, víctimas e implementación, verificación y refrendación. ${ }^{41}$

Desde un comienzo, tanto la Cumbre de Mujeres como la Subcomisión de Género se vieron forzadas a ubicarse en los límites epistémicos de lo posible y lo transgresor. Esto se debió a que en los dos espacios fue incluida la comunidad LGBT como parte de una agenda fuertemente determinada por una episteme feminista criolla radical. Esto provocó una dinámica en la que el discurso sobre los derechos de las mujeres en el conflicto armado generó rápidos referentes a un conocimiento común, mientras que los esfuerzos de integración de la población LGBT quedaron limitados, primero, por la falta de información específica sobre su experiencia en el conflicto; segundo, por la consecuencial ausencia de evidencia que permitiera identificar en dónde el género como categoría relativa a esta población era relevante; y, tercero, por los dilemas que planteaba la estrecha episteme que se había construido con base en el feminismo radical. ${ }^{42}$

Aunque ya existía documentación sobre homicidios selectivos de población LGBTI en contextos de conflicto y en relación con los regímenes de heterosexualidad dominante impuestos por algunos grupos armados ilegales, la experticia acumulada para el momento de los diálogos con las FARC no era suficiente para demostrar que incluir dentro de la categoría género lo LGBTI permitía análisis más refinados y precisos de cuestiones como despojo de tierras, el impacto de la economía de las drogas ilícitas y la participación política, entre otros. ${ }^{43}$ Ahora, el marco conceptual del feminismo radical no hacía más que camuflar esos vacíos, pues su modo de operación totalista tiene la virtualidad de transformar cualquier violencia desplegada a través de la sexualidad en una matriz expresada en términos binarios femenino/

41 Mesa de Conversaciones, Comunicado Conjunto La Habana, 11 de septiembre de 2014, https://www.mesadeconversaciones.com.co/sites/default/files/Comunicado\%20Conjunto\%2C\%20 La\%20Habana\%2C\%2011\%20septiembre\%202014-Versi_n\%20Espa_ol.pdf.

42 Mauricio Albarracín Caballero y Juan Carlos Rincón, "De las víctimas invisibles a las víctimas dignificadas: los retos del enfoque diferencial para la población LGBTi en la ley de víctimas". Revista de Derecho Público, Universidad de los Andes, n. ${ }^{\circ} 31$ (2013), https://derechopublico.uniandes. edu.co/components/com_revista/archivos/derechopub/pub396.pdf; Cumbre Nacional de Mujeres y Paz, Sistematización; Mesa de Conversaciones. "Acuerdo final para la terminación del conflicto y la construcción de una paz estable y duradera”, 37,38, 41, 47, https://www.mesadeconversaciones.com. co/sites/default/files/24_08_2016acuerdofinalfinalfinal-1472094587.pdf

43 Véase Albarracín Caballero y Rincón, "De las víctimas invisibles". 
masculino. En ese sentido, no ha sido una coincidencia que el feminismo radical en sus versiones foráneas y criollas haya insistido que la violencia sexual en contra de hombres sea, por un lado, una excepción y, por otro, una reinterpretación de la dominación masculina en la que un hombre resulta feminizado por otro. ${ }^{44}$

Esto explica por qué lo que a primera vista parecía una conquista de la comunidad LGBTI, terminó siendo una constatación de la persistencia de la episteme de lo posible. En efecto, unir el proyecto LGBTI a las reivindicaciones de género surgidas bajo la égida de las letradas permitía abrigar la esperanza de que la categoría género era neutra y promovía por ese solo hecho los derechos de estas dos poblaciones sin distingos. En ese sentido, abría la puerta para concebir que el camino a seguir para la comunidad LGBTI era construir desde lo ya establecido por las letradas, sin necesidad de poner excesivo énfasis en la creación de interpretaciones jurídicas propias para insertarse como víctimas particulares del conflicto armado. Sin embargo, no solo el acuerdo firmado con las FARc, sino también lo sucedido alrededor del proceso de negociación demostraron lo errado de ese cálculo.

Las campañas para priorizar el tema de la violencia en contra de las mujeres en el conflicto fueron bastante visibles durante los cuatro años de negociación. Las letradas pusieron al servicio de esta causa lo aprendido en más de tres décadas de activismo alrededor de los derechos de las mujeres para capturar la atención de los medios de comunicación. La violencia sexual fue el tema central y recurrente de estas. El propósito era mandar un mensaje claro al Gobierno, a las FArc y a la opinión pública sobre la imposibilidad de otorgar amnistías por este delito. Una de las campañas más exitosas fue Cinco Claves, una iniciativa promovida en el 2015 por las letradas a través de algunas de sus organizaciones: Red Nacional de Mujeres, Corporación

44 Véase Luz Piedad Caicedo, Gravedad penal de la violencia sexual cometida en el marco del conflicto armado colombiano, http://www.humanas.org.co/archivos/humanas_documento_pon_48Ponencia_ Gravedad_penal_de_la_Violencia_Sexual.pdf; Corporación Humanas Colombia, Guía para llevar casos, 21-22; Instituto Nacional de Medicina Legal y Ciencias Forenses. Violencia sexual y tortura en desaparición forzada, 7, https://info.undp.org/docs/pdc/Documents/COL/00048240_35.\%20Violencia \%20sexual \%20y \%20tortura \%20en \%20desaparicion \%20forzada \%20Medicina \%20Legal. pdf; Sandesh Sivakumaran, "Sexual violence against men in armed conflict". European Journal of International Law 18, n. 2 (2007); Janet Halley, “Sexuality harassment”, en Left legalism/left critique, editado por Wendy Brown y Janet Halley (Londres: Dule University Press, 2002). 
Sisma Mujer, Corporación Humanas Colombia y No es Hora de Callar. $\mathrm{Su}$ eficacia radicó en que supo recoger, traducir y comunicar de manera sencilla todo el conocimiento acumulado por las letradas con base en el feminismo radical en cinco líneas específicas de acción: ${ }^{45}$ 1) compromiso de erradicación de la violencia sexual por parte del Gobierno y las FARC en el marco del desescalamiento de las hostilidades; 2) creación de una comisión de la verdad exclusiva para esclarecer la violencia sexual que fue sufrida por mujeres y niñas; 3) tratamiento diferencial para el delito de violencia sexual en los procesos judiciales que se siguieran de la implementación del Acuerdo y prohibición de amnistías con respecto a este; 4) establecimiento de un programa especial de reparaciones para las mujeres y niñas víctimas de violencia sexual; y 5) diseño de un plan para la construcción de una sociedad incluyente para las mujeres y niñas en el posconflicto. ${ }^{46}$

Ninguna otra estrategia asociada a los temas de género tuvo tanto eco como la de las cinco claves. La cuestión de la violencia sexual primordialmente heterosexual como experiencia de género paradigmática del conflicto dominó la narrativa alrededor del proceso con las FARC. Las voces diversas, ya fuera en el tema de mujeres o LGBTI, no tuvieron el mismo interés o habilidad para crear un mensaje y comunicarlo. La facilidad con que el mensaje de las letradas fue difundido y apropiado no solo tiene que ver con su destreza en reconfigurar un complejo marco teórico feminista radical en un manifiesto concreto y poderoso de unas cuantas páginas y videos, sino con que la historia oficial del conflicto 1) ya había integrado efectivamente una lectura de género hecha desde el feminismo radical, es

45 Véase Jineth Bedoya, Red Nacional de Mujeres, Corporación Sisma Mujer y Corporación Humanas Colombia, "Cinco claves para el tratamiento de la violencia sexual en el proceso de paz", https://www.youtube.com/watch?v=xc7uqkZexo0; Jineth Bedoya, Red Nacional de Mujeres, Corporación Sisma Mujer y Corporación Humanas Colombia,"1. Cinco claves para un tratamiento diferenciado de la violencia sexual en los acuerdos de paz", https://www.youtube.com/watch?v=nF12W_pRMMI; Marcela Osorio Granados, "Cinco lineamientos para tratar la violencia sexual en los acuerdos de paz en La Habana”. El Espectador, 19 de junio del 2016, http://colombia2020.elespectador.com/politica/ cinco-lineamientos-para-tratar-la-violencia-sexual-en-los-acuerdos-de-paz-de-la-habana; "Llamado a La Habana por violencia sexual", El Tiempo, 16 de junio del 2015, http://www.eltiempo.com/ politica/proceso-de-paz/proceso-de-paz-llamado-a-la-habana-por-violencia-sexual/15954456

46 Red Nacional de Mujeres, Corporación Sisma Mujer, Corporación Humanas Colombia y No es Hora de Callar. "Cinco claves para un tratamiento diferencial de la violencia sexual en los acuerdos sobre la justicia transicional en el proceso de paz", http://www.humanas.org.co/archivos/ Cinco_claves_de_la_violencia_sexual_en_los_acuerdos_sobre_justicia_transicional-completo.pdf 
decir, desde la violencia sexual en contra de las mujeres, 2) la cual era lo suficientemente tradicional como para ser fácilmente aceptada hasta por los grupos más conservadores.

No solo la Corte Constitucional contribuyó a generar este sentido común del enfoque de género del conflicto, sino el Congreso a través de leyes como la 1448 y la $1719 .{ }^{47}$ Esta última, aprobada en el 2014 para facilitar el acceso a la justicia a las víctimas de violencia sexual, cimentó aún más la idea de que sufrir este delito es marcador de lo femenino. Es interesante anotar que durante el trámite de esta ley ninguno de los partidos políticos se opuso o manifestó reservas frente a esta postura. ${ }^{48}$ Aquellas escasas voces que solicitaron un enfoque más inclusivo o neutro en el que se integrara a la población masculina fueron acalladas con argumentos feministas radicales. ${ }^{49}$ De la misma manera, la Procuraduría General de la Nación demostró su compromiso con dicha temática durante los años que estuvo a cargo de esta el conservador Alejandro Ordóñez. ${ }^{50}$

Las letradas hicieron presencia física y teórica en La Habana. Hablaron directamente con la Subcomisión de Género, le entregaron propuestas y constituyeron el marco conceptual por default para entender la violencia basada en género del conflicto. ${ }^{51} \mathrm{Su}$ feminismo radical, entonces, definiría

47 Además del Auto 092 del 2008, la Corte Constitucional expidió los autos 098 del 2013 y 009 del 2015 en los que se valió del poder expansivo del código de la desproporción para introducir lecturas de género de otras situaciones que estaban impactando a hombres y mujeres en el contexto del conflicto, tales como la minería ilegal y los ataques al activismo de derechos humanos.

48 Congreso de la República, Gaceta del Congreso, n. ${ }^{\circ} 473$ (2012): 5-33; Congreso de la República, Gaceta del Congreso, n. 567 (2012): 4-22; Congreso de la República, Gaceta del Congreso, n. ${ }^{\circ}$ 152 (2013): 6-21; Congreso de la República, Gaceta del Congreso, n. 652 (2013): 24-40.

49 Congreso de la República, Gaceta del Congreso, n.o 153 (2013): 9-10.

50 Véase Procuraduría General de la Nación, Consultoría para la evaluación y seguimiento a las politicas públicas y programas de atención integral, prevención, promoción y protección de los derechos de las mujeres víctimas de la violencia sexual en el marco del conflicto armado colombiano, material no publicado; Procuraduría General de la Nación, Directiva n. 006 de 2011; Procuraduría General de la Nación, Directiva n. $^{\circ} .005$ de 2015.

51 "En La Habana, enfoque de género se plasma en los acuerdos", Verdad Abierta, 26 de julio del 2016, http://www.verdadabierta.com/procesos-de-paz/farc/6348-en-la-habana-enfoque-degenero-se-plasma-en-acuerdos; "En medio de la polémica, llega el último grupo de víctimas a La Habana”, El Pais, 16 de diciembre 16 del 2014, http://www.elpais.com.co/elpais/judicial/noticias/ medio-polemica-llego-ultimo-grupo-victimas-habana 
el contenido del Acuerdo firmado el 24 de agosto del 2016 y que fuera rechazado en el plebiscito del 2 de octubre del mismo año.

\section{Un acuerdo letrado}

Las negociaciones con las FARC no tienen parangón en lo que se refiere a la inclusión de temas de género en el Acuerdo y a la participación de las mujeres en el desarrollo de las conversaciones. Este resultado se debe a la presión del movimiento social de mujeres primordialmente y seguramente constituirá un referente para futuros procesos de paz. ${ }^{52}$ No obstante, ese enfoque de género que fue incluido en el Acuerdo refleja un entendimiento específico de lo que es ser hombre y mujer en el conflicto armado, que apenas dejó espacios para desarrollar interpretaciones y, por tanto, propuestas más abiertas a la diversidad de las experiencias y los sujetos que han enfrentado las consecuencias de un país en guerra. Lo paradójico es que algunos de los opositores del Acuerdo pretenden ver en este una amenaza para el orden heterosexual de la sociedad colombiana, cuando en efecto sucede todo lo contrario: la perspectiva de género del Acuerdo es conservadora y su posición sobre la ordenación de la sexualidad se finca básicamente en la heterosexualidad.

Aunque las menciones al género son profusas, la verdad es que esta categoría es primordialmente utilizada para reforzar el binario hombre/ mujer, hacer un compromiso en materia de igualdad de derechos con respecto a este y reiterar la vulnerabilidad de lo femenino. En unas cuantas ocasiones el género es asociado con orientación sexual o identidad, pero se trata de menciones sin contenido operativo que tienen más un objetivo de agregación: la población LGBTI es una más entre tantas que han sufrido un impacto diferenciado. El Acuerdo no especifica en qué consiste ese daño particular y suma a esta comunidad con otras tan disímiles como las constituidas por campesinos, sindicalistas, ganaderos, empresarios, etc. Tal vez el único aparte que podría tener la virtualidad de generar pánico queer es aquel

52 Hasta ese momento los procesos de paz más recientes habían apenas incluido el tema de las mujeres en el conflicto. Véase Ruth Rubio-Marín (Ed.), What happened to the women? Gender and reparations for human rights violations (Nueva York: International Center for Transitional Justice, 2006); Pascha Bueno-Hansen, Feminist and human rights struggles in Peru: decolonizing transitional justice (Urbana: University of Illinois Press, 2015); Foinnuala Aoláin, "Advancing feminist positioning in the field of transitional justice". The International Journal of Transitional Justice 6 (2012). 
relacionado con el punto 2 sobre participación política. En este se lee que el Gobierno adquiere el compromiso de apoyar la creación y consolidación de organizaciones y movimientos sociales LGBTI, entre otros, y de promover una cultura democrática a través de medidas que hagan frente al sexismo y la discriminación por orientación o identidad de género. ${ }^{53}$

La invocación del género tuvo como propósito cardinal establecer los enlaces con los referentes usuales para incorporar medidas para remediar las situaciones de discriminación y violencia en contra de las mujeres ya identificadas en años anteriores. De ahí que el género se hubiera convertido en una categoría operativa para este grupo en cuestiones de acceso a la propiedad inmueble rural, a la participación política y a la justicia. Estos campos ya habían sido estudiados por las letradas y su diagnóstico estaba inevitablemente cruzado por el feminismo radical. No en vano los autos 092 del 2008, 098 del 2013 y 009 del 2015 de la Corte Constitucional y las leyes 1448 del 2011 y 1719 del 2014 tocan estas temáticas. El Acuerdo es la encarnación del sentido común de género creado en Colombia alrededor del conflicto armado, uno afincado en la inevitable división sexual entre hombres y mujeres, mantenida a través de la presencia del delito paradigmático de género: la violencia sexual. Ningún otro crimen mereció la creación de un equipo especial en la Unidad de Investigación y Acusación que hace parte de la Jurisdicción Especial para la Paz, ni una mención específica en el componente de Medidas de Recuperación Emocional a Nivel Individual. ${ }^{54}$

Quizá, la única novedad que presenta el Acuerdo en esta cuestión es el despliegue de la retórica del feminismo radical para proponer una lectura de género de un tema emergente: la política de drogas ilícitas. Como este asunto promete convertirse en uno de los nuevos locus de producción de conocimiento alrededor del conflicto en los años por venir, las letradas hicieron uso del carácter expansivo y totalista de su marco conceptual para establecer una conexión íntima entre esta cuestión y las mujeres. Con ese fin, ligaron los fenómenos de consumo de drogas y narcotráfico con la incidencia de violencia sexual. De esa manera, allanaron el camino para consolidar una visión feminista radical de otra de las aristas del conflicto y convirtieron el fenómeno de las drogas ilícitas en otro de los escenarios en

\footnotetext{
53 Mesa de Conversaciones, "Acuerdo final”, 37-38, 41, 47.

54 Mesa de Conversaciones, "Acuerdo final", 149 y 161.
} 
que los hombres dominan sexualmente a las mujeres. Así, toda consecuencia económica o social de este fenómeno podrá ser leída inevitablemente como otra manifestación y reiteración de la jerarquía sexual en la que descansa el patriarcado. ${ }^{55}$

El Acuerdo de La Habana es un resumen del conocimiento que ha construido la sociedad colombiana alrededor del conflicto armado. Es un documento que recoge la episteme en la que nos encontramos, nos muestra sus potencialidades y deficiencias, así como las posibles oportunidades para su alteración. Su enfoque de género nos habla del triunfo del feminismo radical en el país, sus nexos con el derecho internacional y la conformación de una élite alrededor de su empleo estratégico. También nos advierte que los lentes teóricos solo captan y privilegian ciertas miradas. Los hombres y las mujeres de las letradas no son ciento por ciento los hombres y las mujeres reales del conflicto. Así mismo, nos muestra que el proyecto de las letradas deja poco espacio para la población LGBTI y que no basta sumarla para hacerla más fuerte, inclusiva o consecuente. Las reivindicaciones LGBTI no pueden ir de la mano del feminismo radical, de manera que deben separarse teóricamente de la agenda de las letradas y comenzar a explorar qué epistemes son necesarias para avanzar en la construcción de un discurso y unas líneas de acción que realmente subviertan las lecturas binarias y heterosexuales hegemónicas. Se puede aprender de las letradas en cuanto a sus estrategias de incidencia, solo de esto y de nada más.

\section{Coda}

El 24 de noviembre el Gobierno nacional y las FARC dieron a conocer el texto revisado del Acuerdo, el cual pretende subsanar muchas de las causas que llevaron a su rechazo en el plebiscito. Esta versión implicó un pasó más en la dirección de la domesticación del género y en la consolidación de su versión más conservadora. Mientras las referencias a la identidad de género y orientación sexual fueron eliminadas, la definición de "enfoque de género"

55 Aunque este tema emergente no ha sido trabajado sistemáticamente por las letradas, la Corporación Humanas Colombia hizo en el 2015 una aproximación preliminar al tema en: Corporación Humanas Chile, Corporación Humanas Colombia, equis Justicia para las Mujeres de México. "Política de drogas y derechos humanos: el impacto en las mujeres", http://www.humanas.org.co/ archivos/Libropoldrogasymujereshumanas.pdf 
aplicable a la totalidad del Acuerdo quedó planteada en términos binarios entre hombres y mujeres y del código de la desproporción. Si el Acuerdo del 24 de agosto nos había mostrado el poder del feminismo radical criollo, el del 12 de noviembre expone sin tapujos cuán conservador puede llegar a ser esta aproximación a la discriminación y violencia en contra de las mujeres. No de otra forma se explica que una vuelta a sus premisas más básicas puede calmar a las voces tradicionales y religiosas que conviertieron el enfoque de género en una razón para no aceptar el contenido del Acuerdo inicial.

El recorrido del proceso de paz y de aprobación de su Acuerdo ha sido una prueba ácida para identificar cuáles son los consensos de la sociedad colombiana en los temas más espinosos que se relacionan directa o indirectamente con el conflicto armado. Este nos ha demostrado que ciertas materias ni siquiera debieron ser mencionadas en su texto, por cuanto su discusión era mejor darla en espacios en los que no estuviera de por medio el posconflicto y la construcción de paz. Lo más aconsejable es ser pragmáticos y aceptar el Acuerdo con su versión domesticada del género y apostarle a dar los debates por concepciones más retadoras en espacios en que el telón de fondo no sea la inminencia de una vuelta a la violencia armada.

\section{Bibliografía}

"En La Habana, enfoque de género se plasma en los acuerdos". Verdad Abierta, 26 de julio del 2016, http://www.verdadabierta.com/procesos-de-paz/ farc/6348-en-la-habana-enfoque-de-genero-se-plasma-en-acuerdos

"En medio de la polémica, llega el último grupo de víctimas a La Habana”. El País, 16 de diciembre 16 del 2014, http://www.elpais.com. co/elpais/judicial/noticias/medio-polemica-llego-ultimo-grupovictimas-habana

"Es una ironía que los hombres decidan si el enfoque de género se saca de los acuerdos". Semana, 17 de octubre del 2016, http://www.semana. $\mathrm{com} /$ nacion/articulo/plebiscito-monica-roa-habla-del-enfoque-degenero-en-los-acuerdos-de-la-habana/499367

"Ideología de género, el caballo de batalla del No al plebiscito". Semana, 9 de septiembre del 2016, http://www.semana.com/nacion/articulo/ideologia-de-genero-el-caballo-de-batalla-del-no-al-plebiscito/493093 
"Llamado a La Habana por violencia sexual". El Tiempo, 16 de junio del 2015, http:/www.eltiempo.com/politica/proceso-de-paz/procesode-paz-llamado-a-la-habana-por-violencia-sexual/15954456

“Proceso de Paz: ¿dónde están las mujeres?”. Semana, 14 de octubre del 2016, http://www.semana.com/nacion/articulo/proceso-de-paz-criticaspor-ausencia-de-mujeres-en-negociaciones-del-plebiscito/499082 "Si en la Habana más mujeres la negociación iría más rápido". Verdad Abierta, 8 de mayo del 2015, http://www.verdadabierta.com/procesos-depaz/farc/5752-si-en-la-mesa-hubiera-mas-mujeres-iria-mas-rapido "Synod15. Final Relatio of the Synod of Bishops to the Holy Father, Francis, 24th October, 2015”. Diócesis de Lancaster - Inglaterra, http:// www.lancasterdiocese.org.uk/wp-content/uploads/2015/11/FinalRelatio15-Final.pdf

Albarracín Caballero, Mauricio y Juan Carlos Rincón. "De las víctimas invisibles a las víctimas dignificadas: los retos del enfoque diferencial para la población LgBTi en la ley de víctimas". Revista de Derecho Público, Universidad de los Andes, n. 31 (2013), https://derechopublico.uniandes.edu.co/components/com_revista/archivos/derechopub/pub396.pdf

Alviar García, Helena y Cristina Jaramillo Sierra. Feminismo y critica juridica. El análisis distributivo como alternativa crítica al legalismo liberal. Bogotá: Siglo del Hombre Editores/Universidad de los Andes, 2012. Aoláin, Foinnuala. "Advancing feminist positioning in the field of transitional justice". The International Journal of Transitional Justice 6 (2012): 205-228.

Auto 092 de 2008, 14 de abril. MP: Manuel José Cepeda. Auto 098 de 2013, 21 de mayo. MP: Luis Ernesto Vargas Silva. Auto 009 de 2015, 27 de enero. MP: Luis Ernesto Vargas Silva.

Bacon, Francis. The new organon or: true directions concerning the interpretation of nature, http://www.earlymoderntexts.com/assets/pdfs/ bacon1620.pdf

Bedoya, Jineth, Red Nacional de Mujeres, Corporación Sisma Mujer y Corporación Humanas Colombia. "Cinco claves para el tratamiento de la violencia sexual en el proceso de paz”, https://www.youtube. $\mathrm{com} /$ watch?v=xc7uqkZexo0 
Bedoya, Jineth, Red Nacional de Mujeres, Corporación Sisma Mujer y Corporación Humanas Colombia. "1. Cinco claves para un tratamiento diferenciado de la violencia sexual en los acuerdos de paz", https:// www.youtube.com/watch?v=nF12W_pRMMI

Bueno-Hansen, Pascha. Feminist and human rights struggles in Peru: decolonizing transitional justice. Urbana: University of Illinois Press, 2015.

Caicedo, Luz Piedad. Gravedad penal de la violencia sexual cometida en el marco del conflicto armado colombiano, http://www.humanas.org.co/ archivos/humanas_documento_pon_48Ponencia_Gravedad_penal_de_la_Violencia_Sexual.pdf

Céspedes-Báez, Lina M. "Conflicto armado colombiano y feminismo radical criollo: una aproximación preliminar a las lecciones aprendidas", en Aristas del conflicto colombiano, editado por María Victoria Uribe y Ana María Forero, 126-133. Bogotá: Editorial Universidad del Rosario, 2014.

Céspedes-Báez, Lina M."Far beyond what is measured: governance feminism and indicators in Colombia. International Law Revista Colombiana de Derecho Internacional, n. ${ }^{\circ} 25$ (2014): 318-323.

Céspedes-Báez, Lina M. "Gender panic and the failure of a peace agreement”. American Journal of International Law Unbound 183 (2016), https://www.asil.org/blogs/symposium-colombian-peace-talksand-international-law-gender-panic-and-failure-peace-agreement Colombia 2020. “¿Ideología o enfoque de género?”. El Espectador, 14 de octubre del 2016, http://colombia2020.elespectador.com/pais/ideologia-o-enfoque-de-genero

Colombia 2020. "Los logros de la Subcomisión de Género en tres acuerdos de La Habana”. El Espectador, 23 de julio del 2016, http://colombia2020.elespectador.com/politica/los-logros-de-la-subcomisionde-genero-en-tres-acuerdos-de-la-habana

Comisión Nacional de Reparación y Reconciliación - Grupo de Memoria Histórica. La tierra en disputa. Memorias del despojo y resistencias campesinas en la Costa Caribe 1960-2010. Bogotá: Editorial Tauros, 2010.

Comité para la Eliminación de la Discriminación contra la Mujer. Recomendación General No. 19, http://www.ipu.org/splz-e/cuenca10/ cedaw_19.pdf

Congreso de la República. Gaceta del Congreso, n. ${ }^{\circ} 473$ (2012): 5-33. 
Congreso de la República. Gaceta del Congreso, n. 567 (2012): 4-22.

Congreso de la República. Gaceta del Congreso, n. ${ }^{\circ} 152$ (2013): 6-21.

Congreso de la República. Gaceta del Congreso, n. ${ }^{\circ} 652$ (2013): 24-40.

Congreso de la República. Gaceta del Congreso, n. ${ }^{\circ} 153$ (2013): 9-10.

Corporación Humanas Colombia. Guia para llevar casos de violencia sexual.

Propuestas de argumentación para enjuiciar crimenes de violencia sexual cometidos cometidos en el marco del conflicto armado colombiano. Bogotá: Ediciones Ántropos, 2009.

Corporación Humanas Chile, Corporación Humanas Colombia, EQUis Justicia para las Mujeres de México. "Política de drogas y derechos humanos: el impacto en las mujeres”, http://www.humanas.org.co/ archivos/Libropoldrogasymujereshumanas.pdf

Corporación Sisma Mujer. Violencia sexual, conflicto armado y justicia en Colombia. Bogotá: Corporación Sisma Mujer, 2007.

Cumbre Nacional de Mujeres y Paz. Sistematización, http://www.humanas. org.co/archivos/Sistematizacumbre_mujeres_y_paz.pdf

De la Calle Lombana, Humberto. "Enfoque de género". El Tiempo, 16 de octubre del 2016, http://www.eltiempo.com/opinion/columnistas/enfoque-de-genero-humberto-de-la-calle-columnista-eltiempo/16727692

Donert, Celia. "Whose utopia? Gender, ideology, and human rights' at the 1975 World Congress of Women in East Berlin", en The breaktbrough. Human rights in the 1970s, editado por Jan Eckel y Samuel Moyn, 6-87. Filadelfia: University of Pennsylvania Press, 2013.

Eagleton, Terry. Ideology: an introduction. Nueva York: Verso, 1991.

Fraser, Nancy. "Rethinking the public sphere. A contribution to the critique of actually existing democracy”, en Justice interruptus: critical reflections on the postsocialist condition, 69-98. Nueva York: Routledge, 1997.

Fraser, Nancy. Iustitia interrupta. Reflexiones criticas desde la posición "postsocialista”. Bogotá: Universidad de los Andes/Siglo del Hombre Editores, 1997.

Guataquí,Juan Carlos. ¿¿Cómo medir la magnitud del problema? La dimensión del desplazamiento en Colombia: la problemática del sistema de registro y caracterización de la población desplazada", en Más allá del desplazamiento. Politicas, derechos y superación del desplazamiento 
forzado en Colombia, editado por César Rodríguez Garavito, 38-71. Bogotá: Universidad de los Andes, 2010.

Halley, Janet. "Sexuality harassment", en Left legalism/left critique, editado por Wendy Brown y Janet Halley, 80-104. Londres: Dule University Press, 2002.

Halley, Janet. Split decisions. How and why take a break from feminism. Princeton: Princeton University Press, 2006.

Halley,Janet. "Rape at Rome: feminist interventions in the criminalization of sex-related violence in positive international criminal law". $M i-$ chigan Journal of International Law 30 n. ${ }^{\circ} 1$ (2008): 1-123.

Harrington, Carol. "Resolution 1325 and post-cold war feminist politics". International Feminist Journal of Politics 13, n. 4 (2011): 557-575.

Instituto Nacional de Medicina Legal y Ciencias Forenses. Violencia sexual y tortura en desaparición forzada, https:/info.undp.org/docs/ pdc/Documents/COL/00048240_35.\%20Violencia\%20sexual\%20 y\%20tortura\%20en\%20desaparicion\%20forzada\%20Medicina $\% 20$ Legal.pdf

International Criminal Court. Rules of procedure and evidence, https://www. icc-cpi.int/iccdocs/pids/legal-texts/rulesprocedureevidenceeng.pdf Lemaitre, Julieta. El derecho como conjuro. Fetichismo legal, violencia y movimientos sociales. Bogotá: Siglo del Hombre Editores/Universidad de los Andes, 2009.

Ley 387 de 1997, 18 de julio. Por la cual se adoptan medidas para la prevención del desplazamiento forzado; la atención, protección, consolidación y esta estabilización socioeconómica de los desplazados internos por la violencia en la República de Colombia.

Ley 30 de 1988,18 de marzo. Por la cual se modifican y adicionan las Leyes 135 de 1961, 1a. de 1968 y 4a. de 1973 y se otorgan unas facultades al Presidente de la República. Diario Oficial 38.264.

Ley 1448 del 2011, 10 de junio. Por la cual se dictan medidas de atención, asistencia y reparación integral a las víctimas del conflicto armado interno y se dictan otras disposiciones. Diario Oficial 48.096.

Ley 1719 del 2014, 18 de junio. Por la cual se modifican algunos artículos de las Leyes 599 de 2000, 906 de 2004 y se adoptan medidas para garantizar el acceso a la justicia de las víctimas de violencia sexual, 
en especial la violencia sexual con ocasión del conflicto armado, y se dictan otras disposiciones. Diario Oficial 49.186.

López Medina, Diego Eduardo. Teoría impura del derecho. La transformación de la cultura jurídica latinoamericana. Bogotá: Legis Editores, 2004. MacKinnon, Catharine A. "Feminism, marxism, method, and the State: toward feminist jurisprudence". Signs: Journal of Women in Culture and Society 8, n. 4 (1983): 635-658.

MacKinnon, Catharine A. Feminism unmodified: discourses on life and law. Cambridge, Mass.: Harvard University Press, 1987.

MacKinnon, Catharine A. Toward a feminist theory of the state. Cambridge, Mass.: Harvard University Press, 1991.

MacKinnon, Catharine. “Rape, genocide, and women's human rights”, en Mass rape. The war against women in Bosnia-Herzegovina, editado por Alexandra Stiglmayer, 183-196. Londres: University of Nebraska Press, 1994.

Mantilla Falcón, Julissa y Rodrigo Uprimny Yepes. “Violencia de Género y Justicia Constitucional en Colombia”, en ¿̇usticia desigual? Género $y$ derechos de las victimas en Colombia, 117-163. Bogotá: Fondo de Desarrollo de las Naciones Unidas para la Mujer —Unifem—, 2009. Meertens, Donny y Margarita Zambrano. "Citizenship deferred: the politics of victimhood, land restitution and gender justice in the Colombian (post?) conflict". The International Journal of Transitional Justice 4 (2010): 189-206.

Mesa de Conversaciones. Comunicado Conjunto La Habana, 11 de septiembre de 2014, https://www.mesadeconversaciones.com.co/sites/default/ files/Comunicado\%20Conjunto\%2C\%20La\%20Habana\%2C\%20 11\%20septiembre\%202014-Versi_n\%20Espa_ol.pdf

Mesa de Conversaciones. "Acuerdo final para la terminación del conflicto y la construcción de una paz estable y duradera", https://www.mesadeconversaciones.com.co/sites/default/files/24_08_2016acuerdo finalfinalfinal-1472094587.pdf

Mesa de Trabajo Mujer y Conflicto Armado. VIII informe sobre violencia sociopolitica contra mujeres, jóvenes y niñas en Colombia. Bogotá: Ediciones Ántropos, 2008. 
Mesa de Trabajo Mujer y Conflicto Armado. IX informe sobre violencia sociopolitica contra mujeres, jóvenes y niñas en Colombia. Bogotá: Ediciones Ántropos, 2009.

Mattei, Ugo. "A theory of imperial law: a study on U.S. hegemony and the Latin resistence". Indiana Journal of Global Legal Studies 10, n. 1 (2003): 383-448.

Mesa de Trabajo Mujer y Conflicto Armado. III informe sobre violencia sociopolitica contra mujeres, jóvenes y niñas en Colombia. Bogotá: Ediciones Ántropos, 2003.

Miller, Alice M. "Sexuality, violence against women, and human rights. Women make demands and ladies get protection". Health and $\mathrm{Hu}$ man Rights Journal 7, n. 2 (2004): 17-47.

Mojica Patiño, José Alberto. "La suma al clamor por un acuerdo ya”. El Tiempo, 16 de octubre del 2016, http://www.eltiempo.com/estilode-vida/gente/iglesia-pide-acuerdo-en-proceso-de-paz/16727642

Osorio Granados, Marcela. "Cinco lineamientos para tratar la violencia sexual en los acuerdos de paz en La Habana”. El Espectador, 19 de junio del 2016, http://colombia2020.elespectador.com/politica/ cinco-lineamientos-para-tratar-la-violencia-sexual-en-los-acuerdosde-paz-de-la-habana

Procuraduría General de la Nación. Consultoría para la evaluación y seguimiento a las politicas públicas y programas de atención integral, prevención, promoción y protección de los derechos de las mujeres victimas de la violencia sexual en el marco del conflicto armado colombiano, material no publicado.

Procuraduría General de la Nación. Directiva n. 006 de 2011.

Procuraduría General de la Nación. Directiva n. ${ }^{\circ} 005$ de 2015.

Quintero, Beatriz. "Las mujeres colombianas y la Asamblea Nacional Constituyente de 1991 - Participación e impactos, 21,22 y 23 de febrero del 2005”. Cepal, http://www.cepal.org/mujer/reuniones/Bolivia/ Beatriz_Quintero.pdf

Rama, Ángel y John Charles Chasteen. The lettered city. Durham: Duke University Press, 1996.

Red Nacional de Mujeres, Corporación Sisma Mujer, Corporación Humanas Colombia y No es Hora de Callar. "Cinco claves para un tratamiento diferencial de la violencia sexual en los acuerdos sobre 
la justicia transicional en el proceso de paz", http://www.humanas. org.co/archivos/Cinco_claves_de_la_violencia_sexual_en_los_acuerdos_sobre_justicia_transicional-completo.pdf

Roth, Francoise, Tamy Guberek y Amelia Hoover Green."Using quantative data to assess conflict-related sexual violence in Colombia: challenges and opportunities". Corporación Punto de Vista, 2011, https:// hrdag.org/content/colombia/SV-report_2011-04-26.pdf

Rubio-Marín, Ruth (Ed.). What happened to the women? Gender and reparations for human rights violations. Nueva York: International Center for Transitional Justice, 2006.

Rueda, Pilar. Documento Marco Conceptual, 2001, http://pmayobre.webs. uvigo.es/textos/cecilia/documento_marco_conceptual.pdf

Sentencia T-025 de 2004, 22 de enero. MP: Manuel José Cepeda.

Sivakumaran, Sandesh. "Sexual violence against men in armed conflict". European Journal of International Law 18, n. 2 (2007): 253-276.

Teubner, Gunther. "Juridification. Concepts, aspects, limits, solutions", en Juridification of social spheres. A comparative analysis in the areas of labor, corporate, antitrust and social welfare law, editado por Gunther Teubner, 3-48. Berlin: Walter De Gruyter, 1987. 


\title{
Derecho del trabajo y construcción de paz en Colombia*
}

\author{
Iván Daniel Jaramillo Jassir
}

En el presente ensayo se analizarán los principales desafíos para el sistema de regulación de las relaciones laborales en el contexto de la implementación de los Acuerdos para la terminación del conflicto suscritos por el Gobierno de Colombia y la guerrilla de las FARC-EP.

Las conexiones entre las teorías de paz emanadas desde las categorías de las relaciones internacionales ${ }^{1} \mathrm{y}$ el derecho del trabajo estructuran el acervo epistemológico del sistema laboral como elemento de construcción de paz.

De cara a la implementación del Acuerdo para la terminación del conflicto, el principal desafío para el sistema de relaciones laborales está determinado por la realización del trabajo decente como causa de paz

* El contenido del artículo corresponde a la ponencia presentada en el marco del XXV Encuentro de Exbecarios del Grupo Bolonia, Castilla-La Mancha, Turín celebrado el 27 de octubre del 2016 en la Universidad del Rosario en Bogotá.

** Profesor de carrera académica de la Universidad del Rosario, abogado de la misma universidad, especialista en Derecho Laboral de la Pontificia Universidad Javeriana. Exbecario del Curso de Especialización para Expertos Latinoamericanos en Problemas del Trabajo y Relaciones Laborales de la oit, magíster en Derecho del Trabajo de la Universidad de Bolonia, Italia, y doctor cum laude en Derecho de la Universidad de Castilla-La Mancha, España. Coordinador Nacional del Proyecto Promoción de Principios y Derechos Fundamentales en el Trabajo de la oit financiado por el Departamento de Estado de los Estados Unidos (2011-2012). Correo electrónico: ivan.jaramillo@ urosario.edu.co

1 Oliver Ramsbotham, Tom Woodhouse y Hugh Miall, Resolución de conflictos, la prevención, gestión y transformación de letales (Barcelona: Institut Catalá Internacional per la Pau, Edicions Bellaterra). 
sostenible, que determina la estrategia de extensión de garantías laborales individuales y colectivas a las relaciones agrarias de producción a través de los esquemas de recepción de excombatientes y resarcimiento de víctimas por conducto de rutas preferenciales de empleabilidad.

En este sentido, el derecho del trabajo constituye un instrumento de paz positiva en la concepción de Johan Galtung ${ }^{2}$ bajo el precepto según el cual el derecho a la paz no debe reducirse únicamente a la ausencia de guerra, sino que este implica también un derecho que "empodera", es decir, da poder a las personas para desarrollarse como tales y para contribuir al desarrollo de la sociedad. Pero, además, es un derecho clave, pues favorece su capacidad para disfrutar de otros derechos humanos, por ejemplo, del derecho del trabajo, a la salud, a la información, a participar en la vida cultural y a estar protegido contra todo acto de violencia, así como a oponerse a las violaciones de los derechos humanos.

\title{
1. Teorías sobre construcción de paz y derecho del trabajo
}

El vínculo entre la paz sostenible y el trabajo resulta consustancial para la génesis de la construcción y consolidación del sistema universal de garantías laborales, como reconoce el preámbulo de la Constitución de la Organización Internacional del Trabajo, en el marco del Tratado de Versalles, ${ }^{3}$ según el cual

\begin{abstract}
Las Altas Partes Contratantes, movidas por sentimientos de justicia y de humanidad y por el deseo de asegurar la paz permanente en el mundo, y a los efectos de alcanzar los objetivos expuestos en este preámbulo, convienen en la siguiente Constitución de la Organización Internacional del Trabajo.
\end{abstract}

El alcance del concepto de paz debe ser analizado incorporando elementos de la estrategia global en materia de construcción de paz estructurada desde el informe del secretario general de la Organización de Naciones Unidas, Boutros Boutros-Ghali, “An agenda for peace”. Definió este tipo de operaciones de paz en el informe que le presentó al Consejo de Seguridad

\footnotetext{
2 Ramsbotham, Woodhouse y Miall, Resolución de conflictos, 50.

3 International Labour Organization. Constitución de la ort, http://www.ilo.org/dyn/normlex/ es/f?p=1000:62:0::NO::P62_LIST_ENTRIE_ID:2453907
} 
el 17 de junio de 1992, titulado "Un programa de paz. Diplomacia preventiva, establecimiento de la paz, y mantenimiento de la paz", a partir del cual se establecen las herramientas que integran la estrategia de paz global:

- Por diplomacia preventiva se entienden las medidas destinadas a evitar que surjan controversias entre dos o más partes, que las controversias existentes se transformen en conflictos y que estos, si ocurren, se extiendan.

- Por establecimiento de la paz se entienden las medidas destinadas a lograr que las partes hostiles lleguen a un acuerdo, fundamentalmente por medios pacíficos, como los previstos en el capítulo VI de la Carta de las Naciones Unidas.

- Por el mantenimiento de la paz se entiende el despliegue de una presencia de las Naciones Unidas en el terreno, hasta ahora con el consentimiento de todas las partes autorizadas, con la participación de personal militar o policial de las Naciones Unidas y, frecuentemente, también de personal civil. Las actividades de mantenimiento de la paz constituyen una técnica que aumenta las posibilidades de prevenir los conflictos y establecer la paz. ${ }^{4}$

En el 2000, se dio un avance importante con el informe redactado a petición del secretario general de las Naciones Unidas, Kofi Annan, quien para esa tarea conformó el Grupo sobre las Operaciones de Paz en las Naciones Unidas. La idea con ese documento era plantear formas más efectivas de proteger a los civiles ante las tragedias reseñadas de la década que había acabado de culminar.

El llamado informe Brahimi ${ }^{5}$ (pues el presidente del grupo fue el argelino Lajdar Brahimi) llegó a importantes conclusiones sobre la forma como se debía reformular la doctrina de paz desde las Naciones Unidas.

He aquí algunas de las conclusiones más sobresalientes sobre las definiciones enunciadas previamente por el antiguo Boutros Boutros Ghali:

4 Consultado en: http://www.un.org/en/sc/repertoire/8992/Chapter\%208/GENERAL\%20 ISSUES/Item \%2029_Agenda\%20for \%20peace.pdf

5 Naciones Unidas, Mantenimiento de la Paz, "Reforma de las actividades de mantenimiento de la paz", http://www.un.org/es/peacekeeping/operations/reform.shtml 
Las operaciones de paz de las Naciones Unidas entrañan tres actividades principales: prevención de conflictos y establecimiento de la paz, mantenimiento de la paz, y consolidación de la paz. La prevención de conflictos a largo plazo ataca las causas estructurales del conflicto a fin de sentar una base sólida para la paz. Cuando esa base se desintegra, se intenta reforzarla mediante medidas de prevención del conflicto, que generalmente consisten en iniciativas diplomáticas. Esta acción preventiva es por definición una actividad discreta: cuando resulta, puede pasar totalmente desapercibida.

El establecimiento de la paz intenta poner coto a los conflictos en curso, mediante los instrumentos de la diplomacia y la mediación. En el establecimiento de la paz pueden intervenir enviados de Gobiernos, grupos de Estados, organizaciones regionales o las Naciones Unidas, o bien grupos extraoficiales y no gubernamentales, como ocurrió, por ejemplo, en las negociaciones que culminaron en un acuerdo de paz para Mozambique. El establecimiento de la paz puede incluso ser obra de una personalidad destacada, que actúa en forma independiente. ${ }^{6}$

El mantenimiento de la paz es una empresa que ya tiene 50 años y ha evolucionado rápidamente en el último decenio de un modelo tradicional y principalmente militar de observar las cesaciones del fuego y las separaciones de las fuerzas después de guerras entre Estados, a un modelo complejo que incorpora muchos elementos, militares y civiles, que cooperan para establecer la paz en el peligroso interregno que sigue a las guerras civiles.

La consolidación de la paz es un término más reciente que, como se usa en este informe, se refiere a las actividades realizadas al final del conflicto para restablecer las bases de la paz y ofrecer los instrumentos para construir sobre ellas algo más que la mera ausencia de la guerra. Por lo tanto, la consolidación de la paz incluye, entre otras cosas, la reincorporación de los excombatientes a la sociedad civil; el fortalecimiento del imperio de la ley (por ejemplo, mediante el adiestramiento y la reestructuración de la policía local y la reforma judicial y penal); el fortalecimiento del respeto de los derechos humanos mediante la vigilancia, la educación y la investigación de los atropellos pasados y presentes; la prestación de asistencia técnica para el desarrollo democrático (incluida la asistencia electoral y el apoyo a

\footnotetext{
6 Cfr. Rafael Grasa y Oscar Mateos, Guía para trabajar en la construcción de paz (Bogotá: Cámara
} de Comercio de Bogotá, 2015). 
la libertad de prensa); y la promoción del empleo de técnicas de solución de conflictos y reconciliación. ${ }^{7}$

En el 2008 el Departamento de Operaciones de Paz de las Naciones Unidas elaboró un nuevo informe del que surgió la Doctrine Capstone, ${ }^{8}$ que insistió en que los tres factores para que las operaciones de paz tuvieran éxito debían ser la legitimidad, la credibilidad y la apropiación local.

El mundo venía de un fuerte debate entre el Norte y el Sur a propósito de la forma en que los países desarrollados habían apelado a ese tipo de operaciones, muchas veces alentadas por intereses geopolíticos, dejando de lado consideraciones humanitarias.

Por eso esa doctrina reafirmó la necesidad de defender los principios de esas operaciones, es decir, la imparcialidad, el consentimiento y el no uso de la fuerza salvo en situaciones de legítima defensa o para defender un mandato.

\section{Acuerdos de paz y derecho del trabajo}

En el contexto colombiano, en la iniciación de diálogos con la guerrilla de las FARC-EP en Oslo, Noruega, en el 2012, se acordaron los seis ejes sobre los que descansarían los diálogos a desarrollarse en La Habana, Cuba, a saber: 1) política de desarrollo agrario integral; 2) participación política; 3) fin del conflicto; 4) solución al problema de las drogas ilícitas; 5) víctimas; y 6) implementación, verificación y refrendación.

La suscripción del "Acuerdo final para la terminación del conflicto y la construcción de una paz estable y duradera" el pasado 24 de agosto del 2016 fue sometido a refrendación popular por conducto de un plebiscito llevado a cabo el pasado 2 de octubre del 2016, siendo rechazado por el $50,21 \%$ y en contraste con un apoyo del $49,78 \%{ }^{9}$, que derivó en el rediseño del Acuerdo de Paz, publicado el 12 de noviembre del 2016. ${ }^{10}$

La paz como valor superior fundante del Estado social de derecho se reconoce en Colombia desde el texto constitucional en lo previsto expre-

\footnotetext{
Craig Zelizer, Integrated peacebuilding (Colorado: Westview press, 2013).

8 Naciones Unidas, Mantenimiento de la Paz, "Reforma de las actividades".

9 “Polarización del país reflejada en resultados del escrutinio”, El Tiempo, 2 de octubre del 2016.

10 Acuerdo de Paz, http://www.acuerdodepaz.gov.co/acuerdos/acuerdo-final
} 
samente en el artículo 22 del ordenamiento superior como derecho fundamental y deberes correlativos que informan el diseño de normas colombiano.

El trabajo como causa de paz se incorpora como elemento de construcción de paz a través de la respuesta en el marco de los procesos de desarme, desmovilización y reincorporación $-D D R-{ }^{11}$ a través de los procesos de readaptación y reincorporación social, al mismo tiempo que sirve de fórmula de resarcimiento de las víctimas del conflicto.

En este contexto, el trabajo fundamenta la construcción de paz en materia de no reincidencia de excombatientes y reparación para víctimas a través del ingreso que deriva de la actividad productiva que habilita el acceso al conjunto de bienes y servicios vitales.

En el marco del proceso de paz en Colombia, el trabajo como elemento de construcción de paz en el marco del posconflicto colombiano constituye causa eficiente de sostenibilidad de los acuerdos de paz y, como tal, debe fundamentar las políticas públicas en materia de empleabilidad y garantía de derechos individuales y colectivos en el posconflicto.

Las perspectivas laborales deben estructurar alternativas de trabajo decente que constituyan esquemas de autosostenibilidad de excombatientes y víctimas que se involucran en un sistema productivo tendencialmente agrario.

El Acuerdo Final contempla como punto específico de la Reforma Rural Integral la formalización laboral rural y la protección social, por el cual se establece el compromiso estatal de diseñar un plan de dignificación del trabajo rural y el respeto de las obligaciones que emanan de los convenios de la oit ratificados por Colombia, que garantizan el trabajo decente en el campo. ${ }^{12}$

El proceso de construcción de paz consecuencial a la firma de los acuerdos demanda un complejo de adaptación de la estructura laboral tradicional, cuyo modelo de relaciones laborales empresariales debe ser adecuado al contexto agrario de producción. ${ }^{13}$

11 Vicenç Fisas, "Introducción al desarme, desmovilización, y reintegración —DDR- de excombatientes”. Quaderns de construcción de Pau, n. 24 (noviembre, 2011).

12 Fundamentalmente se hace referencia a la Recomendación 202 del 2002 sobre Pisos de Protección Social, el Convenio 129 y la Recomendación 133 sobre Inspección del Trabajo en la Agricultura.

13 Organización Internacional del Trabajo, Trabajar en el campo en el siglo XXI: realidad y perspectivas del empleo rural en América Latina y el Caribe (Lima: Panorama Laboral Temático, 2015). 
El diseño de la política de intervención laboral debe enfocarse en la corrección de las brechas que derivan de la informalidad rural que alcanza el $88 \%$ y el enfoque asistencial que debe ser progresivamente sustituido por estímulos a la formalidad y el acceso a las modalidades de trabajo que involucran la explotación de la tierra, que caracterizan y diferencian el trabajo agrario.

El contenido del Acuerdo Final incluye el establecimiento de una renta básica mensual para los miembros de las FARC-EP durante 24 meses, equivalente al $90 \%$ del salario mínimo, así como la garantía estatal de aportes al sistema de seguridad social, siempre que no se vinculen al sistema productivo, y la asignación de dos millones de pesos al momento de la terminación de las zonas veredales transitorias de normalización.

De la misma manera, cada integrante de las FARC-EP en proceso de reincorporación tendrá derecho, por una vez, a un apoyo económico para emprender un proyecto productivo, individual o colectivo, por la suma de ocho millones de pesos (US\$2.667).

La presencia de agentes institucionales que procuren el respeto de las garantías laborales constituye un elemento esencial de afirmación de los derechos al trabajo, tradicionalmente ignorado en el espacio rural, a través de la adecuación de un sistema de inspección, vigilancia y control agrario.

El cumplimiento del Acuerdo en materia de la vinculación de mujeres rurales al sistema productivo y las garantías sociales que acompañan la implementación de acciones afirmativas para el acceso igualitario al trabajo encuentra en la implementación y reglamentación de la Ley 731 del 2002 una herramienta para el diseño del esquema de mejora de la calidad de vida de ellas.

La ampliación de la cobertura del sistema de protección social para la vejez para la población rural de la tercera edad en condiciones de extrema pobreza determinará el fortalecimiento de los denominados beneficios económicos periódicos — BEPS - y el programa Colombia Mayor, sobre los que no debe descansar el eje central del régimen pensional, el cual debe enfocarse en incentivos a la formalización laboral, y la consecuente construcción y financiación mutual y solidaria de derechos pensionales.

En este contexto, el trabajo fundamenta la construcción de paz en materia de no reincidencia de excombatientes y reparación para víctimas 
a través del ingreso que deriva de la actividad productiva que habilita el acceso al conjunto de bienes y servicios vitales.

En el marco de la política de reinserción social, más de 50.000 combatientes se han desmovilizado y han entrado en la ruta de la reintegración alcanzando solo un $20 \%$ de reintegración total, al tiempo que un $24 \%$ se encuentra en situación de plena reincidencia, $14 \%$ de riesgo medio-alto y $42 \%$ en un riesgo bajo-medio de reincidencia. ${ }^{14}$

El "laboratorio" del proceso de desmovilización debe constituir parámetros para el proceso de reintegración de los 7000 combatientes de las FARC-EP ${ }^{15}$ que se calcula entrarán en la ruta de incorporación social, para lo cual resultará determinante el diseño de políticas activas de empleabilidad articuladas en el Servicio Público de Empleo con enfoque rural.

La caracterización de los excombatientes que han participado de los procesos de reintegración, que refleja un $17 \%$ de analfabetismo y un porcentaje del $46 \%$ de educación hasta el tercer grado de primaria, demuestra la demanda de formación para el trabajo como estrategia principal de readaptación laboral. ${ }^{16}$

El desafío no se agota en las políticas de recepción de excombatientes, sino que debe, además, incorporar la segunda dimensión de la problemática que se deriva de la finalización del conflicto, la cual enmarca el tema de la atención de 8.074.272 víctimas del conflicto armado. ${ }^{17}$

En materia de reparación a víctimas, debe prestarse especial atención al cumplimiento de la obligación gubernamental de adoptar un programa de rehabilitación laboral en concordancia con lo previsto en la Ley 1448 del 2011 y la efectividad de las actividades que adelante la Mesa Permanente de Reparación Colectiva al Movimiento Sindical creada mediante el Decreto 624 del 2016.

\footnotetext{
14 Agenda para la Reincorporación y la Normalización —ARN—, "Preguntas y respuestas sobre la dimensión productiva”, http://www.reintegracion.gov.co/es/la-reintegracion/Paginas/faqs-productiva. aspx

15 Vicenç Fisas, Anuario de procesos de paz 2016 (Barcelona: Escola de cultura de Pau, Icaria Editorial, 2016).

16 ARN, "Preguntas y respuestas".

17 "Revelan cifras de víctimas del conflicto armado en Colombia", Telesur, 9 de abril del 2017, http://www.telesurtv.net/news/Revelan-cifra-de-victimas-del-conflicto-armado-en-Colombia-20170409-0034.html
} 


\section{Normas internacionales del trabajo y derecho del trabajo para la paz}

La Recomendación de la Organización Internacional del Trabajo sobre la organización del empleo (transición de la guerra a la paz), 1944 (n. ${ }^{\circ} 71$ ), adoptada en las postrimerías de la Segunda Guerra Mundial, se centró en la necesaria reorganización del empleo y la reconstrucción económica, y sentó las bases para la promoción de la paz y la prosperidad, y la respuesta a algunas de las causas principales de los conflictos, como son la pobreza, las privaciones y las injusticias.

En el marco de la 105 Conferencia Internacional del Trabajo del 2016, se llevó a cabo el debate sobre la revisión de la recomendación en cuestión en el contexto de la propuesta sobre empleo y trabajo decente para la paz y la resiliencia, en el que se evidencian las necesidades de adaptación del instrumento para la promoción de la paz en el contexto de los conflictos del siglo XxI. El informe en cuestión enseña: ${ }^{18}$

La situación hoy en día, más de setenta años después de la adopción de la Recomendación núm. 71, es mucho más compleja, ya que se han producido cambios tanto en la naturaleza de los propios conflictos como en las respuestas necesarias. Además de ocuparse de las situaciones generadas por los conflictos, la oIt también ha tenido que responder a los requerimientos de sus Miembros y abordar otros tipos de crisis, como los desastres. Su experiencia en estos ámbitos atestigua la importancia decisiva de las estrategias de creación de empleo y de promoción del trabajo decente, en particular en los Estados que se encuentran en situaciones frágiles, ya sea a causa de un conflicto, de un desastre o de otros eventos catastróficos.

En el documento que se discutió aparece una definición de "resiliencia", concepto en boga pero novedoso para la normativa internacional. Refiere a la capacidad de anticipar, resistir, adaptarse y recuperarse de los conflictos y desastres con medios que apoyen el desarrollo económico y reduzcan la

18 Organización Internacional del Trabajo. “Informe V”, http://www.ilo.org/ilc/ILCSessions/105/ reports/reports-to-the-conference/WCMS_358381/lang--es/index.htm 
vulnerabilidad. El proyecto de recomendación recupera para esos tiempos los principios rectores de las normas internacionales.

No podemos dejar de observar que la guerra subvierte a modo tal la seguridad y el bienestar de la población, con pérdida de vidas y destrucción, que las dificultades para la aplicación de las normas internacionales del trabajo se agravan sustancialmente. Sin embargo, al tenerlas en la mira y sostener los principios de trabajo decente y protección social, disminuye el riesgos de que se agraven sus consecuencias.

Dicha recomendación se refiere en especial a las políticas de empleo en las transiciones de la guerra a la paz, con evidente referencia al segundo conflicto mundial, puesto que el documento fue aprobado en 1944.

\section{Derecho del trabajo agrario para la paz}

Como se advirtió en precedente, el primer punto que ocupó la atención de la mesa de negociación entre las FARC-EP y el Gobierno nacional de Colombia estuvo enmarcado en la concertación de una política de desarrollo agrario integral.

Lo anterior se explica por la extracción agraria del grupo guerrillero desde su fundación en 1964 en Marquetalia y su consecuente demanda de intervención social en lo rural en Colombia, que presenta informalidad del $90 \%{ }^{19}$ según el Ministerio del Trabajo en Colombia.

En este sentido, el elenco de compromisos de formalización laboral rural y protección social que emanan del Acuerdo de Paz, suscrito entre el Gobierno nacional y las FARC-EP, se orienta a la formalización del trabajo rural a través de:

- Campañas para la erradicación del trabajo infantil y medidas inmediatas para la erradicación de las peores formas de trabajo infantil.

- La garantía de protección social, mediante un beneficio económico periódico para los trabajadores del campo en edad de jubilarse y de un subsidio de riesgos laborales, proporcional a un ahorro individual acompañado de un subsidio por parte del Estado.

19 Departamento Nacional de Planeación, Informe El campo colombiano: un camino hacia el bienestar y la paz: misión para la transformación del campo (Bogotá: Departamento Nacional de Planeación, 2015). 
- La promoción y estímulo de procesos organizativos de los trabajadores del campo a través de formas asociativas basadas en la solidaridad y la cooperación, de tal forma que se facilite el acceso a servicios del Estado orientados al bienestar de los trabajadores.

- La promoción de la vinculación laboral de las personas en situación de discapacidad.

- La promoción de la vinculación laboral de las mujeres en áreas productivas no tradicionales.

- La capacitación a los trabajadores agrarios y a las empresas en materia de obligaciones y derechos laborales, y el fomento de la cultura de la formalización laboral.

- El fortalecimiento del sistema fijo de inspección laboral y la creación de un sistema móvil de inspección en las áreas rurales que permita que los trabajadores puedan exigir debidamente sus derechos laborales y tramitar adecuadamente conflictos de carácter laboral.

- Los planes y programas social y ambientalmente sostenibles que se desarrollarán en las zonas rurales se harán con el concurso de la mano de obra de las comunidades de la zona - hombres y mujeres-. Las condiciones laborales de estos programas se adecuarán a la normativa internacional y nacional, y se regirán por los principios de dignidad y equidad.

- La extensión de programas para la protección eficaz del riesgo económico de la vejez hacia la población rural de tercera edad en extrema pobreza que no está cubierta por el sistema de seguridad social, considerando las necesidades especiales de las mujeres adultas mayores.

- Promover esquemas de protección al embarazo, parto, lactancia y atención en salud para el recién nacido, ampliando progresivamente en cobertura y calidad los sistemas de salud y el subsidio familiar, con enfoque especial en la mujer trabajadora del campo. ${ }^{20}$

En materia de regulación del trabajo rural se encuentran puntos de quiebre con el modelo tradicional de regulación capital-trabajo que procura

20 Acuerdo de Paz, http://www.acuerdodepaz.gov.co/acuerdos/acuerdo-final 
gobernar el derecho del trabajo al intervenir un tercer factor productivo: la tierra cuya explotación determina formas cíclicas o variables de producción. ${ }^{21}$

En atención a la idea esbozada, los hallazgos en el terreno empírico de las formas de contratación agrarias en Colombia, como resultado de la investigación desarrollada por el Observatorio de Tierras de la Universidad del Rosario, demuestran el vínculo basado en formas de contratación que no coinciden con el contrato de trabajo del régimen laboral:

- Contrato de arrendamiento

- Contrato de comodato

- Compraventa de fruto

- Sociedad agraria de transformación

- Cooperativa agraria de trabajo asociado

- Asociación agraria y campesina

- Sociedad de hecho

- Cuentas en participación

- Contrato de aparcería

- Contrato de usufructo

En el texto del Acuerdo de Paz se incluye como medida de formalización laboral en forma prevalente estímulos a la economía solidaria y cooperativa que escapan a las tradicionales categorías de vinculación del contrato de trabajo en los siguientes términos:

Con el propósito de estimular diferentes formas asociativas de trabajo de o entre pequeños y medianos productores y productoras, basadas en la solidaridad y la cooperación, y que promuevan la autonomía económica y la capacidad organizativa en especial de las mujeres rurales, y fortalezcan la capacidad de los pequeños productores y productoras de acceder a bienes y servicios, comercializar sus productos y en general mejorar sus condiciones de vida, de trabajo y de producción, el Gobierno Nacional creará e implementará el Plan Nacional de fomento a la economía solidaria y cooperativa rural.

21 Pranab Bardhan, The economic theory of agrarian institutions (Oxford: Oxford University Press, 2004). 
En concordancia con los esquemas de producción agrarios, debe diseñarse la implementación de incentivos al ahorro para acceder a un financiamiento menos costoso para la adquisición de activos e insumos para la producción, y facilitar el acceso a mecanismos de aseguramiento para la producción que cubran contingencias por cambios climáticos.

En el campo colombiano la tasa de trabajo infantil rural es de más del 15,6\%, mientras que en las ciudades es de 6,7\%; la informalidad en el agro es de cerca del $90 \%$, casi el doble que el promedio nacional; las mujeres ganan el $60 \%$ del sueldo de los hombres; al tiempo que solo el 14\% cotiza a salud como se evidencia en la tabla que se inserta a continuación que demuestra la creciente informal del sistema de relaciones laborales en el campo colombiano. ${ }^{22}$

Tabla 1. Indicadores del sistema laboral agrario colombiano

\begin{tabular}{|l|c|c|c|c|}
\hline & $\begin{array}{c}\text { Empresay } \\
\text { convenios colectivos }\end{array}$ & \%rabajadores & $\%$ \\
\hline Población ocupada total & & 100 & 3.543 .601 & $16,1 / 100$ \\
\hline Población ocupada sector agropecuario & & 30.154 & 340.771 & $1,5 / 9,6$ \\
\hline $\begin{array}{l}\text { Empresas y trabajadores agrícolas afiliados sistema riesgos } \\
\text { laborales }\end{array}$ & 455 & & 89.361 & 2,55 \\
\hline Sindicatos y afiliados sector agropecuario & 52 & 37.242 & 10,9 \\
\hline Sindicatos y trabajadores asalariados organizados & 238 & 0,8 & 23.278 & $0,6 / 6,8$ \\
\hline $\begin{array}{l}\text { Convenios colectivos de trabajo vigentes y cobertura, sector } \\
\text { agropecuario }\end{array}$ & 503.474 & & & \\
\hline Ingreso promedio trabajadores agrícolas $(\$)$ & & & & \\
\hline
\end{tabular}

Fuente: DANE, Fasecolda, Escuela Nacional Sindical, Sistema de Información Sindical y Laboral (sisLAB), Subsistema Dinámica de la Contratación Colectiva, con datos del Ministerio de Trabajo

La estacionalidad del esquema de producción agraria determina la diversificación de las actividades de los trabajadores del campo, la temporalidad en materia de vinculación laboral ${ }^{23}$ y la demanda de esquemas de protección social que faciliten el acceso en materia de afiliación y cotización para las coberturas del sistema en el sector agrario.

\footnotetext{
22 Departamento Nacional de Planeación, Informe El campo colombiano.

23 Organización Internacional del Trabajo, Trabajar en el campo.
} 


\section{Acción sindical en materia de participación ciudadana y garantías para el ejercicio del derecho a la movilización y protesta social}

El Acuerdo de Paz suscrito entre el Gobierno de Colombia y las FarcEP el 24 de noviembre del 2016 establece en el punto 2, como parte de la "Participación política: apertura democrática para construir la paz", en el punto 2.2.1, la promoción del desarrollo de "garantías para los movimientos y organizaciones sociales".

Como parte de los compromisos que derivan del Acuerdo en materia de participación política, se prevé el respeto del derecho de constitución de organizaciones sociales y la promoción de la resolución pacífica de conflictos y el diálogo social:

En atención al derecho de todas las personas a constituir organizaciones sociales del más variado tipo; a formar parte de ellas y a difundir sus plataformas; a la libertad de expresión y al disenso; al pluralismo y la tolerancia; a la acción política o social a través de la protesta y la movilización; y teniendo en cuenta la necesidad de una cultura política para la resolución pacífica de los conflictos y la obligación del Estado de garantizar el diálogo deliberante y público, se adoptarán medidas para garantizar el reconocimiento, fortalecimiento y empoderamiento de todos los movimientos y organizaciones sociales, según sus repertorios y sus plataformas de acción social. ${ }^{24}$

En este sentido, la promoción de la libertad sindical en su triple acepción, libertad de asociación, negociación y huelga, se integra al desarrollo de los puntos relativos a las garantías de participación ciudadana.

Como complemento de los compromisos referidos deben promoverse las garantías para la movilización y protesta pacífica, en el marco de las cuales debe revisarse el espectro normativo para estimular el ejercicio de los derechos que derivan de la libertad sindical, al tenor de lo establecido en el punto 2.2.2 del Acuerdo Final, que establece:

${ }^{24}$ Acuerdo de Paz, http://www.acuerdodepaz.gov.co/acuerdos/acuerdo-final 
La movilización y la protesta pacífica, como formas de acción política, son ejercicios legítimos del derecho a la reunión, a la libre circulación, a la libre expresión, a la libertad de conciencia y a la oposición en una democracia. Su práctica enriquece la inclusión política y forja una ciudadanía crítica, dispuesta al diálogo social y a la construcción colectiva de Nación. Más aún, en un escenario de fin del conflicto se deben garantizar diferentes espacios para canalizar las demandas ciudadanas, incluyendo garantías plenas para la movilización, la protesta y la convivencia pacífica. Junto con la movilización y la protesta pacífica se deberán garantizar los derechos de los y las manifestantes y de los demás ciudadanos y ciudadanas. ${ }^{25}$

El desarrollo de las garantías de participación ciudadana y movilización social comporta la adecuación de la estructura normativa en materia de libertad sindical, al menos en referencia al paquete normativo propuesto por la cartera laboral en materia de: 1) prohibición de pactos colectivos en empresas donde exista sindicato; 2) negociación sectorial; 3) regulación de las limitaciones del ejercicio del derecho de huelga; 4) extensión del ámbito subjetivo de la titularidad del derecho de negociación colectiva a trabajadores independientes; y 5) fortalecer la tutela penal de las garantías que emanan de la libertad sindical.

\section{Conclusiones}

$\mathrm{El}$ rediseño de los Acuerdos de Paz debe incluir la estrategia de extensión del sistema de protección laboral al campo, cuyos indicadores demuestran la inexistencia de los estándares de trabajo decente en el espacio rural que resulta determinante en el rediseño de la política de reinserción para la sostenibilidad de los Acuerdos.

Los desafíos en materia de formación para el trabajo como fórmula de reincorporación y garantía de ciudadanía social son la base en la que descansa la reincoporación de los excombatientes de las FARC-EP al sistema de relaciones laborales prevalentemente agrario.

Es necesario incluir en la narrativa de la construcción de paz que deriva de los Acuerdos las dimensiones laborales que legitimen la política de

\footnotetext{
25 Ibid.
} 
reinserción laboral agraria, que procura la sostenibilidad de la estrategia de construcción de paz y no reincidencia de excombatientes.

El déficit de protección laboral y social en el marco de los sistemas de producción agrarios debe ser corregido a través de la adaptación del modelo forsista de regulación de la ecuación capital-trabajo para reconocer e incluir en el ámbito de derechos los esquemas de producción agrarios que involucra la tripleta capital-tierra-trabajo.

Como advierte el Observatorio Laboral de la Universidad del Rosario en el comunicado a propósito del resultado del plebiscito celebrado el pasado 2 de octubre:
(...) el resultado del plebiscito no puede servir como una excusa para que el Gobierno no intervenga el campo. Se trata de pagar una deuda histórica por el olvido estatal de estas zonas. Se debe llevar a cabo un programa de formalización masiva en estos territorios, se deben garantizar sus prestaciones y seguridad social. Sobre todo en el tema pensional, pues existe una población vulnerable que se está dejando a su suerte.

Resulta necesario robustecer el servicio público de empleo para fortalecer los mecanismos de vinculación entre la oferta y la demanda de trabajo, estableciendo rutas de acceso preferentes para excombatientes y víctimas del conflicto.

Es recomendable rediseñar el programa del servicio público de "empleo rural temporal" hacia el incentivo de modalidades de vinculación con vocación de estabilidad.

Además, la administración de trabajo debe enfocar los esfuerzos en materia de inspección, vigilancia y control en el sector agrario para lograr la efectividad de los derechos y las garantías de los trabajadores agrarios y el acceso al conjunto de bienes servicios vitales a través del trabajo.

El trabajo en el posconflicto debe ser un elemento fundamental en la construcción de paz para promover la reintegración social de excombatientes y la recuperación en el campo, al tiempo que constituye parte de los sistemas de reparación a las víctimas del conflicto. 


\section{Bibliografía}

"Revelan cifras de víctimas del conflicto armado en Colombia". Telesur, 9 de abril del 2017, http://www.telesurtv.net/news/Revelan-cifra-devictimas-del-conflicto-armado-en-Colombia-20170409-0034.html

"Polarización del país reflejada en resultados del escrutinio". El Tiempo, 2 de octubre del 2016.

Acuerdo de Paz, http://www.acuerdodepaz.gov.co/acuerdos/acuerdo-final Agenda para la Reincorporación y la Normalización — ARN-. "Preguntas y respuestas sobre la dimensión productiva”, http://www.reintegracion. gov.co/es/la-reintegracion/Paginas/faqs-productiva.aspx

Bardhan, Pranab. The economic theory of agrarian institutions. Oxford: Oxford University Press, 2004.

Departamento Nacional de Planeación. Informe El campo colombiano: un camino hacia el bienestar y la paz: misión para la transformación del campo. Bogotá: Departamento Nacional de Planeación, 2015.

Fisas, Vicenç. "Introducción al desarme, desmovilización, y reintegración —DDR - de excombatientes". Quaderns de construcción de Pau, n. ${ }^{\circ}$ 24 (noviembre, 2011).

Fisas, Vicenç. Anuario de procesos de paz 2016. Barcelona: Escola de cultura de Pau, Icaria Editorial, 2016.

Grasa, Rafael y Oscar Mateos. Guia para trabajar en la construcción de paz. Bogotá: Cámara de Comercio de Bogotá, 2015.

International Labour Organization. Constitución de la oit, http://www.ilo. org/dyn/normlex/es/f?p=1000:62:0::NO::P62_LIST_ENTRIE_ ID:2453907

Naciones Unidas, Mantenimiento de la Paz. "Reforma de las actividades de mantenimiento de la paz", http://www.un.org/es/peacekeeping/ operations/reform.shtml

Organización Internacional del Trabajo. Trabajar en el campo en el siglo XXI: realidad y perspectivas del empleo rural en América Latina y el Caribe. Lima: Panorama Laboral Temático, 2015.

Organización Internacional del Trabajo. "Informe V", http://www.ilo. org/ilc/ILCSessions/105/reports/reports-to-the-conference/ WCMS_358381/lang--es/index.htm 
Ramsbotham, Oliver, Tom Woodhouse y Hugh Miall, Resolución de conflictos, la prevención, gestión y transformación de letales. Barcelona: Institut Catalá Internacional per la Pau, Edicions Bellaterra.

Zelizer, Craig. Integrated peacebuilding. Colorado: Westview press, 2013. 


\title{
Estado empático y ciudadanía precaria: reflexiones en torno al caso emblemático de Bellavista (Bojayá-Colombia)*
}

\author{
Lina Buchely ${ }^{* *}$
}

\section{Introducción}

Llegamos tarde a la reunión. Las personas que nos esperaban estaban en la casa parroquial de Bellavista nuevo y no en Bellavista viejo, lugar donde había ocurrido la masacre el 2 de mayo, hace 14 años. Cuando entramos, un líder del Comité de Víctimas del Dos de Mayo — CVDM- estaba hablando. Él había estado con nosotros en Cali hacía dos semanas en un evento del Centro de Estudios Afrodiaspóricos, y a él le debíamos poder asistir a la asamblea sobre el Cristo Negro de Bojayá.

Sentadas había, más o menos, 50 personas. Había representantes de todas las comunidades: Bellavista, Pogue, Tanguí, Puertoconto, Tadó, entre otras. El líder del cvdm hablaba de la dificultad de sacar al Cristo Negro de La Habana, de la cantidad de trámites y papeles

* Este documento se basa en mi trabajo de campo como investigadora del proyecto "Políticas del perdón y el retorno: Bojayá, 15 años después”. Este es un proyecto conjunto de la Universidad Icesi, institución donde laboro, y el Centro Nacional de Memoria Histórica. Sin embargo, las reflexiones personales que le dan origen y sustento a este capítulo no comprometen ni representan a ninguna de las dos instituciones.

** Doctora en Derecho de la Universidad de los Andes. Directora del Programa de Derecho de la Universidad Icesi. Correo electrónico: 1fbuchely@icesi.edu.co 
para conseguirlo, de que había tocado mutilar sus brazos de dos metros de altura para que fuera posible traerlo en el avión. Todos y todas escuchaban atentos.

El municipio de Bojayá está ubicado en el Atrato medio, área rural dispersa. Para llegar ahí se necesita un transporte fluvial entre Quibdó y Bellavista, que dura entre tres y cinco horas y cuesta ochenta mil pesos en su valor comercial (pagados a pangueros ${ }^{1}$ en la orilla del Atrato en Quibdó, cerca de la catedral). Según el último censo de población realizado en el 2005 por el Departamento Administrativo Nacional de Estadística —DANE-, tiene 9941 habitantes: $58 \%$ son afrocolombianos y $41 \%$ indígenas. E1 $95 \%$ no ha cubierto sus necesidades básicas desde $1993^{2}$ (Vergara-Figueroa, 2016). En Bellavista, su cabecera municipal, existe solo un puesto de salud, no un hospital. Las personas que no residen allí deben acceder a los servicios de salud por vía fluvial. En ese contexto, el 19 de septiembre del 2016, el Comité de Víctimas del Dos de Mayo — CvDM - convocó a una reunión para discutir la aceptación o no del "Cristo Negro de Bojayá" que entregó las FARC-EP a la comunidad.

Bojayá es un caso emblemático del conflicto armado interno por los hechos ocurridos el 2 de mayo del 2002. Ese día, en combates entre el Frente 58 de las FARC-EP y el Bloque Élmer Cárdenas de las Autodefensas Unidas de Colombia - AUC-, murieron más de 80 personas que se resguardaban en la parroquia de Bellavista, la cabecera municipal. Después de catorce años de la masacre, la Fiscalía no ha terminado con éxito el proceso de identificación de los cuerpos. Los duelos y ritos mortuorios de las víctimas no han podido realizarse. Según el informe del Centro Nacional de Memoria Histórica - $\mathrm{CNMH}-,{ }^{3} 126$ personas aún tienen esquirlas en sus cuerpos y afectaciones en su salud derivadas del ataque. En su mayoría, la población afectada no ha recibido la atención médica y psicológica necesaria. Ocho

\footnotetext{
1 Las "pangas" son lanchas a motor que transitan por el río Atrato. Se conoce como "pangueros" a los conductores de estas lanchas.

2 Aurora Vergara-Figueroa, “¿Cómo puede Bojayá perdonar?”, La Silla Vacía, 5 de octubre del 2016, http://lasillavacia.com/silla-llena/red-de-la-paz/historia/como-puede-bojaya-perdonar-58207

3 Centro Nacional de Memoria Histórica $-\mathrm{CNMH}-$, Bojayá: la guerra sin limites (Bogotá: Taurus, 2010).
} 
personas han muerto después de la masacre con diagnóstico de cáncer, patología que para la comunidad está asociada de manera directa con el estallido de la pipeta ese 2 de mayo.

Bojayá también se ha convertido en un ícono del perdón. Los resultados de sus votaciones frente al plebiscito sorprendieron al mundo entero. Más de 90\% de la población que participó — que no es mucha dada la precariedad de los puestos de votación y la exclusión de la comunidad indígena de estos procesos - votó positivamente para respaldar los Acuerdos de La Habana. Su experiencia como comunidad, además, ha tenido gran exposición mediática. En la ceremonia de firma del Acuerdo Final, el 26 de septiembre en Cartagena, mujeres de Pogue cantaron un alabao, ${ }^{4}$ imagen que se volvió rápidamente tendencia en las redes sociales. Sus voces decían:

\author{
Nos violaron el derecho, \\ en nuestra comunidad, \\ ni a la pesca ni al trabajo \\ nos dejaban llegar. \\ Queremos justicia y paz \\ que venga de corazón, \\ pa' que llegue a nuestros campos, \\ salud, paz y educación. ${ }^{5}$
}

Desde enero del 2016, la Universidad Icesi, como parte del Grupo Regional de Memoria Histórica, y el cnmh han venido trabajando de manera conjunta en el municipio, en el marco del proyecto "Políticas del perdón y el retorno: Bojayá, 15 años después”. Este proyecto, liderado por un equipo multidisciplinario compuesto por varios docentes de la Universidad interesados en temas relacionados con la construcción de memoria, el enfoque

4 Los alabaos son cantos no musicalizados que cuentan historias de dolor con voces desgarradoras y hacen parte de los ritos mortuorios de la comunidad de Bojayá. Su potencia y su belleza han sido admiradas y documentadas por universidades colombianas y extranjeras. Sobre los alabados de Pogue, véase Cantadoras de Pogue, El oficio de cantar la memoria - Las musas de Pogue (Universidad de British Columbia y el cnmh, 2012); Centro Nacional de Memoria Histórica. Pogue: un pueblo, una familia, un río. Historias contadas por la comunidad de Pogue (Usaid y огм).

5 Vergara, “¿Cómo puede Bojayá perdonar?”. 
étnico y la perspectiva de género, da continuidad a un proceso extenso que el Centro ha desarrollado en la zona con las víctimas de la masacre del 2 de mayo del 2002.

Este documento se basa en mi trabajo como investigadora vinculada al Grupo Regional de Memoria y especialmente en la reconstrucción de esta experiencia a la luz de la lectura de las emociones y la política que ofrece la antropología del estado. ${ }^{6,7}$ Usé técnicas etnográficas, como la observación participante y las entrevistas, para documentar los hallazgos que analizo. Realicé las observaciones durante mis visitas a las comunidades de Bojayá (en su mayoría, a Bellavista, aunque también registro otras a Pogue y La Loma), las reuniones del CNMH en Bojayá y Bogotá, las sesiones de trabajo a la Unidad de Víctimas de Quibdó, los encuentros con el cvdm y en eventos relacionados con el proceso de aprobación de los acuerdos de $\mathrm{La}$ Habana y el posterior reconocimiento al presidente Santos con el Nobel de $\mathrm{Paz}$, hechos sucedidos entre enero y noviembre del 2016. También recurro a las entrevistas con un miembro del cvDM y las conversaciones con varios funcionarios del CNMH. En general, sigo la metodología de acción sin daño desarrollada por el Centro Nacional de Memoria Histórica para hacer las intervenciones en las comunidades.

Cada sección del texto comienza con viñetas etnográficas basadas en las notas de campo de mi tercera visita a Bojayá, entre el 19 y el 22 de septiembre del 2016. Estas reconstruyen lo sucedido alrededor del Cristo Negro de Bojayá como mecanismo de reparación simbólica ofrecido por las FARC-EP a la comunidad. Esta experiencia condensa de manera especial los tres aspectos centrales de mi análisis: 1) el carácter emocional de las manifestaciones oficiales desarrolladas en escenarios de conflicto; 2) la ciudadanía precaria que construyen las víctimas de violencia política inmersas actualmente en procesos de construcción de memoria histórica: perdón, duelo y reparación; 3) la fragmentación y ambigüedad que

6 Mateusz Laszczkowski y Madeleine Reeves, “Affective states - entanglements, suspensions, suspicions". Social Analysis 59, n. 4 (2015).

7 Usaré la palabra estado con minúscula. Este cambio, pese a que va en contravía de las normas de la Real Academia de la Lengua, marca una postura teórica determinada que pretende desmitificar los estudios sobre esta categoría en las ciencias sociales. Véase Philip Abrams, "Notes on the difficulty of studying the state". Journal of Historical Sociology $1 \mathrm{n} .{ }^{\circ} 1$ (1988). 
representan esos escenarios de discusión para el estado colombiano en el proceso de posconflicto. ${ }^{8}$

\section{Bellavista y las burocracias "blandas"}

La primera mujer en hablar, tras darle la palabra a la comunidad, era conocida. DC, como le decían, es una vecina muy cercana del Barrio Bellaluz. En su intervención, propuso varios puntos importantes. E1 primero de ellos era que el Cristo era visto como una imposición de las Farc a la comunidad. ¿Cómo era posible que no se les hubiera ni siquiera preguntado antes de elaborarlo? ¿Por qué no se les había preguntado si se sentían cómodos con ese mecanismo de "reparación simbólica”, como lo llamaba la guerrilla? ¿Por qué justamente un Cristo, el objeto de su fe? En el segundo punto, DC resaltó la importancia del Cristo original de la iglesia de Bellavista: mutilado, sobrevivió a la masacre, y quizá por esto cuenta con especial devoción. Ya Bellavista tenía su Cristo y no necesitaba otro. Estaba bien si otra comunidad quería el Cristo, pero, para DC, Bellavista no lo necesitaba, o al menos eso se había discutido en reuniones previas entre los vecinos.

Después habló un hombre de Pogue, NA. Su posición era completamente distinta. Hablaba del perdón y de la paz, y de lo importante que sería aceptar el Cristo como un símbolo que ayudaría en la coyuntura de la firma de los acuerdos de La Habana. Insistía en que el Cristo debía de estar en Bellavista, como "epicentro" de la masacre.

Mi trabajo anterior ha estado relacionado con la manera en que la antropología del estado se pregunta por las manifestaciones físicas de este, cómo las documenta y las estudia. Esa experiencia, aunada a mi entrenamiento

\footnotetext{
8 Las viñetas etnográficas fueron seleccionadas por su relación con aspectos teóricos que deseo resaltar en el texto: la existencia de una ciudadanía por frustración (que no por dignidad y participación, como lo enseña el mito liberal) y el carácter negociado (y político) del perdón y la memoria. El texto de las viñetas hace parte de una sola narración y ha sido fragmentado para la construcción de este texto.
} 
disciplinar como abogada, me ha dejado la obsesión de relatar las presencias del estado. En Bojayá, el ejercicio ha sido difícil. Hay una presencia notable del Ejército. Existen unas pocas oficinas de entidades promotoras de salud y de empresas prestadoras de servicios públicos, una registraduría, algunos jardines de primera infancia del Instituto Colombiano de Bienestar Familiar, entre otros.

Sin embargo, pese a lo emblemático del caso y la "feria de chalecos" de instituciones internacionales, universidades y organizaciones no gubernamentales que han visitado la zona, interesadas en documentar sus procesos, es evidente que Bojayá está olvidada por las que llamo las "burocracias duras" del estado, es decir, por las entidades con competencias centrales en la asignación de presupuestos (Presidencia, ministerios, departamentos administrativos). Allí los representantes estatales son personas vinculadas al Centro Nacional de Memoria Histórica y a la Unidad de Víctimas, ambas adscritas al Departamento para la Prosperidad Social — DPs-, con vigencias temporales a partir de la Ley 1448 del 2011 y presupuestos exiguos. Estas burocracias "blandas" no tienen oficinas permanentes en el territorio. Van ocasionalmente a acompañar procesos específicos, siempre relacionados con lo que aquí llamaré gestiones emocionales: construcción de memoria, elaboraciones de duelo, propuestas de perdón.

Según mis observaciones, la comunidad de Bojayá está politizada, tiene fuertes procesos de participación y empoderamiento. En mis pocas visitas, presencié al menos tres reuniones generales en las que se discutían asuntos de interés colectivo con representantes de todas las comunidades. Sin excepción, esos asuntos estaban relacionados con la masacre, su reconocimiento como víctimas y los procesos de reparación que el estado había previsto para ellos.

Un elemento que me llamó la atención en las visitas fue la manera en que la identidad de víctima tiene expresiones cotidianas poderosas. En el momento de su expedición, la Ley 1448 del 2011 generó muchas discusiones en torno a la etiqueta utilizada legalmente para nombrar a los afectados, sobrevivientes, desplazados o víctimas del conflicto armado. ${ }^{9}$ Cada etiqueta traía unas implicaciones profundas. Se les llamó víctimas, y ser víctimas, en

9 Julieta Lemaitre Ripoll, "Diálogo sin debate: la participación en los decretos de la Ley de Víctimas”. Revista de Derecho Público 31 (2013). 
el estado actual del posconflicto - y me refiero a sus efectos cotidianos más básicos, relacionados con los trámites y las acciones de las personas afectadas en su vida diaria - significa poseer un lugar de enunciación caracterizado por dos elementos: 1) ser beneficiario especial y prioritario (discursivamente) de prestaciones públicas encaminadas a la reparación integral; 2) tener algo que la literatura ha denominado "superioridad moral" en las transacciones con las burocracias públicas ${ }^{10}$.

Pese a que me incomoda su nombre, después de haber compartido con los mal llamados "superiores morales" (y me gustaría enfatizar en la crueldad del enunciado), esta etiqueta remite a una especie de principio de no cuestionamiento, condescendencia y privilegio de las víctimas. En efecto, y concentrados en el mundo de los intercambios burocráticos, este elemento remite a actuaciones concretas como la inversión de la carga de la prueba, el seguimiento de protocolos especiales y el principio de no victimización secundaria en los procesos de interacción con los empleados públicos. ${ }^{11}$

Es fascinante ver cómo esta característica de la literatura no es reconocible, por ejemplo, por quienes empiezan sus procesos de reclamación en Cali. En lugares como las Unidades de Atención y Orientación - UAO- a población desplazada, las víctimas del conflicto no hablan de un "privilegio" frente a las burocracias públicas, sino de maltrato e indignidad derivados de su situación. ${ }^{12}$

10 Esteban Restrepo, “Cómo garantizar justicia a los desplazados. El desplazamiento como paria. La garantía de los derechos a la verdad, la justicia y la reparación de las víctimas del delito de desplazamiento forzado en Colombia", en Más allá del desplazamiento (Bogotá: Ediatorial Universidad de los Andes, 2010).

11 Helena Alviar García y Isabel Cristina Jaramillo Sierra, Feminismo y crítica jurídica: el análisis distributivo como alternativa crítica al legalismo liberal (Bogotá: Siglo del Hombre-Universidad de los Andes, 2012).

12 Gabriela Recalde, “En lo que esté a mi alcance les ayudo'. Los funcionarios de base y las víctimas en el proceso de declaración para la inscripción en el Registro Único de Víctimas del conflicto armado", en Etnografías burocráticas, coordinado por Isabel Cristina Jaramillo y Lina Buchely (Bogotá: Uniandes, en proceso de edición). La Ley 1448 del 2011 dispone el diseño de un andamiaje institucional para atender y reparar a las víctimas del conflicto armado, que se fundamenta en las estructuras burocráticas creadas por las leyes anteriores: los sistemas de atención para población desplazada (Ley 387 de 1997), para población de víctimas (Ley 418 de 1997) y la estrategia de reparación individual por vía administrativa del Decreto 1290 del 2008. Las UAO son parte de la infraestructura nacional y local consolidada mediante la Ley 387 de 1997, específicamente las ubicadas en los municipios, y los programas de asistencia en vivienda y líneas de crédito de la Ley 418 de 1997. 
Ahora bien, lo que llamo "ciudadanía precaria" surge de las construcciones anteriores. La gestión emocional del estado construye los discursos de protección de las víctimas como un elemento central para su interacción. Esos guiones son empoderadores y detonantes de procesos comunitarios exitosos en la experiencia, por ejemplo, de Bojayá. Sin embargo, ese reconocimiento precariza las formas en las que los ciudadanos se relacionan con el estado y hacen sus exigencias. Mientras el tema "emocional" conduce sus interacciones, las discusiones materiales sobre la ciudadanía socia ${ }^{13}$ son anuladas.

\title{
2. El estado empático: gestión emocional y estrategias de duelo
}

\begin{abstract}
Dos mujeres de Bellavista lo siguieron en las intervenciones. La primera se refirió a la imposición y la violencia del gesto. Era una imposición que se les dijera cómo perdonar, con qué perdonar y qué regalos aceptar. Era ofensivo, además, que el gesto incluyera un objeto de fe. Esto era una burla, una mofa. La segunda mujer habló del dolor que le generaría ver al Cristo que les enviaban las FARC en el lugar desde donde se había disparado la pipeta. Mencionó las esquirlas que tenía en su pierna izquierda, los calambres que no la dejaban dormir por la noche, la injusticia del gesto. Además, los victimarios decidían cómo repararlos, y no ellos. Ella necesitaba atención médica, no un Cristo. Necesitaba un mejor centro de salud, una casa habitable. Necesitaba una reparación material.

Después de esa intervención, el ánimo se calentó. Varias de las mujeres le decían al único hombre que manifestó estar abierto a la recepción del Cristo que les fuera a llevar "razones" a los guerrilleros. Esto lo molestó y empezó a desacreditar esas opiniones. Era evidente que las fronteras entre víctimas y victimarios no eran claras ahí.
\end{abstract}

13 Bajo la etiqueta del bienestar se organizan las transacciones típicas de la política social, entendidas como unas prestaciones obligatorias del estado hacia los ciudadanos dentro de un esquema de ciudadanía social. Thomas H. Marshall, Citizenship and social class (Londres: Pluto Press, 1992). Según esta visión de los estados liberales, la ciudadanía social entra a completar los derechos civiles y políticos con la preocupación por la igualdad material. Esa preocupación por "lo social" fue incorporada en las constituciones de los países latinoamericanos con la etiqueta de los derechos económicos sociales y culturales (DESC). Gosta Esping-Andersen, Social foundations of postindustrial economies (Oxford-Nueva York: Oxford University Press, 1999). 
Las emociones están en el centro de las discusiones en torno al estado. En la teoría hobbesiana del contractualismo, por ejemplo, el Leviatán surge para controlar el temor de las personas a morir en una situación de amenaza de todos contra todos. Entendido de esta manera, el estado es la respuesta al miedo. ${ }^{14}$ Por el contrario, en las teorías críticas, ese miedo no se instala de manera individual. El individuo no es una unidad de transacción política; por el contario, solo la relación con sus semejantes le permite reconocer relaciones sistemáticamente asimétricas. ${ }^{15}$

En las teorías contemporáneas, autores como Partha Chatterjee explican cómo sentimientos de frustración y desconsuelo construyen los cuerpos de las sociedades actuales. El proyecto liberal de estado no coincide con la realidad de la mayoría de ciudadanos del mundo (dada la vastedad del mal llamado "tercer mundo") y la política se convierte en una suerte de atención paliativa para mermar la desilusión del proyecto político no alcanzado. Ser ciudadanos en el tercer mundo nos enseña que nuestra experiencia política se relaciona más con esa frustración frente a lo incumplido que con la satisfacción por lo alcanzado. ${ }^{16}$

En ese contexto, se ha visibilizado recientemente la idea de incluir el afecto en la vida política. Esa discusión considera al estado un sujeto social en la vida cotidiana, atendiendo a la experiencia subjetiva del poder del estado (en la vida de las personas) y a las técnicas, intensidades y mecanismos por los cuales se reproduce todos los días como forma de gobierno y disciplina. Desde esta perspectiva, el estado aparece como una gestión emocional que interactúa de manera afectiva con las personas, y de ese modo aparece en su vida.

La literatura de las burocracias callejeras ${ }^{17}$ ya nos ha mostrado cómo esa gestión emocional se visibiliza por medio de personas que, revestidas de competencias de autoridad, llevan la idea del estado a la vida de los

14 Thomas Hobbes, Leviatán: la materia, forma y poder de un Estado eclesiástico y civil (Madrid: Alianza, 1999).

15 Louis Althusser, Ideología y aparatos ideológicos del Estado (Buenos Aires: Nueva Visión, 2003).

16 Partha Chatterjee, The politics of the governed-Reflections on popular politics in most of the world (Nueva York: Columbia University Press, 2004).

17 Peter Hupe, Michel Hill y Aurélien Buffat, "Introduction: defining and understanding streetlevel bureaucracy", en Understanding street-level bureaucracy, editado por Peter Hupe, Michel Hill y Aurélien Buffat (Bristol: Policy Press, 2016). 
beneficiarios de los programas sociales. Pese a ello, concebir el estado como afecto aleja la atención de los mecanismos que le permiten convertirse en la autoridad misma (poder institucional) o en provisiones materiales (ciudadanía social). Es la mera empatía lo que aparece en la vida de las personas. ${ }^{18}$ En consecuencia, el estado no debe ser entendido como una ficción que debe ser deconstruida, como lo proponían las aproximaciones anteriores a la antropología del estado, ${ }^{19}$ sino como una relación sustantiva. Es una interacción, un intercambio de quejas, reclamos, apelaciones, anhelos que, hechos a partir de registros emocionales, se inscriben en formas jurídicas que median esas relaciones (derechos, privilegios, prerrogativas). El derecho es, entonces, una forma de nombrar la emoción, el afecto. ${ }^{20}$ Que el estado sea una emoción es entonces una buena aproximación desde el punto de vista descriptivo.

La etnografía burocrática empezó a dar cuenta de esto cuando subrayó cómo las burocracias callejeras operaban mediante la producción y circulación del miedo, la esperanza y la sospecha, además de recurrir a tácticas de gobernanza como la clasificación, la inscripción y la organización. ${ }^{21} \mathrm{El}$ estado es un objeto de inversión emocional, un lugar de miedo, paranoia y sospecha mutua, lo cual, por supuesto, es un avance importante para las investigaciones que indagan cómo el estado se hace material o cómo aparece en la vida de las personas. La politización del afecto de espacios particulares o el acto de vincular esas manifestaciones emocionales a símbolos políticos y discursos hace que el estado se vuelva tangible y cobre una existencia espacial o real. Este modo de aparecer es una forma de gobierno y de la "insustanciabilidad del poder" del mismo estado. ${ }^{22}$

El estado, por tanto, no necesita ser entendido como entidad, limitada, invisible, abstracta; puede ser visto como una caja de resonancia afectiva entre

18 Madeleine Reeves, "Fixing the border: On the affective life of the state in southern Kyrgyzstan”. Environment and Planning 29, n. 5 (2011).

19 Abrams, "Notes on the difficulty".

20 Reeves, "Fixing the border".

${ }^{21}$ Yael Navaro-Yashin, "Affective spaces, melancholic objects: ruination and the production of anthropological knowledge". Journal of the Royal Antbropological Institute 15, n. 1 (2009).

22 Michael Taussig, The nervous system (Nueva York: Routledge, 1992). 
distintas personas y cosas. ${ }^{23}$ En las secciones siguientes, de conformidad con este guion, desarrollaré cómo esta aproximación puede resultar productiva para analizar los procesos públicos de construcción de ciudadanía de las víctimas de Bellavista, Bojayá. En este contexto, la viñeta etnográfica de la asamblea para decidir la aceptación o no del Cristo Negro me permitirá analizar los procesos emocionales que constituyen los procesos políticos y públicos en el territorio, encargados de mediar las relaciones entre aquellos sujetos que se llaman "víctimas" y aquellos denominados "estado".

\section{El estado emocional dentro de nosotros: realidades colombianas}

Para distensionar el ambiente, el líder del Comité de Víctimas del Dos de Mayo — CvDM- intervino para recordar por qué estos escenarios son claves para fortalecerse a sí mismo y cómo todas las opiniones son válidas. Igualmente, las personas del Centro Nacional de Memoria Histórica recordaron dos cosas: primero, que Bojayá ya no era más Bojayá, era la nación entera dando mensajes de reconciliación. El resultado de esa asamblea, el perdón que pudiera dar la comunidad recibiendo el gesto de las FARC era muy importante para la coyuntura. Segundo, que las opciones no eran solamente dos. No estaban frente a una decisión de recibirlo o rechazarlo. La comunidad podía también usar el escenario para recibir el Cristo como un gesto de reconciliación, pero condicionar la reparación a algunos puntos importantes, como la exhumación e identificación de los muertos, las inversiones en salud, la revisión del sistema de indemnizaciones por fiducias.

E1 líder del crdm terminó esa parte de la sesión hablando como miembro de la comunidad, y no como miembro del Comité. Para él, el Cristo debía ser recibido como un símbolo del perdón que pusiera fecha a algunas acciones que debían ser realizadas por las FARC.

El estado es emocional en todas partes. Podría construir un argumento aquí sobre cómo existe el estado emocional en las zonas afectadas por la

23 Michael Taussig, The magic of the State (Nueva York: Routledge, 1997). 
violencia, lejanas y distantes. Debo admitir que ese fue mi primer impulso, pero la lejanía no es un elemento explicativo cuando hablamos del estado como gestión emocional.

Cuando estoy en un Centro de Atención Distrital Especializado - CADE- en Bogotá o en cualquiera de las oficinas de las empresas municipales de Cali - Emcali-, puedo ver la misma escena: personas descargando su rabia en una ventanilla, haciendo reclamos fuertes por insatisfacciones, presentando quejas por malos servicios. En otras palabras, soy testigo de "altercados burocráticos". Observo la misma interacción afectiva en los procesos de rendición de cuentas o en una audiencia de aclaración de pliegos en el Fondo Financiero de Proyectos de Desarrollo — FonadeLa existencia del estado como emoción no constituye necesariamente una forma de precarización.

En lugares como Bojayá, percibía intuitivamente las emociones como una manifestación de precariedad. En ese guion, la emoción aparece como una forma subpolítica: ellos no tienen estado, tienen emociones. Pero ya hemos visto, de la mano de los trabajos de las etnografías del estado, que esta es una forma singular de gestión emocional que se presenta como pública, oficial. No es entonces la distancia lo que explica que el estado se convierta en emoción; la emoción, como manifestación pública, no implica por sí misma una forma de pauperización o de precariedad. ${ }^{24}$

Es innegable, por ejemplo, que el CNMH es la presencia del estado más visible en Bojayá. En una entrevista con un líder del cvDM, él mencionó que "ellos (las personas del CNMH) son los locos del estado". ${ }^{25}$ Están ahí y se dedican a cosas "locas". "Locas" describe en su narrativa un tránsito irregular de las funciones públicas: se preocupan por la construcción de la memoria, por la reparación, por el perdón. Pero, además, están representando al estado en un lugar donde sistemáticamente este no ha hecho presencia.

El CNMH fue creado para reunir y recuperar material relativo a las violaciones que menciona el artículo 147 de la Ley de Víctimas y Restitución de Tierras. Su metodología de acción sin daño hace énfasis en las

\footnotetext{
${ }^{24}$ Nancy Fraser y Linda Gordon, "Una genealogía de la 'dependencia'. Rastreando una palabra clave del Estado Benefactor en los Estados Unidos”, en Iustitia Interrupta. Reflexiones críticas desde la posición "postsocialista", editado por Nancy Fraser (Bogotá: Siglo del Hombre, 1997).

25 Líder del CvDM, entrevistado por la autora, 9 de septiembre del 2016.
} 
intervenciones no extractivas del territorio, en la interacción dignificante con las víctimas y en la importancia de los procesos comunitarios que las empoderen. Habla de memoria, habla de duelo, habla de perdón. El Centro desarrolla actividades terapéuticas que buscan fortalecer los tejidos sociales de la comunidad, respetar sus voces, hacer eco de sus resistencias. ${ }^{26}$ Sus funcionarios son cuidadosos en determinar qué quiere la comunidad que se cuente y cómo quiere que se haga.

El Centro es una entidad sin mucho presupuesto y "pequeña" en términos de visibilidad en el organigrama de lo público estatal; sin embargo, ha sido especialmente efectivo para instalar la emoción como centro del debate político en la comunidad de Bellavista. Para esta población -y quiero escribir esto sin que mal entiendan mi intención-, hace visible su dolor. La masacre puso a Bojayá en el centro de las discusiones sobre las víctimas civiles del conflicto armado. Es un caso emblemático por el poder de sus hechos y símbolos — un ataque en una parroquia donde murieron población civil indefensa y niños-, por lo dolorosos e impresionantes, que se cruza, además, con elementos estructurales de abandono: es Chocó, Atrato medio, población afro e indígena, etc.

Bellavista, lugar donde ocurrió la masacre en el 2002, es distinta a otras poblaciones de Bojayá como consecuencia de dicho ataque. Sus casas son producto de indemnizaciones parciales que dio el gobierno Uribe y son notablemente más cómodas que las viviendas palafíticas de otros lugares de la región. Tiene calles demarcadas, parques, monumentos. Sus habitantes viven, como lo dije al principio, con las necesidades básicas insatisfechas. Pero hay precariedades mayores en las comunidades cercanas. Esto es innegable. ${ }^{27}$

La centralidad del evento de violencia y su reconocimiento como víctimas ha llevado a que sean esos elementos los que predominen en los escenarios políticos, en la manera de construir la conciencia del nosotros colectivo, en el modo de imaginarse a ellos mismos. ${ }^{28}$ La masacre es un lugar

26 Nota de campo, salida 5, Bogotá, reunión de Grupos Regionales de Memoria, 21 de octubre $\operatorname{del} 2016$.

27 Nota de campo, salida 1, Bellavista, conmemoración 14 años de la masacre, 29 de abril-3 de mayo del 2016.

28 Nota de campo, salida 1. 
importante de su vida política. Es un evento fundacional, originario. ${ }^{29}$ Ante esto, la presencia del estado en forma de centro de memoria ha contribuido al enconamiento de la identidad de víctimas como forma de politización. En consecuencia, las interacciones con el estado están constantemente mediadas por solicitudes relacionadas con la masacre y se inscriben dentro de sus sucesos, sus recuerdos. Esto, además, lo mencionan una y otra vez los representantes de las entidades públicas. Fue muy ilustrativo, por ejemplo, cuando una funcionaria de la Unidad de Víctimas afirmó en una reunión en Bellavista que no era posible construir un hospital, porque las acciones de reparación permitidas por la Ley 1448 los tenían que devolver a la situación anterior en la que estaban: antes no tenían hospital, ahora tampoco. ${ }^{30}$

El énfasis en la existencia emocional del estado ha desplazado las solicitudes propias de la ciudadanía social. Y no quiero decir aquí que pedir agua, salud, educación, no sea emocional. Estoy señalando que politizar a la comunidad en torno a la masacre y su identidad de víctimas precariza sus relaciones de ciudadanía y la pone en lugares marginales de contacto con el estado. En este contexto, lo que hacen el Centro y la Unidad de Víctimas en Bojayá es "regatear" prestaciones públicas duras. ${ }^{31}$

$\mathrm{Al}$ principio de este texto caractericé al CNMH como una burocracia "blanda". Uso el adjetivo para enfatizar su marginalidad (está adscrito al DPs), su temporalidad (la Ley 1448 del 2011 le puso como término el 2021) y su precariedad (tiene un exiguo presupuesto propio). ${ }^{32}$ En la voz de algunos de sus funcionarios, el Centro gasta parte importante de su tiempo tratando de "articular" competencias públicas para cumplir derechos de las víctimas: se reúne con los ministerios de educación, salud, vivienda. Pese a ello, esas interacciones son fallidas. ${ }^{33}$

29 La nostalgia y el dolor son sentimientos recurrentes en los hitos políticos e históricos que narran los procesos políticos. El duelo, la melancolía y la catástrofe son formas recurrentes con las que contamos nuestra independencia, nuestra unidad como comunidad, nuestra construcción como comunidad política. Andrés Castillejo-Cuéllar, "De la nostalgia, la violencia y la palabra: tres viñetas etnográficas sobre el recuerdo”. Revista Nómadas 29 (2008).

30 Nota de campo, visita 1.

31 Chatterjee, The politics of the governed.

32 Funcionario de CNMH, entrevistado por la autora, 18 de marzo del 2016.

33 Nota de campo, salida 3, Bellavista, fiestas patronales, 13-20 de julio del 2016. 
Los relatos de sus funcionarios dan cuenta de la fragilidad de su relación con las burocracias duras. Constantemente aluden al riesgo de que el Centro se acabe por presiones políticas. Ante esta situación, perciben a las universidades como una institucionalidad paralela en la que pueden "instalar" el conocimiento que han adquirido sobre construcción de memoria histórica. ${ }^{34}$ Sus relatos también refieren la ambivalencia de su identidad: pueden considerarse funcionarios públicos o investigadores independientes. Por ejemplo, para hacer seguimiento a las recomendaciones que el CNMH había hecho en el informe "Bojayá: la guerra sin límites", el equipo jurídico del proyecto necesitaba identificar las instituciones públicas a las que el CNMH hacía referencia. Muchas de las recomendaciones estaban vinculadas a instituciones inexistentes y el seguimiento no pudo realizarse en esos casos. Cuando indagué en las instituciones públicas por estas referencias, me encontré con esta respuesta: "ellos no tienen ni idea de donde están parados (...). Es que eso es más como un centro de investigación, no es formalmente una institución del estado". ${ }^{35}$

Una situación como esta resulta más llamativa cuando, en las oficinas de la Unidad de Víctimas de Quibdó, se refieren a los miembros del Comité de Víctimas de Bojayá (el mismo cVDM) como representantes “oficiales" de lo que sucede en el municipio. ${ }^{36}$ Mientras son identificados como voceros de la comunidad, representan un estado que los traiciona; de hecho, los mismos funcionarios en los territorios los reconocen como "mediadores oficiales". ${ }^{37}$

Los anteriores ejemplos indican que el estado en Bojayá es una cadena de eslabones falsos: el CNMH es una de las instituciones presentes, pero ella misma tiene conexiones frágiles con las entidades públicas y los enlaces públicos son personas que, pese a desarrollar una labor comunitaria visible e importante, no tienen ningún vínculo formal con el estado: no responden a un contrato de prestación de servicios, a un nombramiento oficial o a un convenio de colaboración.

34 Nota de campo, salida 5, Bogotá, reunión de Grupos Regionales de Memoria, octubre 21 $\operatorname{del} 2016$.

35 Nota de campo, salida 5, Bogotá, reunión de Grupos Regionales de Memoria, 21 de octubre $\operatorname{del} 2016$.

36 Notas de campo, salida 2, Quibdó, reunión con unidad de víctimas y cvDM, 2-3 de junio $\operatorname{del} 2016$.

37 Notas de campo, salida 2. 
Por otra parte, el rol de los miembros del Comité de Víctimas de Bojayá y otras organizaciones comunitarias, como el Consejo Comunitario Mayor de la Asociación Campesina Integral del Atrato - Cocomacia-, es singular para dar cuenta de la precariedad de las presencias estatales en Bellavista. Aunque no son abogados ni tienen ninguna experiencia dentro de la burocracia oficial, estas personas no solo han sido las cabezas visibles del proceso de lucha posterior a la masacre: han liderado la gestión documental, el envío de solicitudes oficiales, la mediación con organismos internacionales como la onU, la orientación de asambleas comunitarias constantes, y la utilización de una jerga especializada en procesos y acciones que los posicione como víctimas del conflicto frente al estado. En ellos, el estado se condensa. Estos hombres y mujeres son archivos ambulantes, recuerdan con claridad fechas e interacciones con el estado; sus memorias personales son las memorias oficiales del conflicto. ${ }^{38}$

La acción cotidiana de estos líderes está altamente burocratizada. Sus formas de movilización y expresión emulan al estado, que los abandona, pero construyen la sensación de su falsa presencia. ${ }^{39}$ Esa existencia del estado en performances burocráticos vacíos de significado o expresiones de vínculos formales con el estado se ha señalado como una de las formas de precarización de lo estatal propia de los contextos neoliberales en países como Colombia. ${ }^{40}$

Pese a esas sensaciones, los representantes del cvDM se han negado de manera sistemática a constituir personas jurídicas u otras figuras legales que lleven a la representación formal de la comunidad. Han sostenido esta posición, aunque la Fiscalía ha desestimado varias veces su liderazgo o mediación hasta tanto no obtengan una personería jurídica. Esto es paradójico puesto que no solo los funcionarios del estado reconocen el liderazgo y la legitimidad de los miembros del cvDM. La comunidad frecuentemente recuerda y ratifica su liderazgo, su solidaridad, su voz.

38 Líder del cvDM, entrevistado por la autora, 9 de septiembre del 2016.

39 Su presencia es, al menos, precaria e inestable. Ellos logran la presencia "transitoria" del Estado por medio de las respuestas a los derechos de petición o de visitas también transitorias de funcionarios de las burocracias duras.

40 Margarita Chaves y Mauricio Montenegro. "Usos y sentidos contemporáneos de lo público". Revista Colombiana de Antropología 51 (2015). 
Procesos tanto nacionales como internacionales aceptan la visibilidad de su gestión. ${ }^{41}$

Según el líder del cvDm entrevistado, uno de los argumentos para negarse a constituir una figura jurídica de representación es la responsabilidad del estado. Para él, una personería jurídica daría a uno de los miembros de la comunidad la responsabilidad por las víctimas, cuando esta le corresponde absolutamente al estado. ${ }^{42}$ Esta resistencia al uso de las formas jurídicas es, en algún sentido, una resistencia frente al estado. Es una queja indirecta que pone de presente ausencias sistemáticas de la presencia estatalizada y, sobre todo, reclama una responsabilidad exclusiva por las víctimas de la masacre. Esto implica que, pese a representar de manera "simbólica" al estado en algunos escenarios, los líderes comunitarios construyen una frontera discursiva que los separa de él: "son ellos, y no nosotros", los responsables de las víctimas.

Ahora bien, ser víctima y visible es un proceso complejo. Da miedo, dolor. La doble condición encierra en el drama, agobia. ${ }^{43}$ Sin embargo, este líder reconoce que esta identidad es la única que le ha permitido su contacto con entidades públicas, el reconocimiento de su pueblo y la visibilidad de su territorio. "Por el dolor existen", dice él. ${ }^{44}$ Ser víctima concentra, de manera contradictoria para estas personas, todas sus desgracias pasadas, pero, al mismo tiempo, la dignidad del reconocimiento presente y la esperanza de una mejora en el futuro.

La existencia del estado en Bellavista habla de esta clase de dramas. Lo público se desvanece en figuras que, pese a tener un rol densamente público, no son estatales. Estas continuas tensiones se recogen en características como la dispersión de lo público, la saturación de la presencia ocasional, la fragilidad de los lazos y la eficacia de los discursos que pronuncian los funcionarios públicos que visitan Bellavista. En la siguiente sección explicaré esta caracterización.

41 Pilar Riaño y Erin Baines, “Cuando el archivo está en el testigo: documentación en escenarios de inseguridad crónica”. Análisis político 4 (2012).

42 Líder del cvdm, entrevistado por la autora, 9 de septiembre del 2016.

43 Ibid.

${ }^{44}$ Líder del cvDM, entrevistado por la autora, 16 de noviembre del 2016. 


\section{El estado del río: dispersión, saturación, fragilidad y eficacia en la experiencia estatal de Bellavista}

Salimos a almorzar. Durante el almuerzo, los funcionarios del Centro Nacional de Memoria Histórica $-\mathrm{CNMH}$ - reconocieron lo complejo de la situación. Mencionaron lo injusto que es poner a la comunidad en situaciones tan difíciles como esta y cuestionaron los actos de las Farc. ¿Cómo se les ocurrió la idea del Cristo? ¿Por qué justo un Cristo? Era realmente una situación bien difícil en la que estábamos.

Llegando de almorzar los ánimos eran distintos. La comida había logrado, una vez más, construir en comunidad lo que la deliberación no pudo. Después del receso, se evaluaron las propuestas de aceptar el Cristo como un gesto de reconciliación y perdón, y enviarlo al Museo de Memoria en Bogotá (lugar al que quedará reducido el CNMH en el 2021). Se descartó la posibilidad de recibirlo sin condiciones o que se entregara a una comunidad distinta a la de Bellavista; finalmente, se acordó recibir el Cristo como un gesto de reparación y se discutieron los puntos que se propondrían a las FARC como claves de la reparación y que permitirían condicionar la aceptación por parte de la comunidad. El encargado de recibir el Cristo sería el Comité de Víctimas del Dos de Mayo.

Al final de esta sesión, un anciano mencionó que eso era como estar escribiendo en el aire, antes de que se firmaran los acuerdos. "No tenemos nada, la paz no está lista y, por lo tanto, la seguridad de la comunidad tampoco existe”. Por esa razón, la reunión terminó con la invitación a firmar por el sí y la filmación de un video en el que los líderes y lideresas de las comunidades se dirigen a los centros urbanos, recordándoles que ellos, como campesinos y campesinas, necesitan la paz para poder trabajar y vivir tranquilos.

El análisis de las viñetas etnográficas seleccionadas sugiere que la ciudadanía precaria a la que me refería en el principio del texto - y que 
alude a la forma de ciudadanía creada por la Ley 1448 — $^{45}$ tiene cuatro características fundamentales en este contexto: fragmentación, saturación, fragilidad y eficacia. La dispersión se refiere a la idea del estado como algo aparentemente homogéneo. Es fácil reconocerla en esos territorios: las competencias de las entidades son difusas y débiles, pero más allá de esto, están dispersas y desagregadas. Las oficinas públicas (de la Unidad de Víctimas, por ejemplo) no se encuentran en centros administrativos condensados (como sucede en algunas ciudades según principios de planeación urbana), sino en zonas periféricas no conectadas con los otros centros administrativos (alcaldías, estaciones de policía).

Adicionalmente, el estado está atomizado en figuras ambiguas que emulan su presencia sin representar su existencia: los miembros del CVDM, los líderes comunitarios, las mujeres que cocinan para la comunidad en las asambleas, los funcionarios del $\mathrm{CNMH}$ con contratos precarios y presencias efímeras. Esa dispersión y opacidad de lo estatal es propia de la manera en la que el estado constituye su poder. ${ }^{46} \mathrm{El}$ caos, el desorden y la inteligibilidad de sus estructuras y lenguajes afianzan su autoridad y ejercen su disciplina. ${ }^{47}$ La unidad jurídica, esa que representa la Ley 1448, que nombra a las víctimas como sujetos de especial protección del estado y crea una estructura institucional para su asistencia, es la forma de coherencia en la que el estado narra su existencia; sin embargo, esa coherencia y unidad no se experimenta en la vida cotidiana de los habitantes de Bellavista.

La saturación es el antónimo de la dispersión. Mientras yo puedo identificar la dispersión del estado en Bojayá, sus habitantes solo perciben la densidad de su presencia. Se sienten sofocados con reuniones constantes, se ven expuestos de manera frecuente a un vocabulario técnico tedioso y paralizante, son acosados por presencias e interpelaciones inusuales en su territorio. El estado para ellos es saturación. Sienten su presencia en los soldados intimidantes en el parque, en sus armas, en sus voces. Se reconoce

45 Este tipo de ciudadanía se remonta por lo menos a la creación del "desplazado" de la Ley 387 de 1997 y se consolida con esta Ley 1448 del 2011. El texto del profesor Esteban Restrepo es iluminador en este sentido. Restrepo, "Cómo garantizar justica”.

46 Alejandra Leal, "Burocracia, justicia y pluralismo jurídico. Una exploración de los espacios del poder en Oaxaca”. Alteridades 16, n. ${ }^{\circ} 31$ (2006).

47 Akhill Gupta, Red tape. Bureaucracy, structural violence and poverty in India (Durham, NC: Duke University Press, 2012). 
robusto en los discursos sofisticados de funcionarios ajenos, en la sensación de estar siendo observados, en la zozobra derivada de visitas constantes de invitados desconocidos.

La fragilidad es contradictoria cuando hablamos del estado saturado. ¿Cómo puede el estado, al mismo tiempo, estar saturado y ser frágil en estos territorios? Ya hablé de la precariedad de las presencias estatales en el Atrato medio. Estas se derivan de la suavidad de las burocracias blandas y la contundencia de las presencias duras. El estado está en las armas de los militares del parque, por supuesto, pero se escapa en los papeles de las asambleas del cNmH o en las visitas de la Unidad de Víctimas. Se vuelve frágil cuando lo que llega es empatía y no hospitales; escucha y no escuelas; condescendencia y no resultados. ${ }^{48} \mathrm{El}$ estado se está convirtiendo aquí en una terapia, en una acción afectiva, siendo la preocupación por las emociones la única manera de evidenciar su existencia en estos territorios. En ese sentido, el "estado empático" sí es una forma de precarización de la ciudadanía en estos territorios.

Finalmente, el estado empático y la ciudadanía precaria son eficaces. Esta eficacia se deriva de la sensación fundacional de la operación del estado liberal desarrollista. ${ }^{49}$ Es el estado que no está, no quiere estar, pero debe lidiar con la expectativa de la presencia. Entonces, aparece en estas formas: trabajando el duelo, escuchando el dolor, reconstruyendo la memoria. El CNMH nombra a los líderes comunitarios que participan en sus actividades como "gestores de memoria". Y la paradoja es que, al mismo tiempo, estas presencias cumplen las promesas de la existencia mientras disimulan ausencias estructurales, disipan reclamos legales y enredan reivindicaciones políticas. Esta es la gestión emocional de la ciudadanía precaria.

Dispersión, saturación, fragilidad y eficacia pueden reconocerse en las viñetas etnográficas analizadas. El escenario mismo nos habla de la centralidad de los intercambios emocionales como representaciones de lo público en territorios como el de Bellavista. La manera en la que las personas enuncian su inconformidad, la disposición del espacio, el tono que usan las

48 Líder del cvdm, entrevistado por la autora, 9 de septiembre del 2016.

49 Luis Eslava, "I feel like a dog with the tail between its legs': on the limits of protest and urban law in our decentralized world”, 2014, https://papers.ssrn.com/sol3/papers.cfm?abstract_id=2270456 
personas para desplegar sus opiniones muestran cuán acostumbradas están a hablar de esto: perdón, rencor, llanto, dolor. Todas estas son expresiones de duelo que reemplazan el ejercicio de la ciudadanía.

El escenario también revela cómo el estado aparece en estos espacios. Llega por el río, se aleja por él. Se muestra preocupado, como los funcionarios del CNMH; inconforme, indignado. Ellos escuchan a la comunidad, la atienden, la conocen. Pueden reconocer sus voces, sus nombres, sus casas. Su rol revierte la jaula de hierro weberiana: son cercanos, conscientes, compasivos. ${ }^{50}$ Hablan del perdón, de la importancia de su dignidad, de su voz como víctimas. Son garantes de la "acción sin daño". Son personas, no estructuras. Son individuos, no servicios. Y mientras eso pasa, el olvido persiste. No llega la luz, el agua. No llega la paz.

Los habitantes de Bojayá tienen clara esa contradicción. Para ellos, no hay tal "reparación integral" de la que habla la Ley 1448 del 2011 y sobre la que insisten con vehemencia los funcionarios del cNMH. ${ }^{51} \mathrm{La}$ reparación es simbólica y material. Existe una división clara, y es evidente que la segunda no ha llegado. Por eso, quienes participan de la audiencia se refieren a sus lesiones, a los hospitales, a las condiciones de sus viviendas, cuando han sido invitados para hablar del perdón y la reconciliación; del perdón de ellos que era en ese momento el perdón de Colombia entera; de la Colombia del estado saturado que les pedía a ellos un gesto de perdón, un gesto de reconciliación...

Pero mientras los enunciados emocionales capturan la escena, los escenarios de la ciudadanía se precarizan. No existe una ciudadanía social en cuanto garantía material para el ejercicio de los derechos civiles y políticos. No existen ni siquiera los canales físicos para que esas reclamaciones puedan darse, porque los funcionarios que los escuchan no son competentes para solucionarlas. Y que no sean competentes les enseña la lección de la que Chatterjee nos hablaba: no son ciudadanos completos.

50 Diego López, "E1 sueño weberiano: claves para una comprensión constitucional de la estructura del Estado colombiano". Revista de Derecho Público de la Universidad de los Andes, 19 (2007).

51 Nota de campo, salida 5, Bogotá, reunión de Grupos Regionales de Memoria, 21 de octubre del 2016. 


\section{Epílogo}

El Cristo estaba en el piso de una antigua iglesia. (...) Me impresionó, primero, su tamaño. Luego, debo decir, me frustró su imagen. No era tan fino como me lo imaginaba. Estaba aún por terminar, la pintura por hacer y estaba aún tosco por la falta de lija. Sus piernas eran más gruesas de lo normal; sus caderas, en cambio, estrechas. Su cara, polémica. Tenía rasgos afro con varias rastas colgando como pelo.

(...) Para Enrique Angulo, el artista cubano que había creado la obra, la escultura incluía tres símbolos de resistencia, por lo que le costaba creer que la comunidad la rechazara. Los pies, por ejemplo, se resistían a ser clavados. Eran unos pies en lucha. El segundo símbolo de resistencia era el color. Era el primer Cristo que originalmente tenía ese color: los dos existentes eran de ese tono como resultado de incendios. Hacer un Cristo negro parecía un acto de rebeldía para un ateo como él. Finalmente, el último símbolo de resistencia era la herida en el dorso. Su visibilidad era mucho más profunda, su sangre más visible, más marcada. Era, sin lugar a dudas, una manera de hablar sobre la masacre y su magnitud.

Meses después, cuando ya se había realizado el plebiscito y el presidente Santos había recibido el Nobel de la Paz, yo estaba en Londres en uno de los reconocimientos al presidente. En el aeropuerto, un inglés que trabaja para Heathrow me dijo: "qué valiente es su país, qué emoción esto que vimos en estos días. Está lleno de personas muy alegres. Me sorprende cómo vinieron aquí y sacaron las banderas, después de tanto dolor" ${ }^{52} \mathrm{Cru}-$ zando el Atlántico, se producía otro ejercicio de construcción simbólica y emocional de lo político. De algún modo, ser ciudadanos en estas fronteras (y quizás en todas) tiene que ver con gestionar ese tipo de emociones: perdón, reconciliación, pertenencia. Pero el hallazgo aquí ha sido que ese tipo de gestiones capturan no solo las acciones macro del estado. Las emociones se esconden y filtran donde nos han enseñado que el estado es solo técnica (leyes, normas, imparcialidad).

52 Nota de campo, salida 6, Londres, reconocimiento al presidente de la República de Colombia como Nobel de Paz, 6-12 de noviembre del 2016. 
Ahí, en Londres, se había realizado una asamblea de perdón. Actos de reconocimiento, de dignificación, de paz. Actos que simbolizan la esperanza. Yo viajé a Bogotá contenta. Al llegar, en la madrugada, un niño hambriento me recordó las distancias entre los dolores cuando me pidió a las 4 am dinero para comer. El estado empático y la ciudadanía precaria hablan de estas contradicciones, de la existencia limitada de los símbolos, de la fragilidad de los procesos emocionales cuando se trata de construir una ciudadanía política.

\section{Bibliografía}

Abrams, Philip. "Notes on the difficulty of studying the state". Journal of Historical Sociology 1 n.o 1 (1988): 58-89.

Althusser, Louis. Ideología y aparatos ideológicos del Estado. Buenos Aires: Nueva Visión, 2003.

Alviar García, Helena y Isabel Cristina Jaramillo Sierra. Feminismo y critica jurídica: el análisis distributivo como alternativa crítica al legalismo liberal. Bogotá: Siglo del Hombre-Universidad de los Andes, 2012. Castillejo-Cuéllar, Andrés. "De la nostalgia, la violencia y la palabra: tres viñetas etnográficas sobre el recuerdo". Revista Nómadas 29 (2008): 8-19.

Cantadoras de Pogue. El oficio de cantar la memoria - Las musas de Pogue. Universidad de British Columbia y el cNmH, 2012.

Centro Nacional de Memoria Histórica. Pogue: un pueblo, una familia, un río. Historias contadas por la comunidad de Pogue. Usaid y orm.

Centro Nacional de Memoria Histórica - $\mathrm{CNMH}-$. Bojayá: la guerra sin límites. Bogotá: Taurus, 2010.

Chatterjee, Partha. The politics of the governed-Reflections on popular politics in most of the world. Nueva York: Columbia University Press, 2004. Chaves, Margarita y Mauricio Montenegro. "Usos y sentidos contemporáneos de lo público”. Revista Colombiana de Antropología 51 (2015): 7-21. Decreto 1290 del 2008, 22 de abril. Por el cual se crea el Programa de Reparación Individual por vía Administrativa para las Víctimas de los Grupos Armados Organizados al Margen de la ley. Diario Oficial 46.958 . 
Eslava, Luis. 'I feel like a dog with the tail between its legs': on the limits of protest and urban law in our decentralized world", 2014, https://papers.ssrn.com/sol3/papers.cfm?abstract_id=2270456

Esping-Andersen, Gosta. Social foundations of postindustrial economies. Oxford-Nueva York: Oxford University Press, 1999.

Fraser, Nancy y Linda Gordon. "Una genealogía de la 'dependencia'. Rastreando una palabra clave del Estado Benefactor en los Estados Unidos", en Iustitia Interrupta. Reflexiones criticas desde la posición "postsocialista", editado por Nancy Fraser, 17-54. Bogotá: Siglo del Hombre, 1997.

Gupta, Akhill. Red tape. Bureaucracy, structural violence and poverty in India. Durham, NC: Duke University Press, 2012.

Hobbes, Thomas. Leviatán: la materia, forma y poder de un Estado eclesiástico y civil. Madrid: Alianza, 1999.

Hupe, Peter, Michel Hill y Aurélien Buffat. "Introduction: defining and understanding street-level bureaucracy", en Understanding streetlevel bureaucracy, editado por Peter Hupe, Michel Hill y Aurélien Buffat, 3-42. Bristol: Policy Press, 2016.

Laszczkowski, Mateusz y Madeleine Reeves. "Affective states - entanglements, suspensions, suspicions”. Social Analysis 59, n. ${ }^{\circ} 4$ (2015): 1-14.

Leal, Alejandra. "Burocracia, justicia y pluralismo jurídico. Una exploración de los espacios del poder en Oaxaca”. Alteridades 16, n. 31 (2006): 39-48.

Ley 387 de 1997, 18 de julio. Por la cual se adoptan medidas para la prevención del desplazamiento forzado; la atención, protección, consolidación y esta estabilización socioeconómica de los desplazados internos por la violencia en la República de Colombia.

Ley 418 de 1997, 26 de diciembre. Por la cual se consagran unos instrumentos para la búsqueda de la convivencia, la eficacia de la justicia y se dictan otras disposiciones. Diario Oficial 43.201.

Ley 1448 del 2011, 10 de junio. Por la cual se dictan medidas de atención, asistencia y reparación integral a las víctimas del conflicto armado interno y se dictan otras disposiciones. Diario Oficial 48.096.

Lemaitre Ripoll,Julieta. "Diálogo sin debate: la participación en los decretos de la Ley de Víctimas”. Revista de Derecho Público 31 (2013): 5-37. 
López, Diego. "El sueño weberiano: claves para una comprensión constitucional de la estructura del Estado colombiano". Revista de Derecho Público de la Universidad de los Andes, 19 (2007): 2-42.

Marshall, Thomas H. Citizenship and social class. Londres: Pluto Press, 1992. Navaro-Yashin, Yael. "Affective spaces, melancholic objects: ruination and the production of anthropological knowledge". Journal of the Royal Anthropological Institute 15, n. ${ }^{\circ} 1$ (2009): 1-18.

Recalde, Gabriela. “En lo que esté a mi alcance les ayudo'. Los funcionarios de base y las víctimas en el proceso de declaración para la inscripción en el Registro Único de Víctimas del conflicto armado", en Etnografías burocráticas, coordinado por Isabel Cristina Jaramillo y Lina Buchely. Bogotá: Universidad de los Andes (en proceso de edición). Reeves, Madeleine. "Fixing the border: On the affective life of the state in southern Kyrgyzstan”. Environment and Planning 29, n. 5 (2011): 905-923.

Restrepo, Esteban. "Cómo garantizar justica a los desplazados. El desplazado como paria. La garantía de los derechos a la verdad, la justicia y la reparación de las víctimas del delito de desplazamiento forzado en Colombia”, en Más allá del desplazamiento, 701-731. Bogotá: Editorial Universidad de los Andes, 2010.

Riaño, Pilar y Erin Baines. "Cuando el archivo está en el testigo: documentación en escenarios de inseguridad crónica”. Análisis politico 4 (2012): 49-70.

Taussig, Michael. The nervous system. Nueva York: Routledge, 1992.

Taussig, Michael. The magic of the State. Nueva York: Routledge, 1997.

Vergara-Figueroa, Aurora. “¿Cómo puede Bojayá perdonar?”. La Silla Vacía, 5 de octubre del 2016, http://lasillavacia.com/silla-llena/red-de-lapaz/historia/como-puede-bojaya-perdonar-58207 
Este libro fue compuesto en caracteres Adobe Caslon

Pro 11,5 puntos, impreso sobre papel propal de 70 gramos y encuadernado con método hot melt en agosto de 2017, en Bogotá, D. C., Colombia Panamericana Formas e Impresos S.A. 